
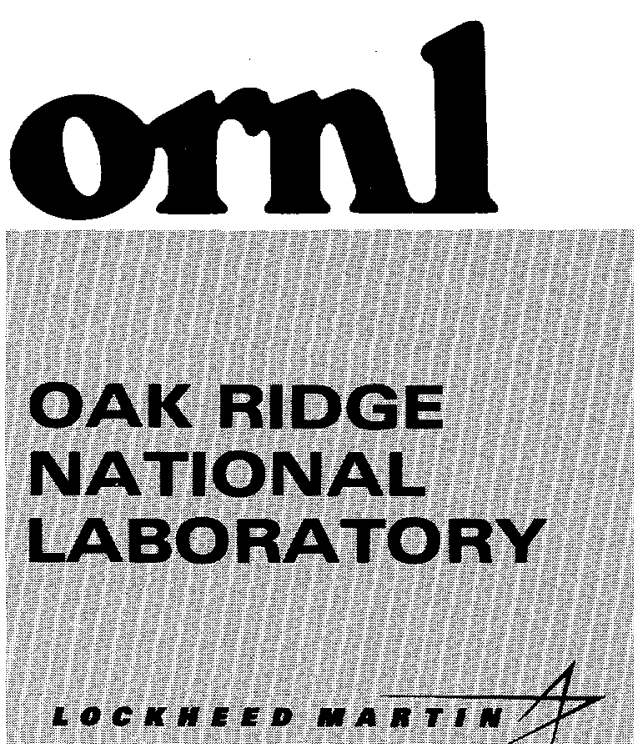

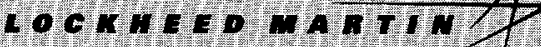

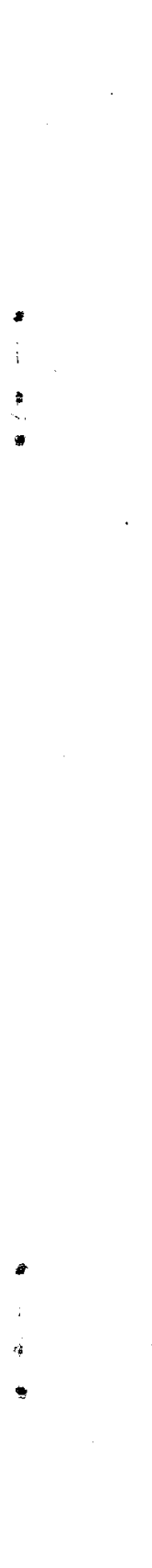

RECEMED

ORNL/TM-13711/N1

JUค 301999

OSTI

Environmental Sciences Division

\begin{abstract}
Laboratory Evaluation of In Situ Chemical Oxidation for Groundwater Remediation, Test Area North, Operable Unit 1-07B, Idaho National Engineering and Environmental Laboratory
\end{abstract}

\author{
Volume One - Main Text and \\ Appendices A and B
}

S. R. Cline

J. M. Giaquinto

M. K. McCracken

D. L. Denton

R. C. Starr 
This report has been reproduced from the best available copy.

Reports are available to the public from the following source.

National Technical Information Service

5285 Port Royal Road

Springfield, VA 22161

Telephone 703-605-6000 (1-800-553-6847)

TDD 703-487-4639

Fax 703-605-6900

E-mail orders@ ntis.fedworld.gov

Web site http://www.ntis.gov/ordering.htm

Reports are available to U.S. Department of Energy (DOE) employees, DOE contractors, Energy Technology Data Exchange (ETDE) representatives, and International Nuclear Information System (INIS) representatives from the following source.

Office of Scientific and Technical Information

P.O. Box 62

Oak Ridge, TN 37831

Telephone 423-576-8401

Fax 423-576-5728

E-mail reports@ adonis.osti.gov

Web site http://www.osti.gov/products/sources.html

Reports produced after January 1, 1996, are generally available via the DOE Information Bridge.

Web site http://www.doe.gov/bridge 
ENVIRONMENTAL SCIENCES DIVISION

\title{
LABORATORY EVALUATION OF IN SITU CHEMICAL OXIDATION FOR GROUNDWATER REMEDIATION, TEST AREA NORTH, OPERABLE UNIT 1-07B, IDAHO NATIONAL ENGINEERING AND ENVIRONMENTAL LABORATORY
}

\author{
Volume One - Main Text and Appendices A and B \\ S. R. Cline, J. M. Giaquinto, M. K. McCracken, D. L. Denton \\ Oak Ridge National Laboratory \\ R. C. Starr \\ Idaho National Engineering and Environmental Laboratory
}

Environmental Sciences Division

Publication No. 4838 (Volume 1)

April 1999

Prepared for the

Idaho Operations Office

U.S. Department of Energy

under budget and reporting code 647058101 (EW 201010 2)

Prepared by the

OAK RIDGE NATIONAL LABORATORY

Oak Ridge, Tennessee 37831-6285

managed by

LOCKHEED MARTIN ENERGY RESEARCH CORP.

for the

U.S. DEPARTMENT OF ENERGY

under contract DE-AC05-96OR22464 



\section{DISCLAIMER}

This report was prepared as an account of work sponsored by an agency of the United States Government. Neither the United States Government nor any agency thereof, nor any of their employees, make any warranty, express or implied, or assumes any legal liability or responsibility for the accuracy, completeness, or usefulness of any information, apparatus, product, or process disclosed, or represents that its use would not infringe privately owned rights. Reference herein to any specific commercial product, process, or service by trade name, trademark, manufacturer, or otherwise does not necessarily constitute or imply its endorsement, recommendation, or favoring by the United States Government or any agency thereof. The views and opinions of authors expressed herein do not necessarily state or reflect those of the United States Government or any agency thereof. 


\section{DISCLAIMER}

Portions of this document may be illegible in electronic image products. Images are produced from the best available original document. 


\section{TABLE OF CONTENTS}

\section{VOLUME ONE}

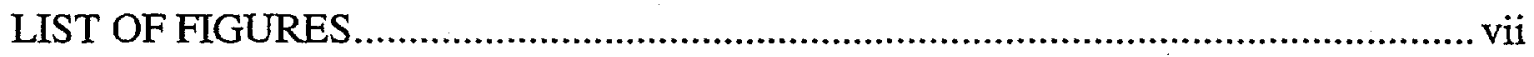

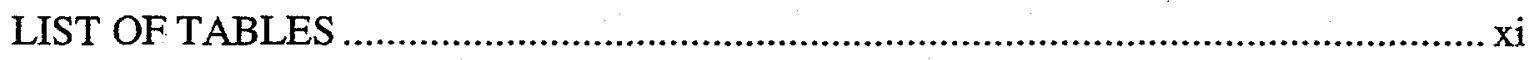

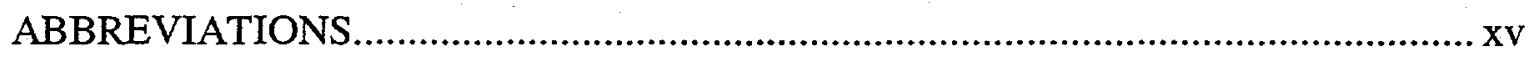

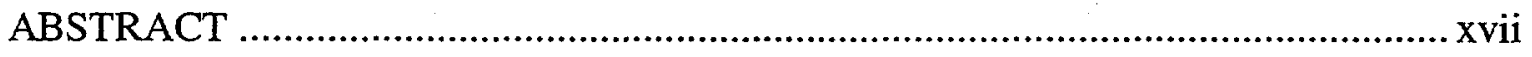

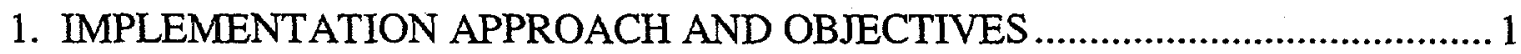

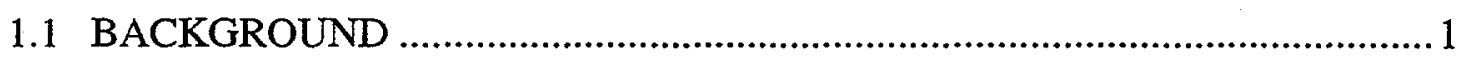

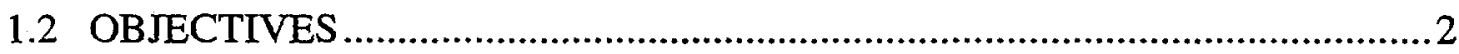

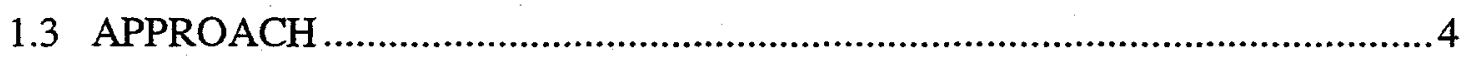

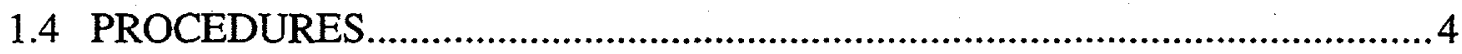

1.4.1. Summary Procedures for Preliminary Laboratory Experiments ..................

1.4.1.1. Reactor Development ...............................................................

1.4.1.2. Determination of Hexane Extraction time of TCE ...................... 6

1.4.1.3. Determination of Equilibration Time of Aggregate Basalt ......... 7

1.4.2. Summary of Procedures for Oxidant Demand Experiments....................... 8

1.4.3. Summary of Procedures for Oxidation Rate Experiments........................ 10

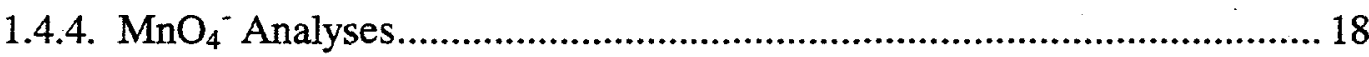

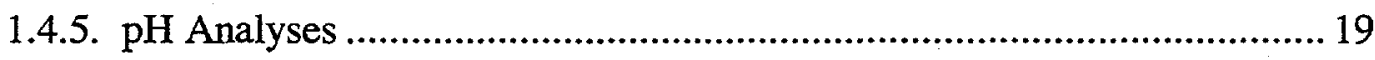

1.4.6. VOC Analyses.................................................................................... 19

1.4.7. Baseline Sludge Characterization and Carbon Analyses ..........................20

2. RESULTS AND DISCUSSION

2.1 TASK 1. PREPARATION OF PROJECT PLANNING DOCUMENTS..........21

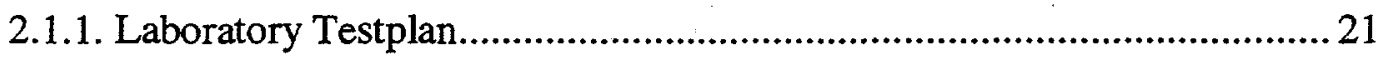

2.1.2. Other Documents Required by ORNL....................................................2

2.2 TASK 2. PRELIMINARY LABORATORY STUDIES .................................22

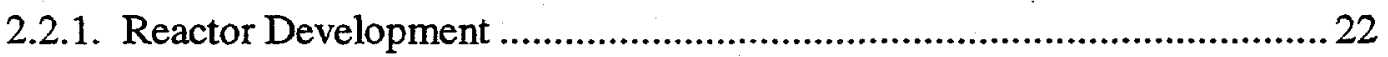

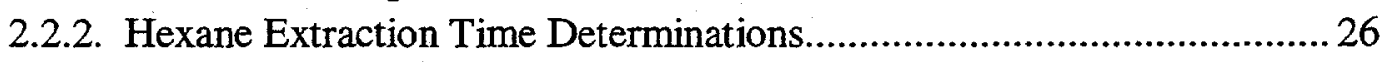

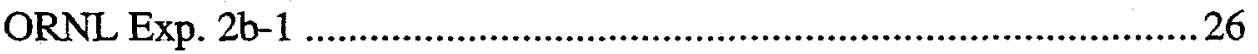

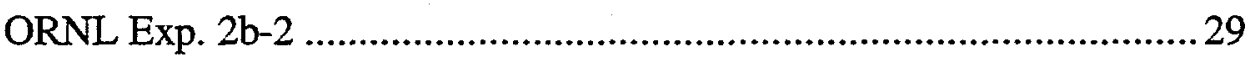

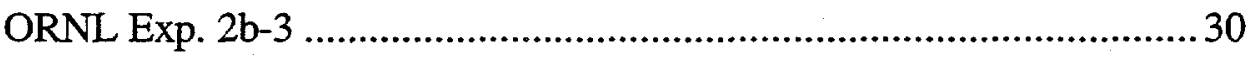

2.2.3. Aggregate Basalt Equilibration Time ...................................................... 33

2.3 TASK 3. MEASUREMENT OF THE OXIDANT DEMAND OF TAN

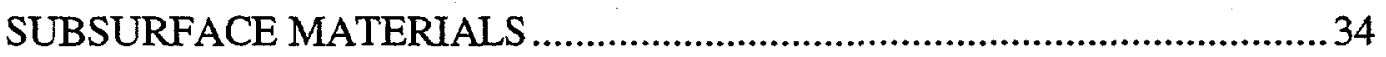

2.3.1. Laboratory Controls and QA ................................................................. 34

2.3.2. Oxidant Demand in Dissolved Plume Media........................................... 34

2.3.3. Oxidant Demand in Hot Spot Media ....................................................... 42 
2.3.4 Summary - Oxidant Demand of TAN Subsurface Materials 50

2.4 TASK 4. MEASUREMENT OF OXIDATION RATES OF TAN

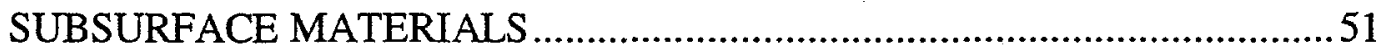

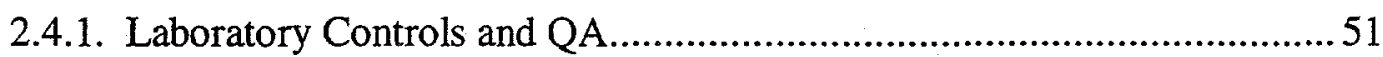

2.4.2. Oxidation Rate of Organic Contaminants in Dissolved Plume Media.....53

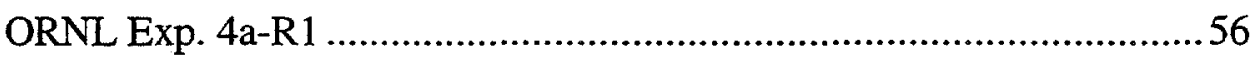

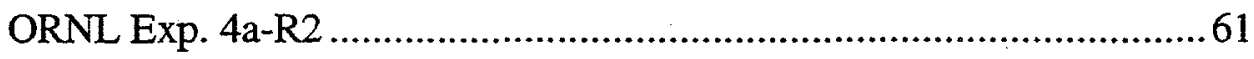

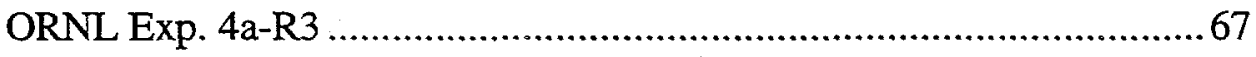

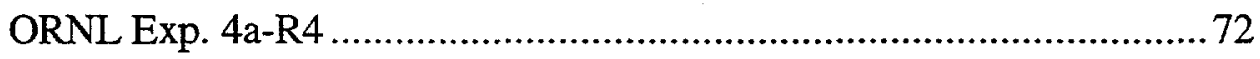

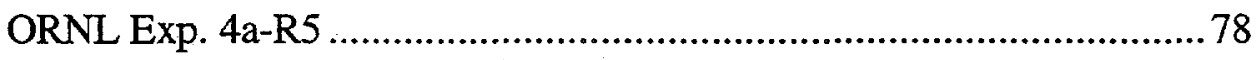

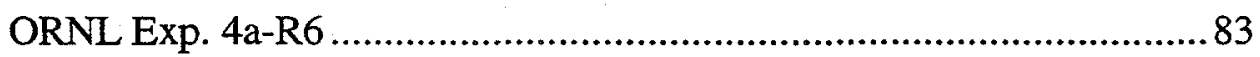

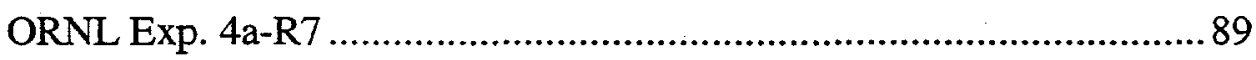

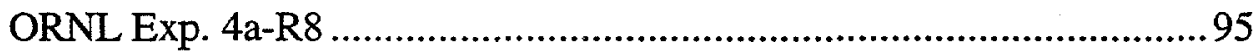

Summary - TCE Oxidation Rate Measurements, Dissolved Plume .... 101

2.4.3. Oxidation Rate of Organic Contaminants in Hot Spot Groundwater..... 111

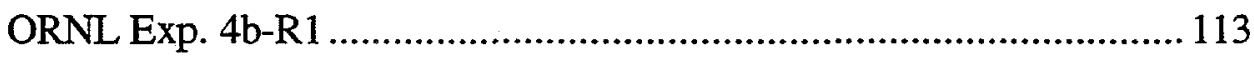

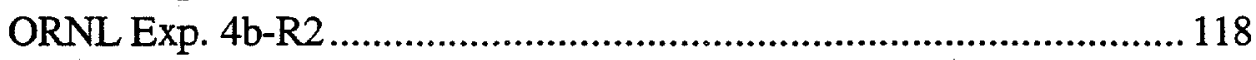

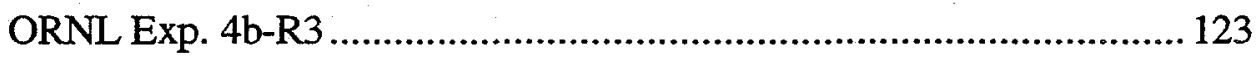

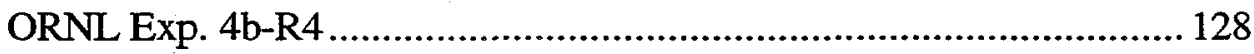

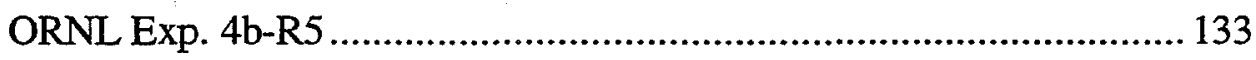

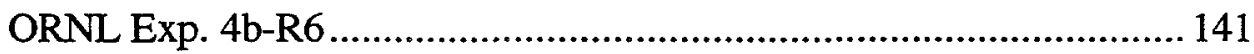

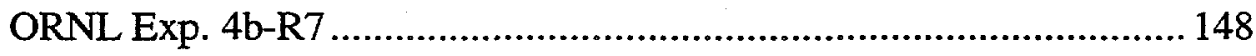

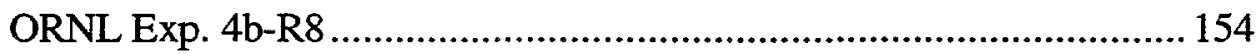

Summary - VOC Oxidation Rate Measurements, Hot Spot GW .......... 159

2.4.4. Oxidation Rate of Organic Contaminants in Hot Spot Sludge .............. 166

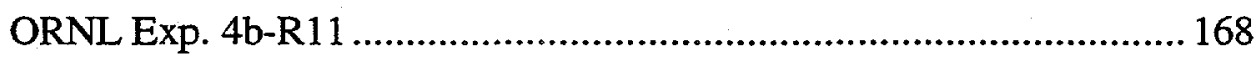

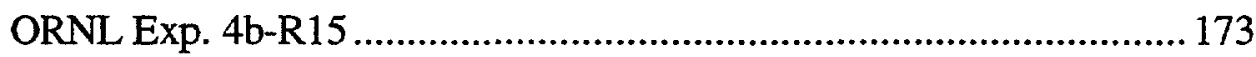

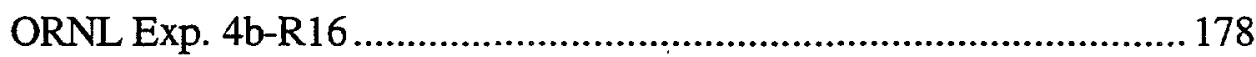

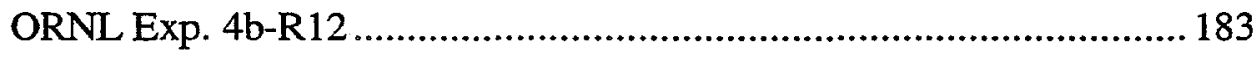

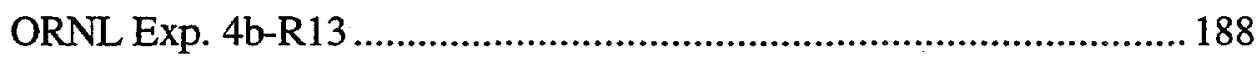

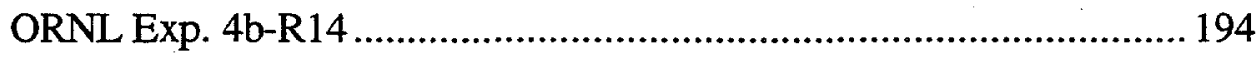

Summary - VOC Oxidation Rate Measurements, Hot Spot Sludge .....200

2.4.5. TSF-05 Sludge Baseline Characteristics and Effect of Oxidation ......... 207

2.4.5.1 Baseline Characterization......................................................207

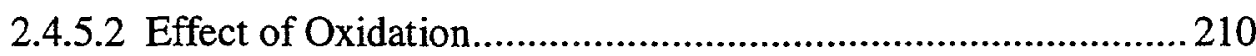

2.4.6. Matrix Spike Experiments ............................................................. 215

ORNL Exp. 2b-1b, Matrix Spike Exp. for Dissolved Plume Media ..... 215

ORNL Exp. 2b-3b, Matrix Spike Exp. for Hot Spot Media .................. 216

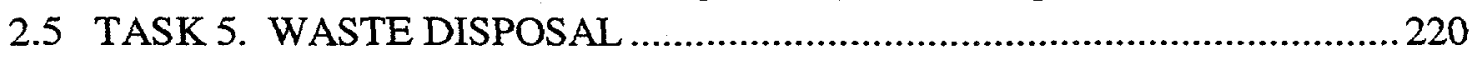




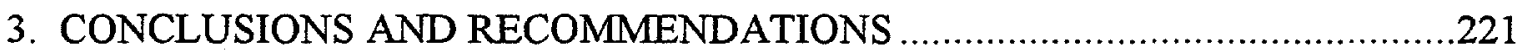

3.1. TASK 1 - PREPARATION OF PROJECT PLANNING DOCUMENTS ....... 221

3.2. TASK 2 - PRELIMINARY LABORATORY STUDIES …........................... 221

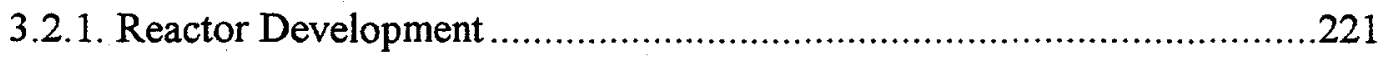

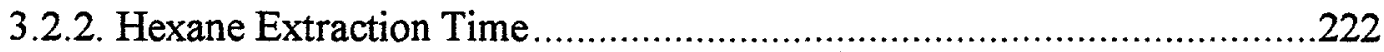

3.2.3. Determination of Equilibration Time for Aggregate Basalt with TCE...222

3.3. TASK 3 - MEASUREMENT OF OXIDANT DEMAND OF TAN

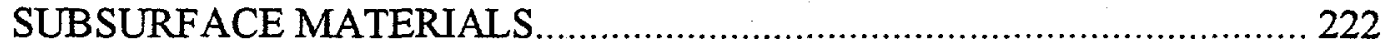

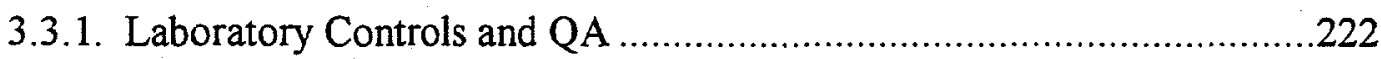

3.3.2. Oxidant Demand in Dissolved Plume Media ......................................223

3.3.3. Oxidant Demand in Hot Spot Media ....................................................223

3.4. TASK 4 - MEASUREMENT OF OXIDATION RATES OF TAN

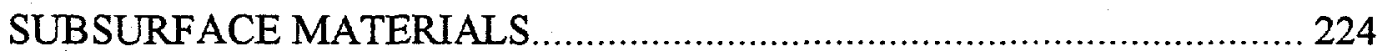

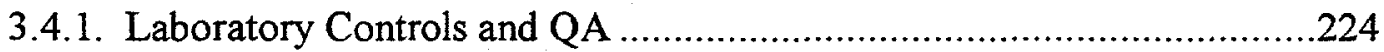

3.4.2. Oxidation Rate of Organic Contaminants in Dissolved Plume Media....224

3.4.3. Oxidation Rate of Organic Contaminants in Hot Spot Media ................225

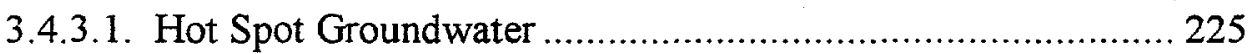

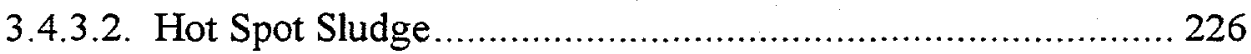

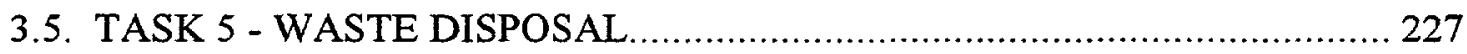

4. REFERENCES

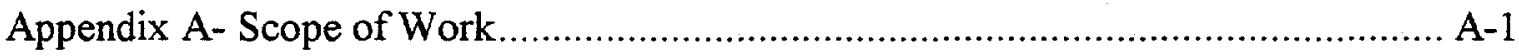

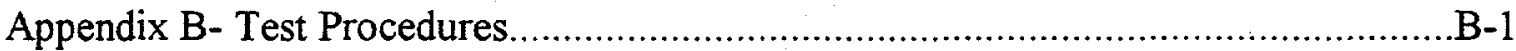

VOLUME TWO

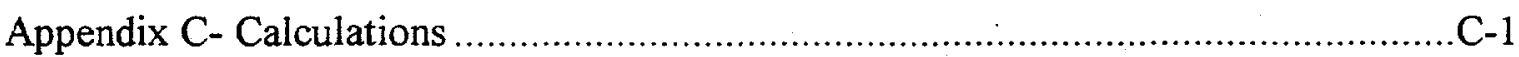

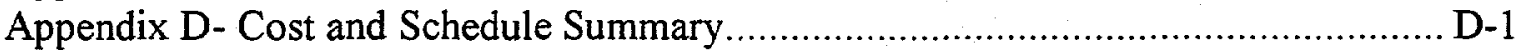

Appendix E- Monthly Progress Reports ................................................................. E-1

VOLUME THREE

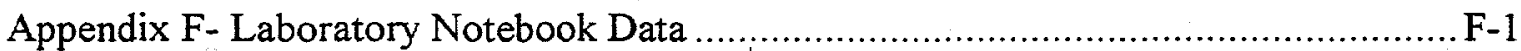

VOLUME FOUR

Appendix G- Calibration Records and Sample Analysis Records .............................. G-1 


\section{LIST OF FIGURES}

Figure 1. Tedlar Bags Used to Spike TAN Site Groundwater with Target VOCs.......... 11

Figure 2. Photograph of the Reaction Vessel used in the Oxidation Experiments..........23

Figure 3. Illustration of the Adapter used in conjunction with the Reaction Vessels......24

Figure 4. Photograph of the Charcoal Desorption Tubes used w/the Reaction Vessels. . 24

Figure 5. TCE Concentrations of the Hexane and Aqueous Phases, ORNL Exp. 2b-1 $\ldots 27$

Figure 6. TCE Concentrations of the Hexane and Aqueous Phases, ORNL Exp. 2b-1...27

Figure 7. TCE Concentrations of the Hexane and Aqueous Phases ORNL Exp. 2b-1....28

Figure 8. TCE Concentrations of the Hexane and Aqueous Phases, ORNL Exp. 2b-3...32

Figure 9. TCE Concentrations of the Hexane and Aqueous Phases, ORNL Exp. 2b-3...32

Figure 10. Oxidant Demand Results for Dissolved Plume Media, ORNL Exp. 3a-R1b.36

Figure 11. Oxidant Demand Results for Dissolved Plume Media, ORNL Exp. 3a-R2b. 37

Figure 12. Oxidant Demand Results for Dissolved Plume Media, ORNL Exp. 3a-R3b. 37

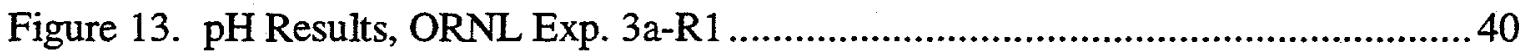

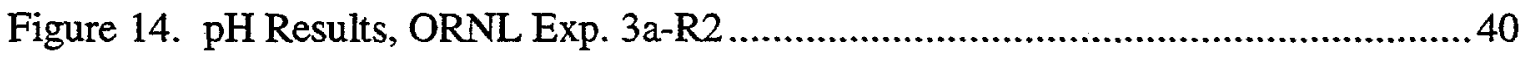

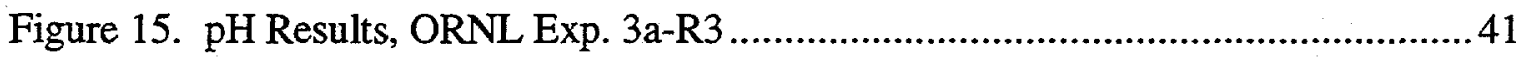

Figure 16. Oxidant Demand Results, Hot Spot Media, ORNL Exp. 3b-R1 .....................44

Figure 17. Oxidant Demand Results, Hot Spot Media, ORNL Exp. 3b-R2 ….................44

Figure 18. Oxidant Demand Results, Hot Spot Media, ORNL Exp. 3b-R3.......................45

Figure 19. Oxidant Demand Results, Hot Spot Media, ORNL Exp. 3b-R4 ....................45

Figure 20. pH Results, Hot Spot Media, ORNL Exp. 3b-R1 .........................................48

Figure 21. pH Results, Hot Spot Media, ORNL Exp. 3b-R2 ………...........................48

Figure 22. pH Results, Hot Spot Media, ORNL Exp. 3b-R3 .......................................49

Figure 23. pH Results, Hot Spot Media, ORNL Exp. 3b-R4 .......................................49

Figure 24. Histogram Illustrating Results of QA/QC Duplicate Sampling......................52

Figure 25. \% Difference of QA/QC Dups vs. the Average Duplicate Concentration. ....52

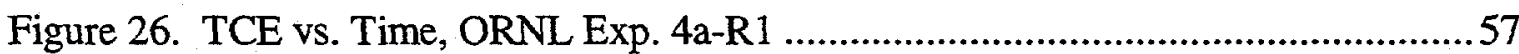

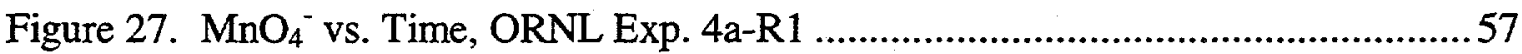

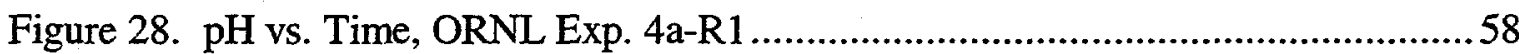

Figure 29. First Order TCE Oxidation Rate Constant, ORNL Exp. 4a-R1 .....................58

Figure 30. First Order TCE Oxidation Rate Constant, ORNL Exp. 4a-R1 ......................59

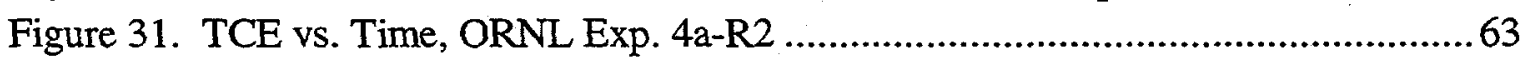

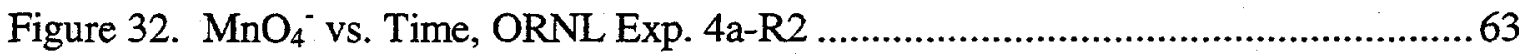

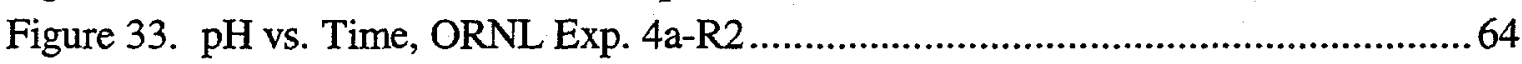

Figure 34. First Order TCE Oxidation Rate Constant, ORNL Exp. 4a-R2 ......................64

Figure 35. First Order TCE Oxidation Rate Constant, ORNL Exp. 4a-R2 …...................65

Figure 36. TCE vs. Time, ORNL Exp. 4a-R3 ………............................................69

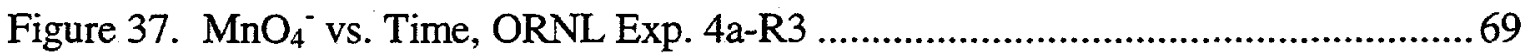

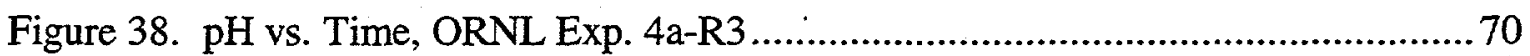

Figure 39. First Order TCE Oxidation Rate Constant, ORNL Exp. 4a-R3 ...................... 70 
Figure 40. TCE vs. Time, ORNL Exp. 4a-R4 ………............................................ 74

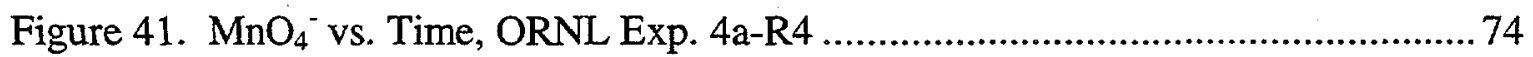

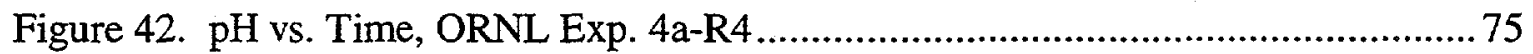

Figure 43. First Order TCE Oxidation Rate Constant, ORNL Exp. 4a-R4 ......................75

Figure 44. First Order TCE Oxidation Rate Constant, ORNL Exp. 4a-R4 .....................76

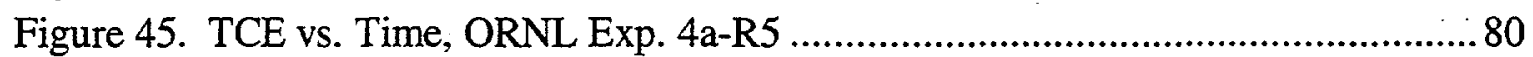

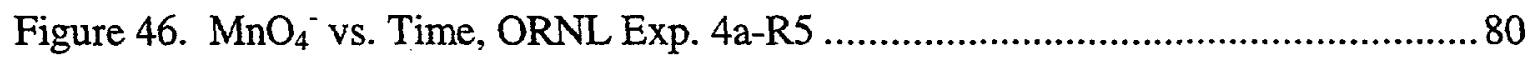

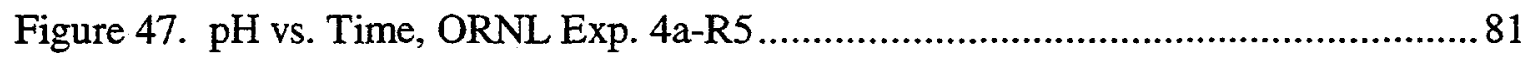

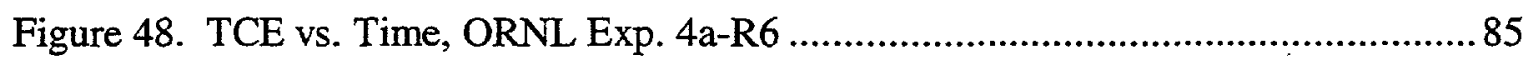

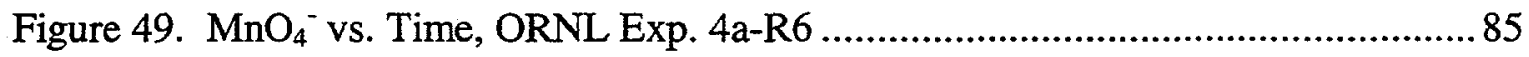

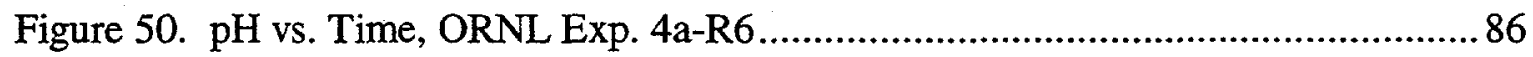

Figure 51. First Order TCE Oxidation Rate Constant, ORNL Exp. 4a-R6...................... 86

Figure 52. First Order TCE Oxidation Rate Constant, ORNL Exp. 4a-R6 ......................87

Figure 53. TCE vs. Time, ORNL Exp. 4a-R7 ......................................................... 91

Figure 54. $\mathrm{MnO}_{4}{ }^{-}$vs. Time, ORNL Exp. 4a-R7 …….............................................. 91

Figure 55. pH vs. Time, ORNL Exp. 4a-R7 ………............................................ 92

Figure 56. First Order TCE Oxidation Rate Constant, ORNL Exp. 4a-R7 ..................... 92

Figure 57. First Order TCE Oxidation Rate Constant, ORNL Exp. 4a-R7 …...................93

Figure 58. TCE vs. Time, ORNL Exp. 4a-R8 ………………................................. 97

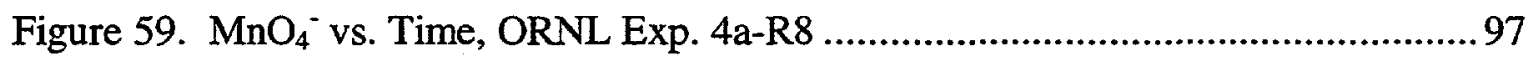

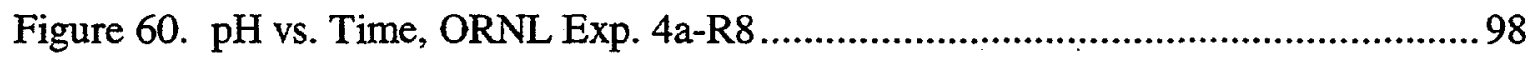

Figure 61. First Order TCE Oxidation Rate Constant, ORNL Exp. 4a-R8......................98

Figure 62. First Order TCE Oxidation Rate Constant, ORNL Exp. 4a-R8 .....................99

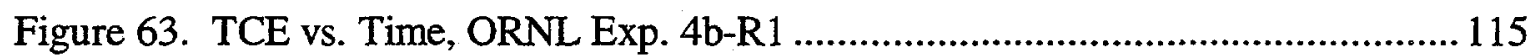

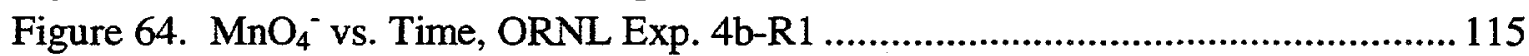

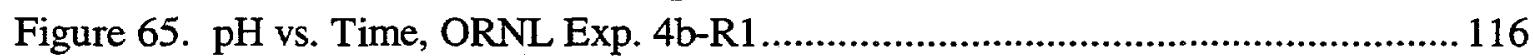

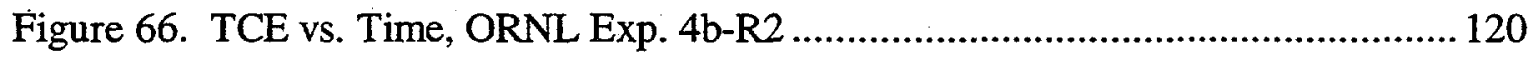

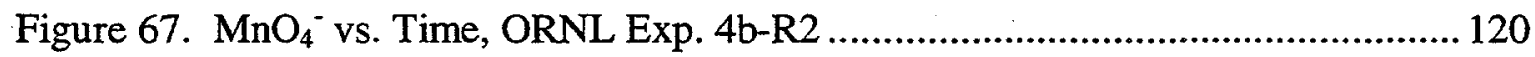

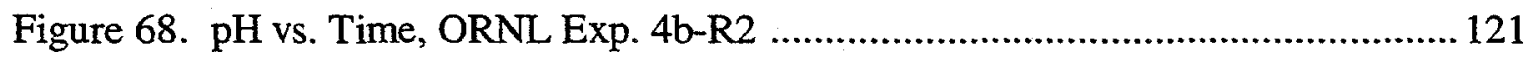

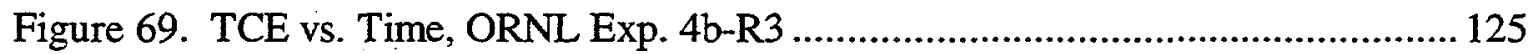

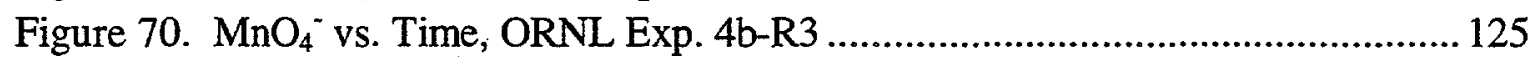

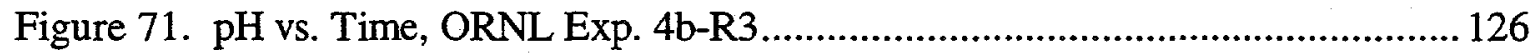

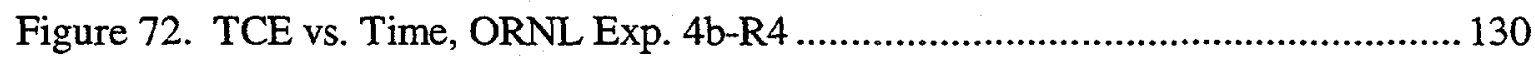

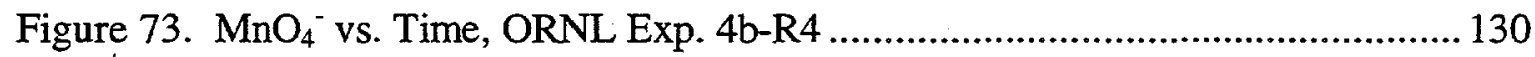

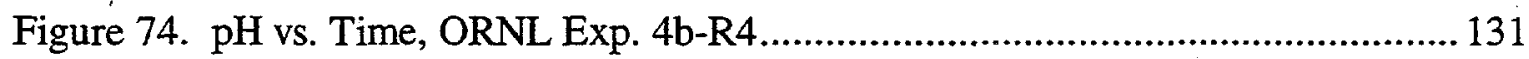

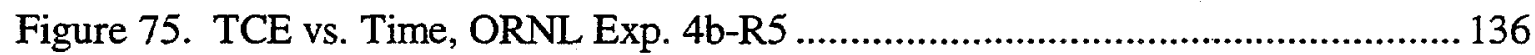

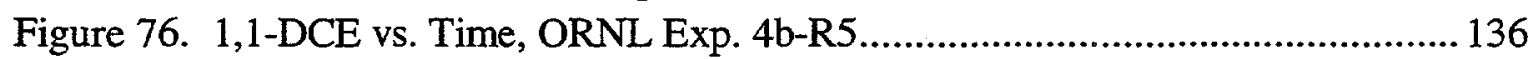

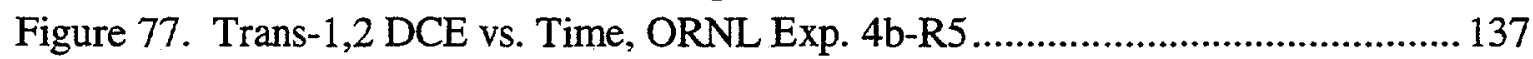

Figure 78. Cis-1,2 DCE vs. Time, ORNL Exp. 4b-R5 ……....................................... 137

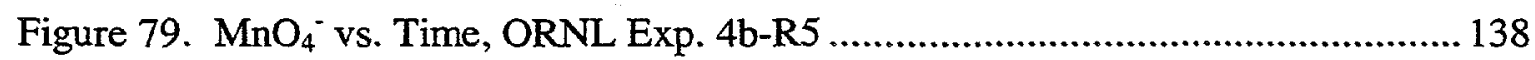

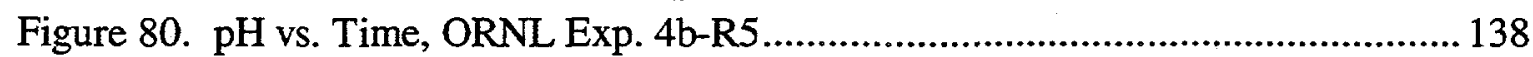


Figure 81. First Order TCE Oxidation Rate Constant, ORNL Exp. 4b-R5.................... 139

Figure 82. First Order TCE Oxidation Rate Constant, ORNL Exp. 4b-R5................... 139

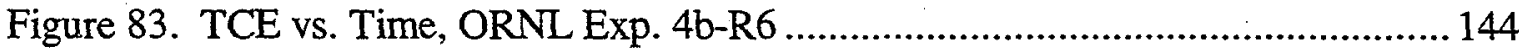

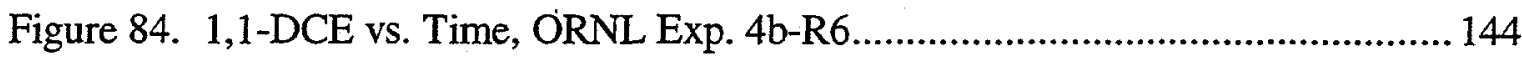

Figure 85. Trans-1,2 DCE vs. Time, ORNL Exp. 4b-R6 ............................................ 145

Figure 86. Cis-1,2 DCE vs. Time, ORNL Exp. 4b-R6 .............................................. 145

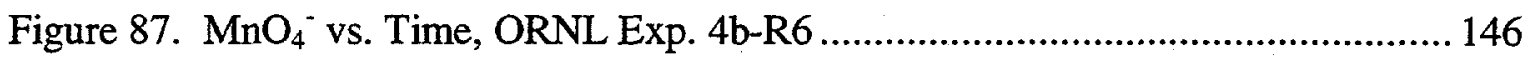

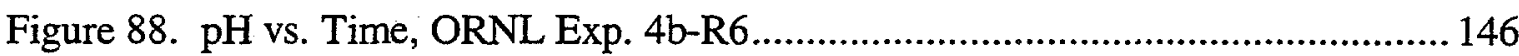

Figure 89. TCE vs. Time, ORNL Exp. 4b-R7 ……….............................................. 151

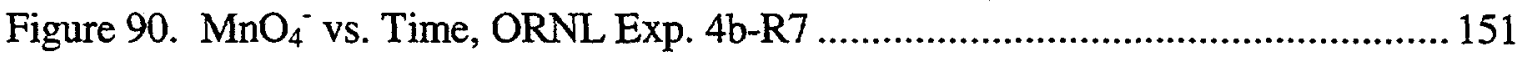

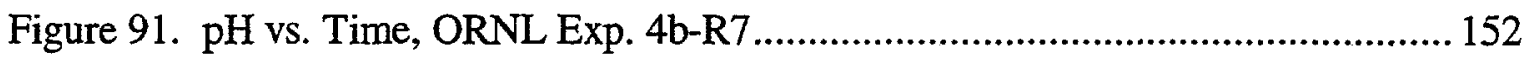

Figure 92. TCE vs. Time, ORNL Exp. 4b-R8 ………........................................... 156

Figure 93. $\mathrm{MnO}_{4}^{-}$vs. Time, ORNL Exp. 4b-R8 ……............................................. 156

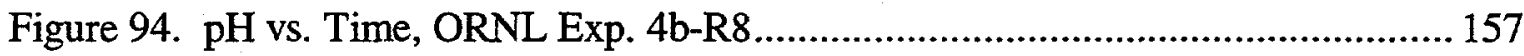

Figure 95. TCE vs. Time, ORNL Exp. 4b-R11 .................................................... 170

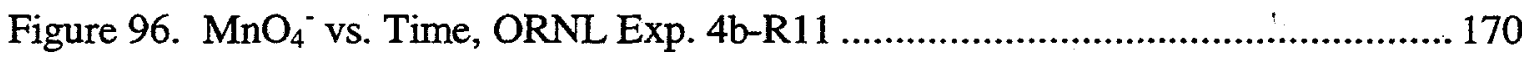

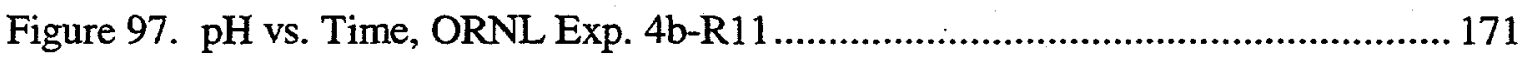

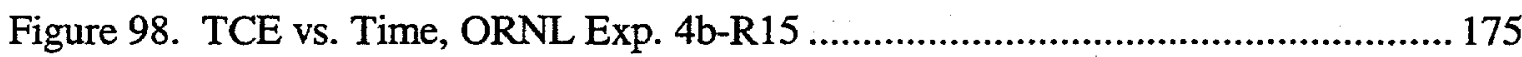

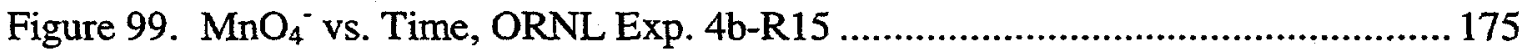

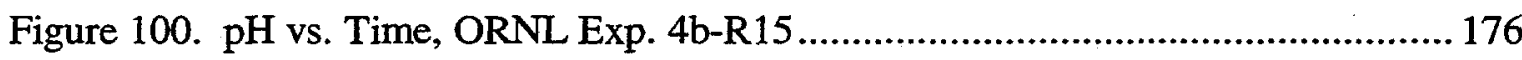

Figure 101. TCE vs. Time, ORNL Exp. 4b-R16 ...................................................... 180

Figure 102. $\mathrm{MnO}_{4}{ }^{-}$vs. Time, ORNL Exp. 4b-R16 ..................................................... 180

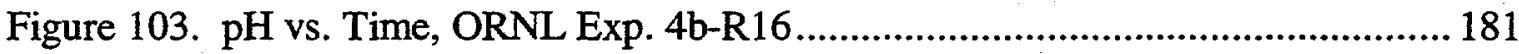

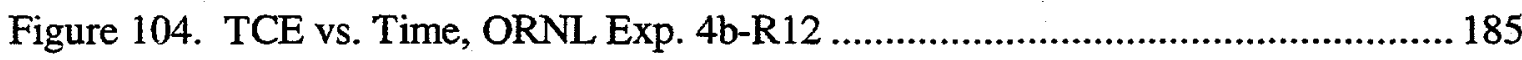

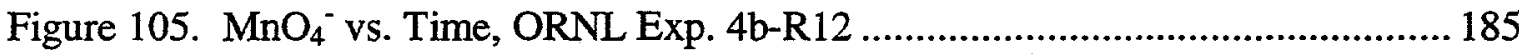

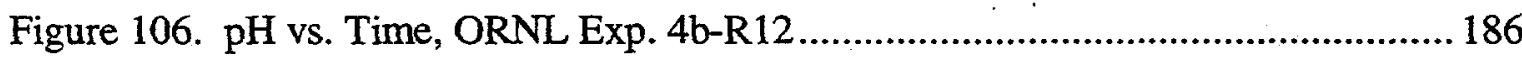

Figure 107. TCE vs. Time, ORNL Exp. 4b-R13 ..................................................... 191

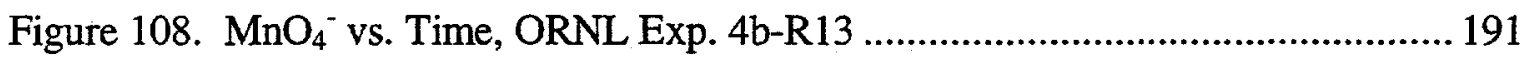

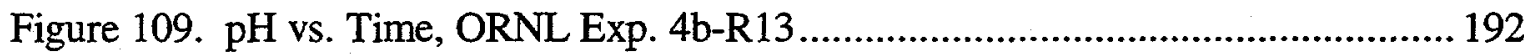

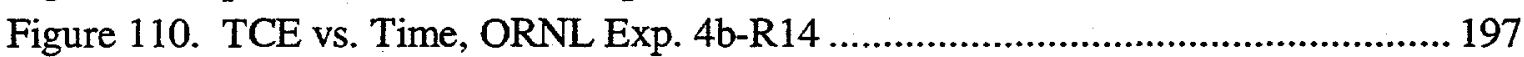

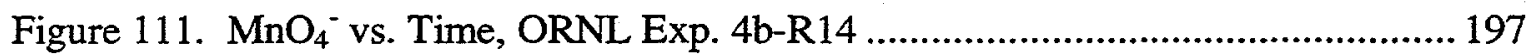

Figure 112. pH vs. Time, ORNL Exp. 4b-R14 ……............................................... 198

Figure 113. First Order TCE Oxidation Rate Constant, ORNL Exp. 4b-R14................ 198

Figure 114. Post-Treatment \%Carbon Value vs. Oxidant Loading for the Task 3b......212

Figure 115. Post-Treatment \%Carbon Oxidized vs. Oxidant Loading for the Task 3b. 212

Figure 116. Post-Treatment Carbon vs TCE Spike Concentration for the Task 4b.......214

Figure 117. Percent of Initial Sludge Carbon Oxidized vs TCE Spike Concentration .. 214

Figure 118. Hexane Aliquot TCE vs. Extraction Time, ORNL Exp. 2b-3b ................ 217

Figure 119. TCE Recovery vs. Hexane Extraction Time, ORNL Exp. 2b-3b ...............218

Figure 120. TCE Recovery vs. Hexane Extraction Time, ORNL Exp. 2b-3b ............... 218

Figure 121. TCE Recovery vs. Hexane Extraction Time, ORNL Exp. 2b-3b .............. 219 



\section{LIST OF TABLES}

Table 1. TAN Site Materials Used in the Laboratory Treatability Studies.....................3

Table 2. Hexane Extraction Time Experiments for the TAN Site Media. .......................7

Table 3. Oxidant Demand Experiments for the Dissolved Plume Media .........................9

Table 4. Oxidant Demand Experiments for the Hot Spot Media................................. 10

Table 5. Oxidation Rate Experiments for the Dissolved Plume Media .......................... 13

Table 6. Oxidation Rate Experiments for Hot Spot Groundwater.............................. 15

Table 7. Oxidation Rate Experiments for Hot Spot Groundwater and Sludge ............... 17

Table 8. Calculated Oxidant Demand Values for the Dissolved Plume Media............... 38

Table 9. Calculated Oxidant Demand Values for the Hot Spot Media .........................46

Table 10. Experimental Identification for the 'Oxidant Demand' (Task 3) Studies........ 50

Table 11. Representative Oxidant Demand for TAN Subsurface Media......................50

Table 12. TCE Mass Balance for ORNL Exp. 4a-R1 ............................................60

Table 13. $\mathrm{MnO}_{4}{ }^{-}$Consumption Data for ORNL Exp. 4a-R1 ..................................60

Table 14. TCE Mass Balance for ORNL Exp. 4a-R2 .........................................66

Table 15. $\mathrm{MnO}_{4}{ }^{-}$Consumption Data for ORNL Exp. 4a-R2 ..................................66

Table 16. TCE Mass Balance for ORNL Exp. 4a-R3 .......................................... 71

Table 17. $\mathrm{MnO}_{4}{ }^{-}$Consumption Data for ORNL Exp. 4a-R3......................................71

Table 18. TCE Mass Balance for ORNL Exp. 4a-R4 ............................................77

Table 19. $\mathrm{MnO}_{4}{ }^{-}$Consumption Data for ORNL Exp. 4a-R4 .................................... 77

Table 20. TCE Mass Balance for ORNL Exp. 4a-R5 ...........................................82

Table 21. $\mathrm{MnO}_{4}{ }^{-}$Consumption Data for ORNL Exp. 4a-R5................................. 82

Table 22. TCE Mass Balance for ORNL Exp. 4a-R6 ........................................... 88

Table 23. $\mathrm{MnO}_{4}{ }^{-}$Consumption Data for ORNL Exp. 4a-R6...................................8 88

Table 24. TCE Mass Balance for ORNL Exp. 4a-R7 ..............................................94

Table 25. $\mathrm{MnO}_{4}{ }^{-}$Consumption Data for ORNL Exp. 4a-R7 ....................................94

Table 26. TCE Mass Balance for ORNL Exp. 4a-R8............................................. 100

Table 27. $\mathrm{MnO}_{4}{ }^{-}$Consumption Data for ORNL Exp. 4a-R8 .................................... 100

Table 28. Experimental Identification for Dissolved Plume Media Experiments......... 101

Table 29. Initial $\mathrm{MnO}_{4}{ }^{-}$Concentrations for Dissolved Plume Media Experiments....... 102

Table 30. Final $\mathrm{MnO}_{4}{ }^{-}$Concentrations for Dissolved Plume Media Experiments ........ 102

Table 31. Initial TCE Concentrations for Dissolved Plume Media Experiments.......... 104

Table 32. Final TCE Concentrations for Dissolved Plume Media Experiments ........... 104

Table 33. Percentage of Initial TCE Mass Oxidized and Removed by Sampling ......... 105

Table 34. Observed Minimum Zero Order TCE Destruction Rates-Per Reactor Basis. 105

Table 35. Observed Minimum Zero Order TCE Destruction Rates-Per Unit Volume' 106

Table 36. Representative Zero Order TCE Oxidation Rates .................................... 107

Table 37. pH Trends for Dissolved Plume Experiments.......................................... 107

Table 38. Summary of the Dissolved Plume Media Oxidation Rate Experiments........ 109

Table 39. TCE Mass Balance for ORNL Exp. 4b-R1 .......................................... 117 
Table 40. $\mathrm{MnO}_{4}{ }^{-}$Consumption Data for ORNL Exp...................................................117

Table 41. TCE Mass Balance for ORNL Exp. 4b-R2 …............................................. 122

Table 42. $\mathrm{MnO}_{4}{ }^{-}$Consumption Data for ORNL Exp. 4b-R2 .................................. 122

Table 43. TCE Mass Balance for ORNL Exp. 4b-R3 ……........................................ 127

Table 44. $\mathrm{MnO}_{4}{ }^{-}$Consumption Data for ORNL Exp. 4b-R3 ……............................... 127

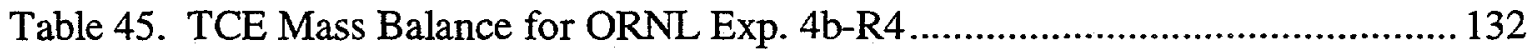

Table 46. $\mathrm{MnO}_{4}{ }^{-}$Consumption Data for ORNL Exp. 4b-R4 .................................... 132

Table 47. TCE Mass Balance for ORNL Exp. 4b-R5 ................................................. 140

Table 48. $\mathrm{MnO}_{4}{ }^{-}$Consumption Data for ORNL Exp. 4b-R5 ....................................... 140

Table 49. TCE Mass Balance for ORNL Exp. 4b-R6 ……........................................ 147

Table 50. $\mathrm{MnO}_{4}{ }^{-}$Consumption Data for ORNL Exp. 4b-R6 ....................................... 147

Table 51. TCE Mass Balance for ORNL Exp. 4b-R7 ……......................................... 153

Table 52. $\mathrm{MnO}_{4}{ }^{-}$Consumption Data for ORNL Exp. 4b-R7 .................................... 153

Table 53. TCE Mass Balance for ORNL Exp. 4b-R8 .............................................. 158

Table 54. $\mathrm{MnO}_{4}{ }^{-}$Consumption Data for ORNL Exp. 4b-R8 ....................................158

Table 55. Experimental Identification for Hot Spot Groundwater Experiments........... 159

Table 56. Initial $\mathrm{MnO}_{4}{ }^{-}$Concentrations, Hot Spot Groundwater Experiments .............. 160

Table 57. Final $\mathrm{MnO}_{4}{ }^{-}$Concentrations, Hot Spot Groundwater Experiments ............... 160

Table 58. Initial Aqueous TCE Concentrations, Hot Spot Groundwater Experiments .. 161

Table 59. Final Aqueous TCE Concentrations,Hot Spot Groundwater Experiments.... 161

Table 60. Percentage of Initial TCE Mass Oxidized and Removed via Sampling ........ 162

Table 61. Observed Minimum Zero Order TCE Destruction Rates-Per Reactor........... 162

Table 62. Observed Minimum Zero Order TCE Destruction Rates -Per Unit Volume 163

Table 63. Observed pH Trends in the Hot Spot Groundwater Experiments .................. 163

Table 64. Summary of the Hot Spot Groundwater Oxidation Rate Experiments........... 164

Table 65. TCE Mass Balance for ORNL Exp. 4b-R11 ….......................................... 172

Table 66. $\mathrm{MnO}_{4}{ }^{-}$Consumption Data for ORNL Exp. 4b-R11 …..............................172

Table 67. TCE Mass Balance for ORNL Exp. 4b-R15 …...........................................177

Table 68. $\mathrm{MnO}_{4}{ }^{-}$Consumption Data for ORNL Exp. 4b-R15 …................................. 177

Table 69. TCE Mass Balance for ORNL Exp. 4b-R16 ……...................................... 182

Table 70. $\mathrm{MnO}_{4}{ }^{-}$Consumption Data for ORNL Exp. 4b-R16 …................................. 182

Table 71. TCE Mass Balance for ORNL Exp. 4b-R12 ….......................................... 187

Table 72. $\mathrm{MnO}_{4}{ }^{-}$Consumption Data for ORNL Exp. 4b-R12 …............................... 187

Table 73. TCE Mass Balance for ORNL Exp. 4b-R13 ….......................................... 193

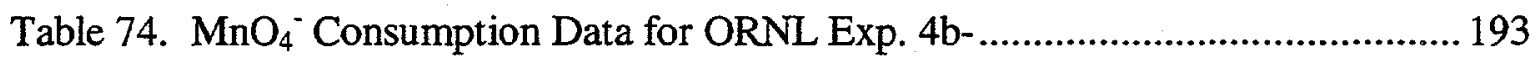

Table 75. TCE Mass Balance for ORNL Exp. 4b-R14 ……........................................ 199

Table 76. $\mathrm{MnO}_{4}{ }^{-}$Consumption Data for ORNL Exp. 4b-R14 ...................................... 199

Table 77. Experimental Identification for Hot Spot Sludge Experiments......................200

Table 78. Initial $\mathrm{MnO}_{4}{ }^{-}$Concentrations, Hot Spot Sludge Experiments......................... 201

Table 79. Final $\mathrm{MnO}_{4}{ }_{4}^{-}$Concentrations, Hot Spot Sludge Experiments ............................201

Table 80. Initial Aqueous TCE Concentrations, Hot Spot Sludge Experiments ........... 202 
Table 81. Final Aqueous TCE Concentrations, Hot Spot Sludge Experiments 203

Table 82. Percentage of TCE Oxidized, Hot Spot Sludge Experiments ..................... 203

Table 83. Observed Minimum Zero Order TCE Destruction Rates-Per Reactor.......... 204

Table 84. Observed Minimum Zero Order TCE Destruction Rates-Per Unit Volume . 204

Table 85. Observed pH Trends in the Hot Spot Groundwater Experiments............... 205

Table 86. Summary of the Hot Spot Sludge Oxidation Rate Experiments.................. 206

Table 87. Baseline TSF-05 Sludge Density and Percent Moisture. ............................ 208

Table 88. Radiochemical Methods used for TSF-05 Sludge Determinations.............. 208

Table 89. Baseline TSF-05 Sludge Radiochemical Analytical Results...................... 209

Table 90. Baseline Total Carbon Values for Raw and Dried TSF-05 Sludges............ 209

Table 91. Post Oxidant Demand Results, TSF-05 Sludge Total Carbon..................... 210

Table 92. Post-Treatment Degradation Rate Results, TSF-05 Sludge Total Carbon. ... 211

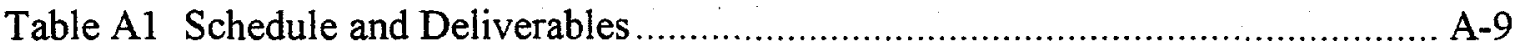

Table A2.1 Laboratory Reaction Study Objectives ……...................................... A-12

Table A2.2 Experimental Variables in Reaction Studies....................................... A-15

Table A2.3 Oxidant Consumption by Dissolved Plume Media ……..................... A-15

Table A2.4 Oxidant Consumption by Hot Spot Media....................................... A-16

Table A2.5 TCE Degradation Rate in Groundwater and Basalt.............................. A-16

Table A2.6 TCE Degradation Rate in Hot Spot Groundwater ................................. A-17

Table A2.7 TCE Degradation Rate in Hot Spot Groundwater and Sludge ................. A-17

Table B2.1 Analytical Methods for Hot Spot Media Sludges..................................... B-23 
, 


$\begin{array}{ll}1,1-D C E & 1,1-D i c h l o r o e t h y l e n e \\ \text { cis-1,2 DCE } & \begin{array}{l}\text { cis-1,2 Dichloroethylene } \\ \text { distilled, deionized }\end{array} \\ \text { DI } & \text { Dilution Factor } \\ \text { DF } & \text { dense, non-aqueous phase liquid } \\ \text { DNAPL } & \text { Electron Capture Detector } \\ \text { ECD } & \text { Environmental Sciences Division (ORNL) } \\ \text { ESD } & \text { gas chromatograph } \\ \text { GC } & \text { groundwater } \\ \text { GW } & \text { Idaho National Environmental Engineering Laboratory } \\ \text { INEEL } & \text { In Situ Chemical Oxidation } \\ \text { ISCO } & \text { Potassium permanganate } \\ \text { KMnO } & \text { liquid to solid ratio } \\ \text { L/S } & \text { method detection limit } \\ \text { MDL } & \text { permanganate anion } \\ \text { MnO }{ }_{4}^{-} & \text {parts per billion } \\ \mu \text { g/L } & \text { parts per million } \\ \text { ppm } & \text { Oak Ridge National Laboratory } \\ \text { ORNL } & \text { Resource Conservation and Recovery Act } \\ \text { RCRA } & \text { Radioactive Materials Analytical Laboratory (ORNL) } \\ \text { RMAL } & \text { statement of work } \\ \text { SOW } & \text { specific gravity } \\ \text { spg } & \text { Test Area North } \\ \text { TAN } & \text { total carbon } \\ \text { TC } & \text { Trichloroethylene } \\ \text { TCE } & \text { total organic carbon } \\ \text { TOC } & \text { trans-1,2 Dichloroethylene } \\ \text { trans-1,2 DCE } & \text { volatile organic analysis } \\ \text { VOA } & \text { volatile organic compound } \\ \text { VOC } & \text { quality assurance and quality control } \\ \text { QAVC } & \end{array}$




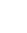




\begin{abstract}
This laboratory investigation was performed to evaluate the feasibility of utilizing in situ chemical oxidation for remediating the secondary source of groundwater contaminants at the Idaho National Engineering and Environmental Laboratory (INEEL) Test Area North (TAN) Site. The study involved trichloroethene (TCE) contaminated media (groundwater, soil, and sludge) from TAN. The effectiveness of the selected oxidant, potassium permanganate $\left(\mathrm{KMnO}_{4}\right)$, was evaluated at multiple oxidant and contaminant concentrations. Experiments were performed to determine the oxidant demand of each medium and the rate of TCE oxidation. The experiments were performed under highly controlled conditions (gas-tight reactors, constant $12^{\circ} \mathrm{C}$ temperature). Multiple parameters were monitored over time including $\mathrm{MnO}_{4}{ }^{-}$and TCE concentrations and $\mathrm{pH}$.

The organic sludge has a very large oxidant demand (70 $\mathrm{mg} \mathrm{MnO} \% / \mathrm{g}$ ) relative to the other media evaluated (0.05-0.2 $\left.\mathrm{mg} \mathrm{MnO}_{4}{ }^{-} / \mathrm{g}\right)$. TCE was rapidly oxidized under all conditions investigated in this study. In most cases, TCE concentrations declined to less than the method detection limit in less than 30 minutes. The oxidation rate appeared to increase with initial TCE concentration. Even the lowest TCE loss rates observed are sufficiently rapid to suggest that in situ chemical oxidation would be effective for remediating dissolved TCE at the INEEL TAN site.
\end{abstract}




\section{IMPLEMENTATION APPROACH AND OBJECTIVES}

\subsection{BACKGROUND}

A laboratory treatability study was recently conducted at the Oak Ridge National Laboratory (ORNL) to evaluate the feasibility of using in situ chemical oxidation (ISCO) for subsurface remediation at the Idaho National Engineering and Environmental Laboratory (INEEL). More specifically, this investigation focused upon using potassium permanganate $\left(\mathrm{KMnO}_{4}\right)$ to remediate a hot spot near the former injection well TSF-05 at INEEL's Test Area North (TAN). The ORNL research team has been involved in laboratory and field investigations of ISCO since 1994 and has the facilities and experience needed to perform the required experiments.

Wastes were disposed into TSF-05 during the period 1953 through 1972. The wastes consisted of organic sewage and industrial waste from manufacturing and maintenance operations. The aquifer beneath TAN is contaminated with chloroethenes and radionuclides. Presently, a plume of trichloroethylene (TCE) extends approximately 10,000 feet downgradient from TSF-05 at concentrations exceeding the regulatory MCL value of $5 \mu \mathrm{g} / \mathrm{L}$. Plumes of tritium $\left({ }^{3} \mathrm{H}\right)$, strontium $\left({ }^{90} \mathrm{Sr}\right)$, and cesium $\left({ }^{137} \mathrm{Cs}\right)$ are much smaller than the TCE plume. Organic sludge in the vicinity of TSF-05, which is derived from sewage and other wastes disposed using TSF-05, is believed to act as a secondary source of dissolved contaminants. ISCO is being evaluated for possible use in destroying chloroethenes in the dissolved phase (both groundwater and matrix porewater), sorbed to geologic material (basalt and fracture-fill material), and associated with the organic sludge. Factors that affect the feasibility of ISCO for subsurface remediation at TAN include (1) the amount of oxidant that would be consumed by reactions with non-targeted materials, i.e. geologic materials, and (2) the effectiveness of ISCO for destroying dissolved chloroethenes and organic sludge. This laboratory investigation was designed and performed to evaluate these factors. Other factors that certainly ISCO feasibility include: mass transfer limitations, accurate delineation of source contamination, and effective oxidant delivery to the source area.

Equations for the typical oxidation of TCE and organic matter as presented below:

$$
\begin{aligned}
& 2 \mathrm{KMnO}_{4}+\mathrm{C}_{2} \mathrm{HCl}_{3} \rightarrow 2 \mathrm{CO}_{2}+2 \mathrm{MnO}_{2}(\mathrm{~s})+2 \mathrm{KCl}+\mathrm{HCl} \\
& \{\text { ORG Matter }\}+\mathrm{MnO}_{4}^{-} \rightarrow \mathrm{CO}_{2}+2 \mathrm{MnO}_{2}(\mathrm{~s})+\mathrm{H}_{2} \mathrm{O}
\end{aligned}
$$

As depicted in the first equation, stoichiometric molar ratio of 2:1 exists for the reaction between $\mathrm{MnO}_{4}{ }^{-}$and TCE. A pH change would also be expected during ISCO due to the generation of $\mathrm{H}^{+}$ ions. Please note that the second equation is a hypothesized reaction due to the complexity of organic matter like that present within the anthropogenic TSF-05 sludge. 


\subsection{OBJECTIVES}

Following initial laboratory shakedown and development work, the laboratory studies performed at ORNL were designed to meet the following objectives:

1. Measure oxidant demand of "dissolved plume media"

2. Measure oxidant demand of "hot spot media"

3. Measure oxidation rate of chloroethenes in the "dissolved plume media"

4. Measure oxidation rate of chloroethenes in "hot spot media"

Actual media from the INEEL TAN site were used in these experiments. A summary of the TAN site materials received by ORNL is presented in Table 1. For the purposes of this treatability study, "dissolved plume media" is defined as any of the following TAN Site materials: TAN-40 groundwater (GW), aggregate basalt, crushed basalt, or sediment. Similarly, TSF-05 GW and organic sludge from the TSF-05 injection well are defined as "hot spot media" in these experiments. Furthermore, as a result of the work performed to meet objectives No. 2 and 4 above, the effectiveness of ISCO for destroying organic sludge was also obtained (see Section 2.4.5). 
Table 1. TAN Site Materials Used in the Laboratory Treatability Studies.

\begin{tabular}{|c|c|c|}
\hline Material & As Received Labeling/Description & $\begin{array}{l}\text { Quantity } \\
\text { Received }\end{array}$ \\
\hline $\begin{array}{l}\text { Dissolved } \\
\text { Plume } \\
\text { Groundwater }\end{array}$ & $\begin{array}{l}\text { Received } 2 / 11 / 98 \\
\text { TAN-40/GW/01 } \\
\text { Collected at } 275 \text {. }\end{array}$ & 60 liters \\
\hline $\begin{array}{l}\text { Hot Spot } \\
\text { Groundwater }\end{array}$ & $\begin{array}{l}\text { Received } 2 / 11 / 98 \\
\text { TSF-05/GW/01 }\end{array}$ & 80 liters \\
\hline $\begin{array}{l}\text { Aggregate } \\
\text { Basalt }\end{array}$ & $\begin{array}{l}\text { Received } 2 / 11 / 98 \\
\text { TAN-37/BSLT/01 }\end{array}$ & $6 \mathrm{~kg}$ \\
\hline Crushed Basalt & $\begin{array}{l}\text { Received } 2 / 11 / 98 \\
\text { TAN-37/BSLT/02 }\end{array}$ & $9 \mathrm{~kg}$ \\
\hline $\begin{array}{l}\text { Sediment } \\
\text { (SED1) }\end{array}$ & $\begin{array}{l}\text { Received } 2 / 11 / 98 \\
\text { TAN-37 Sed/01 } \\
\text { Received } 3 / 3 / 98 \\
\text { Q-R Interbed } \\
322 \text { TAN } 33 \\
\text { Frac/Fill TAN-38 \& TAN-40 }\end{array}$ & $\begin{array}{l}100 \mathrm{~g} \\
500 \mathrm{~g} \\
50 \mathrm{~g} \\
775 \mathrm{~g}\end{array}$ \\
\hline $\begin{array}{l}\text { Sediment } \\
\text { (SED2) }\end{array}$ & $\begin{array}{l}\text { Received } 7 / 31 / 98 \\
\text { Sediment from TAN-33 Borehole } \\
\text { (Interbed beneath and within the } \\
\text { TAN aquifer) } \\
\text { Sample 1 (213.5'-228') } \\
\text { Sample } 2\left(348^{\prime}-353^{\prime}\right) \\
\text { Sample } 3\left(366^{\prime}\right) \\
\left.\text { Sample } 4 \text { (QR } 441^{\prime}\right) \\
\left.\text { Sample } 5 \text { (CI } 144^{\prime}\right)\end{array}$ & $\begin{array}{l}149 \mathrm{~g} \\
85 \mathrm{~g} \\
10 \mathrm{~g} \\
190 \mathrm{~g} \\
113 \mathrm{~g}\end{array}$ \\
\hline TSF-05 Sludge & $\begin{array}{l}\text { Received } 2 / 27 / 98 \& 3 / 2 / 98 \\
\text { Depth: } 307.5 '-310^{\prime}\end{array}$ & $\begin{array}{l}20 \text { liters } \\
(36 \mathrm{~kg})\end{array}$ \\
\hline
\end{tabular}




\subsection{APPROACH}

Activities conducted during this study were guided by the scope of work (SOW) transmitted to ORNL. The SOW included preliminary activities to prepare for the laboratory experiments and a framework of parameters and variables to be evaluated in order to accomplish the objectives described in Section 1.2. Guidelines for disposing of the laboratory residuals and preparing monthly cost and technical progress reports were also included in the SOW. Specifically, the SOW consisted of the following eight (8) tasks:

Task 1. Preparation of Project Planning Documents

Task 2. Preliminary Laboratory Studies

Task 3. Measurement of the Oxidant Demand of TAN Subsurface Materials

Task 4. Measurement of Oxidation Rates of the TAN Subsurface Materials

Task 5. Waste Disposal

Task 6. Progress Reports

Task 7. Preparation of Final Report

Task 8. Presentation of the Laboratory Results

Several of these eight main tasks involved multiple subtasks. For additional details, the SOW can be found in this report as Appendix A. The majority of the laboratory activities were associated with Tasks 3 and 4 of the SOW, which were further divided into studies involving the dissolved plume media and the hot spot media. Due to the higher radionuclide activity of the TSF-05 sludge, most experiments involving the hot spot media were conducted at ORNL's Radioactive Materials Analytical Laboratory (RMAL). The RMAL is functionally a part of ORNL's Chemical and Analytical Sciences Division. ORNL's Environmental Sciences Division (ESD) performed all the experiments involving the dissolved plume media. Furthermore, ESD performed the all the VOC analyses for both ORNL research teams.

\subsection{PROCEDURES}

A detailed laboratory testplan with step by step instructions needed to execute the laboratory experiments was prepared by ORNL. This section describes the general procedure/approach used for each type of experiment and/or task. This section also describes many of the QA/QC elements that were written into the testplan. The laboratory testplan is included in this report as Appendix B if further details regarding the mechanics of each experiment are desired. Any significant deviations from the testplan and/or problems encountered during execution of the experiments are presented within the results and discussion section of this report (Section 2.0) for the affected experiment(s). 


\subsubsection{Summary Procedures for Preliminary Laboratory Experiments}

The preliminary laboratory experiments (Task 2 SOW in Appendix A) were conducted to assess whether the equipment and/or approach planned for the experiments in Tasks 3 and 4 of the SOW were appropriate. The general methodology used for each Task 2 subtask is discussed here.

\subsubsection{Reactor Development}

The oxidation experiments utilizing TCE-spiked TAN media and $\mathrm{KMnO}_{4}$ (SOW Task 4) must be performed under controlled conditions to minimize and quantify VOC losses from the reaction vessels due to volatilization. Zero headspace extraction vessels used by the ORNL research team in the past could not be used due to their small sample capacity $(130 \mathrm{~mL})$. Thus, alternative reactors had to be acquired and tested. These experiments were designed using the TCE mass balance as the main criterion to evaluate reactor acceptability. Most reactor acceptability experiments were conducted at room temperature using distilled water as the TCE spiked medium. This development task was an iterative process until the right combination of sampling ports, gaskets, etc. was achieved. Procedures used in the numerous shakedown experiments are not presented here. Instead, a summary of the procedure used to evaluate the final reactor configuration can be found in Section 2.2.1 along with a description of the selected reactor. 


\subsubsection{Determination of Hexane Extraction time of TCE from TAN Media}

TCE was extracted from aqueous and solid media by hexane extraction, and the hexane was analyzed by gas chromatography. Before the experimental procedures for the oxidation experiments could be finalized, experiments were performed to determine the optimum extraction time for transferring TCE from the solid and aqueous phases of the TAN site media into the hexane phase. In these batch experiments, TAN site groundwater was spiked with TCE and allowed to equilibrate overnight at $12-15^{\circ} \mathrm{C}$ with each type of solid phase media at $\approx 4: 1$ liquid/soil (weight basis). (Extraction of TCE from the groundwater alone was also evaluated.) A summary of the hexane extraction time experiments is presented in Table 2. Each test condition was conducted in duplicate.

After equilibration of the spiked groundwater with the solid phase material (when applicable), the contents of each vessel ( $40 \mathrm{~mL}$ vials) were transferred to a larger container $(125 \mathrm{~mL}$ glass jar) and extracted with an equal volume of hexane. The extraction portion of the experiment was conducted at room temperature. At various time points during the extraction step, samples from both the hexane and aqueous phases were collected and analyzed for TCE as discussed below in Section 1.4.4. For these experiments, the aqueous phase samples pulled from the second container were extracted for an additional 30 minutes prior to analysis. The detailed procedures used for these experiments can be found in the laboratory testplan (Appendix B) under the applicable Exp. ID listed in Table 2. 
Table 2. Hexane Extraction Time Experiments for the TAN Site Media.

\begin{tabular}{|l|lccccc|}
\hline $\begin{array}{l}\text { ORNL } \\
\begin{array}{l}\text { Exp. } \\
\text { I.D. }\end{array}\end{array}$ & Media Used & $\begin{array}{c}\text { Basalt } \\
\text { Form }\end{array}$ & $\begin{array}{c}\text { L/S } \\
\text { Ratio }\end{array}$ & $\begin{array}{c}\text { Initial } \\
\text { TCE } \\
\text { Conc. } \\
(\mu \mathrm{g} / \mathrm{L})\end{array}$ & $\begin{array}{c}\text { Initial Organic } \\
\text { Co-Contaminant } \\
\text { Conc. } \\
(\mu \mathrm{g} / \mathrm{L})\end{array}$ & $\begin{array}{c}\text { Initial } \\
\mathrm{MnO}_{4}{ }^{-} \\
\text {Conc. } \\
(\%)\end{array}$ \\
\hline \multirow{5}{*}{ 2b-1 } & TAN-40 GW & NA & NA & 1,000 & 0 & 0.0 \\
& TAN-40 GW & NA & NA & 1,000 & 0 & 0.0 \\
& TAN-40 GW/basalt & Crushed & $4: 1$ & 1,000 & 0 & 0.0 \\
& TAN-40 GW/basalt & Crushed & $4: 1$ & 1,000 & 0 & 0.0 \\
& TAN-40 GW/SED1 & NA & $4: 1$ & 1,000 & 0 & 0.0 \\
& TAN-40 GW/SED1 & NA & $4: 1$ & 1,000 & 0 & 0.0 \\
\hline \multirow{5}{*}{ 2b-2 } & TAN-40 GW & NA & NA & 1,000 & 0 & 0.0 \\
& TAN-40 GW & NA & NA & 1,000 & 0 & 0.0 \\
& TAN-40 GW/basalt & Aggregate & $4: 1$ & 1,000 & 0 & 0.0 \\
& TAN-40 GW/basalt & Aggregate & $4: 1$ & 1,000 & 0 & 0.0 \\
\hline \multirow{3}{*}{ 2b-3 } & TSF-05 GW & NA & NA & 100,000 & 0 & 0.0 \\
& TSF-05 GW & NA & NA & 100,000 & 0 & 0.0 \\
& TSF-05 GW/Sludge & NA & $4: 1$ & 100,000 & 0 & 0.0 \\
& TSF-05 GW/Sludge & NA & $4: 1$ & 100,000 & 0 & 0.0 \\
\hline
\end{tabular}

a. Experimental identifier used by ORNL in the collection and interpretation of the test data.

\subsubsection{Determination of Equilibration Time of the Aggregate Basalt with TCE Solutions}

The length of time needed to equilibrate TCE concentrations in matrix pore water of aggregate basalt pieces (i.e. 1/4 to 1 inch diameter) with TCE concentrations in the surrounding (bulk) water is unknown. Thus, there experiments were designed to assess the needed spiking time that would be required for spiking the aggregate basalt in the Task 4 experiments. The goal of this task was to determine the length of time required for equilibrium to be reached between TCE in the matrix pore water and the surrounding solution. Two different experimental approaches were attempted at ORNL for this task. Unfortunately, neither technique yielded definitive results.

In the first experimental approach, an initial TCE spike concentration of $1,000 \mu \mathrm{g} / \mathrm{L}$ was used $\left(12-15^{\circ} \mathrm{C}\right)$. A study by Pavlostathis and Jaglal (1991) involving TCE sorption onto a silty sand indicated quasi-equilibrium within a period of three (3) days. However, other studies with PCE and course grain bulk material show equilibration to be on the order of 20 days, whereas equilibration using pulverized material was approximately 1 day (Ball, 1991). This experiment employed the use of several $40 \mathrm{~mL}$ volatile organic analysis (VOA) vials that were filled with either aggregate basalt or crushed basalt and TCE-spiked TAN-40 GW at a 4:1 Liquid to Soil (L/S) ratio. (The samples containing crushed basalt were used for comparison.) These vials were sacrificially sampled and analyzed for TCE at various times ranging from 2 hours to 21 days. The TCE analyses technique used in this experiment involved a hexane extraction of the aqueous samples prior to analysis (see Section 1.4.6 for additional information). Experimental controls (TCE-spiked TAN-40 groundwater with no solid phase) were also carried through the experiment to help account for losses via volatilization, biodegradation, or sorption of TCE onto 
the test equipment, etc. There was no attempt to assess parameters such as ionic strength, $\mathrm{pH}$, etc. The detailed procedure used in this experiment can be found in Appendix B.

In the second experimental attempt for this task, the general approach used was similar. However, many steps were slightly modified (See Appendix B) in order to measure for TCE via a purge and trap technique rather than performing a hexane extraction. Additional information regarding why these experiments were inconclusive is presented in Section 2.2.3.

\subsubsection{Summary of Procedures for Oxidant Demand Experiments}

The batch oxidant demand experiments (Task 3 in the SOW) were performed to determine the amount of oxidant consumed by each type of TAN site media received from INEEL. TCE was removed from all TAN site media used in the oxidant demand experiments prior to the start of each experiment. To remove TCE from the media as received from INEEL, groundwater was sparged with air and solid phase material was oven dried at $100^{\circ} \mathrm{C}$ for a minimum of 4 hours. It should be noted that experiments were not performed to determine whether this step affected the oxidant demand of the TAN media.

Tables 3 and 4 summarize the factors evaluated during each oxidant demand experiment performed for the dissolved plume media and hot spot media, respectively. The dissolved phase media were evaluated using initial oxidant solution concentrations of $0.01 \%, 0.1 \%$ and $1 \%$ $\mathrm{MnO}_{4}$. The hot spot media were subjected to initial oxidant solution concentrations of $0.01 \%$, $0.1 \%, 1 \%$, and $3 \% \mathrm{MnO}_{4}^{-}$. Each TAN site medium was evaluated in duplicate

As presented in Tables 3 and 4, each solid phase medium was evaluated using a 4:1 L/S ratio. All oxidant demand experiments were performed under controlled temperature conditions. Each ORNL research team acquired an incubator/shaking chamber (Innova 4230), allowing all oxidant demand experiments to be conducted at a constant $12^{\circ} \mathrm{C}$. All test samples were also agitated via a reciprocating shaker at $200-250 \mathrm{rpm}$. The groundwater $(\approx 400 \mathrm{~mL})$ and solid phase material $(\approx 100 \mathrm{~g}$, when applicable) were first added to $500 \mathrm{~mL}$ Erlenmeyer flasks and allowed to equilibrate overnight at $12^{\circ} \mathrm{C}$. (The mass of each medium added was measured and recorded.) $\mathrm{A}$ sample aliquot $(\approx 6.5 \mathrm{~mL})$ was then collected for $\mathrm{pH}$ and $\mathrm{MnO}_{4}{ }^{-}$analyses prior to the addition of oxidant to the flasks (reactors). (Further information regarding the $\mathrm{pH}$ and $\mathrm{MnO}_{4}{ }^{-}$analyses is presented in Sections 1.4.2 and 1.4.3, respectively.) Oxidant was then added to each reactor in accordance with Tables 3 and 4 . Initial target $\mathrm{MnO}_{4}{ }^{-}$concentrations of $0.01 \%$ and $0.1 \%$ were obtained by spiking the reactors with a known volume of $\mathrm{MnO}_{4}{ }^{-}$stock solution $\left(\approx 4 \% \mathrm{MnO}_{4}{ }^{-}\right)$ prepared with distilled water. Use of a high concentration $\mathrm{MnO}_{4}{ }^{-}$stock solution to obtain the initial target $\mathrm{MnO}_{4}{ }^{-}$concentrations of $1 \%$ and $3 \%$ was not feasible since the maximum solubility of $\mathrm{KMnO}_{4}$ is $\approx 5 \%$ at room temperature. Instead, the mass of crystalline $\mathrm{KMnO}_{4}$ needed to achieve the desired starting $\mathrm{MnO}_{4}{ }^{-}$concentration was added to each reactor. An additional aliquot $(\approx 6.5 \mathrm{~mL})$ was removed from each reactor for $\mathrm{pH}$ and $\mathrm{MnO}_{4}{ }^{-}$analyses at approximately $0.5 \mathrm{hr}, 1 \mathrm{hr}, 2 \mathrm{hrs}, 4 \mathrm{hrs}, 20 \mathrm{hrs}$, and $24 \mathrm{hrs}$ after oxidant addition for the dissolved plume media. Suspecting that the oxidant consumption is more rapid for the hot spot media, the experiments in Table 4 were also sampled at $\approx 10$ minutes after the reaction start time. In all cases, the sampling times were noted and recorded. After the final sampling period (typically $24 \mathrm{hrs}$ for most experiments), the contents of the test reactors were discarded, and laboratory determined data 
were used to compute the mass of oxidant consumed by each TAN site material. Sample calculations are presented in Appendix C. Results are presented in Section 2.3.

Table 3. Oxidant Demand Experiments for the Dissolved Plume Media. ${ }^{a .}$

\begin{tabular}{|c|c|c|c|c|c|c|}
\hline \begin{tabular}{|l} 
ORNL \\
Exp. \\
I.D.
\end{tabular} & Media Used & $\begin{array}{l}\text { Basalt } \\
\text { Form }\end{array}$ & $\begin{array}{c}\text { L/S } \\
\text { Ratio } \\
\text { (wt:wt) }\end{array}$ & $\begin{array}{c}\text { Initial } \\
\text { TCE } \\
\text { Conc. } \\
(\mu \mathrm{g} / \mathrm{L})\end{array}$ & $\begin{array}{c}\text { Initial Organic } \\
\text { Co-Contaminant } \\
\text { Conc. } \\
(\mu \mathrm{g} / \mathrm{L})\end{array}$ & $\begin{array}{c}\text { Initial } \\
\mathrm{MnO}_{4}^{-} \\
\text {Conc. } \\
(\%)\end{array}$ \\
\hline \multirow{8}{*}{$3 a-R 1$} & TAN-40 GW & NA & NA & 0 & 0 & 0.01 \\
\hline & TAN-40 GW & NA & NA & 0 & 0 & 0.01 \\
\hline & TAN-40 GW/basalt & Crushed & 4:1 & 0 & 0 & 0.01 \\
\hline & TAN-40 GW/basalt & Crushed & $4: 1$ & 0 & 0 & 0.01 \\
\hline & TAN-40 GW/basalt & Aggregate & $4: 1$ & 0 & 0 & 0.01 \\
\hline & TAN-40 GW/basalt & Aggregate & $4: 1$ & 0 & 0 & 0.01 \\
\hline & TAN-40 GW/SED1 & NA & 4:1 & 0 & 0 & 0.01 \\
\hline & TAN-40 GW/SED1 & NA & $4: 1$ & 0 & 0 & 0.01 \\
\hline \multirow{8}{*}{$3 a-R 2$} & TAN-40 GW & NA & NA & 0 & 0 & 0.10 \\
\hline & TAN-40 GW & NA & NA & 0 & 0 & 0.10 \\
\hline & TAN-40 GW/basalt & Crushed & $4: 1$ & 0 & 0 & 0.10 \\
\hline & TAN-40 GW/basalt & Crushed & $4: 1$ & 0 & 0 & 0.10 \\
\hline & TAN-40 GW/basalt & Aggregate & $4: 1$ & 0 & 0 & 0.10 \\
\hline & TAN-40 GW/basalt & Aggregate & 4:1 & 0 & 0 & 0.10 \\
\hline & TAN-40 GW/SED1 & NA & $4: 1$ & 0 & 0 & 0.10 \\
\hline & TAN-40 GW/SED1 & NA & $4: 1$ & 0 & 0 & 0.10 \\
\hline \multirow{8}{*}{$3 a-R 3$} & TAN-40 GW & NA & NA & 0 & 0 & 1.00 \\
\hline & TAN-40 GW & NA & NA & 0 & 0 & 1.00 \\
\hline & TAN-40 GW/basalt & Crushed & $4: 1$ & 0 & 0 & 1.00 \\
\hline & TAN-40 GW/basalt & Crushed & $4: 1$ & 0 & 0 & 1.00 \\
\hline & TAN-40 GW/basalt & Aggregate & $4: 1$ & 0 & 0 & 1.00 \\
\hline & TAN-40 GW/basalt & Aggregate & $4: 1$ & 0 & 0 & 1.00 \\
\hline & TAN-40 GW/SED1 & NA & $4: 1$ & 0 & 0 & 1.00 \\
\hline & TAN-40 GW/SED1 & NA & 4:1 & 0 & 0 & 1.00 \\
\hline
\end{tabular}

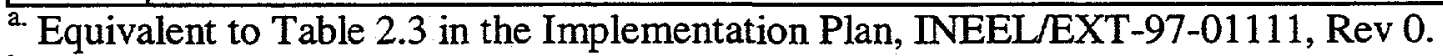

b. Experimental identifier used by ORNL in the collection and interpretation of the test data. 
Table 4. Oxidant Demand Experiments for the Hot Spot Media. ${ }^{\text {a. }}$

\begin{tabular}{|c|c|c|c|c|c|c|}
\hline $\begin{array}{l}\text { ORNL } \\
\text { Exp. } \\
\text { I.D. }\end{array}$ & Media Used & $\begin{array}{c}\text { Basalt } \\
\text { Form }\end{array}$ & $\begin{array}{c}\mathrm{L} / \mathrm{S} \\
\text { Ratio } \\
\text { (wt:wt) }\end{array}$ & $\begin{array}{c}\text { Initial TCE } \\
\text { Conc. } \\
(\mu \mathrm{g} / \mathrm{L})\end{array}$ & $\begin{array}{c}\text { Initial Organic } \\
\text { Co-Contaminant } \\
\text { Conc. } \\
(\mu \mathrm{g} / \mathrm{L})\end{array}$ & $\begin{array}{c}\text { Initial } \\
\mathrm{MnO}_{4}^{-} \\
\text {Conc. } \\
(\%)\end{array}$ \\
\hline \multirow{4}{*}{$3 b-R 1$} & TSF-05 GW & NA & NA & 0 & 0 & 0.01 \\
\hline & TSF-05 GW & $\mathrm{NA}$ & NA & 0 & 0 & 0.01 \\
\hline & TSF-05 GW/sludge & $\mathrm{NA}$ & $4: 1$ & 0 & 0 & 0.01 \\
\hline & TSF-05 GW/sludge & $\mathrm{NA}$ & $4: 1$ & 0 & 0 & 0.01 \\
\hline \multirow{4}{*}{$3 b-R 2$} & TSF-05 GW & $\mathrm{NA}$ & $\overline{\mathrm{NA}}$ & 0 & 0 & 0.10 \\
\hline & TSF-05 GW & NA & NA & 0 & 0 & 0.10 \\
\hline & TSF-05 GW/sludge & NA & $4: 1$ & 0 & 0 & 0.10 \\
\hline & TSF-05 GW/sludge & NA & $4: 1$ & 0 & 0 & 0.10 \\
\hline \multirow{4}{*}{ 3b-R3 } & TSF-05 GW & NA & NA & 0 & 0 & 1.00 \\
\hline & TSF-05 GW & NA & NA & 0 & 0 & 1.00 \\
\hline & TSF-05 GW/sludge & NA & $4: 1$ & 0 & 0 & 1.00 \\
\hline & TSF-05 GW/sludge & NA & 4:1 & 0 & 0 & 1.00 \\
\hline \multirow{4}{*}{ 3b-R4 } & TSF-05 GW & NA & $\overline{\mathrm{NA}}$ & 0 & $\overline{0}$ & 3.00 \\
\hline & TSF-05 GW & NA & NA & 0 & 0 & 3.00 \\
\hline & TSF-05 GW/sludge & NA & $4: 1$ & 0 & 0 & 3.00 \\
\hline & TSF-05 GW/sludge & NA & 4:1 & 0 & 0 & 3.00 \\
\hline
\end{tabular}

${ }^{2 .}$ Equivalent to Table 2.4 in the Implementation Plan, INEEL/EXT-97-01111, Rev 0.

${ }^{b}$ Experimental identifier used by ORNL in the collection and interpretation of the test data.

\subsubsection{Summary of Procedures for Oxidation Rate Experiments}

The batch oxidation rate experiments (Task 4 in the SOW) were performed to determine the rate and extent of volatile organic compound (VOC) oxidation by $\mathrm{KMnO}_{4}$ in the presence of the various INEEL TAN media under investigation.

To better control initial conditions, removal of residual VOCs was attempted for all TAN site media used in experimentation. Groundwater was sparged with air and solid phase material was oven dried at $100^{\circ}$ for a minimum of 4 hours. The general approach for these experiments was similar to that described earlier for the oxidant demand studies in Section 1.4.2; however, the addition of the VOC spiking step and the subsequent VOC analyses increased the complexity of the test procedure.

Table 5 summarizes the oxidation experiments conducted using the dissolved plume media. Tables 6 and 7 summarize the factors evaluated during the oxidation experiment performed on the hot spot groundwater alone and for hot spot groundwater/sludge mixture, respectively. Since the actual contamination levels of the dissolved phase media are lower than those of the hot spot media, the dissolved plume media was only spiked with TCE at two levels: $100 \mu \mathrm{g} / \mathrm{L}$ and 1,000 $\mu \mathrm{g} / \mathrm{L}$. In addition, only initial target $\mathrm{MnO}_{4}{ }^{-}$concentrations of $0.01 \%$ and $0.1 \%$ were evaluated. The hot spot media were spiked at three different initial VOC levels, with one of them having a 
non-aqueous phase component. (The majority of the hot spot work involved TCE as the target VOC.) The hot spot treatment experiments were investigated using four (4) initial oxidant solution concentrations: $0.01 \%, 0.1 \%, 1 \%$, and $3 \% \mathrm{MnO}_{4}$

Each initial test condition was conducted in duplicate. Duplicate controls (containing the VOCspiked GW, but no $\mathrm{MnO}_{4}{ }^{-}$or solid phase medium) were included in each experimental run. As will be presented and discussed in Section 2, these controls provided a QA/QC check on the ability of the reactors to maintain gas-tight conditions and minimize VOC losses resulting from volatilization. Data collected from the control reactors were later used in the mass computations that were performed to evaluate oxidation effectiveness.

Each solid phase medium was evaluated using a 4:1 L/S ratio with the appropriate VOC-spiked TAN site groundwater. The procedure for the VOC spiking step varied depending upon the initial VOC concentration that was desired. The different approaches used are included in the laboratory testplan (Appendix B). With the exception of the DNAPL test conditions in Tables 6 and 7, a single spike solution was prepared within a 5 liter Tedlar bag (see Figure 1) for each experiment, then distributed among the test reactors. This approach allowed the initial VOC concentration to be relatively constant within a particular experimental run. In general, the solid phase material $(\approx 100 \mathrm{~g}$, when applicable) was added to reaction vessel followed by distribution of the spiked groundwater $(\approx 400 \mathrm{~mL})$. In all cases, the spiked groundwater or groundwater/solid phase slurry was allowed to equilibrate at least overnight at $12^{\circ} \mathrm{C}$ while being shaken. (The mass of each medium added was measured and recorded.)

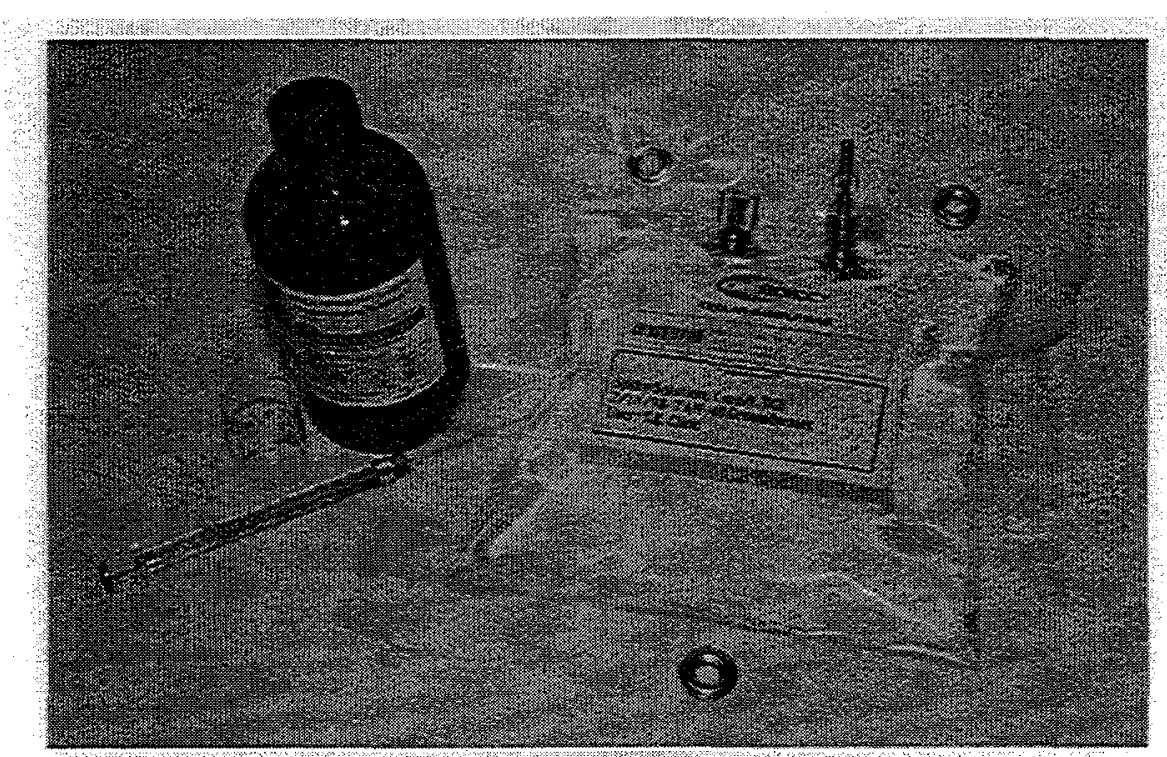

Figure 1. Tedlar Bags Used to Spike TAN Site Groundwater with Target VOCs. 
As in the oxidant demand studies, a sample aliquot $(\approx 7-10 \mathrm{~mL})$ was then collected for VOC, $\mathrm{pH}$, and $\mathrm{MnO}_{4}{ }^{-}$analyses prior to the addition of oxidant to the reactors. (Further information regarding the $\mathrm{pH}, \mathrm{MnO}_{4}{ }^{-}$, and $\mathrm{VOC}$ analyses is presented in Sections 1.4.4 through 1.4.6. Oxidant was then added to each reactor in accordance with Tables 5,6 , and 7 . The initial target $\mathrm{MnO}_{4}{ }^{-}$concentrations of $0.01 \%$ and $0.1 \%$ were obtained by spiking the reactors with a known volume a $\mathrm{MnO}_{4}{ }^{-}$stock solution $\left(\approx 4 \% \mathrm{MnO}_{4}{ }^{-}\right)$prepared with distilled water. Use of a highly concentrated $\mathrm{MnO}_{4}{ }^{-}$stock solution to obtain the initial target $\mathrm{MnO}_{4}{ }^{-}$concentrations of $1 \%$ and $3 \%$ was not feasible since the solubility of $\mathrm{KMnO}_{4}$ is near $5 \%$ at room temperature. Instead, the mass of crystalline $\mathrm{KMnO}_{4}$ needed to achieve the desired starting $\mathrm{MnO}_{4}{ }^{-}$concentration was added to each reactor. The reactors were immediately placed back onto the reciprocating shaker (200-250 rpm) inside of the $12^{\circ} \mathrm{C}$ incubator.

An additional aliquot $(\approx 7-10 \mathrm{~mL}$ ) was removed from each reactor and subjected to $\mathrm{VOC}, \mathrm{pH}$, and $\mathrm{MnO}_{4}{ }^{-}$analyses approximately $0.5 \mathrm{hr}, 1 \mathrm{hr}, 2 \mathrm{hrs}, 4 \mathrm{hrs}, 20 \mathrm{hrs}$, and $24 \mathrm{hrs}$ after oxidant injection in both the dissolved plume media and hot spot media studies. The actual sampling time was noted and recorded each time. To obtain an indication of sample variability, a duplicate sample was collected from one of the test reactors during each sampling interval. After the final sampling period (typically $24 \mathrm{hrs}$ for most experiments), the entire contents of the "treatment" reactors $(300+\mathrm{mL})$ were extracted with hexane $(\approx 400 \mathrm{~mL})$ for eventual VOC analyses (see Section 1.4.6). All laboratory data were then used to compute the mass of oxidant consumed by the VOC spiked media and the extent of VOC oxidation. Sample calculations are presented in Appendix C. Results are presented in Section 2.4. 
Table 5. Oxidation Rate Experiments for the Dissolved Plume Media. ${ }^{\text {a. }}$

\begin{tabular}{|c|c|c|c|c|c|c|}
\hline \begin{tabular}{|l} 
ORNL \\
Exp. \\
I.D.
\end{tabular} & Media Used & $\begin{array}{c}\text { Basalt } \\
\text { Form }\end{array}$ & $\begin{array}{c}\mathrm{L} / \mathrm{S} \\
\text { Ratio } \\
\text { (wt:wt) }\end{array}$ & $\begin{array}{l}\text { Initial } \\
\text { TCE } \\
\text { Conc. } \\
(\mu \mathrm{g} / L)\end{array}$ & $\begin{array}{c}\text { Initial Organic } \\
\text { Co-Contaminant } \\
\text { Conc. } \\
(\mu \mathrm{g} / \mathrm{L})\end{array}$ & $\begin{array}{c}\text { Initial } \\
\mathrm{MnO}_{4}^{-} \\
\text {Conc. } \\
(\%)\end{array}$ \\
\hline \multirow{6}{*}{$4 a-R 1$} & Control TAN-40 GW & NA & NA & 100 & 0 & 0 \\
\hline & Control TAN-40 GW & NA & NA & 100 & 0 & 0 \\
\hline & TAN-40 GW & NA & $\mathrm{NA}$ & 100 & 0 & 0.01 \\
\hline & TAN-40 GW & NA & NA & 100 & 0 & 0.01 \\
\hline & TAN-40 GW & NA & NA & 100 & 0 & 0.10 \\
\hline & TAN-40 GW & NA & NA & 100 & 0 & 0.10 \\
\hline \multirow{6}{*}{$4 a-R 2$} & Control TAN-40 GW & NA & NA & 1,000 & 0 & 0 \\
\hline & Control TAN-40 GW & NA & NA & 1,000 & 0 & 0 \\
\hline & TAN-40 GW & NA & NA & 1,000 & 0 & 0.01 \\
\hline & TAN-40 GW & NA & NA & 1,000 & 0 & 0.01 \\
\hline & TAN-40 GW & NA & NA & 1,000 & 0 & 0.10 \\
\hline & TAN-40 GW & NA & $\mathrm{NA}$ & 1,000 & 0 & 0.10 \\
\hline \multirow{6}{*}{$4 a-R 3$} & Control TAN- $40 \mathrm{GW}$ & NA & NA & 100 & 0 & 0 \\
\hline & Control TAN-40 GW & NA & NA & 100 & 0 & 0 \\
\hline & TAN-40 GW/basalt & Crushed & $4: 1$ & 100 & 0 & 0.01 \\
\hline & TAN-40 GW/basalt & Crushed & 4:1 & 100 & 0 & 0.01 \\
\hline & TAN-40 GW/basalt & Crushed & 4:1 & 100 & 0 & 0.10 \\
\hline & TAN-40 GW/basalt & Crushed & 4:1 & 100 & 0 & 0.10 \\
\hline \multirow{6}{*}{$4 a-R 4$} & Control TAN-40 GW & NA & NA & 100 & 0 & 0 \\
\hline & Control TAN-40 GW & NA & NA & 100 & 0 & 0 \\
\hline & TAN-40 GW/ basalt & Aggregate & 4:1 & 100 & 0 & 0.01 \\
\hline & TAN-40 GW/ basalt & Aggregate & 4:1 & 100 & 0 & 0.01 \\
\hline & TAN-40 GW/basalt & Aggregate & $4: 1$ & 100 & 0 & 0.10 \\
\hline & TAN-40 GW/basalt & Aggregate & 4:1 & 100 & 0 & 0.10 \\
\hline
\end{tabular}

${ }^{2 .}$ Equivalent to Table 2.5 in the Implementation Plan, INEEL/EXT-97-01111, Rev 0.

b. Experimental identifier used by ORNL in the collection and interpretation of the test data. 
Table 5 Continued. Oxidation Rate Experiments for the Dissolved Plume Media. ${ }^{\text {a. }}$

\begin{tabular}{|c|c|c|c|c|c|c|}
\hline $\begin{array}{l}\text { ORNL } \\
\text { Exp. } \\
\text { I.D. }{ }^{\circ} .\end{array}$ & Media Used & $\begin{array}{l}\text { Basalt } \\
\text { Form }\end{array}$ & $\begin{array}{c}\mathrm{L} / \mathrm{S} \\
\text { Ratio } \\
\text { (wt:wt) }\end{array}$ & $\begin{array}{l}\text { Initial } \\
\text { TCE } \\
\text { Conc. } \\
(\mu \mathrm{g} / \mathrm{L})\end{array}$ & $\begin{array}{c}\text { Initial Organic } \\
\text { Co-Contaminant } \\
\text { Conc. } \\
(\mu \mathrm{g} / \mathrm{L})\end{array}$ & $\begin{array}{c}\text { Initial } \\
\mathrm{MnO}_{4}^{-} \\
\text {Conc. } \\
(\%)\end{array}$ \\
\hline \multirow{6}{*}{$4 a-R 5$} & Control TAN-40 GW & NA & NA & 1,000 & 0 & 0 \\
\hline & Control TAN-40 GW & NA & NA & 1,000 & 0 & 0 \\
\hline & TAN-40 GW/basalt & Crushed & $4: 1$ & 1,000 & 0 & 0.01 \\
\hline & TAN-40 GW/basalt & Crushed & $4: 1$ & 1,000 & 0 & 0.01 \\
\hline & TAN-40 GW/basalt & Crushed & 4:1 & 1,000 & 0 & 0.10 \\
\hline & TAN-40 GW/basalt & Crushed & $4: 1$ & 1,000 & 0 & 0.10 \\
\hline \multirow{6}{*}{ 4a-R6 } & Control TAN-40 GW & $\overline{\mathrm{NA}}$ & N.A & 1,000 & 0 & 0 \\
\hline & Control TAN-40 GW & NA & NA & 1,000 & 0 & 0 \\
\hline & TAN-40 GW/basalt & Aggregate & $4: 1$ & 1,000 & 0 & 0.01 \\
\hline & TAN-40 GW/basalt & Aggregate & 4:1 & 1,000 & 0 & 0.01 \\
\hline & TAN-40 GW/basalt & Aggregate & $4: 1$ & 1,000 & 0 & 0.10 \\
\hline & TAN-40 GW/basalt & Aggregate & $4: 1$ & 1,000 & 0 & 0.10 \\
\hline \multirow{6}{*}{$4 a-R 7$} & Control TAN-40 GW & NA & NA & 100 & 0 & 0 \\
\hline & Control TAN-40 GW & NA & NA & 100 & 0 & 0 \\
\hline & TAN-40 GW/sediment & NA & $4: 1$ & 100 & 0 & 0.01 \\
\hline & TAN-40 GW/sediment & NA & $4: 1$ & 100 & 0 & 0.01 \\
\hline & TAN-40 GW/sediment & NA & $4: 1$ & 100 & 0 & 0.10 \\
\hline & TAN-40 GW/sediment & NA & $4: 1$ & 100 & 0 & 0.10 \\
\hline \multirow{6}{*}{$4 a-R 8$} & Control TAN-40 GW & NA & NA & 1,000 & 0 & 0 \\
\hline & Control TAN-40 GW & NA & NA & 1,000 & 0 & 0 \\
\hline & TAN-40 GW/sediment & NA & $4: 1$ & 1,000 & 0 & 0.01 \\
\hline & TAN-40 GW/sediment & NA & $4: 1$ & 1,000 & 0 & 0.01 \\
\hline & TAN-40 GW/sediment & NA & $4: 1$ & 1,000 & 0 & 0.10 \\
\hline & TAN-40 GW/sediment & NA & $4: 1$ & 1,000 & 0 & 0.10 \\
\hline
\end{tabular}

a. Equivalent to Table 2.5 in the Implementation Plan, INEEL/EXT-97-01111, Rev 0.

b. Experimental identifier used by ORNL in the collection and interpretation of the test data. 
Table 6. Oxidation Rate Experiments for Hot Spot Groundwater. ${ }^{\text {a. }}$

\begin{tabular}{|c|c|c|c|c|c|c|}
\hline \begin{tabular}{|l|} 
ORNL \\
Exp. \\
I.D.
\end{tabular} & Media Used & $\begin{array}{c}\text { Basalt } \\
\text { Form }\end{array}$ & $\begin{array}{c}\text { L/S } \\
\text { Ratio } \\
\text { (wt:wt) }\end{array}$ & $\begin{array}{l}\text { Initial } \\
\text { TCE } \\
\text { Conc. } \\
\text { (ug/L) }\end{array}$ & $\begin{array}{c}\text { Initial Organic } \\
\text { Co-Contaminant } \\
\text { Conc. } \\
(\mu \mathrm{g} / \mathrm{L})\end{array}$ & $\begin{array}{c}\text { Initial } \\
\mathrm{MnO}_{4} \\
\text { Conc. } \\
(\%)\end{array}$ \\
\hline \multirow{6}{*}{$4 b-R 1$} & Control-TSF-05 GW & NA & NA & 10,000 & 0 & 0 \\
\hline & Control-TSF-05 GW & NA & NA & 10,000 & 0 & 0 \\
\hline & TSF-05 GW & NA & NA & 10,000 & 0 & 0.01 \\
\hline & TSF-05 GW & NA & NA & 10,000 & 0 & 0.01 \\
\hline & TSF-05 GW & NA & NA & 10,000 & 0 & 0.10 \\
\hline & TSF-05 GW & NA & NA & 10,000 & 0 & 0.10 \\
\hline \multirow{6}{*}{$4 \mathrm{~b}-\mathrm{R} 2$} & Control-TSF-05 GW & NA & NA & 10,000 & 0 & 0 \\
\hline & Control-TSF-05 GW & NA & NA & 10,000 & 0 & 0 \\
\hline & TSF-05 GW & NA & NA & 10,000 & 0 & 1.00 \\
\hline & TSF-05 GW & NA & NA & 10,000 & 0 & 1.00 \\
\hline & TSF-05 GW & NA & NA & 10,000 & 0 & 3.00 \\
\hline & TSF-05 GW & NA & NA & 10,000 & 0 & 3.00 \\
\hline \multirow{6}{*}{ 4b-R3 } & Control-TSF-05 GW & $\mathrm{NA}$ & NA & 100,000 & 0 & $\overline{0}$ \\
\hline & Control-TSF-05 GW & NA & NA & 100,000 & 0 & 0 \\
\hline & TSF-05 GW & NA & NA & 100,000 & 0 & 0.01 \\
\hline & TSF-05 GW & NA & NA & 100,000 & 0 & 0.01 \\
\hline & TSF-05 GW & NA & NA & 100,000 & 0 & 0.10 \\
\hline & TSF-05 GW & NA & NA & 100,000 & 0 & 0.10 \\
\hline \multirow{6}{*}{$4 \mathrm{~b}-\mathrm{R} 4$} & Control-TSF-05 GW & $\mathrm{NA}$ & NA & 100,000 & 0 & 0 \\
\hline & Control-TSF-05 GW & NA & NA & 100,000 & 0 & 0 \\
\hline & TSF-05 GW & NA & NA & 100,000 & 0 & 1.00 \\
\hline & TSF-05 GW & NA & NA & 100,000 & 0 & 1.00 \\
\hline & TSF-05 GW & NA & NA & 100,000 & 0 & 3.00 \\
\hline & TSF-05 GW & NA & NA & 100,000 & 0 & 3.00 \\
\hline
\end{tabular}

a. Equivalent to Table 2.6 in the Implementation Plan, INEEL/EXT-97-01111, Rev 0.

b. Experimental identifier used by ORNL in the collection and interpretation of the test data. 
Table 6 Continued. Oxidation Rate Experiments for Hot Spot Groundwater. ${ }^{\text {a. }}$

\begin{tabular}{|c|c|c|c|c|c|c|}
\hline $\begin{array}{l}\text { Exp. } \\
\text { I.D. }\end{array}$ & Media Used & $\begin{array}{l}\text { Basalt } \\
\text { Form }\end{array}$ & $\begin{array}{c}\text { L/S } \\
\text { Ratio } \\
\text { (wt:wt) }\end{array}$ & $\begin{array}{l}\text { Initial } \\
\text { TCE } \\
\text { Conc. } \\
(\mu \mathrm{g} / \mathrm{L})\end{array}$ & $\begin{array}{c}\text { Initial Organic } \\
\text { Co-Contaminant } \\
\text { Conc. } \\
(\mu \mathrm{g} / \mathrm{L})\end{array}$ & $\begin{array}{c}\text { Initial } \\
\mathrm{MnO}_{4}^{-} \\
\text {Conc. } \\
(\%)\end{array}$ \\
\hline & Control-TSF-05 GW & NA & NA & 100,000 & 10,000 & 0 \\
\hline & Control-TSF-05 GW & NA & NA & 100,000 & 10,000 & 0 \\
\hline \multirow[t]{4}{*}{ 4b-R5 } & TSF-05 GW & NA & NA & 100,000 & 10,000 & 0.01 \\
\hline & TSF-05 GW & $\mathrm{NA}$ & $\mathrm{NA}$ & 100,000 & 10,000 & 0.01 \\
\hline & TSF-05 GW & NA & NA & 100,000 & 10,000 & 0.10 \\
\hline & TSF-05 GW & $\mathrm{NA}$ & NA & 100,000 & 10,000 & 0.10 \\
\hline \multirow{6}{*}{ 4b-R6 } & Control-TSF-05 GW & NA & NA & 100,000 & 10,000 & 0 \\
\hline & Control-TSF-05 GW & NA & NA & 100,000 & 10,000 & 0 \\
\hline & TSF-05 GW & NA & NA & 100,000 & 10,000 & 1.00 \\
\hline & TSF-05 GW & NA & NA & 100,000 & 10,000 & 1.00 \\
\hline & TSF-05 GW & NA & NA & 100,000 & 10,000 & 3.00 \\
\hline & TSF-05 GW & NA & NA & 100,000 & 10,000 & 3.00 \\
\hline \multirow{6}{*}{$4 \mathrm{~b}-\mathrm{R} 7$} & Control-TSF-05 GW & $\mathrm{NA}$ & NA & $2,000,000^{c}$ & 0 & 0 \\
\hline & Control-TSF-05 GW & NA & NA & $2,000,000^{c}$ & 0 & 0 \\
\hline & TSF-05 GW & NA & NA & $2,000,000^{c}$ & 0 & 0.01 \\
\hline & TSF-05 GW & NA & NA & $2,000,000^{c}$ & 0 & 0.01 \\
\hline & TSF-05 GW & NA & NA & $2,000,000^{c}$ & 0 & 0.10 \\
\hline & TSF-05 GW & NA & NA & $2,000,000^{c}$ & 0 & 0.10 \\
\hline \multirow{6}{*}{ 4b-R8 } & Control-TSF-05 GW & NA & NA & $2,000,000^{c}$ & 0 & 0 \\
\hline & Control-TSF-05 GW & NA & NA & $2,000,000^{c}$ & 0 & 0 \\
\hline & TSF-05 GW & NA & NA & $2,000,000^{\mathrm{c}}$ & 0 & 1.00 \\
\hline & TSF-05 GW & NA & NA & $2,000,000^{c}$ & 0 & 1.00 \\
\hline & TSF-05 GW & NA & NA & $2,000,000^{c}$ & 0 & 3.00 \\
\hline & TSF-05 GW & NA & NA & $2,000,000^{c}$ & 0 & 3.00 \\
\hline
\end{tabular}

${ }^{\text {a. Equivalent to Table } 2.6 \text { in the Implementation Plan, INEEL/EXT-97-01111, Rev } 0 .}$

b. Experimental identifier used by ORNL in the collection and interpretation of the test data.

c. Indicates that TCE is present as a DNAPL. 
Table 7. Oxidation Rate Experiments for Hot Spot Groundwater and Sludge. a,c.

\begin{tabular}{|c|c|c|c|c|c|c|}
\hline $\begin{array}{l}\text { Exp. } \\
\text { I.D. }\end{array}$ & Media Used & $\begin{array}{l}\text { Basalt } \\
\text { Form }\end{array}$ & $\begin{array}{c}\mathrm{L} / \mathrm{S} \\
\text { Ratio } \\
\text { (wt:wt) }\end{array}$ & $\begin{array}{l}\text { Initial } \\
\text { TCE } \\
\text { Conc. } \\
(\mu \mathrm{g} / \mathrm{L}) \\
\end{array}$ & $\begin{array}{c}\text { Initial Organic } \\
\text { Co-Contaminant } \\
\text { Conc. } \\
(\mu \mathrm{g} / \mathrm{L})\end{array}$ & $\begin{array}{r}\text { Initial } \\
\mathrm{MnO}_{4}{ }^{-} \\
\text {Conc. } \\
(\%) \\
\end{array}$ \\
\hline \multirow{7}{*}{$4 \mathrm{~b}-\mathrm{R} 9$} & TSF-05 GW/sludge & NA & $4: 1$ & 0 & 0 & 0 \\
\hline & Control-TSF-05 GW & $\mathrm{NA}$ & NA & 10,000 & 0 & 0 \\
\hline & Control-TSF-05 GW & NA & NA & 10,000 & 0 & 0 \\
\hline & TSF-05 GW/studge & $\mathrm{NA}$ & $4: 1$ & 10,000 & $\theta$ & $\theta .01$ \\
\hline & TSF-05 GW/sludge & NA & $4: 1$ & 10,000 & $\theta$ & $\theta .01$ \\
\hline & FSF-05GW/sludge & $\mathrm{NA}$ & $4: 1$ & 10,000 & $\theta$ & $\theta .10$ \\
\hline & TSF 05 GW/sludge & NA & $4: 1$ & 10,000 & $\theta$ & $\theta .10$ \\
\hline \multirow{6}{*}{$4 b R 10$} & EolTSF 05 GW & NA & NA & 10,000 & $\bar{\theta}$ & $\bar{\theta}$ \\
\hline & GentTSF 05GW & $\mathrm{NA}$ & NA & 10,000 & $\theta$ & $\theta$ \\
\hline & TSF-05-GW/studge & NA & $4: 1$ & 10,000 & $\theta$ & 1.00 \\
\hline & TSF-05GW/studge & $\mathrm{NA}$ & $4: 1$ & 10,000 & $\theta$ & 1.00 \\
\hline & TSF 05 GW/studge & NA & $4: 1$ & 10,000 & $\theta$ & 3.00 \\
\hline & TSF 05-GW/sludge & NA & $4: 1$ & 10,000 & $\theta$ & 3.00 \\
\hline \multirow{6}{*}{$\begin{array}{c}\text { 4b-R11 } \\
\text { Replaced } \\
4 b-R 9\end{array}$} & Control-TSF-05 GW & NA & NA & $\approx 40,000^{\mathrm{d}}$. & 0 & 0 \\
\hline & Control-TSF-05 GW & NA & NA & $\approx 40,000^{\mathrm{d}}$ & 0 & 0 \\
\hline & TSF-05 GW/sludge & NA & $4: 1$ & $\approx 40,000^{\mathrm{d}}$ & 0 & 0.01 \\
\hline & TSF-05 GW/sludge & NA & $4: 1$ & $\approx 40,000^{\mathrm{d}}$. & 0 & 0.01 \\
\hline & TSF-05 GW/sludge & NA & $4: 1$ & $\approx 40,000^{\mathrm{d}}$. & 0 & 0.10 \\
\hline & TSF-05 GW/sludge & NA & 4:1 & $\approx 40,000^{\mathrm{d}}$ & 0 & 0.10 \\
\hline \multirow{6}{*}{ 4b-R12 } & Control-TSF-05 GW & NA & NA & 100,000 & 0 & 0 \\
\hline & Control-TSF-05 GW & NA & NA & 100,000 & 0 & 0 \\
\hline & TSF-05 GW/sludge & NA & $4: 1$ & 100,000 & 0 & 1.00 \\
\hline & TSF-05 GW/sludge & NA & $4: 1$ & 100,000 & 0 & 1.00 \\
\hline & TSF-05 GW/sludge & NA & 4:1 & 100,000 & 0 & 3.00 \\
\hline & TSF-05 GW/sludge & 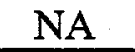 & $4: 1$ & 10 & 0 & 0 \\
\hline
\end{tabular}

${ }^{2 .}$ Equivalent to Table 2.7 in the Implementation Plan, INEEL/EXT-97-01111, Rev 0.

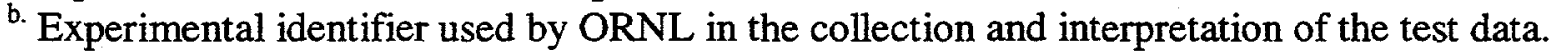

${ }^{c}$. Strike-through text indicates an experiment that was not completed due to problems that developed. All such experiments were re-performed, but were assigned a different ORNL Exp. I.D.

${ }^{d}$ Although the target TCE concentration for this run was $100,000 \mu \mathrm{g} / \mathrm{L}$, the actual TCE spike concentration was $40,000 \mu \mathrm{g} / \mathrm{L}$. Thus, this experiment was used to replace experiment $4 \mathrm{~b}-\mathrm{R} 9$. (4b-R16 replaced 4b-R11) 
Table 7 Continued. Oxidation Rate Experiments for Hot Spot Groundwater and Sludge. ${ }^{\text {a. }}$

\begin{tabular}{|c|c|c|c|c|c|c|}
\hline $\begin{array}{l}\text { Exp. } \\
\text { I.D. }\end{array}$ & Media Used & $\begin{array}{l}\text { Basalt } \\
\text { Form }\end{array}$ & $\begin{array}{c}\mathrm{L} / \mathrm{S} \\
\text { Ratio } \\
\text { (wt:wt) }\end{array}$ & $\begin{array}{l}\text { Initial } \\
\text { TCE } \\
\text { Conc. } \\
(\mu \mathrm{g} / \mathrm{L}) \\
\end{array}$ & $\begin{array}{c}\text { Initial Organic } \\
\text { Co-Contaminant } \\
\text { Conc. } \\
(\mu \mathrm{g} / \mathrm{L})\end{array}$ & $\begin{array}{c}\text { Initial } \\
\mathrm{MnO}_{4} \\
\text { Conc. } \\
(\%) \\
\end{array}$ \\
\hline \multirow{6}{*}{$4 b-R 13$} & Control-TSF-05 GW & NA & NA & $2,000,000^{\mathrm{c}}$ & 0 & $\overline{0}$ \\
\hline & Control-TSF-05 GW & NA & NA & $2,000,000^{c}$ & 0 & 0 \\
\hline & TSF-05 GW/sludge & NA & $4: 1$ & $2,000,000^{\mathrm{c}}$ & 0 & 0.01 \\
\hline & TSF-05 GW/sludge & NA & $4: 1$ & $2,000,000^{c .}$ & 0 & 0.01 \\
\hline & TSF-05 GW/sludge & NA & $4: 1$ & $2,000,000^{c .}$ & 0 & 0.10 \\
\hline & TSF-05 GW/sludge & NA & $4: 1$ & $2,000,000^{\mathrm{c} .}$ & 0 & 0.10 \\
\hline \multirow{6}{*}{ 4b-R14 } & Control-TSF-05 GW & NA & $\mathrm{NA}$ & $2,000,000^{\mathrm{c}}$ & 0 & 0 \\
\hline & Control-TSF-05 GW & NA & NA & $2,000,000^{\mathrm{c}}$ & 0 & 0 \\
\hline & TSF-05 GW/sludge & NA & $4: 1$ & $2,000,000^{c .}$ & 0 & 1.00 \\
\hline & TSF-05 GW/sludge & NA & $4: 1$ & $2,000,000^{c}$ & 0 & 1.00 \\
\hline & TSF-05 GW/sludge & NA & $4: 1$ & $2,000,000^{\mathrm{c} .}$ & 0 & 3.00 \\
\hline & TSF-05 GW/sludge & NA & 4:1 & $2,000,000^{\mathrm{c}}$ & 0 & 3.00 \\
\hline \multirow{6}{*}{$\begin{array}{c}\text { 4b-R15 } \\
\text { Replaced } \\
4 b-R 10\end{array}$} & Control-TSF-05 GW & $\overline{\mathrm{NA}}$ & $\overline{\mathrm{NA}}$ & 10,000 & 0 & $\overline{0}$ \\
\hline & Control-TSF-05 GW & NA & NA & 10,000 & 0 & 0 \\
\hline & TSF-05 GW/sludge & NA & 4:1 & 10,000 & 0 & 1.00 \\
\hline & TSF-05 GW/sludge & NA & $4: 1$ & 10,000 & 0 & 1.00 \\
\hline & TSF-05 GW/sludge & NA & 4:1 & 10,000 & 0 & 3.00 \\
\hline & TSF-05 GW/sludge & NA & $4: 1$ & 10,000 & 0 & 3.00 \\
\hline \multirow{6}{*}{$\begin{array}{c}4 \mathrm{~b}-\mathrm{R} 16 \\
\text { Replaced } \\
4 b-R I 1\end{array}$} & Control-TSF-05 GW & NA & NA & 100,000 & 0 & 0 \\
\hline & Control-TSF-05 GW & NA & NA & 100,000 & 0 & 0 \\
\hline & TSF-05 GW/sludge & NA & $4: 1$ & 100,000 & 0 & 0.01 \\
\hline & TSF-05 GW/sludge & NA & 4:1 & 100,000 & 0 & 0.01 \\
\hline & TSF-05 GW/sludge & NA & $4: 1$ & 100,000 & 0 & 0.10 \\
\hline & TSF-05 GW/sludge & NA & $4: 1$ & 100,000 & 0 & 0.10 \\
\hline
\end{tabular}

a. Equivalent to Table 2.7 in the Implementation Plan, INEEL/EXT-97-01111, Rev 0.

b. Experimental identifier used by ORNL in the collection and interpretation of the test data.

c. Indicates that TCE is present as a DNAPL.

\subsection{4. $\mathrm{MnO}_{4}^{-}$Analyses}

A portion of each sample aliquot collected from the reactors during both the oxidant demand and the oxidation rate studies was used for $\mathrm{MnO}_{4}{ }^{\circ}$ analysis. This portion was first passed through a $0.45 \mu \mathrm{m}$ membrane syringe filter (cellulose acetate) to remove particulates from the aqueous sample. (Tests for $\mathrm{MnO}_{4}{ }^{-}$sorption onto the filters were not performed, but is expected to be negligible given the concentrations being evaluated.) The sample was then analyzed colorimetrically using a $\mathrm{Hach}^{\mathrm{TM}} \mathrm{D} / \mathrm{R} 2000$ spectrophotometer (wavelength $=525 \mathrm{~nm}$ ). The spectrophotometer was calibrated using $\mathrm{MnO}_{4}{ }^{-}$standards (50 $\mathrm{mg} / \mathrm{L} \mathrm{MnO}_{4}{ }^{-}$maximum) prepared using the same technical grade $\mathrm{KMnO}_{4}$ used in the oxidant demand and oxidation rate experiments. Most aliquot samples required dilution prior to analysis in order to obtain absorbance and/or concentration values in the linear calibration range of the instrument. The spectrophotometers were zeroed using DI (distilled, deionized) water blanks. The instrument 
used by ORNL/ESD provided absorbance values, which were then manually converted to concentration values using the calibration curve (absorbance vs. concentration) obtained from the standards. The instrument used by ORNL/RMAL was programmed to provide output in units of concentration ( $\mathrm{mg} / \mathrm{L} \mathrm{MnO}_{4}{ }^{-}$) using the absorbance data obtained from calibration standards. Calibration check samples (typically $10 \mathrm{mg} / \mathrm{L}$ and $50 \mathrm{mg} / \mathrm{L} \mathrm{MnO}_{4}{ }^{-}$) were analyzed each time aliquot samples were analyzed. Results of the calibration checks were recorded in the laboratory research notebooks (Appendix F). Note that the $\mathrm{MnO}_{4}^{-}$parameter was not defined as a decision making criterion in the SOW; therefore, formal data packages for these measurements were not required and/or prepared.

\subsection{5. pH Analyses}

A portion of each sample aliquot collected from the reactors during both the oxidant demand and the oxidation rate studies was used for $\mathrm{pH}$ analysis. This portion was not filtered prior to analysis, however, the small quantity of solids present with an aqueous aliquot was not expected to significantly affect the $\mathrm{pH}$ of the aqueous solution. The $\mathrm{pH}$ meters used by both ORNL research teams were calibrated with and/or checked against standard $\mathrm{pH}$ buffer solutions (typically $\mathrm{pH} 4$ and 7). The instrument was recalibrated if the readings obtained for the buffer solutions drifted significantly (i.e., $>15 \%$ or $1 \mathrm{pH}$ unit $\max$ ) during the time period that samples were being analyzed. Note that the $\mathrm{pH}$ parameter was not defined as a decision making criterion in the SOW; therefore, formal data packages for the $\mathrm{pH}$ measurements were not required and/or prepared.

\subsubsection{VOC Analyses}

VOC analyses were conducted on aliquot samples collected from the oxidation rate experiments listed in Tables 5,6 , and 7 . An unfiltered portion $(\approx 3 \mathrm{~mL})$ of each sample aliquot was added to a vial ( $12 \mathrm{~mL}$, Teflon septum, glass) containing a known volume $(\approx 3 \mathrm{~mL})$ of hexane. It is important to note that, to minimize volatilization of VOCs, this portion of the sample aliquot was immediately added to a hexane-filled vial before any other analyses ( $\mathrm{pH}$ and $\mathrm{MnO}_{4}^{-}$) were conducted. The glass vial was then weighed again to determine the mass of the aliquot added. It was assumed that the mass of solids present in this portion of the sample aliquot was negligible. Therefore the mass of sample added was equivalent to the volume of the aqueous sample (assumed spg=1.0). The assumption that the mass of particulates in the unfiltered aliquots was negligible was evaluated by determining the mass of solids retained on a $0.45 \mu \mathrm{m}$ membrane after filtering supernatant from reactors that contained the same media used in this experiment. For a $10 \mathrm{~mL}$ sample of a groundwater slurry ( $4: 1 \mathrm{~L} / \mathrm{S}$ ratio), $0.017 \mathrm{~g}$ of crushed basalt, $0.00001 \mathrm{~g}$ of aggregate basalt, and $0.007 \mathrm{~g}$ of sediment were retained. Since the mass of solids retained was significantly less than the masses present in the slurries, it was assumed that this assumption was valid. The unfiltered samples were extracted for 2 hrs before the hexane extract was analyzed via gas chromatography.

All of the VOC analyses were conducted using a gas chromatograph (GC) equipped with an electron capture detector (ECD). All sample injections were performed using an autosampler (1 $\mu \mathrm{L}$ direct injection). Over $90 \%$ of the samples were analyzed using a Hewlett Packard (HP) 5890 Series II GC that was configured and optimized to resolve TCE as the target analyte. In fact, all VOC analyses were conducted on this instrument except those from experiments 4b-R5 and $4 \mathrm{~b}-\mathrm{R} 6$ in Table 6 (the co-contaminants experiments). For these optimized TCE analyses, a 
HP- 5 capillary column ( $50 \mathrm{~m}$ length $\times 0.32 \mathrm{~mm} \mathrm{ID} \times 0.52 \mu \mathrm{m}$ film thickness) was used. The oven temperature was held at $50^{\circ} \mathrm{C}$ for 2 minutes and was then ramped at $10^{\circ} \mathrm{C} / \mathrm{min}$ until the maximum over temperature of $105^{\circ} \mathrm{C}$ was reached and then held for 2 additional minutes. Helium was the carrier gas for this setup, with a column flowrate of $2.2 \mathrm{~mL} /$ minute. The detector temperature was $275^{\circ} \mathrm{C}$. The GC software also produced electronic files (Microsoft Excel format) of the chromatographic run results.

The samples from experiments 4b-R5 and 4b-R6 were analyzed using a second HP $5890 \mathrm{GC}$ optimized to resolve both TCE and the co-contaminants used in experiments $4 \mathrm{~b}-\mathrm{R} 5$ and $4 \mathrm{~b}-\mathrm{R} 6$. For these analyses, a J\&W Scientific DB-624 capillary column ( $30 \mathrm{~m}$ length $\times 0.53 \mathrm{~mm}$ ID $\times 3$ $\mu \mathrm{m}$ film thickness) was used. Samples were introduced via $1 \mu \mathrm{L}$ direct injections (autosampler). The oven temperature was held at $50^{\circ} \mathrm{C}$ for 0.3 minutes and was then ramped at $5^{\circ} \mathrm{C} / \mathrm{min}$ until the maximum over temperature of $100^{\circ} \mathrm{C}$ was reached. The temperature was then immediately ramped at $50^{\circ} \mathrm{C}$ until a final temperature of $150^{\circ} \mathrm{C}$ was attained. The total run time was 11.3 minutes. Nitrogen was the carrier gas for this setup, with a column flowrate of $4.2 \mathrm{~mL} /$ minute. The injector temperature was $70^{\circ} \mathrm{C}$, and the detector temperature was $300^{\circ} \mathrm{C}$. The $\mathrm{GC}$ software also produced electronic files (Microsoft Excel format) of the chromatographic run results.

Information regarding the QAVQC attributes of the GC data are outlined in the SOW (Appendix A) for the oxidation rate experiments. In general, however, each sample analyzed was assigned a unique ORNL GC sample number for tracking purposes. Sample concentrations were determined using a 5 point calibration curve prepared following guidelines in EPA Method 8000B (USEPA, 1997). A calibration check standard (typically $100 \mu \mathrm{g} / \mathrm{L}$ ) was analyzed at the beginning and end of each GC sequence. A sample blank was analyzed at the beginning and end of a GC sequence and after every 10 or 11 samples. Samples were re-analyzed with a different dilution factor if either (1) the concentration of the extract exceeded that of the largest calibration standard or (2) the concentration of a diluted extract was less than that of the lowest calibration standard. Any sample values that deviated from this approach or samples where the target analyte was not detected are clearly flagged and indicated in the results presented in Section 2.4. Finally, example calculations that illustrate how the GC values obtained for the hexane extracts were converted back to aqueous phase concentrations are presented in Appendix C.

\subsubsection{Baseline Sludge Characterization and Carbon Analyses}

A description of the procedures used to characterize the untreated TSF-05 sludge (moisture, bulk density, percent carbon, etc.) is included in Section 2.4 .5 along with the results of the baseline characterization work. The approach and results used to assess the effect of oxidation on the TSF-0.5 sludge is also presented in Section 2.4.5. 


\section{RESULTS AND DISCUSSION}

\subsection{TASK 1. PREPARATION OF PROJECT PLANNING DOCUMENTS}

\subsubsection{Laboratory Testplan}

Preparation of the laboratory testplan, which is presented in Appendix B, was initiated in January 1998. The testplan contains the standard procedures for the experimental tasks (Tasks 2-4 in the SOW) conducted during this treatability study. The first draft of the laboratory testplan was submitted to INEEL for concurrence. However, the testplan has undergone modifications throughout the course of the treatability study, primarily as a result of findings discovered in the Task 2 development work that necessitated changes in the way the oxidant demand and oxidation rate experiments were to be conducted. The most current version of the testplan is presented in Appendix B. It is against this version of the testplan that any experimental deviations that occurred will be discussed in the following sections.

\subsubsection{Other Documents Required by ORNL}

In addition the laboratory testplan, several other documents had to be in place before ORNL could begin the actual experimental work. The documentation that was obtained is listed below.

1. Documentation of PCB concentrations of TSF-05 sludge being less than TSCA action levels (Electronic mail correspondence from R.C. Starr-INEEL, dated: 2-12-98)

2. NEPA Project Review Summary, and Categorical Exclusion Assignment (ORNL memo from D.C. Parzyck-ORNL, dated: 1-28-98)

3. Project Environmental, Safety, Health, and Quality Evaluation (Approved by B.M. Ross-ORNL, ESH\&Q Evaluation No. 9801-15, dated: 1-6-98)

4. Notification to ORNL of intent to perform a U.S. EPA Treatability Study (Submitted 12-17-98, Approved by J.H. Taylor-ORNL)

5. Determination that TAN Site Material is not subject to USDA quarantine regulations (Electronic mail correspondence from A.S. Dixon-ORNL, dated: 12-12-98) 


\subsection{TASK 2. PRELIMINARY LABORATORY STUDIES}

\subsubsection{Reactor Development}

After several weeks of laboratory testing, equipment substitutions, and minor modifications, a relatively simple but effective reaction vessel was selected for use in the oxidation treatment experiments. A description of the selected test reactor and its QAVQC attributes are discussed here.

The final reactor design, which is illustrated in Figure 2, consisted of a glass, $500 \mathrm{~mL}$ Erlenmeyer flask equipped with a gas-tight adapter/closure. The flask has a ground glass, 29/42 standard taper opening. The adapter (Figure 3 ) is a non-stock item acquired from ACE Glass, Inc. The matching $29 / 42$ standard taper fitting of the adapter was fitted with a $0.076 \mathrm{~mm}$ thick Teflon sleeve to provide a gas-tight connection. The adapter was also equipped with a gas-tight Teflon stopcock that remained closed except during aliquot sampling. (Note that tests to assess TCE sorption onto Teflon were not performed.) The stopcock opening is $2 \mathrm{~mm}$ in diameter. Aliquot sampling was performed using a long $25 \mathrm{~cm}$ (10 inch) stainless steel syringe having a $1.83 \mathrm{~mm}$ OD (also pictured in Figure 2). Thus, only $0.51 \mathrm{~mm}^{2}$ of the sampling port opening was open to the atmosphere during aliquot sampling, further minimizing VOC losses. During aliquot sampling, the long syringe was attached to a $10 \mathrm{~mL}$ disposable, polyethylene syringe and lowered through the vertical sampling port, through the stopcock opening, and into the reactor. The upper $8 \mathrm{~mm}$ OD sampling port is closed off using a rubber septum after sampling is complete. (Attempts were originally made to inject the needle through this septum, but the thick wall of the syringe cored out the septum.) The aliquot sampling step of procedure easily takes less than 10 seconds to complete.

The second (horizontal) sampling port was equipped with a charcoal desorption tube (Supelco, ORBO brand). Such desorption tubes (See Figure 4) are typically used in industrial hygiene air sampling operations; however, it was used here to help quantify the amount of VOC that might be escaping from the Teflon stopcock. The desorption tubes contain two (2) separate charcoal beds. The first bed (positioned closest to the sampling port) contains $100 \mathrm{mg}$ of charcoal, and the second bed contains $50 \mathrm{mg}$ of charcoal. After the last aliquot sample is collected from the reactor, each charcoal bed is extracted into a known volume of hexane. As with the aqueous samples collect during the experiment, the mass of charcoal transferred into hexane is determined gravimetrically. These samples are then analyzed for VOCs similar to the aqueous aliquot samples.

During the overnight contaminant equilibration periods, a solid glass $29 / 42$ stopper was used in place of the sampling port adapter discussed above. This prevented the potential contamination of the charcoal desorption tubes prior to the start of the oxidation reactions. The solid stoppers were replaced by the adapters (1) after the $T=0$ samples were collected for the $G W$ control reactors or (2) immediately after oxidant was added to the treatment reactors. 


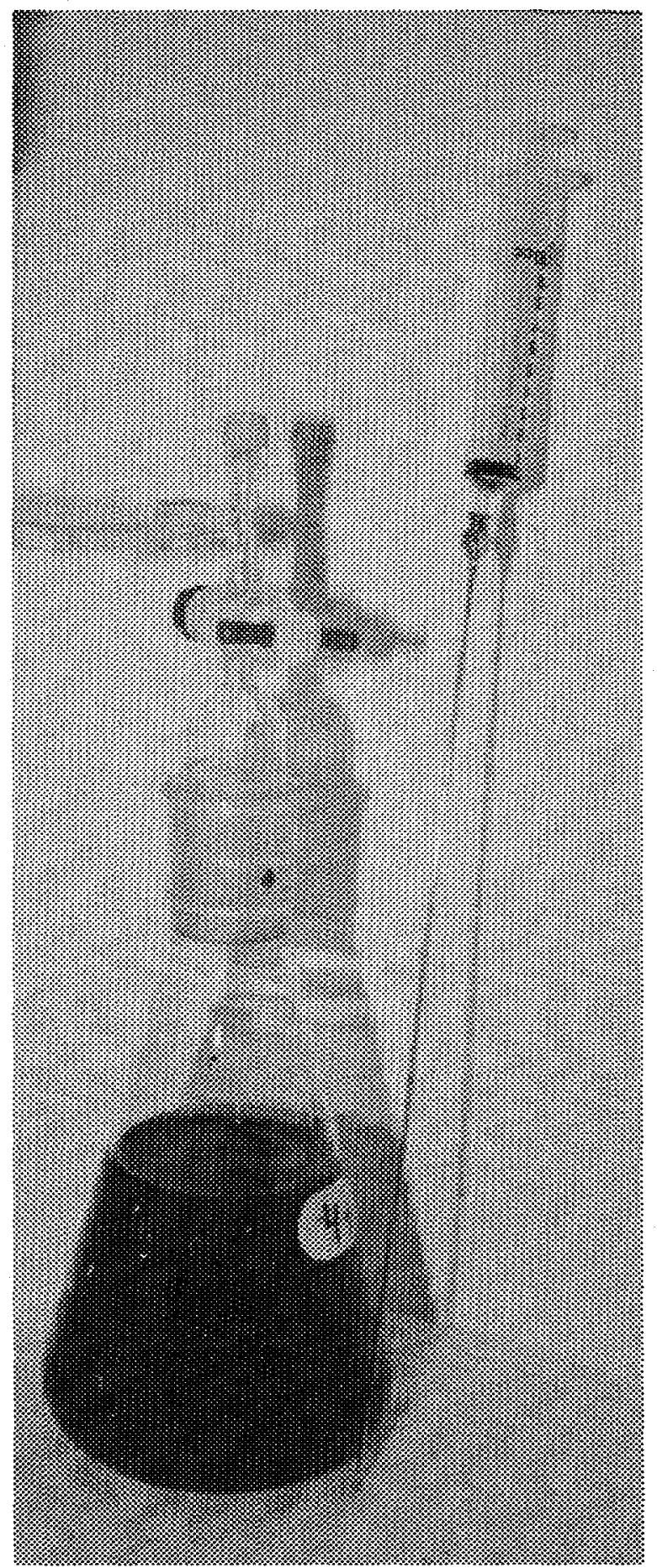

Figure 2. Photograph of the Reaction Vessel used in the Oxidation Experiments. 


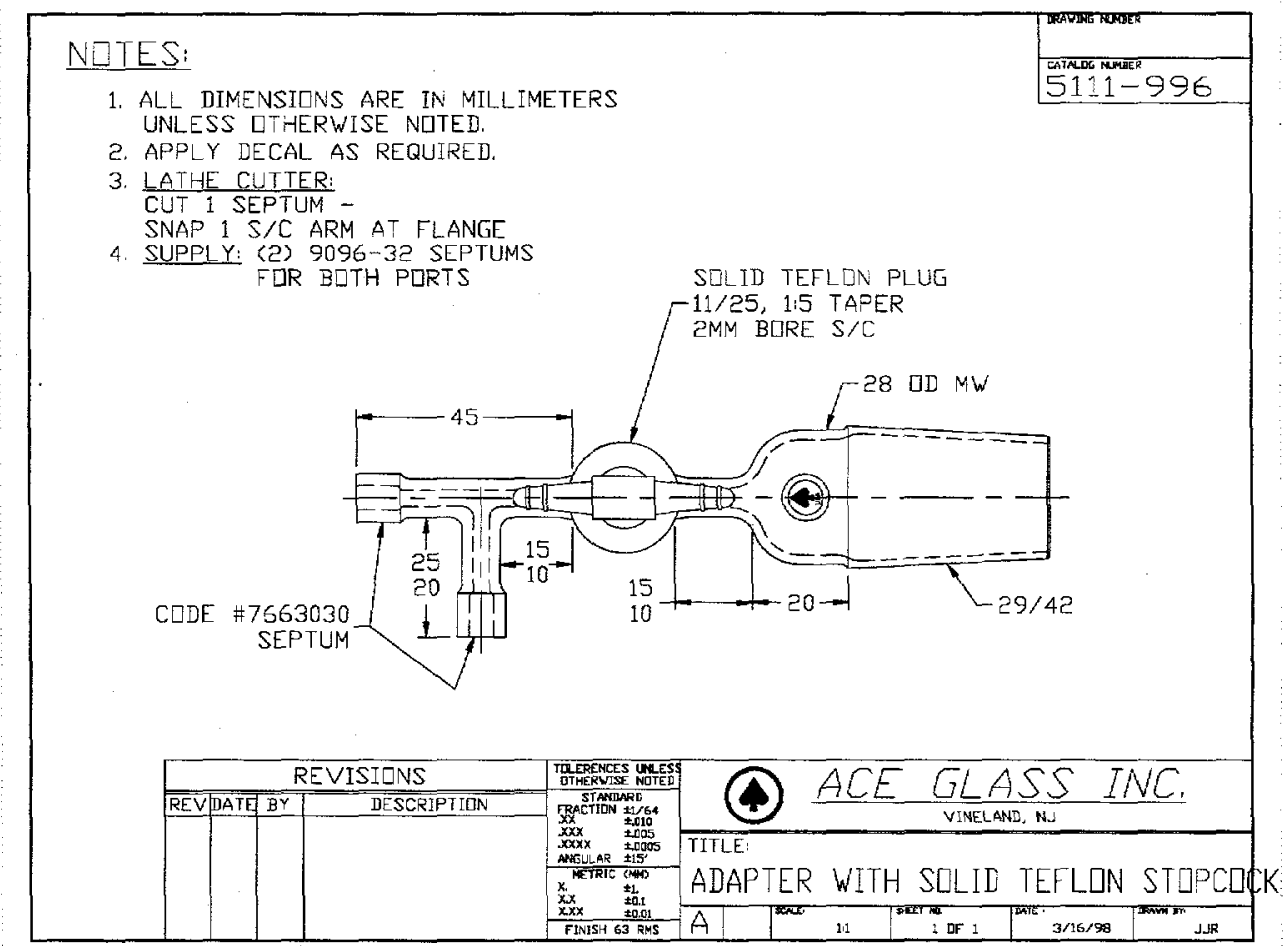

Figure 3. Illustration of the Adapter used in conjunction with the Reaction Vessels.

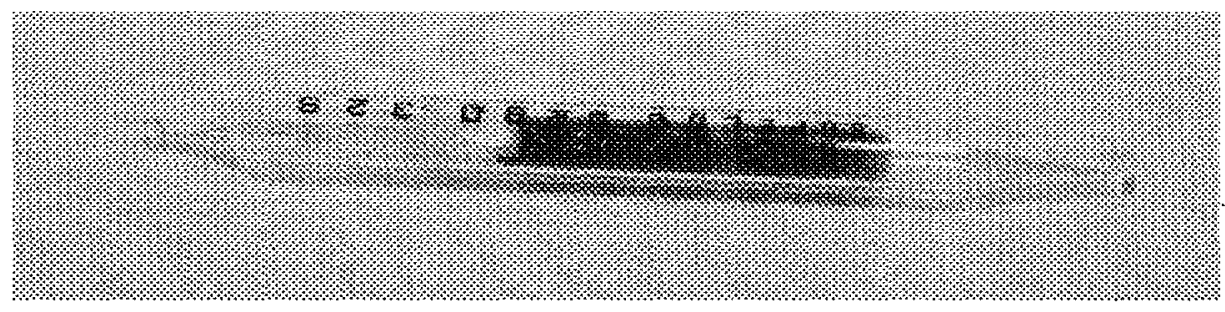

Figure 4. Photograph of the Charcoal Desorption Tubes used with the Reaction Vessels. 
This final reactor configuration was experimentally evaluated by filling the flask with $500 \mathrm{~mL}$ of distilled water. This volume of water was spiked with TCE (target $100 \mu \mathrm{g} / \mathrm{L}$ TCE) and allowed to equilibrate at $12^{\circ} \mathrm{C}$ for 22 hours with the glass stopper in place. At time $\mathrm{T}=0$, the solid stopper was replaced with the adapter and two initial aliquot samples were collected and processed for TCE analysis as discussed in Section 1.4.6. Similarly, duplicate aliquot samples were also collected at 1,2,4,21, and $24 \mathrm{hrs}$ after the initial sampling. The procedure for this final performance verification is included in the laboratory testplan as experiment 2a-3-B.

The resulting aqueous TCE concentration did not change with time. The average TCE value of all 12 aliquots collected was $106 \mu \mathrm{g} / \mathrm{L}$ with a standard deviation of $3 \mu \mathrm{g} / \mathrm{L}$. No TCE was detected in either bed of the carbon desorption tube. A TCE mass balance was then performed. The cumulative quantity of TCE present in the aliquots was calculated, and the mass of TCE remaining in the flask was computed by multiplying the final aliquot TCE concentration by the volume of solution remaining in the flask. When compared to the TCE present at the initial sampling, $98.7 \%$ of the TCE was accounted for. (The TCE mass potentially present in the headspace was not computed, but was expected to be small since no TCE was detected in the desorption tubes.) Thus, this reactor configuration was considered appropriate, particularly when considering that a given reactor will not be sampled in duplicate at every time interval as was done here.

The duplicate sampling at every interval was conducted to determine if plastic disposable syringes would adsorb a significant amount of TCE. Thus, at each time period, one sample was collected using a glass syringe, and the second sample was collected using a plastic syringe. Half of the six (6) sampling periods yielded higher aqueous TCE concentrations for samples collected using glass syringes (maximum 5.3\% greater). Conversely, the other 3 sampling periods resulted in higher aqueous TCE concentrations for the samples from the plastic syringe (maximum 4\% greater). The average difference between values obtained for the glass and plastic syringes was only $0.1 \%$. Thus, it was concluded that the use of plastic disposable syringes did not bias the results, and therefore plastic syringes were used in the remaining experiments. 


\subsubsection{Hexane Extraction Time Determinations}

ORNL Exp. $2 b-1$

All dissolved plume media were investigated in this experiment with the exception of aggregate basalt. Results of the hexane extraction experiments are presented in Figures 5, 6, and 7 for the TAN-40 GW only, crushed basalt and TAN-40 GW, and sediment and TAN-40 GW, respectively. The (\#1) and (\#2) notations included in the figure legends refer to the duplicate reactors evaluated for that test condition.

Per the testplan for experiment $2 \mathrm{~b}-1$, aliquots of both the aqueous and hexane phases were collected at each time period. Greater than $99.9 \%$ of the total TCE recovered at the $2 \mathrm{hr}$ sampling point was found in the hexane phase. In addition, there was not a significant increase in the TCE concentration of the hexane phase between $2 \mathrm{hrs}$ and $24 \mathrm{hrs}$ for any of these materials. Thus, a $2 \mathrm{hr}$ hexane extraction time was selected for use in the subsequent oxidation rate experiments.

TCE mass balances were also performed for each test condition. Average TCE recoveries of $91 \%, 95 \%$, and $94 \%$ were obtained for the sediment and GW, crushed basalt and GW, and GW only reactors, respectively. The TCE mass unaccounted for is not expected to exist as residual contamination on the sediment or crushed basalt since the recoveries obtained for the groundwater only case were comparable to those obtained for the GW and solids reactors. These mass balance computations are strongly influenced by the value used for the initial TCE concentration of the spiked groundwater. Here, the duplicate analyses of the initial spike solution were in close agreement (average $=722 \mu \mathrm{g} / \mathrm{L}, \sigma=3 \mu \mathrm{g} / \mathrm{L}$ ). The potential for VOC losses, however, certainly existed between the time these initial samples were collected and the time the vials were equilibrated (overnight) and finally transferred to the extraction bottles for the start of the actual hexane extraction test. There was certainly some TCE lost as a result of the transfer step from the $40 \mathrm{~mL}$ VOA vial to the $125 \mathrm{~mL}$ extraction bottle. Laboratory gravimetric data indicated that an average of $98.5 \%$ of the initial $\mathrm{GW}$ or $\mathrm{GW} /$ soil slurry was successfully transferred to the extraction jar. (The procedure used for final extraction of the reactors in the oxidation rate studies was modified as a direct result of this finding.)

While factored out of the TCE mass recovery computations, a procedural problem did affect some of the data collected from this experiment. As written in the testplan, two samples were collected from the aqueous phase of the extraction at each time point. One of these aqueous samples was filtered $(0.45 \mu \mathrm{m})$ in an attempt to determine the "true" aqueous concentration. Unfortunately, subsequent lab experiments provided evidence that the filters absorbed TCE, thereby making the data TCE obtained for these samples invalid. For the purpose of the mass balance, the volume of the filtered sample was used in the computations, but the TCE concentration of the filtered sample was assumed to be the same as the value obtained for the unfiltered aqueous sample. As direct result of this finding, the testplan was modified and aqueous samples for VOC analyses were not filtered during the oxidation rate experiments. 


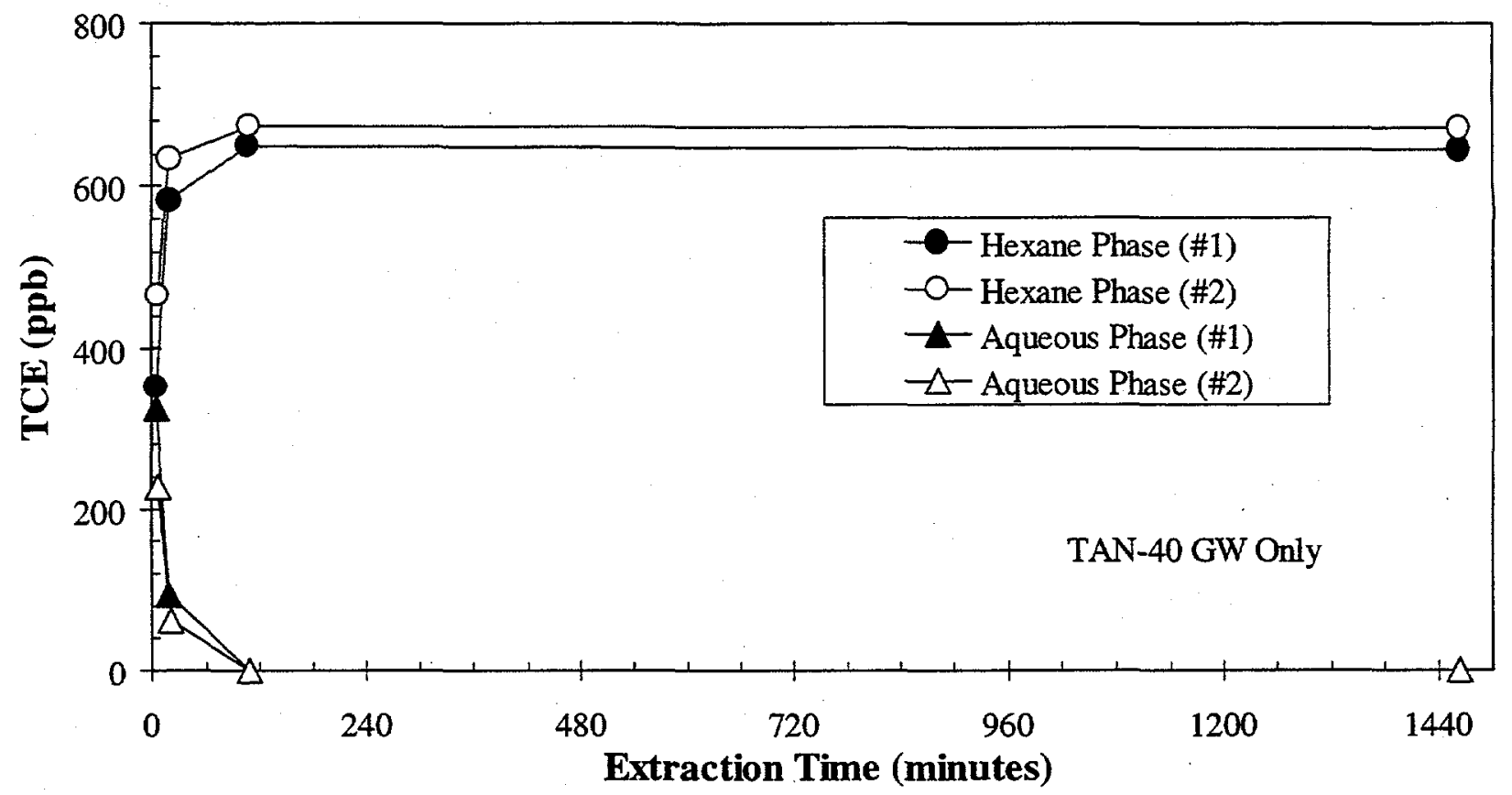

Figure 5. TCE Concentrations of the Hexane and Aqueous Phases from Extraction of TAN-40 GW Only. Initial TCE Conc. $=932 \mu \mathrm{g} / \mathrm{L}$, ORNL Exp. $2 \mathrm{~b}-1$.

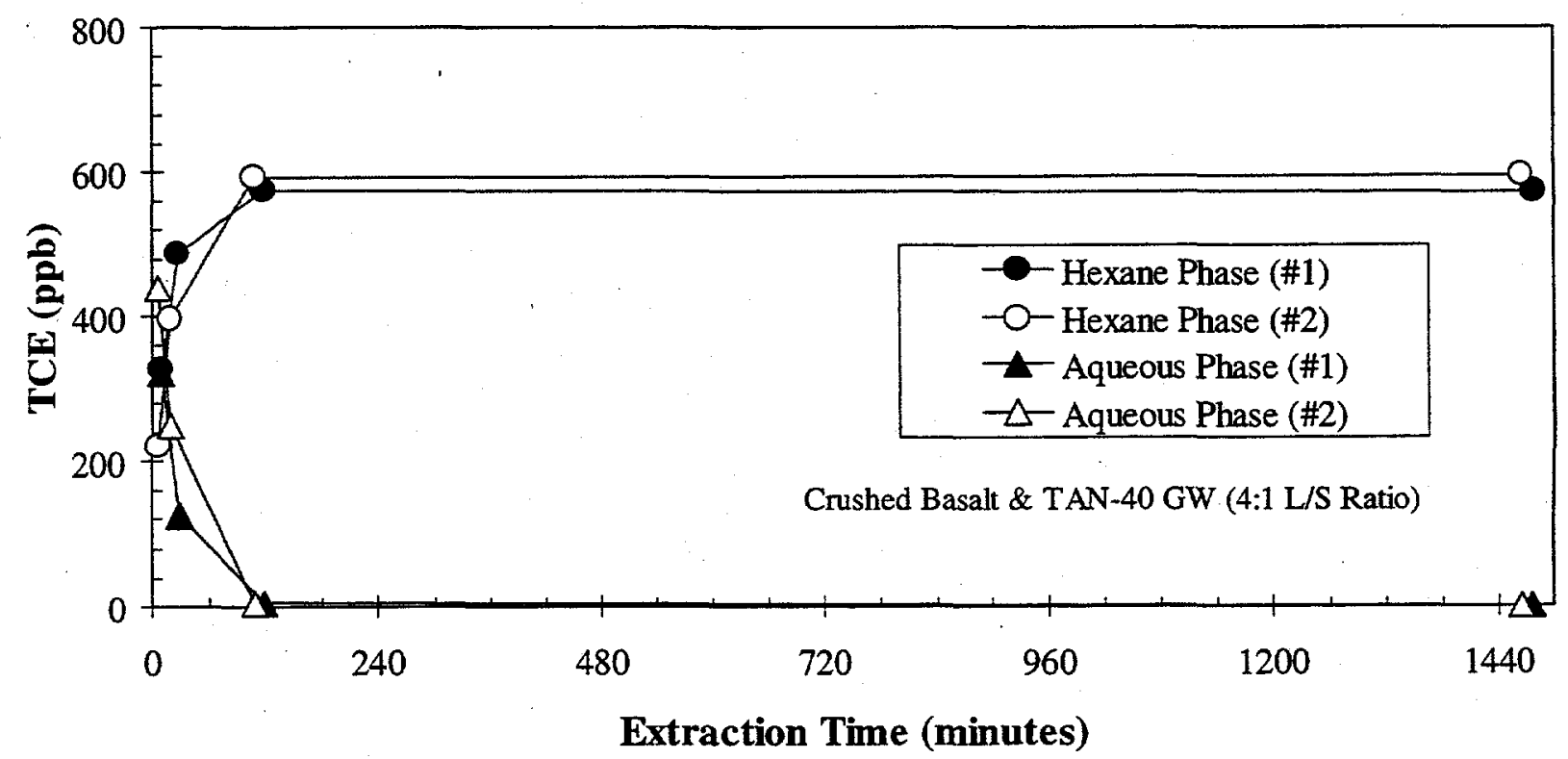

Figure 6. TCE Concentrations of the Hexane and Aqueous Phases from Extraction of Crushed Basalt in TAN-40 GW. Initial TCE Conc. $=932 \mu \mathrm{g} / \mathrm{L}$, ORNL Exp. $2 \mathrm{~b}-1$. 


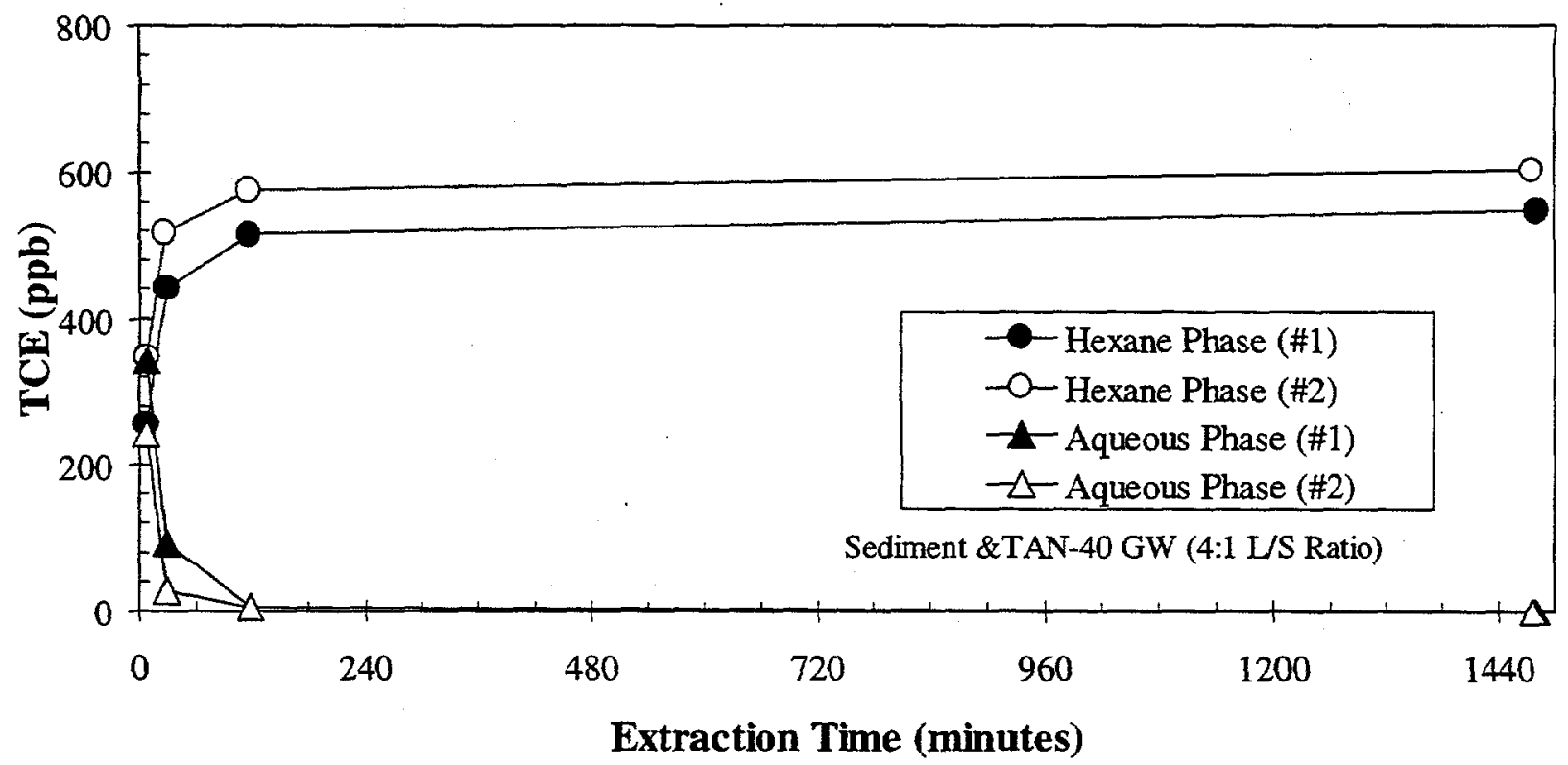

Figure 7. TCE Concentrations of the Hexane and Aqueous Phases from Extraction of Sediment in TAN-40 GW. Initial TCE Conc. $=932 \mu \mathrm{g} / \mathrm{L}$, ORNL Exp. $2 \mathrm{~b}-1$. 
This experiment was intended to investigate the optimum time needed to extract TCE from aggregate basalt. This experiment could not properly be performed until the results from the aggregate basalt equilibration study (ORNL Exps. 2c-1 and 2c-2) were obtained. Given difficulties encountered in performing the equilibration study and the resulting schedule slip, this experiment was not performed. Instead, it was assumed that a $2 \mathrm{hr}$ extraction time would be appropriate for the aggregate basalt too. This deviation from the SOW was not expected to have a significant impact on the overall information gained from this treatability study. In fact, the majority of the hexane extractions performed during the oxidation experiments involving aggregate basalt were essentially groundwater extractions. The large, heavier aggregate basalt would not be present in the aqueous aliquots collected during the course of an experiment. However, the only exception is the extraction of the entire treatment reactor at the end of each experiment. Lower residual TCE values may be obtained if $2 \mathrm{hrs}$ of extraction is not adequate for nearly complete extraction into the hexane. 
ORNL Exp. $2 b-3$

The hexane extraction time needed for the hot spot media was determined in this experiment. Results of the hot spot hexane extraction experiments are presented in Figures 8 and 9 for the TSF-05 GW only, and TSF-05 GW and sludge cases, respectively. The (\#1) and (\#2) notations included in the figure legends refer to the duplicate reactors evaluated for that test condition.

As observed for the dissolved plume media, hexane quickly extracted TCE from the aqueous and slurry phases. It should be noted that the concentrations of the hexane phases associated with the extractions of the TSF-05 GW only containers (Figure 8) were expected to be greater than those from the GW and Sludge extractions (Figure 9). This is because all the samples (GW and GW \& Sludge) were extracted with approximately the same volume of hexane, but the GW only vials contained a larger volume of spiked GW (and therefore more TCE) than did the slurry containers.

The ultimate hexane concentration to be achieved for each type of extraction could not be explicitly determined. It is believed the value obtained for the initial spike solution was less than the true starting concentration. The first attempt to analyze the spike solution resulted in GC values that exceeded the maximum standard for the calibration curve. The second analysis of the TCE-spiked groundwater resulted in an initial TCE concentration of $77,400 \mu \mathrm{g} / \mathrm{L}(\sigma=2,300$ $\mu \mathrm{g} / \mathrm{L})$. However, this second analysis could not be performed until more than a week after the experiment had been completed. Thus, it is suspected that volatilization during storage caused the measured concentration to be less than the true initial concentration. As a result, all of the hexane TCE concentrations obtained at $2 \mathrm{hrs}$ and beyond exceeded that which theoretically could be present. The TSF-05 GW controls (Figure 8) appeared to reach a steady hexane TCE concentration. Thus, it was assumed that TCE was completely extracted from the groundwater. The average percentage of "initial" TCE mass extracted from the TSF-05 GW controls was computed to be $152 \%$. (The $>100 \%$ recovery is a result of the true concentration being greater than the measured initial concentration as discussed above.)

There is more variability in both the hexane and aqueous phase TCE concentrations for the TSF05 slurries (Figure 9). Assuming 152\% as the maximum amount of TCE to be extracted, 116\% and $154 \%$ of the initial TCE was present in the hexane phase at $\mathrm{T}=2 \mathrm{hrs}$. After $24 \mathrm{hrs}, 155 \%$ and $176 \%$ of the initial TCE was present in the hexane phase. It is unknown why the TCE mass in the hexane phase of the duplicate (\#2) increased beyond anticipated the expected quantity. There is the possibility that (1) "residual" TCE was present on the sludge used even after oven drying or (2) the hexane began to evaporate during the $20+$ hrs of extraction, which in effect concentrated the TCE. The latter theory is supported by the fact that the vapor pressure of hexane $\left(120 \mathrm{~mm}\right.$ vs @ $\left.20^{\circ} \mathrm{C}\right)$ is greater than that of TCE $\left(60 \mathrm{~mm} @ 20^{\circ} \mathrm{C}\right)$ (Verschueren 1983). As observed in Figure 9, the aqueous TCE concentrations appeared to increase at $24 \mathrm{hrs}$. This phenomenon seems unlikely, unless re-adsorption of TCE were occurring. It is likely that at least some of these apparent increases in TCE concentrations (both hexane and aqueous phases) are a result of the analytical sample holding time. All samples were collected at the appropriate time period, but none were analyzed until after the $24 \mathrm{hr}$ samples were collected. Hence, it is probable that all of the TCE concentrations reported (with the exception of the T=24 hrs samples) are underestimates of the actual TCE concentrations present at that time period. 
Given the anomalies observed during this experiment, it was truly unknown which factor(s) affected the data most significantly (i.e., extraction time or sample holding time). Thus, a $2 \mathrm{hr}$ extraction time was chosen for the TSF-05 sludge Task 4 experiments. The use of a $2 \mathrm{hr}$ extraction was also beneficial in the conduct of the experiments and general laboratory operations. A matrix spike study not originally planned was also conducted after all the SOW Tasks 3 and 4 work was completed. This spike study (See Section 2.4.6) was conducted to help determine if the results observed here for the TSF-05 sludge were "real". 


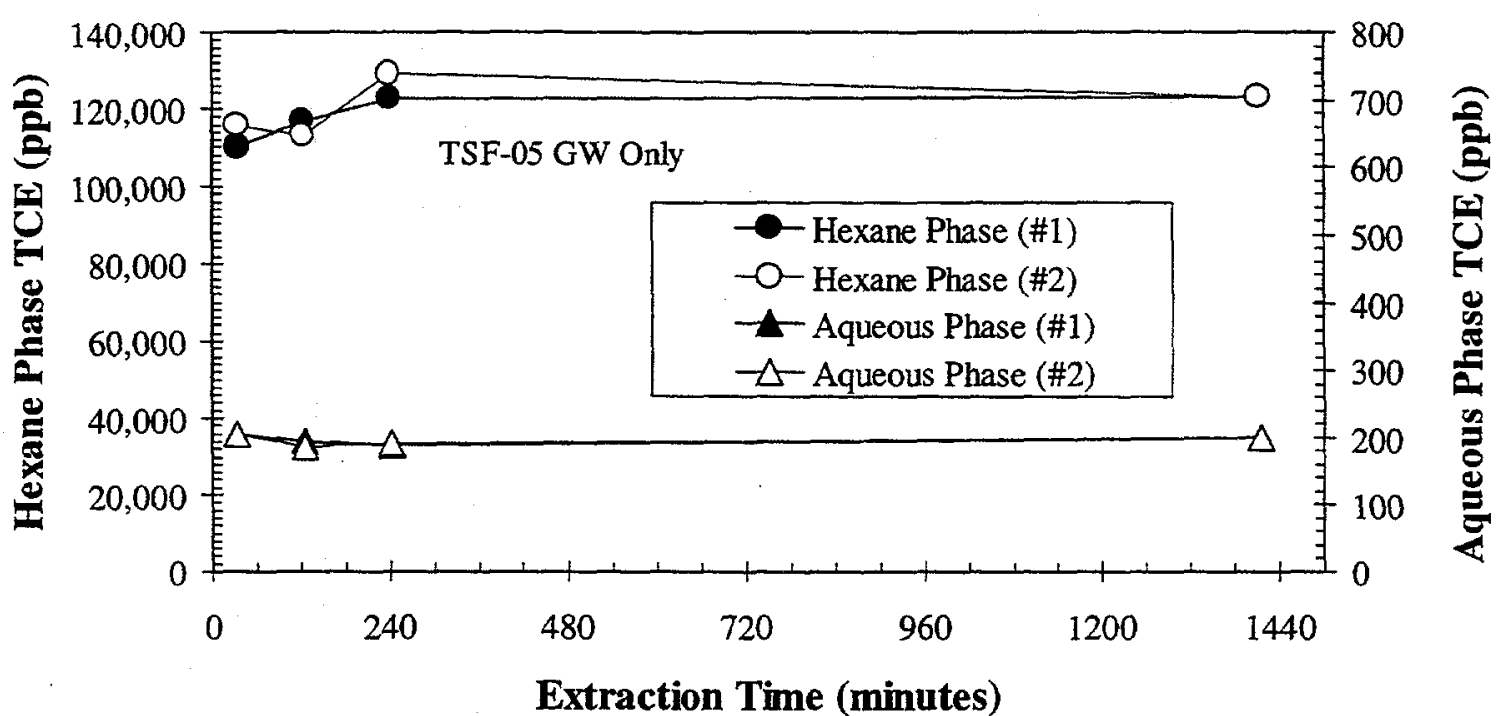

Figure 8. TCE Concentrations of the Hexane and Aqueous Phases from Extraction of TSF-05 GW Only. Initial TCE Conc. $=77,400 \mu \mathrm{g} / \mathrm{L}$, ORNL Exp. $2 \mathrm{~b}-3$.

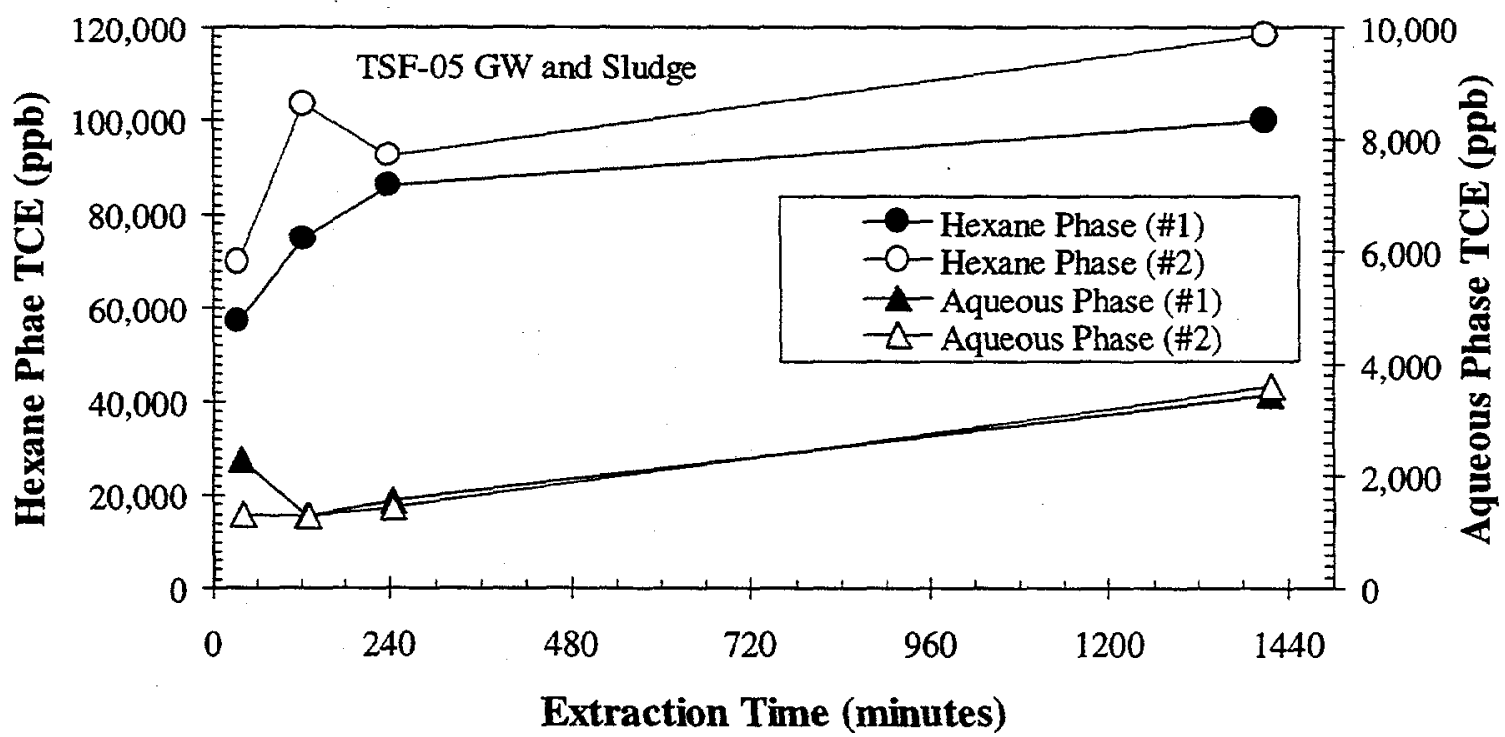

Figure 9. TCE Concentrations of the Hexane and Aqueous Phases from Extraction of TSF-05 GW and Sludge. Initial TCE Conc. $=77,400 \mu \mathrm{g} / \mathrm{L}$, ORNL Exp. $2 \mathrm{~b}-3$. 


\subsubsection{Aggregate Basalt Equilibration Time}

As discussed in Section 1.4.1.3, the experimental results obtained for task $2 \mathrm{c}$ were inconclusive in terms of determining the appropriate spiking/equilibration time needed for the aggregate basalt medium. This experiment involved measuring the TCE concentration of the aqueous portion of a test sample after various equilibration periods. Individual vials, containing no headspace, were sacrificially subsampled at each sampling period as a means to minimize losses associated with volatilization. Aqueous TCE concentrations decreased during the 21 day test period. The average TCE decreases were $30 \%, 32 \%$, and $29 \%$ for the groundwater control, crushed basalt, and aggregate basalt samples, respectively. With the highest TCE losses from the groundwater control samples, the observed TCE decreases could not explicitly be attributed to sorption or uptake by the TAN basalt media. Further investigation of these results lead to the conclusion that the procedure used for this experiment $(2 \mathrm{c}-1)$ was not valid. The $0.45 \mu \mathrm{m}$ membrane filters that were used prior to extraction with hexane at least contributed to the TCE losses observed. In an independent experiment, these filters were found to absorb approximately $10-20 \%$ of a 1,000 $\mu \mathrm{g} / \mathrm{L}$ TCE solution (See Appendix E, March Monthly Report).

Upon realizing these procedural shortcomings, the testplan was modified, and a second equilibration experiment (Exp. 2c-2 in Appendix B) was conducted. In this experiment, the samples were not filtered before TCE analyses. The aqueous samples were also analyzed via purge and trap analyses rather than via a hexane extraction, for the additional transfer sample handling step required in transferring the aqueous aliquot into hexane was likely another source of TCE loss. The results of the second experiment, however, were similar to the first experiment in that the losses observed in the basalt samples correlated well with the TCE losses observed in the groundwater control samples. It is believed that a majority the TCE loss is associated with septa leakage during such long sample holding times (i.e., $>>7$ day sample holding time criterion established by EPA for VOC analyses).

Since a specific equilibration time could not be determined, the aggregate basalt was equilibrated with TCE for the same amount of time as the other TAN Site media (i.e., overnight) in the Task 4 experiments. Furthermore, the fact that an equilibration time could not be determined for the aggregate basalt was not expected to impact the task 4 results since all experiments in Task 4 were performed in agitated, temperature controlled incubators. However, one should consider this effect when attempting to design and implement ISCO in the field, where pore water conditions will be much different.

Beyond the discussion that is presented above, the experimental data for the equilibration studies are not plotted or included elsewhere in this report (e.g, Appendix C) in order to avoid confusion and mis-interpretation of the data. 


\subsection{TASK 3. MEASUREMENT OF THE OXIDANT DEMAND OF TAN SUBSURFACE MATERIALS}

\subsubsection{Laboratory Controls and QA}

Since the oxidant demand experiments did not involve the use of TCE or other volatile compounds, gas-tight conditions did not have to be maintained for these experiments. In addition to the $\mathrm{QA} / \mathrm{QC}$ techniques already discussed for $\mathrm{pH}$ and $\mathrm{MnO}_{4}{ }^{-}$analyses (calibrations, filtering, etc.), all pipette and analytical balances used in these experiments were calibrated each day'of use. The testplan procedure for these experiments involved the extensive use of gravimetric determinations to obtain accurate initial starting masses of $\mathrm{KMnO}_{4}$ and TAN site media being used in the following experiments. A distilled water "control" sample was carried throughout each of the dissolved plume media experiments. Oxidant was added to this control to provide a baseline for evaluating the TAN site materials.

\subsubsection{Oxidant Demand in Dissolved Plume Media}

The dissolved plume media oxidant demand experiments were performed twice. The data values obtained from the initial attempt were difficult to interpret, requiring a refinement/modification of the test procedure. Problems were encountered in determining the true oxidant concentrations in the test reactors. Often the final, measured oxidant concentration was greater than the initial concentration that was computed using the laboratory gravimetric data. To alleviate this problem, a new calibration curve was prepared, and the use of stock $\mathrm{MnO}_{4}{ }^{-}$solutions was implemented as the means to add oxidant to test reactors with low target $\mathrm{MnO}_{4}{ }^{-}$doses rather than via addition of crystalline $\mathrm{KMnO}_{4}$. (This procedural modification was also made to the oxidation rate procedures.)

The $\mathrm{MnO}_{4}{ }^{-}$concentration data obtained from the aliquot sampling is presented in Figure 10 for the $0.01 \%(100 \mathrm{mg} / \mathrm{L}) \mathrm{MnO}_{4}{ }^{-}$initial oxidant experiment. The duplicate test reactors for each test condition are represented in the legend by the (\#1) and (\#2) notations. (This graphing scheme is used for most plots of the oxidant demand and oxidation rate data included in this report). The initial $\mathrm{MnO}_{4}{ }^{-}$value is a calculated value based on several pieces of laboratory data. Detailed explanations regarding such computations are included in Appendix $C$. The remaining data points are measured values obtained from the $\mathrm{MnO}_{4}{ }^{-}$analyses. Residual oxidant was still present after the $24 \mathrm{hr}$ reaction time, indicating that the initial oxidant demand of the dissolved plume media is not extensive or rapid. As expected, the sediment and crushed basalt media consume more oxidant than the aggregate basalt.

Similar results are presented in Figure 11 for the $0.1 \%(1,000 \mathrm{mg} / \mathrm{L}) \mathrm{MnO}_{4}{ }^{-}$initial oxidant experiment. The $\mathrm{MnO}_{4}{ }^{-}$values for a given reactor are more sporadic, and trends among the various media types, while similar to those in Figure 10, are less distinct. One particular anomaly is the marked drop in the $\mathrm{MnO}_{4}{ }^{-}$concentration of the distilled water and TAN-40 GW samples at the end of the reaction period. No additional laboratory observations were recorded that would explain this phenomenon.

Oxidant demand results of the $1 \% \cdot \mathrm{MnO}_{4}{ }^{-}$experiments are presented in Figure 12. As expected there appears to be little oxidant consumption from any of the dissolved plume media. 
Crystalline $\mathrm{KMnO}_{4}$ was used in this experiment, while a concentrated $\mathrm{MnO}$ - stock solution was used in the previous experiments. Thus, the apparent oxidant demand early in the reaction period (Figure 12) is likely attributed to the inability of the solid $\mathrm{KMnO}_{4}$ to dissolve rapidly enough, even though the first aliquot sampling period in this experiment was increased to 1 hour to allow more time for $\mathrm{KMnO}_{4}$ to solublize. The initial oxidant mass added was determined gravimetrically using an analytical balance with a \pm 0.0001 gram resolution, hence there is a great deal of confidence in the initial $\mathrm{MnO}_{4}{ }^{-}$concentrations. Preparation of the sample dilutions needed for the $\mathrm{MnO}_{4}{ }^{-}$analyses is certainly an area in which experimental/human error could have contributed to the variability of the oxidant values, particularly for the experiments involving the higher initial $\mathrm{MnO}_{4}{ }^{-}$concentrations. Dilutions, for example of 50 and 500 were required for aliquot samples from the $0.1 \%$ and $1 \%$ experiments. However, the value added of performing extremely accurate dilutions is not warranted when considering that the accuracy of the spectrophotometer itself is only $\pm 0.2 \mathrm{mg} / \mathrm{L}$. Because the $\mathrm{MnO}_{4}{ }^{-}$data was not intended to be a decision making criterion (see SOW, Appendix A), the standards prepared and used to calibrate the spectrophotometer were not titrated or measured against a known standard. Finally, it is unknown why the oxidant demand of the distilled water control is so much greater than that of the TAN Site materials in Figure 12. This effect was not observed in Figures 10 and 11 and is thought to be a laboratory artifact rather than a real effect.

The data from these experiments were further evaluated to obtain oxidant demand or consumption values for each discrete type of dissolve plume media. This value could be readily obtained for the TAN- $40 \mathrm{GW}$. However, further computations were needed to obtain such consumption data for the solid phase media since the experiments were conducted using a GW and solids slurry. Both the measured and "derived" consumption values are presented in Table 8 for the dissolved plume media. To standardize the consumption data, the values in Table 8 represent the amount of $\mathrm{MnO}_{4}{ }^{-}$consumed per unit of TAN media or DI water after a 24 hour reaction time. To be more precise, the data in Table 8 represent the difference in overall oxidant mass at the two reaction points ( $T=0$ and $24 \mathrm{hrs}$ ), and does not depict any of the fluctuations observed in $\mathrm{MnO}_{4}{ }^{-}$concentrations between these two sample points. The oxidant mass consumed was determined by the difference in the beginning and ending aqueous $\mathrm{MnO}_{4}{ }^{-}$ concentrations and multiplying that value by the initial liquid volume that was present in the reactor at $\mathrm{T}=0 \mathrm{hrs}$. This approach yields a conservative, maximum oxidant demand value (for the given time period), for it does not account for any $\mathrm{MnO}_{4}{ }^{-}$mass removed by aliquot sampling.

Note that a more refined oxidant consumption value can be determined by computing the cumulative mass of oxidant consumed during each sampling interval. This second approach, however, will yield a lower total consumption values since the mass of $\mathrm{MnO}_{4}{ }^{-}$associated with the aliquot samples must be accounted for since it is no longer available to be consumed within the test reactors. The degree of error between the two techniques does not become significant unless the bulk of the consumption occurs toward the end of the test period. The test data and the subsequent calculations discussed here are presented in Appendix $\mathrm{C}$ for each oxidant demand experiment.

These oxidant consumption values were then divided by the total mass of TAN site media (GW or GW \& Solid) initially added to the each reactor. (The specific gravity of TAN-40 GW is 
assumed to be 1.0.) To derive the oxidant demand for the basalt and sediment, the $\mathrm{MnO}_{4}{ }^{-}$mass predicted to be associated with the GW was subtracted from the total oxidant consumption value for the slurry according to the equation presented in Table 8 .

The resulting oxidant demand values obtained for the crushed basalt, aggregate basalt, and sediment at the $0.01 \%$ and $0.1 \%$ loadings are in good agreement with each other. The negative values obtained for aggregate basalt and sediment for the $1 \% \mathrm{MnO}_{4}{ }^{-}$experiment are because the measured $\mathrm{MnO}_{4}{ }^{-}$concentration of the TAN- $40 \mathrm{GW}$ at $24 \mathrm{hrs}$ is less than that of the slurry reactors (See Figure 12).

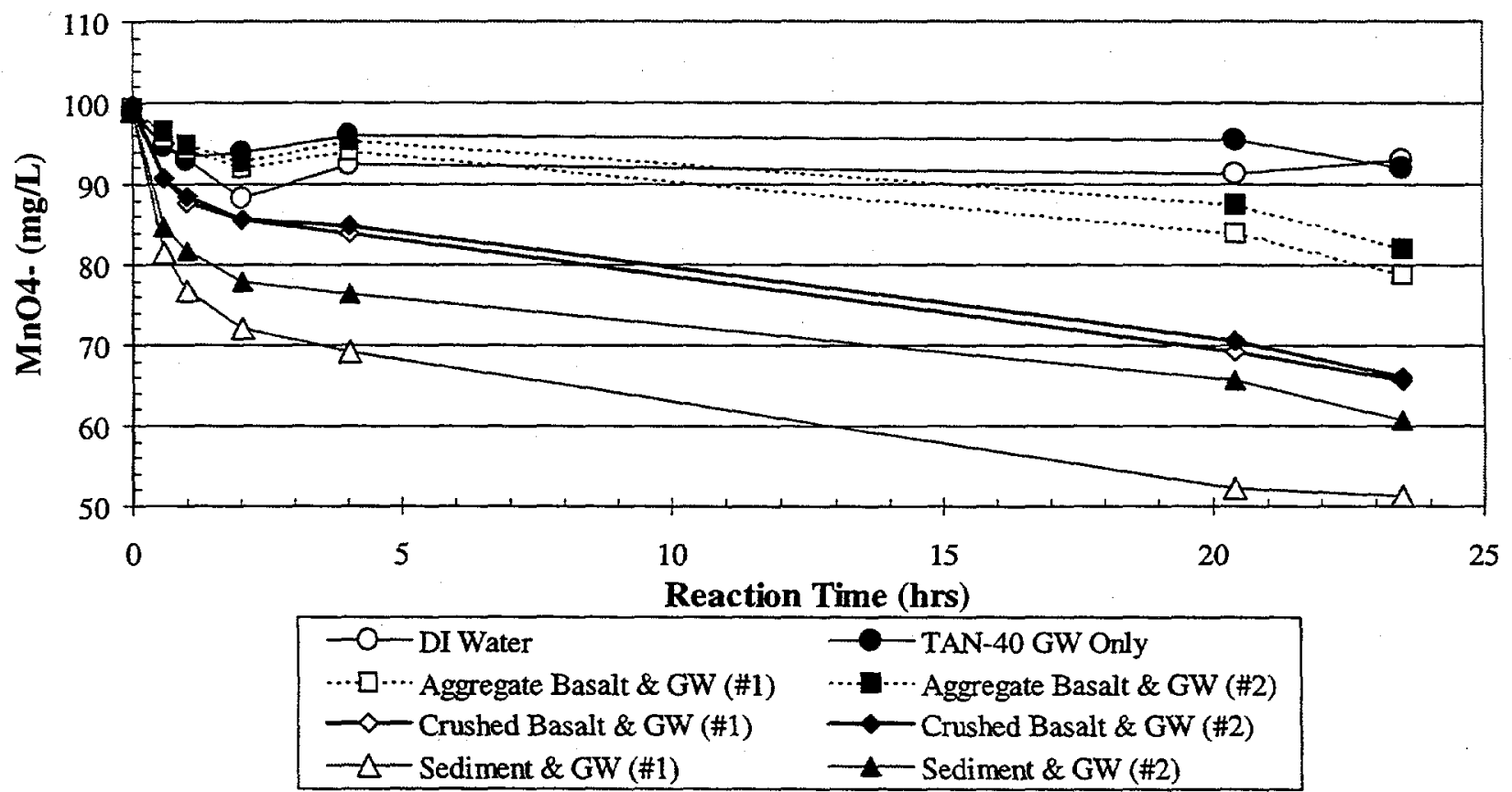

Figure 10. Oxidant Demand Results for Dissolved Plume Media, Initial $\mathrm{MnO}_{4}=0.01 \%$ (ORNL Exp. 3a-Rlb, Conducted at $12^{\circ} \mathrm{C}$ and $4: 1 \mathrm{~L} / \mathrm{S}$ ratio where applicable) 


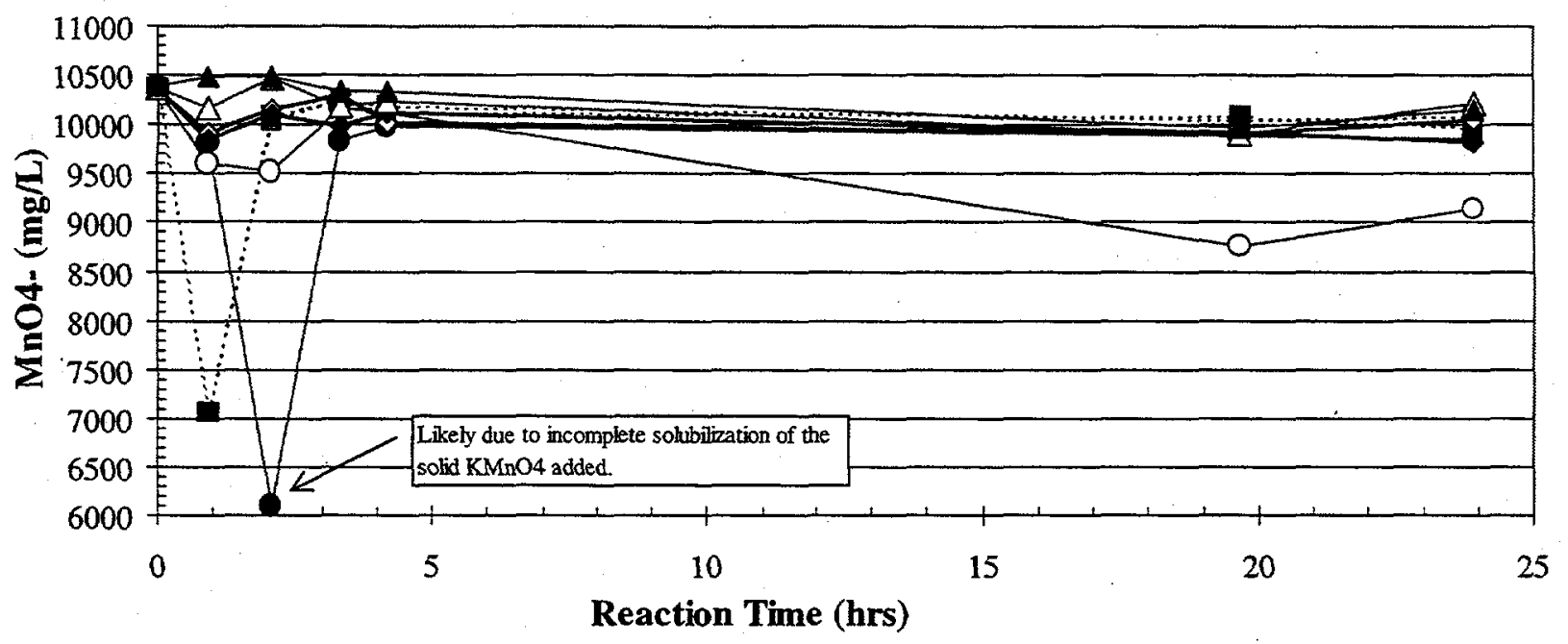

\begin{tabular}{ll|}
$-0-$ DI Water & - TAN-40 GW Only \\
$\cdots \square \cdot$ Aggregate Basalt \& GW (\#1) & $\cdots$ Aggregate Basalt \& GW (\#2) \\
- - Crushed Basalt \& GW (\#1) & - Crushed Basalt \& GW (\#2) \\
$-\triangle-$ Sediment \& GW (\#1) & - - Sediment \& GW (\#2) \\
\hline
\end{tabular}

Figure 11. Oxidant Demand Results for Dissolved Plume Media, Initial $\mathrm{MnO}_{4}{ }^{-}=0.1 \%$ (ORNL Exp. 3a-R2b, Conducted at $12^{\circ} \mathrm{C}$ and $4: 1 \mathrm{~L} / \mathrm{S}$ ratio where applicable)

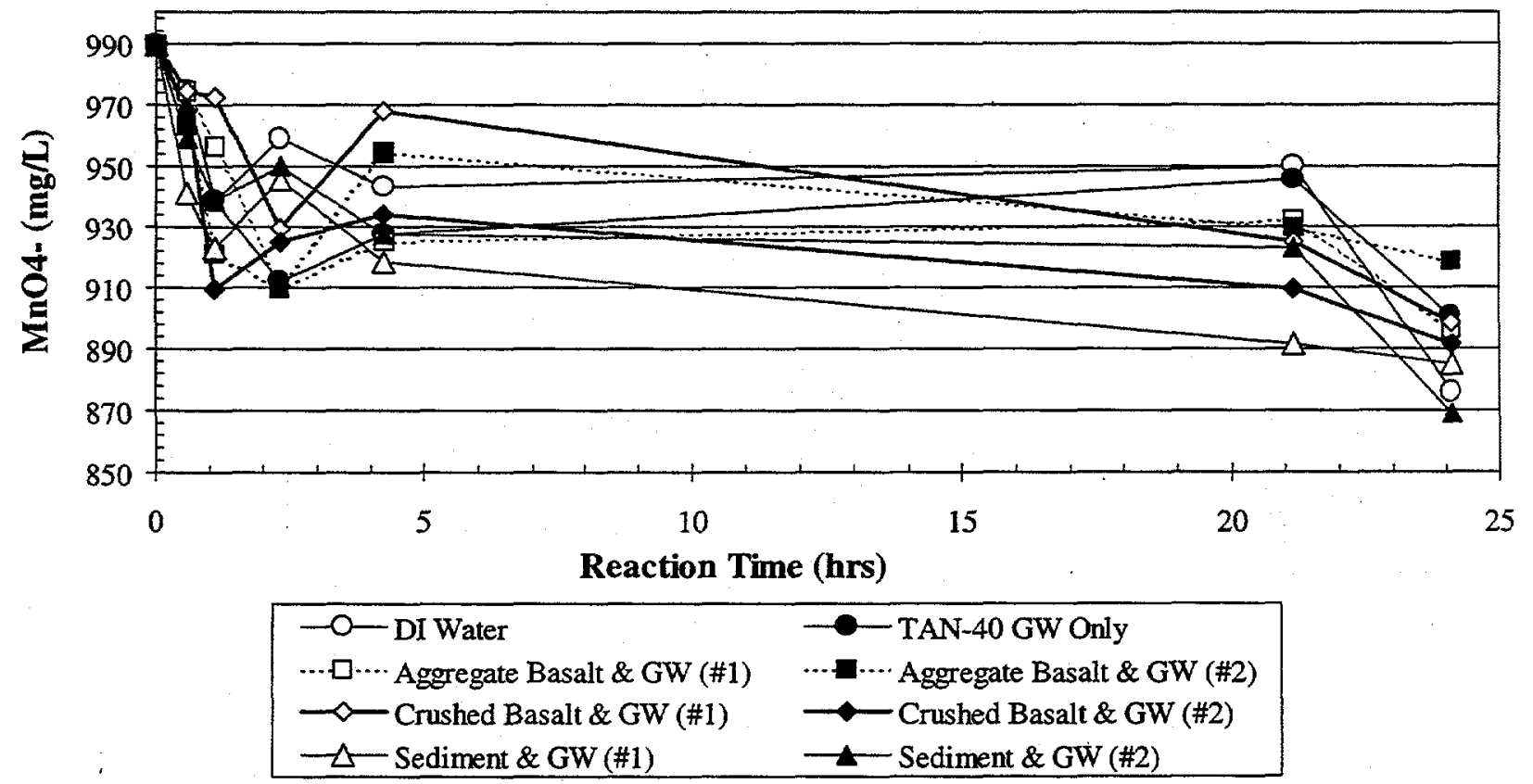

Figure 12. Oxidant Demand Results for Dissolved Plume Media, Initial $\mathrm{MnO}_{4}{ }^{-}=1 \%$ (ORNL Exp. 3a-R3b, Conducted at $12^{\circ} \mathrm{C}$ and $4: 1 \mathrm{~L} / \mathrm{S}$ ratio where applicable) 
Table 8. Calculated Oxidant Demand Values for the Dissolved Plume Media. a,b.

\begin{tabular}{|c|c|c|c|c|c|c|}
\hline \multirow[b]{3}{*}{ Test Media } & \multicolumn{6}{|c|}{ Initial $\mathrm{MnO}_{4}{ }^{-}$Concentration } \\
\hline & \multicolumn{2}{|c|}{$0.01 \%$} & \multicolumn{2}{|c|}{$0.1 \%$} & \multicolumn{2}{|c|}{$1.0 \%$} \\
\hline & $\begin{array}{l}\text { Initial } \\
\text { Loading } \\
\end{array}$ & Consumed & $\begin{array}{l}\text { Initial } \\
\text { Loading }\end{array}$ & Consumed & $\begin{array}{l}\text { Initial } \\
\text { Loading }\end{array}$ & Consumed \\
\hline Distilled Water & 0.1 & 0.001 & 1.0 & 0.09 & 10.4 & 0.97 \\
\hline TAN-40 GW & 0.1 & 0.005 & 1.0 & 0.07 & 10.4 & 0.41 \\
\hline GW \& Crushed Basalt & 0.08 & 0.03 & 0.8 & 0.08 & 8.2 & 0.33 \\
\hline GW \& Aggregate Basalt & 0.08 & 0.01 & 0.8 & 0.07 & 8.2 & 0.27 \\
\hline GW \& Sediment & 0.08 & 0.04 & 0.8 & 0.11 & 8.2 & 0.19 \\
\hline Crushed Basalt $^{c}$ & $\mathrm{NA}$ & 0.11 & $\mathrm{NA}$ & 0.09 & NA & 0.05 \\
\hline Aggregate Basalt ${ }^{\mathrm{c}}$ & $\mathrm{NA}$ & 0.05 & $\mathrm{NA}$ & 0.04 & $\mathrm{NA}$ & -.233 \\
\hline Sediment ${ }^{c}$ & NA & 0.15 & NA & 0.18 & NA & -.835 \\
\hline
\end{tabular}

2. All values in units of [ $\mathrm{mg} \mathrm{MnO}_{4}{ }^{-1} \mathrm{~g}$ of TAN Site Media or DI Water]

b. Consumption values represent a $24 \mathrm{hr}$ reaction time. Values presented for the $\mathrm{GW}$ slurries are the averages of duplicate samples.

c. Derived by subtracting the GW consumption component from the total oxidant consumption of the slurry via the following equation:

Solid Phase Demand $(\mathrm{mg} / \mathrm{g})=\left[\right.$ Total- $\left(\mathrm{GW}\right.$ Demand $\left.\left.\mathrm{x} \mathrm{Wt} \mathrm{t}_{\mathrm{Gw}}\right)\right] /\left(\mathrm{Wt}_{\mathrm{soid}}\right)$

Where: Total= total mass of $\mathrm{MnO}_{4}{ }^{-}(\mathrm{mg})$ consumed by the slurry.

GW Demand $=$ demand determined from experiments $(\mathrm{mg} / \mathrm{g})$ involving $\mathrm{GW}$ only

$\mathrm{Wt}_{\mathrm{GW}}=$ mass of $\mathrm{GW}$ in the slurry

$\mathrm{Wt}_{\mathrm{sobi}}=$ mass of solid in the slurry

In summary, as indicated in Table 8 , for both the $.01 \%$ and $0.1 \% \mathrm{MnO}_{4}{ }^{-}$experiments the oxidant demand of the aggregate basalt is $\approx 0.05 \mathrm{mg} / \mathrm{g}$ and approximately double that for the crushed basalt $(\approx 0.1 \mathrm{mg} / \mathrm{g})$. Similarly, the oxidant demand of the sediment is approximately $0.2 \mathrm{mg} / \mathrm{g}$ for both initial oxidant loadings. Due to the low oxidant demand of distilled water and the dissolved plume media, the variation observed in the $1 \%$ data is likely due to (1) the very small differences in concentration being measured being less than the precision of the analytical technique employed and/or (2) common laboratory errors in the handling of and the gravimetric determination of the initial $\mathrm{KMnO}_{4}$ mass added to each reactor.

As mentioned previously, the oxidant demand experiments had to be repeated due to problems associated with the $\mathrm{MnO}_{4}{ }^{-}$analyses. (The $\mathrm{MnO}_{4}{ }^{-}$results of the repeated experiments plotted in Figures 10-12). In order to expedite completion of the repeated experiments, $\mathrm{pH}$ values were not measured for the repeated experiments. However, the $\mathrm{pH}$ data from the initial experiments are presented in Figures 13, 14, and 15. There was no indication why the $\mathrm{pH}$ results from the first experiments would not be acceptable to determining $\mathrm{pH}$ trends related to the different types of dissolved plumed media.

The initial $\mathrm{pH}$ of the sediment slurries before oxidant addition are consistently less $\approx 0.5 \mathrm{pH}$ units) than that of the basalt or TAN-40 groundwater. Changes in $\mathrm{pH}$, however, that result from 
oxidant addition and subsequent consumption appear to be small. Although small in magnitude, the most evident $\mathrm{pH}$ changes were observed in the experiment involving $1 \% \mathrm{MnO}_{4}{ }^{-}$. Oxidant addition appears to initially increase the system $\mathrm{pH}$ for the groundwater and basalt samples. In contrast, the $\mathrm{pH}$ of the sediment material decreases further as a result of oxidant addition. Thus, $\mathrm{pH}$ changes due to oxidant addition are at least in part affected by the chemical characteristics of the TAN site media. Additional discussion and presentation of $\mathrm{pH}$ data will be presented in the Task 4 work. 


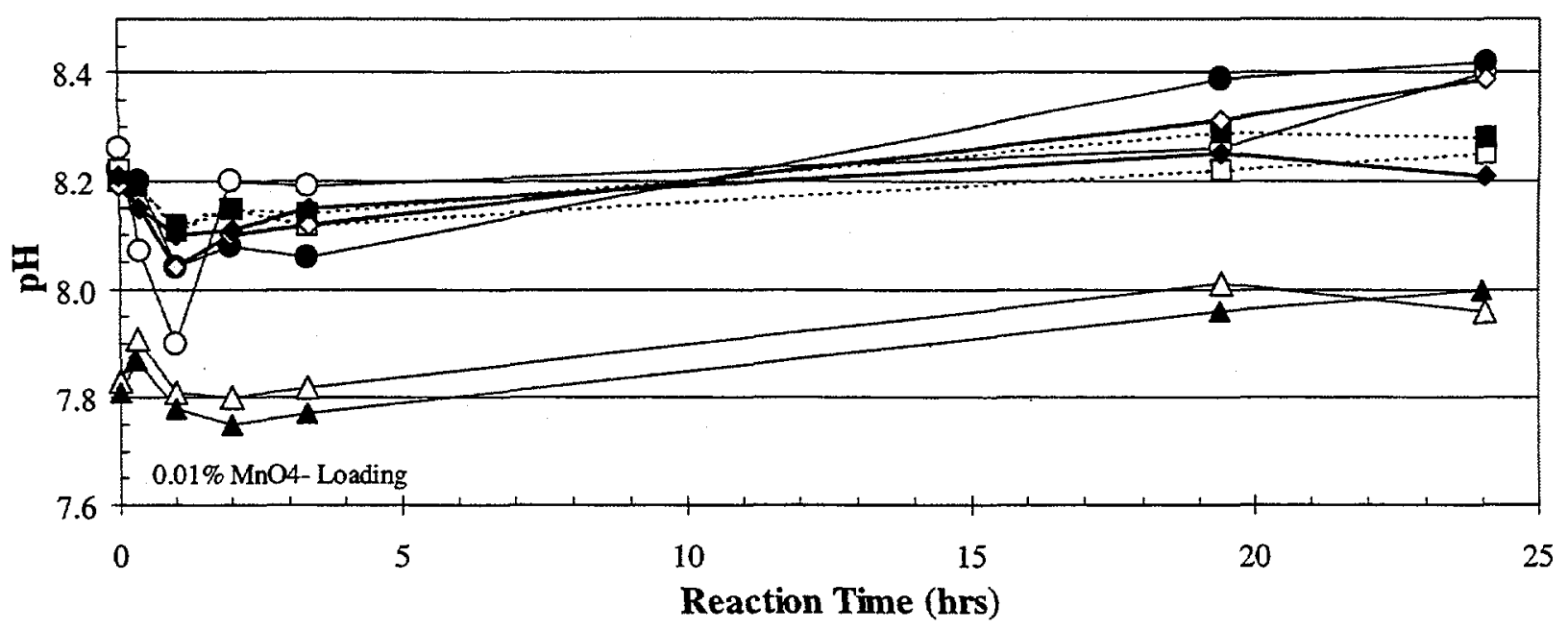

\begin{tabular}{|ll|}
\hline- TAN-40 GW Only & - TAN-40 GW Only \\
$\cdots \square \cdots$ Aggregate Basalt \& GW (\#1) & $\cdots \cdots$ Aggregate Basalt \& GW (\#2) \\
$-\checkmark$ Crushed Basalt \& GW (\#1) & - Crushed Basalt \& GW (\#2) \\
$\triangle$ Sediment \& GW (\#1) & - Sediment \& GW (\#2) \\
\hline
\end{tabular}

Figure 13. $\mathrm{pH}$ Results Obtained During Consumption of Dissolved Plume Media, Initial $\mathrm{MnO}_{4}{ }^{-}$ $=0.01 \%\left(\mathrm{ORNL}\right.$ Exp. $3 \mathrm{a}-\mathrm{R} 1$, Conducted at $12^{\circ} \mathrm{C}$ and $4: 1 \mathrm{~L} / \mathrm{S}$ ratio where applicable)

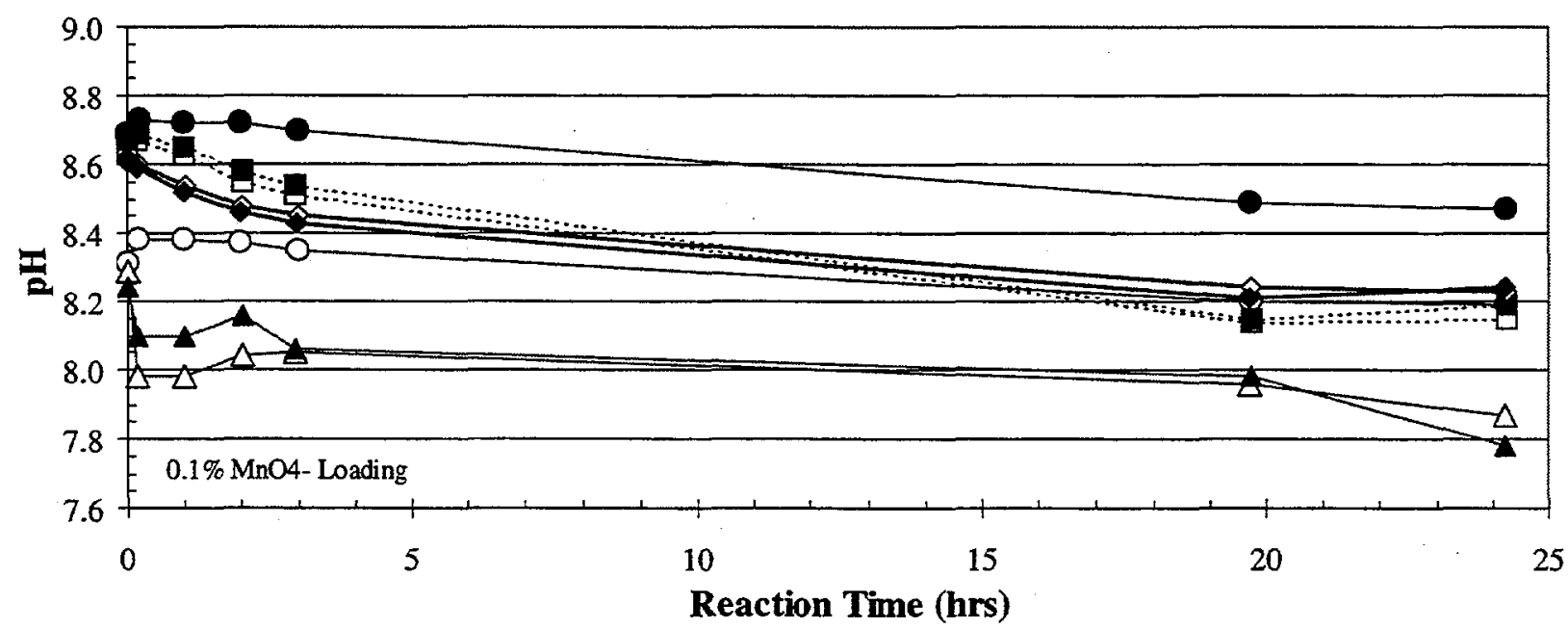

\begin{tabular}{|c|c|}
\hline $\begin{array}{l}- \text { TAN-40 GW Only } \\
\cdots \square \text { Aggregate Basalt \& GW (\#1) } \\
\checkmark \text { Crushed Basalt \& GW (\#1) } \\
\triangle-\text { Sediment \& GW (\#1) }\end{array}$ & $\begin{array}{l}\text { - TAN-40 GW Only } \\
\ldots \text { Aggregate Basalt \& GW (\#2) } \\
\text { C Crushed Basalt \& GW (\#2) } \\
\text { - Sediment \& GW (\#2) }\end{array}$ \\
\hline
\end{tabular}

Figure 14. $\mathrm{pH}$ Results Obtained During Consumption of Dissolved Plume Media, Initial $\mathrm{MnO}_{4}{ }^{-}$ $=0.10 \%\left(\mathrm{ORNL}\right.$ Exp. $3 \mathrm{a}-\mathrm{R} 2$, Conducted at $12^{\circ} \mathrm{C}$ and $4: 1 \mathrm{~L} / \mathrm{S}$ ratio where applicable) 


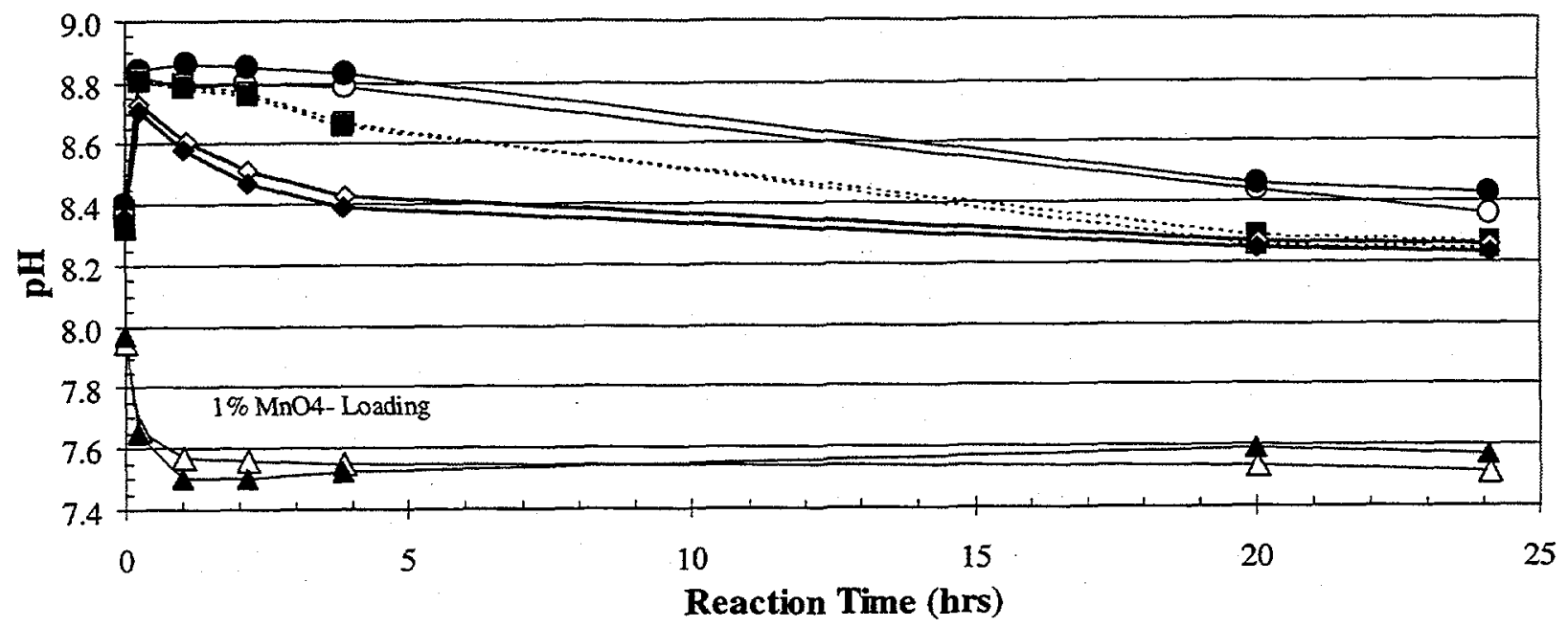

\begin{tabular}{|c|c|}
\hline $\begin{array}{l}-\mathrm{O}-\text { TAN-40 GW Only } \\
\cdots \square \cdots \text { Aggregate Basalt \& GW (\#1) } \\
\sim-\text { Crushed Basalt \& GW (\#1) } \\
\neg-\text { Sediment \& GW (\#1) }\end{array}$ & $\begin{array}{l}- \text { - TAN-40 GW Only } \\
\cdots \cdots \text { Aggregate Basalt \& GW (\#2) } \\
- \text { Crushed Basalt \& GW (\#2) } \\
\rightarrow-\text { Sediment \& GW (\#2) }\end{array}$ \\
\hline
\end{tabular}

Figure 15. $\mathrm{pH}$ Results Obtained During Consumption of Dissolved Plume Media, Initial $\mathrm{MnO}_{4}{ }^{-}$ $=1 \%$ (ORNL Exp. 3a-R3, Conducted at $12^{\circ} \mathrm{C}$ and $4: 1 \mathrm{~L} / \mathrm{S}$ ratio where applicable) 


\subsubsection{Oxidant Demand in Hot Spot Media}

The oxidant demand of the hot spot media was determined in a similar fashion as that of the dissolved media with a few notable differences presented here. A distilled water control sample was not used in these experiments; instead, two (2) TSF-05 GW samples were used. A stock $\mathrm{MnO}_{4}{ }^{-}$solution was not used for the initial $\mathrm{MnO}_{4}{ }^{-}$addition into the $0.01 \%$ and $0.1 \% \mathrm{MnO}_{4}{ }^{-}$test reactors. An equivalent mass of solid $\mathrm{KMnO}_{4}$ was added instead. As discussed in Section 1.4.2, the first sampling time was set at 10 minutes in hopes of being able to more accurately quantify the initial oxidant consumption rate. Unfortunately, as the plots reflect, the slow solubization time of the crystalline $\mathrm{KMnO}_{4}$ impeded those efforts. Some variability in the $\mathrm{MnO}_{4}{ }^{-}$measured concentrations was also observed in these experiments but is not as readily apparent due to the large scale needed for the vertical axes. Preparation of the sample dilutions needed for the $\mathrm{MnO}_{4}{ }^{-}$analyses is certainly an area in which experimental/human error could have contributed to some of this variability of the oxidant values

The $\mathrm{MnO}_{4}{ }^{-}$concentration data obtained from the aliquot sampling is presented in Figure 16 for the $0.01 \%(100 \mathrm{mg} / \mathrm{L}) \mathrm{MnO}_{4}{ }^{-}$initial oxidant concentration experiment. As in the dissolved plume experiments, the initial $\mathrm{MnO}_{4}{ }^{-}$values presented in Figure 16 are calculated values based on several pieces of laboratory data. Detailed explanations regarding such computations are included in Appendix $\mathrm{C}$. The remaining data points are measured values obtained from the $\mathrm{MnO}_{4}{ }^{-}$analyses. It is readily apparent that the TSF-05 sludge exerts a sufficiently high oxidant demand to completely consume all added oxidant within the first 10 minutes of interaction. As noted on Figure 16, the apparent consumption of $\mathrm{MnO}_{4}{ }^{-}$in the TSF- $05 \mathrm{GW}$ only reactors is likely due to the lack of equilibration time. Nearly identical results were obtained for $0.1 \%$ $(1,000 \mathrm{mg} / \mathrm{L}) \mathrm{MnO}_{4}{ }^{-}$initial oxidant concentration experiment and are presented in Figure 17.

Oxidant demand results of the $1 \% \mathrm{MnO}_{4}{ }^{-}$experiments are presented in Figure 18. Here, the initial loading appears to be great enough to allow the consumption reactions to be observed and quantified. Averaging the $\mathrm{MnO}_{4}{ }^{-}$concentrations of the duplicate TSF- $05 \mathrm{GW}$ and sludge slurries, results in a consumption rate of $250-900 \mathrm{mg} \mathrm{MnO}_{4}{ }^{-} /$hour between the $0.5 \mathrm{hr}$ and $4 \mathrm{hr}$ sampling periods. The actual time at which the oxidant was consumed was not captured temporally, thus a consumption rate cannot be computed for the period after $\mathrm{T}=4$ hours.

Oxidant demand results of the $3 \% \mathrm{MnO}_{4}^{-}$experiments are presented in Figure 19. For this oxidant loading, the TSF- $05 \mathrm{GW}$ and sludge slurry did not completely consume the available $\mathrm{MnO}_{4}{ }^{-}$within the $24 \mathrm{hr}$ reaction time. Averaging the $\mathrm{MnO}_{4}{ }^{-}$concentrations of the duplicate TSF$05 \mathrm{GW}$ and sludge slurries results in a consumption rate of $615-700 \mathrm{mg} \mathrm{MnO}_{4}^{-} /$hour between $1 \mathrm{hr}$ and $4 \mathrm{hr}$ sampling periods. The rate of consumption then appears to slow to an average of 132 $\mathrm{mg} \mathrm{MnO}_{4}{ }^{-} / \mathrm{hr}$ between 4 and $24 \mathrm{hrs}$. Because residual oxidant was still present in the slurry samples at $24 \mathrm{hrs}$, these reactors were allowed to continue reacting for an additional three days. Residual $\mathrm{MnO}_{4}{ }^{-}$was still present after 95 total hours. The average consumption rate between 24 and $95 \mathrm{hrs}$ declined to $34 \mathrm{mg} \mathrm{MnO}_{4}{ }^{-} / \mathrm{hr}$.

The raw data for these experiments were further evaluated to obtain an oxidant demand or consumption value for TSF-05 sludge itself. Both the measured and "derived" consumption values are presented in Table 9 for the hot spot plume media. To standardize the consumption 
data, the values in Table 9 represent the amount of $\mathrm{MnO}_{4}{ }^{-}$consumed per unit of hot spot media after a 24 hour reaction time. The approach used to obtain the oxidant demand of the TSF-05 is the same as that used for the dissolved plume media discussed above in Section 2.3.2. Since the $0.01 \%, 0.1 \%$, and $1 \%$ experiments resulted in complete oxidation consumption within $24 \mathrm{hrs}$, only the value obtained for the $3 \%$ initial oxidant concentration experiment is meaningful. The oxidant demand of the TSF-05 sludge is about $70 \mathrm{mg} \mathrm{MnO}_{4} / \mathrm{mg}$ sludge. A semi-log plot of the consumption data was also prepared to ascertain whether the consumption rate was first order with respect to the $\mathrm{MnO}_{4}{ }^{-}$concentration; however, a linear trend was not observed throughout the reaction interval. 


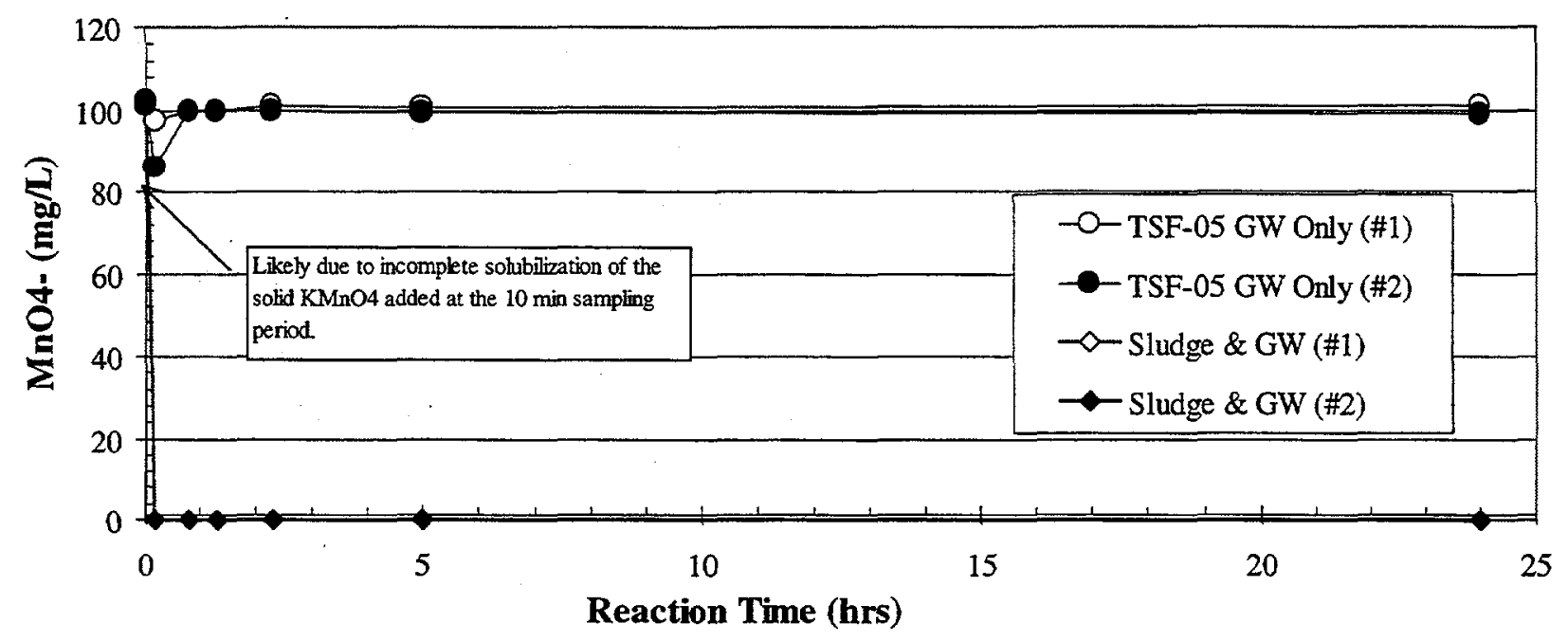

Figure 16. Oxidant Demand Results for Hot Spot Media, Initial $\mathrm{MnO}_{4}{ }^{-}=0.01 \%$ (ORNL Exp. $3 \mathrm{~b}-\mathrm{R} 1$, Conducted at $12^{\circ} \mathrm{C}$ and $4: 1 \mathrm{~L} / \mathrm{S}$ ratio where applicable)

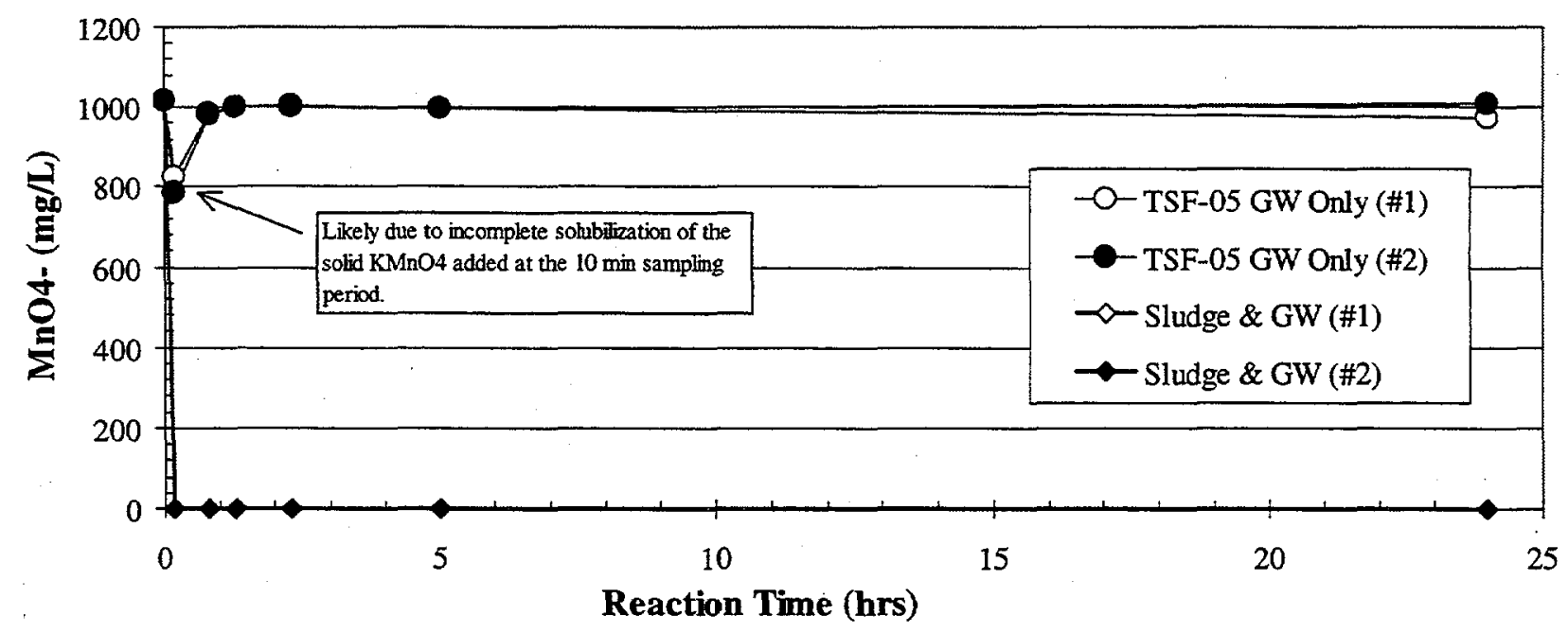

Figure 17. Oxidant Demand Results for Hot Spot Media, Initial $\mathrm{MnO}_{4}=0.10 \%$ (ORNL Exp. $3 \mathrm{~b}-\mathrm{R} 2$, Conducted at $12^{\circ} \mathrm{C}$ and $4: 1 \mathrm{~L} / \mathrm{S}$ ratio where applicable) 


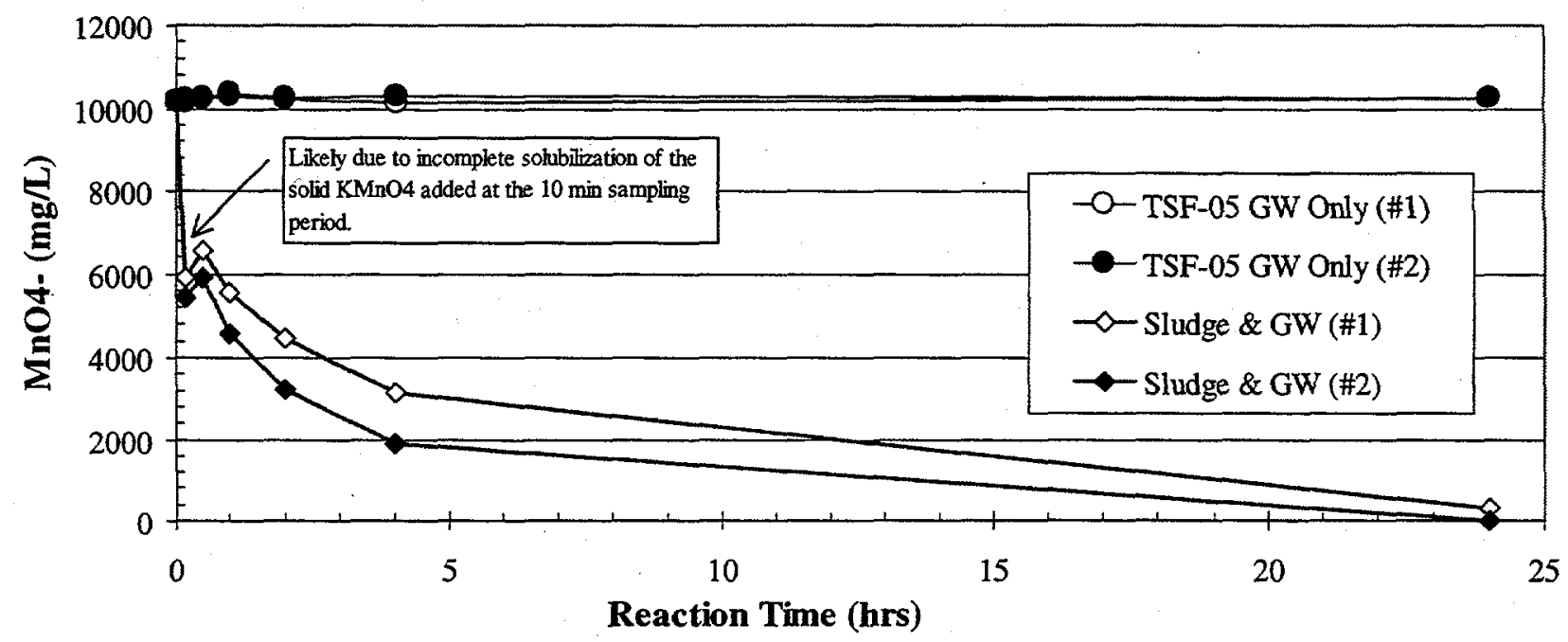

Figure 18. Oxidant Demand Results for Hot Spot Media, Initial $\mathrm{MnO}_{4}=1 \%$ (ORNL Exp. 3b$\mathrm{R} 3$, Conducted at $12^{\circ} \mathrm{C}$ and $4: 1 \mathrm{~L} / \mathrm{S}$ ratio where applicable)

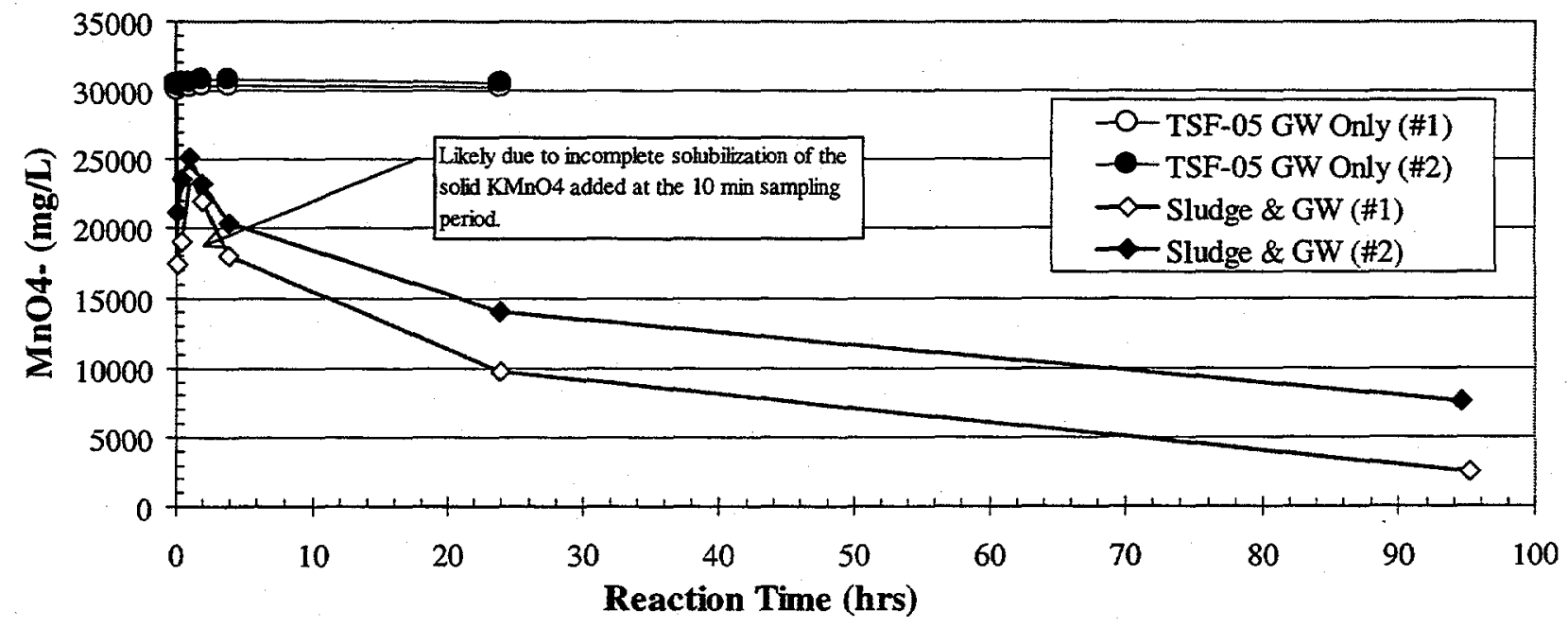

Figure 19. Oxidant Demand Results for Hot Spot Media, Initial $\mathrm{MnO}_{4}{ }^{-}=3 \%$ (ORNL Exp. 3b$\mathrm{R} 4$, Conducted at $12^{\circ} \mathrm{C}$ and $4: 1 \mathrm{~L} / \mathrm{S}$ ratio where applicable) 
Table 9. Calculated Oxidant Demand Values for the Hot Spot Media. a,b.

\begin{tabular}{|c|c|c|c|c|c|c|c|c|}
\hline \multirow{3}{*}{$\begin{array}{l}\text { Test } \\
\text { Media }\end{array}$} & \multicolumn{8}{|c|}{ Initial $\mathrm{MnO}_{4}{ }^{-}$Concentration } \\
\hline & \multicolumn{2}{|c|}{$0.01 \%$} & \multicolumn{2}{|c|}{$0.1 \%$} & \multicolumn{2}{|c|}{$1 \%$} & \multicolumn{2}{|c|}{$3 \%$} \\
\hline & $\begin{array}{l}\text { Initial } \\
\text { Loading }\end{array}$ & Consumed & $\begin{array}{l}\text { Initial } \\
\text { Loading }\end{array}$ & Consumed & $\begin{array}{l}\text { Initial } \\
\text { Loading }\end{array}$ & Consumed & $\begin{array}{l}\text { Initial } \\
\text { Loading }\end{array}$ & Consumed \\
\hline $\begin{array}{l}\text { TSF-05 } \\
\text { GW } \\
\text { Only }\end{array}$ & 0.1 & 0.002 & 1.0 & 0.02 & 10.2 & -0.08 & 30.5 & 0.10 \\
\hline $\begin{array}{l}\text { TSF-05 } \\
\text { GW \& } \\
\text { Sludge }\end{array}$ & 0.08 & $0.08^{d}$ & 0.8 & $0.8^{d}$ & 8.1 & $7.9^{d}$ & 24.1 & 14.7 \\
\hline $\begin{array}{l}\text { TSF-05 } \\
\text { Sludge }^{\text {c }}\end{array}$ & NA & $0.36^{d}$ & NA & $3.5^{\mathrm{d}}$ & $\mathrm{NA}$ & $38.2^{d}$ & NA & 69.5 \\
\hline
\end{tabular}

a. All values in units of [mg $\mathrm{MnO}_{4}{ }^{-} / \mathrm{g}$ of TAN Site Media]

b. Consumption values represent a $24 \mathrm{hr}$ reaction time. Values presented for the GW slurries are the averages of duplicate samples.

c. Derived by subtracting the $\mathrm{GW}$ consumption component from the total oxidant consumption of the slurry via the following equation:

Solid Phase Demand $(\mathrm{mg} / \mathrm{g})=\left[\right.$ Total-(GW Demand $\left.\left.\times \mathrm{Wt}_{\mathrm{GW}}\right)\right] /\left(\mathrm{Wt}_{\mathrm{solid}}\right)$

Where: Total $=$ total mass of $\mathrm{MnO}_{4}{ }^{-}(\mathrm{mg})$ consumed by the slurry.

GW Demand= demand determined from experiments $(\mathrm{mg} / \mathrm{g})$ involving GW only

$\mathrm{Wt}_{\mathrm{GW}}=$ mass of $\mathrm{GW}$ in the slurry

$\mathrm{Wt}_{\text {solid }}=$ mass of solid in the slurry

d. All of available oxidant was consumed before the oxidant demand was satisfied.

The $\mathrm{pH}$ values were also tracked during the hot spot oxidant demand studies. The results are presented in Figures $20-23$ for the $0.01 \%, 0.1 \%, 1 \%$ and $3 \% \mathrm{MnO}_{4}{ }^{-}$experiments. A few observations can be made from these figures: The $\mathrm{pH}$ of the TSF-05 GW (at $12^{\circ} \mathrm{C}$ ) was around 8 for all four (4) of the oxidant loadings investigated. (Some variation in the initial TSF-05 GW chemistry, e.g. $\mathrm{pH}$ values, was expected since the containers of TSF-05 GW received from INEEL were not combined/mixed prior to experimentation). The $\mathrm{pH}$ 's of the slurries, on the other hand, were lower at an average of 7.6 after an overnight equilibration period with the TSF$05 \mathrm{GW}$ at $12^{\circ} \mathrm{C}$. (Note: the $\mathrm{pH}$ values plotted at $\mathrm{T}=0$ were measured immediately prior to oxidant addition.) Upon oxidant addition, the $\mathrm{pH}$ values of the TSF-05 GW only reactors increased from $\approx 7.9$ to 8.3 for both the $0.01 \%$ and $0.1 \% \mathrm{MnO}_{4}{ }^{-}$treatments. Similarly, reactor pH's increased to $\approx 8.6$ and $\approx 9$ for the $1 \%$ and $3 \% \mathrm{MnO}_{4}{ }^{-}$treatments. These $\mathrm{pH}$ increases in the GW reactors is likely due to the change in the ionic strength of the reactors following oxidant addition. The pH's of the slurry reactors, on the other hand, all decreased with addition of the oxidant. This was expected as a result of oxidation of organic matter (See equation 2). For the $0.1 \%$ and $0.1 \% \mathrm{MnO}_{4}^{-}$reactors (Figures 20 and 21 ), the $\mathrm{pH}$ dropped to $\approx 0.5 \mathrm{pH}$ units at the beginning of the reaction period. This decrease occurs immediately and persists until all of the $\mathrm{MnO}_{4}{ }^{-}$is consumed. The reactor $\mathrm{pH}$ values remained steady for the rest of the reaction period. The $\mathrm{pH}$ values of the $1 \%$ and $3 \% \mathrm{MnO}_{4}{ }^{-}$reactors also initially decrease by approximately the same magnitude. For these two oxidant loadings, however, the reactor $\mathrm{pH}$ increased after this initial oxidation reaction occurred. In fact, the final $\mathrm{pH}$ values for these latter slurry reactors 
rebounded to at least the starting ( $\mathrm{T}=0 \mathrm{hrs}$ ) values. Note from Figures 22 and 23 that a residual oxidant concentration existed beyond the $4 \mathrm{hr}$ sampling period. As observed for TSF- $05 \mathrm{GW}$ only reactors, this excess $\mathrm{MnO}_{4}{ }^{-}$was likely the cause of the $\mathrm{pH}$ increases after sludge consumption slowed and/or ceased. The preceding discussion suggests that the overall (net) $\mathrm{pH}$ change experienced in a TSF-05 slurry reactor are a combination of $\mathrm{pH}$ increases due to the ionic strength of the oxidant and $\mathrm{pH}$ decreases as a result of $\mathrm{H}^{+}$generation during oxidation. Thus, the final $\mathrm{pH}$ of such a slurry system is dependent upon the relative amounts of oxidant and oxidizible material present. 


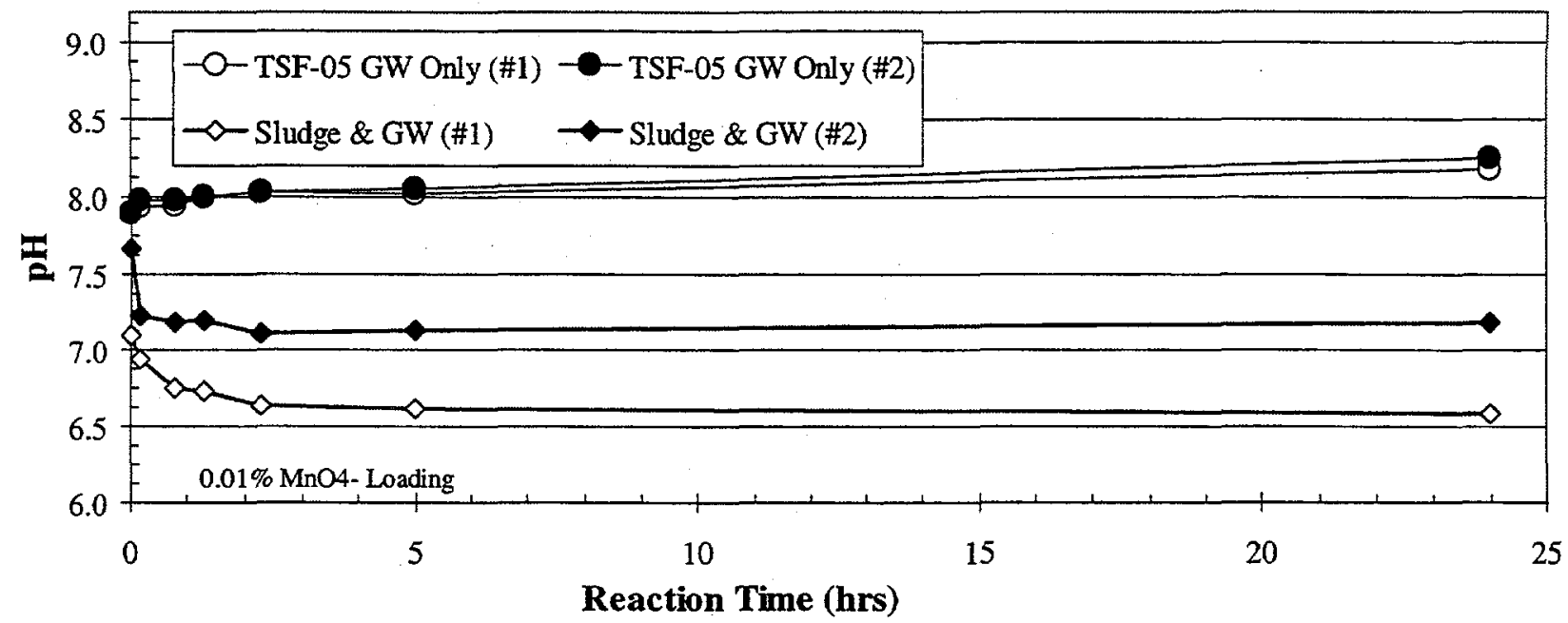

Figure 20. $\mathrm{pH}$ Results Obtained During Consumption of Hot Spot Media, Initial $\mathrm{MnO}_{4}{ }^{-}=0.01 \%$ (ORNL Exp. 3b-R1, Conducted at $12^{\circ} \mathrm{C}$ and $4: 1 \mathrm{~L} / \mathrm{S}$ ratio where applicable)

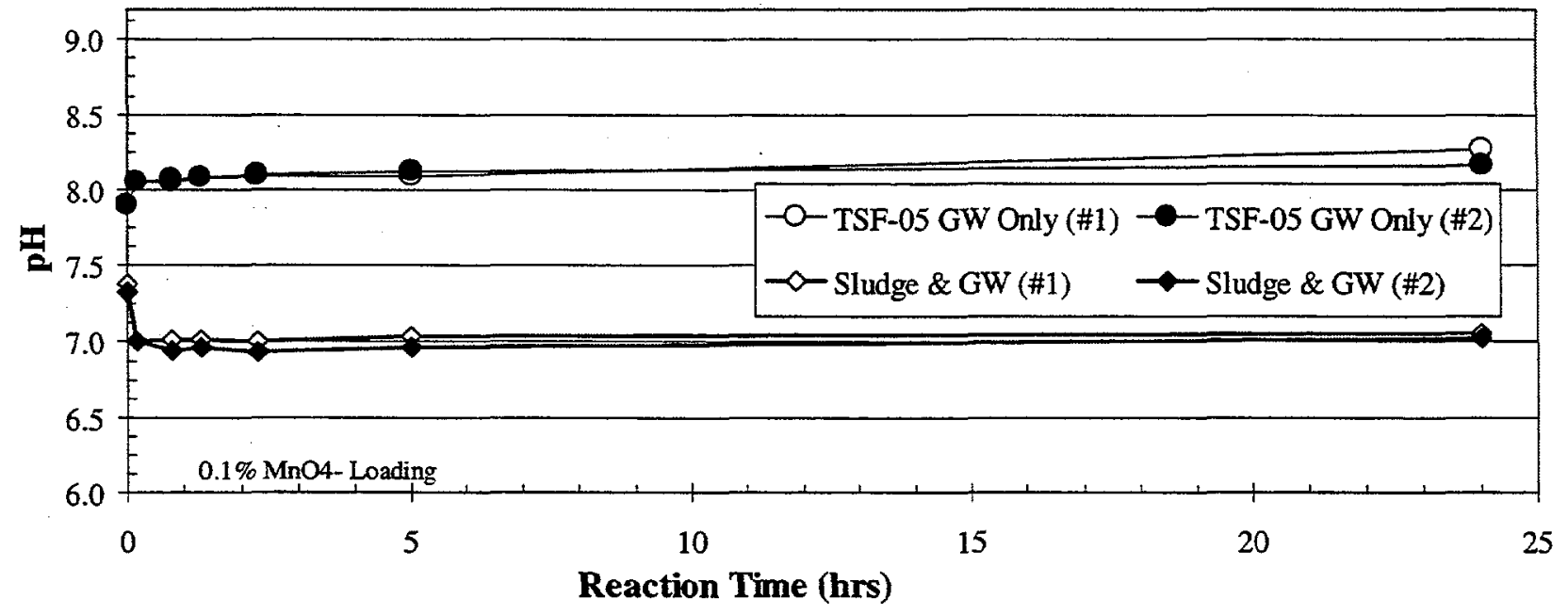

Figure 21. $\mathrm{pH}$ Results Obtained During Consumption of Hot Spot Media, Initial $\mathrm{MnO}_{4}{ }^{-}=0.10 \%$ (ORNL Exp. 3b-R2, Conducted at $12^{\circ} \mathrm{C}$ and $4: 1 \mathrm{~L} / \mathrm{S}$ ratio where applicable) 


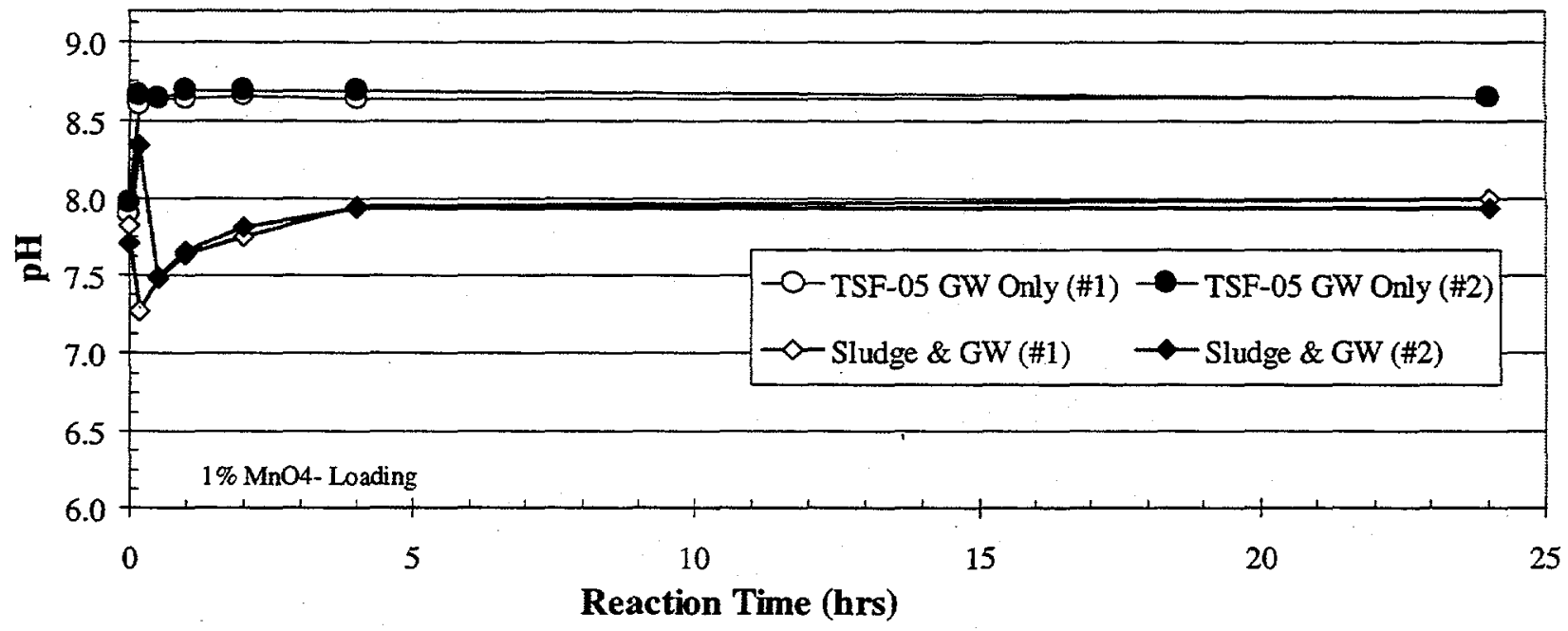

Figure 22. $\mathrm{pH}$ Results Obtained During Consumption of Hot Spot Media, Initial $\mathrm{MnO}_{4}{ }^{-1}=1 \%$ (ORNL Exp. 3b-R3, Conducted at $12^{\circ} \mathrm{C}$ and $4: 1 \mathrm{~L} / \mathrm{S}$ ratio where applicable)

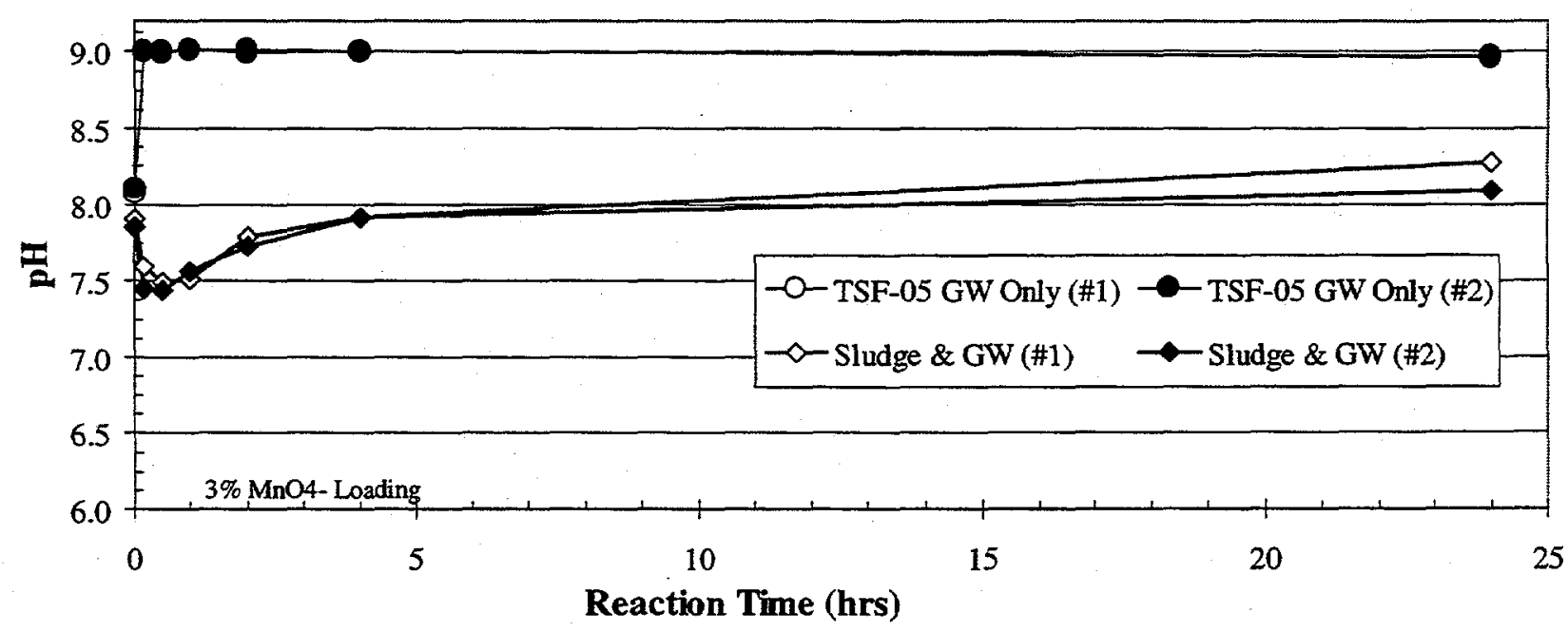

Figure 23. $\mathrm{pH}$ Results Obtained During Consumption of Hot Spot Media, Initial $\mathrm{MnO}_{4}{ }^{-}=3 \%$ (ORNL Exp. 3b-R4, Conducted at $12^{\circ} \mathrm{C}$ and $4: 1 \mathrm{~L} / \mathrm{S}$ ratio where applicable) 


\subsubsection{Summary - Oxidant Demand of TAN Subsurface Materials}

This set of experiments measured the oxidant demand exerted by materials from the subsurface beneath TAN, including both natural geologic materials (groundwater, basalt, and fracture-fill material) and anthropogenic organic sludge. The $\mathrm{MnO}_{4}{ }^{-}$concentrations investigated range from $0.01 \%$ to $3 \%$, which is the same range investigated in the oxidation rate experiments described in Section 2.4

The experimental identification for this series of experiments is presented in Table 10.

Table 10. Experimental Identification for the 'Oxidant Demand' (Task 3) Studies.

\begin{tabular}{|c|c|c|}
\hline $\begin{array}{c}\text { MnO4- } \\
\text { Concentration (\%) }\end{array}$ & $\begin{array}{c}\text { Dissolve Plume } \\
\text { Media Experiments }\end{array}$ & $\begin{array}{c}\text { Hot Spot Media } \\
\text { Experiments }\end{array}$ \\
\hline 0.01 & 3aR1b & 3b-R1 \\
\hline 0.1 & 3aR2b & $3 \mathrm{~b}-\mathrm{R} 2$ \\
\hline 1 & 3aR3b & $3 \mathrm{~b}-\mathrm{R} 3$ \\
\hline 3 & Not Evaluated & $3 \mathrm{~b}-\mathrm{R} 4$ \\
\hline
\end{tabular}

Representative values of the oxidant demand of subsurface materials from TAN, including media from both the dissolved plume and the hot spot, are given in Table 11. For comparison, the oxidant demand determined in a previous study (Istok, personal communication) of surficial basalt from Hell's Half Acre was approximately $1 \mathrm{mg} \mathrm{MnO}_{4}{ }^{-1} / \mathrm{g}$ basalt. The oxidant demand determined in this study for geologic materials (i.e. not organic sludge) are at least on half order of magnitude less than that value, while the oxidant demand of organic sludge is approximately two orders of magnitude larger.

Table 11. Representative Oxidant Demand for TAN Subsurface Media.

\begin{tabular}{|c|c|}
\hline TAN Site Medium & $\begin{array}{c}\text { Oxidant Demand } \\
\text { (mg MnO} \\
\left.{ }^{-} / \mathrm{g} \text { Medium }\right)\end{array}$ \\
\hline TAN-40 GW & 0.01 \\
\hline TSF-05 GW & 0.02 \\
\hline Crushed Basalt & 0.05 \\
\hline Aggregate Basalt & 0.1 \\
\hline Sediment & 0.2 \\
\hline TSF-05 Sludge & 70 \\
\hline
\end{tabular}




\subsection{TASK 4. MEASUREMENT OF OXIDATION RATES OF TAN SUBSURFACE MATERIALS}

\subsubsection{Laboratory Controls and QA}

During the oxidation rate studies, between 800-900 aliquot samples were collected and analyzed for VOCs (primarily TCE), $\mathrm{pH}$, and $\mathrm{MnO}_{4}{ }^{\circ}$. Over 550 additional QA/QC samples directly related to QA/QC were also analyzed for VOCs (160 duplicate aliquot samples, $\approx 300$ desorption tube extractions, and $\approx 100$ "final reactor" extractions.)

During each experiment presented in Section 2.4, duplicate aliquot samples were collected from one of the test reactors at each sampling period. A comparison (\% difference basis) was made between the two TCE values obtained for a given time point. In all, 160 duplicate aliquot samples were collected. A histogram of the percent difference between duplicate samples is presented in Figure 24. The average \% difference between duplicate samples was 3\%. Greater than $90 \%$ of the duplicates evaluated had a $\%$ difference of less than $20 \%$. In addition, $67 \%$ of the duplicates evaluated had a \% difference of less than $1 \%$. When the \% difference values of duplicate samples are compared to the average aqueous TCE concentration of the duplicates (Figure 25) the degree of variability between duplicates appears the greatest at the lower TCE concentrations. This is expected. In fact, most of the larger \%difference values observed in this entire treatability here were associated with samples where at least one of the duplicates yielded TCE concentrations less than the minimum detection limit.

TCE mass balances were performed at the end of each oxidation experiment discussed in this section. Since good agreement exists between duplicate samples, the mass balances were computed assuming that the concentrations of any duplicate samples were the same. More specifically, the TCE concentration was assumed to be the same as the first (sample "a") of the two duplicate samples collected. Finally, to better facilitate the discussion of the individual experiments, the results of the remaining QA/QC samples for (collected primarily for the mass balance calculations) are presented and discussed in concert with the actual test data. 


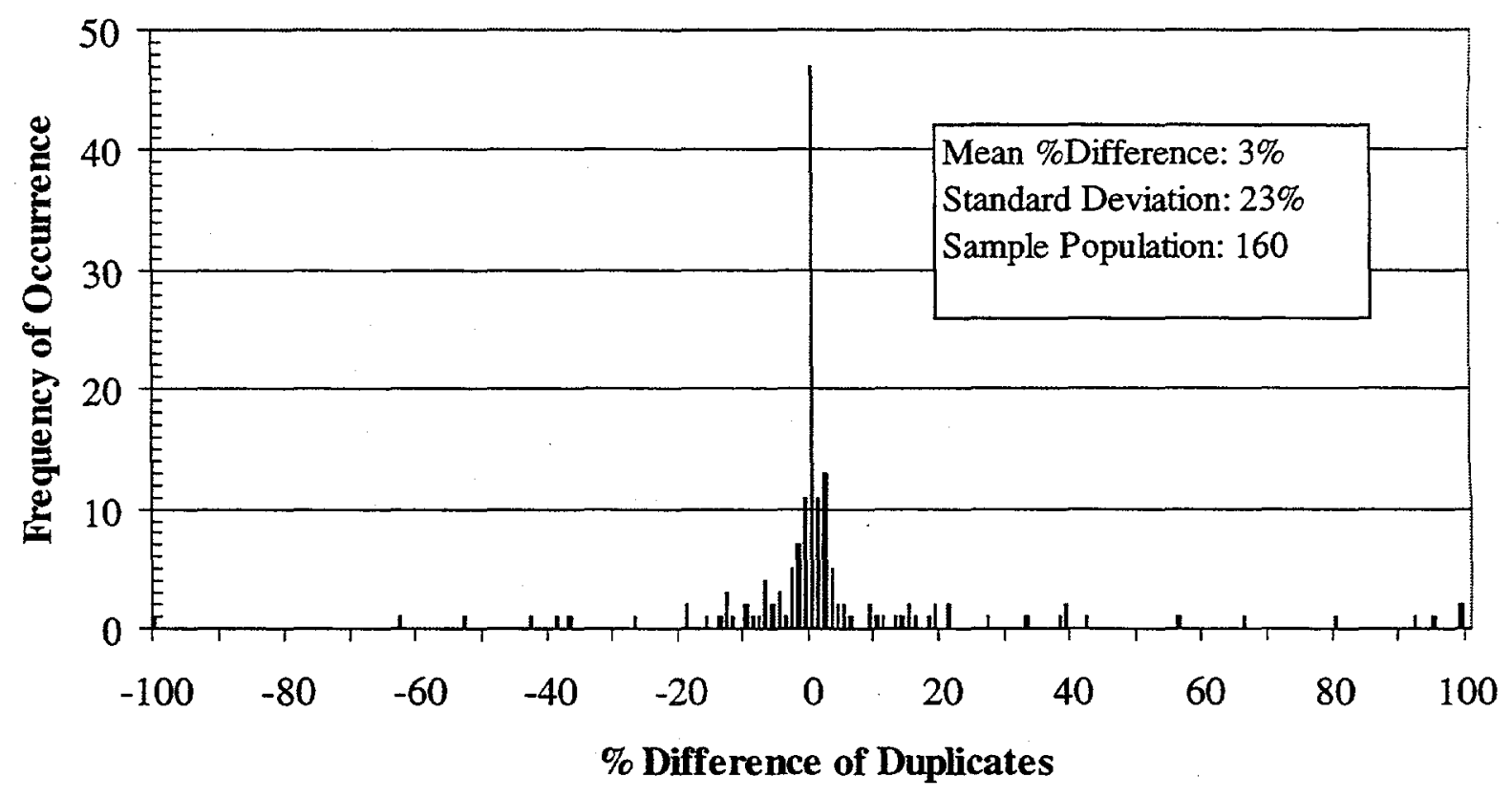

Figure 24. Histogram Illustrating Results of QA/QC Duplicate Sampling.

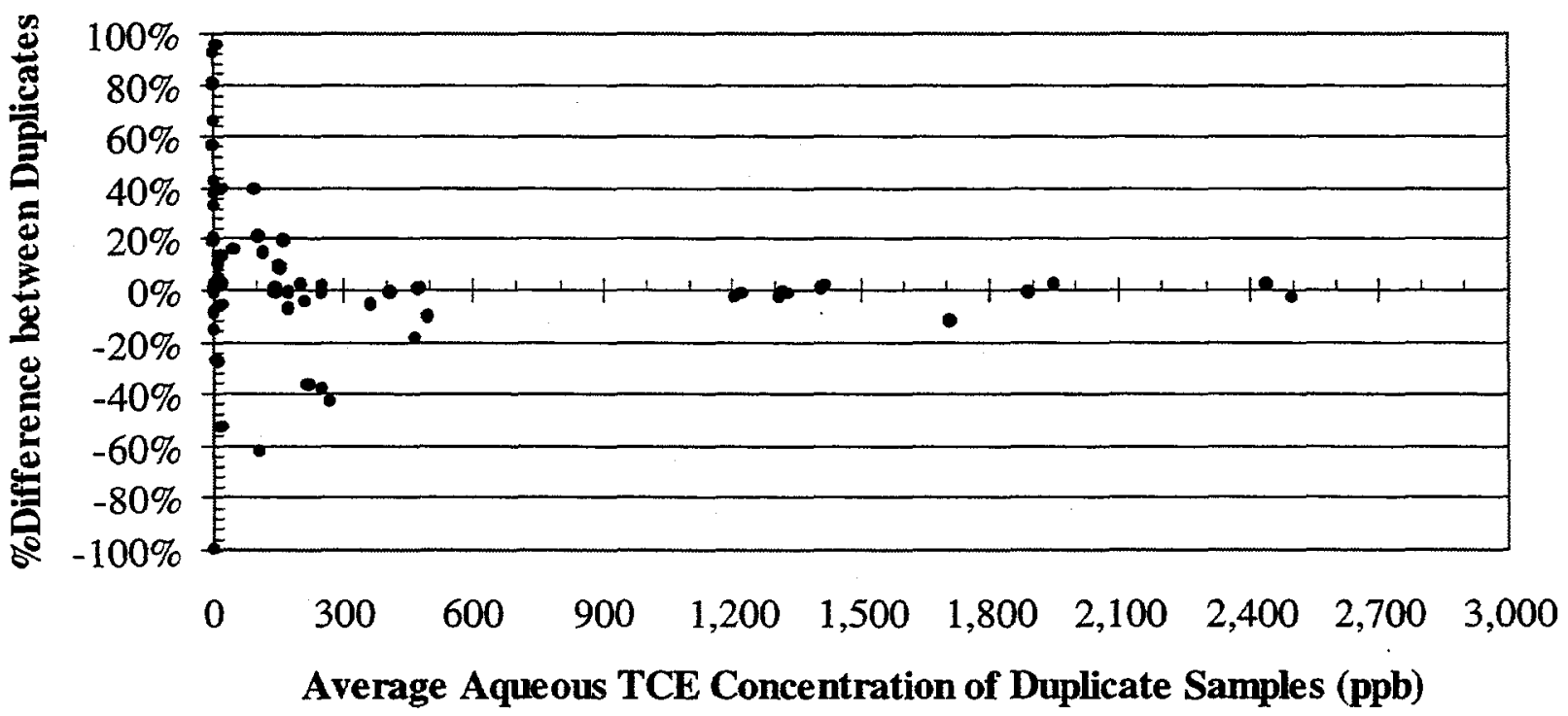

Figure 25. \% Difference of QA/QC Duplicates vs. the Average Duplicate Concentration. 


\subsubsection{Oxidation Rate of Organic Contaminants in Dissolved Plume Media}

Eight (8) separate oxidation rate experiments were performed using the dissolved plume media. Each experimental discussion is identified in this section by the ORNL Exp. $\mathrm{D}$ that is presented in Table 5. In general, plots of "TCE vs. Time", " $\mathrm{MnO}_{4}{ }^{-}$vs. Time", and "pH vs. Time" are presented for each experiment. For all plots of TCE vs. Reaction time: values resulting from analyses in which the sample extract concentration was out of the calibration range are clearly labeled.

In addition to the plots, summary tables for the TCE and $\mathrm{MnO}_{4}{ }^{-}$data are also presented for each experiment. Several parameters are included in the TCE mass balance tables (e.g., Table 12). The approach and/or calculations made to obtain each of the values presented in the mass balance tables are presented below.

As will be observed in the following experimental discussions, most of the actual TCE spike concentrations for this series of experiments were approximately doubled that of the target TCE spike concentrations presented in Table 5.

\section{TCE MASS BALANCE TABLE DESCRIPTION}

- Column 1, "Test Conditions" refers the experimental condition. In this column "Control" refers to reactors containing only TAN GW and no oxidant. The (\#1) and (\#2) notations included in parentheses refer to the duplicate reactors evaluated. The number followed by the percentage sign is the nominal initial $\mathrm{MnO}_{4}{ }^{-}$concentration added to the treatment reactors.

- Column 2, "Total Initial Mass" refers to the TCE mass added to each reactor. For the GW control reactors and treatment reactors containing TAN-40 GW only (Exps. 4a-R1 \& 4a-R2) this value is determined by the following equation: (Aqueous TCE Conc. at $\mathrm{T}=0$ ) $\mathrm{x}(\mathrm{GW}$ Volume in the Non-Slurry Reactor) Note: $\mathrm{T}=0$ sampling occurred after overnight equilibration and immediately before oxidant addition to the treatment reactors. For reactors containing both TAN-40 GW and a solid phase media, the initial total TCE mass is computed by the following equation: (Average Aqueous TCE Conc. at $\mathrm{T}=0$ of the $2 \mathrm{GW}$ Controls) $\mathrm{x}$ (GW volume in the Slurry Reactor). It is computed in this way, as opposed to using the measured aqueous concentration in the slurry reactor at $\mathrm{T}=0$, in the event that some TCE is sorbed to the solid phase at $\mathrm{T}=0$.

- Column 3, "Initial Aqueous Mass". For all cases, this value is computed by multiplying the Aqueous TCE Conc. at $T=0$ for a given reactor by the volume of $\mathrm{GW}$ added to that reactor. Note: The aqueous concentration at $\mathrm{T}=0$ for each reactor is used here rather than the concentration of the spiked GW before it is distributed to the individual reactors and equilibrated. (This approach effectively accounts for the any TCE lost during equilibration from the mass balance calculations performed for the actual oxidation reactions.) For the reactors containing both TAN-40 GW and a solid phase medium, another value is also presented in Column 3 of the mass balance tables. This "\% Sorbed" value represents the fraction of TCE at $\mathrm{T}=0$ partitioned to the solid phase. It is computed for each $\mathrm{GW} / \mathrm{solid}$ phase slurry via the following equation: 
- Column 4, "Mass Sorbed on Orbo Tubes" represents the summed TCE mass found on each charcoal bed of the reactor's desorption tube at the end of the reaction period ( $T=24 \mathrm{hrs}$ ). The TCE mass was obtained by extraction of charcoal beds with hexane. If TCE is detected on the desorption tubes, it is realized that the value obtained represents a minimum that was volatilized since the entire reactor headspace volume would not pass through the desorption tube. The values in percent (\%) for this column represent the percentage of the Total Initial Mass (column 1 of the Table) found within the Orbo Tube.

- Column 5, "Mass Remaining in Reactor" represents the TCE mass still present in each reactor following the reaction period ( $\mathrm{T}=24 \mathrm{hrs}$ ). For the Control reactors and test reactors containing TAN-40 GW only (Exps. 4a-R1 and 4a-R2), this value was computed by the following equation: (Aqueous TCE concentration at $\mathrm{T}=24 \mathrm{hrs}$ ) $\mathrm{x}$ (Init. GW volume -Cum. Vol. of Aliquot Samples). For treatment reactors containing a slurry of GW and solid-phase media, the remaining TCE mass in the reactor was obtained by extracting the entire contents remaining in the reactor after $\mathrm{T}=24 \mathrm{hrs}$ with hexane $(\approx 1: 1 \mathrm{v} / \mathrm{v}$ extraction). For both cases, the values in $\%$ for this column represent the percentage of the Total Initial Mass (column 1 of the Table) still present in the reactor.

- Column 6, "Cum. Mass Removed in Aliquots" represents the mass of TCE removed from the reactor as a result of the aliquot sampling. In all cases, this column is computed by summing the masses of TCE that were found in each aliquot interval for a given reactor, i.e., $\Sigma$ (Aqueous TCE Conc. $x$ Aliquot Volume). The values in parentheses for this column represent the percentage of the Total Initial Mass (Column 1 of the Table) removed from the reactor (and thereby not subjected to oxidation) during the course of the experiment.

- Column 7, "Cum. Aqueous Mass Oxidized" represents the TCE mass initially in the aqueous phase that was considered to have been oxidized during the reaction period. The oxidized TCE masses presented in this column were computed by summing the change in aqueous TCE mass obtained for each sampling period, i.e., $\Sigma[$ (Aq. TCE Conc. $T=x-$ Aq. TCE Conc. $\mathrm{T}=\mathrm{x}+1) \mathrm{X}$ GW Vol. $\mathrm{T}=\mathrm{x}$ ]. Thus, this approach corrects for TCE removed via previous aliquot samplings. Again, the \% values in this column represent the percentage of the Total Initial Mass (Column 1 of the Table) believed to have been oxidized. It is important to note that this component of the mass balance does not take into account any TCE initially sorbed to a solid phase media.

- Column 8, "Total Mass Recovered" is the sum of the TCE masses found in four (4) different "compartments" at the end of the reaction period ( $\mathrm{T}=24 \mathrm{hrs}$ ), i.e., Col. $4+\mathrm{Col} .5+\mathrm{Col} .6+$ Col. 7. The \% values for this column represent the percentage of the Total Initial Mass (Column 1 of the Table) that was accounted for during the course of the experiment.

For each TCE oxidation experiment presented in this section, a oxidant consumption summary table is presented (e.g. Table 13). The approach and/or calculations made to obtain each of the values presented in the oxidant consumption tables are presented below. 


\section{$\mathrm{MnO}_{4}{ }^{-}$CONSUMPTION TABLE DESCRIPTION}

- Column 1, "Test Conditions" refers the experimental condition. The (\#1) and (\#2) notations included in parentheses refer to the duplicate reactors evaluated. The number followed by the percentage sign is the nominal initial $\mathrm{MnO}_{4}{ }^{-}$concentration added to the treatment reactors $\left(0.01 \%, 0.1 \%, 1 \%\right.$, or $\left.3 \% \mathrm{MnO}_{4}{ }^{-}\right)$.

- Column 2, "Initial Oxidant" represents the oxidant $\left(\mathrm{MnO}_{4}{ }^{-}\right)$mass added to each reactor. For the oxidant loadings of $0.01 \%$ and $0.1 \% \mathrm{MnO}_{4}{ }^{-}$this value was computed by multiplying the concentration of the stock $\mathrm{MnO}_{4}{ }^{-}$spiking solution used by the volume of stock solution used. For oxidant loadings of $1 \%$ and $3 \% \mathrm{MnO}_{4}{ }^{-}$, this value was computed by multiplying the mass of crystalline $\mathrm{KMnO}_{4}$ added to each reactor (gravimetrically determined) by the $\mathrm{MnO}_{4}{ }^{-}$ $/ \mathrm{KMnO}_{4}$ mole fraction $(0.753)$.

- Column3, "Initial Loading". For all cases, this value is computed dividing the value presented in Column 1 by the total mass of TAN site media (groundwater and solid phase) added to each slurry reactor. These masses were determined gravimetrically.

- Column 4, "Cum. Consumed" represents the $\mathrm{MnO}_{4}{ }^{-}$mass that was consumed at the end of the reaction period. This value was obtained by difference between the initial $\mathrm{MnO}_{4}{ }^{-}$ concentration between the final aliquot $\mathrm{MnO}_{4}{ }^{-}$concentration. The exact equations used to compute the initial aqueous oxidant concentration varied based up the oxidant spiking method employed. (The exact equations used are presented in Appendix C, Calculations.) The final aqueous $\mathrm{MnO}_{4}{ }^{-}$concentrations of each aliquot were determined via spectrophotometry. These values are also presented in Appendix C.

- Column 5, "Cum Consumed" represents the same value determined in Column 3 but is expressed in units of consumption per gram of TAN site media. The mass of TAN site media used (groundwater and solid phase mass) is the same as the value used in Column3.

Also note that variation in the initial TAN- $40 \mathrm{GW}$ chemistry, e.g. $\mathrm{pH}$ values, is expected since each dissolved plume media experiment was conducted using a different batch of TAN-40 GW that had been sparged for varying amounts of time. (The containers of TAN-40 GW received from INEEL were not combined/mixed prior to experimentation). 
ORNL Exp. 4a-R1

(TAN-40, No Solids, 100 TCE, 0 Other, $0.01 \%$ and $0.1 \% \mathrm{MnO}_{4}{ }^{-}$)

Only TAN-40 GW was evaluated in this experiment. The TCE, $\mathrm{MnO}_{4}{ }^{-}$and $\mathrm{pH}$ values with time are presented in Figures 26, 27, and 28, respectively. Tables 12 and 13 provide additional TCE mass balance and oxidant consumption information. The (\#1) and (\#2) notations included in both the figure legends and the first column of these tables refer to the duplicate reactors evaluated for that test condition.

No significant deviations from the testplan procedures were made in this experiment.

After equilibration, the initial aqueous TCE concentration of the spike solution was $190 \mu \mathrm{g} / \mathrm{L}$. After transfer to the test reactors, the spiked groundwater TCE concentration ranged between 169 and $182 \mu \mathrm{g} / \mathrm{L} \mathrm{TCE}$ ( $\mathrm{T}=0$ aliquots) prior to the start of the oxidation reaction. Excellent TCE mass balances were obtained from the control reactors. The lowest TCE recovery of $93 \%$ was obtained for the second control sample (see drop in TCE concentration for that reactor in Figure 26).

It is believed that the observed reductions in TCE concentrations for the treatment reactors were primarily due to oxidation since (1) the recoveries of the GW controls were high and (2) TCE was not detected in the extracts from the charcoal desorption tubes from either the control or the treatment reactors. Complete TCE oxidation occurred within $3 \mathrm{hrs}$ for the $0.01 \% \mathrm{MnO}_{4}^{-}$ treatments and within the first $0.5 \mathrm{hrs}$ for the $0.1 \% \mathrm{MnO}_{4}{ }^{-}$reactors. The three aqueous TCE data points between $\mathrm{T}=0$ and $\mathrm{T}=1.6 \mathrm{hrs}$ were used to compute the reaction rate for the initial, rapid step of the oxidation reaction in the $0.01 \%$ reactors. The data were plotted as $\ln \left(\mathrm{C} / \mathrm{C}_{\mathrm{o}}\right)$ vs. Time in Figures 29 and 30 for the first and second $0.01 \%$ reactors in order to approximate a first order reaction rate constant, $k$. The linear regression resulted in an average first order rate constant of $k=1.78 \mathrm{hr}^{-1}$. While the fit of the data to a first order rate constant may not be optimal, attempts to evaluate other rate models were not made since the mechanisms occurring in such a complex system are not known. Enough data points were not available to compute a rate constant for the $0.1 \% \mathrm{MnO}_{4}{ }^{-}$reactors; however, the observed oxidation rate is greater than $0.2 \mathrm{mg} \mathrm{TCE} / \mathrm{hr}$.

While all of the TCE was consumed, little of the initial $\mathrm{MnO}_{4}{ }^{-}$added was consumed by the TCE spiked TAN-40 GW mixture (Table 13). The $\mathrm{pH}$ of the reactors was affected by both the addition of the oxidant and the subsequent oxidation reaction that occurred. The $\mathrm{pH}$ of the test reactors loaded with the $0.01 \% \mathrm{MnO}_{4}{ }^{-}$did not begin to effectively increase until after the TCE had been oxidized. For the $0.1 \% \mathrm{MnO}_{4}^{-}$oxidant loading, there was not an initial $\mathrm{pH}$ decrease, although TCE was completely oxidized. Instead, the overall reactor pHs quickly increased. It is likely that any $\mathrm{pH}$ reductions that did occur as a result of TCE oxidation were very small in comparison to the $\mathrm{pH}$ effect imparted by addition of the $0.1 \% \mathrm{MnO}_{4}{ }^{-}$oxidant solution. 


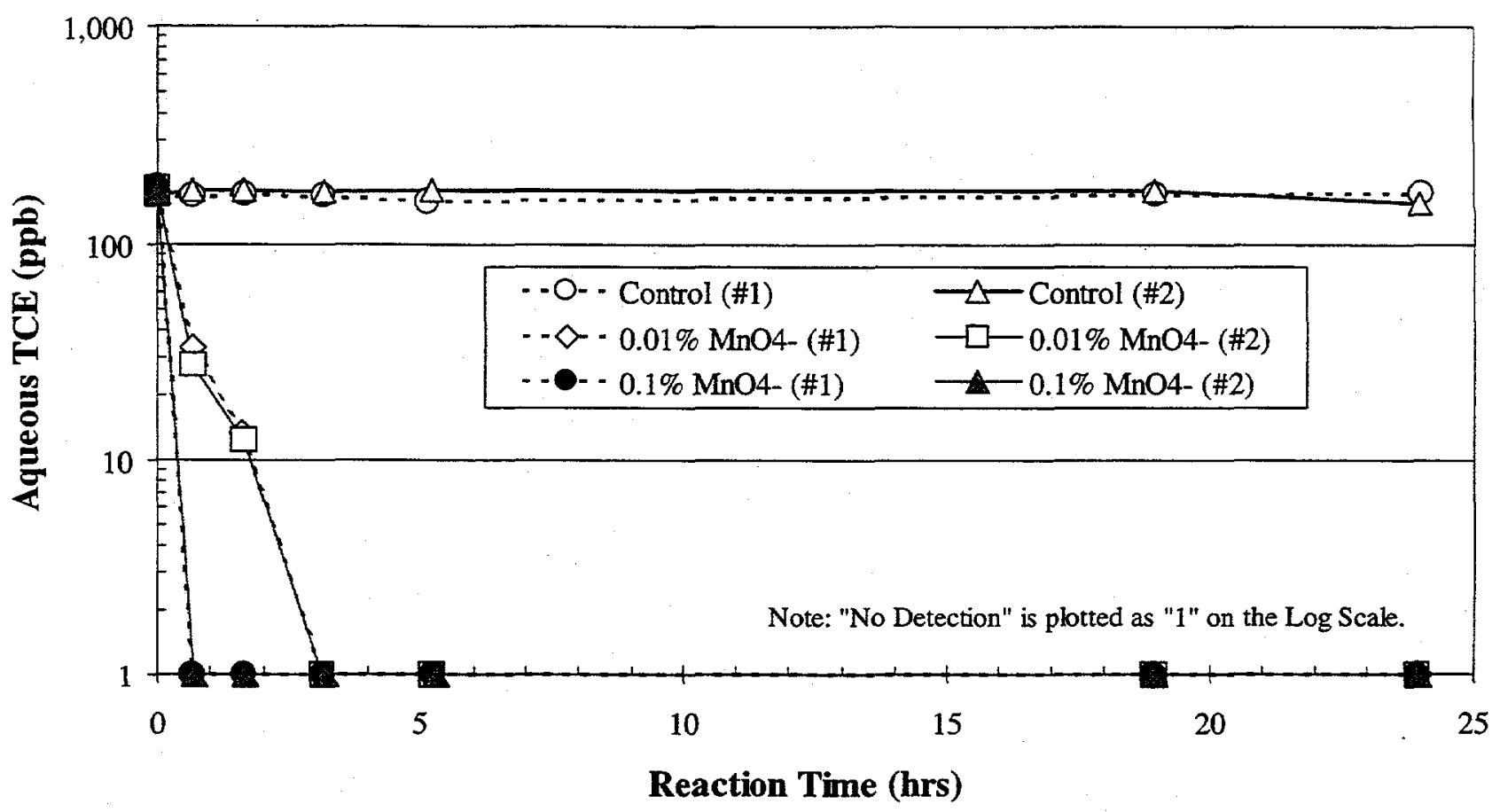

Figure 26. TCE vs. Time, TAN-40 GW Only, (ORNL Exp. 4a-R1, Initial TCE $=100 \mu \mathrm{g} / \mathrm{L}$, Conducted at $12^{\circ} \mathrm{C}$ )

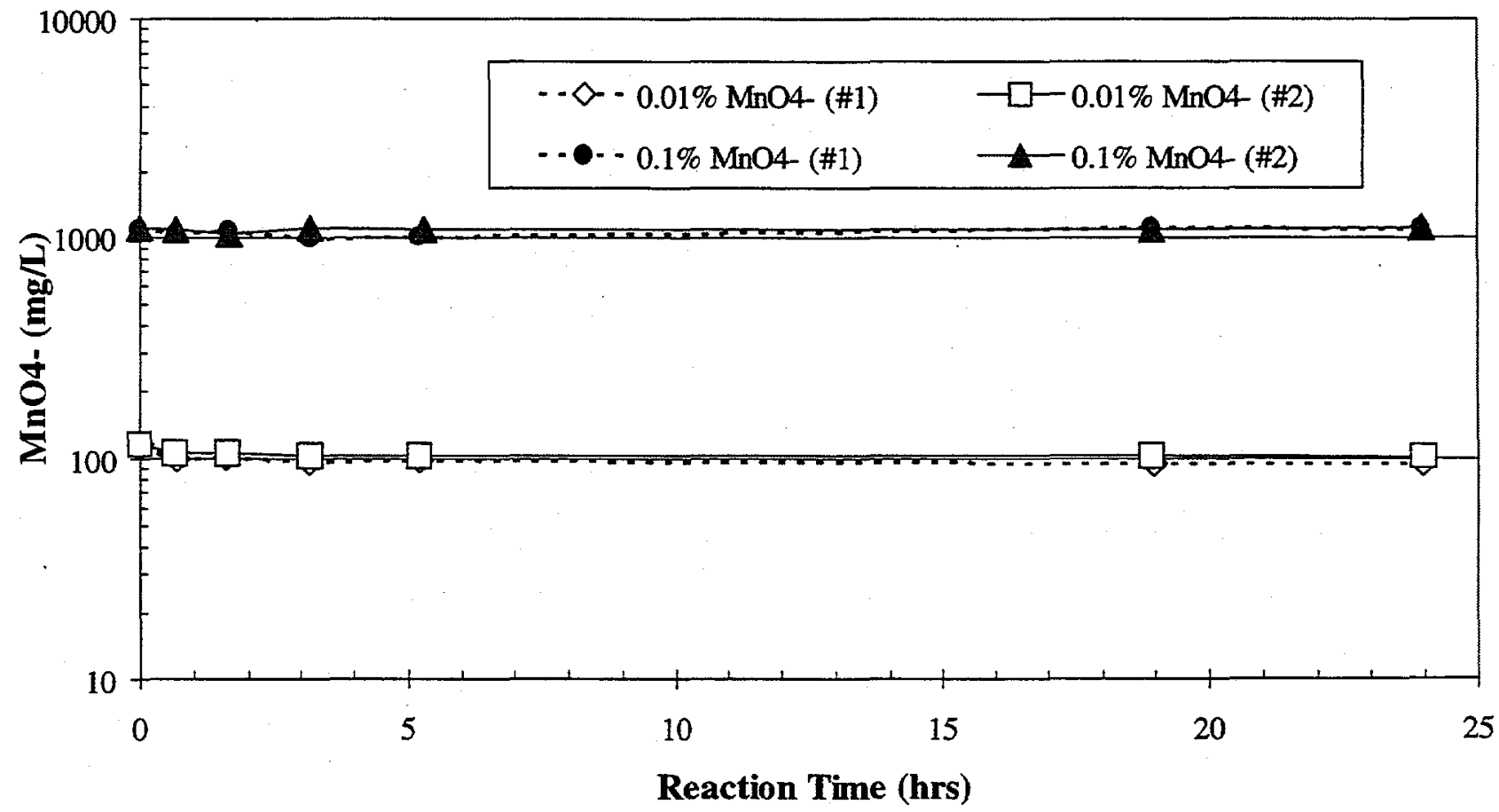

Figure 27. $\mathrm{MnO}_{4}{ }^{-}$vs. Time, TAN-40 GW Only, (ORNL Exp. 4a-R1, Initial TCE $=100 \mu \mathrm{g} / \mathrm{L}$, Conducted at $12^{\circ} \mathrm{C}$ ) 


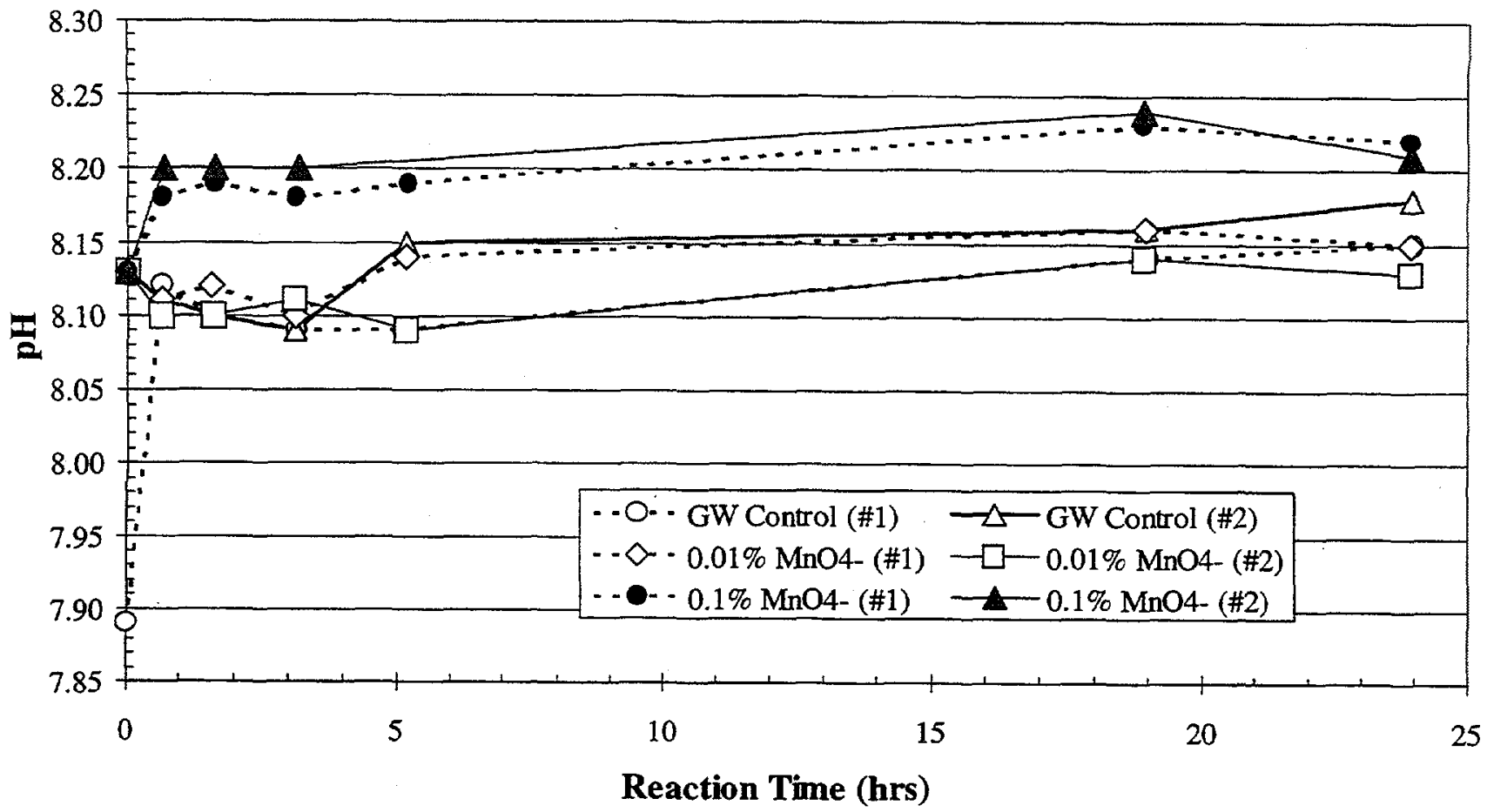

Figure 28. pH vs. Time, TAN-40 GW Only, (ORNL Exp. 4a-R1, Initial TCE $=100 \mu \mathrm{g} / \mathrm{L}$, Conducted at $12^{\circ} \mathrm{C}$ )

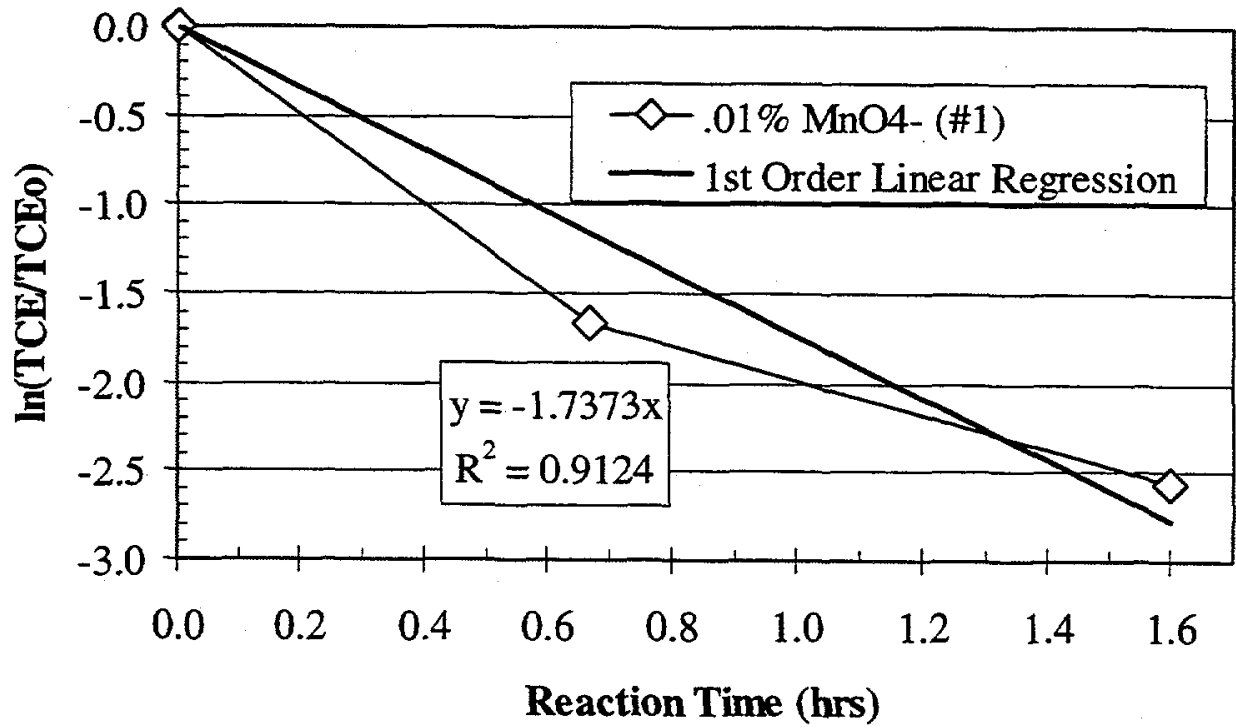

Figure 29 First Order TCE Oxidation Rate Constant for the $0.01 \% \mathrm{MnO}_{4}^{-}$(\#1) Reactor, TAN$40 \mathrm{GW}$ Only, (ORNL Exp. 4a-R1, Initial TCE $=100 \mu \mathrm{g} / \mathrm{L}$, Conducted at $12^{\circ} \mathrm{C}$,) 


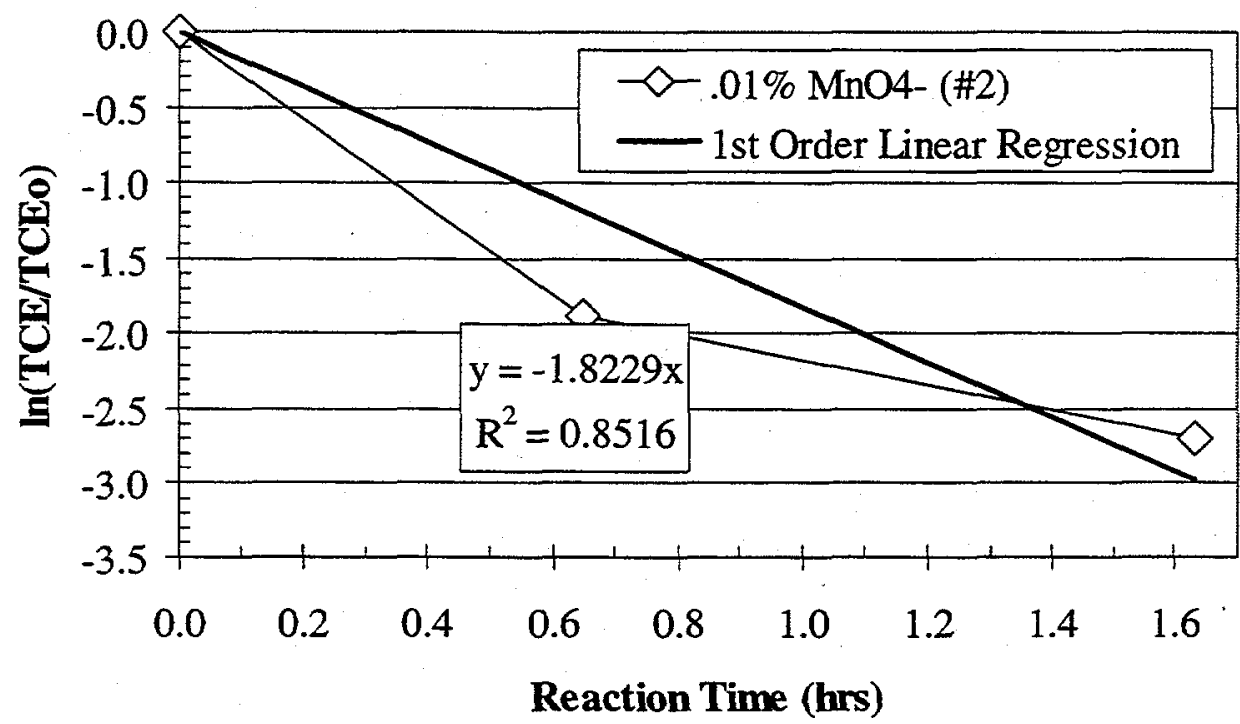

Figure 30 First Order TCE Oxidation Rate Constant for the $0.01 \% \mathrm{MnO}_{4}{ }^{-}(\# 2)$ Reactor, TAN$40 \mathrm{GW}$ Only, (ORNL Exp. 4a-R1, Initial TCE $=100 \mu \mathrm{g} / \mathrm{L}$, Conducted at $12^{\circ} \mathrm{C}$ ) 
Table 12. TCE Mass Balance for ORNL Exp. 4a-R1 (TAN-40 GW Only).

\begin{tabular}{|c|c|c|c|c|c|c|c|}
\hline Test Condition & $\begin{array}{l}\text { Total } \\
\text { Initial } \\
\text { Mass } \\
\text { (mg) }\end{array}$ & \begin{tabular}{|l} 
Initial \\
Aqueous \\
Mass \\
$(\mathrm{mg})$
\end{tabular} & $\begin{array}{l}\text { Mass } \\
\text { Sorbed on } \\
\text { Orbo Tubes } \\
\text { (mg) }\end{array}$ & $\begin{array}{l}\text { Mass } \\
\text { Remaining } \\
\text { in Reactor } \\
\text { (mg) }\end{array}$ & $\begin{array}{l}\text { Cum. Mass } \\
\text { Removed in } \\
\text { Aliquots } \\
\text { (mg) }\end{array}$ & $\begin{array}{l}\text { Cum. } \\
\text { Aqueous } \\
\text { Mass } \\
\text { Oxidized } \\
\text { (mg) }\end{array}$ & $\begin{array}{l}\text { Total } \\
\text { Mass } \\
\text { Recovered } \\
\text { (mg) }\end{array}$ \\
\hline Control (\#1) & 0.09 & 0.09 & $\begin{array}{c}0.000 \\
0 \%\end{array}$ & $\begin{array}{l}0.08 \\
90 \%\end{array}$ & $\begin{array}{l}0.01 \\
12 \%\end{array}$ & $\begin{array}{l}\text { NA } \\
\text { NA }\end{array}$ & $\begin{array}{c}0.1 \\
102 \%\end{array}$ \\
\hline Control (\#2) & 0.09 & 0.09 & $\begin{array}{c}0.000 \\
0 \%\end{array}$ & $\begin{array}{l}0.07 \\
82 \%\end{array}$ & $\begin{array}{l}0.01 \\
11 \%\end{array}$ & $\begin{array}{l}\mathrm{NA} \\
\mathrm{NA}\end{array}$ & $\begin{array}{c}0.1 \\
93 \%\end{array}$ \\
\hline $0.01 \%(\# 1)$ & 0.09 & 0.09 & $\begin{array}{c}0.000 \\
0 \%\end{array}$ & $\begin{array}{c}0.00 \\
0 \%\end{array}$ & $\begin{array}{c}0.002 \\
2 \%\end{array}$ & $\begin{array}{l}0.09 \\
98 \%\end{array}$ & $\begin{array}{c}0.1 \\
100 \%\end{array}$ \\
\hline $0.01 \%(\# 2)$ & 0.10 & 0.10 & $\begin{array}{c}0.000 \\
0 \%\end{array}$ & $\begin{array}{c}0.00 \\
0 \%\end{array}$ & $\begin{array}{c}0.002 \\
2 \%\end{array}$ & $\begin{array}{l}0.09 \\
98 \%\end{array}$ & $\begin{array}{c}0.1 \\
100 \%\end{array}$ \\
\hline $0.1 \%(\# 1)$ & 0.10 & 0.10 & $\begin{array}{c}0.000 \\
0 \%\end{array}$ & $\begin{array}{c}0.00 \\
0 \%\end{array}$ & $\begin{array}{c}0.001 \\
1 \%\end{array}$ & $\begin{array}{c}0.10 \\
100 \%\end{array}$ & $\begin{array}{c}0.1 \\
102 \%\end{array}$ \\
\hline $0.1 \%(\# 2)$ & 0.09 & 0.09 & $\begin{array}{c}0.000 \\
0 \%\end{array}$ & $\begin{array}{c}0.00 \\
0 \%\end{array}$ & $\begin{array}{c}0.001 \\
1 \%\end{array}$ & $\begin{array}{c}0.09 \\
100 \%\end{array}$ & $\begin{array}{c}0.1 \\
102 \%\end{array}$ \\
\hline
\end{tabular}

Table 13. $\mathrm{MnO}_{4}{ }^{-}$Consumption Data for ORNL Exp. 4a-R1 (TAN-40 GW Only). ${ }^{\text {a. }}$

\begin{tabular}{|c|c|c|c|c|}
\hline Test Condition & $\begin{array}{l}\text { Initial } \\
\text { Oxidant } \\
\left(\mathrm{mg} \mathrm{MnO}_{4}^{-}\right)\end{array}$ & \begin{tabular}{|l|} 
Initial \\
Loading \\
$\left(\mathrm{mg} \mathrm{MnO}_{4}^{-} / \mathrm{g}\right)$ \\
\end{tabular} & $\begin{array}{l}\text { Cum. } \\
\text { Consumed } \\
\left(\mathrm{mg} \mathrm{MnO}_{4}^{-}\right) \\
\end{array}$ & \begin{tabular}{|l|} 
Cum. \\
Consumed \\
$\left(\mathrm{mg} \mathrm{MnO}_{4} / \mathrm{g}\right)$ \\
\end{tabular} \\
\hline $0.01 \%(\# 1)$ & 59.7 & 0.11 & 10.39 & 0.02 \\
\hline $0.01 \%(\# 2)$ & 59.7 & 0.11 & 6.68 & 0.01 \\
\hline $0.1 \%(\# 1)$ & 596.8 & 1.09 & 0.78 & 0.00 \\
\hline $0.1 \%(\# 2)$ & 596.8 & 1.11 & 0.26 & 0.00 \\
\hline
\end{tabular}

a. Consumption is computed after $24 \mathrm{hr}$ reaction time. 
ORNL Exp. 4a-R2

(TAN-40, No Solids, 1000 TCE, 0 Other, $0.01 \%$ and $0.1 \% \mathrm{MnO}_{4}{ }^{-}$)

Only TAN-40 GW was evaluated in this experiment. The TCE, $\mathrm{MnO}_{4}{ }^{-}$and $\mathrm{pH}$ values with time are presented in Figures 31, 32, and 33, respectively. Tables 14 and 15 provide additional TCE mass balance and oxidant consumption information. The (\#1) and (\#2) notations included in both the figure legends and the first column of these tables refer to the duplicate reactors evaluated for that test condition.

Known Testplan Deviations:

The only significant deviation from the testplan procedure was the method used to prepare the spiked groundwater. Here, the air-sparged GW was temperature equilibrated first, then it was spiked via a saturated TCE solution for $2-3$ hrs prior to distribution into the test reactors.

(Testplan procedures state that the air-sparged GW should be spiked at room temperature and then equilibrated overnight at $12^{\circ} \mathrm{C}$ ).

Following temperature equilibration, the average initial aqueous TCE concentration of the spike solution was $1440 \mu \mathrm{g} / \mathrm{L}(\sigma=39 \mu \mathrm{g} / \mathrm{L})$. After transfer to the test reactors, the spiked groundwater TCE concentration ranged between 1414 and $1497 \mu \mathrm{g} / \mathrm{L}$ TCE (T=0 aliquots for the test reactors) prior to the start of the oxidation reaction. TCE recoveries of $91 \%$ and $98 \%$ were obtained for the control reactors. From the aliquot TCE concentrations of the control samples, it appears that the first control reactor was losing TCE via volatilization. Its TCE concentration steadily decreased from $1,430 \mu \mathrm{g} / \mathrm{L}$ at $\mathrm{T}=0 \mathrm{hrs}$ to $1,296 \mu \mathrm{g} / \mathrm{L}$ at $\mathrm{T}=24 \mathrm{hrs}$. The second control reactor, on the other hand, started with an initial TCE concentration of $1,351 \mu \mathrm{g} / \mathrm{L}$ and an ending concentration of $1,323 \mu \mathrm{g} / \mathrm{L}$ (average of 6 aliquots $=1,360 \mu \mathrm{g} / \mathrm{L}$ ).

It is believed that the observed reductions in TCE concentrations for the treatment reactors were primarily due to oxidation since recoveries of the GW controls were high and TCE was not observed in the extracts from the charcoal desorption tubes. The data suggests that complete TCE oxidation occurred within $5 \mathrm{hrs}$ for the second $0.01 \% \mathrm{MnO}_{4}{ }^{-}$reactor and within the first 2 hrs for both of the $0.1 \% \mathrm{MnO}_{4}{ }^{-}$reactors (Figure 31). The residual TCE present in the first $0.01 \%$ $\mathrm{MnO}_{4}{ }^{-}$reactor $(\approx 10 \mu \mathrm{g} / \mathrm{L})$ was not expected. Evidence of any analytical problems (e.g., solvent blank contamination) does not exist to dispute the reported TCE concentrations.

The four aqueous TCE data points between $\mathrm{T}=0$ and $\mathrm{T}=3.2 \mathrm{hrs}$ were used to compute the reaction rate for the initial, rapid step of the oxidation reaction in the $0.01 \%$ reactors. The data were plotted as $\ln \left(\mathrm{C} / \mathrm{C}_{\mathrm{o}}\right)$ vs. Time in Figures 34 and 35 for the first and second $0.01 \%$ reactors in order to approximate a first order reaction rate constant, $k$. The linear regression resulted in an average first order rate constant of $k=1.51 \mathrm{hr}^{-1}$. While the fit of the data to a first order rate constant may not be optimal, attempts to evaluate other rate models were not made since the mechanisms occurring in such a complex system are not known. Enough data points were not available to compute a rate constant for the $0.1 \% \mathrm{MnO}_{4}{ }^{-}$reactors; however, the observed oxidation rate is greater than $0.34 \mathrm{mg}$ TCE$/ \mathrm{hr}$.

While all the TCE was consumed, little of the initial $\mathrm{MnO}_{4}{ }^{-}$added was consumed by the TCE spiked TAN-40 GW mixture. While it is unknown why a residual TCE concentration existed in 
the first $0.01 \%$ reactor, there is a correlation between the slowed TCE oxidation rate and an observed decrease in $\mathrm{MnO}_{4}{ }^{-}$between $6 \mathrm{hrs}$ and 24 hours. The oxidation reactions appear to have produced an overall net decrease in the $\mathrm{pH}$ of the systems. The $\mathrm{pH}$ decrease was more pronounced in the 0.01\% $\mathrm{MnO}_{4}^{-}$reactors. As discussed in Exp. 4a-R1, the higher final pHs for the $0.1 \% \mathrm{MnO}_{4}{ }^{-}$reactors is likely due to the fact that the ionic strength of $0.1 \%$ oxidant is considerably greater than that of the $0.01 \%$ oxidant solution. All of these observed $\mathrm{pH}$ changes however are small; in fact, the $\mathrm{pH}$ values for the control reactors (no oxidant added) also decreased by approximately the same amount as the $0.01 \% \mathrm{MnO}_{4}{ }^{-}$reactors. 


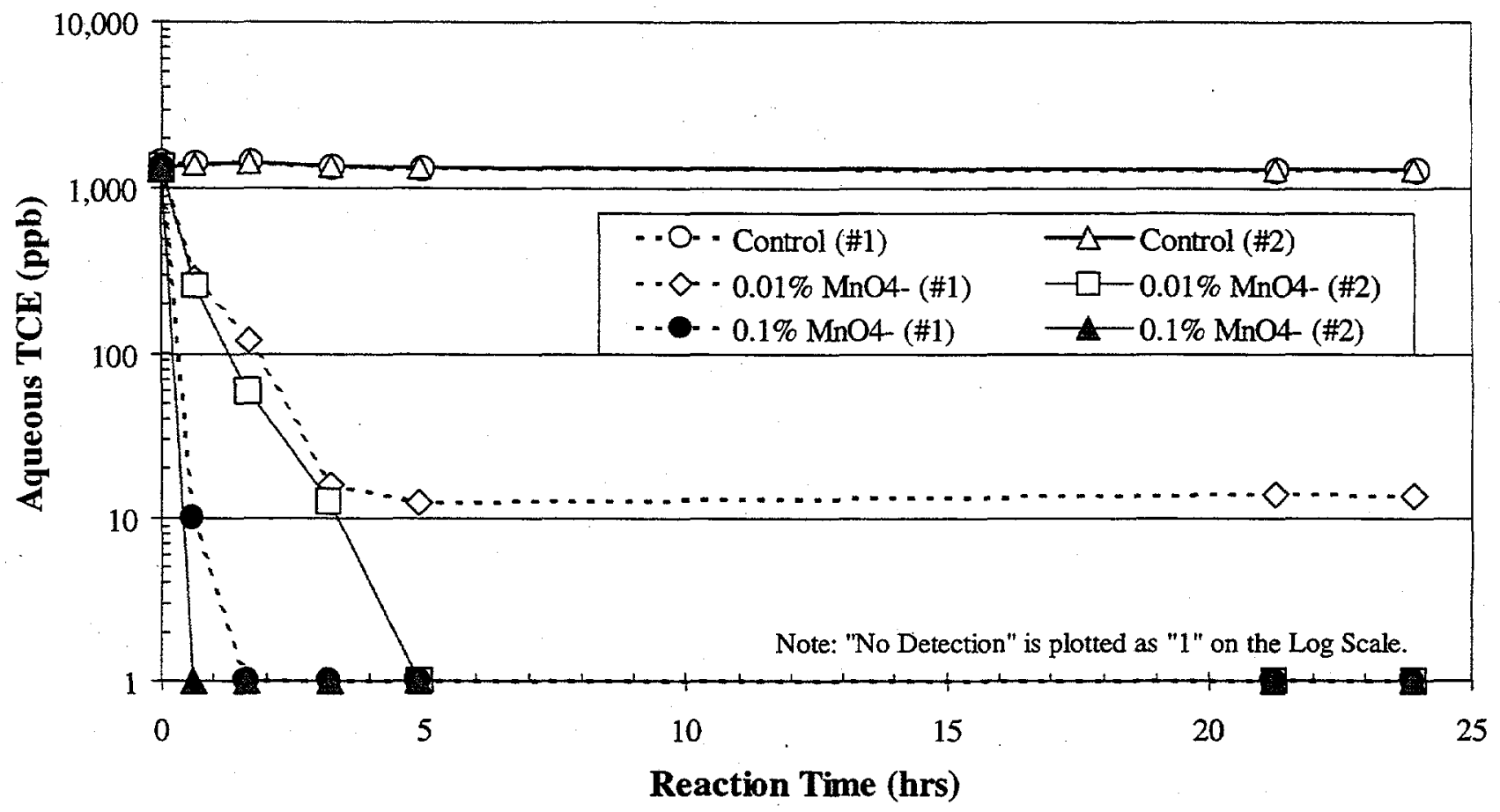

Figure 31. TCE vs. Time, TAN-40 GW Only, (ORNL Exp. 4a-R2, Initial TCE $=1000 \mu \mathrm{g} / \mathrm{L}$, Conducted at $12^{\circ} \mathrm{C}$ )

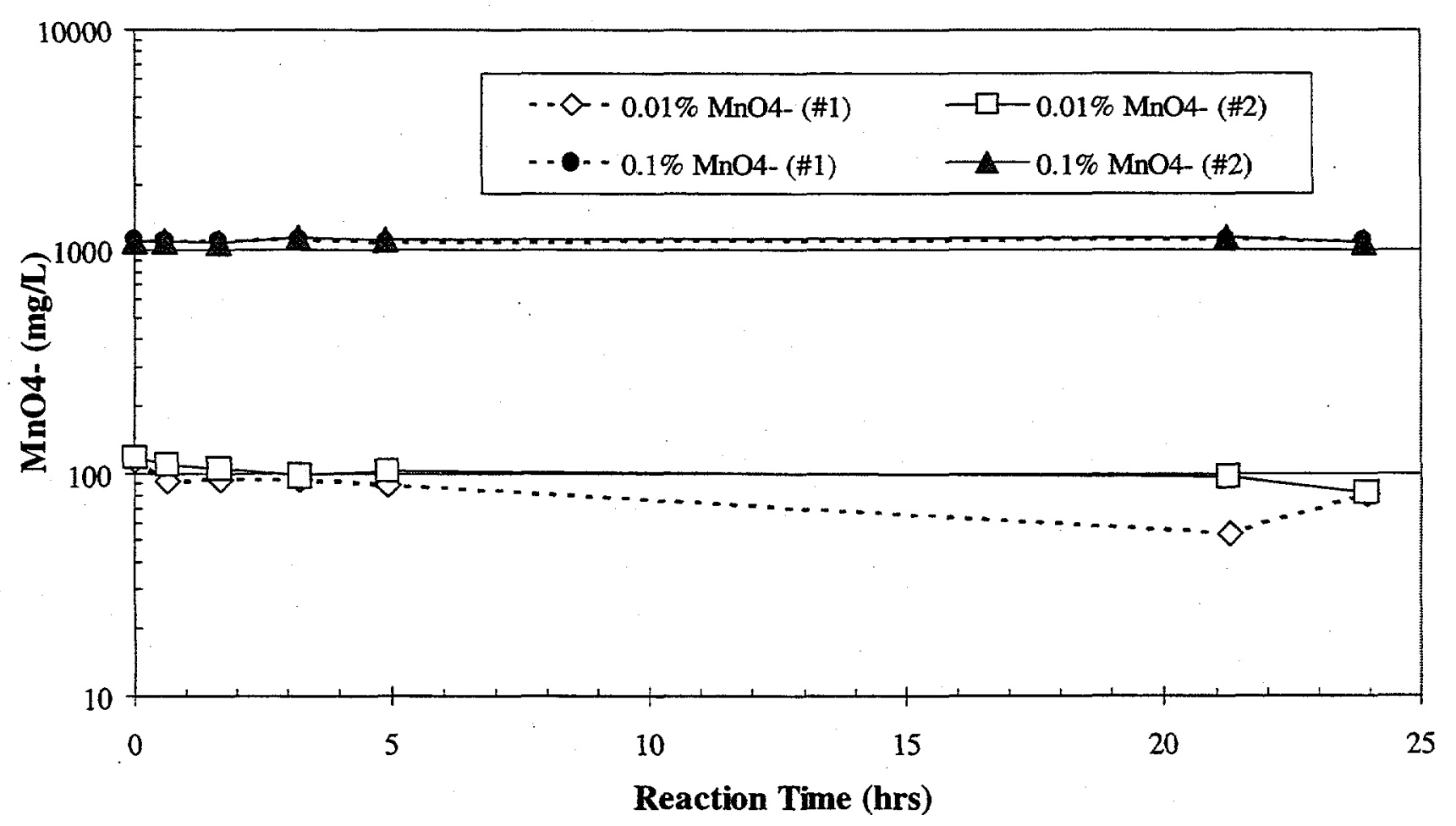

Figure 32. $\mathrm{MnO}_{4}{ }^{-}$vs. Time, TAN-40 GW Only, (ORNL Exp. 4a-R2, Initial TCE $=1000 \mu \mathrm{g} / \mathrm{L}$, Conducted at $12^{\circ} \mathrm{C}$ ) 


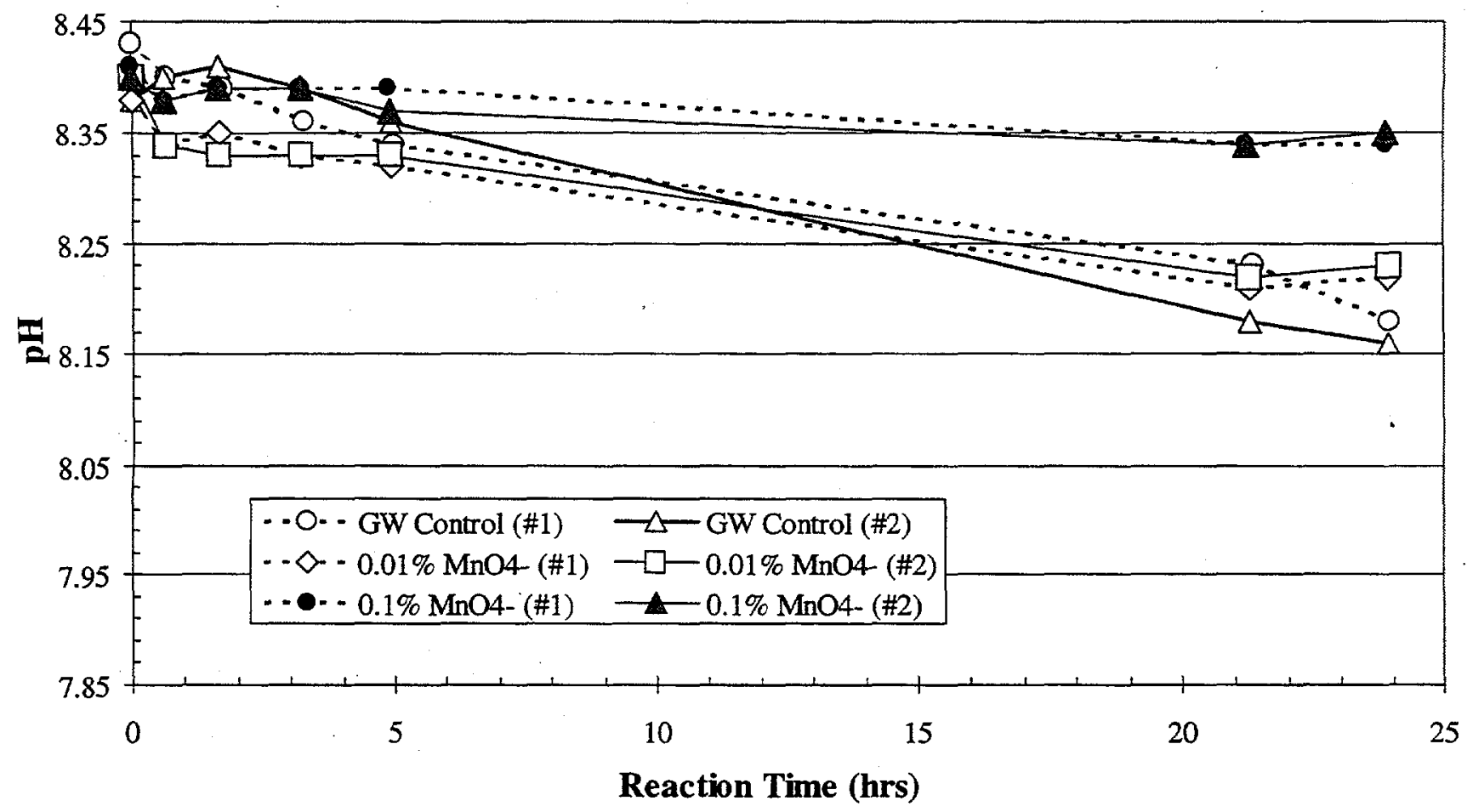

Figure 33. $\mathrm{pH}$ vs. Time, TAN-40 GW Only, (ORNL Exp. 4a-R2, Initial TCE $=1000 \mu \mathrm{g} / \mathrm{L}$, Conducted at $12^{\circ} \mathrm{C}$ )

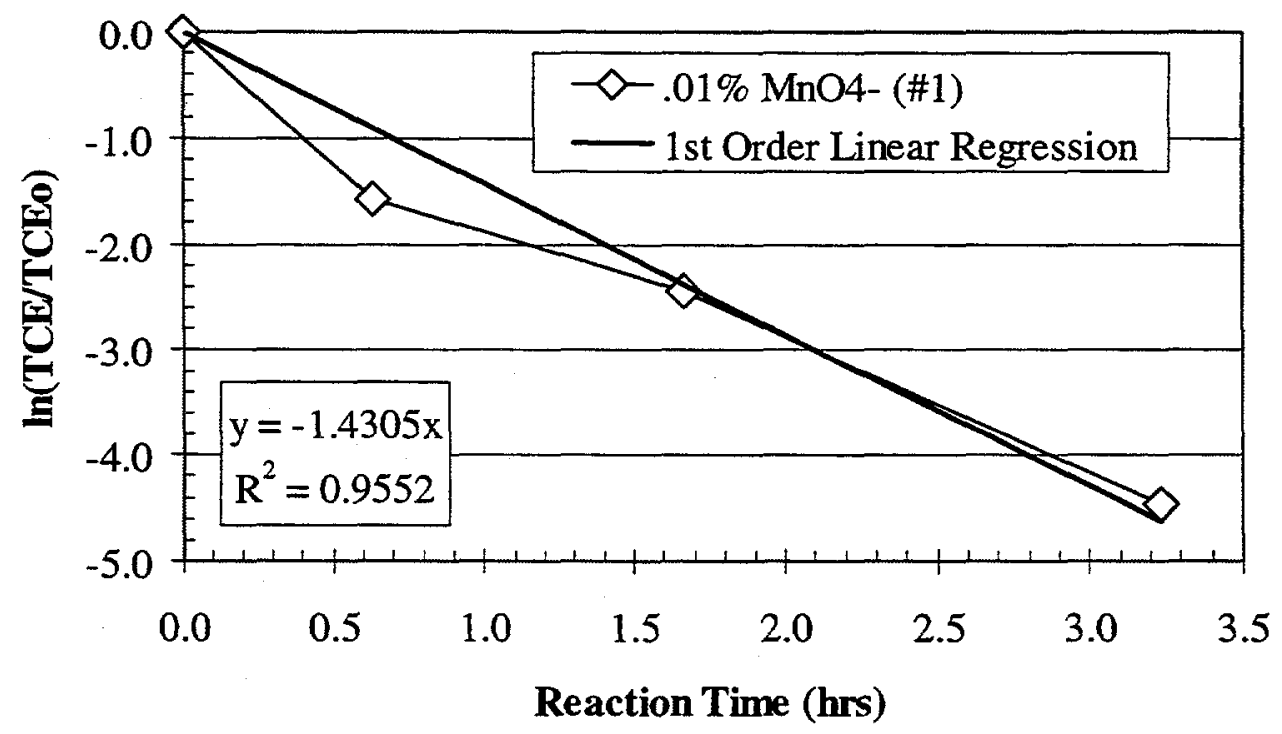

Figure 34 First Order TCE Oxidation Rate Constant for the $0.01 \% \mathrm{MnO}_{4}^{-}$(\#1) Reactor, TAN$40 \mathrm{GW}$ Only, (ORNL Exp. 4a-R2, Initial TCE $=1,000 \mu \mathrm{g} / \mathrm{L}$, Conducted at $12^{\circ} \mathrm{C}$ ) 


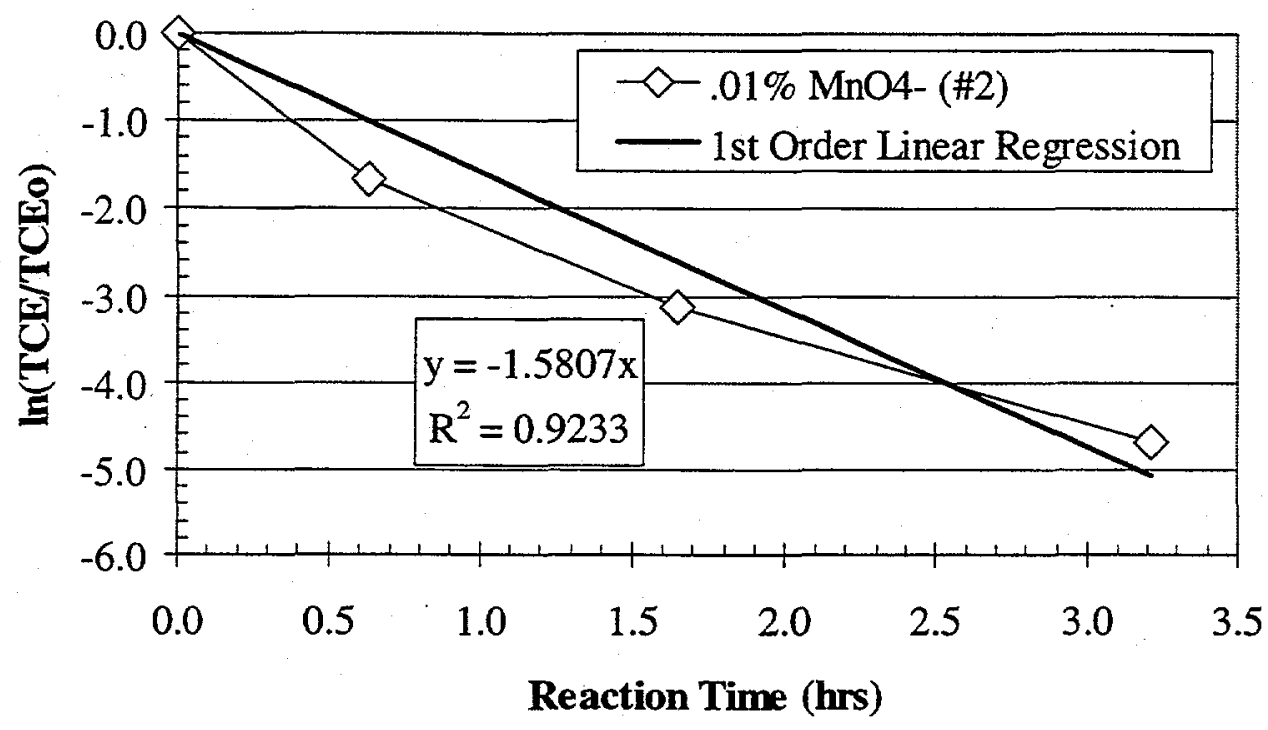

Figure 35 First Order TCE Oxidation Rate Constant for the $0.01 \% \mathrm{MnO}_{4}^{-}(\# 1)$ Reactor, TAN$40 \mathrm{GW}$ Only, (ORNL Exp. 4a-R2, Initial TCE $=1,000 \mu \mathrm{g} / \mathrm{L}$, Conducted at $12^{\circ} \mathrm{C}$ ) 
Table 14. TCE Mass Balance for ORNL Exp. 4a-R2 (TAN-40 GW Only).

\begin{tabular}{|l|l|l|l|l|l|l|l|}
\hline Test Condition & $\begin{array}{l}\text { Total } \\
\text { Initial } \\
\text { Mass } \\
(\mathrm{mg})\end{array}$ & $\begin{array}{l}\text { Initial } \\
\text { Aqueous } \\
\text { Mass } \\
(\mathrm{mg})\end{array}$ & $\begin{array}{l}\text { Mass } \\
\text { Sorbed on } \\
\text { Orbo Tubes } \\
(\mathrm{mg})\end{array}$ & $\begin{array}{l}\text { Mass } \\
\text { Remaining in } \\
\text { Reactor (mg) }\end{array}$ & $\begin{array}{l}\text { Cum. } \\
\text { Mass } \\
\text { Removed } \\
\text { in Aliquots } \\
(\mathrm{mg})\end{array}$ & $\begin{array}{l}\text { lum. } \\
\text { Aqueous } \\
\text { Mass } \\
\text { Oxidized } \\
(\mathrm{mg})\end{array}$ & $\begin{array}{l}\text { Total Mass } \\
\text { Recovered } \\
(\mathrm{mg})\end{array}$ \\
\hline Control (\#1) & 0.73 & 0.73 & $\begin{array}{c}0.000 \\
0 \%\end{array}$ & $\begin{array}{c}0.58 \\
79 \%\end{array}$ & $\begin{array}{c}0.09 \\
12 \%\end{array}$ & $\begin{array}{l}\text { NA } \\
\text { NA }\end{array}$ & $\begin{array}{c}0.7 \\
91 \%\end{array}$ \\
\hline Control (\#2) & 0.68 & 0.68 & 0.000 & 0.59 & 0.08 & NA & 0.7 \\
& & & $0 \%$ & $87 \%$ & $11 \%$ & NA & $98 \%$ \\
\hline $0.01 \%(\# 1)$ & 0.70 & 0.70 & 0.000 & 0.00 & 0.014 & 0.68 & 0.7 \\
& & & $0 \%$ & $0 \%$ & $2 \%$ & $97 \%$ & $99 \%$ \\
\hline $0.01 \%(\# 2)$ & 0.68 & 0.68 & 0.000 & 0.00 & 0.012 & 0.67 & 0.7 \\
& & & $0 \%$ & $0 \%$ & $2 \%$ & $98 \%$ & $100 \%$ \\
\hline $0.1 \%(\# 1)$ & 0.69 & 0.69 & 0.000 & 0.00 & 0.009 & 0.70 & 0.7 \\
& & & $0 \%$ & $0 \%$ & $1 \%$ & $101 \%$ & $102 \%$ \\
\hline $0.1 \%(\# 2)$ & 0.67 & 0.67 & 0.000 & 0.00 & 0.009 & 0.68 & 0.7 \\
& & & $0 \%$ & $0 \%$ & $1 \%$ & $101 \%$ & $102 \%$ \\
\hline
\end{tabular}

Table 15. $\mathrm{MnO}_{4}{ }^{-}$Consumption Data for ORNL Exp. 4a-R2 (TAN-40 GW Only).

\begin{tabular}{|l|l|l|l|l|}
\hline Test Condition & $\begin{array}{l}\text { Initial } \\
\text { Oxidant } \\
\left(\mathrm{mg} \mathrm{MnO}_{4}\right)\end{array}$ & $\begin{array}{l}\text { Initial } \\
\text { Loading } \\
\left(\mathrm{mg} \mathrm{MnO}_{4}^{-} / \mathrm{g}\right)\end{array}$ & $\begin{array}{l}\text { Cum. } \\
\text { Consumed } \\
\left(\mathrm{mg} \mathrm{MnO}_{4}\right)\end{array}$ & $\begin{array}{l}\text { Cum. } \\
\text { Consumed } \\
\left(\mathrm{mg} \mathrm{MnO}_{4} / \mathrm{g}\right)\end{array}$ \\
\hline $0.01 \%(\# 1)$ & 58.0 & 0.11 & 17.72 & 0.04 \\
\hline $0.01 \%(\# 2)$ & 58.0 & 0.12 & 18.44 & 0.04 \\
\hline $0.1 \%(\# 1)$ & 580.4 & 1.11 & 7.80 & 0.01 \\
\hline $0.1 \%(\# 2)$ & 580.4 & 1.11 & 8.97 & 0.02 \\
\hline
\end{tabular}

a. Consumption is computed after $24 \mathrm{hr}$ reaction time. 
ORNL Exp. 4a-R3

(TAN-40, Crushed Basalt, 100 TCE, 0 Other, $0.01 \%$ and $0.1 \% \mathrm{MnO}_{4}{ }^{-}$)

Slurries of TAN-40 GW and crushed basalt were evaluated in this experiment. The TCE, $\mathrm{MnO}_{4}{ }^{-}$ and $\mathrm{pH}$ values with time are presented in Figures 36, 37, and 38, respectively. Tables 16 and 17 provide additional TCE mass balance and oxidant consumption information. The (\#1) and (\#2) notations included in both the figure legends and the first column of these tables refer to the duplicate reactors evaluated for that test condition.

No deviations from the procedures described in the testplan were made.

As explained at the beginning of this section, the total initial mass of TCE in a reactor that contained both GW and a solid phase media was computed differently than for a reactor that contained only GW. Here, the initial masses of TCE in the reactors containing a slurry of crushed basalt were computed by averaging the TCE concentration in the aqueous controls (at $\mathrm{T}=0 \mathrm{hrs}$ ) and multiplying that by the aqueous volume present in the slurry reactor. The rationale for using this approach is the fact that the TAN site solid phase media may adsorb or retain a significant quantity of the initial TCE added. Because of the solid phase present in these reactors, the "Total Mass Recovered" column values in Table 16 are based on an assumed total initial TCE mass, rather than the measured initial aqueous TCE mass. (This technique for determining the total initial TCE mass was performed on all experiments like this only involving a solid phase medium.)

After overnight equilibration, the average initial aqueous TCE concentration of the spike solution was $180 \mu \mathrm{g} / \mathrm{L}(\sigma=8 \mu \mathrm{g} / \mathrm{L})$. After transfer to the test reactors and equilibration with the crushed basalt, the groundwater TCE concentration ranged between 144 and $164 \mu \mathrm{g} / \mathrm{L}$ TCE (T=0 aliquots) prior to the start of the oxidation reaction. TCE recoveries of $94 \%$ and $97 \%$ were obtained for the control reactors. No TCE was observed in the extracts from the charcoal desorption tubes from either the control or the treatment reactors. Note that the total recoveries presented in Table 16 for treatment reactors are all greater than $100 \%$ because of the mass balance approach used for this experiment (see above). Since the resulting \%Sorbed values presented in Table 16 are negative, it is believed that the crushed basalt media was not initially adsorbing TCE. The \%Sorbed values are negative because the initial aqueous concentration of the slurries were greater than the average initial concentration of the groundwater controls. (Refer to the beginning of Section of 2.4 .2 for a more detailed description of how the \%Sorbed values are computed.) If the "\% Sorbed" values were added to the "Total Mass Recovered" values in Table 16, it is evident that the true recovery for the treatment would be nearly $100 \%$.

TCE oxidation was complete within $3 \mathrm{hrs}$ for the $0.01 \% \mathrm{MnO}_{4}{ }^{-}$reactors and within $0.5 \mathrm{hrs}$ for the $0.1 \% \mathrm{MnO}_{4}{ }^{-}$reactors. This trend is similar to that observed in Exp. 4a-R1 involving TAN-40 GW only spiked at $100 \mu \mathrm{g} / \mathrm{L}$. The three aqueous TCE data points between $\mathrm{T}=0$ and $\mathrm{T}=1.6 \mathrm{hrs}$ were used to compute the reaction rate for the initial, rapid step of the oxidation reaction of the $0.01 \% \mathrm{MnO}_{4}{ }^{-}$reactors. The data were plotted as $\ln \left(\mathrm{C} / \mathrm{C}_{\mathrm{o}}\right)$ vs. Time in Figure 39 for the first $0.01 \%$ reactor in order to approximate a first order reaction rate constant, $k$. The linear regression resulted in a first order rate constant of $k=2.32 \mathrm{hr}^{-1}$. (Enough data points were not available to obtain a rate constant for the second $0.01 \% \mathrm{MnO}_{4}{ }^{-}$reactor.) While the fit of the data to a first order rate constant may not be optimal, attempts to evaluate other rate models were not 
made since the mechanisms occurring in such a complex system are not known. Enough data points were not available to compute a rate constant for the $0.1 \% \mathrm{MnO}_{4}$ reactors; however, the observed oxidation rate is greater than $0.14 \mathrm{mg} \mathrm{TCE} / \mathrm{hr}$.

More $\mathrm{MnO}_{4}{ }^{-}$was consumed (Table 17) here than in the TAN-40 GW only case (Table 13). Hence, the additional $\mathrm{MnO}_{4}{ }^{-}$consumption observed here is likely attributed to oxidation/destruction of crushed basalt. When compared to the $\mathrm{pH}$ values of the control reactors, oxidant addition resulted in a small, net $\mathrm{pH}$ increases for both the $0.01 \%$ and $0.1 \% \mathrm{MnO}_{4}{ }^{-}$ reactors. As expected, the magnitude of this $\mathrm{pH}$ increase was the greatest for the $0.1 \% \mathrm{MnO}_{4}{ }^{-}$ reactors. Note: the increases in $\mathrm{pH}$ at the very end of the reaction period appear to result from a change in instrument performance (i.e., new calibration, etc) since nearly all reactors behave similarly. 


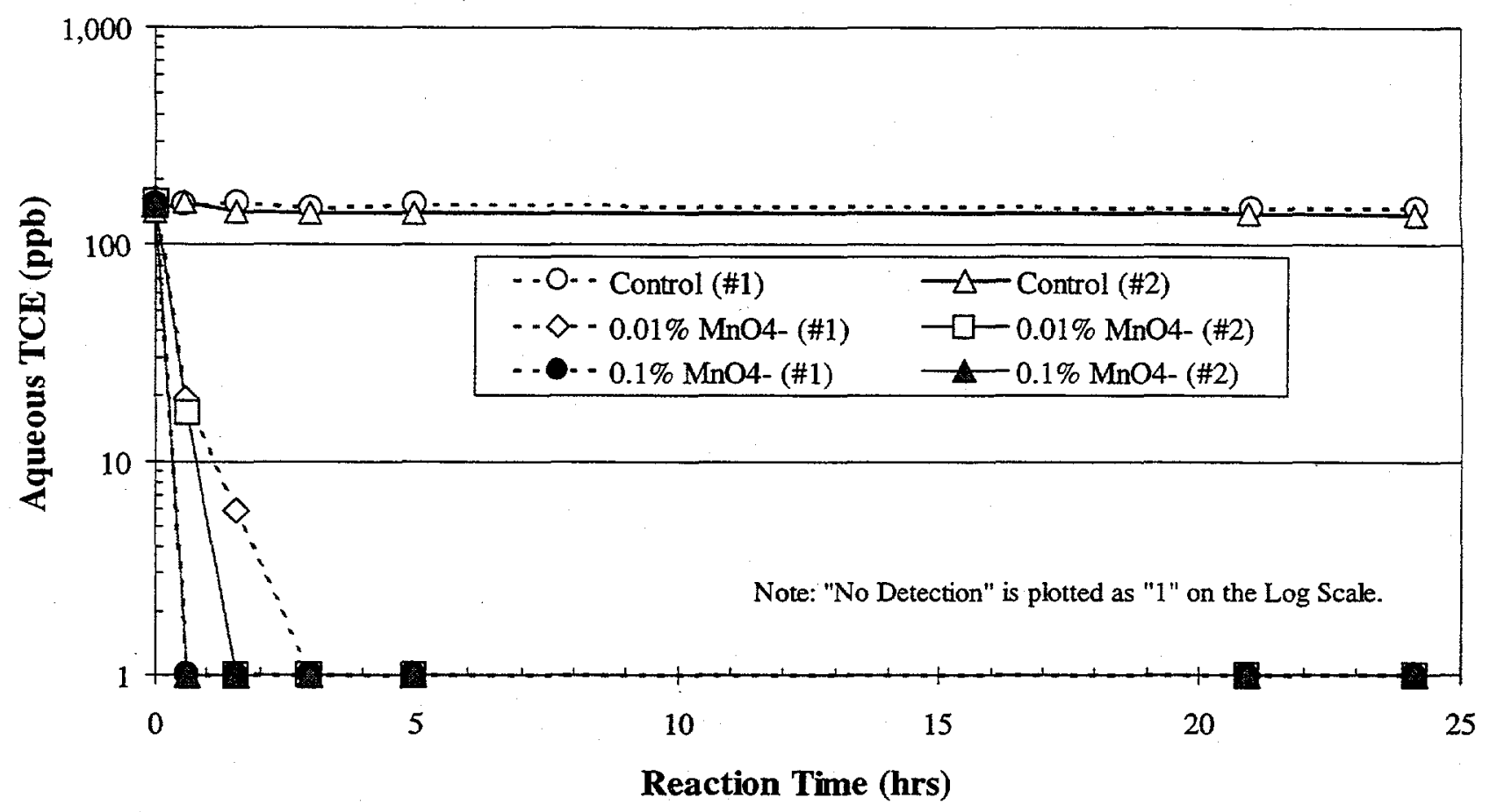

Figure 36. TCE vs. Time, TAN-40 GW \& Crushed Basalt, (ORNL Exp. 4a-R3, Initial TCE= $100 \mu \mathrm{g} / \mathrm{L}$, Conducted at $12^{\circ} \mathrm{C}, 4: 1 \mathrm{~L} / \mathrm{S}$ Ratio)

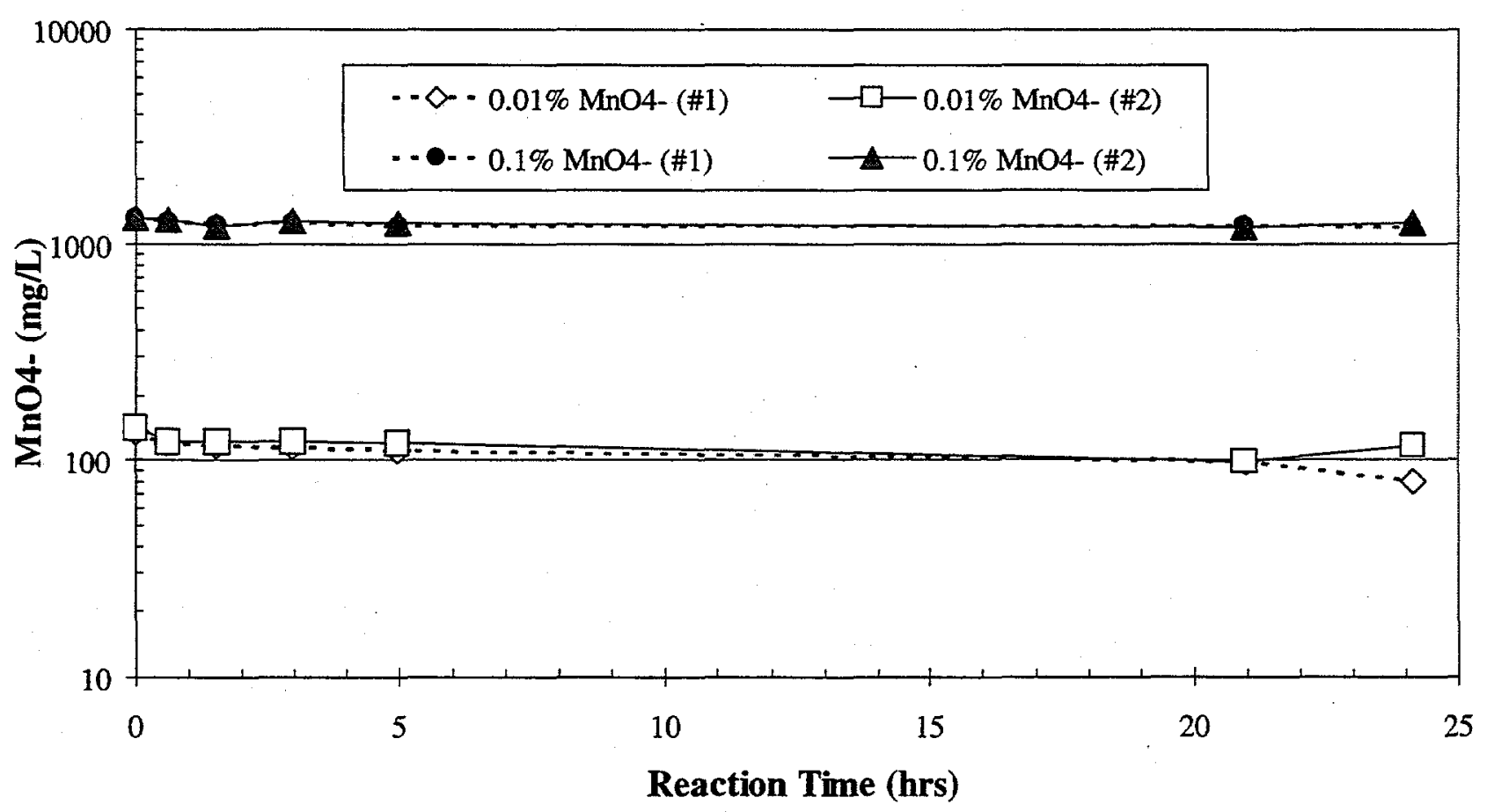

Figure 37. $\mathrm{MnO}_{4}^{-}$vs. Time, TAN-40 GW \& Crushed Basalt, (ORNL Exp. 4a-R3, Initial TCE= $100 \mu \mathrm{g} / \mathrm{L}$, Conducted at $12^{\circ} \mathrm{C}, 4: 1 \mathrm{~L} / \mathrm{S}$ Ratio) 


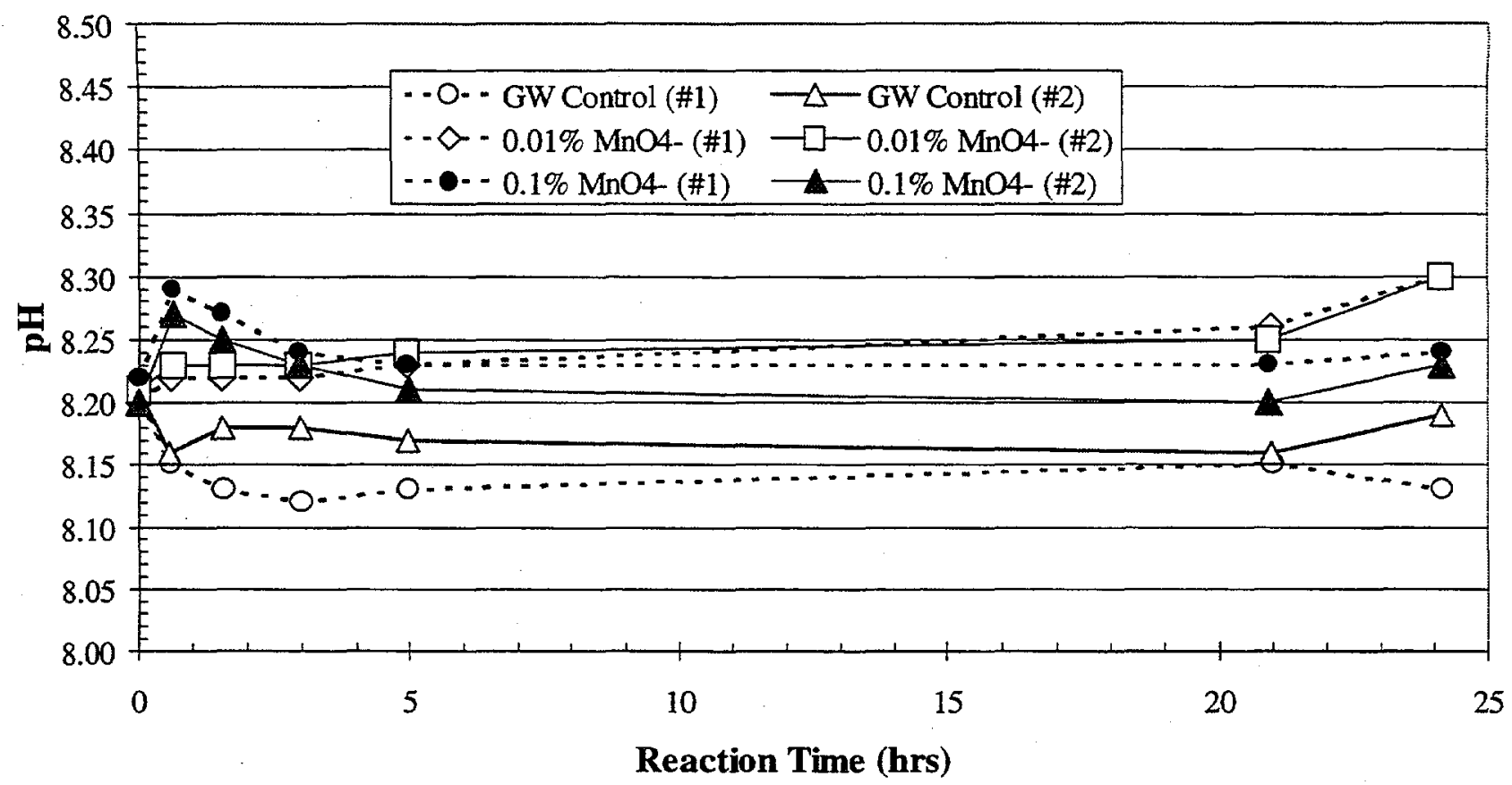

Figure 38. $\mathrm{pH}$ vs. Time, TAN-40 GW \& Crushed Basalt, (ORNL Exp. 4a-R3, Initial TCE $=100$ $\mu \mathrm{g} / \mathrm{L}$, Conducted at $12^{\circ} \mathrm{C}, 4: 1 \mathrm{~L} / \mathrm{S}$ Ratio)

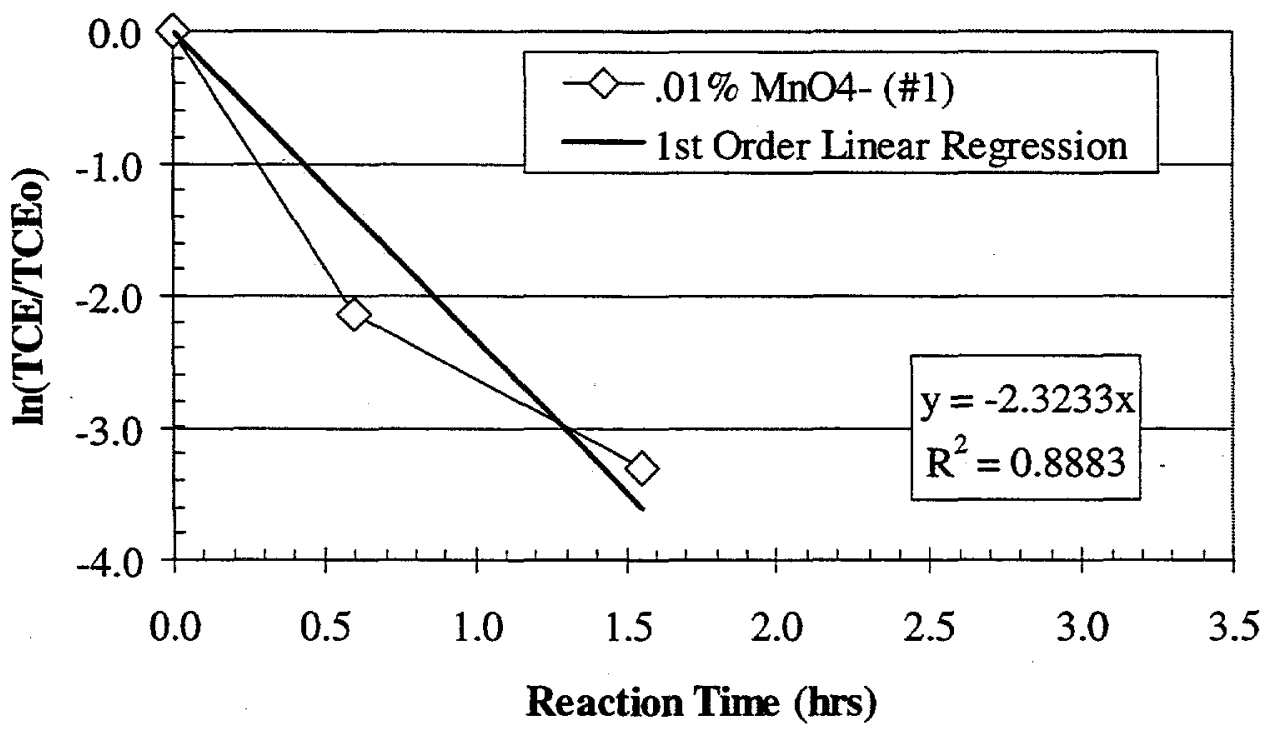

Figure 39 First Order TCE Oxidation Rate Constant for the $0.01 \% \mathrm{MnO}_{4}^{-}(\# 1)$ Reactor, TAN$40 \mathrm{GW}$ and Crushed Basalt, (ORNL Exp. 4a-R3, Initial TCE $=1000 \mu \mathrm{g} / \mathrm{L}$, Conducted at $12^{\circ} \mathrm{C}, 4: 1 \mathrm{~L} / \mathrm{S}$ Ratio) 
Table 16. TCE Mass Balance for ORNL Exp. 4a-R3 (TAN-40 GW \& Crushed Basalt).

\begin{tabular}{|c|c|c|c|c|c|c|c|}
\hline Test Condition & \begin{tabular}{|l} 
Total \\
Initial \\
Mass \\
$(\mathrm{mg})^{2}$.
\end{tabular} & \begin{tabular}{|l} 
Initial \\
Aqueous \\
Mass \\
(mg)
\end{tabular} & \begin{tabular}{|l|} 
Mass \\
Sorbed on \\
Orbo Tubes \\
$(\mathrm{mg})$
\end{tabular} & $\begin{array}{l}\text { Mass } \\
\text { Remaining in } \\
\text { Reactor (mg) }\end{array}$ & \begin{tabular}{|l|} 
Cum. \\
Mass \\
Removed \\
in Aliquots \\
(mg) \\
\end{tabular} & \begin{tabular}{|l|} 
Cum. \\
Aqueous \\
Mass \\
Oxidized \\
(mg) \\
\end{tabular} & $\begin{array}{l}\text { Total Mass } \\
\text { Recovered } \\
\text { (mg) }\end{array}$ \\
\hline \multirow[t]{2}{*}{ Control (\#1) } & 0.08 & 0.08 & 0.000 & 0.07 & 0.01 & $\mathrm{NA}$ & 0.1 \\
\hline & & & $0 \%$ & $83 \%$ & $11 \%$ & NA & $94 \%$ \\
\hline \multirow[t]{2}{*}{ Control (\#2) } & 0.08 & 0.08 & 0.000 & 0.06 & 0.01 & NA & 0.1 \\
\hline & & & $0 \%$ & $86 \%$ & $11 \%$ & NA & $97 \%$ \\
\hline \multirow{2}{*}{$0.01 \%(\# 1)$} & 0.07 & 0.07 & 0.000 & 0.00 & 0.001 & 0.07 & 0.1 \\
\hline & \%Sorbed: & $-8 \%$ & $0 \%$ & $0 \%$ & $2 \%$ & $106 \%$ & $108 \%$ \\
\hline \multirow{2}{*}{$0.01 \%(\# 2)$} & 0.07 & 0.07 & 0.000 & 0.00 & 0.001 & 0.07 & 0.1 \\
\hline & \%Sorbed: & $-5 \%$ & $0 \%$ & $0 \%$ & $2 \%$ & $103 \%$ & $105 \%$ \\
\hline \multirow[t]{2}{*}{$0.1 \%(\# 1)$} & 0.07 & 0.07 & 0.000 & 0.00 & 0.001 & 0.07 & 0.1 \\
\hline & \%Sorbed: & $-2 \%$ & $0 \%$ & $0 \%$ & $2 \%$ & $102 \%$ & $104 \%$ \\
\hline \multirow[t]{2}{*}{$0.1 \%(\# 2)$} & 0.07 & 0.07 & 0.000 & 0.00 & 0.001 & 0.07 & 0.1 \\
\hline & \%Sorbed: & $-2 \%$ & $0 \%$ & $0 \%$ & $2 \%$ & $102 \%$ & $104 \%$ \\
\hline
\end{tabular}

a. Total Initial for slurries computed using the average initial aqueous TCE concentration of the GW control samples $(A v g=151 \mu \mathrm{g} / \mathrm{L}, \sigma=11 \mu \mathrm{g} / \mathrm{L})$. For $\mathrm{GW}$ controls, Total Initial = Initial Aqueous.

Table 17. $\mathrm{MnO}_{4}{ }^{-}$Consumption Data for ORNL Exp. 4a-R3 (TAN-40 GW \& Crushed Basalt).

\begin{tabular}{|l|c|c|l|l|}
\hline Test Condition & $\begin{array}{l}\text { Initial } \\
\text { Oxidant } \\
\left(\mathrm{mg} \mathrm{MnO}_{4}\right)\end{array}$ & $\begin{array}{l}\text { Initial } \\
\text { Loading } \\
\left(\mathrm{mg} \mathrm{MnO}_{4} / \mathrm{g}\right)\end{array}$ & $\begin{array}{l}\text { Cum. } \\
\text { Consumed } \\
\left(\mathrm{mg} \mathrm{MnO}_{4}\right)\end{array}$ & $\begin{array}{l}\text { Cum. } \\
\text { Consumed } \\
\left(\mathrm{mg} \mathrm{MnO}_{4} / \mathrm{g}\right)\end{array}$ \\
\hline $0.01 \%(\# 1)$ & 60.5 & 0.11 & 24.57 & 0.04 \\
\hline $0.01 \%(\# 2)$ & 60.5 & 0.11 & 10.39 & 0.02 \\
\hline $0.1 \%(\# 1)$ & 605.0 & 1.09 & 61.42 & 0.11 \\
\hline $0.1 \%(\# 2)$ & 605.0 & 1.08 & 30.36 & 0.05 \\
\hline
\end{tabular}

a. Consumption is computed after $24 \mathrm{hr}$ reaction time. 
ORNL Exp. 4a-R4

(TAN-40, Aggregate Basalt, 100 TCE, 0 Other, $0.01 \%$ and $0.1 \% \mathrm{MnO}_{4}{ }^{-}$)

Slurries of TAN-40 GW and aggregate basalt were evaluated in this experiment. The TCE, $\mathrm{MnO}_{4}{ }^{-}$and $\mathrm{pH}$ values with time are presented in Figures 40,41 , and 42, respectively. Tables 18 and 19 provide additional TCE mass balance and oxidant consumption information. The (\#1) and (\#2) notations included in both the figure legends and the first column of these tables refer to the duplicate reactors evaluated for that test condition.

No deviations from the testplan procedure were made in this experiment.

After overnight equilibration, the average initial aqueous TCE concentration of the spike solution was $164 \mu \mathrm{g} / \mathrm{L}(\sigma=30 \mu \mathrm{g} / \mathrm{L})$. After transfer to the test reactors and equilibration with the aggregate basalt, the groundwater TCE concentration ranged between 128 and $144 \mu \mathrm{g} / \mathrm{L} \mathrm{TCE}$ ( $\mathrm{T}=0$ aliquots) prior to the start of the oxidation reaction. TCE recoveries of $94 \%$ and $102 \%$ were obtained for the control reactors. No TCE was observed in the extracts from the charcoal desorption tubes from either the control or the treatment reactors.

In this experiment, the total recovered TCE was less than $100 \%$ for 3 of the 4 treatment reactors. The initial aqueous TCE values for these 3 reactors were slightly lower than those observed for the TAN-40 GW controls. This suggests that TCE was initially (1) adsorbed by the aggregate basalt and/or (2) trapped within the intra-particle porewater spaces. Differences in the predicted total TCE mass and the initial measured aqueous TCE mass for these three treatment reactors results in predicted adsorption values of $2 \%, 4 \%$, and $8 \%$ (see Table 18). These predicted adsorption values are maximum values; i.e., assuming no volatilization occurred, etc. Unfortunately, the TCE equilibration experiments attempted for the aggregate basalt (SOW Task 2c) did not provide meaningful results to further verify this potential retention mechanism.

Although less than $100 \%$ recoveries were obtained, it is believed that complete oxidation of both sorbed and aqueous TCE did occur. If adsorption mechanisms were to preclude the sorbed TCE from being oxidized, one would have expected TCE to be detected in the extraction of the entire reactor following the $24 \mathrm{hrs}$ reaction period. However, No TCE was found in that component of the mass balance. If the "\% Sorbed" values in Table 18 are added to the "\%Cumulative Aqueous Mass Oxidized", a total TCE oxidized value at or near $100 \%$ is obtained.

The TCE data presented in Figure 40 indicate that complete TCE oxidation occurred within 2 hrs and within $0.5 \mathrm{hrs}$ for the $0.01 \%$ and $0.1 \% \mathrm{MnO}_{4}{ }^{-}$reactors, respectively. This trend is similar to that observed in Exp. $4 \mathrm{a}-\mathrm{R} 1$ involving TAN-40 GW spiked at $100 \mu \mathrm{g} / \mathrm{L}$. For the $0.01 \% \mathrm{MnO}_{4}^{-}$ reactors, the two aqueous $\mathrm{TCE}$ data points ( $\mathrm{T}=0$ and $\mathrm{T}=0.5 \mathrm{hrs}$ ) were used to compute the reaction rate for the initial, rapid step of the oxidation reaction. The data were plotted in Figures 43 and 44 as $\ln \left(\mathrm{C} / \mathrm{C}_{\mathrm{o}}\right)$ vs. Time in order to approximate a first order reaction rate constant, $k$. The linear regressions resulted in an average first order rate constant of $k=4.28 \mathrm{hr}^{-1}$. Note that each of these rate constants were computed using only 2 points, and thus the resulting $R^{2}$ values of 1.00 should be viewed with skepticism. Enough data points are not available to compute a rate constant for the $0.1 \%$ reactors; however, the observed oxidation rate is greater than $0.12 \mathrm{mg} \mathrm{TCE} / \mathrm{hr}$ for these reactors. 
The plots of the $\mathrm{MnO}_{4}{ }^{-}$and $\mathrm{pH}$ vs. reaction time follow similar trends to those that have already been discussed. As expected, the amount of oxidant consumed falls between that consumed by TCE-spiked TAN-40 GW only (Exp. 4a-R1) and TCE-spike Crushed Basalt (Exp. 4a-R3). There was a net $\mathrm{pH}$ increase of approximately $0.3 \mathrm{pH}$ units at $24 \mathrm{hrs}$ as a result of the oxidant addition and subsequent oxidation reactions that took place. 


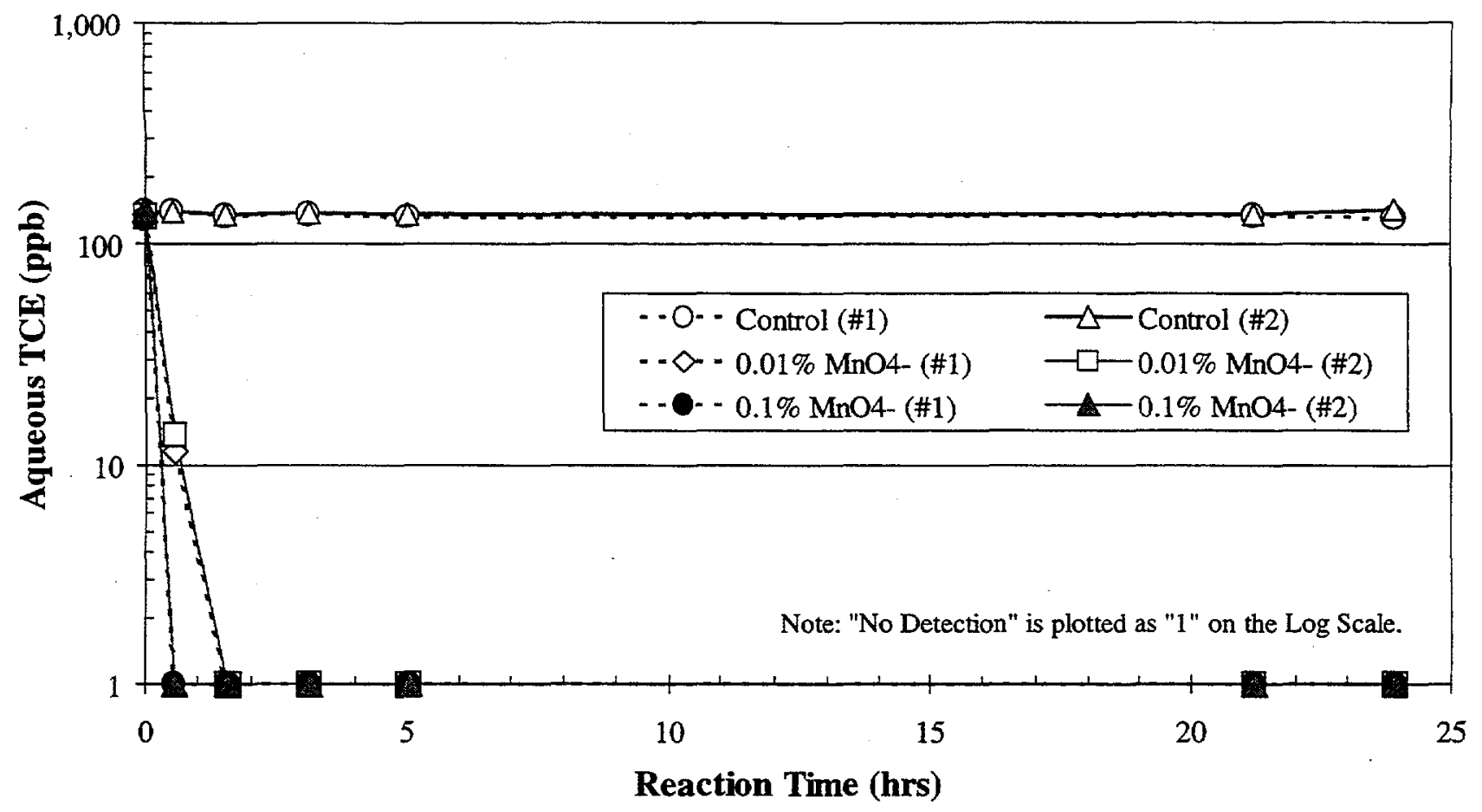

Figure 40. TCE vs. Time, TAN-40 GW \& Aggregate Basalt, (ORNL Exp. 4a-R4, Initial TCE= $100 \mu \mathrm{g} / \mathrm{L}$, Conducted at $12^{\circ} \mathrm{C}, 4: 1 \mathrm{~L} / \mathrm{S}$ Ratio)

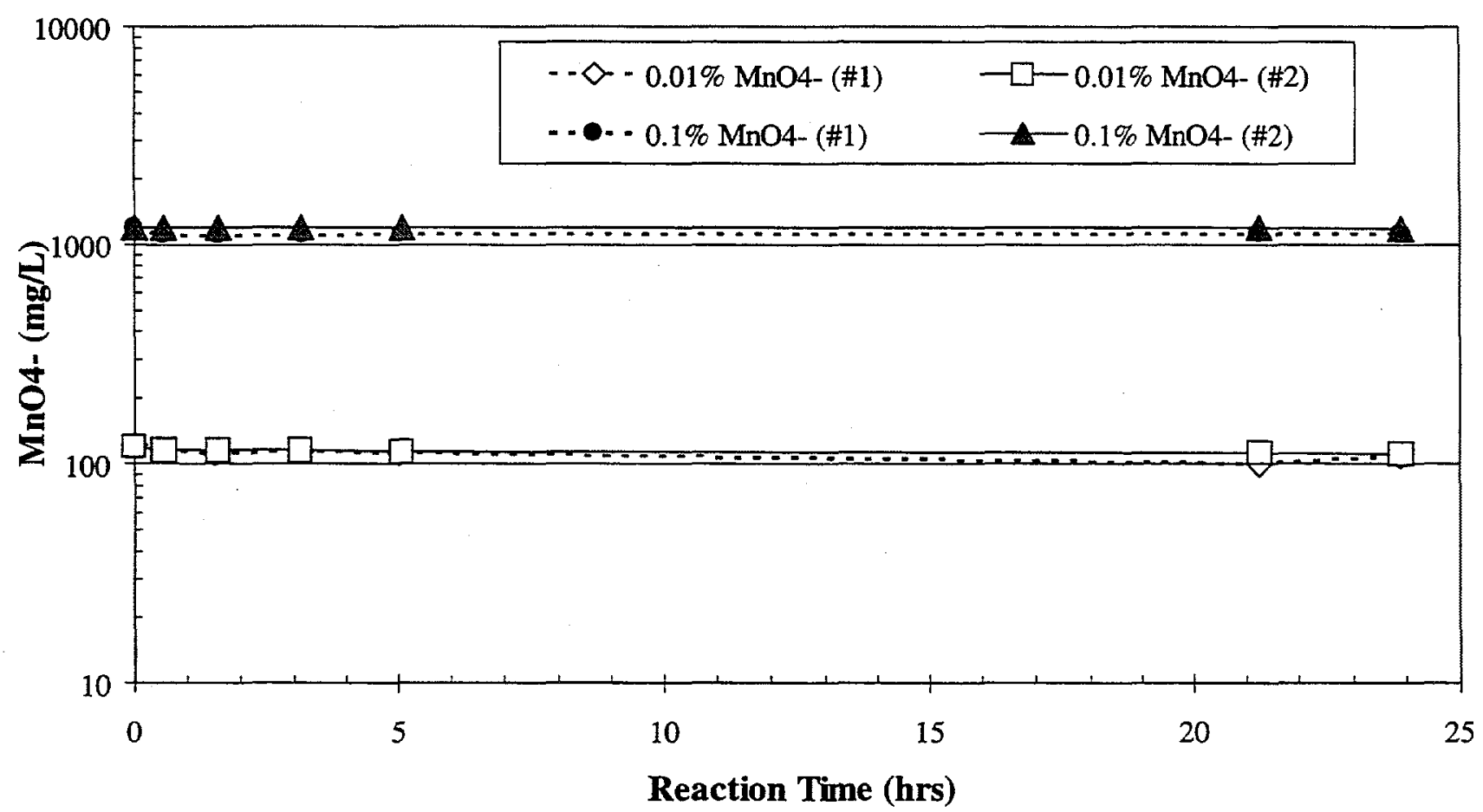

Figure 41. $\mathrm{MnO}_{4}{ }^{-}$vs. Time, TAN-40 GW \& Aggregate Basalt, (ORNL Exp. 4a-R4, Initial $\mathrm{TCE}=100 \mu \mathrm{g} / \mathrm{L}$, Conducted at $12^{\circ} \mathrm{C}, 4: 1 \mathrm{~L} / \mathrm{S}$ Ratio) 


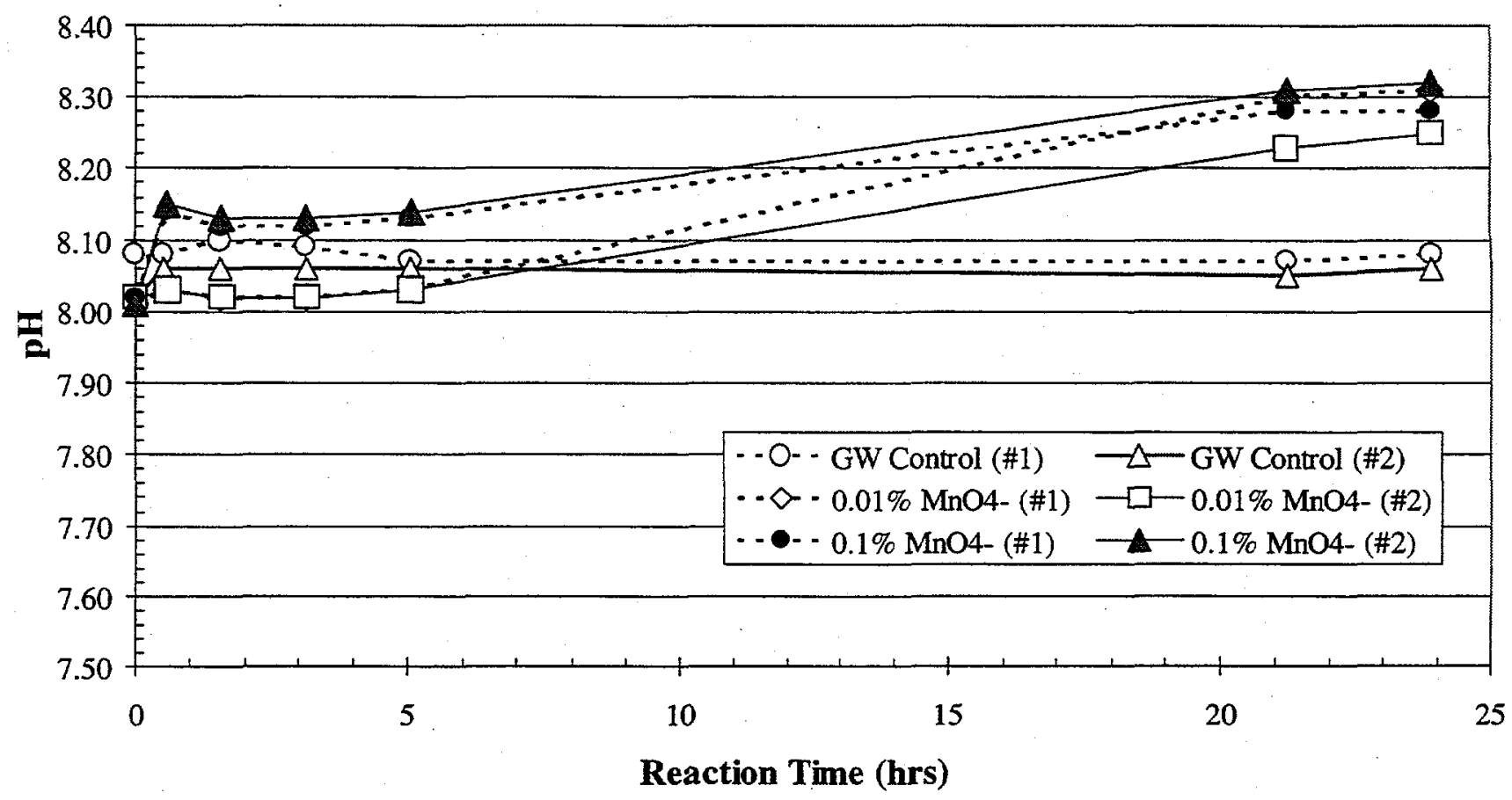

Figure 42. $\mathrm{pH}$ vs. Time, TAN-40 GW \& Aggregate Basalt, (ORNL Exp. 4a-R4, Initial TCE= $100 \mu \mathrm{g} / \mathrm{L}$, Conducted at $12^{\circ} \mathrm{C}, 4: 1 \mathrm{~L} / \mathrm{S}$ Ratio)

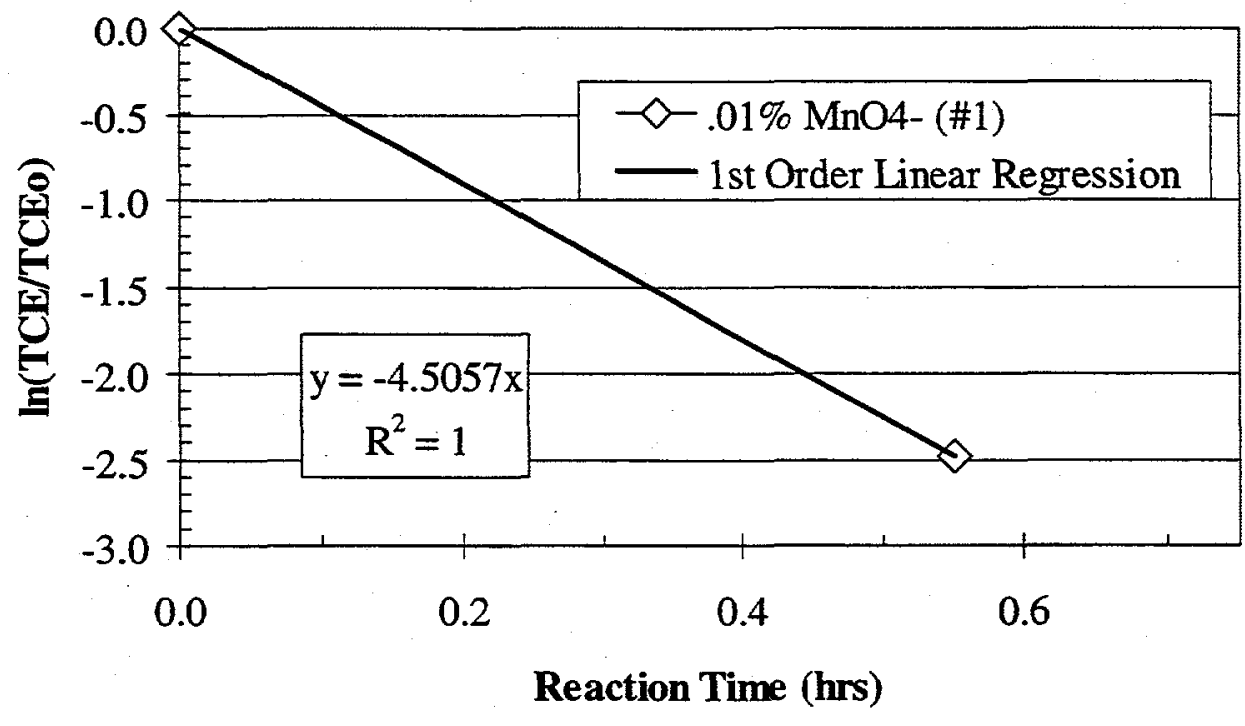

Figure 43. First Order TCE Oxidation Rate Constant for the $0.01 \% \mathrm{MnO}_{4}^{-}(\# 1)$ Reactor, TAN$40 \mathrm{GW} \&$ Aggregate Basalt, (ORNL Exp. 4a-R4, Initial TCE $=100 \mu \mathrm{g} / \mathrm{L}$, Conducted at $12^{\circ} \mathrm{C}, 4: 1 \mathrm{~L} / \mathrm{S}$ Ratio) 


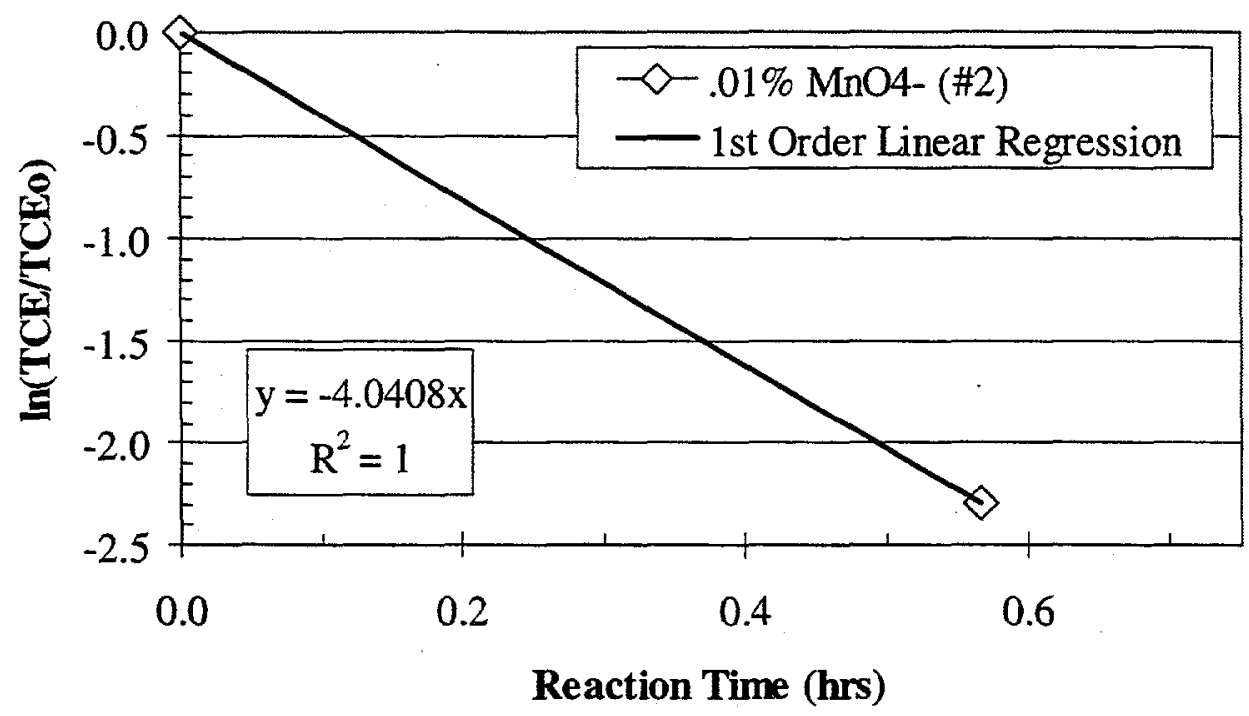

Figure 44. First Order TCE Oxidation Rate Constant for the $0.01 \% \mathrm{MnO}_{4}^{-}(\# 2)$ Reactor, TAN$40 \mathrm{GW} \&$ Aggregate Basalt, (ORNL Exp. 4a-R4, Initial TCE $=100 \mu \mathrm{g} /$, Conducted at $12^{\circ} \mathrm{C}, 4: 1 \mathrm{~L} / \mathrm{S}$ Ratio) 
Table 18. TCE Mass Balance for ORNL Exp. 4a-R4 (TAN-40 GW \& Aggregate Basalt).

\begin{tabular}{|c|c|c|c|c|c|c|c|}
\hline Test Condition & $\begin{array}{l}\text { Total } \\
\text { Initial } \\
\text { Mass } \\
(\mathrm{mg})^{\mathrm{a}}\end{array}$ & \begin{tabular}{|l} 
Initial \\
Aqueous \\
Mass \\
(mg)
\end{tabular} & $\begin{array}{l}\text { Mass } \\
\text { Sorbed on } \\
\text { Orbo Tubes } \\
\text { (mg) }\end{array}$ & $\begin{array}{l}\text { Mass } \\
\text { Remaining in } \\
\text { Reactor (mg) }\end{array}$ & \begin{tabular}{|l|} 
Cum. \\
Mass \\
Removed \\
in Aliquots \\
(mg) \\
\end{tabular} & \begin{tabular}{|l|} 
Cum. \\
Aqueous \\
Mass \\
Oxidized \\
(mg) \\
\end{tabular} & $\begin{array}{l}\text { Total Mass } \\
\text { Recovered } \\
\text { (mg) }\end{array}$ \\
\hline \multirow{2}{*}{ Control (\#1) } & 0.07 & 0.07 & .0.0 & 0.00 & 0.01 & NA & 0.1 \\
\hline & & & $0 \%$ & $82 \%$ & $11 \%$ & NA & $94 \%$ \\
\hline \multirow{2}{*}{ Control (\#2) } & 0.07 & 0.07 & 0.000 & 0.06 & 0.01 & $\mathrm{NA}$ & 0.1 \\
\hline & & & $0 \%$ & $90 \%$ & $12 \%$ & $\mathrm{NA}$ & $102 \%$ \\
\hline \multirow{2}{*}{$0.01 \%(\# 1)$} & 0.06 & 0.06 & 0.000 & 0.00 & 0.001 & 0.05 & 0.1 \\
\hline & \% Sorbed: & $2 \%$ & $0 \%$ & $0 \%$ & $2 \%$ & $96 \%$ & $98 \%$ \\
\hline \multirow{2}{*}{$0.01 \%(\# 2)$} & 0.06 & 0.05 & 0.000 & 0.00 & 0.001 & 0.05 & 0.1 \\
\hline & \%Sorbed: & $4 \%$ & $0 \%$ & $0 \%$ & $2 \%$ & $93 \%$ & $95 \%$ \\
\hline \multirow{2}{*}{$0.1 \%(\# 1)$} & 0.06 & 0.05 & 0.000 & 0.00 & 0.001 & 0.05 & 0.1 \\
\hline & \%Sorbed: & $8 \%$ & $0 \%$ & $0 \%$ & $2 \%$ & $92 \%$ & $94 \%$ \\
\hline \multirow[t]{2}{*}{$0.1 \%(\# 2)$} & 0.06 & 0.06 & 0.000 & 0.00 & 0.001 & 0.06 & 0.1 \\
\hline & \%Sorbed: & 54 & $0 \%$ & $0 \%$ & $2 \%$ & 103 & $105 \%$ \\
\hline
\end{tabular}

a. Total Initial for slurries computed using the average initial aqueous TCE concentration of the $\mathrm{GW}$ control samples (Avg=140 $\mu \mathrm{g} / \mathrm{L}, \sigma=1 \mu \mathrm{g} / \mathrm{L}$ ). For $\mathrm{GW}$ controls, Total Initial = Initial Aqueous.

Table 19. $\mathrm{MnO}_{4}{ }^{-}$Consumption Data for ORNL Exp. 4a-R4 (TAN-40 GW \& Aggregate Basalt).

\begin{tabular}{|l|c|c|c|c|}
\hline Test Condition & $\begin{array}{l}\text { Initial } \\
\text { Oxidant } \\
\left.\left(\mathrm{mg} \mathrm{MnO}_{4}\right)^{-}\right)\end{array}$ & $\begin{array}{l}\text { Initial } \\
\text { Loading } \\
\left(\mathrm{mg} \mathrm{MnO}_{4}^{-} / \mathrm{g}\right)\end{array}$ & $\begin{array}{l}\text { Cum. } \\
\text { Consumed } \\
\left(\mathrm{mg} \mathrm{MnO}_{4}\right)\end{array}$ & $\begin{array}{l}\text { Cum. } \\
\text { Consumed } \\
\left(\mathrm{mg} \mathrm{MnO}_{4} / \mathrm{g}\right)\end{array}$ \\
\hline $0.01 \%(\# 1)$ & 48.3 & 0.10 & 5.16 & 0.01 \\
\hline $0.01 \%(\# 2)$ & 48.3 & 0.10 & 3.81 & 0.01 \\
\hline $0.1 \%(\# 1)$ & 482.6 & 0.95 & 29.67 & 0.06 \\
\hline $0.1 \%(\# 2)$ & 482.6 & 0.95 & 6.79 & 0.01 \\
\hline
\end{tabular}

a. Consumption is computed after $24 \mathrm{hr}$ reaction time. 
ORNL Exp. 4a-R5

(TAN-40, Crushed Basalt, 1000 TCE, 0 Other, $0.01 \%$ and $0.1 \% \mathrm{MnO}_{4}^{-}$)

Slurries of TAN-40 GW and Crushed basalt were evaluated in this experiment. The TCE, $\mathrm{MnO}_{4}{ }^{-}$ and $\mathrm{pH}$ values with time are presented in Figures 45, 46, and 47, respectively. Tables 20 and 21 provide additional TCE mass balance and oxidant consumption information. The (\#1) and (\#2) notations included in both the figure legends and the first column of these tables refer to the duplicate reactors evaluated for that test condition.

No deviations from the testplan procedure were made in this experiment.

After equilibration, the average initial aqueous TCE concentration of the spike solution was 1350 $\mu \mathrm{g} / \mathrm{L}(\sigma=5 \mu \mathrm{g} / \mathrm{L})$. After transfer to the test reactors and equilibration with the crushed basalt, the groundwater TCE concentration ranged between 1259 and $1319 \mu \mathrm{g} / \mathrm{L}$ TCE (T=0 aliquots) prior to the start of the oxidation reaction. Comparison of the total initial TCE masses with the initial aqueous TCE masses (Table 20), leads to predicted TCE adsorption values between -2 and $3 \%$ for the crushed basalt used in this experiment.

TCE contamination (8-12 $\mu \mathrm{g} / \mathrm{L}$ ) was observed in the GC QA/QC checks blanks for this experiment. The TCE values obtained from the experimental samples further suggest that the hexane used to extract the aqueous samples and the carbon desorption tubes may have been contaminated with a small, unknown amount of TCE. Presence of TCE on the charcoal beds of the desorption tubes could be attributed to volatilization. It is suspected, however, that it is largely a result of the solvent contamination problem, particularly since the second charcoal bed sample, in several instances; contained detectable amounts of TCE while the first charcoal bed did not. The experiment was not repeated. The overall results from this experiment were very similar to those obtained in the previous dissolved plume tests that had been conducted. Thus, it did not appear prudent or cost effective to repeat the experiment in light of the benefits that would be gained.

TCE recoveries for the control samples were $94 \%$ and $95 \%$, suggesting that some TCE may have been lost to volatilization. The degree of potential volatilization, however, cannot be completely estimated due to the potential contamination of the charcoal desorption tubes discussed above.

Again, complete oxidation of the added TCE was not observed in this experiment. With the exception of the first $0.1 \% \mathrm{MnO}_{4}{ }^{-}$reactor, extracts from all the other treatment reactors contained approximately a $10-20 \mu \mathrm{g} / \mathrm{L}$ residual TCE concentration. The residual TCE is likely to be a result of sample/solvent contamination problem. While the presence of the additional TCE complicates the interpretation of the mass balance, the amount of solvent contamination is small and does not completely invalidate general trends observed in the TCE oxidation reactions. The general trend of rapid TCE oxidation was still observed. If one were to assume that the residual TCE concentration are due to contamination, complete TCE oxidation likely occurred within 5 hrs and within $0.5 \mathrm{hrs}$ for the $0.01 \%$ and $0.1 \% \mathrm{MnO}_{4}{ }^{-}$reactors, respectively. Although there are greater than three TCE data points present, a rate constant was not computed for this experiment since it is likely that the accuracy of the some of the data points is questionable. However, 
observed rates of TCE oxidation are estimated to be greater than and $1.0 \mathrm{mg} \mathrm{TCE} / \mathrm{hr}$ for the $0.01 \%$ and $0.1 \% \mathrm{MnO}_{4}{ }^{-}$reactors, respectively.

Little oxidant was consumed by the treatment reactors. In fact, the $\mathrm{MnO}_{4}{ }^{-}$consumption values from this experiment (Table 21) are similar to those obtained in Experiment 4a-R2, the TAN-40 GW only case (Table 15). It is not known what phenomenon lead to the negative oxidant value for the second $0.1 \% \mathrm{MnO}_{4}{ }^{-}$reactor. From the $\mathrm{pH}$ plot (Figure 47), the treatment reactors appear to experience a slight $\mathrm{pH}$ drop before ultimately reaching a net $\mathrm{pH}$ increase during the course of the $24 \mathrm{hr}$ reaction period. It is interesting to note that the trend in $\mathrm{pH}$ for second $0.1 \% \mathrm{MnO}_{4}{ }^{-}$ reactor, which resulted in a negative oxidant value, did not follow that of the other treatment reactors evaluated in this experiment. 


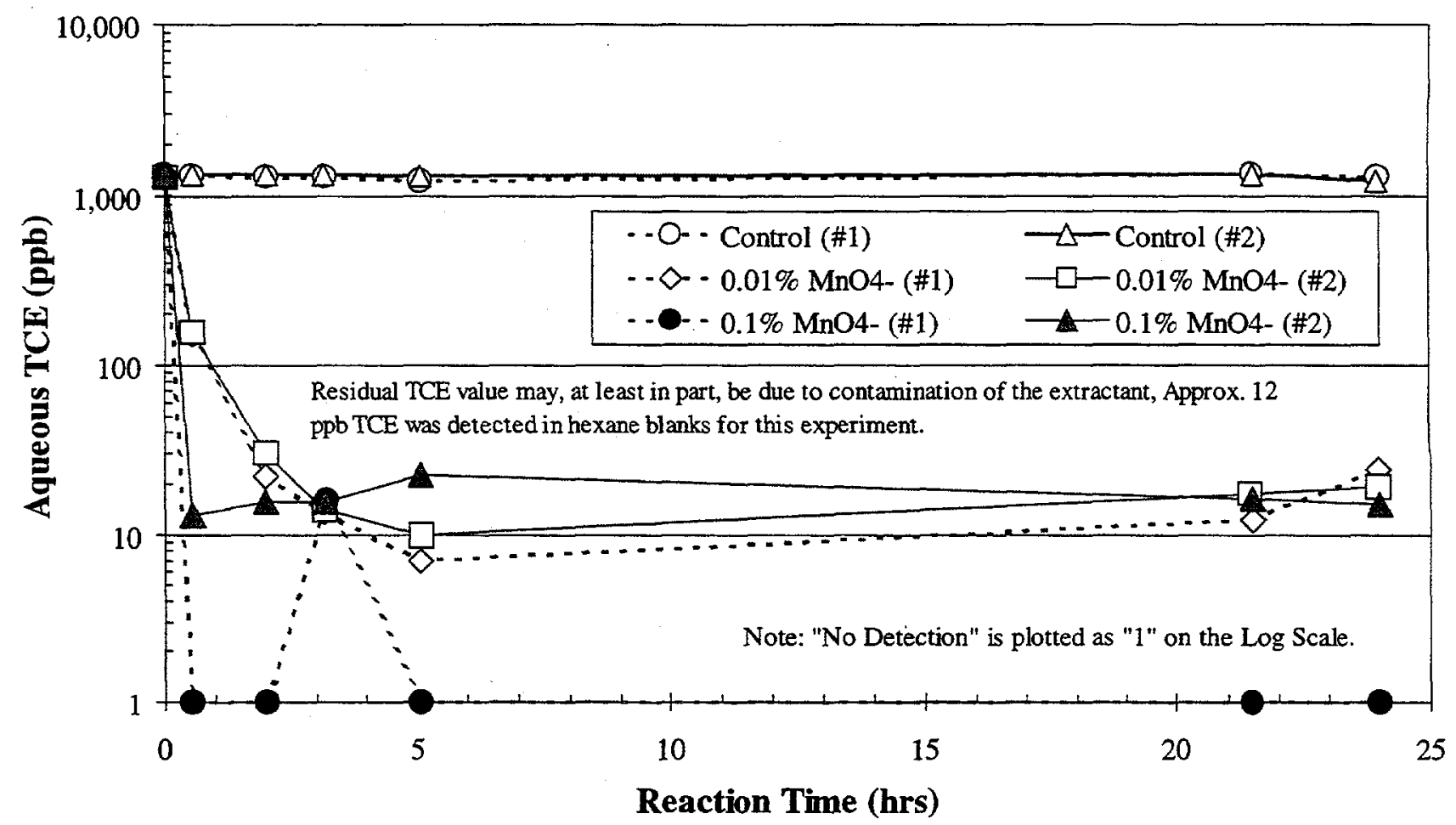

Figure 45. TCE vs. Time, TAN-40 GW \& Crushed Basalt, (ORNL Exp. 4a-R5, Initial TCE= $1000 \mu \mathrm{g} / \mathrm{L}$, Conducted at $12^{\circ} \mathrm{C}, 4: 1 \mathrm{~L} / \mathrm{S}$ Ratio)

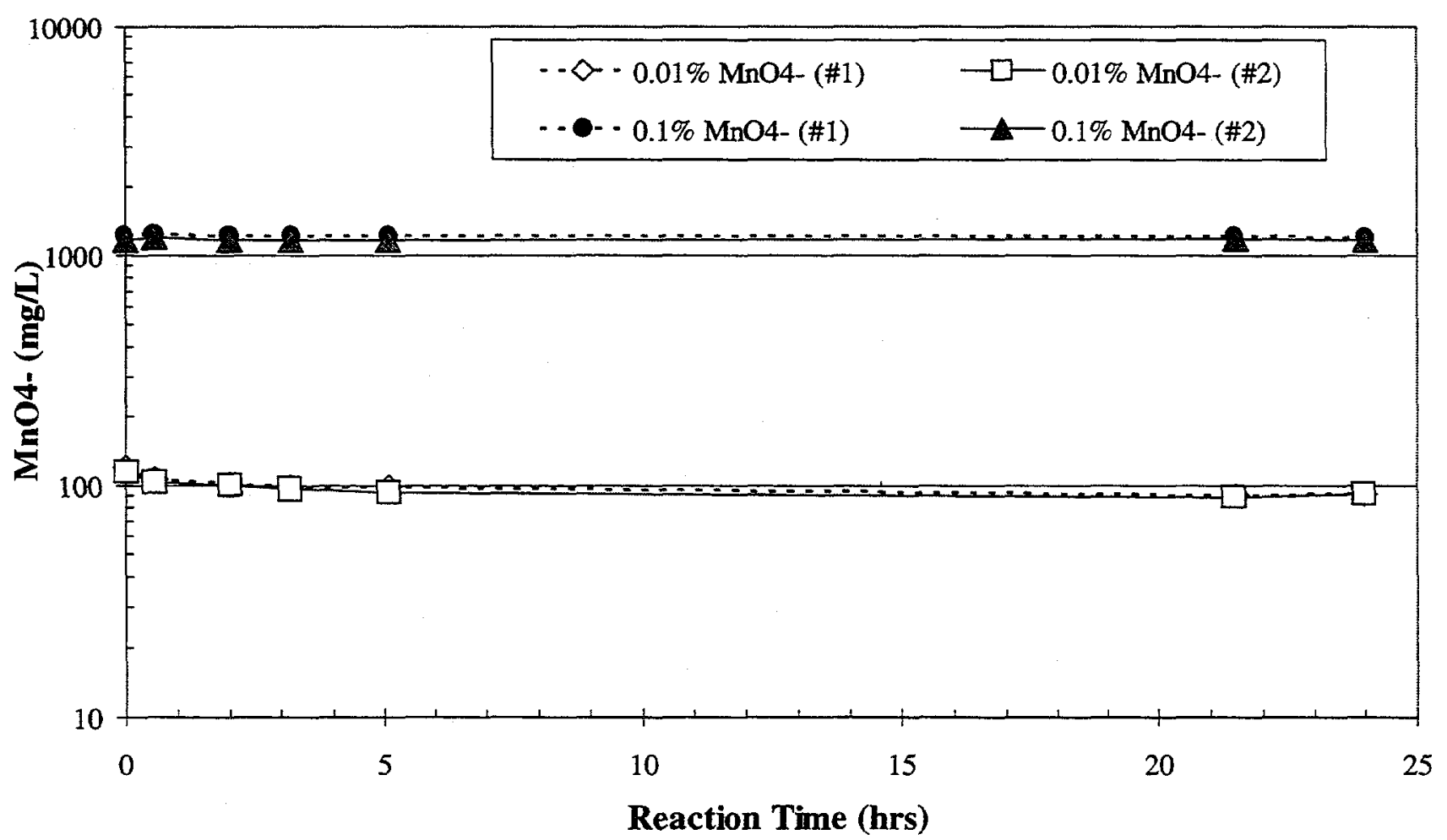

Figure 46. $\mathrm{MnO}_{4}{ }^{-}$vs. Time, TAN-40 $\mathrm{GW} \&$ Crushed Basalt, (ORNL Exp. 4a-R5, Initial TCE= $1000 \mu \mathrm{g} / \mathrm{L}$, Conducted at $12^{\circ} \mathrm{C}, 4: 1 \mathrm{~L} / \mathrm{S}$ Ratio) 


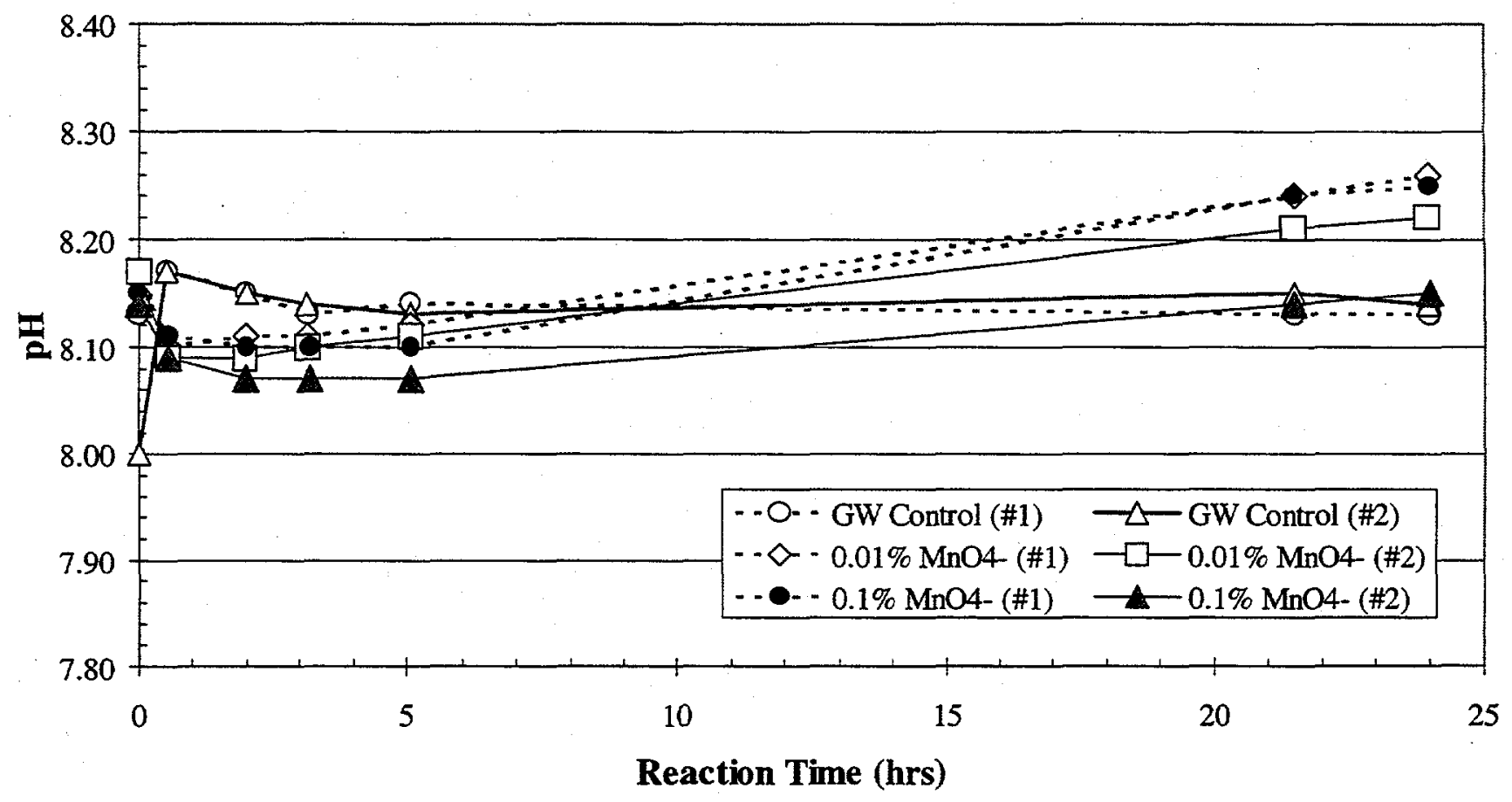

Figure 47. $\mathrm{pH}$ vs. Time, TAN-40 GW \& Crushed Basalt, (ORNL Exp. 4a-R5, Initial TCE= $1000 \mu \mathrm{g} / \mathrm{L}$, Conducted at $12^{\circ} \mathrm{C}, 4: 1 \mathrm{~L} / \mathrm{S}$ Ratio) 
Table 20. TCE Mass Balance for ORNL Exp. 4a-R5 (TAN-40 GW \& Crushed Basalt).

\begin{tabular}{|c|c|c|c|c|c|c|c|}
\hline Test Condition & $\begin{array}{l}\text { Total } \\
\text { Initial } \\
\text { Mass } \\
(\mathrm{mg})^{2}\end{array}$ & $\begin{array}{l}\text { Initial } \\
\text { Aqueous } \\
\text { Mass } \\
(\mathrm{mg})\end{array}$ & \begin{tabular}{|l|} 
Mass \\
Sorbed on \\
Orbo Tubes \\
$(\mathrm{mg})$
\end{tabular} & \begin{tabular}{|l|} 
Mass \\
Remaining in \\
Reactor (mg)
\end{tabular} & \begin{tabular}{|l} 
Cum. \\
Mass \\
Removed \\
in Aliquots \\
(mg) \\
\end{tabular} & \begin{tabular}{|l|} 
Cum. \\
Aqueous \\
Mass \\
Oxidized \\
(mg) \\
\end{tabular} & $\begin{array}{l}\text { Total Mass } \\
\text { Recovered } \\
\text { (mg) }\end{array}$ \\
\hline \multirow{2}{*}{ Control (\#1) } & \multirow[t]{2}{*}{0.65} & \multirow[t]{2}{*}{0.65} & -05 & $\overline{0.5}$ & 0.08 & NA & 0.6 \\
\hline & & & $0 \%$ & $85 \%$ & $11 \%$ & NA & $96 \%$ \\
\hline \multirow{2}{*}{ Control (\#2) } & \multirow[t]{2}{*}{$\overline{0.64}$} & \multirow[t]{2}{*}{0.64} & $3.79 \mathrm{E}-05$ & 0.54 & 0.08 & NA & $\overline{0.6}$ \\
\hline & & & $0 \%$ & $85 \%$ & $12 \%$ & NA & $97 \%$ \\
\hline \multirow{2}{*}{$0.01 \%(\# 1)$} & 0.53 & 0.51 & \multirow{2}{*}{$\begin{array}{c}3.94 \mathrm{E}-05 \\
0 \%\end{array}$} & \multirow{2}{*}{$\begin{array}{c}0.01 \\
1 \%\end{array}$} & \multirow{2}{*}{$\begin{array}{c}0.011 \\
2 \%\end{array}$} & \multirow{2}{*}{$\begin{array}{l}0.49 \\
94 \%\end{array}$} & \multirow{2}{*}{$\begin{array}{c}0.5 \\
97 \%\end{array}$} \\
\hline & \%Sorbed: & $3 \%$ & & & & & \\
\hline \multirow{2}{*}{$0.01 \%(\# 2)$} & 0.54 & 0.53 & \multirow{2}{*}{$\begin{array}{c}2.71 \mathrm{E}-05 \\
0 \%\end{array}$} & \multirow{2}{*}{$\begin{array}{l}0.00 \\
0 \%\end{array}$} & \multirow{2}{*}{$\begin{array}{c}0.011 \\
2 \%\end{array}$} & \multirow{2}{*}{$\begin{array}{l}0.52 \\
95 \%\end{array}$} & \multirow{2}{*}{$\begin{array}{c}0.5 \\
97 \%\end{array}$} \\
\hline & \%Sorbed: & $2 \%$ & & & & & \\
\hline \multirow{2}{*}{$0.1 \%(\# 1)$} & 0.50 & 0.48 & \multirow{2}{*}{$\begin{array}{c}0.00 \mathrm{E}+00 \\
0 \%\end{array}$} & \multirow{2}{*}{$\begin{array}{l}0.00 \\
0 \%\end{array}$} & \multirow{2}{*}{$\begin{array}{c}0.009 \\
2 \%\end{array}$} & \multirow{2}{*}{$\begin{array}{l}0.49 \\
98 \%\end{array}$} & \multirow{2}{*}{$\begin{array}{c}0.5 \\
100 \%\end{array}$} \\
\hline & \%Sorbed: & $3 \%$ & & & & & \\
\hline \multirow{2}{*}{$0.1 \%(\# 2)$} & 0.53 & 0.53 & $3.64 \mathrm{E}-05$ & 0.01 & $\overline{0.010}$ & 0.54 & 0.6 \\
\hline & \%Sorbed: & $-2 \%$ & $0 \%$ & $2 \%$ & $2 \%$ & $102 \%$ & $105 \%$ \\
\hline
\end{tabular}

a. Total Initial for slurries computed using the average initial aqueous TCE concentration of the $\mathrm{GW}$ control samples (Avg=1,297 $\mu \mathrm{g} / \mathrm{L}, \sigma=30 \mu \mathrm{g} / \mathrm{L})$. For $\mathrm{GW}$ controls, Total Initial = Initial Aqueous.

Table 21. $\mathrm{MnO}_{4}{ }^{-}$Consumption Data for ORNL Exp. 4a-R5 (TAN-40 GW \& Crushed Basalt).

\begin{tabular}{|l|c|l|l|l|}
\hline Test Condition & $\begin{array}{l}\text { Initial } \\
\text { Oxidant } \\
\left(\mathrm{mg} \mathrm{MnO}_{4}\right)\end{array}$ & $\begin{array}{l}\text { Initial } \\
\text { Loading } \\
\left(\mathrm{mg} \mathrm{MnO}_{4}^{-} / \mathrm{g}\right)\end{array}$ & $\begin{array}{l}\text { Cum. } \\
\text { Consumed } \\
\left(\mathrm{mg} \mathrm{MnO}_{4}^{-}\right)\end{array}$ & $\begin{array}{l}\text { Cum. } \\
\text { Consumed } \\
\left(\mathrm{mg} \mathrm{MnO}_{4} / \mathrm{g}\right)\end{array}$ \\
\hline $0.01 \%(\# 1)$ & 47.7 & 0.10 & 11.14 & 0.02 \\
\hline $0.01 \%(\# 2)$ & 47.7 & 0.09 & 10.01 & 0.02 \\
\hline $0.1 \%(\# 1)$ & 477.0 & 0.97 & 8.47 & 0.02 \\
\hline $0.1 \%(\# 2)$ & 477.0 & 0.93 & -4.39 & -0.01 \\
\hline
\end{tabular}

a. Consumption is computed after $24 \mathrm{hr}$ reaction time. 
ORNL Exp. 4a-R6

(TAN-40, Aggregate Basalt, 1000 TCE, 0 Other, $0.01 \%$ and $0.1 \% \mathrm{MnO}_{4}{ }^{-}$)

Slurries of TAN- $40 \mathrm{GW}$ and aggregate basalt were evaluated in this experiment. The TCE, $\mathrm{MnO}_{4}{ }^{-}$and $\mathrm{pH}$ values with time are presented in Figures 48, 49, and 50, respectively. Tables 22 and 23 provide additional TCE mass balance and oxidant consumption information. The (\#1) and (\#2) notations included in both the figure legends and the first column of these tables refer to the duplicate reactors evaluated for that test condition.

A procedural change was made to the testplan for this experiment. The TCE-spiked TAN-40 $\mathrm{GW}$ was only mixed/equilibrated for $3 \mathrm{hrs}$ (instead of overnight) prior to being added to the reactors and equilibrated with the aggregate basalt. The change was made due to a leak observed in the Tedlar spiking bag. The control and $0.01 \% \mathrm{MnO}_{4}{ }^{-}$reactors were quickly filled using the spike solution still within the Tedlar bag. The two $0.1 \% \mathrm{MnO}_{4}{ }^{-}$test reactors were filled using an approximate 50/50 mixture of remaining groundwater in the Tedlar bag with that which had leaked out onto the spill containment tray. Hence, it was expected that the initial TCE mass for these $0.1 \% \mathrm{MnO}_{4}{ }^{-}$test reactors would be low.

After the shortened equilibration period, the average initial aqueous TCE concentration of the spike solution was $2,440 \mu \mathrm{g} / \mathrm{L}(\sigma=140 \mu \mathrm{g} / \mathrm{L})$. After transfer to the test reactors and equilibration with the aggregate basalt, the groundwater TCE concentration ranged between 2,304 and 2,574 $\mu \mathrm{g} / \mathrm{L}$ TCE ( $\mathrm{T}=0$ aliquots) for the control and $0.01 \% \mathrm{MnO}_{4}{ }^{-}$reactors. The initial aqueous TCE concentration within the $0.1 \% \mathrm{MnO}_{4}{ }^{-}$reactors was $635 \mu \mathrm{g} / \mathrm{L}(\sigma=16 \mu \mathrm{g} / \mathrm{L})$ prior to the start of the oxidation reaction. The control reactors yielded total TCE recoveries of $99 \%$ and $97 \%$ after the $24 \mathrm{hr}$ reaction period. Thus, it was again believed that the reactors minimized the amount of TCE lost via volatilization. TCE was not found on the charcoal desorption tubes or in the final treatment reactor extractions. Total TCE recoveries for the $0.01 \% \mathrm{MnO}_{4}{ }^{-}$reactors were only $91 \%$ and $93 \%$. A closer look at the data reveals that initial aqueous TCE concentrations of in both of these slurry reactors were $8 \%$ lower than that of the groundwater controls. (A very similar adsorption/retention value was observed for the aggregate basalt in Exp.4a-R4). Since TCE was not present when the remaining basalt and GW was extracted at the end of the test period, it is expected that all of the total initial TCE present was oxidized. Even if this assumption is correct, the TCE fraction initially associated with the aggregate basalt would still not appear in the "Cumulative Aqueous Mass Oxidized" column of Table 22. (This part of the mass balance only takes beginning and ending aqueous concentrations into account.) However, if one assumes that the aggregate bound TCE is oxidized, effective total TCE recoveries of $99 \%$ and $101 \%$ are obtained for the $0.01 \% \mathrm{MnO}_{4}{ }^{-}$test reactors. This assumption appears valid since the control reactors for this experiment yielded high TCE recovery values.

Since the total initial TCE in the $0.1 \% \mathrm{MnO}_{4}{ }^{-}$reactors is computed using the average concentration of the $\mathrm{GW}$ controls at $\mathrm{T}=0$, the resulting total TCE recoveries are only $\approx 26 \%$. Unfortunately, there are no QAVQC samples to ascertain the total initial TCE mass in the $0.1 \%$ $\mathrm{MnO}_{4}{ }^{-}$reactors (due to the leak in the Tedlar bag). However, if one were to assume that the aggregate basalt in these reactors initially adsorbed $8 \%$ of the total initial TCE (as in the case of the $0.01 \% \mathrm{MnO}_{4}{ }^{-}$reactors), total initial TCE masses of $0.29 \mathrm{mg}$ and $0.26 \mathrm{mg}$ would result for the first and second $0.1 \% \mathrm{MnO}_{4}{ }^{-}$reactors, respectively. Recalculation of the Cumulative Aqueous 
Mass Oxidized component of the mass balance would then yield a value of $94 \%$ being oxidized for both $0.1 \% \mathrm{MnO}_{4}^{-}$reactors. Similarly, total effective recoveries for these reactors would then be in the range of $96 \%$ and $97 \%$ for the first and second $0.1 \% \mathrm{MnO}_{4}{ }^{-}$reactor, respectively.

The rate of TCE oxidation by the $0.01 \% \mathrm{MnO}_{4}{ }^{-}$reactors appeared were slower for this experiment than that observed in other dissolved plume media experiments. From the TCE data in Figure 48, a TCE residual was present in the first $0.01 \% \mathrm{MnO}_{4}{ }^{-}$reactor until the final aliquot samples were collected. There is no information to suggest that this residual TCE is not "real". TCE oxidation appeared to follow a 2-step process, with the first step $(\approx 0-5 \mathrm{hrs})$ being rapid. The aqueous TCE data between $\mathrm{T}=0$ and $\mathrm{T}=3 \mathrm{hrs}$ was used to compute the reaction rate for the initial, rapid step of the oxidation reaction. The data were plotted in Figure 51 as $\ln \left(\mathrm{C} / \mathrm{C}_{\mathrm{o}}\right)$ vs. Time in order to approximate a first order reaction rate constant, $k$. The linear regression resulted in a first order rate constant of $k=1.83 \mathrm{hr}^{-1}$. While the fit of the data to a first order rate constant may not be optimal, attempts to evaluate other rate models were not made since the mechanisms occurring in such a complex system are not known.

Complete oxidation was observed for the second $0.01 \% \mathrm{MnO}_{4}{ }^{-}$reactor within $5 \mathrm{hrs}$. If calculated as in previous experiments, an observed oxidation rate of $0.2 \mathrm{mg}$ TCE$/ \mathrm{hr}$ is obtained for the second $0.01 \% \mathrm{MnO}_{4}{ }^{-}$reactor. An attempt was also made to compute the first order reaction rate constant(s) for the TCE data (T=0-3 hrs) from the second $0.01 \% \mathrm{MnO}_{4}{ }^{-}$reactor. The plot of the first order relationship is presented in Figure 52, and a first order rate constant of $2.12 \mathrm{hr}^{-1}$ was obtained. Thus, the rate constants obtained for both of the $0.01 \% \mathrm{MnO}_{4}{ }^{-}$reactors are similar.

Complete TCE oxidation occurred within $2 \mathrm{hrs}$ in the $0.1 \% \mathrm{MnO}_{4}{ }^{-}$reactors. Enough data points are not available to compute a rate constant; however, the observed oxidation rate is greater than $0.14 \mathrm{mg} \mathrm{TCE} / \mathrm{hr}$ for the $0.1 \% \mathrm{MnO}_{4}{ }^{-}$reactors. Note, however, that the initial TCE mass was significantly less than expected to the leak in the Tedlar bag and was assumed to be $\approx 0.28 \mathrm{mg}$ TCE (see above).

Finally, as with all the dissolved plume media experiments conducted, little oxidant consumption was observed. The lower $\mathrm{MnO}_{4}{ }^{-}$consumption for the second $0.01 \% \mathrm{MnO}_{4}{ }^{-}$reactor (Table 23) is likely related to accuracy and precision of the spectrophotometry. The $\mathrm{MnO}_{4}{ }^{-}$values for this reactor (Figure 49) change little during the reaction period until the last sample aliquot is collected.

Only small changes in $\mathrm{pH}$ were observed $(<0.2 \mathrm{pH}$ units). However, in this experiment, the final $\mathrm{pH}$ values of the slurries were less than the values before oxidant addition (Figure 50). This is easily explained by the fact that the initial starting $\mathrm{pH}$ of the TAN-40 GW for this experiment was $\approx 8.4$, which was slightly highly than that observed in most other dissolved plume experiments. (Note: A similar trend was also observed in Exp. 4a-R2.) 


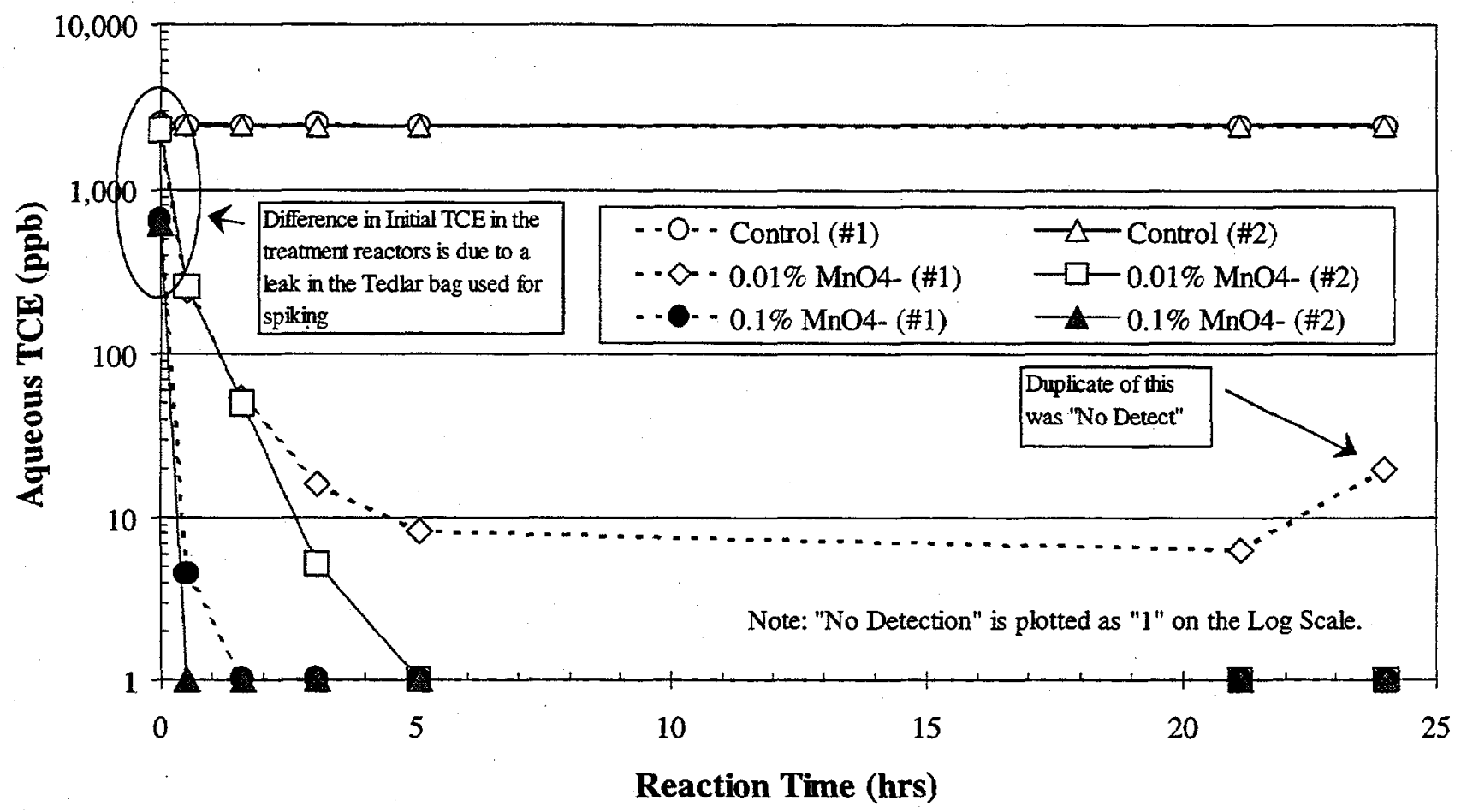

Figure 48. TCE vs. Time, TAN-40 GW \& Aggregate Basalt, (ORNL Exp. 4a-R6, Initial TCE= $1000 \mu \mathrm{g} / \mathrm{L}$, Conducted at $12^{\circ} \mathrm{C}, 4: 1 \mathrm{~L} / \mathrm{S}$ Ratio)

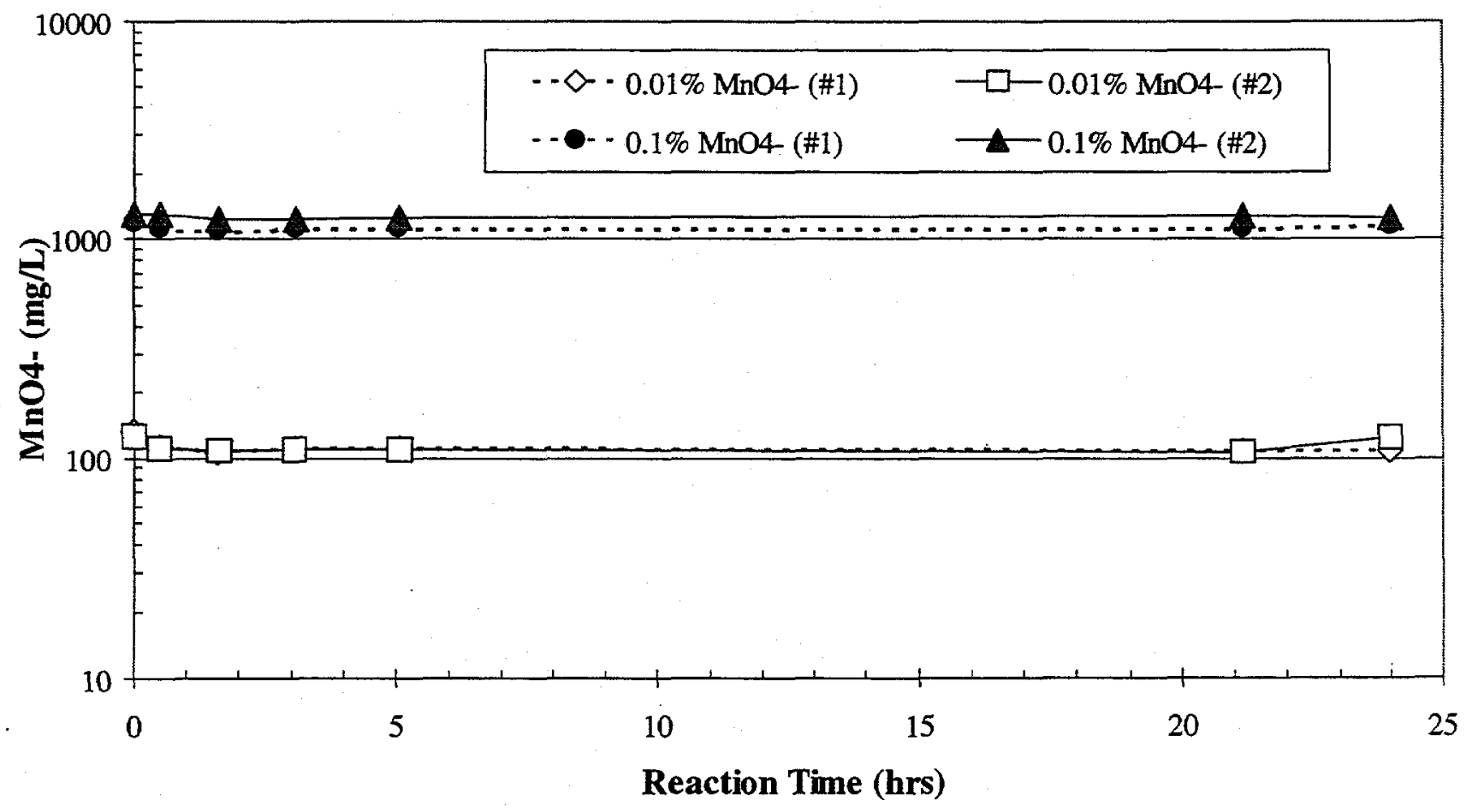

Figure 49. $\mathrm{MnO}_{4}^{-}$vs. Time, TAN-40 GW \& Aggregate Basalt, (ORNL Exp. 4a-R6, Initial $\mathrm{TCE}=1000 \mu \mathrm{g} / \mathrm{L}$, Conducted at $12^{\circ} \mathrm{C}, 4: 1 \mathrm{~L} / \mathrm{S}$ Ratio) 


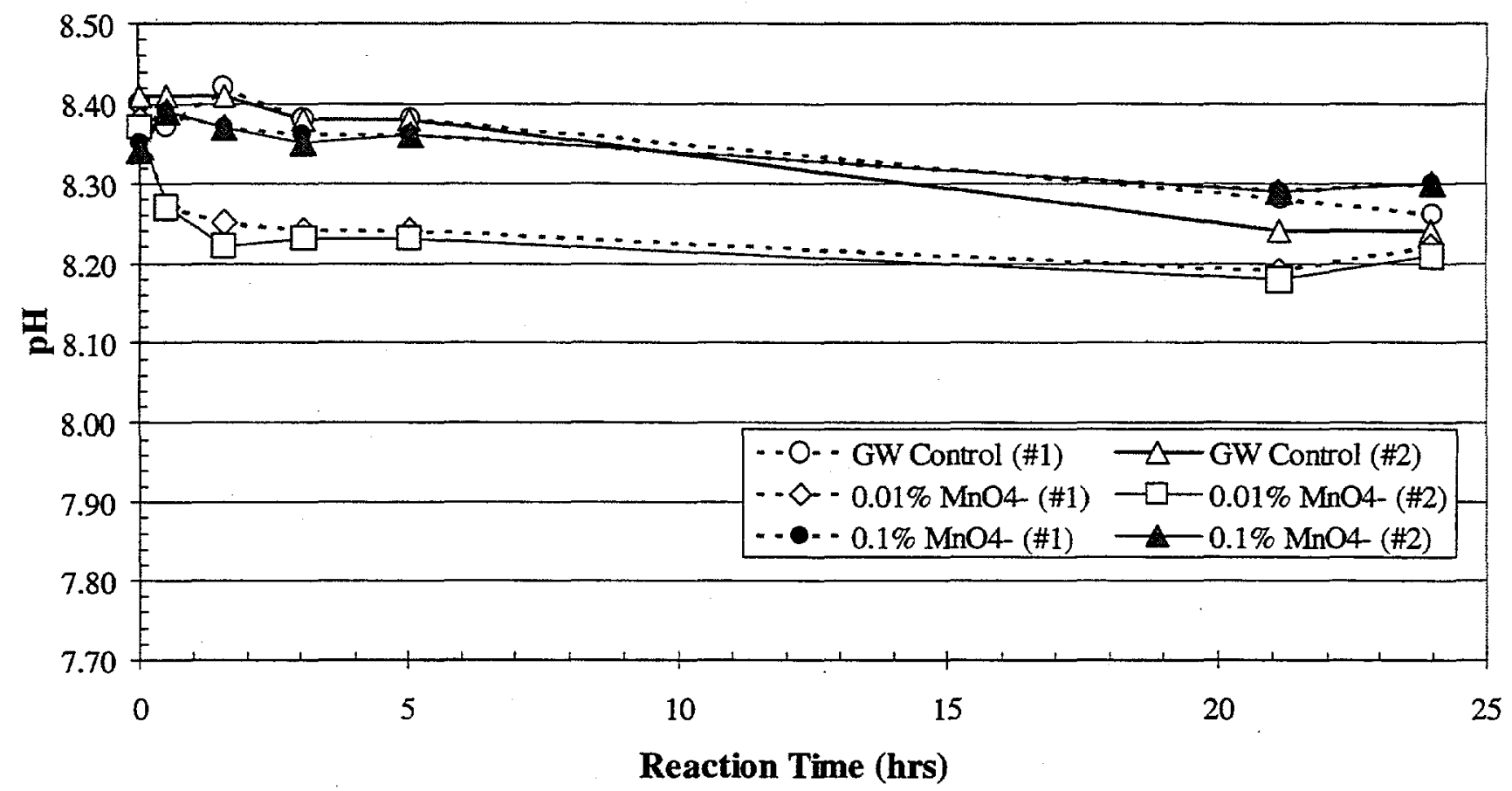

Figure 50. $\mathrm{pH}$ vs. Time, TAN-40 GW \& Aggregate Basalt, (ORNL Exp. 4a-R6, Initial TCE= $1000 \mu \mathrm{g} / \mathrm{L}$, Conducted at $12^{\circ} \mathrm{C}, 4: 1 \mathrm{~L} / \mathrm{S}$ Ratio)

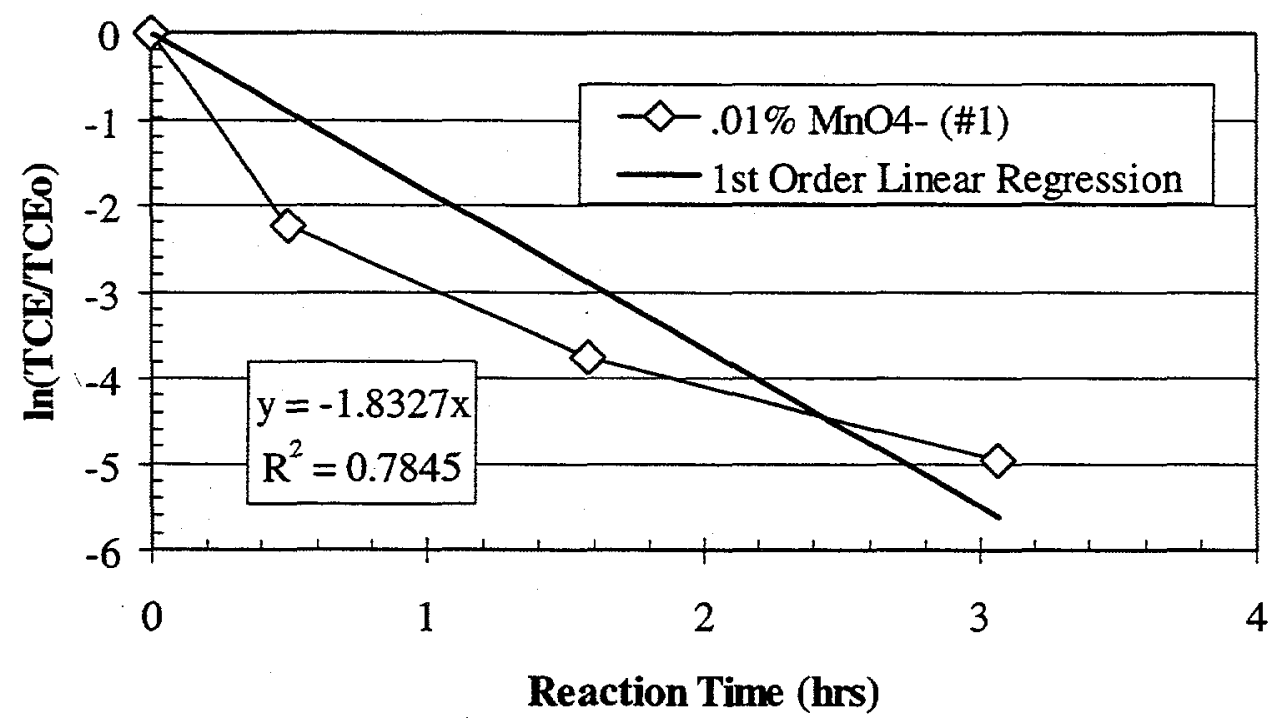

Figure 51. First Order TCE Oxidation Rate Constant for the $0.01 \% \mathrm{MnO}_{4}^{-}(\# 1)$ Reactor, TAN$40 \mathrm{GW} \&$ Aggregate Basalt, (ORNL Exp. 4a-R6, Initial TCE $=1000 \mu \mathrm{g} / \mathrm{L}$, Conducted at $12^{\circ} \mathrm{C}, 4: 1 \mathrm{~L} / \mathrm{S}$ Ratio) 


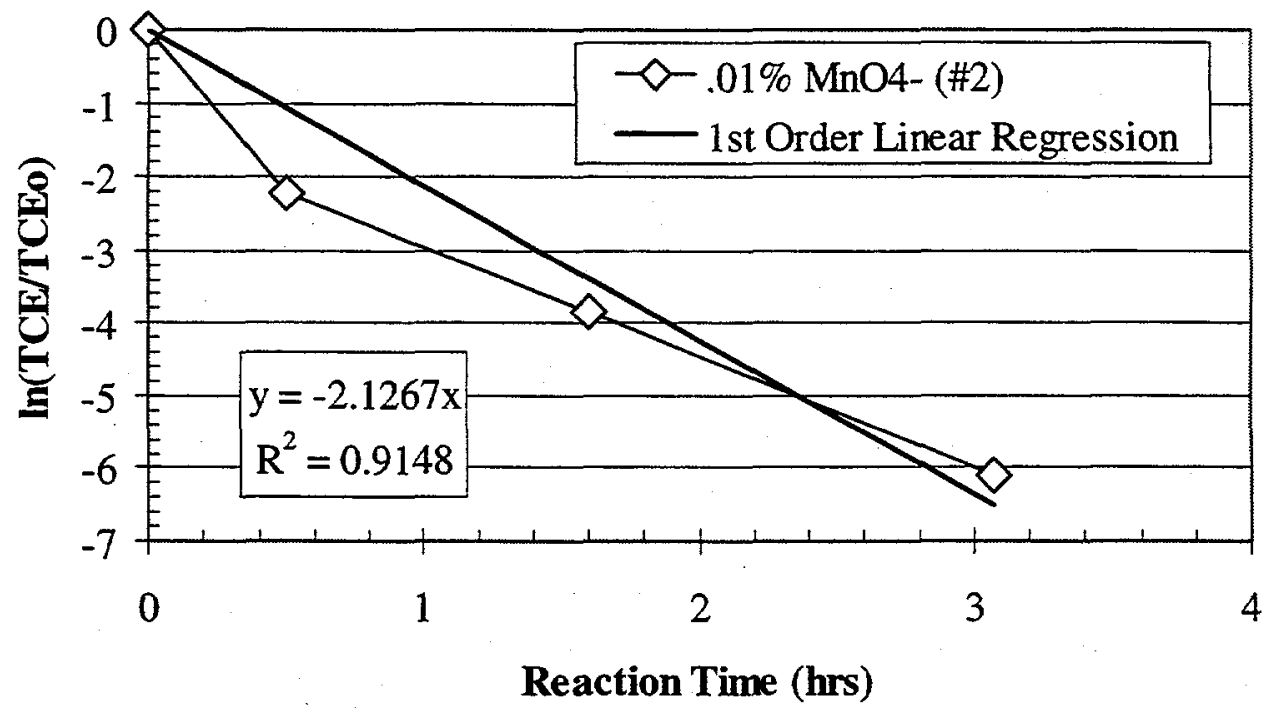

Figure 52. First Order TCE Oxidation Rate Constant for the $0.01 \% \mathrm{MnO}_{4}^{-}(\# 2)$ Reactor, TAN$40 \mathrm{GW} \&$ Aggregate Basalt, (ORNL Exp. 4a-R6, Initial TCE $=1000 \mu \mathrm{g} / \mathrm{L}$, Conducted at $12^{\circ} \mathrm{C}, 4: 1 \mathrm{~L} / \mathrm{S}$ Ratio) 
Table 22. TCE Mass Balance for ORNL Exp. 4a-R6 (TAN-40 GW \& Aggregate Basalt).

\begin{tabular}{|c|c|c|c|c|c|c|c|}
\hline Test Condition & $\begin{array}{l}\text { Total } \\
\text { Initial } \\
\text { Mass } \\
\text { (mg) }^{\text {a. }}\end{array}$ & $\begin{array}{l}\text { Initial } \\
\text { Aqueous } \\
\text { Mass } \\
\text { (mg) }\end{array}$ & \begin{tabular}{|l|} 
Mass \\
Sorbed on \\
Orbo Tubes \\
(mg)
\end{tabular} & \begin{tabular}{|l|} 
Mass \\
Remaining in \\
Reactor (mg)
\end{tabular} & \begin{tabular}{|l|} 
Cum. \\
Mass \\
Removed \\
in Aliquots \\
(mg) \\
\end{tabular} & \begin{tabular}{|l} 
Cum. \\
Aqueous \\
Mass \\
Oxidized \\
(mg) \\
\end{tabular} & \begin{tabular}{|l} 
Total Mass \\
Recovered \\
$(\mathrm{mg})$
\end{tabular} \\
\hline \multirow{2}{*}{ Control (\#1) } & 1.25 & 1.25 & 0.000 & 1.10 & 0.15 & NA & 1.2 \\
\hline & & & $0 \%$ & $87 \%$ & $12 \%$ & $\mathrm{NA}$ & $99 \%$ \\
\hline \multirow{2}{*}{ Control (\#2) } & 1.22 & 1.22 & 0.000 & 1.03 & 0.15 & NA & 1.2 \\
\hline & & & $0 \%$ & $85 \%$ & $12 \%$ & NA & $97 \%$ \\
\hline \multirow{2}{*}{$0.01 \%(\# 1)$} & 0.98 & 0.89 & 0.000 & 0.00 & 0.022 & 0.87 & 0.9 \\
\hline & \%Sorbed: & $8 \%$ & $0 \%$ & $0 \%$ & $2 \%$ & $89 \%$ & $91 \%$ \\
\hline \multirow[t]{2}{*}{$0.01 \%(\# 2)$} & 1.02 & 0.94 & 0.000 & 0.00 & 0.019 & 0.93 & 0.9 \\
\hline & \%Sorbed: & $8 \%$ & $0 \%$ & $0 \%$ & $2 \%$ & $91 \%$ & $93 \%$ \\
\hline \multirow{2}{*}{$0.1 \%(\# 1)$} & $1.05^{\dagger}$ & 0.27 & 0.000 & 0.00 & 0.005 & 0.27 & 0.3 \\
\hline & \%Sorbed: & $74 \%^{\dagger}$ & $0 \%{ }^{\dagger}$ & $0 \%{ }^{\dagger}$ & $0 \%^{\dagger}$ & $26 \%^{\dagger}$ & $26 \%{ }^{*}$ \\
\hline \multirow{2}{*}{$0.1 \%(\# 2)$} & $0.96^{\dagger}$ & 0.24 & 0.000 & 0.00 & 0.004 & 0.24 & 0.2 \\
\hline & \%Sorbed: & $75 \%{ }^{\dagger}$ & $0 \%{ }^{\dagger}$ & $0 \%{ }^{\dagger}$ & $0 \%{ }^{\dagger}$ & $25 \%{ }^{\dagger}$ & $26 \% \%^{\dagger}$ \\
\hline
\end{tabular}

a. Total Initial for slurries computed using the average initial aqueous TCE concentration of the GW control samples $(\operatorname{Avg}=2,516 \mu \mathrm{g} / \mathrm{L}, \sigma=81 \mu \mathrm{g} / \mathrm{L})$. For $\mathrm{GW}$ controls, Total Initial = Initial Aqueous.

Total Initial TCE mass is unknown due to leak in spiking solution container prior to distribution of TAN-40 GW to this reactor.

Table 23. $\mathrm{MnO}_{4}{ }^{-}$Consumption Data for ORNL Exp. 4a-R6 (TAN-40 GW \& Aggregate Basalt).

\begin{tabular}{|c|c|c|c|c|}
\hline Test Condition & $\begin{array}{l}\text { Initial } \\
\text { Oxidant } \\
\left(\mathrm{mg} \mathrm{MnO}_{4}{ }^{-}\right)\end{array}$ & $\begin{array}{l}\text { Initial } \\
\text { Loading } \\
\left(\mathrm{mg} \mathrm{MnO}_{4}^{-} / \mathrm{g}\right)\end{array}$ & $\begin{array}{l}\text { Cum. } \\
\text { Consumed } \\
\left(\mathrm{mg} \mathrm{MnO}_{4}^{-}\right) \\
\end{array}$ & 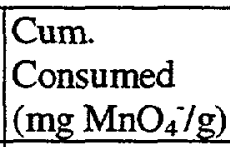 \\
\hline $0.01 \%(\# 1)$ & 50.3 & 0.10 & 9.08 & 0.02 \\
\hline $0.01 \%(\# 2)$ & 50.3 & 0.10 & 0.81 & 0.00 \\
\hline $0.1 \%(\# 1)$ & 503.1 & 0.96 & 22.91 & 0.04 \\
\hline $0.1 \%(\# 2)$ & 503.1 & 1.03 & 13.46 & 0.03 \\
\hline
\end{tabular}

a. Consumption is computed after $24 \mathrm{hr}$ reaction time. 
ORNL Exp. 4a-R7

(TAN-40, SED1, $100 \mathrm{TCE}, 0$ Other, $0.01 \%$ and $0.1 \% \mathrm{MnO}_{4}{ }^{-}$)

Slurries of TAN- $40 \mathrm{GW}$ and sediment were evaluated in this experiment. The TCE, $\mathrm{MnO}_{4}{ }^{-}$and $\mathrm{pH}$ values with time are presented in Figures 53, 54, and 55, respectively. Tables 24 and 25 provide additional TCE mass balance and oxidant consumption information. The (\#1) and (\#2) notations included in both the figure legends and the first column of these tables refer to the duplicate reactors evaluated for that test condition.

No deviations were made to the testplan during the conduct of this experiment. However, this experiment was performed using the first sediment sample received by ORNL (SED1 in Table 1)

After equilibration, the average initial aqueous TCE concentration of the spike solution was 274 $\mu \mathrm{g} / \mathrm{L}(\sigma=6 \mu \mathrm{g} / \mathrm{L})$. After transfer to the test reactors and equilibration with the sediment, the groundwater TCE concentrations ranged between 206 and $255 \mu \mathrm{g} / \mathrm{L}$ TCE ( $\mathrm{T}=0$ aliquots). This apparent reduction may be a result of either (1) loss via volatilization during the transfer or (2) adsorption onto the TAN sediment. The control reactors yielded total TCE recoveries of $92 \%$ and $96 \%$ after the $24 \mathrm{hr}$ reaction period, indicating that some loss or volatilization may have occurred. However, no TCE was not found on the charcoal desorption tubes from any of the control or treatment reactors. Recall, however, that not all of the headspace volume of each reactor is passed through the desorption tubes.

Initial TCE adsorption by the sediment of $7-19 \%$ is indicated by the data in Table 24 . Since TCE was not found in the last few aqueous aliquots (see Figure 53) or in the final reactor extractions after $24 \mathrm{hrs}$, it is again suspected that any TCE sorbed by the sediment was oxidized during the reaction period. Assuming that the sorbed TCE mass oxidized yields effective total TCE recoveries of $100 \%$ for both $0.01 \% \mathrm{MnO}_{4}{ }^{-}$reactors and $103 \%$ for both $0.1 \% \mathrm{MnO}_{4}{ }^{-}$reactors.

Complete TCE oxidation occurred within $3 \mathrm{hrs}$ for the $0.01 \% \mathrm{MnO}_{4}{ }^{-}$reactors and within $0.5 \mathrm{hrs}$ for the $0.1 \% \mathrm{MnO}_{4}{ }^{-}$reactors. For the $0.01 \% \mathrm{MnO}_{4}{ }^{-}$reactors, the aqueous TCE data between $\mathrm{T}=0$ and $\mathrm{T}=2 \mathrm{hrs}$ was used to compute the reaction rate for the initial, rapid step of the oxidation reaction. The data were plotted in Figures 56 and 57 as $\ln \left(C / C_{0}\right)$ vs. Time in order to approximate a first order reaction rate constant, $k$. The linear regressions resulted in an average first order rate constant of $k=2.16 \mathrm{hr}^{-1}$. While the fit of the data to a first order rate constant may not be optimal, attempts to evaluate other rate models were not made since the mechanisms occurring in such a complex system are not known. There were not enough available data points to accurately compute a rate constant for the $0.1 \% \mathrm{MnO}_{4}{ }^{-}$reactors, the observed oxidation rates was greater than $0.19 \mathrm{mg} \mathrm{TCE} / \mathrm{hr}$ for those reactors.

As with all dissolved plume media evaluated, significant oxidant consumption was not observed in this experiment. The oxidation consumption masses observed were on the order of those observed for slurries of crushed and aggregate basalt that were nominally spiked with $100 \mu \mathrm{g} / \mathrm{L}$ TCE (Experiments. 4a-R3 and 4a-R4).

The $\mathrm{pH}$ values obtained here for the sediment and TAN- $40 \mathrm{GW}$ slurries were distinctly different than those obtained for the TAN site basalt (crushed or aggregate). First, the initial $\mathrm{pH}$ values of 
the treatment reactors (before oxidant was added) were about $0.2 \mathrm{pH}$ units less than those observed for the two TAN-40 GW control reactors. The $\mathrm{pH}$ values in the treatment reactors clearly decrease as the oxidation reactions go to completion. Unlike the TAN basalt material, an overall net increase in $\mathrm{pH}$ at the end of the reaction period was not observed in any of the treatment reactors. In fact, a net decrease was observed for the $0.1 \% \mathrm{MnO}_{4}{ }^{-}$reactors. The same trend was also observed in the oxidant consumption work (See Figures 14 and 15). This phenomenon may be due to the buffer capacity of the sediment being lower than that of basalt. Thus, the sediment may not be able to buffer the $\mathrm{H}^{+}$ions created as a result of the oxidation reactions. The $\mathrm{pH}$ decrease may also be due to chemistry effects caused by the destruction (via oxidation) of some of the organic matter present in the TAN sediment. Regardless of the mechanisms at work, the $\mathrm{pH}$ changes that were observed after oxidant addition were small $(<0.2$ pH units). 


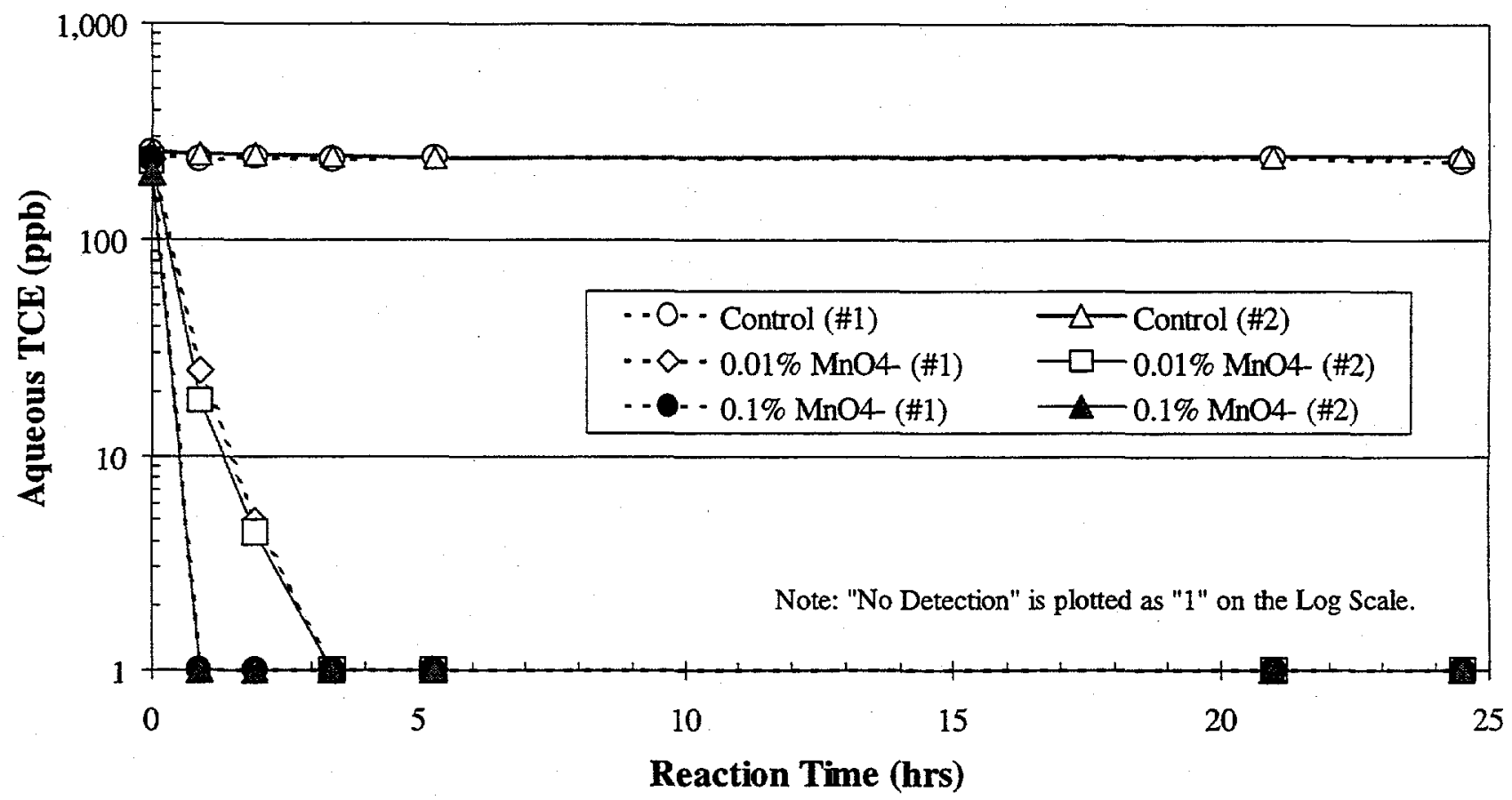

Figure 53. TCE vs. Time, TAN-40 GW \& Sediment, (ORNL Exp. 4a-R7, Initial TCE $=100$ $\mu \mathrm{g} / \mathrm{L}$, Conducted at $12^{\circ} \mathrm{C}, 4: 1 \mathrm{~L} / \mathrm{S}$ Ratio)

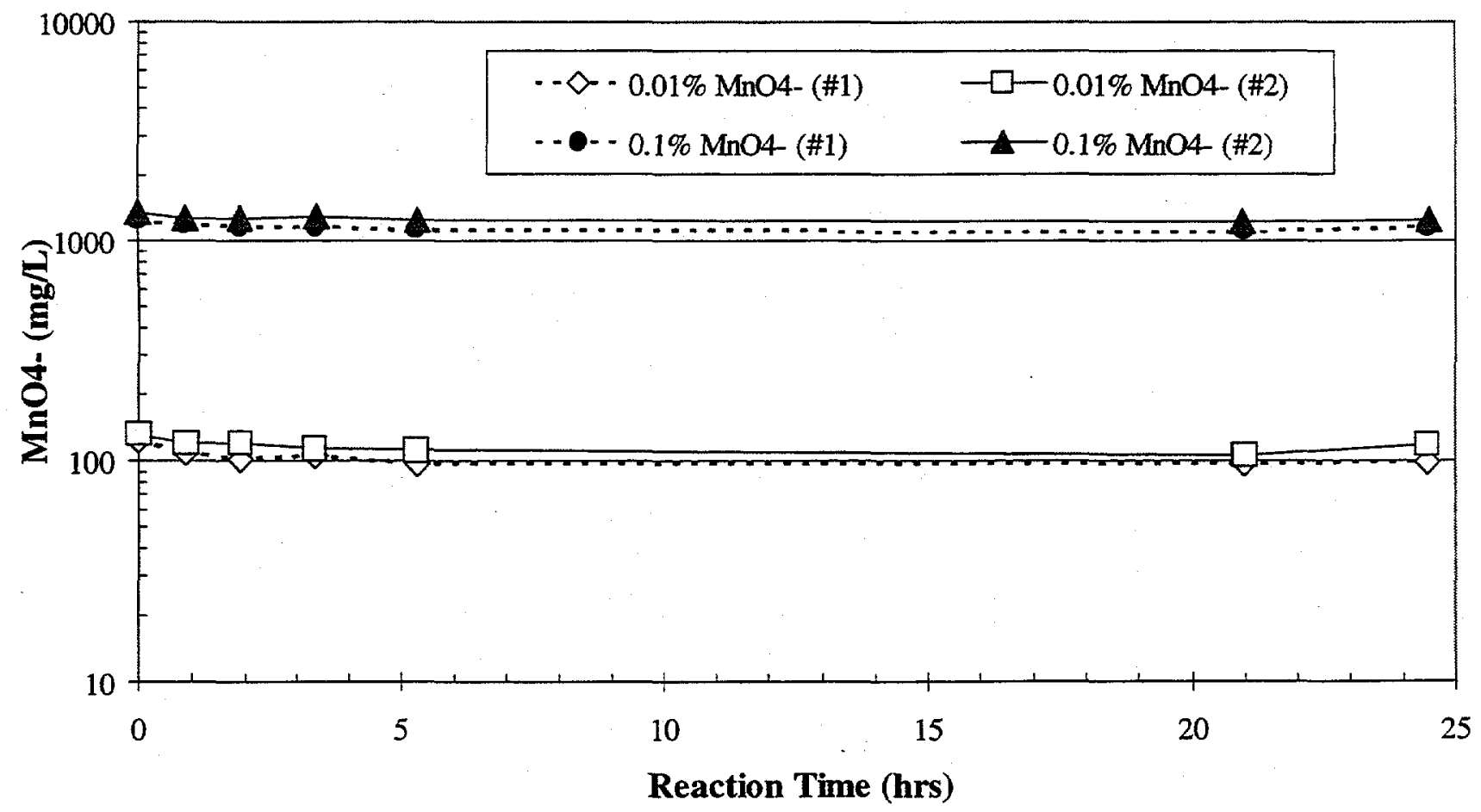

Figure 54. $\mathrm{MnO}_{4}{ }^{-}$vs. Time, TAN-40 GW \& Sediment, (ORNL Exp. 4a-R7, Initial TCE $=100$ $\mu \mathrm{g} / \mathrm{L}$, Conducted at $12^{\circ} \mathrm{C}, 4: 1 \mathrm{~L} / \mathrm{S}$ Ratio) 


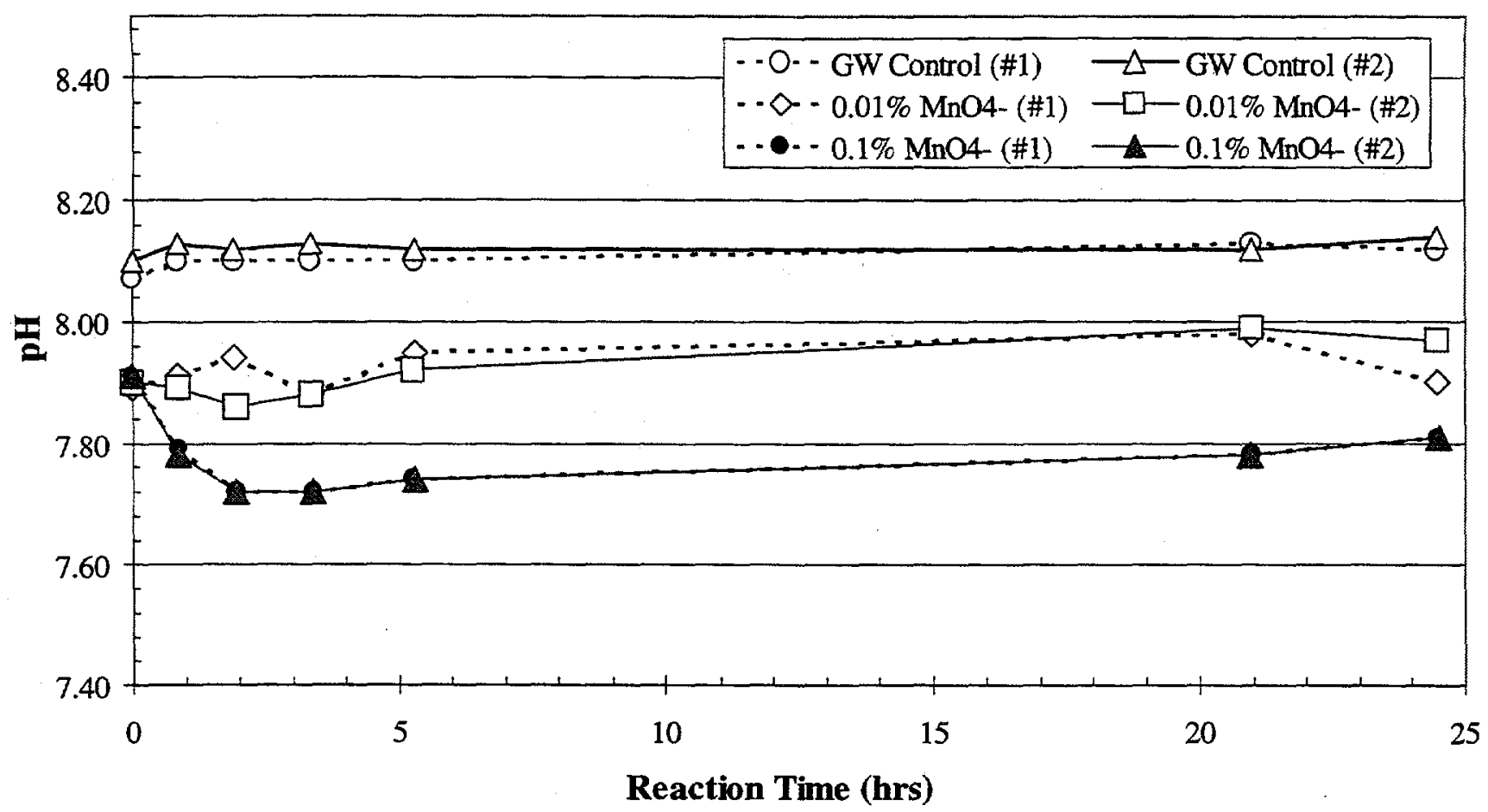

Figure 55. pH vs. Time, TAN-40 GW \& Sediment, (ORNL Exp. 4a-R7, Initial TCE $=100 \mu \mathrm{g} / \mathrm{L}$, Conducted at $12^{\circ} \mathrm{C}, 4: 1 \mathrm{~L} / \mathrm{S}$ Ratio)

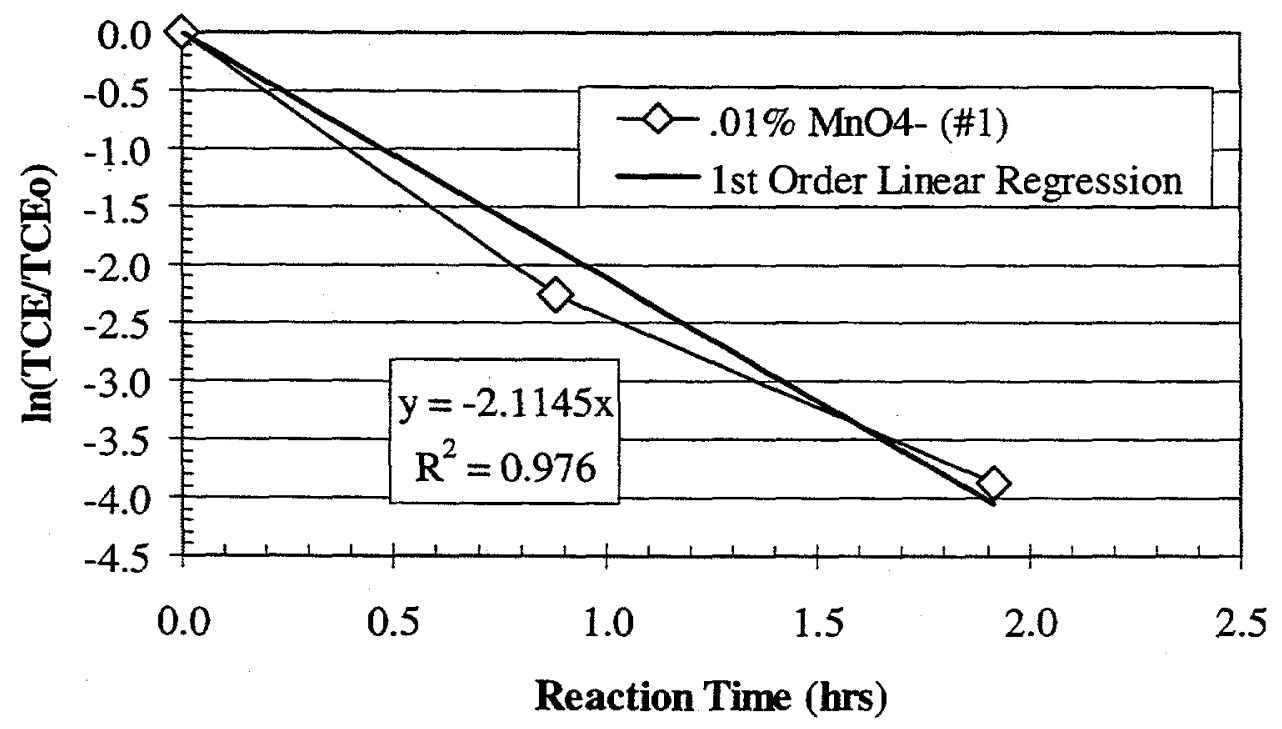

Figure 56 First Order TCE Oxidation Rate Constant for the $0.01 \% \mathrm{MnO}_{4}^{-}$(\#1) Reactor, TAN$40 \mathrm{GW} \&$ Sediment, (ORNL Exp. 4a-R7, Initial TCE $=100 \mu \mathrm{g} / \mathrm{L}$, Conducted at $12^{\circ} \mathrm{C}, 4: 1 \mathrm{~L} / \mathrm{S}$ Ratio) 


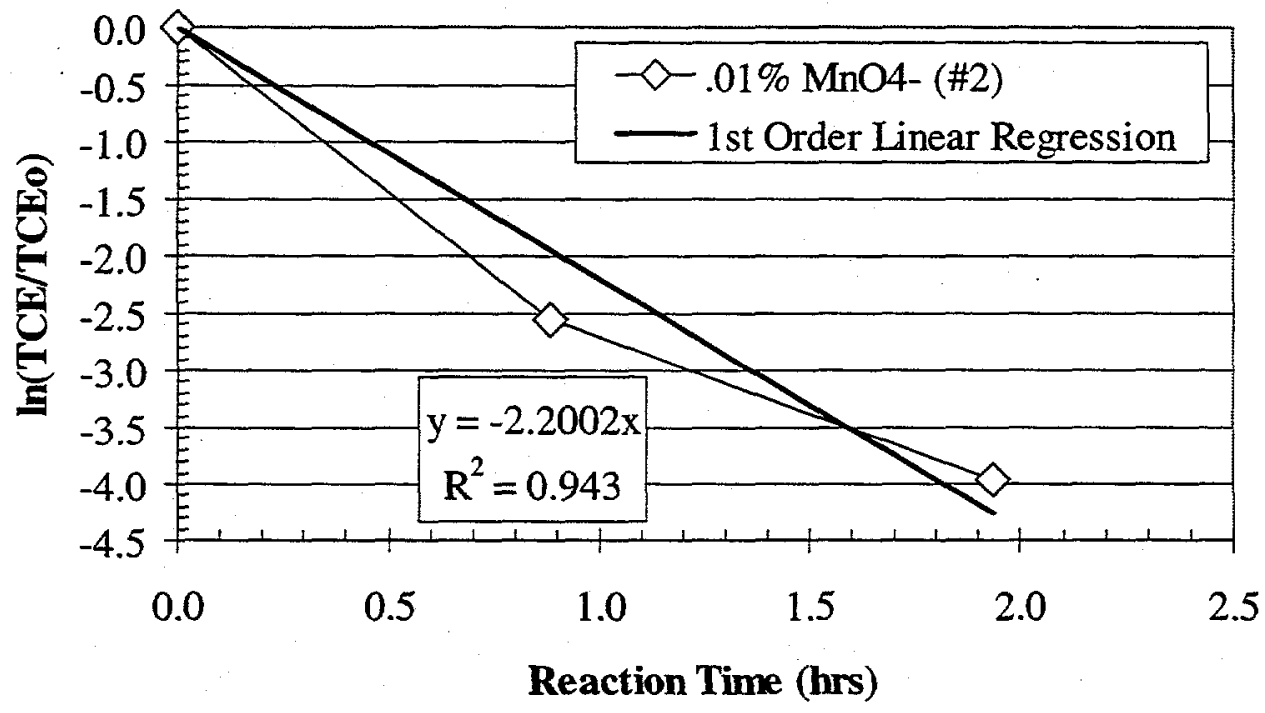

Figure 57 First Order TCE Oxidation Rate Constant for the $0.01 \% \mathrm{MnO}_{4}^{-}(\# 2)$ Reactor, TAN$40 \mathrm{GW} \&$ Sediment, (ORNL Exp. 4a-R7, Initial TCE $=100 \mu \mathrm{g} / \mathrm{L}$, Conducted at $12^{\circ} \mathrm{C}, 4: 1 \mathrm{~L} / \mathrm{S}$ Ratio) 
Table 24. TCE Mass Balance for ORNL Exp. 4a-R7 (TAN-40 GW \& Sediment).

\begin{tabular}{|c|c|c|c|c|c|c|c|}
\hline Test Condition & $\begin{array}{l}\text { Total } \\
\text { Initial } \\
\text { Mass } \\
\text { (mg) }\end{array}$ & \begin{tabular}{|l} 
Initial \\
Aqueous \\
Mass \\
$(\mathrm{mg})$
\end{tabular} & $\begin{array}{l}\text { Mass } \\
\text { Sorbed on } \\
\text { Orbo Tubes } \\
(\mathrm{mg})\end{array}$ & $\begin{array}{l}\text { Mass } \\
\text { Remaining in } \\
\text { Reactor (mg) }\end{array}$ & \begin{tabular}{|l|} 
Cum. \\
Mass \\
Removed \\
in Aliquots \\
(mg) \\
\end{tabular} & \begin{tabular}{|l|} 
Cum. \\
Aqueous \\
Mass \\
Oxidized \\
(mg) \\
\end{tabular} & \begin{tabular}{|l} 
Total Mass \\
Recovered \\
(mg)
\end{tabular} \\
\hline \multirow[t]{2}{*}{ Control (\#1) } & 0.12 & 0.12 & 0.000 & 0.10 & 0.01 & NA & 0.1 \\
\hline & & & $0 \%$ & $82 \%$ & $11 \%$ & NA & $92 \%$ \\
\hline \multirow[t]{2}{*}{ Control (\#2) } & 0.12 & 0.12 & 0.000 & 0.10 & 0.01 & $\mathrm{NA}$ & 0.1 \\
\hline & & & $0 \%$ & $84 \%$ & $12 \%$ & $\mathrm{NA}$ & $96 \%$ \\
\hline \multirow{2}{*}{$0.01 \%(\# 1)$} & 0.11 & 0.10 & 0.000 & 0.00 & 0.002 & 0.10 & 0.1 \\
\hline & \%Sorbed: & $7 \%$ & $0 \%$ & $0 \%$. & $2 \%$ & $92 \%$ & $93 \%$ \\
\hline \multirow[t]{2}{*}{$0.01 \%(\# 2)$} & 0.10 & 0.09 & 0.000 & 0.00 & 0.002 & 0.09 & 0.1 \\
\hline & \%Sorbed: & $8 \%$ & $0 \%$ & $0 \%$ & $2 \%$ & $90 \%$ & $92 \%$ \\
\hline \multirow[t]{2}{*}{$0.1 \%(\# 1)$} & 0.10 & 0.10 & 0.000 & 0.00 & 0.002 & 0.10 & 0.1 \\
\hline & \%Sorbed: & $7 \%$ & $0 \%$ & $0 \%$ & $2 \%$ & $94 \%$ & $96 \%$ \\
\hline \multirow[t]{2}{*}{$0.1 \%(\# 2)$} & 0.09 & 0.08 & 0.000 & 0.00 & 0.001 & 0.08 & 0.1 \\
\hline & \%ororbed: & $19 \%$ & $0 \%$ & $0 \%$ & $1 \%$ & $82 \%$ & $84 \%$ \\
\hline
\end{tabular}

a. Total Initial for slurries computed using the average initial aqueous TCE concentration of the $\mathrm{GW}$ control samples $(\operatorname{Avg}=253 \mu \mathrm{g} / \mathrm{L}, \sigma=2 \mu \mathrm{g} / \mathrm{L})$. For $\mathrm{GW}$ controls, Total Initial = Initial Aqueous.

Table 25. $\mathrm{MnO}_{4}{ }^{-}$Consumption Data for ORNL Exp. 4a-R7 (TAN-40 GW \& Sediment).

\begin{tabular}{|l|l|l|l|l|}
\hline Test Condition & $\begin{array}{l}\text { Initial } \\
\text { Oxidant } \\
\left(\mathrm{mg} \mathrm{MnO}_{4}{ }^{-}\right)\end{array}$ & $\begin{array}{l}\text { Initial } \\
\text { Loading } \\
\left(\mathrm{mg} \mathrm{MnO}_{4}^{-} / \mathrm{g}\right)\end{array}$ & $\begin{array}{l}\text { Cum. } \\
\text { Consumed } \\
\left(\mathrm{mg} \mathrm{MnO}_{4}\right)\end{array}$ & $\begin{array}{l}\text { Cum. } \\
\text { Consumed } \\
\left(\mathrm{mg} \mathrm{MnO}_{4} / \mathrm{g}\right)\end{array}$ \\
\hline $0.01 \%(\# 1)$ & 50.4 & 0.10 & 9.98 & 0.02 \\
\hline $0.01 \%(\# 2)$ & 50.4 & 0.10 & 5.28 & 0.01 \\
\hline $0.1 \%(\# 1)$ & 504.1 & 0.99 & 28.28 & 0.06 \\
\hline $0.1 \%(\# 2)$ & 504.1 & 1.08 & 37.44 & 0.08 \\
\hline
\end{tabular}

a. Consumption is computed after $24 \mathrm{hr}$ reaction time. 
ORNL Exp. 4a-R8

(TAN-40, SED2, 1000 TCE, 0 Other, $0.01 \%$ and $0.1 \% \mathrm{MnO}_{4}$ )

Slurries of TAN-40 GW and sediment were evaluated in this experiment. The TCE, $\mathrm{MnO}_{4}{ }^{-}$and $\mathrm{pH}$ values with time are presented in Figures 58, 59, and 60, respectively. Tables 26 and 27 provide additional TCE mass balance and oxidant consumption information. The (\#1) and (\#2) notations included in both the figure legends and the first column of these tables refer to the duplicate reactors evaluated for that test condition.

No deviations were made to the testplan during the conduct of this experiment. However, this experiment was performed using the second batch of sediment material received by ORNL (SED2 in Table 1).

After equilibration, the average initial aqueous TCE concentration of the spike solution was $1,892 \mu \mathrm{g} / \mathrm{L}(\sigma=69 \mu \mathrm{g} / \mathrm{L})$. After transfer to the test reactors and equilibration with the sediment, the aqueous TCE concentrations in the slurries were lower than those observed in the groundwater controls. In fact, the TAN sediment (SED2) adsorbed an average of $11 \%$ of the total initial TCE added (Table 26). A decrease in the aqueous TCE concentrations of the control reactors with time was observed and culminated in final TCE recovery values of only $88 \%$ and $90 \%$ for the first and second control reactors, respectively. Closer examination of the aliquot TCE data for the control reactors revealed that most of the loss occurred immediately following the $\mathrm{T}=0 \mathrm{hrs}$ sampling period. The TCE concentrations then held relatively constant throughout the remainder of the reaction period. The loss of TCE from the control reactors was likely via volatilization. However, no TCE was found on the charcoal desorption tubes from any of the control or treatment reactors. (Recall that not all of the headspace volume of each reactor is passed through the desorption tubes.)

For the treatment reactors, TCE was not detected at $24 \mathrm{hrs}$ either in the aqueous aliquot sample or in the extraction of the reactor contents following collection of the last aliquot sample. If the initial adsorbed fraction is assumed to be oxidized along with the aqueous TCE, which is supported by the lack of TCE detection in the final reactor extractions, effective total TCE recoveries for the treatment reactors would range between $100-103 \%$. While complete oxidation TCE present is likely, it should be understood that some of the initial TCE may have been lost to volatilization in this experiment since both control reactors experienced a significant loss of TCE between the $\mathrm{T}=0 \mathrm{hrs}$ and $\mathrm{T}=0.5 \mathrm{hrs}$ sampling periods.

From Figure 58, the aqueous TCE concentrations were readily reduced to no detection within hours for each treatment reactors (with the exception of the first $0.01 \% \mathrm{MnO}_{4}{ }^{-}$reactor). While the oxidation rate within the first $0.01 \% \mathrm{MnO}_{4}^{-}$reactors appeared to slow after $\mathrm{T}=5 \mathrm{hrs}$, TCE was ultimately not detected at $24 \mathrm{hrs}$. An attempt to calculate a rate constant for both $0.01 \% \mathrm{MnO}_{4}{ }^{-}$ reactors was performed using the TCE data between $\mathrm{T}=0$ and $\mathrm{T}=3 \mathrm{hrs}$. The aqueous TCE data were plotted in Figure 61 and Figure 62 as $\ln \left(\mathrm{C} / \mathrm{C}_{0}\right)$ vs. Time for the first and second $0.01 \%$ reactor, respectively. These linear regression resulted in first order rate constants of $k=1.57 \mathrm{hr}^{-1}$ and $1.70 \mathrm{hr}^{-1}$. While the fit of the data to a first order rate constant may not be optimal, attempts to evaluate other rate models were not made since the mechanisms occurring in such a complex system are not known. These first order rate constants are lower than those obtained in Exp. 4a- 
R6 for the aggregate basalt. As will be presented in a summary table for the dissolved plume experiments, the initial TCE mass was $\approx 25 \%$ greater for the aggregate basalt experiment. Thus, the TCE oxidation rate may be dependent upon the initial TCE concentration.

As observed previously for the dissolved plume media, complete TCE oxidation occurred within $0.5 \mathrm{hrs}$ for the $0.1 \% \mathrm{MnO}_{4}{ }^{-}$reactors. Enough data points are not available to compute a rate constant; however, the observed oxidation rate is greater than $1.6 \mathrm{mg} \mathrm{TCE} / \mathrm{hr}$ for the $0.1 \% \mathrm{MnO}_{4}{ }^{-}$ reactors.

As with all dissolved plume media evaluated, little oxidant consumption was observed. In fact, negative oxidant consumption values were obtained for the $0.1 \% \mathrm{MnO}_{4}{ }^{-}$reactors. As discussed previously, this result likely stems from the inability to accurately quantify very small changes in $\mathrm{MnO}_{4}{ }^{-}$concentrations with the spectrophotometer used.

The $\mathrm{pH}$ values initially decreased as the oxidation reactions went to completion. The final $\mathrm{pH}$ values for this sediment experiment, however, were distinctly different than those obtained for the TAN site basalt. The results are similar to those obtained from the other sediment experiment (Exp. 4a-R7). After the initial $\mathrm{pH}$ decrease associated with active oxidation, the $\mathrm{pH}$ values for the $0.01 \% \mathrm{MnO}_{4}{ }^{-}$reactors nearly increased back to their initial values. The $\mathrm{pH}$ values of the $0.1 \% \mathrm{MnO}_{4}{ }^{-}$reactors, on the other hand, did not rebound after the initial oxidation reactions. Instead, the slurry $\mathrm{pH}$ values remained $\approx 0.2-0.3 \mathrm{pH}$ units below their initial values (before oxidant addition). This phenomenon again may have resulted from the lack of sediment buffering capacity to counteract the formation of the $\mathrm{H}^{+}$ions released during either TCE or sediment oxidation. 


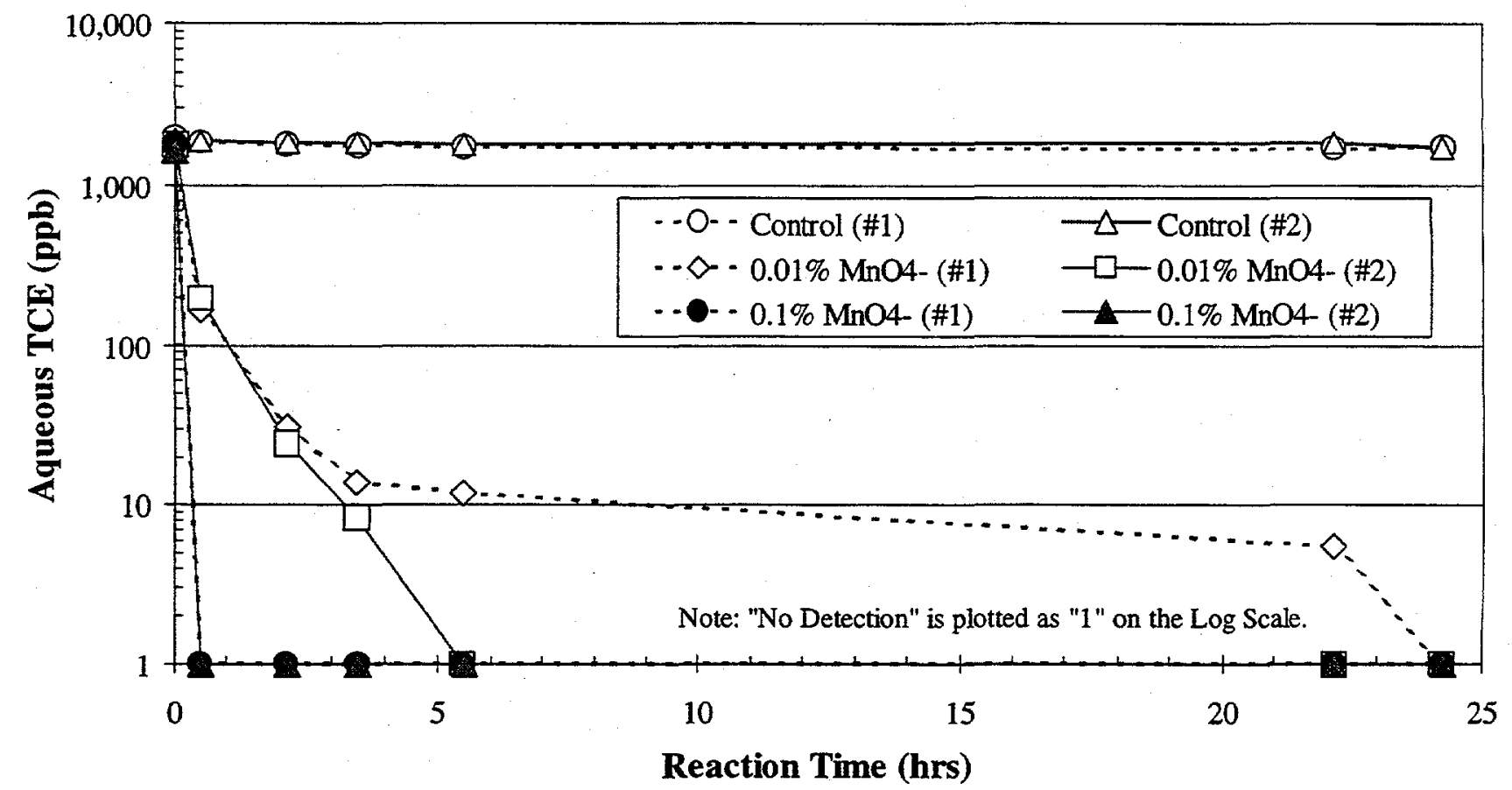

Figure 58. TCE vs. Time, TAN-40 GW \& Sediment, (ORNL Exp. 4a-R8, Initial TCE $=1000$ $\mu \mathrm{g} / \mathrm{L}$, Conducted at $12^{\circ} \mathrm{C}, 4: 1 \mathrm{~L} / \mathrm{S}$ Ratio)

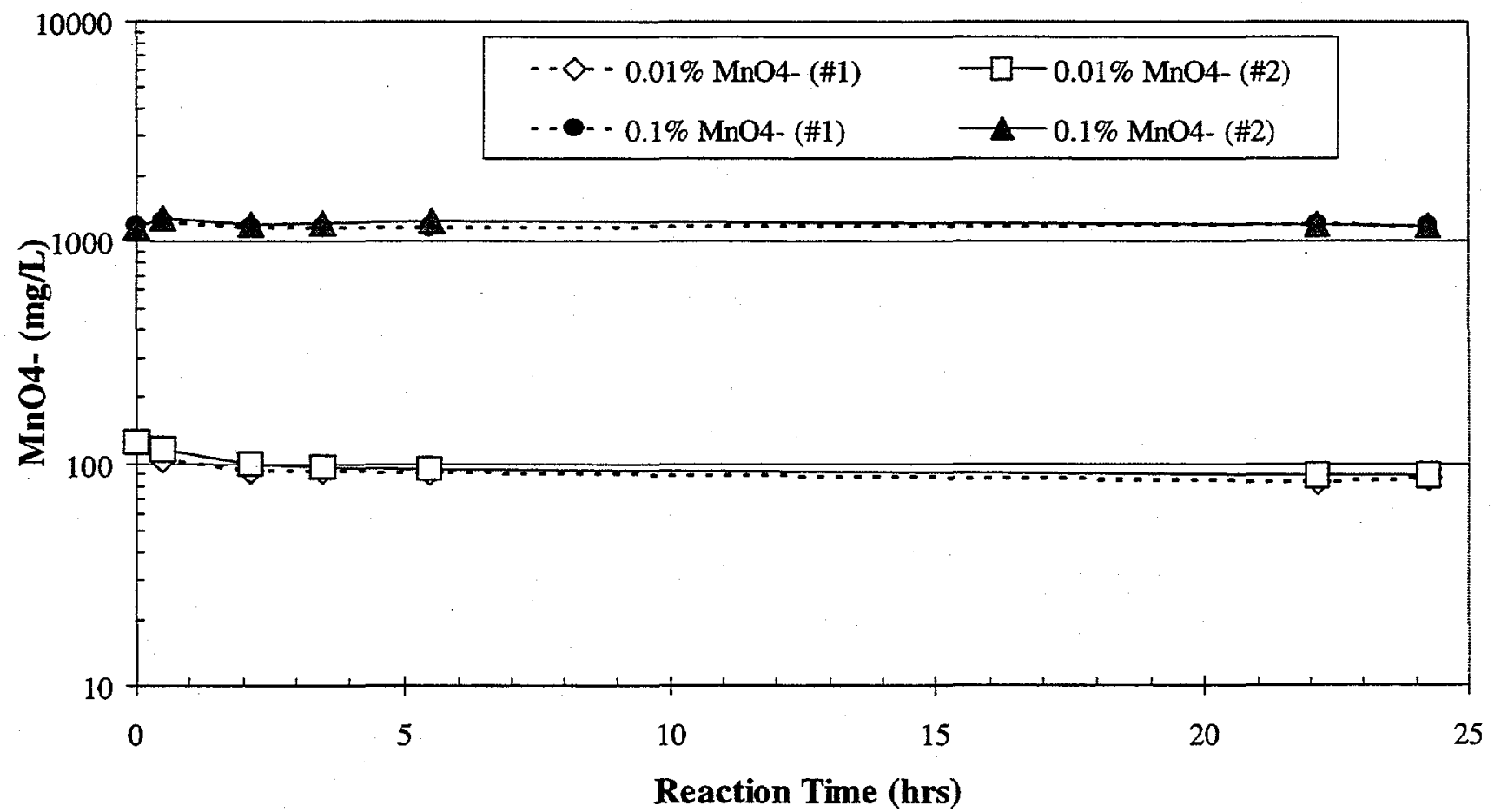

Figure 59. $\mathrm{MnO}_{4}{ }^{-}$vs. Time, TAN-40 GW \& Sediment, (ORNL Exp. 4a-R8, Initial TCE $=1000$ $\mu \mathrm{g} / \mathrm{L}$, Conducted at $12^{\circ} \mathrm{C}, 4: 1 \mathrm{~L} / \mathrm{S}$ Ratio) 


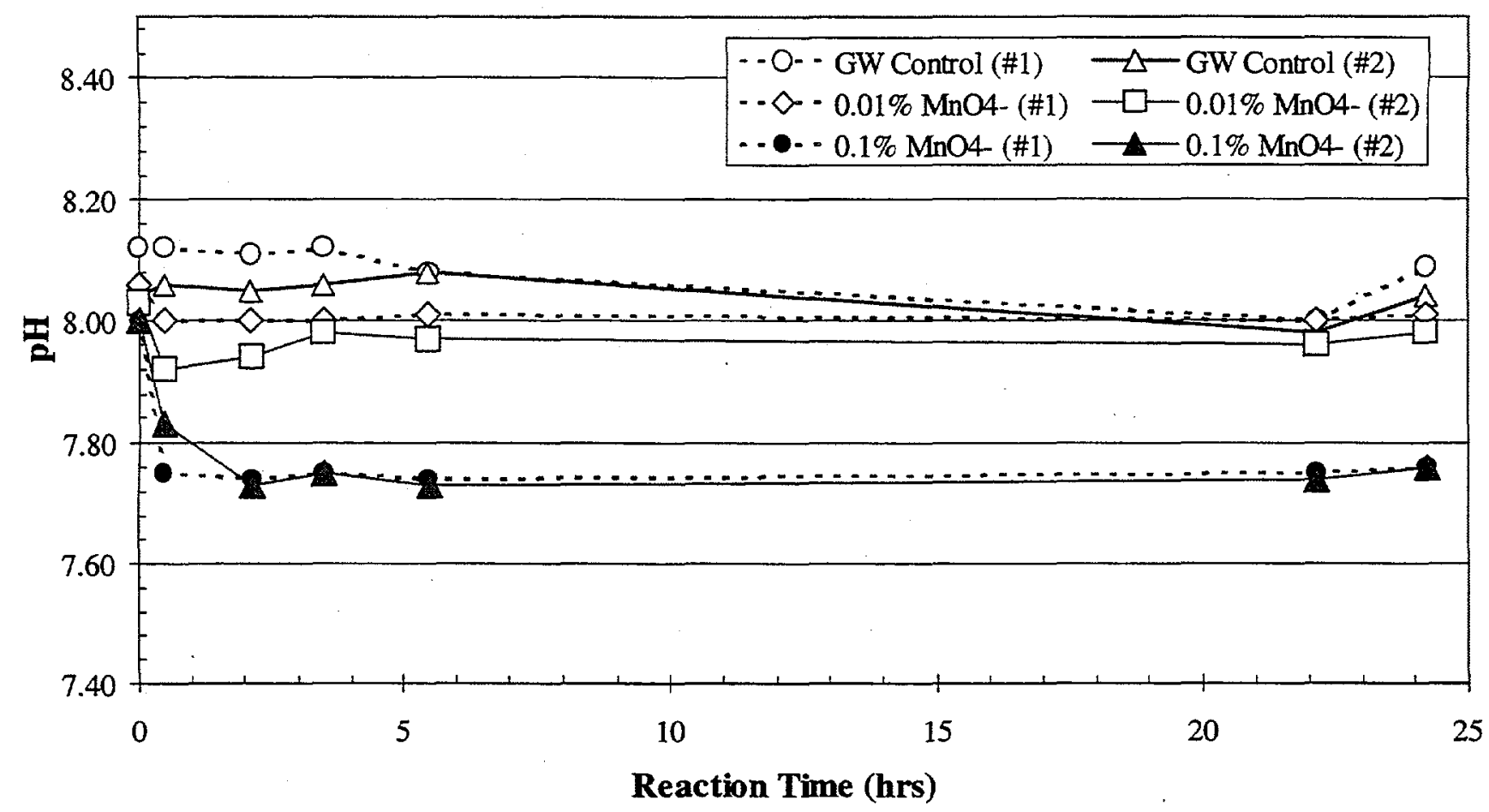

Figure 60. $\mathrm{pH}$ vs. Time, TAN-40 GW \& Sediment, (ORNL Exp. 4a-R8, Initial TCE $=1000$ $\mu \mathrm{g} / \mathrm{L}$, Conducted at $12^{\circ} \mathrm{C}, 4: 1 \mathrm{~L} / \mathrm{S}$ Ratio)

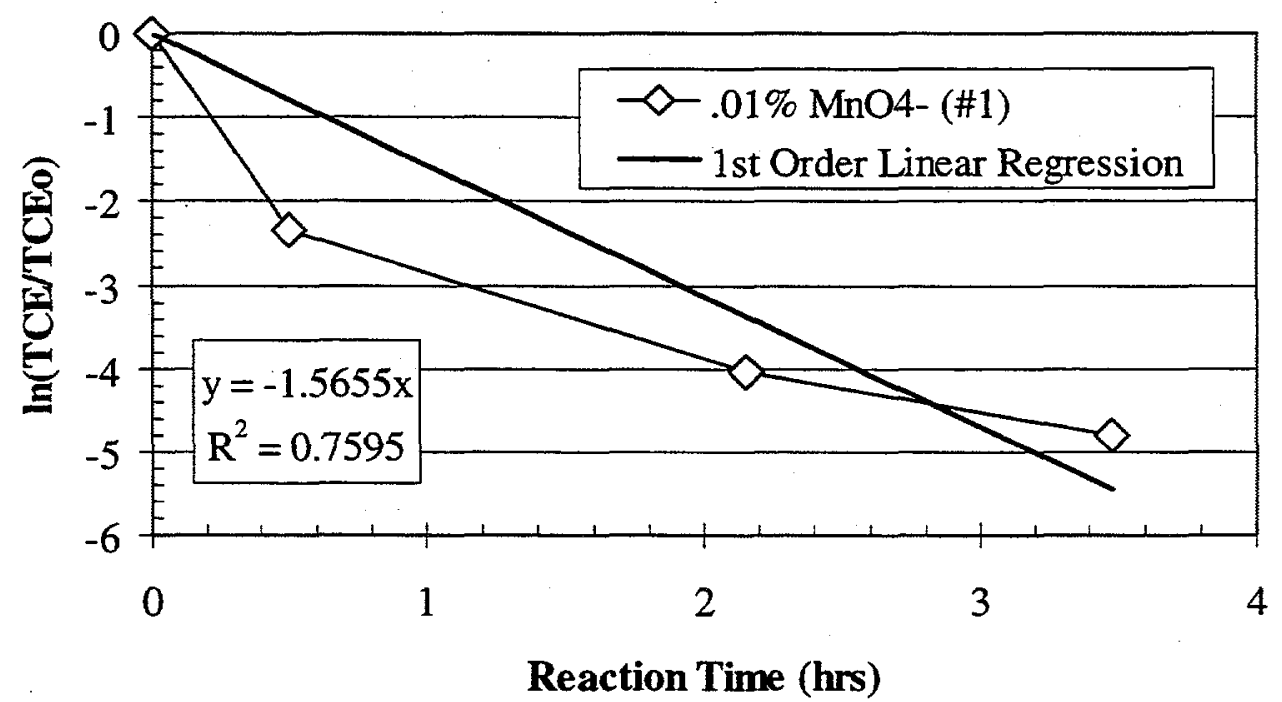

Figure 61. First Order TCE Oxidation Rate Constant for the $0.01 \% \mathrm{MnO}_{4}^{-}(\# 1)$ Reactor, TAN$40 \mathrm{GW} \&$ Sediment, (ORNL Exp. 4a-R8, Initial TCE $=1000 \mu \mathrm{g} / \mathrm{L}$, Conducted at $12^{\circ} \mathrm{C}, 4: 1 \mathrm{~L} / \mathrm{S}$ Ratio) 


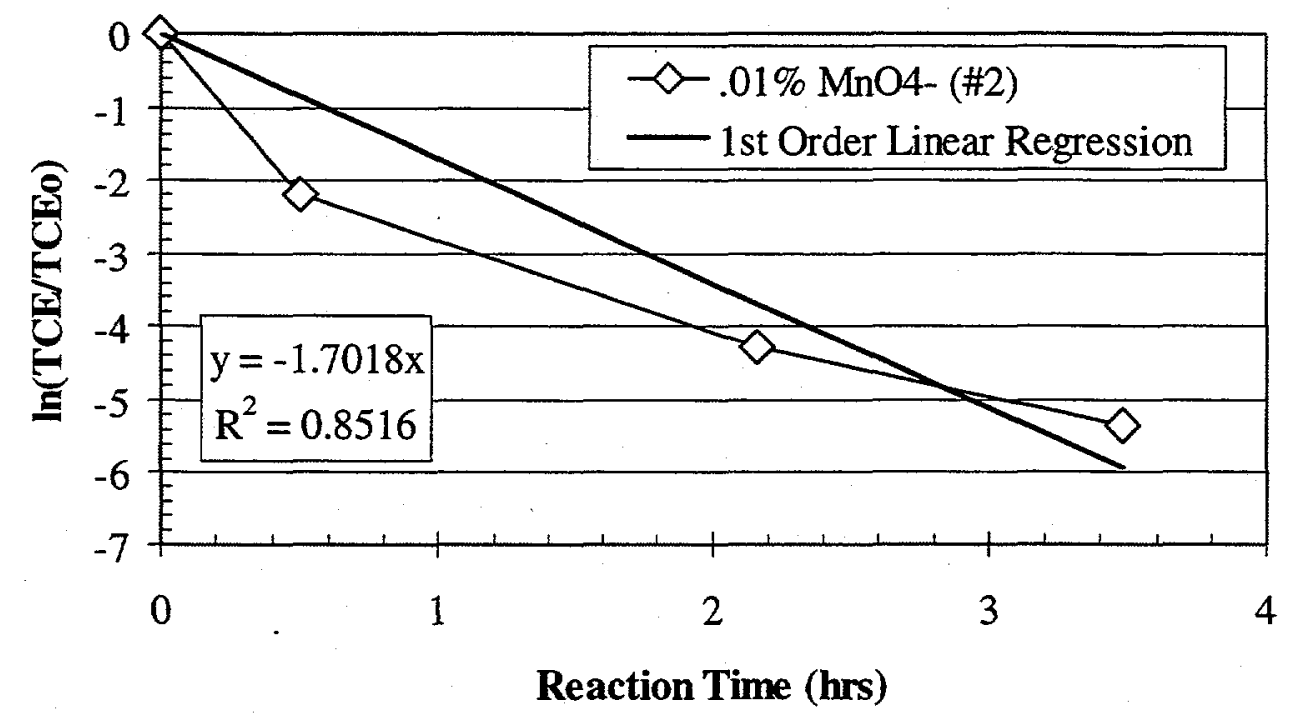

Figure 62. First Order TCE Oxidation Rate Constant for the $0.01 \% \mathrm{MnO}_{4}^{-}(\# 2)$ Reactor, TAN$40 \mathrm{GW} \&$ Sediment, (ORNL Exp. 4a-R8, Initial TCE $=1000 \mu \mathrm{g} / \mathrm{L}$, Conducted at $12^{\circ} \mathrm{C}, 4: 1 \mathrm{~L} / \mathrm{S}$ Ratio) 
Table 26. TCE Mass Balance for ORNL Exp. 4a-R8 (TAN-40 GW \& Sediment).

\begin{tabular}{|c|c|c|c|c|c|c|c|}
\hline Test Condition & $\begin{array}{l}\text { Total } \\
\text { Initial } \\
\text { Mass } \\
(\mathrm{mg})^{2}\end{array}$ & $\begin{array}{l}\text { Initial } \\
\text { Aqueous } \\
\text { Mass } \\
\text { (mg) }\end{array}$ & \begin{tabular}{|l} 
Mass \\
Sorbed on \\
Orbo Tubes \\
(mg)
\end{tabular} & $\begin{array}{l}\text { Mass } \\
\text { Remaining in } \\
\text { Reactor (mg) }\end{array}$ & \begin{tabular}{|l|} 
Cum. \\
Mass \\
Removed \\
in Aliquots \\
(mg) \\
\end{tabular} & \begin{tabular}{|l} 
Cum. \\
Aqueous \\
Mass \\
Oxidized \\
(mg) \\
\end{tabular} & \begin{tabular}{|l} 
Total Mass \\
Recovered \\
$(\mathrm{mg})$
\end{tabular} \\
\hline \multirow{2}{*}{ Control (\#1) } & 0.98 & 0.98 & 0.000 & 0.75 & 0.11 & NA & 0.9 \\
\hline & & & $0 \%$ & $77 \%$ & $11 \%$ & NA & $87 \%$ \\
\hline \multirow[t]{2}{*}{ Control (\#2) } & 0.97 & 0.97 & 0.000 & 0.76 & 0.11 & NA & 0.9 \\
\hline & & & $0 \%$ & $79 \%$ & $11 \%$ & NA & $90 \%$ \\
\hline \multirow[t]{2}{*}{$0.01 \%(\# 1)$} & 0.74 & 0.65 & 0.000 & 0.00 & 0.014 & 0.64 & 0.7 \\
\hline & \%Sorbed: & $12 \%$ & $0 \%$ & $0 \%$ & $2 \%$ & $87 \%$ & $89 \%$ \\
\hline \multirow{2}{*}{$0.01 \%(\# 2)$} & 0.75 & 0.68 & 0.000 & 0.00 & 0.014 & 0.67 & 0.7 \\
\hline & \%Sorbed: & $9 \%$ & $0 \%$ & $0 \%$ & $2 \%$ & $90 \%$ & $91 \%$ \\
\hline \multirow[t]{2}{*}{$0.1 \%(\# 1)$} & 0.77 & 0.71 & 0.000 & 0.00 & 0.013 & 0.72 & 0.7 \\
\hline & \%Sorbed: & $8 \%$ & $0 \%$ & $0 \%$ & $2 \%$ & $93 \%$ & $95 \%$ \\
\hline \multirow[t]{2}{*}{$0.1 \%(\# 2)$} & 0.79 & 0.67 & 0.000 & 0.00 & 0.011 & 0.68 & 0.7 \\
\hline & \%Sorbed: & $15 \%$ & $0 \%$ & $0 \%$ & $1 \%$ & $86 \%$ & $87 \%$ \\
\hline
\end{tabular}

a. Total Initial computed using the average initial aqueous TCE concentration of the GW control samples (Avg=1,954 $\mu \mathrm{g} / \mathrm{L}, \sigma=28 \mu \mathrm{g} / \mathrm{L})$.

Table 27. $\mathrm{MnO}_{4}{ }^{-}$Consumption Data for ORNL Exp. 4a-R8 (TAN-40 GW \& Sediment).

\begin{tabular}{|l|c|l|l|l|}
\hline Test Condition & $\begin{array}{l}\text { Initial } \\
\text { Oxidant } \\
\left(\mathrm{mg} \mathrm{MnO}_{4}\right)\end{array}$ & $\begin{array}{l}\text { Initial } \\
\text { Loading } \\
\left(\mathrm{mg} \mathrm{MnO}_{4}^{-} / \mathrm{g}\right)\end{array}$ & $\begin{array}{l}\text { Cum. } \\
\text { Consumed } \\
\left(\mathrm{mg} \mathrm{MnO}_{4}\right)\end{array}$ & $\begin{array}{l}\text { Cum. } \\
\text { Consumed } \\
\left(\mathrm{mg} \mathrm{MnO}_{4} / \mathrm{g}\right)\end{array}$ \\
\hline $0.01 \%(\# 1)$ & 47.4 & 0.10 & 15.33 & 0.03 \\
\hline $0.01 \%(\# 2)$ & 47.4 & 0.10 & 13.50 & 0.03 \\
\hline $0.1 \%(\# 1)$ & 474.2 & 0.95 & -0.81 & 0.00 \\
\hline $0.1 \%(\# 2)$ & 474.2 & 0.92 & -12.58 & -0.02 \\
\hline
\end{tabular}

\footnotetext{
${ }^{2}$ Consumption is computed after $24 \mathrm{hr}$ reaction time.
} 


\section{Summary - TCE Oxidation Rate Measurements, Dissolved Plume Media}

This set of experiments measured the rate of TCE oxidation in the presence of geologic media (groundwater, basalt, and fracture fill material [sediment]) from the 'dissolved plume' at TAN, i.e. down gradient of the hot spot. The concentrations of $\mathrm{MnO}_{4}{ }^{-}$used in this experiment $(0.01 \%$ and $0.1 \% \mathrm{MnO}_{4}{ }^{-}$) are lower than the concentrations used in the parallel experiments using media from the hot spot because the oxidant demands of dissolved plume media are less than those of hot spot media. Summary Data from this series of experiments are presented in Tables 28 through 38. (Table 38 is a complete summarization of these experiments and the data presented in Tables 28 through 37. )

Table 28 lists the experimental identification used by ORNL for this series of experiments.

Table 28 Experimental Identification for Dissolved Plume Media Experiments.

\begin{tabular}{|c|c|c|}
\hline $\begin{array}{c}\text { Nominal } \\
\mathrm{MnO}_{4}^{-} \text {Concentration }\end{array}$ & $\begin{array}{c}\text { Nominal TCE Concentration } \\
100 \mu \mathrm{g} / \mathrm{L}\end{array}$ \\
\hline Groundwater Only & \multicolumn{3}{c|}{$1000 \mu \mathrm{g} / \mathrm{L}$} \\
\hline $0.01 \%$ & $4 \mathrm{aR} 1$ & $4 \mathrm{aR} 2$ \\
\hline $0.1 \%$ & $4 \mathrm{aR} 1$ & $4 \mathrm{aR} 2$ \\
\hline Groundwater and Crushed Basalt & $4 \mathrm{aR} 5$ \\
\hline $0.01 \%$ & $4 \mathrm{aR} 3$ & $4 \mathrm{aR} 5$ \\
\hline $0.1 \%$ & $4 \mathrm{aR} 3$ & $4 \mathrm{aR} 6$ \\
\hline Groundwater and Aggregate Basalt \\
\hline $0.01 \%$ & $4 \mathrm{aR} 4$ & $4 \mathrm{aR} 6$ \\
\hline $0.1 \%$ & $4 \mathrm{aR} 4$ & $4 \mathrm{aR} 8$ \\
\hline Groundwater and Sediment & $4 \mathrm{aR} 8$ \\
\hline $0.01 \%$ & $4 \mathrm{a} 4 \mathrm{R} 7$ & \\
\hline $0.1 \%$ & $4 \mathrm{a} 4 \mathrm{R} 7$ & \\
\hline
\end{tabular}

The initial and final $\mathrm{MnO}_{4}{ }^{-}$concentrations in this series of experiments are presented in Tables 29 and 30, respectively. The $\mathrm{MnO}_{4}{ }^{-}$concentrations used in these experiments were high enough that $\mathrm{MnO}_{4}{ }^{-}$was present at the end of each experiment, and thus TCE oxidation was not limited by low $\mathrm{MnO}_{4}{ }^{-}$concentrations. This is in contrast to the 'hot spot media' experiments described in following sections (2.4.3 and 2.4.4). 
Table 29. Initial Aqueous $\mathrm{MnO}_{4}{ }^{-}$Concentrations for Dissolved Plume Media Experiments. ${ }^{\text {a. }}$

\begin{tabular}{|c|c|c|}
\hline $\begin{array}{c}\text { Nominal } \\
\mathrm{MnO}_{4}{ }^{-} \text {Concentration }\end{array}$ & \multicolumn{3}{c|}{ Nominal TCE Concentration } \\
$100 \mu \mathrm{g} / \mathrm{L}$ & $1000 \mu \mathrm{g} / \mathrm{L}$ \\
\hline Groundwater Only & 115 & 117 \\
\hline $0.01 \%$ & 1,100 & 1,112 \\
\hline $0.1 \%$ & 138 & 117 \\
\hline \multicolumn{3}{|c|}{ Groundwater and Crushed Basalt } \\
\hline $0.01 \%$ & 1,322 & 1,191 \\
\hline $0.1 \%$ & 120 & 129 \\
\hline Groundwater and Aggregate Basalt & 1,244 \\
\hline $0.01 \%$ & 1,186 & 126 \\
\hline $0.1 \%$ & 127 & 1,170 \\
\hline Groundwater and Sediment & 1,287 & 0.45 \\
\hline $0.01 \%$ & & \\
\hline $0.1 \%$ & & \\
\hline
\end{tabular}

a. Average Concentration of 2 test reactors $\left(\mathrm{mg} / \mathrm{L} \mathrm{MnO}_{4}{ }^{-}\right)$. All samples filtered $(0.45 \mu \mathrm{m})$ prior to analysis.

Table 30. Final $\mathrm{MnO}_{4}{ }^{-}$Concentrations for Dissolved Plume Media Experiments. ${ }^{\text {a. }}$

\begin{tabular}{|c|c|c|}
\hline $\begin{array}{c}\text { Nominal } \\
\mathrm{MnO}_{4}^{-} \text {Concentration }\end{array}$ & $\begin{array}{c}\text { Nominal TCE Concentration } \\
\mathrm{g} / \mathrm{L}\end{array}$ \\
\hline Groundwater Only & 99 & $1000 \mu \mathrm{g} / \mathrm{L}$ \\
\hline $0.01 \%$ & 1,100 & 80 \\
\hline $0.1 \%$ & 99 & 1,095 \\
\hline Groundwater and Crushed Basalt & 91 \\
\hline $0.01 \%$ & 1,221 & 1,185 \\
\hline $0.1 \%$ & 109 & 116 \\
\hline Groundwater and Aggregate Basalt & 1,200 \\
\hline $0.01 \%$ & 1,141 & 88 \\
\hline $0.1 \%$ & \multicolumn{3}{|}{} \\
\hline Groundwater and Sediment & 108 & 1,186 \\
\hline $0.01 \%$ & 1,202 & \\
\hline $0.1 \%$ & & \\
\hline
\end{tabular}

a. Average Concentration of 2 test reactors $\left(\mathrm{mg} / \mathrm{L} \mathrm{MnO}_{4}{ }^{-}\right)$. All samples filtered $(0.45 \mu \mathrm{m})$ prior to analysis.

Tables 31 and 32 show the initial and final aqueous TCE concentrations in the $\mathrm{MnO}_{4}^{-}$- spiked reactors. Note that the TCE concentrations included in these tables do not include TCE that was originally bound to the TAN solid phases that might have been present in the test reactors. As observed in Table 31, the actual TCE spike concentrations for the dissolved plume media experiments were typically greater than the target (nominal) TCE concentrations. In fact, the average TAN-40 GW spike concentrations were 200 and $1,780 \mu \mathrm{g} / \mathrm{L}$ for experiments having target TCE spike concentrations of 100 and $1,000 \mu \mathrm{g} / \mathrm{L} \mathrm{TCE}$, respectively. This anomaly is 
believed to have resulted from the use of a saturated TCE solution to prepare the spiked groundwater solution (see Appendix B, Testplan). Volumes of saturated TCE needed for spiking were made with the assumption that the maximum aqueous TCE solubility was near $1,000 \mathrm{mg} / \mathrm{L}$. It is suspected that its actual concentration was somewhat greater since DNAPL was also present in the bottom of the saturated solution container. While nearly double the desired values, the actual TCE spike concentrations are all within the same order of magnitude of the nominal, target values.

Table 33 shows the percentage of TCE oxidized and removed during sampling. (These values were obtained from the mass balance tables presented previously in this section.) TCE . concentrations in control reactors remained approximately constant, while TCE concentrations declined to less than method detection limits (MDLs) in reactors that contained $\mathrm{MnO}_{4}{ }^{-}$. This demonstrates that oxidation of TCE by $\mathrm{MnO}_{4}{ }^{-}$is the predominant mechanism whereby TCE was destroyed. 
Table 31. Initial TCE Concentrations for Dissolved Plume Media Experiments. ${ }^{\text {a. }}$

\begin{tabular}{|c|c|c|}
\hline $\begin{array}{c}\text { Nominal } \\
\mathrm{MnO}_{4}{ }^{-} \text {Concentration }\end{array}$ & $\begin{array}{c}\text { Nominal TCE Concentration } \\
100 \mu \mathrm{g} / \mathrm{L}\end{array}$ & $1000 \mu \mathrm{g} / \mathrm{L}$ \\
\hline Groundwater Only & 178 & 1,368 \\
\hline $0.01 \%$ & 179 & 1,319 \\
\hline $0.1 \%$ & 162 & 1,266 \\
\hline Groundwater and Crushed Basalt & 1,288 \\
\hline $0.01 \%$ & 154 & 2,314 \\
\hline $0.1 \%$ & 136 & 636 \\
\hline Groundwater and Aggregate Basalt & 1,753 \\
\hline $0.01 \%$ & 136 & 1,724 \\
\hline $0.1 \%$ & 235 & 221 \\
\hline
\end{tabular}

a. Average Concentration of 2 test reactors $(\mu \mathrm{g} / \mathrm{L}$ TCE).

b. Initial TCE concentration is unknown due to a leak in the spiking solution container prior to filling these reactors.

Table 32. Final TCE Concentrations for Dissolved Plume Media Experiments. ${ }^{\text {a. }}$

\begin{tabular}{|c|c|c|}
\hline Nominal & \multicolumn{2}{|c|}{ Nominal TCE Concentration } \\
\hline $\mathrm{MnO}_{4}{ }^{-}$Concentration & $100 \mu \mathrm{g} / \mathrm{L}$ & $1000 \mu \mathrm{g} / \mathrm{L}$ \\
\hline \multicolumn{3}{|l|}{ Groundwater Only } \\
\hline $0.01 \%$ & ND & $\mathrm{ND}, 14$ \\
\hline $0.1 \%$ & ND & $\mathrm{ND}$ \\
\hline \multicolumn{3}{|c|}{ Groundwater and Crushed Basalt } \\
\hline $0.01 \%$ & ND & $22^{b}$ \\
\hline $0.1 \%$ & $\mathrm{ND}$ & $\mathrm{ND}, 15^{\mathrm{b}}$ \\
\hline \multicolumn{3}{|c|}{ Groundwater and Aggregate Basalt } \\
\hline $0.01 \%$ & ND & $\mathrm{ND}, 20$ \\
\hline $0.1 \%$ & ND & $\mathrm{ND}^{\mathrm{c} .}$ \\
\hline \multicolumn{3}{|l|}{ Groundwater and Sediment } \\
\hline $0.01 \%$ & ND & ND \\
\hline $0.1 \%$ & $\mathrm{ND}$ & ND \\
\hline
\end{tabular}

a. Average Concentration of 2 test reactors $(\mu \mathrm{g} / \mathrm{L}$ TCE).

b. TCE Contamination detected in hexane GC blanks.

c. Initial TCE concentration is unknown due to a leak in the spiking solution container prior to filling these reactors. 
Table 33. Percentage of Initial TCE Mass Oxidized and Removed by Sampling. ${ }^{\text {a. }}$

\begin{tabular}{|c|c|c|}
\hline $\begin{array}{c}\text { Nominal } \\
\mathrm{MnO}_{4}{ }^{-} \text {Concentration }\end{array}$ & $100 \mu \mathrm{g} / \mathrm{L}$ & $1000 \mu \mathrm{g} / \mathrm{L}$ \\
\hline Groundwater Only & 100 & 100 \\
\hline $0.01 \%$ & 101 & 102 \\
\hline $0.1 \%$ & 106 & 97 \\
\hline Groundwater and Crushed Basalt & 100 \\
\hline $0.01 \%$ & 104 & 92 \\
\hline $0.1 \%$ & 97 & $26^{\mathrm{b}}$ \\
\hline Groundwater and Aggregate Basalt & \\
\hline $0.01 \%$ & 100 & 90 \\
\hline $0.1 \%$ & \multicolumn{3}{|}{} \\
\hline Groundwater and Sediment & 93 & 91 \\
\hline $0.01 \%$ & 89 & \\
\hline $0.1 \%$ & &
\end{tabular}

a. Average Value determined from 2 test reactors (wt\%)

b. Initial TCE concentration is unknown due to a leak in the spiking solution container prior to filling these reactors.

The rate of TCE oxidation on 'per reactor' and 'per unit volume' bases are presented in Tables 34 and 35 , respectively. These are lower bound estimates of the zero order reaction rate.

Table 34. Observed Minimum Zero Order TCE Destruction Rates - Per Reactor Basis, Dissolved Plume Media. ${ }^{\text {a. }}$

\begin{tabular}{|c|c|c|}
\hline $\begin{array}{c}\text { Nominal } \\
\mathrm{MnO}_{4}{ }^{-} \text {Concentration }\end{array}$ & $\begin{array}{c}\text { Nominal TCE Concentration } \\
100 \mu \mathrm{g} / \mathrm{L}\end{array}$ \\
\hline Groundwater Only & 0.03 & 0.14 \\
\hline $0.01 \%$ & 0.2 & 0.34 \\
\hline $0.1 \%$ & 0.02 & 0.11 \\
\hline Groundwater and Crushed Basalt & 1.0 \\
\hline $0.01 \%$ & 0.14 & 0.2 \\
\hline $0.1 \%$ & 0.03 & 0.14 \\
\hline Groundwater and Aggregate Basalt & \\
\hline $0.01 \%$ & 0.12 & 0.15 \\
\hline $0.1 \%$ & 0.04 & 1.6 \\
\hline Groundwater and Sediment & 0.19 & \\
\hline $0.01 \%$ & & \\
\hline $0.1 \%$ & & \\
\hline
\end{tabular}

a. Values are the average of 2 test reactors ( $\mathrm{mg}$ TCE $/ \mathrm{hr}$ per reactor). Computed by dividing the Average Initial TCE Mass present in each reactor by the earliest aliquot sampling time at which TCE was not detected. Each reactor contained nominally $400 \mathrm{~mL}$ water and, if a solid phase was present, $100 \mathrm{~g}$ of solid media. See Appendix $\mathrm{C}$ for actual $\mathrm{GW}$ and solid phase masses in each reactor. 
Table 35. Observed Minimum Zero Order TCE Destruction Rates -Per Unit Volume Basis, Dissolved Plume Media. ${ }^{2 .}$

\begin{tabular}{|c|c|c|}
\hline $\begin{array}{c}\text { Nominal } \\
\mathrm{MnO}_{4}^{-} \text {Concentration }\end{array}$ & \multicolumn{2}{|c|}{$\begin{array}{c}\text { Nominal TCE Concentration } \\
100 \mu \mathrm{g} / \mathrm{L}\end{array}$} \\
\hline Groundwater Only & \multicolumn{3}{|c|}{$1000 \mu \mathrm{g} / \mathrm{L}$} \\
\hline $0.01 \%$ & $0.06^{\dagger}$ & $0.28^{\dagger}$ \\
\hline $0.1 \%$ & 0.36 & 0.64 \\
\hline Groundwater and Crushed Basalt & 0.27 \\
\hline $0.01 \%$ & $0.04^{\dagger}$ & 2.5 \\
\hline $0.1 \%$ & 0.30 & $0.50^{\dagger}$ \\
\hline Groundwater and Aggregate Basalt \\
\hline $0.01 \%$ & $0.07^{\dagger}$ & 0.33 \\
\hline $0.1 \%$ & 0.29 & $0.4^{\dagger}$ \\
\hline Groundwater and Sediment & & 4 \\
\hline $0.01 \%$ & $0.10^{\dagger}$ & \\
\hline $0.1 \%$ & 0.48 & \\
\hline
\end{tabular}

a. Values are the average of 2 test reactors (mg TCE/L per hour). Values were computed by dividing the Average Initial TCE Mass present in each reactor by both (1) the earliest aliquot sampling time (hrs) at which TCE was not detected and (2) the average initial liquid volume in the reactor ( $\mathrm{GW}$ and $\mathrm{MnO}_{4}{ }^{-}$stock solution).

$\dagger$ A corresponding first order rate constant is included in Table 38 for this test case.

- TCE oxidation was rapid at the $\mathrm{MnO}_{4}{ }^{-}$concentrations utilized $(0.01 \%$ and $0.1 \%)$ in these tests. TCE concentrations typically declined to less than MDLs within $0.5-5$ hours. Cases in which TCE concentrations did not decline to less than MDLs are attributed to low level contamination of the hexane used for extracting the samples prior to $\mathrm{GC}$ analysis.

- TCE oxidation was so rapid that the data resolution is insufficient to calculate reliable reaction rate parameters.

- TCE oxidation was often complete before the first sample was collected (typically approximately 0.5 hours after the start of oxidation). Therefore, neither a zero order reaction rate nor a first order reaction rate constant can be calculated for these cases. Instead, a lower bound of the zero order reaction rate was calculated by assuming that the TCE concentration reached zero at the time that the first sample was collected.

- In other cases, TCE concentrations declined to less than the MDL between the first and second samples. In these cases, lower bound of the a zero order reaction rate was calculated by assuming that the TCE concentration reached zero at the time that the second sample was collected.

- In cases where TCE concentrations were greater than the MDL in both the first and second samples, a first order reaction rate constant was calculated.

- The TCE oxidation rate increased with $\mathrm{MnO}_{4}{ }^{-}$concentration. 
- The calculated TCE oxidation rate also increased with TCE concentration. However, this may be an artifact of estimating a lower bound of the reaction rate (see items items above) instead of having sufficient data resolution to calculate an actual reaction rate. Higher initial TCE concentrations cause the estimated lower bound of the reaction rate to be greater.

- The TCE oxidation rate does not appear to be sensitive to the type of geologic medium tested (groundwater only, aggregate basalt, crushed basalt, and sediment). Although the rates calculated for sediment and crushed basalt at high TCE and permanganate concentrations are much higher than for other materials, closer inspection of the results shows that the differences between materials can be attributed to variations in initial TCE concentration and the lack of data resolution (i.e., the time at which concentrations declined to less than MDL was not determined more closely than less than $\approx 0.5$ or $\approx 2$ hours).

Observed zero order reaction rates (mg TCE / $\mathrm{L} /$ hour), averaged for all four materials are shown in Table 36.

Table 36. Representative Zero Order TCE Oxidation Rates. ${ }^{\text {a. }}$

\begin{tabular}{|c|c|c|}
\hline $\mathrm{MnO}_{4}{ }^{-}$ & \multicolumn{2}{|c|}{ TCE Concentration } \\
Concentration & $\begin{array}{c}100 \\
(\mu \mathrm{g} / \mathrm{L})\end{array}$ & $\begin{array}{c}1000 \\
(\mu \mathrm{g} / \mathrm{L})\end{array}$ \\
\hline $0.01(\%)$ & 0.1 & 0.4 \\
\hline $0.1(\%)$ & 0.4 & 2 \\
\hline
\end{tabular}

a. Rate value presented in mg TCE / L per hour

Observed $\mathrm{pH}$ trends for these experiments are presented in Table 37.

Table 37. $\mathrm{pH}$ Trends for Dissolved Plume Experiments. ${ }^{\text {a. }}$

\begin{tabular}{|c|c|c|}
\hline $\begin{array}{c}\text { Nominal } \\
\mathrm{MnO}_{4}{ }^{-} \text {Concentration }\end{array}$ & $\begin{array}{c}\text { Nominal TCE Concentration } \\
100 \mu \mathrm{g} / \mathrm{L}\end{array}$ \\
\hline Groundwater Only & \multicolumn{3}{c|}{} \\
\hline $0.01 \%$ & +0.05 & -0.2 \\
\hline $0.1 \%$ & +0.2 & -0.1 \\
\hline Groundwater and Crushed Basalt & +0.1 \\
\hline $0.01 \%$ & +0.1 & +0.1 \\
\hline $0.1 \%$ & +0.1 & -0.2 \\
\hline Groundwater and Aggregate Basalt & -0.1 \\
\hline $0.01 \%$ & +0.3 & -0.1 \\
\hline $0.1 \%$ & +0.3 & -0.2 \\
\hline Groundwater and Sediment & 0 & \\
\hline $0.01 \%$ & -0.1 & \\
\hline $0.1 \%$ & &
\end{tabular}

a. Values represent net $\mathrm{pH}$ changes. 
- Changes in $\mathrm{pH}$ were small in all experiments, typically only a few tenths of a $\mathrm{pH}$ unit. No patterns are apparent, indicating that $\mathrm{pH}$ would not be a useful parameter for monitoring ISCO at these $\mathrm{MnO}_{4}{ }^{-}$and TCE concentrations for the dissolved plume media.

A complete summary of the preceding tables is presented in Table 38 for all the oxidation rate experiments conducted on the dissolved plume media. 
Table 38. Summary of the Dissolved Plume Media Oxidation Rate Experiments.

\begin{tabular}{|c|c|c|c|c|c|c|c|}
\hline $\begin{array}{l}\text { ORNL } \\
\text { Exp. } \\
\text { No. }\end{array}$ & $\begin{array}{l}\text { Dissolved } \\
\text { Plume } \\
\text { Media }\end{array}$ & $\begin{array}{l}\text { Nominal } \\
\text { Initial } \\
\text { TCE } \\
(\mu \mathrm{g} / \mathrm{L})\end{array}$ & \begin{tabular}{|l|} 
Avg. \\
Initial \\
TCE \\
Mass \\
(mg) \\
\end{tabular} & $\begin{array}{l}\text { TCE Oxidation } \\
\text { Observed Rates } \\
\text { (mg TCE/hr·Reactor } \\
\text { Contents) }^{\dagger}\end{array}$ & $\begin{array}{l}\text { Initial } \\
\mathrm{MnO}_{4}^{-} \\
(\mathrm{wt} \%)\end{array}$ & $\begin{array}{l}\text { Max. } \mathrm{MnO}_{4}^{-} \\
\text {Consumed } \\
\left(\mathrm{mg} \mathrm{MnO}_{4}^{-1 / g)}\right.\end{array}$ & $\begin{array}{l}\text { pH Trends } \\
\text { (After 24 hrs) }\end{array}$ \\
\hline \multirow[t]{2}{*}{$4 \mathrm{a}-\mathrm{R} 1$} & \multirow[t]{2}{*}{$\begin{array}{l}\text { TAN-40 } \\
\text { GW }\end{array}$} & \multirow[t]{2}{*}{100} & 0.10 & $\begin{array}{l}\text { Complete ( }<3 \mathrm{hrs} \text { ) } \\
\text { Obs. Rate } \geq 0.03 \\
\text { Avg } \boldsymbol{k}=\mathbf{1 . 7 8} \mathbf{~ h r}^{-1}\end{array}$ & $0.01 \%$ & 0.02 & $\begin{array}{l}<0.05 \text { Net } \\
\text { Increase }\end{array}$ \\
\hline & & & 0.10 & $\begin{array}{l}\text { Complete }(<0.5 \mathrm{hr}) \\
\text { Obs. Rate } \geq 0.2\end{array}$ & $0.1 \%$ & 0.00 & $\begin{array}{l}<0.2 \mathrm{Net} \\
\text { Increase }\end{array}$ \\
\hline \multirow[t]{2}{*}{$4 a-R 2$} & \multirow[t]{2}{*}{$\begin{array}{l}\text { TAN-40 } \\
\text { GW }\end{array}$} & \multirow[t]{2}{*}{1000} & 0.69 & $\begin{array}{l}\text { Complete }^{1}(<5 \mathrm{hrs}) \\
\text { Obs. Rate } \geq 0.14 \\
\text { Avg } \boldsymbol{k}=\mathbf{1 . 5 1} \mathbf{~ h r}^{-1}\end{array}$ & $0.01 \%$ & 0.04 & $\begin{array}{l}<0.2 \mathrm{Net} \\
\text { Decrease }\end{array}$ \\
\hline & & & 0.68 & $\begin{array}{l}\text { Complete }(<2 \mathrm{hrs}) \\
\text { Obs. Rate } \geq 0.34\end{array}$ & $0.1 \%$ & 0.02 & $\begin{array}{l}<0.1 \mathrm{Net} \\
\text { Decrease }\end{array}$ \\
\hline \multirow[t]{2}{*}{$4 a-R 3$} & \multirow{2}{*}{$\begin{array}{l}\text { Crushed } \\
\text { Basalt \& } \\
\text { TAN-40 } \\
\text { GW }\end{array}$} & \multirow[t]{2}{*}{100} & 0.07 & $\begin{array}{l}\text { Complete }(<3 \mathrm{hrs}) \\
\text { Obs. Rate } \geq 0.02 \\
\text { Avg } k=\mathbf{2 . 3 2} \mathbf{~ h r}^{-1}\end{array}$ & $0.01 \%$ & 0.04 & $\begin{array}{l}<0.1 \mathrm{Net} \\
\text { Increase }\end{array}$ \\
\hline & & & 0.07 & $\begin{array}{l}\text { Complete }(<0.5 \mathrm{hr}) \\
\text { Obs. Rate } \geq 0.14\end{array}$ & $0.1 \%$ & 0.11 & $\begin{array}{l}<0.1 \mathrm{Net} \\
\text { Increase }\end{array}$ \\
\hline \multirow[t]{2}{*}{$4 a-R 5$} & \multirow{2}{*}{$\begin{array}{l}\text { Crushed } \\
\text { Basalt \& } \\
\text { TAN-40 } \\
\text { GW }\end{array}$} & \multirow[t]{2}{*}{1000} & 0.54 & $\begin{array}{l}\text { Complete }^{2}(\approx 5 \mathrm{hrs}) \\
\text { Obs. Rate } \geq 0.11\end{array}$ & $0.01 \%$ & 0.02 & $\begin{array}{l}<0.1 \mathrm{Net} \\
\text { Increase }\end{array}$ \\
\hline & & & 0.52 & $\begin{array}{l}\text { Complete }^{2}(\approx 0.5 \mathrm{hr}) \\
\text { Obs. Rate } \geq 1.0\end{array}$ & $0.1 \%$ & 0.02 & $\begin{array}{l}<0.1 \mathrm{Net} \\
\text { Increase }\end{array}$ \\
\hline \multirow[t]{2}{*}{ 4a-R4 } & \multirow{2}{*}{$\begin{array}{l}\text { Aggregate } \\
\text { Basalt \& } \\
\text { TAN-40 } \\
\text { GW }\end{array}$} & \multirow[t]{2}{*}{100} & 0.06 & $\begin{array}{l}\text { Complete }(<2 \mathrm{hrs}) \\
\text { Obs. Rate } \geq 0.03 \\
\text { Avg } k=\mathbf{4 . 2 8} \mathbf{~ h r}^{-1} \\
\end{array}$ & $0.01 \%$ & 0.01 & $\begin{array}{l}<0.3 \mathrm{Net} \\
\text { Increase }\end{array}$ \\
\hline & & & 0.06 & $\begin{array}{c}\text { Complete }(<0.5 \mathrm{hr}) \\
\text { Obs. } \text { Rate } \geq \mathbf{0 . 1 2}\end{array}$ & $0.1 \%$ & 0.06 & $\begin{array}{l}<0.3 \mathrm{Net} \\
\text { Increase }\end{array}$ \\
\hline \multirow[t]{2}{*}{ 4a-R6 } & \multirow{2}{*}{$\begin{array}{l}\text { Aggregate } \\
\text { Basalt \& } \\
\text { TAN-40 } \\
\text { GW }\end{array}$} & \multirow[t]{2}{*}{1000} & 1.0 & $\begin{array}{l}\text { Complete }(<5 \mathrm{hrs})^{1} \\
\text { Obs. Rate } \geq 0.2 \\
\text { Avg } \boldsymbol{k}=\mathbf{1 . 9 8} \mathbf{~ h r}^{-1}\end{array}$ & $0.01 \%$ & $0.02^{3}$ & $\begin{array}{l}<0.2 \text { Net } \\
\text { Decrease }\end{array}$ \\
\hline & & & $0.28^{4}$ & $\begin{array}{l}\text { Complete }(<2 \mathrm{hrs}) \\
\text { Obs. Rate } \geq 0.14^{4}\end{array}$ & $0.1 \%$ & 0.04 & $\begin{array}{l}<0.1 \mathrm{Net} \\
\text { Decrease }\end{array}$ \\
\hline
\end{tabular}


Table 38 (continued)

\begin{tabular}{|c|c|c|c|c|c|c|c|}
\hline $\begin{array}{l}\text { ORNL } \\
\text { Exp. } \\
\text { No. }\end{array}$ & $\begin{array}{l}\text { Dissolved } \\
\text { Plume } \\
\text { Media }\end{array}$ & $\begin{array}{l}\text { Nominal } \\
\text { Initial } \\
\text { TCE } \\
(\mu \mathrm{g} / \mathrm{L})\end{array}$ & \begin{tabular}{|l} 
Avg. \\
Initial \\
TCE \\
Mass \\
(mg)
\end{tabular} & $\begin{array}{l}\text { TCE Oxidation } \\
\text { Observed Rates } \\
\text { (mg TCE/hr.Reactor } \\
\text { Contents) }\end{array}$ & $\begin{array}{l}\mathrm{Initial}^{-} \\
\mathrm{MnO}_{4} \\
(\mathrm{wt} \%)\end{array}$ & $\begin{array}{l}\text { Max. } \mathrm{MnO}_{4}{ }^{-} \\
\text {Consumed } \\
\left(\mathrm{mg} \mathrm{MnO}_{4}^{-1 / \mathrm{g})}\right.\end{array}$ & $\begin{array}{l}\text { pH Trends } \\
\text { (After } 24 \mathrm{hrs)}\end{array}$ \\
\hline \multirow[t]{2}{*}{$4 a-R 7$} & \multirow{2}{*}{$\begin{array}{l}\text { Sediment } \\
\text { (SED1) \& } \\
\text { TAN-40 } \\
\text { GW }\end{array}$} & \multirow[t]{2}{*}{100} & 0.11 & $\begin{array}{l}\text { Complete }(<3 \mathrm{hrs}) \\
\text { Obs. Rate } \geq 0.04 \\
\text { Avg } \boldsymbol{k}=\mathbf{2 . 1 6} \mathbf{~ h r}^{-1} \\
\end{array}$ & $0.01 \%$ & 0.02 & $\begin{array}{l}\text { No Net } \\
\text { Change }\end{array}$ \\
\hline & & & 0.10 & $\begin{array}{l}\text { Complete }(<0.5 \mathrm{hr}) \\
\text { Obs. Rate } \geq 0.19\end{array}$ & $0.1 \%$ & 0.08 & $\begin{array}{l}<0.1 \mathrm{Net} \\
\text { Decrease }\end{array}$ \\
\hline \multirow[t]{2}{*}{ 4a-R8 } & \multirow{2}{*}{$\begin{array}{l}\text { Sediment } \\
\text { (SED2) \& } \\
\text { TAN-40 } \\
\text { GW }\end{array}$} & \multirow[t]{2}{*}{1000} & 0.75 & $\begin{array}{l}\text { Complete }(<5 \mathrm{hrs})^{1} \\
\text { Obs. Rate } \geq 0.15 \\
\text { Avg } \boldsymbol{k}=\mathbf{1 . 6 4} \mathbf{~ h r}^{-1}\end{array}$ & $0.01 \%$ & 0.03 & $\begin{array}{l}<0.05 \text { Net } \\
\text { Decrease }\end{array}$ \\
\hline & & & 0.78 & $\begin{array}{l}\text { Complete }(<0.5 \mathrm{hr}) \\
\text { Obs. Rate } \geq 1.6\end{array}$ & $0.1 \%$ & 0.00 & $\begin{array}{l}0.2-0.3 \text { Net } \\
\text { Decrease }\end{array}$ \\
\hline
\end{tabular}

$\dagger$ Observed Oxidation Rate= (Total Initial mg TCE)/(X hrs.Reactor Contents); Where X represents the earliest sampling time at which TCE was not detected in the aqueous aliquot. Where available, the predicted first order reaction rate constant, $k$, is presented.

"Reactor Contents" are nominally $400 \mathrm{~mL}$ TCE-spiked GW and $100 \mathrm{~g}$ Solid Phase (if applicable). See Appendix $\mathrm{C}$ for actual GW and solid phase masses in each reactor.

1 One of the duplicate samples contained a $10 \mu \mathrm{g} / \mathrm{L}$ TCE residual.

2 It is assumed that the reactions were completed. Residual TCE was present due to a solvent contamination problem. The reported values are estimates.

3 maximum based on the first $0.01 \% \mathrm{MnO}_{4}{ }^{-}$reactor only.

4 Low due to the fact that the initial TCE was less for these reactors $(0.28 \mathrm{mg}$ TCE rather than $1 \mathrm{mg} \mathrm{TCE}$ as in the case of $0.01 \%$ reactors) 


\subsubsection{Oxidation Rate of Organic Contaminants in Hot Spot Groundwater}

Eight (8) separate oxidation rate experiments were performed for the hot spot groundwater (TSF=05 GW). Each experiment is discussed below and identified by the ORNL Experiment IDs presented earlier in Table 6. In general, plots of "TCE vs. Time", " $\mathrm{MnO}_{4}{ }^{-}$vs. Time", and "pH vs. Time" are presented for each experiment. For all plots of TCE vs. Reaction time: any values resulting from analyses in which the sample extract concentration was out of the GC calibration range are clearly labeled. Note that some experiments were continued after $24 \mathrm{hrs}$. Such a modification is clearly noted in the experimental discussions.

In addition to the plots, summary tables for the TCE and $\mathrm{MnO}_{4}{ }^{-}$data are presented for each experiment. Several parameters are included in the TCE mass balance tables (e.g., Table 39). The approach and/or calculations made to obtain each of the values presented in the TCE mass balance tables are presented below. (Descriptions of the $\mathrm{MnO}_{4}{ }^{-}$consumption tables are presented at the beginning of Section 2.4.2.)

\section{TCE MASS BALANCE TABLE DESCRIPTION}

- Column 1, "Test Conditions" refers the experimental condition. In this column "Control" refers to reactors containing only TSF-05 GW and no oxidant. The (\#1) and (\#2) notations included in parentheses refer to the duplicate reactors evaluated. The number followed by the percentage sign is the nominal initial $\mathrm{MnO}_{4}{ }^{-}$concentration added to the treatment reactors.

- Column 2, "Total Initial Mass" refers to the TCE mass added to each reactor. For the control reactors and treatment reactors containing TSF- 05 GW this value is determined by the following equation: (Aqueous TCE Conc. at $T=0$ ) $x$ ( $G W$ Volume in the Reactor) Note: $T=0$ sampling occurred after overnight equilibration and immediately before oxidant addition to the treatment reactors.

- Column3, "Initial Aqueous Mass" For all cases, this value is computed by multiplying the Aqueous TCE Conc. at $\mathrm{T}=0$ for a given reactor by the volume of $\mathrm{GW}$ added to that reactor. Note: The aqueous concentration at $\mathrm{T}=0$ for each reactor is used here rather than the concentration of the spiked GW before it is distributed to the individual reactors and equilibrated. (This approach effectively "removes" or accounts for the any TCE lost during equilibration from the mass balance calculations performed for the actual oxidation reactions.)

- Column 4, "Mass Sorbed on Orbo Tubes" represents the summed TCE mass found on each charcoal bed of the reactor's desorption tube at the end of the reaction period. The TCE mass was obtained by extraction of charcoal beds with hexane. If TCE is detected on the desorption tubes, it is realized that the value obtained represents a minimum that was volatilized since the entire reactor headspace volume would not pass through the desorption tube. The values in parentheses for this column represent the percentage of the Total Initial Mass (Column 1 of the Table) found within the Orbo Tube. 
- Column 5, "Mass Remaining in Reactor" represents the TCE mass still present in each reactor following the reaction period. For the control reactors and treatment reactors, this value was computed by the following equation: (Aqueous TCE concentration at $\mathrm{T}=24 \mathrm{hrs}$ ) $\mathrm{x}$ (Init. GW volume-Cum. Vol. of Aliquot Samples). The values in parentheses for this column represent the percentage of the Total Initial Mass (Column 1 of the Table) still present in the reactor.

- Column 6, "Cum. Mass Removed in Aliquots" represents the mass of TCE removed from the reactor via aliquot sampling. In all cases, this column is computed by summing the masses of TCE that were found in each aliquot interval for a given reactor, i.e., $\Sigma$ (Aqueous TCE Conc. $x$ Aliquot Volume). The values in parentheses for this column represent the percentage of the Total Initial Mass (Column 1 of the Table) removed from the reactor (and thereby not subjected to oxidation) during the course of the experiment.

- Column 7, "Cum. Aqueous Mass Oxidized" represents the TCE mass initially in the aqueous phase that was considered to have been oxidized during the reaction period. The oxidized TCE masses presented in this column were computed by summing the change in aqueous TCE mass obtained for each sampling period, i.e., $\Sigma[$ (Aq. TCE Conc. $T=x-$ Aq. TCE Conc. $T=x+1) \times$ GW Vol. $T=x$ ]. Thus, this approach corrects for TCE removed via previous aliquot samplings. This component of the mass balance can be difficult to interpret, particularly when the final TCE concentration for a given sampling interval is greater than the initial TCE concentration. Such an occurrence will be noted in the following discussions of the hot spot groundwater experiments. Again, the values in parentheses for this column represent the percentage of the Total Initial Mass (Column 1 of the Table) believed to have been oxidized.

- Column 8, "Total Mass Recovered" is the sum of the TCE masses found in four (4) different "compartments" at the end of the reaction period ( $\mathrm{T}=24 \mathrm{hrs}$ ), i.e., Col. $4+\mathrm{Col} .5+\mathrm{Col} .6+$ Col. 7. The values in parentheses for this column represent the percentage of the Total Initial Mass (Column 1 of the Table) that was accounted for during the course of the experiment.

Also note that variation in the initial TSF-05 GW chemistry, e.g. pH values, is expected since each hot spot groundwater experiment was conducted using a different batch of TSF-05 GW that had been sparged for varying amounts of time. (The containers of TSF- $05 \mathrm{GW}$ received from INEEL were not combined/mixed prior to experimentation).

NOTE: A different mass balance approach was required for the experiments involving DNAPL phase TCE. Deviations and/or variations of the above approach are presented in the individual results and discussion sections for those experiments. 
ORNL Exp. 4b-R1

(TSF-05 GW, No Sludge, 10000 TCE, 0 Other, $0.01 \%$ and $0.1 \% \mathrm{MnO}_{4}{ }^{-}$)

This experiment investigated the oxidation of TSF-05 GW spiked at $10,000 \mu \mathrm{g} / \mathrm{L} \mathrm{TCE}$. The TCE, $\mathrm{MnO}_{4}{ }^{-}$and $\mathrm{pH}$ values with time are presented in Figures 63,64 , and 65 , respectively. Tables 39 and 40 provide additional TCE mass balance and oxidant consumption information. The (\#1) and (\#2) notations included in both the figure legends and the first column of these tables refer to the duplicate reactors evaluated for that test condition.

This experiment was performed without significant deviations from the testplan procedure.

After equilibration, the average initial aqueous TCE concentration of the spike solution was $15,545 \mu \mathrm{g} / \mathrm{L}(\sigma=612 \mu \mathrm{g} / \mathrm{L})$. After transfer to the test reactors, the groundwater TCE concentration ranged between 13,100 and $14,700 \mu \mathrm{g} / \mathrm{L}$ ( $\mathrm{T}=0$ aliquots) prior to the start of the oxidation reactions.

TCE contamination (4-5 $\mu \mathrm{g} / \mathrm{L}$ ) was observed in the GC QA/QC blanks for this experiment. The TCE values obtained from the experimental samples further suggest that the hexane used to extract the aqueous samples and the carbon desorption tubes may have been contaminated with a small, unknown amount of TCE. The presence of TCE on the charcoal beds of the desorption tubes could be attributed to volatilization. It is suspected, however, that it is largely a result of the solvent contamination problem. In several cases, more TCE was found on the second charcoal bed of the desorption tubes (Figure 4) than on the first charcoal bed which was closer to the sampling port opening. (Note: Clean desorption tubes were also placed in the incubator in a subsequent experiment to verify that the headspace of the incubator was not the source of this TCE "contamination", and TCE was not detected in these later extractions.) Although solvent contamination was suspected, the experiment was not repeated. The amount of contamination was small, and the overall results from this experiment were very similar to those obtained in the other TSF-05 GW experiments that were conducted. Thus, it did not appear prudent or cost effective to repeat the experiment in light of the benefits that would be gained.

TCE recoveries for the control samples were $102 \%$ and $95 \%$, suggesting that little TCE was lost to volatilization. (The $>100 \%$ recovery may be a result of the solvent contamination problem.) Accurate estimates of the TCE volatilized from the control samples, however, cannot be made. due to the potential contamination of the charcoal desorption tubes discussed above.

Although the TCE oxidation of greater than an order of magnitude was initially observed, all treatment reactors contained $\mathrm{a} \approx 200 \mu \mathrm{g} / \mathrm{L}$ TCE residual at the end of the reaction period (regardless of initial oxidant loading). Since a residual oxidant was present following the reaction period, the TCE residual is likely to be a result of the solvent contamination during sample extraction. The presence of the additional TCE complicates the interpretation of the mass balance. Fortunately, the amount of solvent contamination $(\approx 200 \mu \mathrm{g} / \mathrm{L}$ TCE$)$ is relatively small compared to the initial spike level (nominal 10,000 $\mu \mathrm{g} / \mathrm{L}$ TCE) and does not completely invalidate general trends observed in the TCE oxidation reactions. In fact, TCE recovery calculations for this experiment indicate TCE oxidation values of $96-100 \%$ in spite of the fact that an aqueous TCE residual was present. 
The general trend of rapid TCE oxidation was still observed. If one were to assume that the residual TCE concentrations $(\approx 200 \mu \mathrm{g} / \mathrm{L}$ ) are due to contamination, complete TCE oxidation likely occurred within $15 \mathrm{hrs}$ and within $0.5 \mathrm{hrs}$ for the $0.01 \%$ and $0.1 \% \mathrm{MnO}_{4}{ }^{-}$reactors, respectively. (These values were determined by extrapolating the initially rapid portion of the curves in Figure 63 to a concentration of $10 \mu \mathrm{g} / \mathrm{L}$ TCE.) Although there are more than three TCE data points present, a rate constant was not computed for this experiment since it is likely that the accuracy of the $\mathrm{T}=5 \mathrm{hrs}$ data points is questionable. However, observed rates of TCE oxidation are estimated to be greater than 0.5 and $13.8 \mathrm{mg} \mathrm{TCE} / \mathrm{hr}$ for the $0.01 \%$ and $0.1 \%$ $\mathrm{MnO}_{4}{ }^{-}$reactors, respectively.

A significant amount of oxidant was consumed by the treatment reactors. Approximately $73 \%$ and $58 \%$ of the initial oxidant mass was consumed in the $0.01 \%$ and $0.1 \% \mathrm{MnO}_{4}{ }^{-}$reactors, respectively. However, the $\mathrm{MnO}_{4}{ }^{-}$consumption values from this experiment (Table 40) indicate that a much greater $\mathrm{MnO}_{4}{ }^{-}$mass was consumed in the $0.1 \% \mathrm{MnO}_{4}{ }^{-}$reactors than observed for the $0.01 \% \mathrm{MnO}_{4}{ }^{-}$reactors. This trend was not observed in the dissolved plume media experiments spiked at much lower TCE concentrations. Since the oxidant demand of the TSF-05 GW was not significantly high (Task 3 work), the oxidant demand observed here was attributed to the large TCE spike concentrations.

The $\mathrm{pH}$ values within the treatment reactors decreased rapidly during the oxidation the TCE spiked GW (Figure 65). The $\mathrm{pH}$ of the $0.01 \% \mathrm{MnO}_{4}{ }^{-}$reactors reached a final $\mathrm{pH}$ value of $\approx 7.8$, a net decrease of $>0.8 \mathrm{pH}$ units. Similarly, the $0.1 \% \mathrm{MnO}_{4}{ }^{-}$loading resulted in final $\mathrm{pH}$ values of $\approx 7.7$, a net decrease of $>0.9 \mathrm{pH}$ units. The rate at which the $\mathrm{pH}$ dropped, however, was greatest for the $0.1 \% \mathrm{MnO}_{4}^{-}$reactors. The general trend of these $\mathrm{pH}$ changes corresponds with the TCE decreases observed (Figure 63). Thus, the $\mathrm{pH}$ decreases appear to be directly related to the oxidation of the TCE in the reactors. 


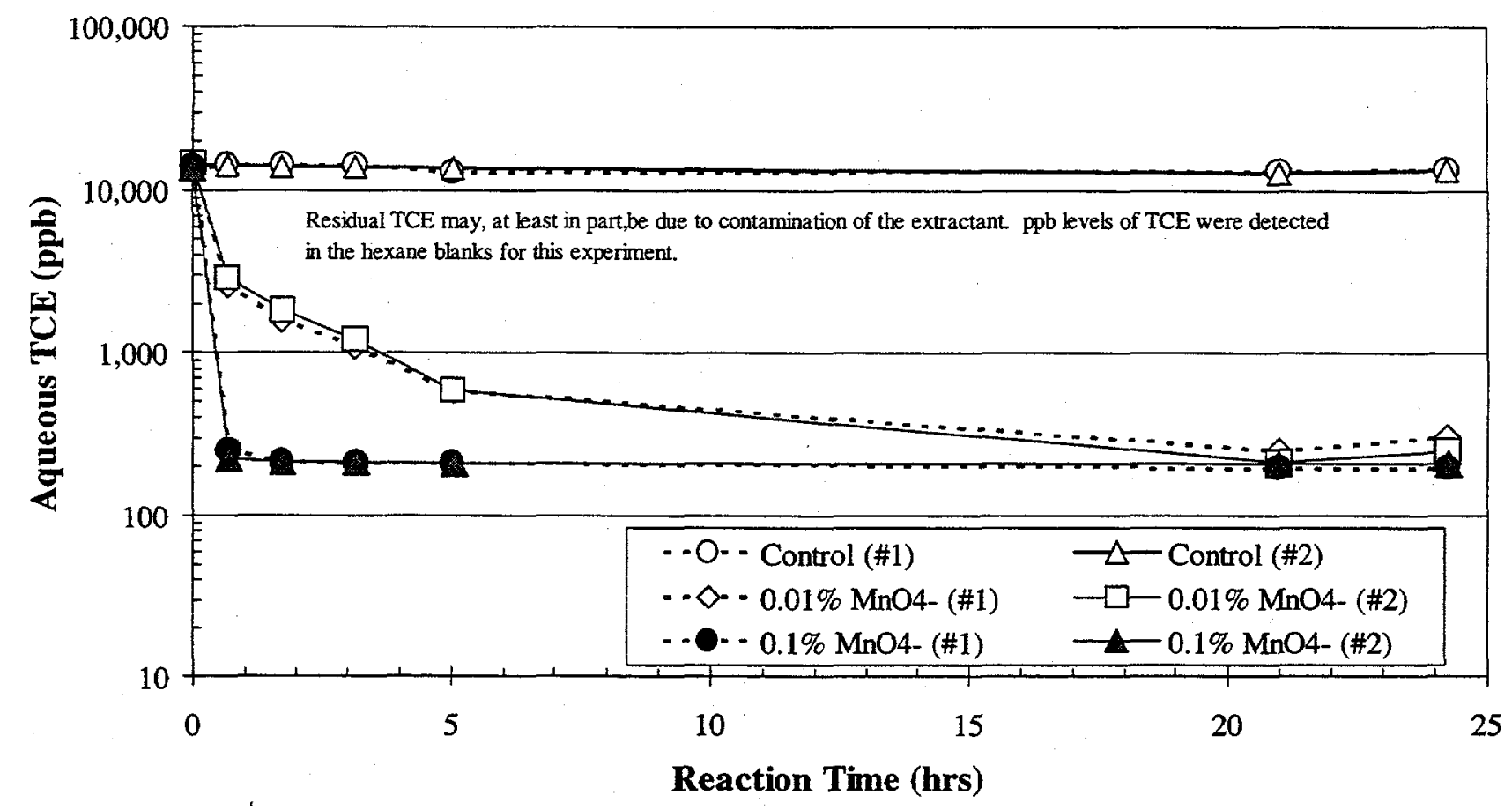

Figure 63. TCE vs. Time, TSF-05 GW, (ORNL Exp. 4b-R1, Initial TCE $=10,000 \mu \mathrm{g} / \mathrm{L}$, Conducted at $12^{\circ} \mathrm{C}$ )

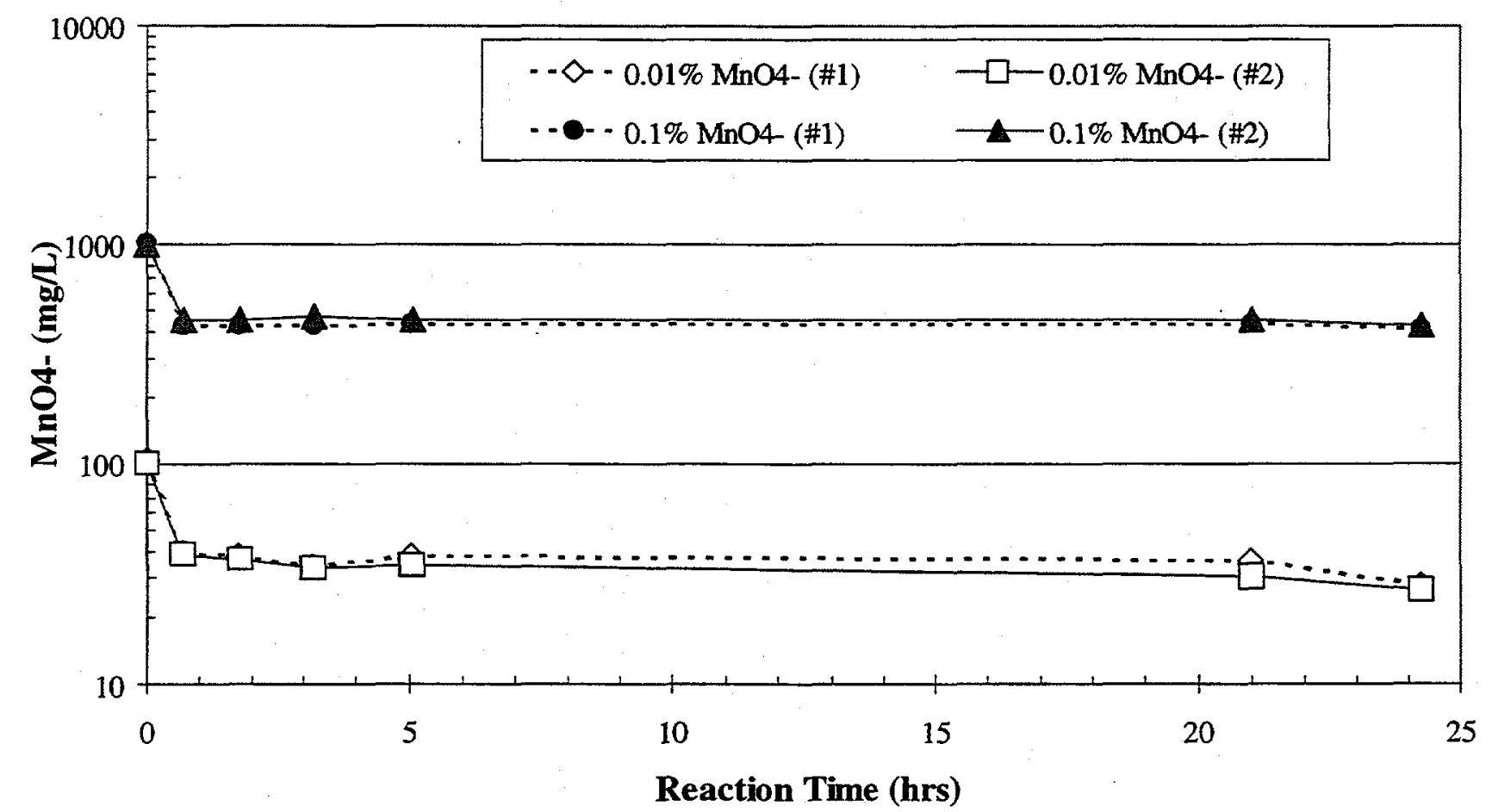

Figure 64. $\mathrm{MnO}_{4}^{-}$vs. Time, TSF-05 GW, (ORNL Exp. 4b-R1, Initial TCE $=10,000 \mu \mathrm{g} / \mathrm{L}$, Conducted at $12^{\circ} \mathrm{C}$ ) 


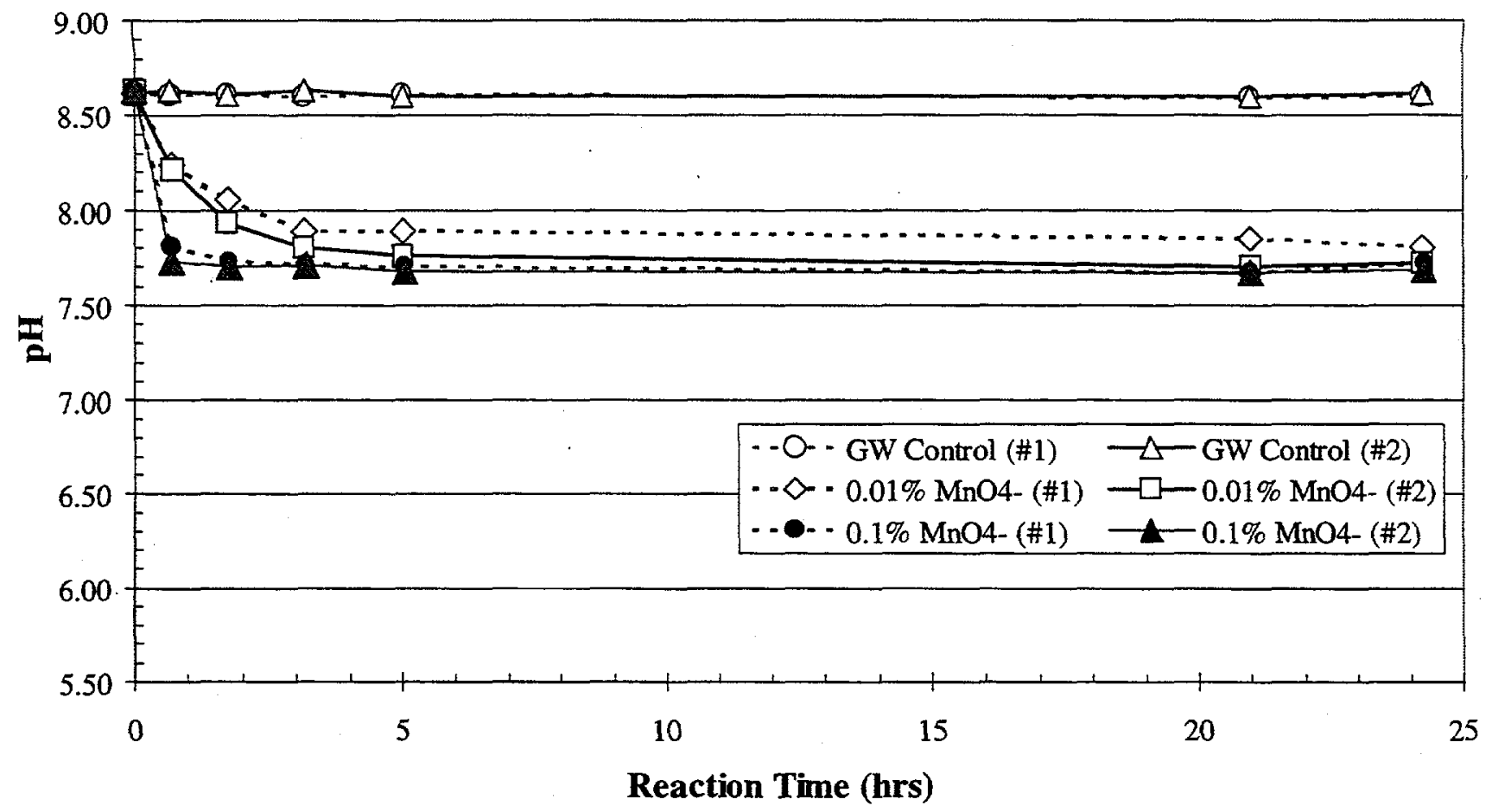

Figure 65. pH vs. Time, TSF-05 GW, (ORNL Exp. 4b-R1, Initial TCE $=10,000 \mu \mathrm{g} / \mathrm{L}$, Conducted at $12^{\circ} \mathrm{C}$ ) 
Table 39. TCE Mass Balance for ORNL Exp. 4b-R1 (TSF-05 GW).

\begin{tabular}{|l|l|l|l|l|l|l|l|}
\hline Test Condition & $\begin{array}{l}\text { Total } \\
\text { Initial } \\
\text { Mass } \\
(\mathrm{mg})\end{array}$ & $\begin{array}{l}\text { Initial } \\
\text { Aqueous } \\
\text { Mass } \\
(\mathrm{mg})\end{array}$ & $\begin{array}{l}\text { Mass } \\
\text { Sorbed on } \\
\text { Orbo Tubes } \\
(\mathrm{mg})\end{array}$ & $\begin{array}{l}\text { Mass } \\
\text { Remaining in } \\
\text { Reactor (mg) }\end{array}$ & $\begin{array}{l}\text { Cum. } \\
\text { Mass } \\
\text { Removed } \\
\text { in Aliquots } \\
(\mathrm{mg})\end{array}$ & $\begin{array}{l}\text { Cum. } \\
\text { Aqueous } \\
\text { Mass } \\
\text { Oxidized } \\
(\mathrm{mg})\end{array}$ & $\begin{array}{l}\text { Total Mass } \\
\text { Recovered } \\
(\mathrm{mg})\end{array}$ \\
\hline Control (\#1) & 6.4 & 6.4 & $\begin{array}{c}0.000 \\
0 \%\end{array}$ & $\begin{array}{c}5.5 \\
87 \%\end{array}$ & $\begin{array}{c}0.9 \\
14 \%\end{array}$ & $\begin{array}{c}\text { NA } \\
\text { NA }\end{array}$ & $\begin{array}{c}6.4 \\
101 \%\end{array}$ \\
\hline Control (\#2) & 7.1 & 7.1 & $\begin{array}{c}0.000 \\
0 \%\end{array}$ & $\begin{array}{c}5.9 \\
83 \%\end{array}$ & $\begin{array}{c}0.8 \\
12 \%\end{array}$ & $\begin{array}{c}\text { NA } \\
\text { NA }\end{array}$ & $\begin{array}{c}6.7 \\
95 \%\end{array}$ \\
\hline $0.01 \%(\# 1)$ & 7.2 & 7.2 & $\begin{array}{c}0.000 \\
0 \%\end{array}$ & $\begin{array}{c}0.00 \\
0 \%\end{array}$ & $\begin{array}{c}0.2 \\
2 \%\end{array}$ & $\begin{array}{c}6.9 \\
96 \%\end{array}$ & $\begin{array}{c}7.0 \\
98 \%\end{array}$ \\
\hline $0.01 \%(\# 2)$ & 7.5 & 7.5 & 0.000 & 0.00 & 0.2 & 7.3 & 7.4 \\
& & & $0 \%$ & $0 \%$ & $2 \%$ & $97 \%$ & $99 \%$ \\
\hline $0.1 \%(\# 1)$ & 6.9 & 6.9 & 0.000 & 0.00 & 0.1 & 6.9 & 7.0 \\
& & & $0 \%$ & $0 \%$ & $2 \%$ & $100 \%$ & $101 \%$ \\
\hline $0.1 \%(\# 2)$ & 6.9 & 6.9 & 0.000 & 0.00 & 0.1 & 6.9 & 7.0 \\
& & & $0 \%$ & $0 \%$ & $2 \%$ & $99 \%$ & $101 \%$ \\
\hline
\end{tabular}

Table 40. $\mathrm{MnO}_{4}{ }^{-}$Consumption Data for ORNL Exp. 4b-R1 (TSF-05 GW).

\begin{tabular}{|c|c|c|c|c|}
\hline Test Condition & $\begin{array}{l}\text { Initial } \\
\text { Oxidant } \\
\left(\mathrm{mg} \mathrm{MnO}_{4}\right)\end{array}$ & $\begin{array}{l}\text { Initial } \\
\text { Loading } \\
\left(\mathrm{mg} \mathrm{MnO}_{4}^{-} / \mathrm{g}\right)\end{array}$ & $\begin{array}{l}\text { Cum. } \\
\text { Consumed } \\
\left(\mathrm{mg} \mathrm{MnO}_{4}\right)\end{array}$ & $\begin{array}{l}\text { Cum. } \\
\text { Consumed } \\
\left(\mathrm{mg} \mathrm{MnO}_{4} / \mathrm{g}\right)\end{array}$ \\
\hline $0.01 \%(\# 1)$ & 51.2 & 0.10 & 37.37 & 0.08 \\
\hline $0.01 \%(\# 2)$ & 51.2 & 0.10 & 37.63 & 0.07 \\
\hline $0.1 \%(\# 1)$ & 511.5 & 1.01 & 303.72 & 0.60 \\
\hline $0.1 \%(\# 2)$ & 511.5 & 1.00 & 293.90 & 0.57 \\
\hline
\end{tabular}

a. Consumption is computed after $24 \mathrm{hr}$ reaction time. 
ORNL Exp. 4b-R2

(TSF-05 GW, No Sludge, 10,000 TCE, 0 Other, $1 \%$ and $3 \% \mathrm{MnO}_{4}{ }^{-}$)

This experiment investigated the oxidation of TSF-05 GW spiked at $10,000 \mu \mathrm{g} / \mathrm{L} \mathrm{TCE}$. The TCE, $\mathrm{MnO}_{4}{ }^{-}$and $\mathrm{pH}$ values with time are presented in Figures 66, 67, and 68, respectively. Tables 41 and 42 provide additional TCE mass balance and oxidant consumption information. The (\#1) and (\#2) notations included in both the figure legends and the first column of these tables refer to the duplicate reactors evaluated for that test condition.

This experiment was performed without significant deviations from the testplan procedure.

After equilibration, the average initial aqueous TCE concentration of the spike solution was $12,426 \mu \mathrm{g} / \mathrm{L}(\sigma=1,470 \mu \mathrm{g} / \mathrm{L})$. After transfer to the test reactors the groundwater TCE concentration ranged between 8,900 and $12,200 \mu \mathrm{g} / \mathrm{L}$ ( $\mathrm{T}=0$ aliquots) prior to the start of the oxidation reactions. While a part of this wide variability may be due to human error in performing sample dilutions, some TCE was likely lost during transfer of the spiked GW to the test reactors.

TCE was not detected in the desorption tube extracts. TCE recoveries for the control samples were only $82 \%$ and $92 \%$. The majority of this TCE loss occurred between the T=0 hrs and $\mathrm{T}=0.5 \mathrm{hrs}$ sampling periods, when the TCE concentrations dropped from $\approx 12,000 \mu \mathrm{g} / \mathrm{L}$ to $\approx 10,000 \mu \mathrm{g} / \mathrm{L}$.

From Figure 66, the rate of disappearance of TCE from the treatment reactors significantly exceeded the rate of TCE loss from the control reactors. Thus, oxidation is the controlling TCE removal mechanism for this experiment, although a small fraction of the TCE disappearance may be due to volatilization. TCE was not detected in any of the four treatment reactors at the end of the $24 \mathrm{hr}$ reaction period. TCE recovery calculations for this experiment indicate TCE oxidation values of $99 \%$ and total TCE recoveries of $100 \%$. Since control reactor recoveries were low (8992\%), one could be conservative and report the maximum TCE oxidation as $82-92 \%$.

It is unknown why the oxidation reaction slowed for the first $1 \% \mathrm{MnO}_{4}{ }^{-}$reactor, but complete TCE oxidation appears to have occurred within $2 \mathrm{hrs}$ for the second $1 \% \mathrm{MnO}_{4}{ }^{-}$reactor. Enough data points are not available to compute a rate constant; however, the observed oxidation rate is greater than $2.65 \mathrm{mg} \mathrm{TCE} / \mathrm{hr}$ for the second $1 \% \mathrm{MnO}_{4}{ }^{-}$reactor. Complete TCE oxidation for both $3 \% \mathrm{MnO}_{4}{ }^{-}$reactors occurred within $0.5 \mathrm{hrs}$, yielding an observed oxidation rate greater than $10 \mathrm{mg} \mathrm{TCE} / \mathrm{hr}$ for the $3 \% \mathrm{MnO}_{4}^{-}$reactors.

As observed in the Task 3 oxidant demand experiments, not all of the initial $\mathrm{MnO}_{4}{ }^{-}$mass added to each reactor was solubilized at the $0.5 \mathrm{hr}$ sampling point. A maximum of $10 \%$ of the initial oxidant was consumed in the $3 \% \mathrm{MnO}_{4}{ }^{-}$reactors. Oxidant consumption in the $1 \% \mathrm{MnO}_{4}{ }^{-}$ reactors varied between $-5 \%$ and $+5 \%$ (see Table 42 ). The occurrence of negative consumption value is likely due to difficulties in performing accurate dilutions $(\mathrm{DF} \approx 1600)$ for the $\mathrm{MnO}_{4}{ }^{-}$ analyses. These low consumption values were not unexpected since there was even a residual $\mathrm{MnO}_{4}{ }^{-}$concentration in the $0.01 \% \mathrm{MnO}_{4}{ }^{-}$reactors of experiment $4 \mathrm{~b}-\mathrm{Rl}$ (Figure 64). 
In this experiment, the $\mathrm{pH}$ values within the treatment reactors rapidly and significantly changed during the oxidation the TCE spiked $\mathrm{GW}$. The $1 \% \mathrm{MnO}_{4}{ }^{-}$reactors experienced an initial $\mathrm{pH}$ decrease of $\approx 0.4 \mathrm{pH}$, but the $\mathrm{pH}$ values then rebounded until a final net $\mathrm{pH}$ decrease of $<0.1 \mathrm{pH}$ units was obtained. (Recall that the $0.01 \%$ and $0.1 \% \mathrm{MnO}_{4}{ }^{-}$reactors in Exp. $4 \mathrm{~b}-\mathrm{R} 1$ also experienced overall $\mathrm{pH}$ decreases as a result of the oxidation reactions.) In contrast, an initial $\mathrm{pH}$ decrease was not observed for the $3 \% \mathrm{MnO}_{4}{ }^{-}$reactors. Moreover, the $3 \% \mathrm{MnO}_{4}{ }^{-}$reactors experienced a pH increase of $\approx 0.4 \mathrm{pH}$ units during the course of the reaction period. This phenomenon may be due to the initially higher $\mathrm{pH}$ of the $3 \% \mathrm{MnO}_{4}{ }^{-}$solution. 


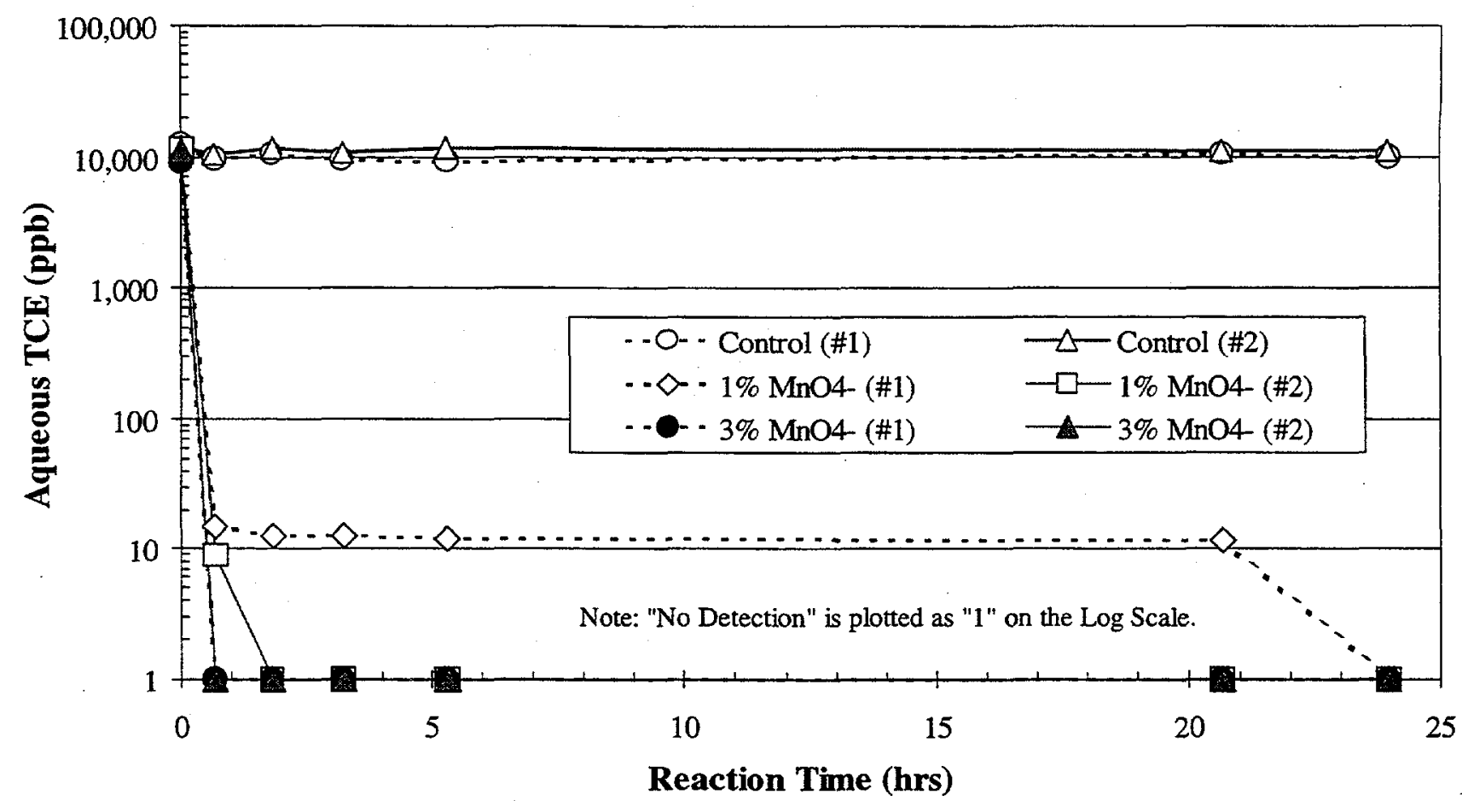

Figure 66. TCE vs. Time, TSF-05 GW, (ORNL Exp. 4b-R2, Initial TCE $=10,000 \mu \mathrm{g} / \mathrm{L}$, Conducted at $12^{\circ} \mathrm{C}$ )

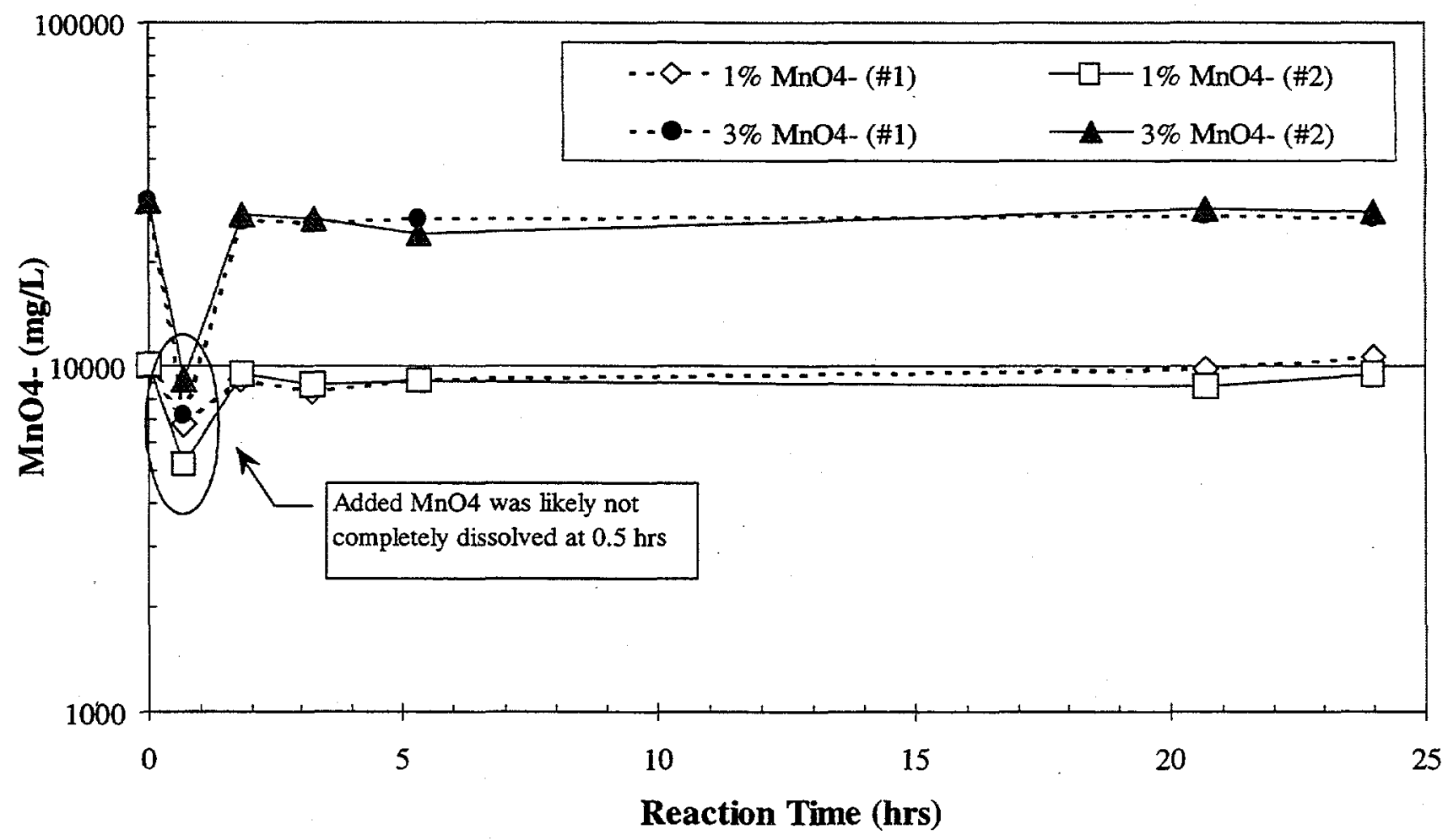

Figure 67. $\mathrm{MnO}_{4}{ }^{-}$vs. Time, TSF-05 GW, (ORNL Exp. 4b-R2, Initial TCE $=10,000 \mu \mathrm{g} / \mathrm{L}$, Conducted at $12^{\circ} \mathrm{C}$ ) 


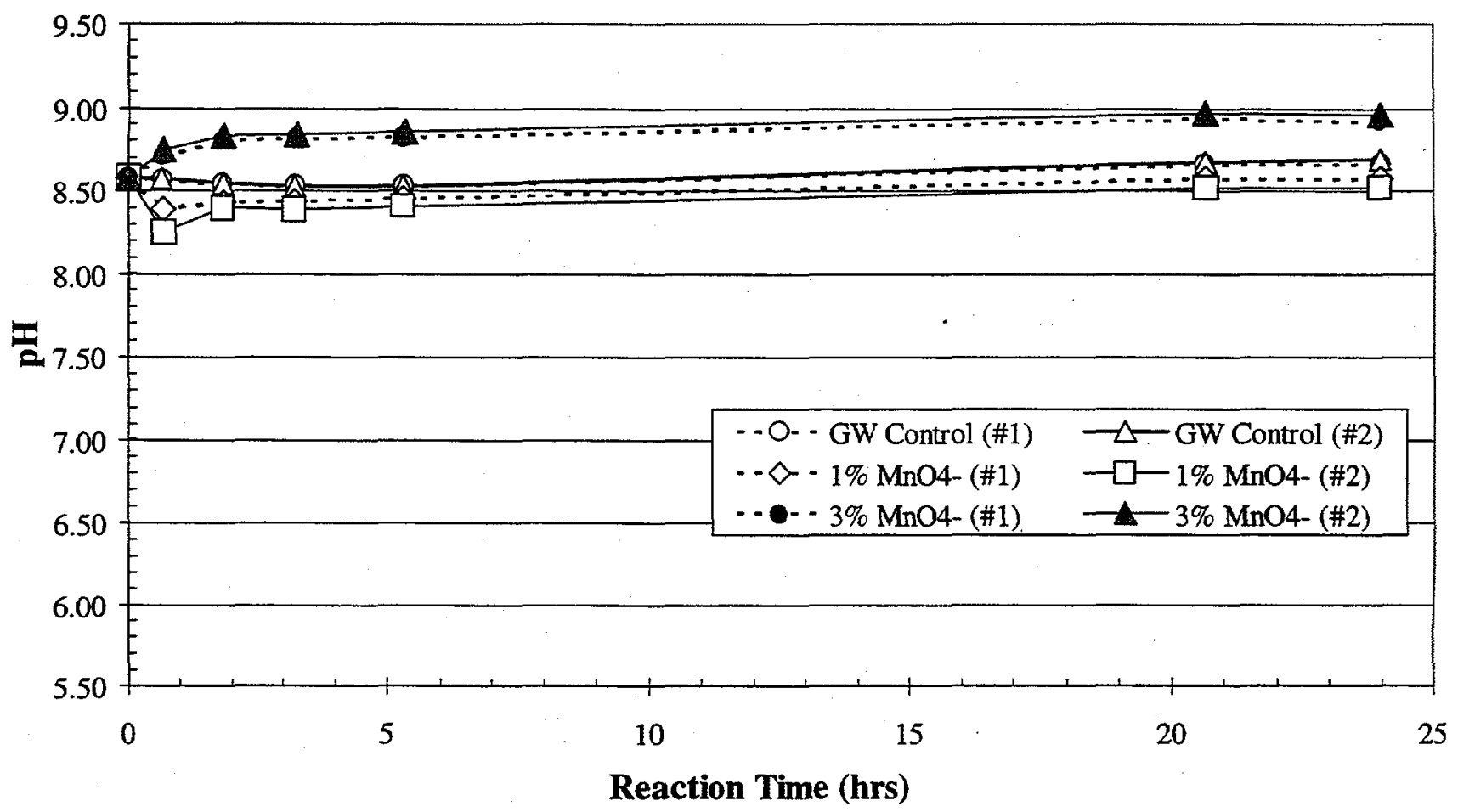

Figure 68. pH vs. Time, TSF-05 GW, (ORNL Exp. 4b-R2 Initial TCE $=10,000 \mu \mathrm{g} / \mathrm{L}$, Conducted at $12^{\circ} \mathrm{C}$ ) 
Table 41. TCE Mass Balance for ORNL Exp. 4b-R2 (TSF-05 GW).

\begin{tabular}{|c|c|c|c|c|c|c|c|}
\hline Test Condition & \begin{tabular}{|l|} 
Total \\
Initial \\
Mass \\
(mg)
\end{tabular} & \begin{tabular}{|l|} 
Initial \\
Aqueous \\
Mass \\
(mg)
\end{tabular} & \begin{tabular}{|l|} 
Mass \\
Sorbed on \\
Orbo Tubes \\
(mg)
\end{tabular} & \begin{tabular}{|l|} 
Mass \\
Remaining in \\
Reactor (mg)
\end{tabular} & \begin{tabular}{|l|} 
Cum. \\
Mass \\
Removed \\
in Aliquots \\
(mg) \\
\end{tabular} & \begin{tabular}{|l|} 
Cum. \\
Aqueous \\
Mass \\
Oxidized \\
(mg) \\
\end{tabular} & $\begin{array}{l}\text { Total Mass } \\
\text { Recovered } \\
\text { (mg) }\end{array}$ \\
\hline Control (\#1) & 6.3 & 6.3 & $\begin{array}{c}0.000 \\
0 \%\end{array}$ & $\begin{array}{r}4.6 \\
73 \% \\
\end{array}$ & $\begin{array}{c}0.6 \\
10 \%\end{array}$ & $\begin{array}{l}\text { NA } \\
\text { NA }\end{array}$ & $\begin{array}{c}5.2 \\
82 \%\end{array}$ \\
\hline Control (\#2) & 6.0 & 6.0 & $\begin{array}{c}0.000 \\
0 \%\end{array}$ & $\begin{array}{r}4.8 \\
81 \% \\
\end{array}$ & $\begin{array}{c}0.6 \\
11 \%\end{array}$ & $\begin{array}{l}\mathrm{NA} \\
\mathrm{NA}\end{array}$ & $\begin{array}{c}5.5 \\
92 \%\end{array}$ \\
\hline $1 \%(\# 1)$ & 4.9 & 4.9 & $\begin{array}{c}0.000 \\
0 \% \\
\end{array}$ & $\begin{array}{l}0.00 \\
0 \% \\
\end{array}$ & $\begin{array}{l}0.1 \\
1 \% \\
\end{array}$ & $\begin{array}{r}4.8 \\
99 \% \\
\end{array}$ & $\begin{array}{c}4.9 \\
100 \% \\
\end{array}$ \\
\hline $1 \%(\# 2)$ & 5.7 & 5.7 & $\begin{array}{c}0.000 \\
0 \%\end{array}$ & $\begin{array}{c}0.00 \\
0 \%\end{array}$ & $\begin{array}{l}0.1 \\
1 \%\end{array}$ & $\begin{array}{r}5.6 \\
99 \%\end{array}$ & $\begin{array}{c}5.7 \\
100 \%\end{array}$ \\
\hline $3 \%(\# 1)$ & 4.4 & 4.4 & $\begin{array}{c}0.000 \\
0 \% \\
\end{array}$ & $\begin{array}{c}0.00 \\
0 \% \\
\end{array}$ & $\begin{array}{l}0.1 \\
1 \% \\
\end{array}$ & $\begin{array}{r}4.4 \\
99 \% \\
\end{array}$ & $\begin{array}{c}4.4 \\
100 \% \\
\end{array}$ \\
\hline $3 \%(\# 2)$ & 5.6 & 5.6 & $\begin{array}{c}0.000 \\
0 \%\end{array}$ & $\begin{array}{c}0.00 \\
0 \%\end{array}$ & $\begin{array}{l}0.1 \\
1 \%\end{array}$ & $\begin{array}{r}5.5 \\
99 \%\end{array}$ & $\begin{array}{c}5.6 \\
100 \%\end{array}$ \\
\hline
\end{tabular}

Table 42. $\mathrm{MnO}_{4}{ }^{-}$Consumption Data for ORNL Exp. 4b-R2 (TSF-05 GW).

\begin{tabular}{|c|l|l|l|l|}
\hline Test Condition & $\begin{array}{l}\text { Initial } \\
\text { Oxidant } \\
\left(\mathrm{mg} \mathrm{MnO}_{4}\right)^{-}\end{array}$ & $\begin{array}{l}\text { Initial } \\
\text { Loading } \\
\left(\mathrm{mg} \mathrm{MnO}_{4} / \mathrm{g}\right)\end{array}$ & $\begin{array}{l}\text { Cum. } \\
\text { Consumed } \\
\left(\mathrm{mg} \mathrm{MnO}_{4}\right)^{-}\end{array}$ & $\begin{array}{l}\text { Cum. } \\
\text { Consumed } \\
\left(\mathrm{mg} \mathrm{MnO}_{4} / \mathrm{g}\right)\end{array}$ \\
\hline $1 \%(\# 1)$ & 4975 & 10.1 & -241 & -0.5 \\
\hline $1 \%(\# 2)$ & 4967 & 10.1 & 291 & 0.6 \\
\hline $3 \%(\# 1)$ & 15065 & 30.6 & 1728 & 3.5 \\
\hline $3 \%(\# 2)$ & 15075 & 30.3 & 1066 & 2.1 \\
\hline
\end{tabular}

a. Consumption is computed after $24 \mathrm{hr}$ reaction time. 
ORNL Exp. 4b-R3

(TSF-05 GW, No Sludge, 100,000 TCE, 0 Other, $0.01 \%$ and $0.1 \% \mathrm{MnO}_{4}{ }^{-}$)

This experiment investigated the oxidation of TSF-05 GW spiked at 100,000 $\mu \mathrm{g} / \mathrm{L}$ TCE. The TCE, $\mathrm{MnO}_{4}{ }^{-}$and $\mathrm{pH}$ values with time are presented in Figures 69, 70, and 71, respectively. Tables 43 and 44 provide additional TCE mass balance and oxidant consumption information. The (\#1) and (\#2) notations included in both the figure legends and the first column of these tables refer to the duplicate reactors evaluated for that test condition.

In this experiment, the method used to prepare the TSF-05 spike solution differed from the approach set forth in the testplan. Here, a small quantity of pure phase TCE $(\approx 280 \mu \mathrm{L})$ was added to the Tedlar bag filled with sparged GW. The approach described in the testplan involved the use of a saturated aqueous TCE solution rather than pure phase TCE in the spiking step. A $96 \mathrm{hr}$ reaction time was also evaluated in this experiment, while the tests were terminated at $24 \mathrm{hrs}$ in the procedure described in the testplan.

After equilibration, the average initial aqueous TCE concentration of the spike solution was $148,400 \mu \mathrm{g} / \mathrm{L}(\sigma=1,020 \mu \mathrm{g} / \mathrm{L})$. After transfer to the test reactors the groundwater TCE concentration ranged between 97,500 and $107,800 \mu \mathrm{g} / \mathrm{L}$ ( $\mathrm{T}=0$ aliquots) prior to the start of the oxidation reactions. While a part of this wide variability may be due to human error in performing sample dilutions, some TCE was likely lost during transfer of the spiked GW to the test reactors.

TCE was detected in the first charcoal bed of the desorption tubes. TCE recoveries for the control samples were $115 \%$ and $116 \%$. A closer examination of the experimental data provides explanation to this apparent net increase in TCE. This experiment was continued past $24 \mathrm{hrs}$ and the last aliquot samples were collected at $\mathrm{T}=96 \mathrm{hrs}$. All aqueous aliquots collected between $\mathrm{T}=0$ hrs and $\mathrm{T}=24 \mathrm{hrs}$ were extracted and analyzed on the day the $24 \mathrm{hr}$ samples were collected. The final $96 \mathrm{hr}$ aliquot sample was immediately extracted and analyzed on the day it was collected. GC performance was well within defined limits on both analysis days (max $5 \%$ drift of calibration check standard). The TCE values obtained for the $24 \mathrm{hr}$ and $96 \mathrm{hr}$ samples were both greater than any obtained from TCE aliquots collected between 0 and 20 hrs. Thus, it is believed that TCE was lost from the diluted 0-20 hrs GC extracts during the time elapsed between sample collection/extraction and sample analysis. Computing the \% recovery of control reactors using the data for the $0-20 \mathrm{hrs}$ timeframe results in recoveries of near $95 \%$. Total TCE recoveries for all four (4) treatment reactors are between 100-103\%.

This discrepancy resulting from sample holding times should not affect the validity of this experiment. In fact, the discrepancy should theoretically result in conservative TCE oxidation rates since a shorter holding time for the $24 \mathrm{hrs}$ aliquots would be expected to produce a larger TCE residual at the end of the reaction period. Hence, the calculated reaction rates are less than the true reaction rates. It should be noted that this sample holding time problem likely affected other experiments. The effect was heightened here because of the very high TCE spike concentrations being evaluated. Thus, this problem is not believed to have adversely affected the results of the other experiments. 
From Figure 69, TCE concentrations initially decreased for the $0.01 \% \mathrm{MnO}_{4}{ }^{-}$reactors, but a residual TCE concentration was still present following the $96 \mathrm{hr}$ reaction period. The slowed TCE oxidation rate observed for the $0.01 \% \mathrm{MnO}_{4}{ }^{-}$reactors at $\approx 4 \mathrm{hrs}$ coincides well with the nearly total depletion of available oxidant for these reactors (Figure 70). Thus, a shortage of available oxidant existed for the $0.01 \% \mathrm{MnO}_{4}{ }^{-}$reactors. This behavior is different than that seen in previous experiments, where the $\mathrm{MnO}_{4}{ }^{-}$masses have always been in excess of that required for TCE oxidation. While not called for in the testplan, the final treatment reactors were also extracted and analyzed in this experiment. The final TCE masses remaining in the reactors (Table 43) were obtained from these extractions. An average of $68 \%$ of the initial TCE was oxidized in the $0.01 \% \mathrm{MnO}_{4}{ }^{-}$reactors. Enough data points are not available to compute a rate constant; however, the observed oxidation rate during the $4 \mathrm{hr}$ period is greater than $7.25 \mathrm{mg}$ TCE/hr.

Complete TCE oxidation occurred in the $0.1 \% \mathrm{MnO}_{4}{ }^{-}$reactors within $0.5 \mathrm{hrs}$. While the reaction proceeded too rapidly to determine a rate constant, an observed oxidation rate of $82 \mathrm{mg} \mathrm{TCE} / \mathrm{hr}$ was determined for the $0.1 \% \mathrm{MnO}_{4}{ }^{-}$reactors.

Essentially all of the initial $0.01 \% \mathrm{MnO}_{4}{ }^{-}$was consumed during the oxidation reaction. $\mathrm{A} \mathrm{MnO}_{4}{ }^{-}$ residual of approximately $1 \mathrm{mg} / \mathrm{L}$ was measured (Figure 70), but the lowest $\mathrm{MnO}_{4}{ }^{-}$calibration standard was $5 \mathrm{mg} / \mathrm{L}$. Excess $\mathrm{MnO}_{4}{ }^{-}$was present in the $0.1 \% \mathrm{MnO}_{4}{ }^{-}$treatment reactors. An average of $18 \%$ of initial $0.1 \% \mathrm{MnO}_{4}{ }^{-}$was consumed during the oxidation of the $100,000 \mu \mathrm{g} / \mathrm{L}$ spiked TSF-05 GW.

The $\mathrm{pH}$ values within the treatment reactors decreased to a much greater extent than observed for the TSF-05 GW experiments spiked at only 10,000 $\mu \mathrm{g} / \mathrm{L}$ (Exp. 4b-R1). Here too, the greatest pH decreases occurred in the $0.1 \% \mathrm{MnO}_{4}{ }^{-}$reactors. Net $\mathrm{pH}$ decreases of 1.5 and $1.8 \mathrm{pH}$ units were observed for the $0.01 \%$ and $0.1 \% \mathrm{MnO}_{4}{ }^{-}$reactors. Since all conditions other than the initial TCE are the same between this experiment and Exp. $4 \mathrm{~b}-\mathrm{R} 1$, the significant $\mathrm{pH}$ reductions must be a result of the TCE oxidation reactions.

Finally, it is interesting to note from Figures 69 and 70 that nearly the same TCE and final $\mathrm{MnO}_{4}{ }^{-}$consumption values would have been obtained for these particular oxidant loadings even if a $24 \mathrm{hr}$ reaction period had been evaluated instead of a $96 \mathrm{hr}$ reaction period. This observation provides confidence in the use of a $24 \mathrm{hr}$ reaction time in other experiments to assess TCE oxidation. 


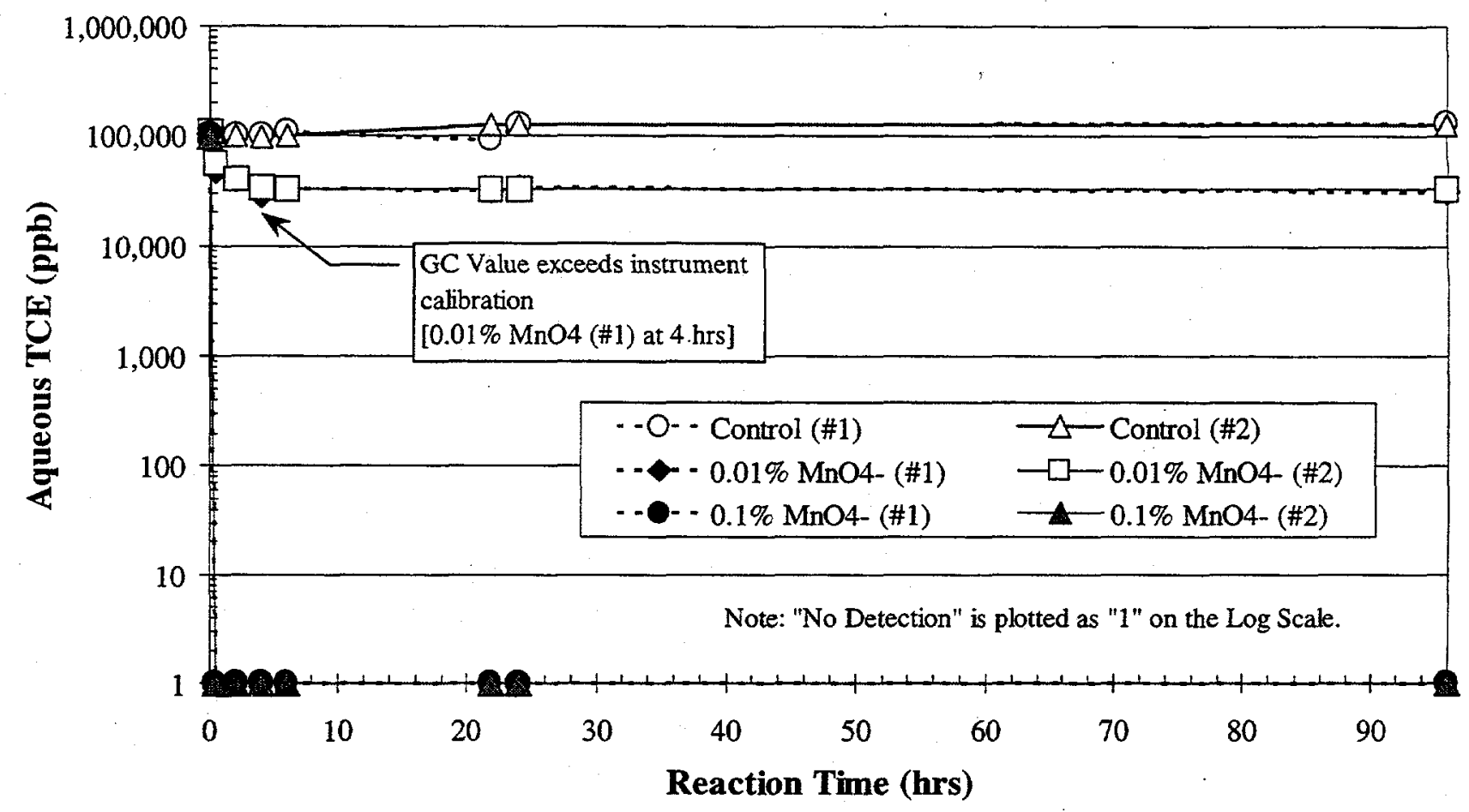

Figure 69. TCE vs. Time, TSF-05 GW, (ORNL Exp. 4b-R3, Initial TCE $=100,000 \mu \mathrm{g} / \mathrm{L}$, Conducted at $12^{\circ} \mathrm{C}$ )

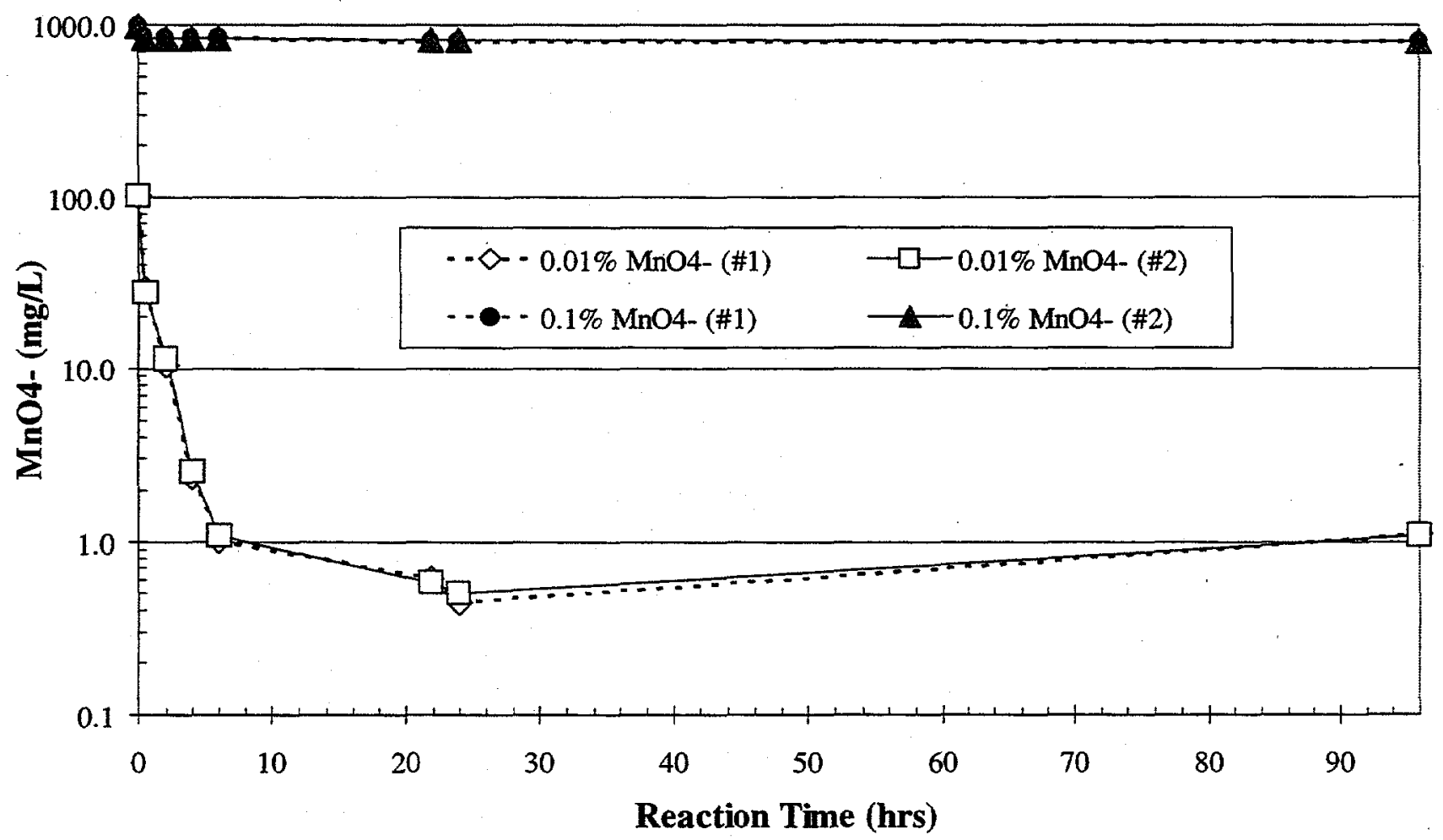

Figure 70. $\mathrm{MnO}_{4}{ }^{-}$vs. Time, TSF-05 GW, (ORNL Exp. 4b-R3, Initial TCE $=100,000 \mu \mathrm{g} / \mathrm{L}$, Conducted at $12^{\circ} \mathrm{C}$ ) 


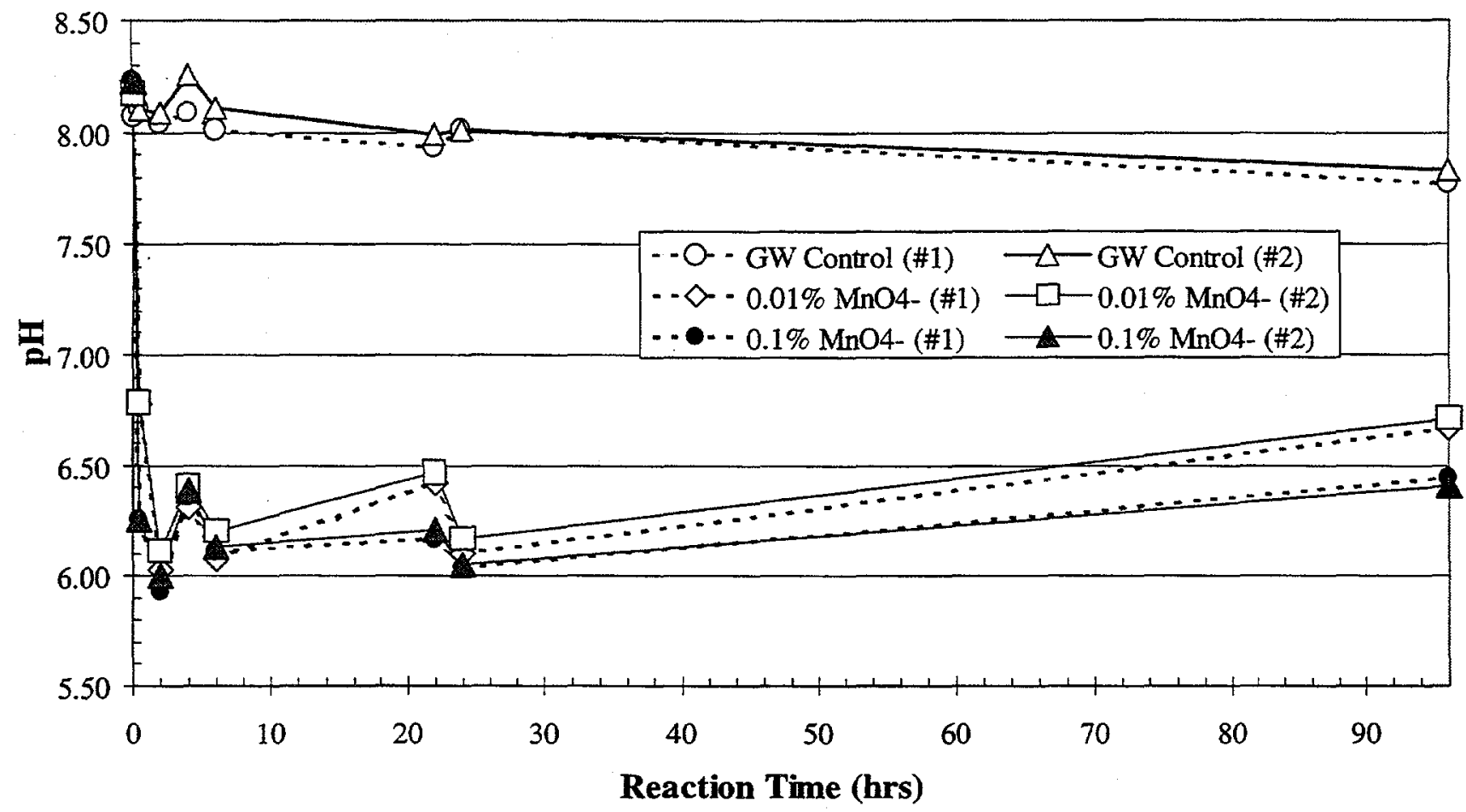

Figure 71. pH vs. Time, TSF-05 GW, (ORNL Exp. 4b-R3, Initial TCE $=100,000 \mu \mathrm{g} / \mathrm{L}$, Conducted at $12^{\circ} \mathrm{C}$ ) 
Table 43. TCE Mass Balance for ORNL Exp. 4b-R3 (TSF-05 GW).

\begin{tabular}{|c|c|c|c|c|c|c|c|}
\hline Test Condition & $\begin{array}{l}\text { Total } \\
\text { Initial } \\
\text { Mass } \\
\text { (mg) }\end{array}$ & \begin{tabular}{|l} 
Initial \\
Aqueous \\
Mass \\
(mg)
\end{tabular} & \begin{tabular}{|l|} 
Mass \\
Sorbed on \\
Orbo Tubes \\
(mg)
\end{tabular} & $\begin{array}{l}\text { Mass } \\
\text { Remaining in } \\
\text { Reactor (mg) }\end{array}$ & $\begin{array}{l}\text { Cum. } \\
\text { Mass } \\
\text { Removed } \\
\text { in Aliquots } \\
(\mathrm{mg}) \\
\end{array}$ & $\begin{array}{l}\text { Cum. } \\
\text { Aqueous } \\
\text { Mass } \\
\text { Oxidized } \\
\text { (mg) }\end{array}$ & $\begin{array}{l}\text { Total Mass } \\
\text { Recovered } \\
(\mathrm{mg})\end{array}$ \\
\hline Control (\#1) & 43 & 43 & $\begin{array}{c}0.012 \\
0 \% \\
\end{array}$ & $\begin{array}{c}39 \\
90 \% \\
\end{array}$ & $\begin{array}{c}11 \\
26 \% \\
\end{array}$ & $\begin{array}{l}\mathrm{NA} \\
\mathrm{NA} \\
\end{array}$ & $\begin{array}{c}50 \\
115 \% \\
\end{array}$ \\
\hline Control (\#2) & 43 & 43 & $\begin{array}{c}0.007 \\
0 \% \\
\end{array}$ & $\begin{array}{r}39 \\
90 \% \\
\end{array}$ & $\begin{array}{c}11 \\
26 \% \\
\end{array}$ & $\begin{array}{l}\text { NA } \\
\text { NA }\end{array}$ & $\begin{array}{c}50 \\
116 \% \\
\end{array}$ \\
\hline $0.01 \%(\# 1)$ & 43 & 43 & $\begin{array}{c}0.006 \\
0 \% \\
\end{array}$ & $\begin{array}{c}10^{\dagger} \\
23 \%^{\dagger} \\
\end{array}$ & $\begin{array}{r}4 \\
9 \% \\
\end{array}$ & $\begin{array}{r}29 \\
69 \% \\
\end{array}$ & $\begin{array}{c}43 \\
101 \% \\
\end{array}$ \\
\hline $0.01 \%(\# 2)$ & 43 & 43 & $\begin{array}{c}0.034 \\
0 \% \\
\end{array}$ & $\begin{array}{c}10^{\dagger} \\
23 \%^{\dagger} \\
\end{array}$ & $\begin{array}{r}4 \\
9 \% \\
\end{array}$ & $\begin{array}{r}29 \\
67 \% \\
\end{array}$ & $\begin{array}{c}43 \\
100 \% \\
\end{array}$ \\
\hline $0.1 \%(\# 1)$ & 42 & 42 & $\begin{array}{c}0.015 \\
0 \% \\
\end{array}$ & $\begin{array}{c}0^{\dagger} \\
0 \% \\
\end{array}$ & $\begin{array}{c}1 \\
3 \% \\
\end{array}$ & $\begin{array}{c}42 \\
100 \% \\
\end{array}$ & $\begin{array}{c}43 \\
103 \% \\
\end{array}$ \\
\hline $0.1 \%(\# 2)$ & 39 & 39 & $\begin{array}{c}0.012 \\
0 \%\end{array}$ & $\begin{array}{c}0^{\dagger} \\
0 \%^{\dagger}\end{array}$ & $\begin{array}{c}1 \\
2 \%\end{array}$ & $\begin{array}{c}39 \\
100 \%\end{array}$ & $\begin{array}{c}40 \\
103 \%\end{array}$ \\
\hline
\end{tabular}

These values were obtained from extractions of the post-treatment reactors.

Table 44. $\mathrm{MnO}_{4}{ }^{-}$Consumption Data for ORNL Exp. 4b-R3 (TSF-05 GW).

\begin{tabular}{|l|c|c|c|c|}
\hline Test Condition & $\begin{array}{l}\text { Initial } \\
\text { Oxidant } \\
\left(\mathrm{mg} \mathrm{MnO}_{4}{ }^{-}\right)\end{array}$ & $\begin{array}{l}\text { Initial } \\
\text { Loading } \\
\left(\mathrm{mg} \mathrm{MnO}_{4}^{-} / \mathrm{g}\right)\end{array}$ & $\begin{array}{l}\text { Cum. } \\
\text { Consumed } \\
\left(\mathrm{mg} \mathrm{MnO}_{4}\right)^{-}\end{array}$ & $\begin{array}{l}\text { Cum. } \\
\text { Consumed } \\
\left(\mathrm{mg} \mathrm{mnO}_{4} / \mathrm{g}\right)\end{array}$ \\
\hline $0.01 \%(\# 1)$ & 39.6 & 0.10 & 39.42 & 0.10 \\
\hline $0.01 \%(\# 2)$ & 39.6 & 0.10 & 39.40 & 0.10 \\
\hline $0.1 \%(\# 1)$ & 396.0 & 0.99 & 73.00 & 0.18 \\
\hline $0.1 \%(\# 2)$ & 396.0 & 0.99 & 68.10 & 0.17 \\
\hline
\end{tabular}

a. Consumption is computed after $96 \mathrm{hr}$ reaction time. 
ORNL Exp. 4b-R4

(TSF-05 GW, No Sludge, 100,000 TCE, 0 Other, $1 \%$ and 3\% $\mathrm{MnO}_{4}{ }^{-}$)

This experiment investigated the oxidation of TSF-05 GW spiked at 100,000 $\mu \mathrm{g} / \mathrm{L}$ TCE. The TCE, $\mathrm{MnO}_{4}{ }^{-}$and $\mathrm{pH}$ values with time are presented in Figures 72, 73, and 74, respectively. Tables 45 and 46 provide additional TCE mass balance and oxidant consumption information. The (\#1) and (\#2) notations included in both the figure legends and the first column of these tables refer to the duplicate reactors evaluated for that test condition.

In this experiment, the method used to prepare the TSF-05 spike solution differed from the approach set forth in the testplan. Here, a small quantity of pure phase TCE $(\approx 280 \mu \mathrm{L})$ was added to the Tedlar bag filled with sparged GW. The approach described in the testplan involved the use of a saturated aqueous TCE solution rather than pure phase TCE in the spiking step. A $96 \mathrm{hr}$ reaction time was also evaluated in this experiment, while the tests were terminated at $24 \mathrm{hrs}$ in the procedure described in the testplan.

After equilibration, the average initial aqueous TCE concentration of the spike solution was $147,03 \mu \mathrm{g} / \mathrm{L}(\sigma=428 \mu \mathrm{g} / \mathrm{L})$. After transfer to the test reactors the groundwater TCE concentration ranged between 102,900 and $110,600 \mu \mathrm{g} / \mathrm{L}(\mathrm{T}=0$ aliquots $)$ prior to the start of the oxidation reactions. While a part of this wide variability may be due to human error in performing sample dilutions, some TCE was likely lost during transfer of the spiked GW to the test reactors.

As in the previous experiment involving 100,000 $\mu \mathrm{g} / \mathrm{L} \mathrm{TCE}$ (Exp. 4b-R3), the extractions of the first charcoal bed of the desorption tubes contained measurable quantities of TCE. Like Experiment 4b-R3, TCE recoveries for the control samples were greater than $100 \%$ (110\% and $114 \%$ ). These two experimental runs were conducted concurrently. Hence, these samples also experienced the same discrepancy between initial and final measured TCE concentrations of the control samples.

This discrepancy resulting from sample holding times should not affect the validity of this experiment. In fact, the discrepancy should theoretically result in conservative TCE oxidation rates since a shorter holding time for the $24 \mathrm{hrs}$ aliquots would be expected to produce a larger TCE residual at the end of the reaction period. Hence, the calculated reaction rates are less than the true reaction rates. It should be noted that this sample holding time problem likely affected other experiments. The effect was heightened here because of the very high TCE spike concentrations being evaluated. This problem is not believed to have adversely affected the results of the other experiments.

From Figure 72 , the complete oxidation of TCE is observed in both the $1 \%$ and $3 \% \mathrm{MnO}_{4}{ }^{-}$ reactors. Total TCE recoveries for all four (4) treatment reactors were $100 \%$. While not called for in the testplan, the final treatment reactors were also extracted and analyzed in this experiment. These extractions also verified the absence of TCE after 96 hrs. Enough TCE data points are not available to compute rate constants; however, the observed oxidation rates are greater than 88 and $84 \mathrm{mg}$ TCE/hr for the $1 \%$ and $3 \% \mathrm{MnO}_{4}^{-}$reactors, respectively. 
While all of the initial $100,000 \mu \mathrm{g} / \mathrm{L}$ TCE was oxidized in this experiment, very little oxidant was consumed in the process (Figure 73 ). Less than $2 \%$ of the initial $\mathrm{MnO}_{4}{ }^{-}$mass was consumed for either initial oxidant loading.

The $\mathrm{pH}$ values within the treatment reactors decreased significantly during the reaction period. The greatest $\mathrm{pH}$ decreases occurred in the $1 \% \mathrm{MnO}_{4}{ }^{-}$reactors. Net $\mathrm{pH}$ decreases of 1.6 and 1.0 $\mathrm{pH}$ units were observed for the $1 \%$ and $3 \% \mathrm{MnO}_{4}{ }^{-}$reactors, respectively. The $\mathrm{pH}$ decreases were less in magnitude than those observed in Exp. $4 \mathrm{~b}-\mathrm{R} 3$ where $0.01 \%$ and $0.1 \% \mathrm{MnO}_{4}{ }^{-}$loadings were evaluated at the same nominal TCE concentration. This effect is likely a result of the greater ionic strength of the $1 \%$ and $3 \%$ residual oxidant solutions when compared to the $0.01 \%$ and $0.1 \% \mathrm{MnO}_{4}{ }^{-}$solutions. This also explains why the net $\mathrm{pH}$ decrease observed for the $3 \%$ $\mathrm{MnO}_{4}{ }^{-}$reactors was less than that for the $1 \% \mathrm{MnO}_{4}{ }^{-}$reactors.

Finally, it is interesting to note from Figures 72 and 73 that nearly the same TCE and final $\mathrm{MnO}_{4}{ }^{-}$consumption values would have been obtained for these particular oxidant loadings even if a $24 \mathrm{hr}$, rather than a $96 \mathrm{hr}$, reaction period had been evaluated. 


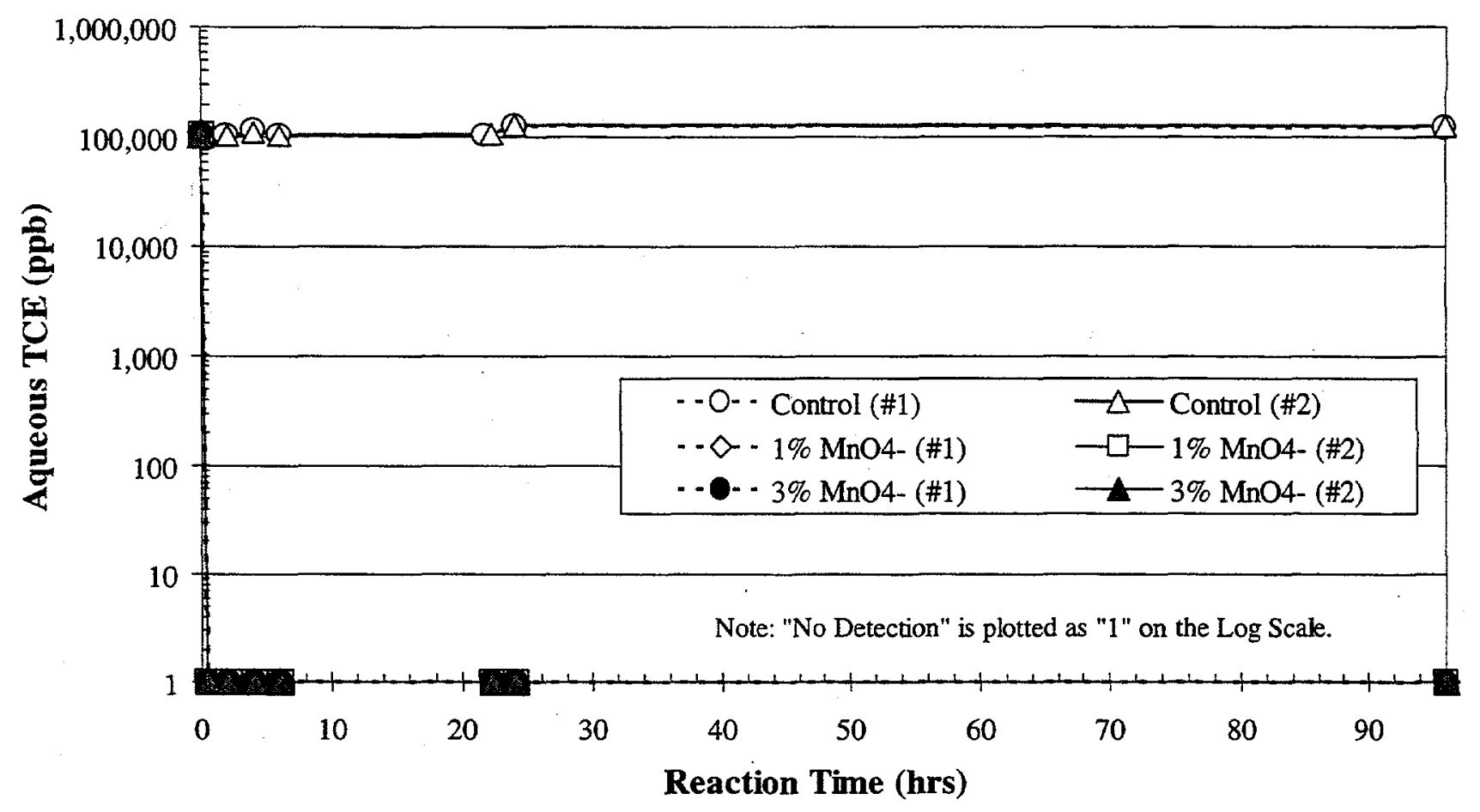

Figure 72. TCE vs. Time, TSF-05 GW, (ORNL Exp. 4b-R4, Initial TCE= 100,000 $\mu \mathrm{g} / \mathrm{L}$, Conducted at $12^{\circ} \mathrm{C}$ )

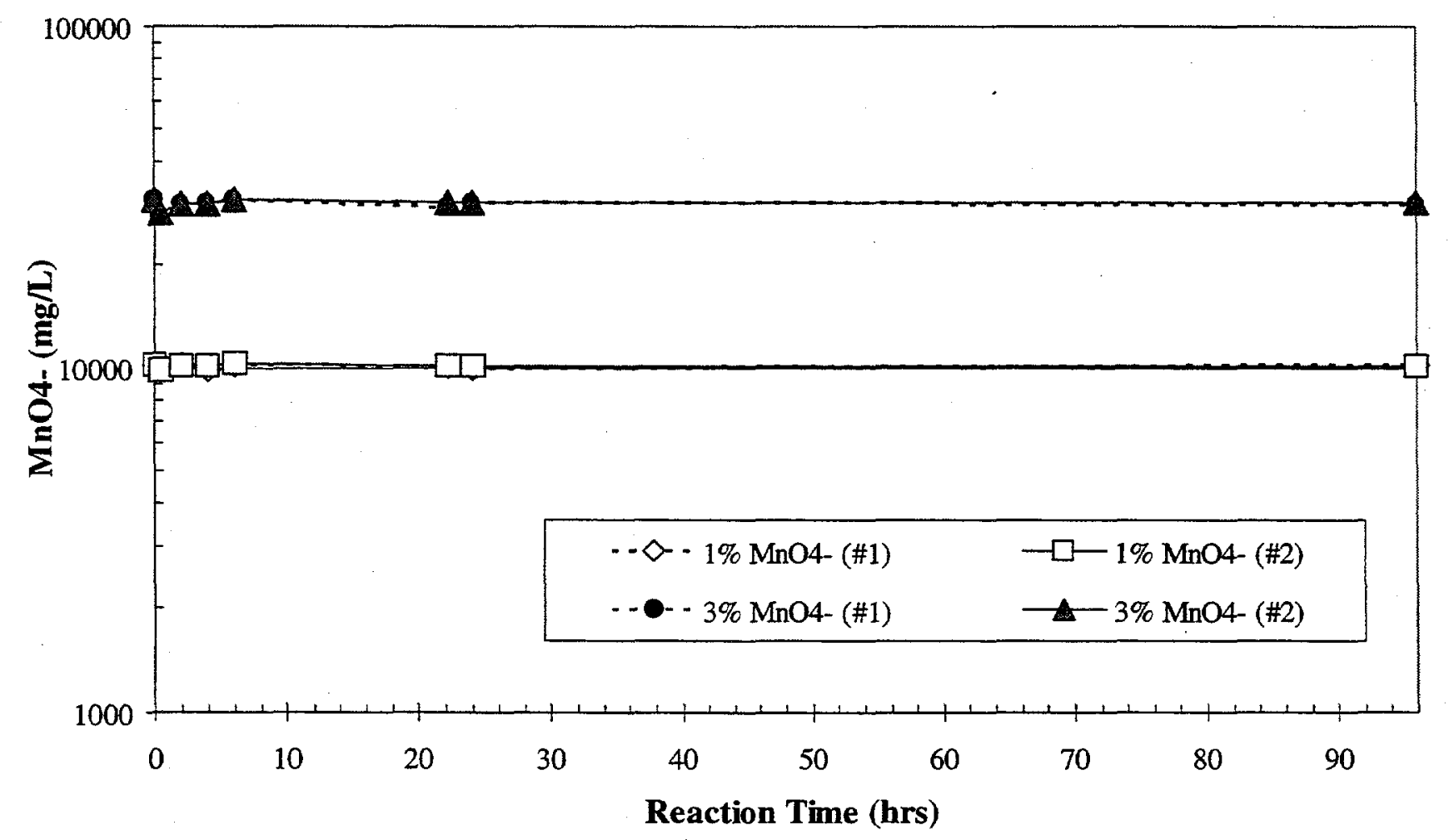

Figure 73. $\mathrm{MnO}_{4}^{-}$vs. Time, TSF-05 GW, (ORNL Exp. 4b-R4, Initial TCE $=100,000 \mu \mathrm{g} / \mathrm{L}$, Conducted at $12^{\circ} \mathrm{C}$ ) 


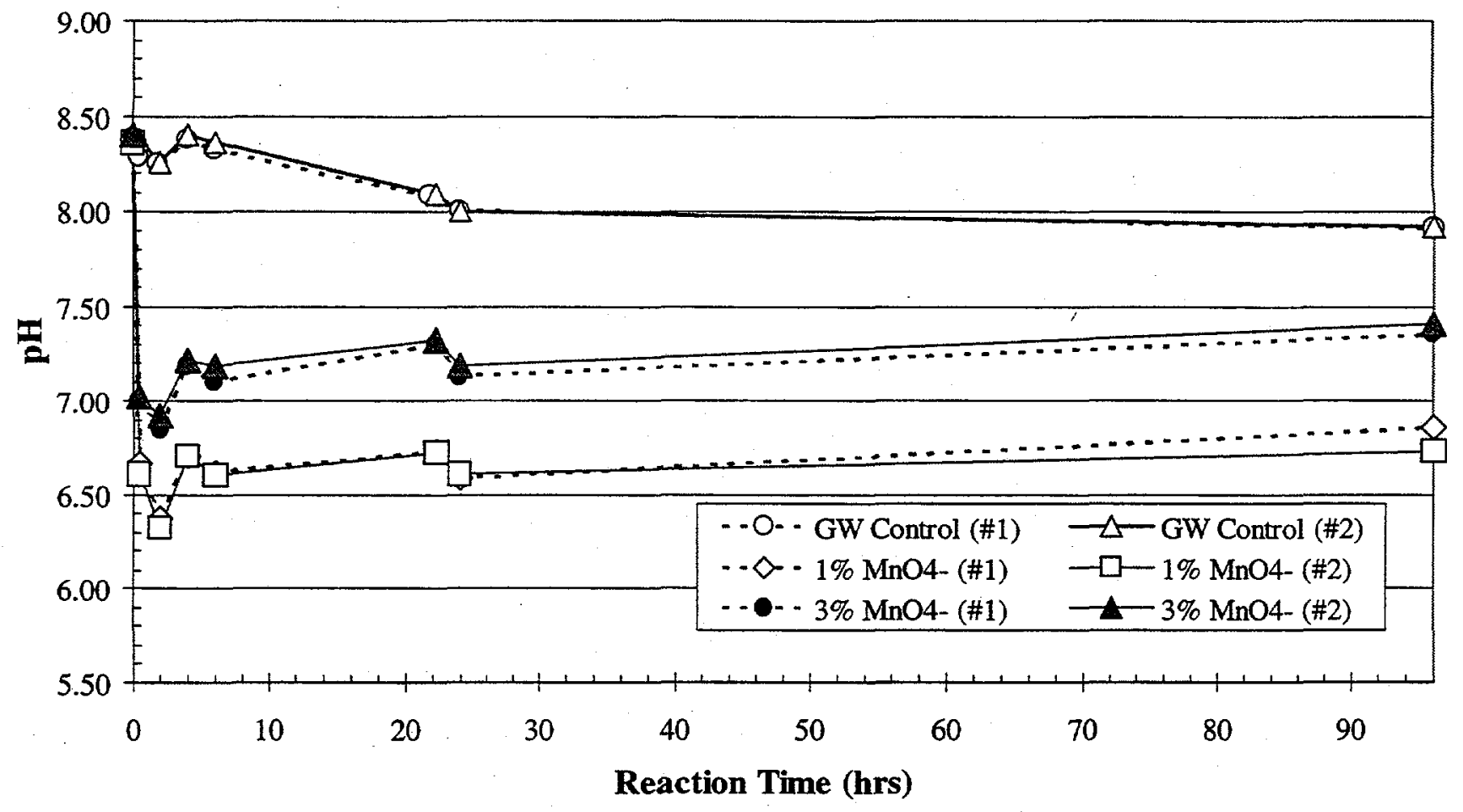

Figure 74. pH vs. Time, TSF-05 GW, (ORNL Exp. $4 \mathrm{~b}-\mathrm{R} 4$ Initial TCE $=100,000 \mu \mathrm{g} / \mathrm{L}$, Conducted at $12^{\circ} \mathrm{C}$ ) 
Table 45. TCE Mass Balance for ORNL Exp. 4b-R4 (TSF-05 GW).

\begin{tabular}{|c|c|c|c|c|c|c|c|}
\hline Test Condition & \begin{tabular}{|l|} 
Total \\
Initial \\
Mass \\
(mg)
\end{tabular} & \begin{tabular}{|l} 
Initial \\
Aqueous \\
Mass \\
$(\mathrm{mg})$
\end{tabular} & \begin{tabular}{|l|} 
Mass \\
Sorbed on \\
Orbo Tubes \\
(mg)
\end{tabular} & \begin{tabular}{|l} 
Mass \\
Remaining in \\
Reactor (mg)
\end{tabular} & \begin{tabular}{|l|} 
Cum. \\
Mass \\
Removed \\
in Aliquots \\
(mg) \\
\end{tabular} & \begin{tabular}{|l|} 
Cum. \\
Aqueous \\
Mass \\
Oxidized \\
(mg) \\
\end{tabular} & $\begin{array}{l}\text { Total Mass } \\
\text { Recovered } \\
\text { (mg) }\end{array}$ \\
\hline Control (\#1) & 43 & 43 & $\begin{array}{c}0.027 \\
0 \%\end{array}$ & $\begin{array}{c}36 \\
84 \% \\
\end{array}$ & $\begin{array}{c}11 \\
26 \%\end{array}$ & $\begin{array}{l}\text { NA } \\
\text { NA }\end{array}$ & $\begin{array}{c}47 \\
110 \%\end{array}$ \\
\hline Control (\#2) & 43 & 43 & $\begin{array}{c}0.005 \\
0 \%\end{array}$ & $\begin{array}{c}38 \\
88 \%\end{array}$ & $\begin{array}{c}11 \\
26 \%\end{array}$ & $\begin{array}{l}\text { NA } \\
\text { NA }\end{array}$ & $\begin{array}{c}49 \\
114 \%\end{array}$ \\
\hline $1 \%(\# 1)$ & 44 & 44 & $\begin{array}{c}0.008 \\
0 \% \\
\end{array}$ & $\begin{array}{c}0 \\
0 \% \\
\end{array}$ & $\begin{array}{c}1 \\
3 \% \\
\end{array}$ & $\begin{array}{c}43 \\
97 \% \\
\end{array}$ & $\begin{array}{c}44 \\
100 \% \\
\end{array}$ \\
\hline $1 \%(\# 2)$ & 43 & 43 & $\begin{array}{c}0.001 \\
0 \%\end{array}$ & $\begin{array}{c}0 \\
0 \%\end{array}$ & $\begin{array}{c}1 \\
3 \%\end{array}$ & $\begin{array}{c}42 \\
97 \%\end{array}$ & $\begin{array}{c}43 \\
100 \%\end{array}$ \\
\hline $3 \%(\# 1)$ & 43 & 43 & $\begin{array}{c}0.004 \\
0 \%\end{array}$ & $\begin{array}{c}0 \\
0 \%\end{array}$ & $\begin{array}{c}1 \\
3 \% \\
\end{array}$ & $\begin{array}{r}42 \\
97 \% \\
\end{array}$ & $\begin{array}{c}43 \\
100 \%\end{array}$ \\
\hline $3 \%(\# 2)$ & 41 & 41 & $\begin{array}{c}0.008 \\
0 \%\end{array}$ & $\begin{array}{c}0 \\
0 \%\end{array}$ & $\begin{array}{c}1 \\
3 \%\end{array}$ & $\begin{array}{c}40 \\
97 \%\end{array}$ & $\begin{array}{c}41 \\
100 \%\end{array}$ \\
\hline
\end{tabular}

These values were obtained from extractions of the post-treatment reactors.

Table 46. $\mathrm{MnO}_{4}{ }^{-}$Consumption Data for ORNL Exp. 4b-R4 (TSF-05 GW).

\begin{tabular}{|c|c|c|l|l|}
\hline Test Condition & $\begin{array}{l}\text { Initial } \\
\text { Oxidant } \\
\left(\mathrm{mg} \mathrm{MnO}_{4}\right)\end{array}$ & $\begin{array}{l}\text { Initial } \\
\text { Loading } \\
\left(\mathrm{mg} \mathrm{MnO}_{4}^{-} / \mathrm{g}\right)\end{array}$ & $\begin{array}{l}\text { Cum. } \\
\text { Consumed } \\
\left(\mathrm{mg} \mathrm{MnO}_{4}\right)\end{array}$ & $\begin{array}{l}\text { Cum. } \\
\text { Consumed } \\
\left(\mathrm{mg} \mathrm{MnO}_{4} / \mathrm{g}\right)\end{array}$ \\
\hline $1 \%(\# 1)$ & 3977 & 10.2 & 83 & 0.2 \\
\hline $1 \%(\# 2)$ & 3977 & 10.2 & 51 & 0.1 \\
\hline $3 \%(\# 1)$ & 12051 & 30.9 & 149 & 0.4 \\
\hline $3 \%(\# 2)$ & 12051 & 30.9 & 149 & 0.4 \\
\hline
\end{tabular}

\footnotetext{
a. Consumption is computed after $96 \mathrm{hr}$ reaction time.
} 
ORNL Exp. 4b-R5

(TSF-05 GW, No Sludge, 100,000 TCE, 10,000 Other, $0.01 \%$ and $0.1 \% \mathrm{MnO}_{4}{ }^{-}$)

This experiment investigated the oxidation of TSF-05 GW spiked at 100,000 $\mu \mathrm{g} / \mathrm{L} \mathrm{TCE}$. In this experiment, TSF-05 GW was also spiked with other VOCs (co-contaminants). In addition to TCE, the groundwater was also spiked with 1,1-DCE; trans-1,2 DCE; and cis-1,2 DCE at a nominal concentration of $10,000 \mu \mathrm{g} / \mathrm{L}$ of each compound. Otherwise, the test conditions evaluated in this experiment were to be the same as those studied in Experiment $4 \mathrm{~b}-\mathrm{R} 3$.

Plots of TCE; 1,1-DCE; trans-1,2 DCE; and cis-1,2 DCE with time are presented in Figures 75, 76,77 , and 78, respectively. Plots of $\mathrm{MnO}_{4}{ }^{-}$and $\mathrm{pH}$ values with time are presented in Figures 79 and 80 , respectively. Tables 47 and 48 provide additional TCE mass balance and oxidant consumption information. The (\#1) and (\#2) notations included in both the figure legends and the first column of these tables refer to the duplicate reactors evaluated for that test condition. Mass balance tables were not prepared for the co-contaminants since the intent of the experiment was to determine whether the presence of these compounds affected the overall TCE oxidation characteristics.

In this experiment, the method used to prepare the TSF-05 spike solution differed from the approach set forth in the testplan. Here, a small quantity of pure phase TCE $(\approx 200 \mu \mathrm{L})$ was added to the Tedlar bag filled with sparged GW. The approach described in the testplan involved the use of a saturated aqueous TCE solution rather than pure phase TCE in the spiking step. The co-contaminants were also added to the Tedlar bag in the same manner.

The GC used in the TCE analyses for this co-contaminants experiment was different than the one used for all other treatment experiments. The instrument was properly calibrated, but the MDL was $10 \mu \mathrm{g} / \mathrm{L}$ rather than the $5 \mu \mathrm{g} / \mathrm{L}$ obtained using the other instrument. A very small amount of TCE was detected in the analysis of the QA/QC solvent blank, which was ran between every 10 or 11 samples. The TCE concentrations determined for the QA/QC blank ranged between 0.2 to $6 \mu \mathrm{g} / \mathrm{L}$. The peak area counts for these analyses were much less than that of the lowest calibration standard $(10 \mu \mathrm{g} / \mathrm{L})$. While these small TCE quantities in the blank sample may be a result of sample carryover, it its not expected to affect the validity of the data. The sequence for the analyses was such that all $\mathrm{T}=0$ samples were analyzed before $\mathrm{T}=0.5$ samples were analyzed, and so forth.

After equilibration, the average initial aqueous TCE concentration of the spike solution was $18,800 \mu \mathrm{g} / \mathrm{L}(\sigma=1,580 \mu \mathrm{g} / \mathrm{L})$. After transfer to the test reactors, the groundwater TCE concentration ranged between 19,340 and $30,580 \mu \mathrm{g} / \mathrm{L}$ ( $\mathrm{T}=0$ aliquots) prior to the start of the oxidation reactions. Although an overnight equilibration (at $12^{\circ} \mathrm{C}$ ) of the spike solution was performed, it is apparent that the pure phase TCE added to the Tedlar bag was not equilibrated long enough before distribution into the test reactors. The initial TCE concentrations of the $0.1 \%$ $\mathrm{MnO}_{4}{ }^{-}$reactors were greater than those of the control and $0.01 \% \mathrm{MnO}_{4}{ }^{-}$reactors. This result makes sense if the water in the Tedlar bag was not well mixed before distribution into the reactors. Being the last reactors to be filled, the $0.1 \% \mathrm{MnO}_{4}{ }^{-}$reactors may have received a higher amount of TCE than the other reactors. This problem was not considered detrimental 
since the aqueous $\mathrm{T}=0 \mathrm{hrs}$ TCE concentrations, which are used in the mass balance computations, were determined for each reactor.

TCE recoveries for the control samples were $110 \%$ and $105 \%$, suggesting that little TCE was lost to volatilization. The $>100 \%$ TCE recoveries in the control were computed because the aqueous TCE concentrations at $\mathrm{T}=24 \mathrm{hrs}$ were greater than those at $\mathrm{T}=0 \mathrm{hrs}$. This phenomenon is either due to (1) the sample holding time effect as noted in Exps. 4b-R3 and 4b-R4 or (2) the occurrence of further TCE spike equilibration (i.e., solubilization of pure phase TCE) during the course of the reaction period. A very small quantity of TCE was detected in the charcoal desorption tubes for the control reactors and the first $0.01 \% \mathrm{MnO}_{4}{ }^{-}$reactor. (The concentrations were significantly less than the MDL and perhaps a result of sample carryover between analyses as discussed above.) TCE recoveries for the four treatment reactors ranged between 100-102\%.

As in other experiments, TCE oxidation of greater than an order of magnitude was initially observed. From Figure 75, however, it appears that all of the TCE was not completely oxidized from the $0.01 \% \mathrm{MnO}_{4}{ }^{-}$reactors, even though a residual $\mathrm{MnO}_{4}{ }^{-}$concentration existed (Figure 79). This is the first experiment in which both a residual TCE and $\mathrm{MnO}_{4}{ }^{-}$concentration existed at the end of the reaction period. These residual TCE concentrations $(\approx 20-110 \mu \mathrm{g} / \mathrm{L}$ at $24 \mathrm{hrs})$ are believed to be "real" and not a result of instrument performance or solvent contamination since the residual concentrations observed here are much greater than the $10 \mu \mathrm{g} / \mathrm{L} \mathrm{MDL}$. Hence, it is possible that the presence of the co-contaminants slowed and/or halted the TCE oxidation reaction.

The aqueous TCE data between $\mathrm{T}=0$ and $\mathrm{T}=3 \mathrm{hrs}$ was used to compute the reaction rate for the initial, rapid step of the oxidation reaction in the $0.01 \% \mathrm{MnO}_{4}{ }^{-}$reactors. The aqueous TCE data were plotted in Figure 81 and Figure 82 as $\ln \left(\mathrm{C} / \mathrm{C}_{\mathrm{o}}\right)$ vs. Time for the first and second $0.01 \%$ reactors, respectively. These linear regressions resulted in first order rate constants of $k=1.66 \mathrm{hr}^{-1}$ and $1.55 \mathrm{hr}^{-1}$. While the fit of the data to a first order rate model may not be optimal, attempts to evaluate other rate models were not made since the mechanisms occurring in such a complex system are not known.

While a residual TCE concentration was measured for the $0.1 \% \mathrm{MnO}_{4}^{-}$reactors, the values obtained are less than that of the lowest calibration standard. Hence, it is very possible that the observed TCE concentrations are not "real". It appears that nearly complete TCE oxidation occurred in the $0.1 \% \mathrm{MnO}_{4}{ }^{-}$reactors at $\mathrm{T}=2 \mathrm{hrs}$. (This value was determined by extrapolating the initially rapid portion of the curve in Figure 75 to a concentration of $1.0 \mu \mathrm{g} / \mathrm{L}$ TCE.) Enough data points are not available to compute a rate constant. However, if one assumes nearly complete TCE oxidation within $2 \mathrm{hrs,}$, an oxidation rate greater than $7.7 \mathrm{mg}$ TCE/hr is obtained for the $0.1 \% \mathrm{MnO}_{4}{ }^{-}$reactors. Note that complete oxidation occurred within $0.5 \mathrm{hrs}$ for all the other TSF-05 GW experiments having a $0.1 \% \mathrm{MnO}_{4}{ }^{-}$loading (Exps. 4b-R1 and 4b-R3). Hence, as noted above for the $0.01 \% \mathrm{MnO}_{4}{ }^{-}$reactors, the TCE oxidation rate observed for the $0.1 \%$ $\mathrm{MnO}_{4}{ }^{-}$loading may also be affected by the presence of the VOC co-contaminants.

As suggested in the above paragraphs, the TCE oxidation rate may be affected by the presence of the co-contaminants. The initial aqueous concentrations ( $\mathrm{T}=0 \mathrm{hrs}$ ) of the co-contaminants were approximately 3,300 $\mu \mathrm{g} / \mathrm{L}$ 1,1-DCE; 3,530 $\mu \mathrm{g} / \mathrm{L}$ trans-1,2 DCE; and 7,400 $\mu \mathrm{g} / \mathrm{L}$ cis-1,2 DCE. 
From Figures 76, 77, and 78, it appears that the control reactors performed effectively in minimizing the volatilization of the co-contaminants. Thus, the rapid decreases in the cocontaminant concentrations within the treatment reactors are due to oxidation mechanisms. (Recall that mass balance computations were not performed on the co-contaminants) Oxidation of 1,1-DCE occurred within $2 \mathrm{hrs}$ for the $0.01 \% \mathrm{MnO}_{4}{ }^{-}$reactors and within $0.5 \mathrm{hrs}$ for the $0.1 \%$ $\mathrm{MnO}_{4}{ }^{-}$reactors. Similarly, complete trans-1,2 DCE oxidation occurred within the first $0.5 \mathrm{hrs}$ after oxidant addition for both initial oxidant loadings. Finally, cis-1,2 DCE oxidation was completed within $3 \mathrm{hrs}$ and within $0.5 \mathrm{hrs}$ for the $0.01 \%$ and $0.1 \% \mathrm{MnO}_{4}{ }^{-}$reactors, respectively.

Approximately $62 \%$ of the oxidant added to the $0.01 \% \mathrm{MnO}_{4}{ }^{-}$reactors was consumed. The rate of oxidant consumption (Figure 79) was gradual for these treatment reactors. This trend correlates well with the slow TCE oxidation rate observed in Figure 75 . Only about $12 \%$ of the initial $\mathrm{MnO}_{4}^{-}$mass was consumed in the $0.1 \% \mathrm{MnO}_{4}{ }^{-}$reactors.

The $\mathrm{pH}$ values within the treatment reactors decreased rapidly during the oxidation of TCE and the co-contaminants (Figure 80 ). The $\mathrm{pH}$ of the $0.01 \% \mathrm{MnO}_{4}{ }^{-}$reactors reached a final $\mathrm{pH}$ value of $\approx 7.4$, a net decrease of $>1 \mathrm{pH}$ unit. Similarly, the $0.1 \% \mathrm{MnO}_{4}{ }^{-}$loading resulted in final $\mathrm{pH}$ values of $\approx 7.2$, a net decrease of $>1.3 \mathrm{pH}$ units. The total concentration of VOCs in this experiment (TCE + co-contaminants) is on the order of 35,000 $\mu \mathrm{g} / \mathrm{L}$ VOCs. Furthermore, the magnitude of the net $\mathrm{pH}$ decreases observed here falls in between that measured in Experiments 4B-R1 and 4B-R3, in which the initial TCE concentrations are nominally 10,000 and 100,000 $\mu \mathrm{g} / \mathrm{L}$, respectively. 


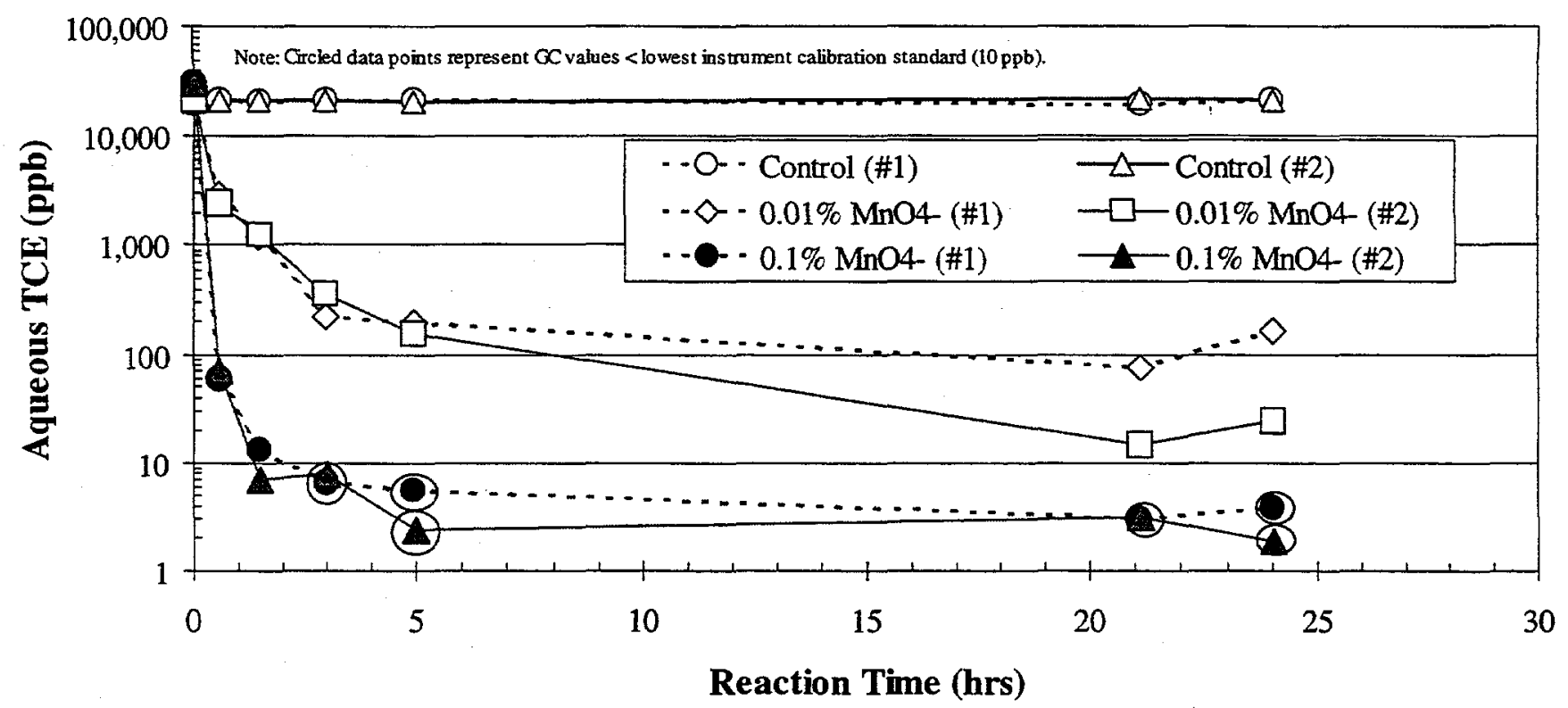

Figure 75. TCE vs. Time, TSF-05 GW, (ORNL Exp. 4b-R5, Initial Target TCE $=100,000 \mu \mathrm{g} / \mathrm{L}$, Co-Contaminants $=10,000 \mu \mathrm{g} / \mathrm{L}$, Conducted at $12^{\circ} \mathrm{C}$ )

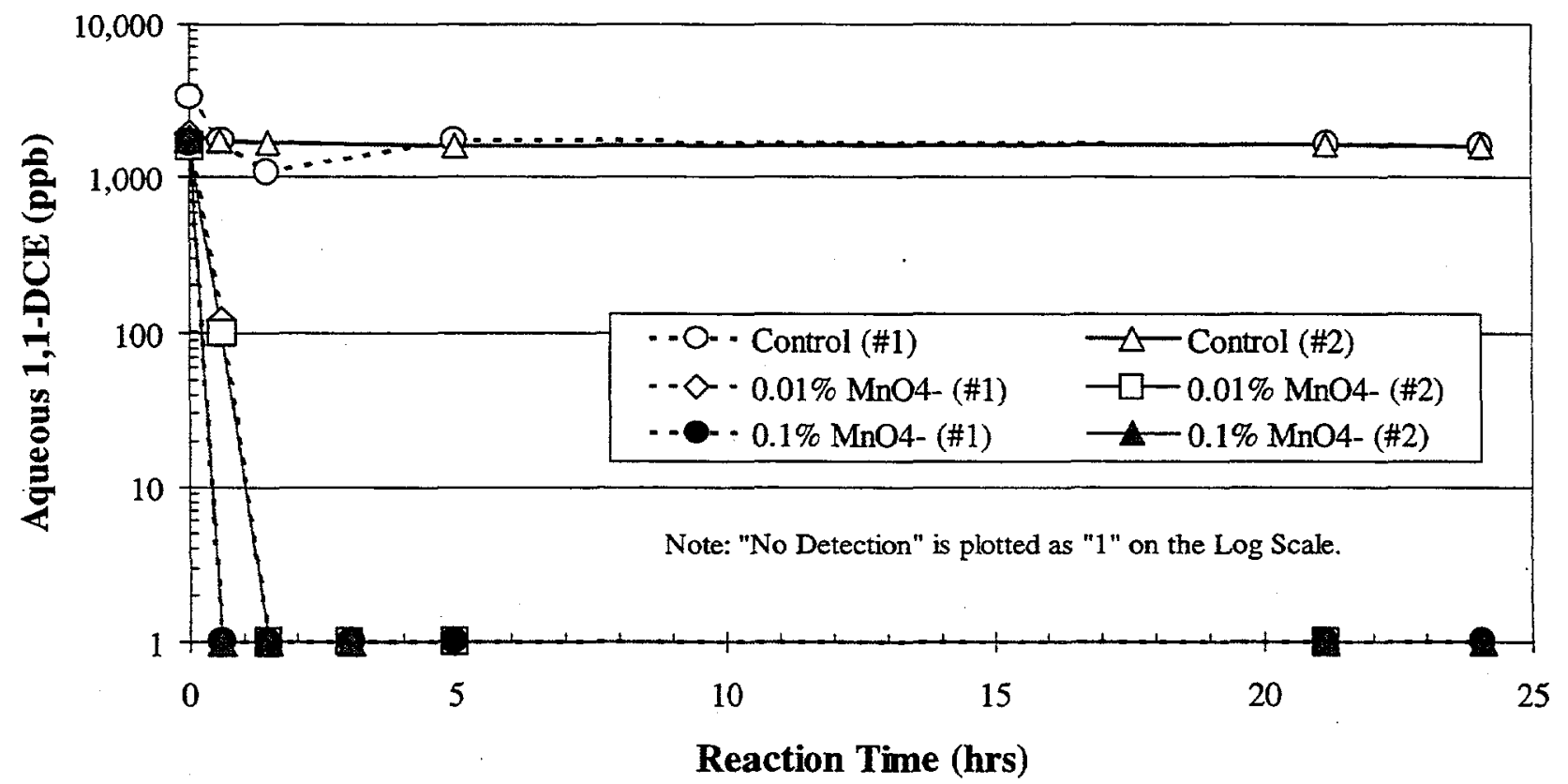

Figure 76. 1,1-DCE vs. Time, TSF-05 GW, (ORNL Exp. 4b-R5, Initial Target TCE $=100,000$ $\mu \mathrm{g} / \mathrm{L}$, Co-Contaminants $=10,000 \mu \mathrm{g} / \mathrm{L}$, Conducted at $12^{\circ} \mathrm{C}$ ) 


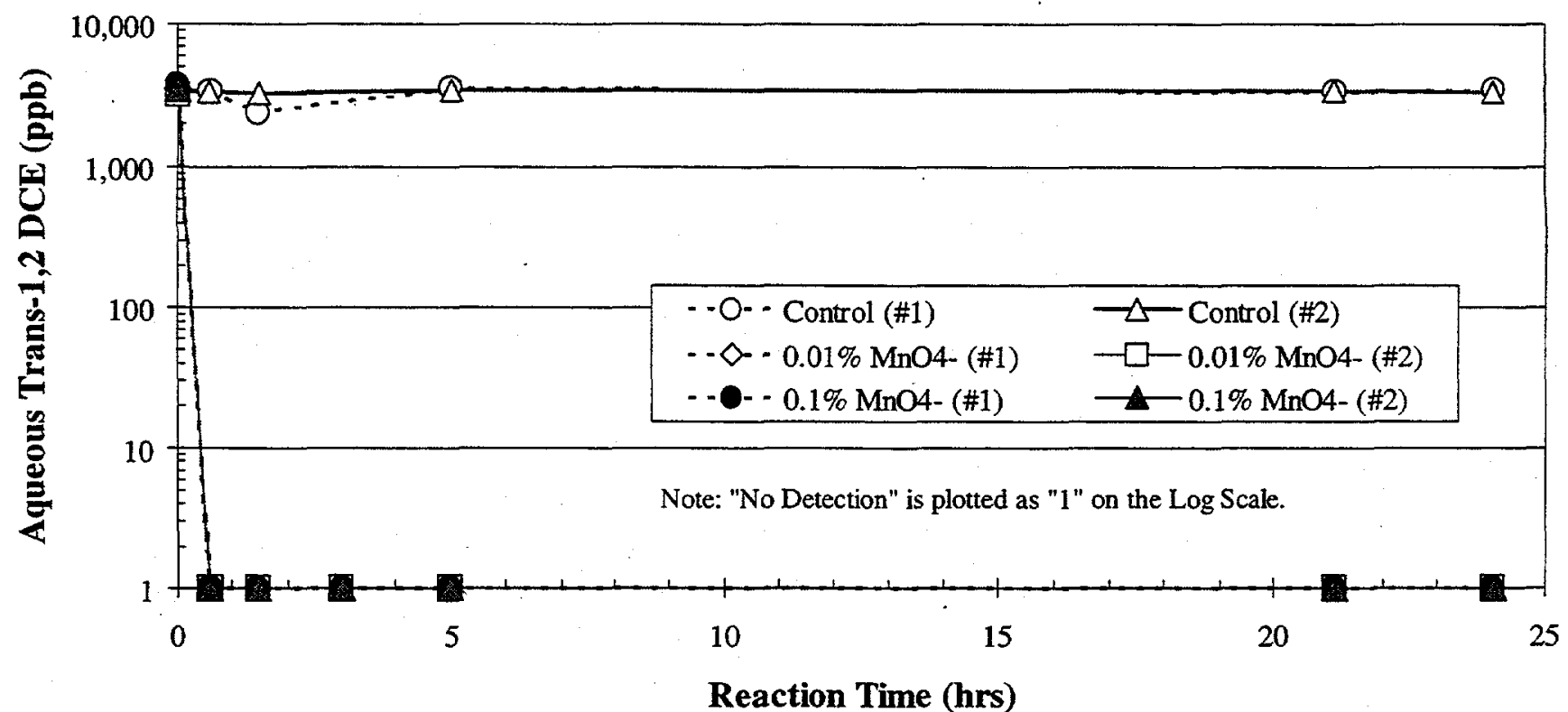

Figure 77. Trans-1,2 DCE vs. Time, TSF-05 GW, (ORNL Exp. 4b-R5, Initial Target TCE= $100,000 \mu \mathrm{g} / \mathrm{L}$, Co-Contaminants $=10,000 \mu \mathrm{g} / \mathrm{L}$, Conducted at $12^{\circ} \mathrm{C}$ )

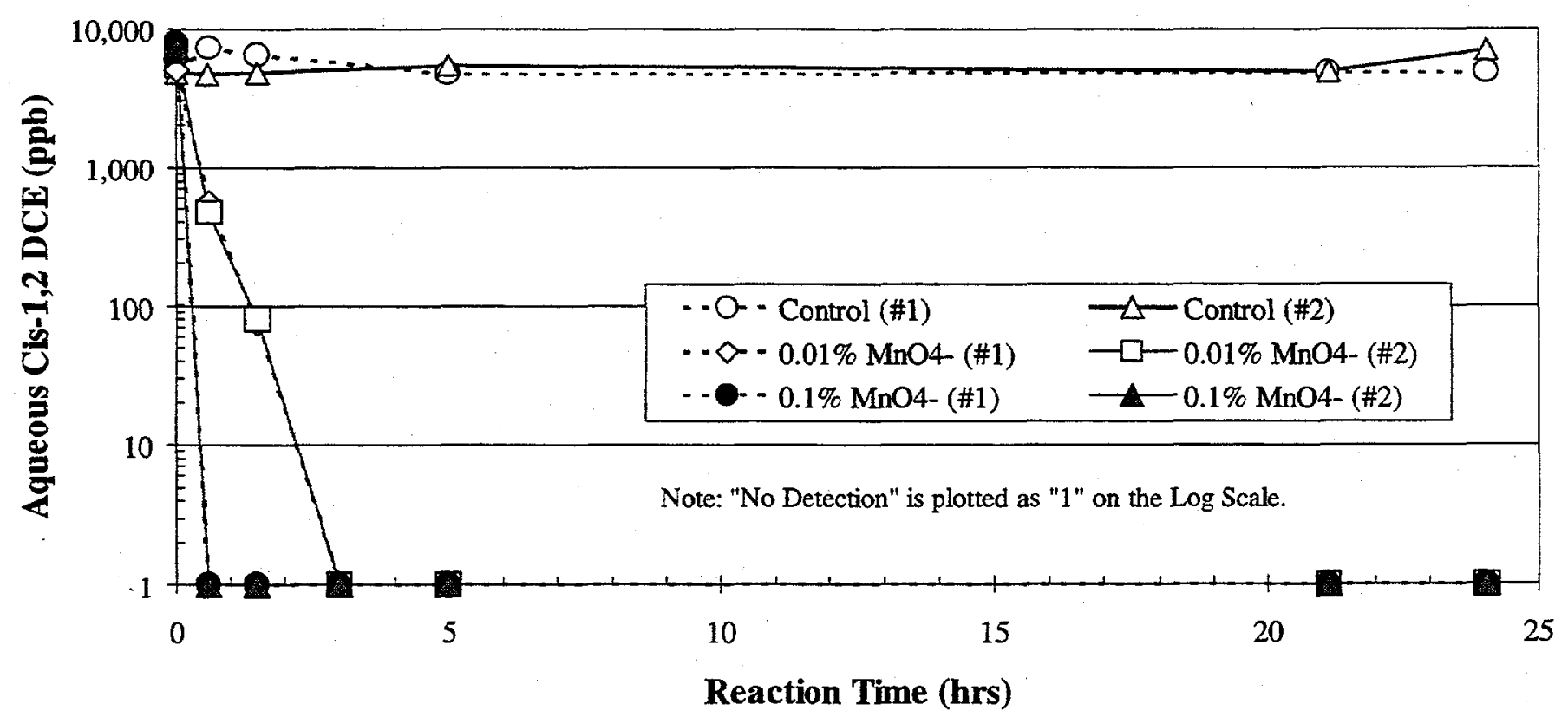

Figure 78. Cis-1,2 DCE vs. Time, TSF-05 GW, (ORNL Exp. 4b-R5, Initial Target TCE= $100,000 \mu \mathrm{g} / \mathrm{L}$, Co-Contaminants $=10,000 \mu \mathrm{g} / \mathrm{L}$, Conducted at $12^{\circ} \mathrm{C}$ ) 


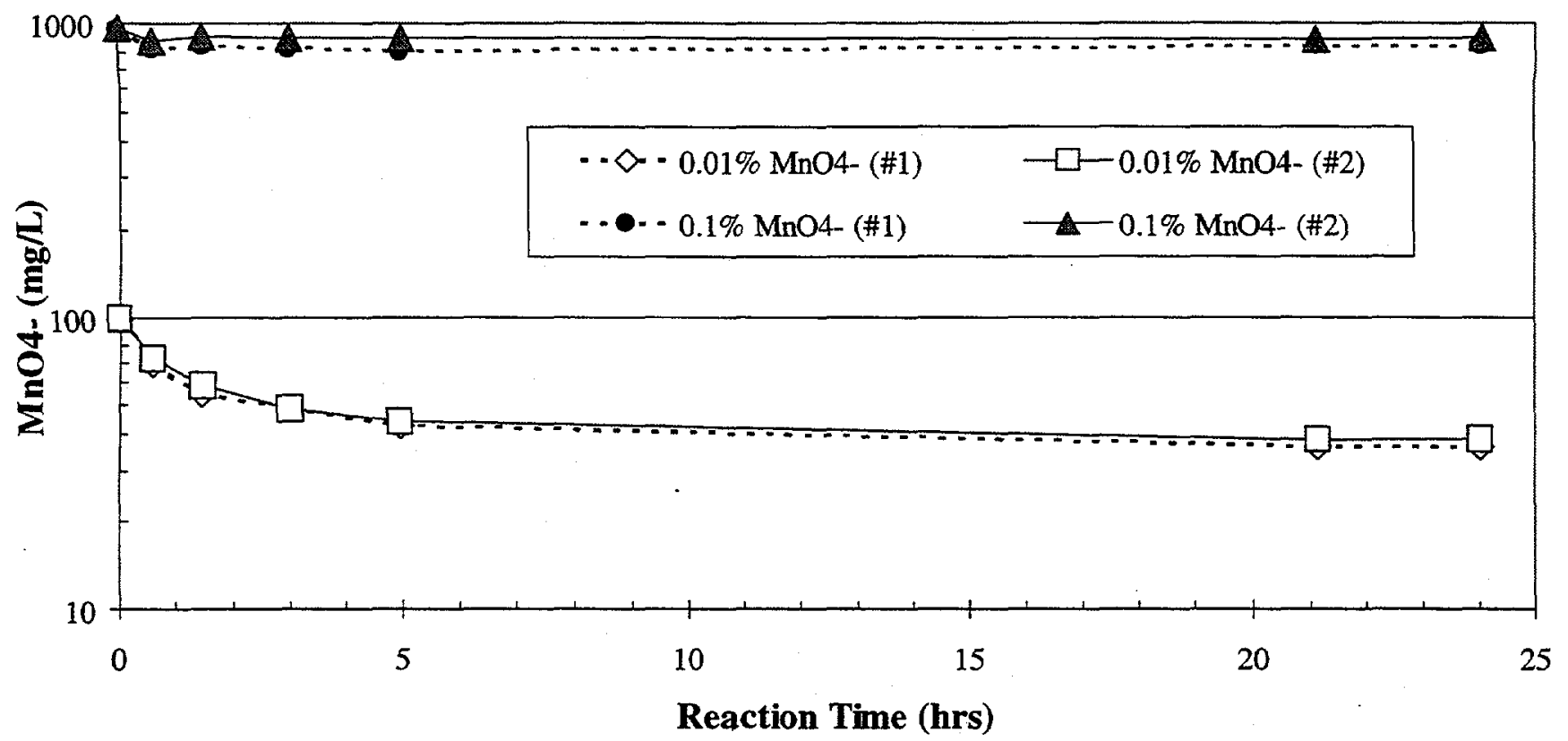

Figure 79. $\mathrm{MnO}_{4}{ }^{-}$vs. Time, TSF- $05 \mathrm{GW}$, (ORNL Exp. $4 \mathrm{~b}-\mathrm{R} 5$, Initial Target TCE $=100,000$ $\mu \mathrm{g} / \mathrm{L}$, Co-Contaminants $=10,000 \mu \mathrm{g} / \mathrm{L}$ Conducted at $12^{\circ} \mathrm{C}$ )

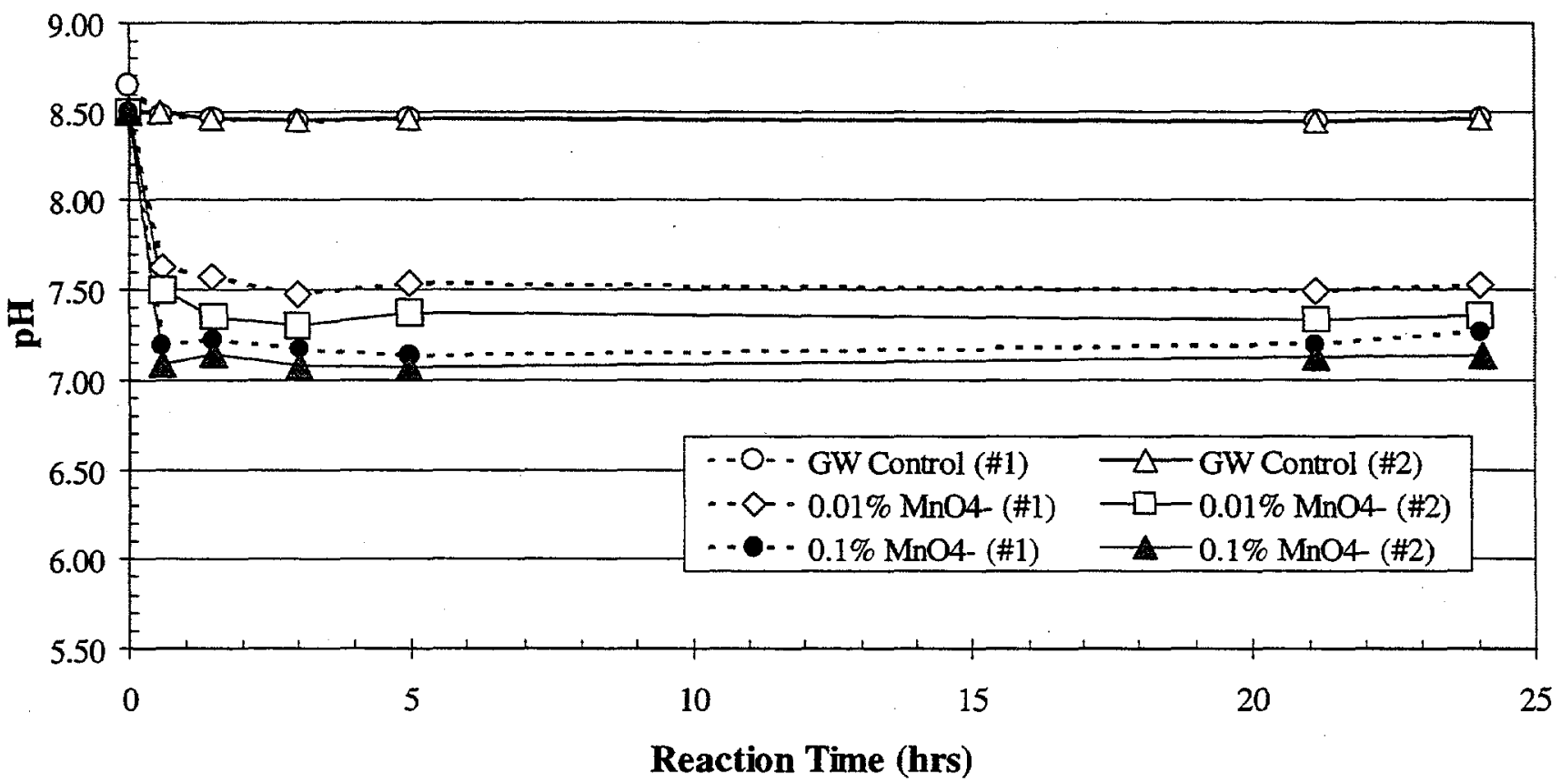

Figure 80. pH vs. Time, TSF-05 GW, (ORNL Exp. 4b-R5 Initial Target TCE $=100,000 \mu \mathrm{g} / \mathrm{L}$, Co-Contaminants $=10,000 \mu \mathrm{g} / \mathrm{L}$ Conducted at $12^{\circ} \mathrm{C}$ ) 


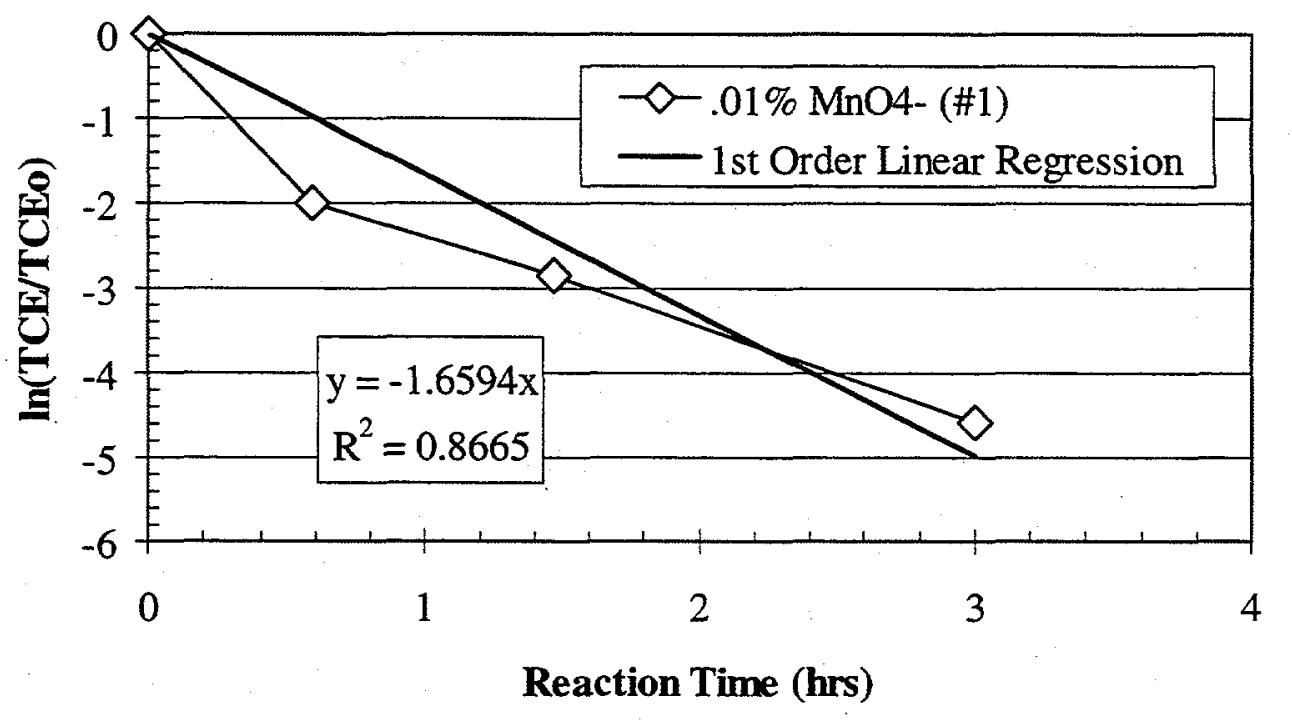

Figure 81. First Order TCE Oxidation Rate Constant for the $0.01 \% \mathrm{MnO}_{4}^{-}$(\#1) Reactor, TSF-05 $\mathrm{GW}$, (ORNL Exp. 4b-R5, Initial TCE $=100,000 \mu \mathrm{g} / \mathrm{L}$, Conducted at $12^{\circ} \mathrm{C}, 4: 1 \mathrm{~L} / \mathrm{S}$ Ratio)

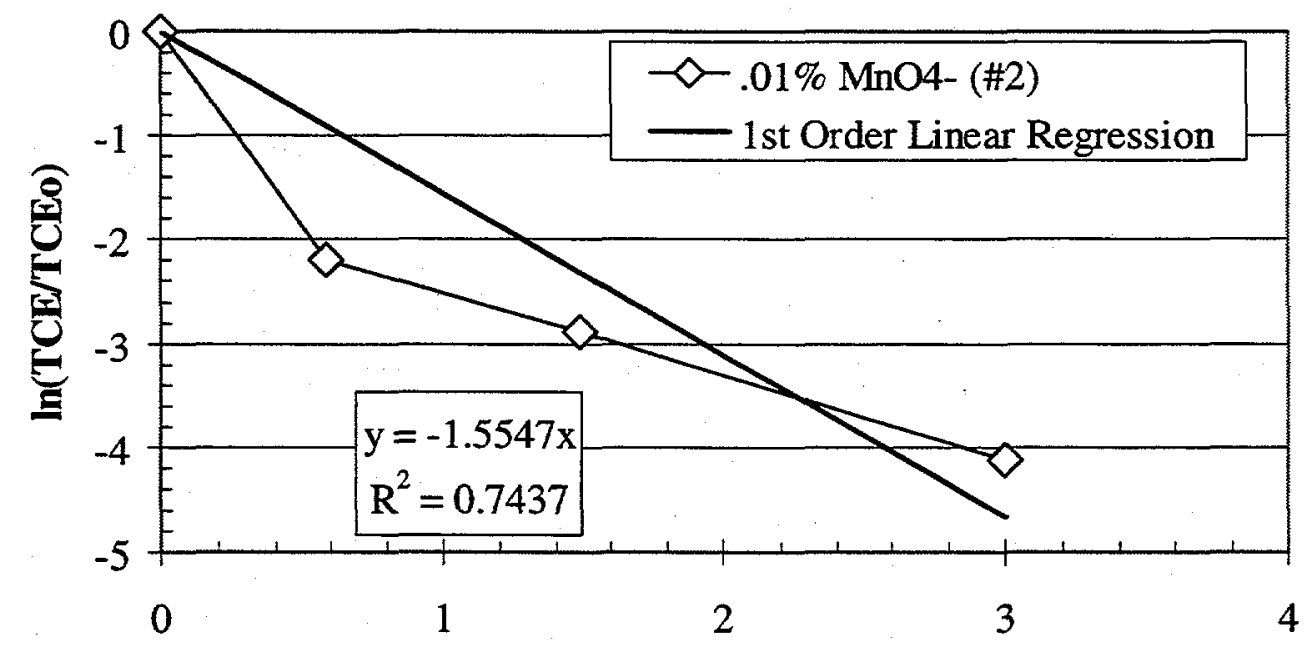

Reaction Time (hrs)

Figure 82. First Order TCE Oxidation Rate Constant for the $0.01 \% \mathrm{MnO}_{4}{ }^{-}(\# 2)$ Reactor, TSF-05 $\mathrm{GW}$, (ORNL Exp. 4b-R5, Initial TCE $=100,000 \mu \mathrm{g} / \mathrm{L}$, Conducted at $12^{\circ} \mathrm{C}, 4: 1 \mathrm{~L} / \mathrm{S}$ Ratio) 
Table 47. TCE Mass Balance for ORNL Exp. 4b-R5 (TSF-05 GW).

\begin{tabular}{|c|c|c|c|c|c|c|c|}
\hline Test Condition & $\begin{array}{l}\text { Total } \\
\text { Initial } \\
\text { Mass } \\
\text { (mg) }\end{array}$ & \begin{tabular}{|l|} 
Initial \\
Aqueous \\
Mass \\
(mg)
\end{tabular} & $\begin{array}{l}\text { Mass } \\
\text { Sorbed on } \\
\text { Orbo Tubes } \\
(\mathrm{mg})\end{array}$ & \begin{tabular}{|l|} 
Mass \\
Remaining in \\
Reactor (mg)
\end{tabular} & \begin{tabular}{|l|} 
Cum. \\
Mass \\
Removed \\
in Aliquots \\
(mg) \\
\end{tabular} & \begin{tabular}{|l} 
Cum. \\
Aqueous \\
Mass \\
Oxidized \\
(mg) \\
\end{tabular} & $\begin{array}{l}\text { Total Mass } \\
\text { Recovered } \\
\text { (mg) }\end{array}$ \\
\hline Control (\#1) & 9.5 & 9.5 & $\begin{array}{c}7.2 \mathrm{E}-06 \\
0 \% \\
\end{array}$ & $\begin{array}{r}9.4 \\
99 \% \\
\end{array}$ & $\begin{array}{c}1.1 \\
11 \% \\
\end{array}$ & $\begin{array}{l}\text { NA } \\
\text { NA }\end{array}$ & $\begin{array}{c}10.4 \\
110 \%\end{array}$ \\
\hline Control (\#2) & 10.1 & 10.1 & $\begin{array}{c}4.6 \mathrm{E}-06 \\
0 \%\end{array}$ & $\begin{array}{c}9.6 \\
94 \%\end{array}$ & $\begin{array}{c}1.1 \\
11 \%\end{array}$ & $\begin{array}{l}\text { NA } \\
\text { NA }\end{array}$ & $\begin{array}{c}10.6 \\
105 \%\end{array}$ \\
\hline $0.01 \%(\# 1)$ & 10.6 & 10.6 & $\begin{array}{c}4.9 \mathrm{E}-06 \\
0 \%\end{array}$ & $\begin{array}{l}0.00 \\
0 \% \\
\end{array}$ & $\begin{array}{l}0.2 \\
2 \% \\
\end{array}$ & $\begin{array}{l}10.4 \\
98 \% \\
\end{array}$ & $\begin{array}{c}10.6 \\
100 \% \\
\end{array}$ \\
\hline $0.01 \%(\# 2)$ & 11.0 & 11.0 & $\begin{array}{c}0.0 \mathrm{E}+00 \\
0 \% \\
\end{array}$ & $\begin{array}{l}0.00 \\
0 \%\end{array}$ & $\begin{array}{l}0.2 \\
2 \% \\
\end{array}$ & $\begin{array}{l}10.8 \\
98 \% \\
\end{array}$ & $\begin{array}{r}11.0 \\
100 \% \\
\end{array}$ \\
\hline $0.1 \%(\# 1)$ & 15.4 & 15.4 & $\begin{array}{c}0.0 \mathrm{E}+00 \\
0 \%\end{array}$ & $\begin{array}{l}0.00 \\
0 \%\end{array}$ & $\begin{array}{l}0.2 \\
1 \%\end{array}$ & $\begin{array}{r}15.6 \\
101 \%\end{array}$ & $\begin{array}{c}15.8 \\
102 \%\end{array}$ \\
\hline $0.1 \%$ & 15.3 & 15.3 & $\begin{array}{c}0.0 \mathrm{E}+00 \\
0 \%\end{array}$ & $\begin{array}{c}0.00 \\
0 \%\end{array}$ & $\begin{array}{l}0.2 \\
1 \%\end{array}$ & $\begin{array}{c}15.5 \\
101 \%\end{array}$ & $\begin{array}{c}15.7 \\
102 \%\end{array}$ \\
\hline
\end{tabular}

Table 48. $\mathrm{MnO}_{4}{ }^{-}$Consumption Data for ORNL Exp. 4b-R5 (TSF-05 GW).

\begin{tabular}{|c|l|l|l|l|}
\hline Test Condition & $\begin{array}{l}\text { Initial } \\
\text { Oxidant } \\
\left(\mathrm{mg} \mathrm{MnO}_{4}^{-}\right)\end{array}$ & $\begin{array}{l}\text { Initial } \\
\text { Loading } \\
\left(\mathrm{mg} \mathrm{MnO}_{4}^{-} / \mathrm{g}\right)\end{array}$ & $\begin{array}{l}\text { Cum. } \\
\text { Consumed } \\
\left.\left(\mathrm{mg} \mathrm{MnO}_{4}\right)^{-}\right)\end{array}$ & $\begin{array}{l}\text { Cum. } \\
\text { Consumed } \\
\left(\mathrm{mg} \mathrm{MnO}_{4} / \mathrm{g}\right)\end{array}$ \\
\hline $0.01 \%(\# 1)$ & 48.7 & 0.10 & 30.7 & 0.06 \\
\hline $0.01 \%(\# 2)$ & 48.7 & 0.10 & 29.7 & 0.06 \\
\hline $0.1 \%(\# 1)$ & 487.3 & 0.95 & 60.3 & 0.12 \\
\hline $0.1 \%(\# 2)$ & 487.3 & 0.96 & 36.7 & 0.07 \\
\hline
\end{tabular}

a Consumption is computed after $24 \mathrm{hr}$ reaction time. 
ORNL Exp. 4b-R6

(TSF-05 GW, No Sludge, 100,000 TCE, 10,000 Other, $1 \%$ and $3 \% \mathrm{MnO}_{4}$ )

This experiment investigated the oxidation of TSF-05 GW spiked at 100,000 $\mu \mathrm{g} / \mathrm{L}$ TCE. In this experiment, TSF-05 GW was also spiked with other VOCs (co-contaminants). In addition to TCE, the groundwater was also spiked with 1,1-DCE; trans-1,2 DCE; and cis-1,2 DCE at a nominal concentration of $10,000 \mu \mathrm{g} / \mathrm{L}$ each compound. Otherwise, the test conditions evaluated in this experiment were to be the same as those studied in Experiment 4b-R4.

Plots of TCE; 1,1-DCE; trans-1,2 DCE; and cis-1,2 DCE with time are presented in Figures 83, 84,85 , and 86 , respectively. Plots of $\mathrm{MnO}_{4}{ }^{-}$and $\mathrm{pH}$ values with time are presented in Figures 87 and 88 , respectively. Tables 49 and 50 provide additional TCE mass balance and oxidant consumption information. The (\#1) and (\#2) notations included in both the figure legends and the first column of these tables refer to the duplicate reactors evaluated for that test condition. Note that mass balance tables were not prepared for the co-contaminants since the intent of the experiment was to determine whether the presence of these compounds affected the overall TCE oxidation characteristics.

In this experiment, the method used to prepare the TSF-05 spike solution differed from the approach set forth in the testplan. Here, a small quantity of pure phase TCE $(\approx 200 \mu \mathrm{L})$ was added to the Tedlar bag filled with sparged GW. The approach described in the testplan involved the use of a saturated aqueous TCE solution rather than pure phase TCE in the spiking step. The co-contaminants were also added to the Tedlar bag in the same manner.

The GC used in the TCE analyses for this co-contaminants experiment was different than the one used for all other treatment experiments. The instrument was properly calibrated, but the minimum detection limit was $10 \mu \mathrm{g} / \mathrm{L}$ rather than the $5 \mu \mathrm{g} / \mathrm{L}$ obtained using the other instrument. A very small amount of TCE was detected in the analysis of the QA/QC solvent blank, which was ran between every 10 or 11 samples. This solvent blank was analyzed nine (9) times during the course of the analytical sequence. TCE was not detected in 5 of these analyses. The remaining 4 analyses of the blank resulted in TCE concentrations between $<1 \mu \mathrm{g} / \mathrm{L}$ and $11 \mu \mathrm{g} / \mathrm{L}$. (The peak area counts for these blanks were less than that of the lowest calibration standard of 10 $\mu \mathrm{g} / \mathrm{L}$.) While these small TCE quantities in the blank sample may be a result of sample carryover, it its not expected to affect the validity of the data. The sequence for the analyses was such that all $\mathrm{T}=0$ samples were analyzed before $\mathrm{T}=0.5$ samples were analyzed, and so forth.

After equilibration, the average initial aqueous TCE concentration of the spike solution was $11,300 \mu \mathrm{g} / \mathrm{L}(\sigma=183 \mu \mathrm{g} / \mathrm{L})$. After transfer to the test reactors, the groundwater TCE concentration ranged between 11,150 and $40,840 \mu \mathrm{g} / \mathrm{L}(\mathrm{T}=0$ aliquots) prior to the start of the oxidation reactions. Although an overnight equilibration (at $12^{\circ} \mathrm{C}$ ) of the spike solution was performed, it is apparent that the pure phase TCE added to the Tedlar bag was not equilibrated long enough before distribution into the test reactors. The initial TCE concentrations of the $3 \%$ $\mathrm{MnO}_{4}{ }^{-}$reactors were greater than those of the control and $1 \% \mathrm{MnO}_{4}{ }^{-}$reactors. This result makes sense if the water in the Tedlar bag was not well mixed before distribution into the reactors. Being the last reactors to be filled, the $3 \% \mathrm{MnO}_{4}{ }^{-}$reactors may have received a higher amount of 
TCE than the other reactors. This problem was not considered detrimental since the aqueous $\mathrm{T}=0 \mathrm{hrs}$ TCE concentrations, which are used in the mass balance computations, were determined for each reactor.

TCE recoveries for the control samples were $97 \%$ and $104 \%$, suggesting that little TCE was lost to volatilization. The $>100 \%$ TCE recovery for the first control reactor was obtained because the aqueous TCE concentration at $\mathrm{T}=24 \mathrm{hrs}$ was greater than that at $\mathrm{T}=0 \mathrm{hrs}$. This phenomenon is either due to (1) the sample holding time effect as noted in Exps. 4b-R3 and 4b-R4 or (2) the occurrence of further TCE spike equilibration (i.e., solubilization of pure phase TCE) during the course of the reaction period. A very small quantity of TCE was detected in the charcoal desorption tubes for most of the test reactors in this experiment. (The concentrations were significantly less than the minimum TCE detection limit and perhaps a result of sample carryover between analyses as discussed above.) TCE recoveries for the four treatment reactors were essentially $100 \%$.

As in other experiments, TCE oxidation of greater than an order of magnitude was initially observed. From Figure 83, however, it appears that all of the TCE was not completely oxidized from the $1 \%$ and $3 \% \mathrm{MnO}_{4}{ }^{-}$reactors, even though a residual $\mathrm{MnO}_{4}{ }^{-}$concentration existed for both oxidant loadings (Figure 87). Note however that all of the values obtained after $\mathrm{T}=0.5 \mathrm{hrs}$ were less than that of the lowest calibration standard. Hence, it is very possible that these residual TCE concentrations are not "real". In fact, It appears that TCE was effectively oxidized in both the $1 \%$ and $3 \% \mathrm{MnO}_{4}{ }^{-}$reactors within the first $1 \mathrm{hr}$. (This value was determined by extrapolating the initially rapid portion of the curves in Figure 83 to a concentration of $0.1 \mu \mathrm{g} / \mathrm{L}$ TCE.) Thus, these are not enough data points available to compute a rate constant. However, if one assumes nearly complete TCE oxidation within $1 \mathrm{hr}$, oxidation rates greater than 6.9 and $17.4 \mathrm{mg} \mathrm{TCE} / \mathrm{hr}$ are obtained for the $1 \%$ and $3 \% \mathrm{MnO}_{4}{ }^{-}$reactors, respectively. Note that complete oxidation occurred within $0.5 \mathrm{hrs}$ for all the other TSF-05 GW experiments with a $3 \%$ $\mathrm{MnO}_{4}{ }^{-}$loading (Exps. 4b-R1 and 4b-R3). Hence, the TCE oxidation rates observed here (at least for the $3 \% \mathrm{MnO}_{4}{ }^{-}$loading) may be affected by the presence of the VOC co-contaminants.

As suggested in the above paragraphs, the TCE oxidation rate may be affected by the presence of the co-contaminants. The initial aqueous concentrations ( $T=0 \mathrm{hrs})$ of the co-contaminants were approximately $15,600 \mu \mathrm{g} / \mathrm{L}$ 1,1-DCE; $16,750 \mu \mathrm{g} / \mathrm{L}$ trans-1,2 DCE; and $11,150 \mu \mathrm{g} / \mathrm{L}$ cis-1,2 DCE. From Figures 84,85 , and 86 it appears that the control reactors performed effectively in minimizing the volatilization of the co-contaminants. Thus, the rapid decreases in the cocontaminant concentrations within the treatment reactors are due to oxidation mechanisms. (Recall that mass balance computations were not performed on the co-contaminants) Oxidation of all the co-contaminants occurred within $0.5 \mathrm{hrs}$ for both the $1 \%$ and $3 \% \mathrm{MnO}_{4}{ }^{-}$reactors.

As observed elsewhere for the nominal $1 \%$ and $3 \%$ oxidant loadings, the $\mathrm{MnO}_{4}{ }^{-}$added (as crystalline $\mathrm{KMnO}_{4}$ ) to the treatment reactors did not readily dissolve (Figure 87). However, an overall 2-4\% net decrease in amount of oxidant present at the end of the reaction period was observed for the $1 \% \mathrm{MnO}_{4}{ }^{-}$reactors. About $23 \%$ of the initial $\mathrm{MnO}_{4}{ }^{-}$mass was consumed in the $3 \% \mathrm{MnO}_{4}{ }^{-}$reactors. 
The $\mathrm{pH}$ values within the treatment reactors decreased rapidly during the oxidation of TCE and the co-contaminants (Figure 88). The greatest $\mathrm{pH}$ decreases occurred in the $1 \% \mathrm{MnO}_{4}{ }^{-}$reactors. As discussed previously, this effect is likely a result of the greater ionic strength of the $3 \%$ oxidant solutions. The $\mathrm{pH}$ of the $1 \% \mathrm{MnO}_{4}{ }^{-}$reactors reached a final $\mathrm{pH}$ value of $\approx 7.3$, a net decrease of $>1.2 \mathrm{pH}$ units. The $3 \% \mathrm{MnO}_{4}{ }^{-}$loading resulted in an average final $\mathrm{pH}$ values of $\approx 7.5$, a net decrease of $>1 \mathrm{pH}$ unit. The total concentration of VOCs in this experiment (TCE + co-contaminants) is on the order of $54,000 \mu \mathrm{g} / \mathrm{L} \mathrm{VOCs}$. The magnitude of the net $\mathrm{pH}$ decreases observed here are similar to those observed in Experiment 4B-R4, where the initial TCE concentrations were also nominally $100,000 \mu \mathrm{g} / \mathrm{L}$ (but with no co-contaminants). 


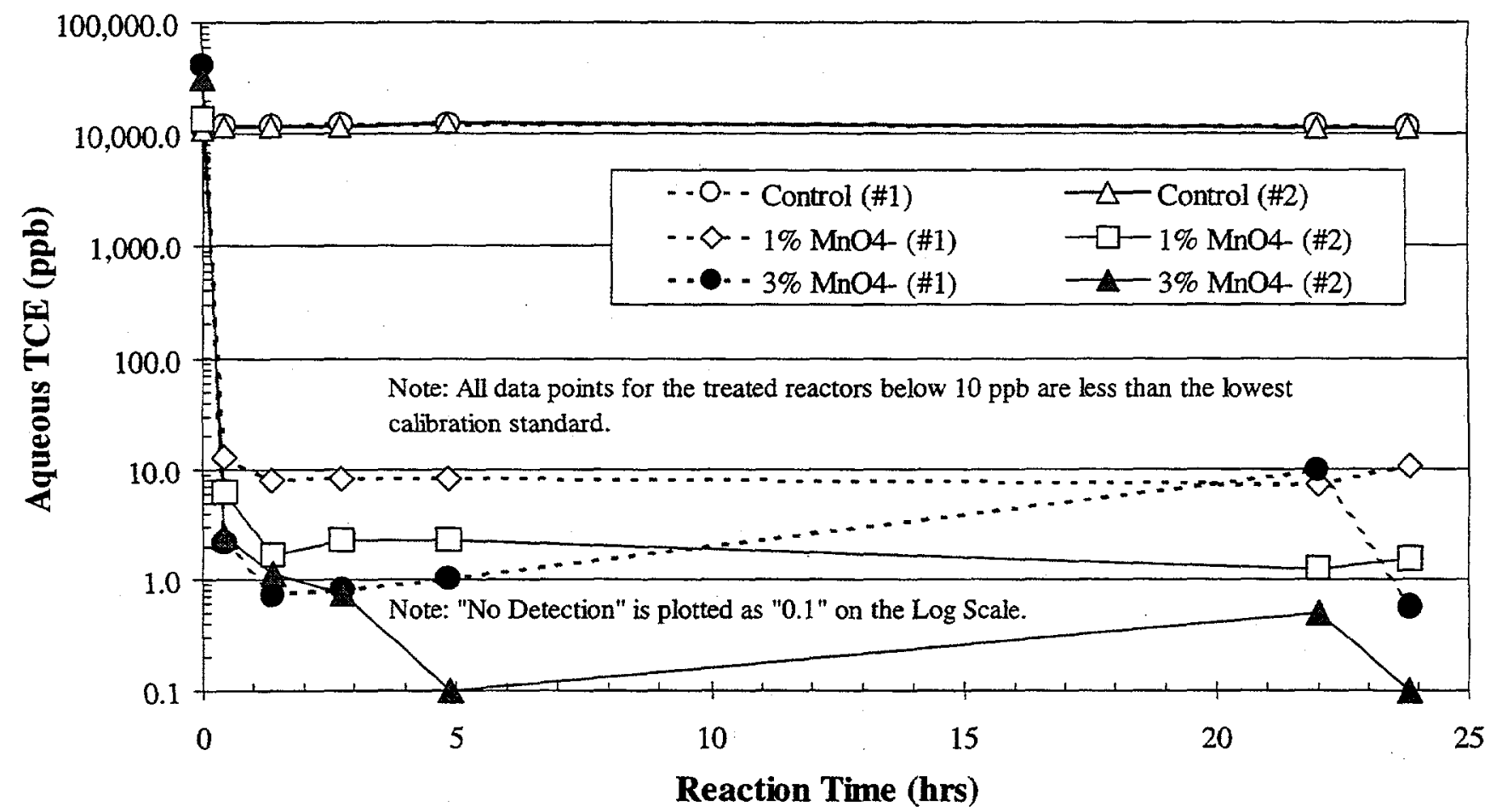

Figure 83. TCE vs. Time, TSF-05 GW, (ORNL Exp. 4b-R6, Initial Target TCE $=100,000 \mu \mathrm{g} / \mathrm{L}$, Co-Contaminants $=10,000 \mu \mathrm{g} / \mathrm{L}$, Conducted at $12^{\circ} \mathrm{C}$ )

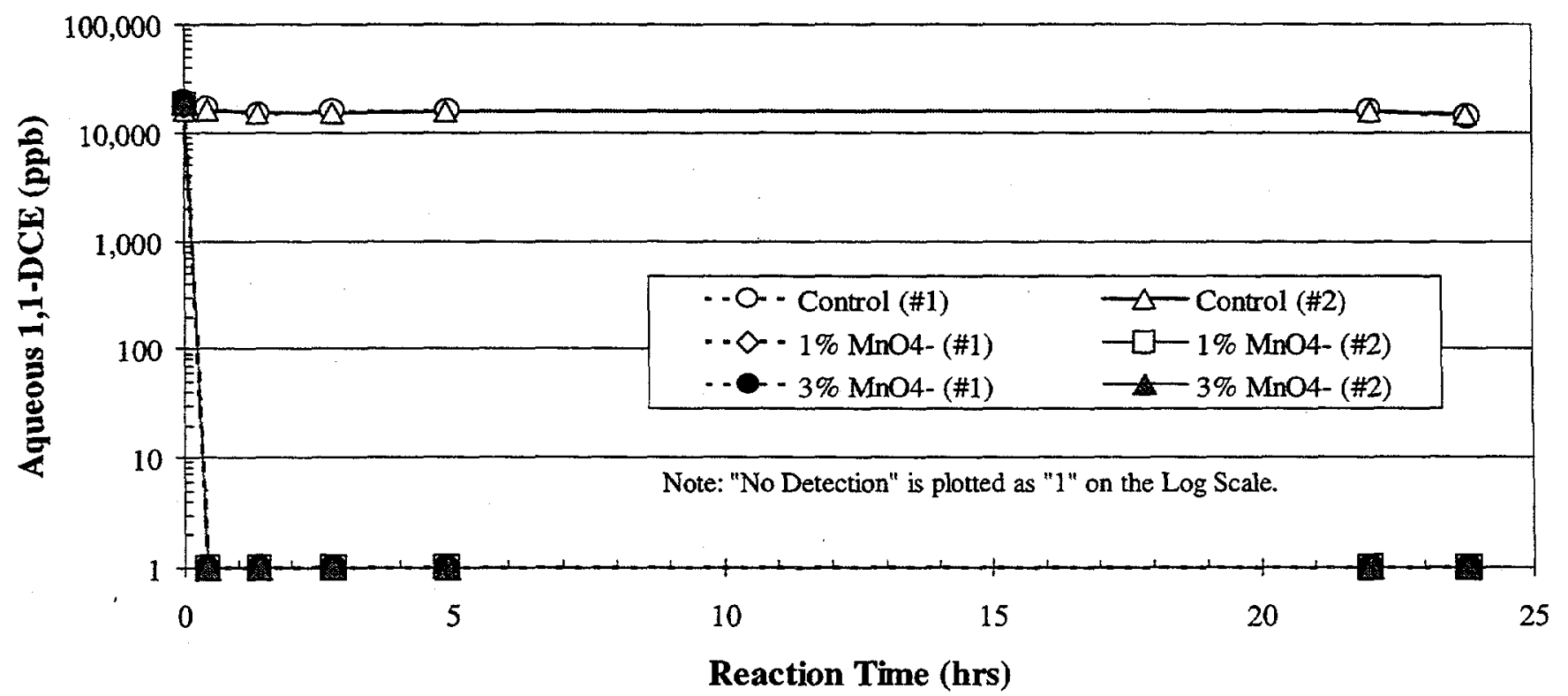

Figure 84. 1,1-DCE vs. Time, TSF-05 GW, (ORNL Exp. 4b-R6, Initial Target TCE= 100,000 $\mu \mathrm{g} / \mathrm{L}$, Co-Contaminants $=10,000 \mu \mathrm{g} / \mathrm{L}$, Conducted at $12^{\circ} \mathrm{C}$ ) 


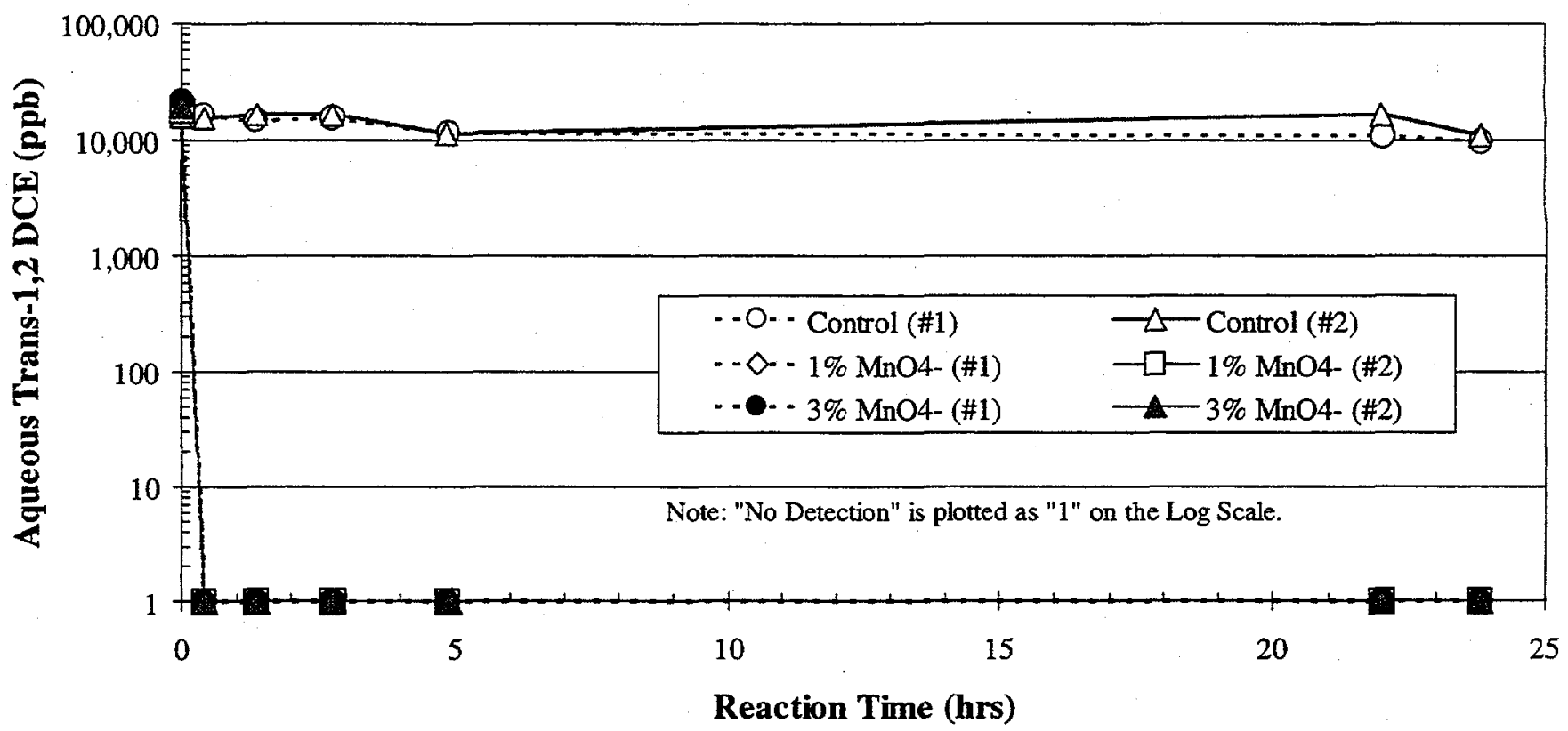

Figure 85. Trans-1,2 DCE vs. Time, TSF-05 GW, (ORNL Exp. 4b-R6, Initial Target TCE= $100,000 \mu \mathrm{g} / \mathrm{L}$, Co-Contaminants $=10,000 \mu \mathrm{g} / \mathrm{L}$, Conducted at $12^{\circ} \mathrm{C}$ )

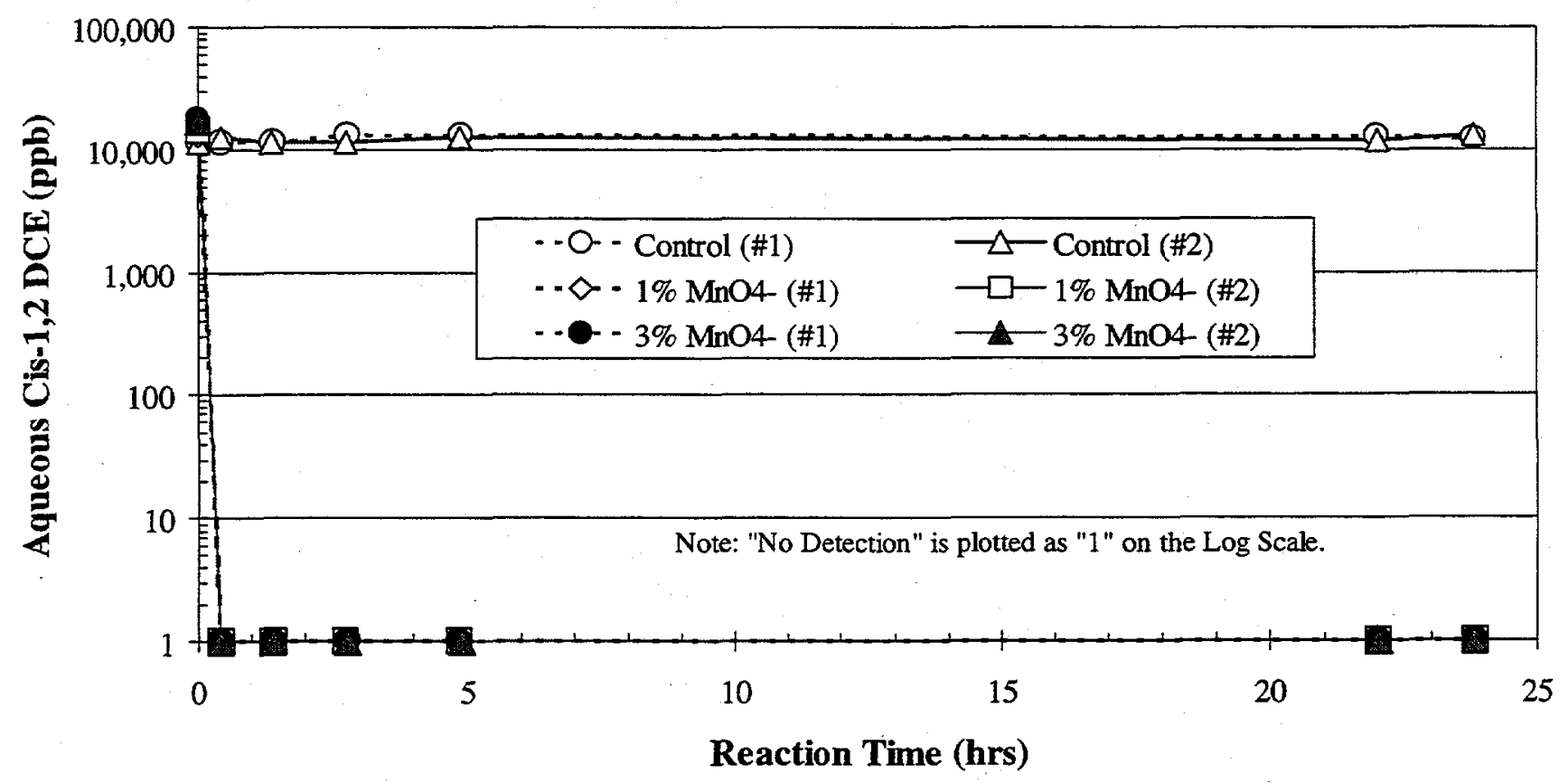

Figure 86. Cis-1,2 DCE vs. Time, TSF-05 GW, (ORNL Exp. 4b-R6, Initial Target TCE= $100,000 \mu \mathrm{g} / \mathrm{L}$, Co-Contaminants $=10,000 \mu \mathrm{g} / \mathrm{L}$, Conducted at $12^{\circ} \mathrm{C}$ ) 


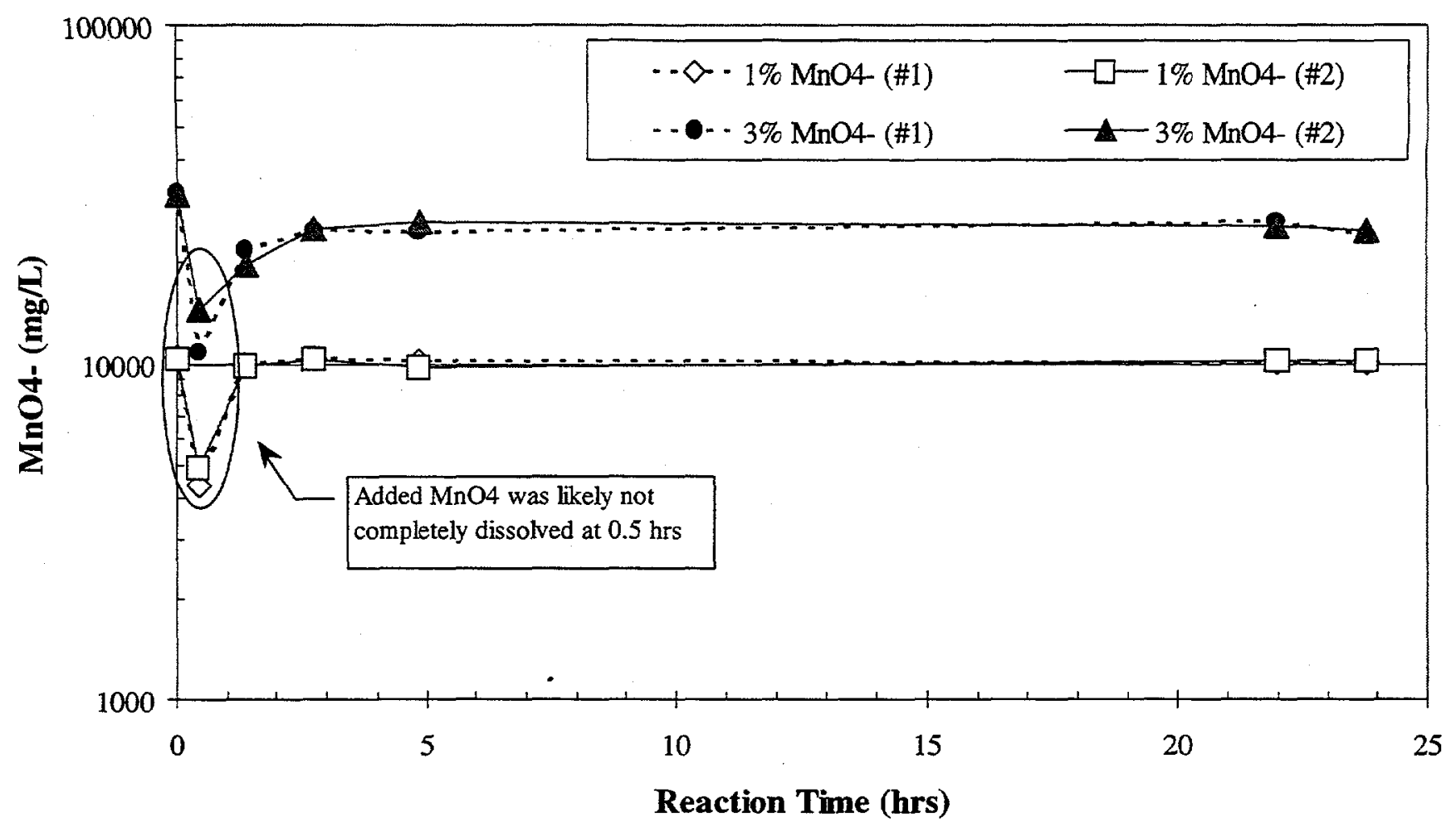

Figure 87. $\mathrm{MnO}_{4}{ }^{-}$vs. Time, TSF-05 GW, (ORNL Exp. 4b-R6, Initial Target TCE $=100,000$ $\mu \mathrm{g} / \mathrm{L}$, Co-Contaminants $=10,000 \mu \mathrm{g} / \mathrm{L}$ Conducted at $12^{\circ} \mathrm{C}$ )

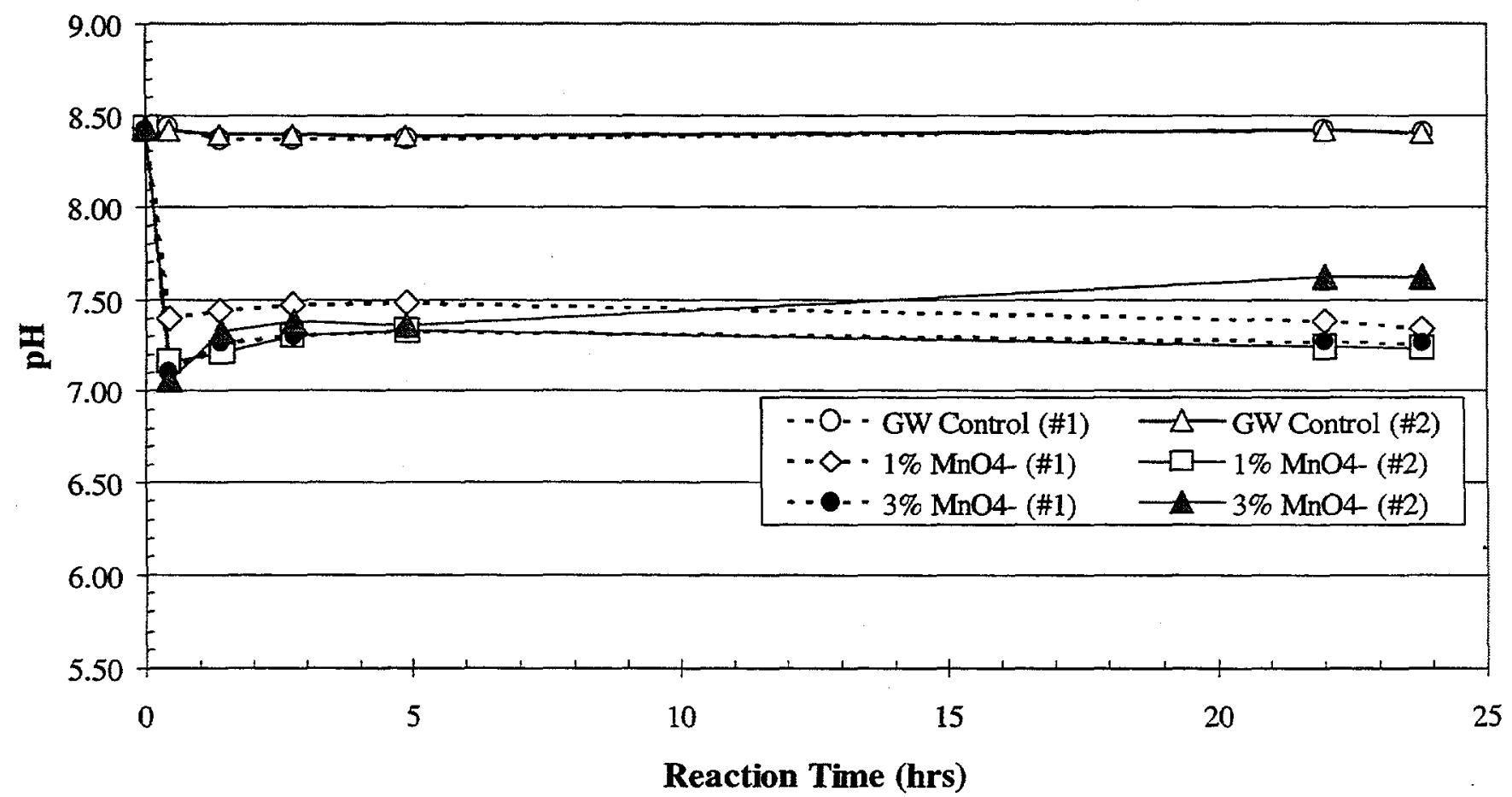

Figure 88. pH vs. Time, TSF-05 GW, (ORNL Exp. 4b-R6 Initial Target TCE $=100,000 \mu \mathrm{g} / \mathrm{L}$, Co-Contaminants $=10,000 \mu \mathrm{g} / \mathrm{L}$ Conducted at $12^{\circ} \mathrm{C}$ ) 
Table 49. TCE Mass Balance for ORNL Exp. 4b-R6 (TSF-05 GW).

\begin{tabular}{|c|c|c|c|c|c|c|c|}
\hline Test Condition & \begin{tabular}{|l|} 
Total \\
Initial \\
Mass \\
(mg)
\end{tabular} & \begin{tabular}{|l} 
Initial \\
Aqueous \\
Mass \\
(mg)
\end{tabular} & $\begin{array}{l}\text { Mass } \\
\text { Sorbed on } \\
\text { Orbo Tubes } \\
(\mathrm{mg})\end{array}$ & $\begin{array}{l}\text { Mass } \\
\text { Remaining in } \\
\text { Reactor (mg) }\end{array}$ & $\begin{array}{l}\text { Cum. } \\
\text { Mass } \\
\text { Removed } \\
\text { in Aliquots } \\
\text { (mg) }\end{array}$ & \begin{tabular}{|l|} 
Cum. \\
Aqueous \\
Mass \\
Oxidized \\
$(\mathrm{mg})$ \\
\end{tabular} & $\begin{array}{l}\text { Total Mass } \\
\text { Recovered } \\
\text { (mg) }\end{array}$ \\
\hline Control (\#1) & 5.8 & 5.8 & $\begin{array}{c}2.8 \mathrm{E}-06 \\
0 \%\end{array}$ & $\begin{array}{c}5.1 \\
87 \%\end{array}$ & $\begin{array}{c}0.6 \\
10 \%\end{array}$ & $\begin{array}{l}\text { NA } \\
\text { NA }\end{array}$ & $\begin{array}{c}5.6 \\
97 \%\end{array}$ \\
\hline Control (\#2) & 5.4 & 5.4 & $\begin{array}{c}3.2 \mathrm{E}-06 \\
0 \%\end{array}$ & $\begin{array}{c}5.0 \\
93 \%\end{array}$ & $\begin{array}{c}0.6 \\
11 \%\end{array}$ & $\begin{array}{l}\text { NA } \\
\text { NA }\end{array}$ & $\begin{array}{c}5.6 \\
104 \%\end{array}$ \\
\hline $1 \%(\# 1)$ & 6.8 & 6.8 & $\begin{array}{c}3.8 \mathrm{E}-06 \\
0 \%\end{array}$ & $\begin{array}{l}0.00 \\
0 \%\end{array}$ & $\begin{array}{l}0.1 \\
1 \%\end{array}$ & $\begin{array}{c}6.7 \\
98 \%\end{array}$ & $\begin{array}{c}6.8 \\
100 \%\end{array}$ \\
\hline $1 \%(\# 2)$ & 6.9 & 6.9 & $\begin{array}{c}2.6 \mathrm{E}-05 \\
0 \%\end{array}$ & $\begin{array}{l}0.00 \\
0 \%\end{array}$ & $\begin{array}{l}0.1 \\
1 \%\end{array}$ & $\begin{array}{c}6.8 \\
99 \% \\
\end{array}$ & $\begin{array}{c}6.9 \\
100 \%\end{array}$ \\
\hline $3 \%(\# 1)$ & 19.5 & 19.5 & $\begin{array}{c}1.3 \mathrm{E}-04 \\
0 \%\end{array}$ & $\begin{array}{l}0.00 \\
0 \%\end{array}$ & $\begin{array}{l}0.3 \\
1 \%\end{array}$ & $\begin{array}{l}19.2 \\
99 \%\end{array}$ & $\begin{array}{c}19.5 \\
100 \%\end{array}$ \\
\hline $3 \%(\# 2)$ & 15.3 & 15.3 & $\begin{array}{c}0.0 \mathrm{E}+00 \\
0 \%\end{array}$ & $\begin{array}{c}0.00 \\
0 \%\end{array}$ & $\begin{array}{l}0.2 \\
1 \%\end{array}$ & $\begin{array}{l}15.1 \\
99 \%\end{array}$ & $\begin{array}{c}15.3 \\
100 \%\end{array}$ \\
\hline
\end{tabular}

Table 50. $\mathrm{MnO}_{4}{ }^{-}$Consumption Data for ORNL Exp. 4b-R6 (TSF-05 GW).

\begin{tabular}{|c|c|c|l|l|}
\hline Test Condition & $\begin{array}{l}\text { Initial } \\
\text { Oxidant } \\
\left(\mathrm{mg} \mathrm{MnO}_{4}{ }^{-}\right)\end{array}$ & $\begin{array}{l}\text { Initial } \\
\text { Loading } \\
\left(\mathrm{mg} \mathrm{MnO}_{4}^{-} / \mathrm{g}\right)\end{array}$ & $\begin{array}{l}\text { Cum. } \\
\text { Consumed } \\
\left(\mathrm{mg} \mathrm{MnO}_{4}^{-}\right)\end{array}$ & $\begin{array}{l}\text { Cum. } \\
\text { Consumed } \\
\left(\mathrm{mg} \mathrm{MnO}_{4} / \mathrm{g}\right)\end{array}$ \\
\hline $1 \%(\# 1)$ & 4974 & 10.5 & 213 & 0.4 \\
\hline $1 \%(\# 2)$ & 4978 & 10.3 & 90 & 0.2 \\
\hline $3 \%(\# 1)$ & 15065 & 32.1 & 3693 & 7.9 \\
\hline $3 \%(\# 2)$ & 15066 & 31.8 & 3226 & 6.8 \\
\hline
\end{tabular}

a. Consumption is computed after $24 \mathrm{hr}$ reaction time. 
ORNL Exp. 4b-R7

(TSF-05 GW, No Sludge, DNAPL TCE, 0 Other, $0.01 \%$ and $0.1 \% \mathrm{MnO}_{4}{ }^{-}$)

This experiment investigated the oxidation of TSF-05 GW spiked at DNAPL TCE Levels; i.e., the groundwater was spiked at $\approx 2 \times 10^{6} \mu \mathrm{g} / \mathrm{L}$ TCE so that a saturated aqueous solution was created.

The TCE, $\mathrm{MnO}_{4}{ }^{-}$and $\mathrm{pH}$ values with time are presented in Figures 89, 90, and 91, respectively. Tables 51 and 52 provide additional TCE mass balance and oxidant consumption information. The (\#1) and (\#2) notations included in both the figure legends and the first column of these tables refer to the duplicate reactors evaluated for that test condition. Note that some of the columns in the mass balance table were computed differently than the method described at the beginning of Section 2.4.3. The deviations to this computational approach are clearly defined in the upcoming discussion of this experiment.

As presented in the testplan, a single TCE spiking solution could not be made and then subsequently distributed among the test reactors for the DNAPL experiments. Instead, a known mass (gravimetric determination) of pure TCE was added directly to each reactor and allowed to equilibrate at $12^{\circ} \mathrm{C}$. Since the initial target TCE concentration $\left(2 \times 10^{6} \mu \mathrm{g} / \mathrm{L}\right)$ was approximately twice the aqueous solubility of TCE $\left(1, \times 10^{6} \mu \mathrm{g} / \mathrm{L} @ 20^{\circ} \mathrm{C}\right)$, a non-aqueous TCE phase (i.e., DNAPL) was expected to exist within each reactor. At the $\mathrm{T}=0 \mathrm{hr}$ time period, the aqueous TCE concentrations were indeed indicative of TCE saturation (average $=1,065,000 \mu \mathrm{g} / \mathrm{L}, \sigma=24,700$ $\mu \mathrm{g} / \mathrm{L}$ ). Due to the spiking approach used, the reactors could potentially have very different initial TCE masses. There was no means of obtaining the total TCE mass in each reactor following equilibration (ie, at the $\mathrm{T}=0 \mathrm{hrs}$ sampling period). Thus, the gravimetric spiking data was used to compute the total initial TCE mass present in each reactor with the gross assumption that no TCE was volatilized during equilibration (Table 51, Column 2).

A reaction period of $96 \mathrm{hrs}$ was evaluated for this experiment rather than the $24 \mathrm{hr}$ period called for in the testplan procedure.

To accurately compute the TCE recoveries for the control and treatment reactors, each reactor should have been extracted at the end of the reaction period. The step was unfortunately not included in the testplan procedure developed for this particular experiment, and the "Mass Remaining in Reactor" column of Table 51 only represents the TCE mass present in the aqueous phase at $\mathrm{T}=96 \mathrm{hrs}$. As a result, total TCE recoveries presented in the mass balance table also do not account for the non-aqueous phase TCE that might be present. (Note that the step to extract each reactor following treatment was properly incorporated into the test procedure prepared for the two DNAPL experiments involving the TSF-05 GW and sludge that are discussed later.)

Although total TCE recoveries were not determined for the reactors, trends observed in the aqueous TCE values of the control reactors suggest that, like Experiments $4 \mathrm{~b}-\mathrm{R} 3$ and $4 \mathrm{~b}-\mathrm{R} 4$, at least some of the variation in the aqueous TCE values is a function of the sample holding time. As observed in Figure 89, aliquot TCE values at T=24 hrs and $96 \mathrm{hrs}$, for example, are generally greater than those obtained at $\mathrm{T}=0 \mathrm{hrs}$ for the control reactors. For this experiment, laboratory notebook records indicate that all $0-24 \mathrm{hr}$ sample extracts were stored at $4^{\circ} \mathrm{C}$ for $\approx 2-3$ days 
before $\mathrm{GC}$ analysis. (This delay is the longest that was ever experienced during the entire INEEL treatability study and is due to an analysis backlog created by the simultaneous collection of samples from two experiments on the same day.)

Despite the time lag between sample collection and sample analysis, TCE oxidation is evident in Figure 89. There was an initial reduction in TCE concentrations for all four of the treatment reactors in the first $0.5 \mathrm{hrs}$ of the reaction period. The magnitude of this overall reduction was the greatest for the $0.1 \% \mathrm{MnO}_{4}{ }^{-}$reactors. As evidenced in Figure 90 and in Table 52, complete consumption of $\mathrm{MnO}_{4}{ }^{-}$occurred within the first $0.5 \mathrm{hrs}$ for both reactors. Thus, as in Experiment 4b-R3 for the $0.01 \% \mathrm{MnO}_{4}{ }^{-}$reactors, all four treatment reactors lacked available $\mathrm{MnO}_{4}{ }^{-}$to allow the oxidation reactions to continue. With all available oxidant depleted at $\mathrm{T}=0.5 \mathrm{hrs}$, it is suspected that the observed increase in aqueous TCE is a result dissolution of additional DNAPL into the aqueous phase.

Since all $\mathrm{MnO}_{4}{ }^{-}$was consumed and a surplus of TCE existed, the oxidized TCE masses obtained in this DNAPL experiment likely represent the upper limit of oxidation that can be achieved by $\mathrm{MnO}_{4}$. The TCE oxidized mass (Table 51, Column 7) was approximated by computing the change in the aqueous TCE mass observed between 0-0.5 hrs. Using this approach, an average of $40 \mathrm{mg}$ TCE $(0.30 \mathrm{mMoles})$ and $193 \mathrm{mg}$ TCE $(1.47 \mathrm{mMoles})$ were oxidized in the $0.01 \%$ and $0.1 \% \mathrm{MnO}_{4}{ }^{-}$reactors, respectively. From the theoretical equation for TCE oxidation by $\mathrm{MnO}_{4}{ }^{-}$ given below, 2 moles of $\mathrm{MnO}_{4}{ }^{-}$are stochiometrically required for complete oxidation of each mole of TCE:

$2 \mathrm{MnO}_{4}{ }^{-}+\mathrm{C}_{2} \mathrm{HCl}_{3} \rightarrow 2 \mathrm{CO}_{2}+2 \mathrm{MnO}_{2}+2 \mathrm{Cl}^{-}+\mathrm{HCl}$

After converting the initial oxidant masses for this experiment (in Table 52) to units of mMoles, experimentally determined molar ratios of $\mathrm{MnO}_{4}{ }^{-}$consumed/TCE oxidized was 1.10 and 2.26 for the $0.01 \%$ and $0.1 \% \mathrm{MnO}_{4}{ }^{-}$reactors, respectively. These molar ratios were computed assuming that any $\mathrm{MnO}_{4}{ }^{-}$consumed by the TSF- $05 \mathrm{GW}$ was minimal as observed in the oxidant demand studies (Table 9). Since it is highly unlikely that the reactions proceeded at less than stochiometric ratio ( 2 moles $\mathrm{MnO}_{4}: 1$ mole TCE) conditions, the approximate mass of TCE mass oxidized was likely overestimated at least for the $0.01 \% \mathrm{MnO}_{4}{ }^{-}$reactors.

Although the oxidation estimates for the non-aqueous TCE cannot be computed, observed aqueous oxidation rates are at least 80 and $386 \mathrm{mg} \mathrm{TCE} / \mathrm{hr}$ for the $0.01 \%$ and $0.1 \% \mathrm{MnO}_{4}{ }^{-}$ reactors, respectively. Note that these values are minimum oxidation rates since TCE oxidized masses used in the calculations only represent TCE oxidized from the aqueous phase.

Essentially all of the initial $0.01 \%$ and $0.1 \% \mathrm{MnO}_{4}{ }^{-}$was consumed during the oxidation reactions. $\mathrm{A}^{-\mathrm{MnO}_{4}}{ }^{-}$residual of less than $1 \mathrm{mg} / \mathrm{L}$ was measured (Figure 90 ) for both cases, but it should be noted that the lowest $\mathrm{MnO}_{4}{ }^{-}$calibration standard was $5 \mathrm{mg} / \mathrm{L}$.

Trends in $\mathrm{pH}$ values for these reactors were similar to those observed in Experiments $4 \mathrm{~b}-\mathrm{R} 1$ and 4b-R3 (Figures 65 and 71) in which all experimental variables except for the initial TCE concentration were the same. The magnitude of the $\mathrm{pH}$ drop observed in these experiments, however, is greatest for this DNAPL experiment. In fact, net $\mathrm{pH}$ decreases of greater than 2.1 and $5.4 \mathrm{pH}$ units were observed here for the $0.01 \%$ and $0.1 \% \mathrm{MnO}_{4}{ }^{-}$reactors. Thus, the degree 
of $\mathrm{pH}$ change appears to be dependent upon the initial TCE concentration present. These significant $\mathrm{pH}$ changes are likely due to the large amount of $\mathrm{H}^{+}$ions released during the oxidation of TCE. These test reactors were also void of any solid phase to help buffer these changes. 


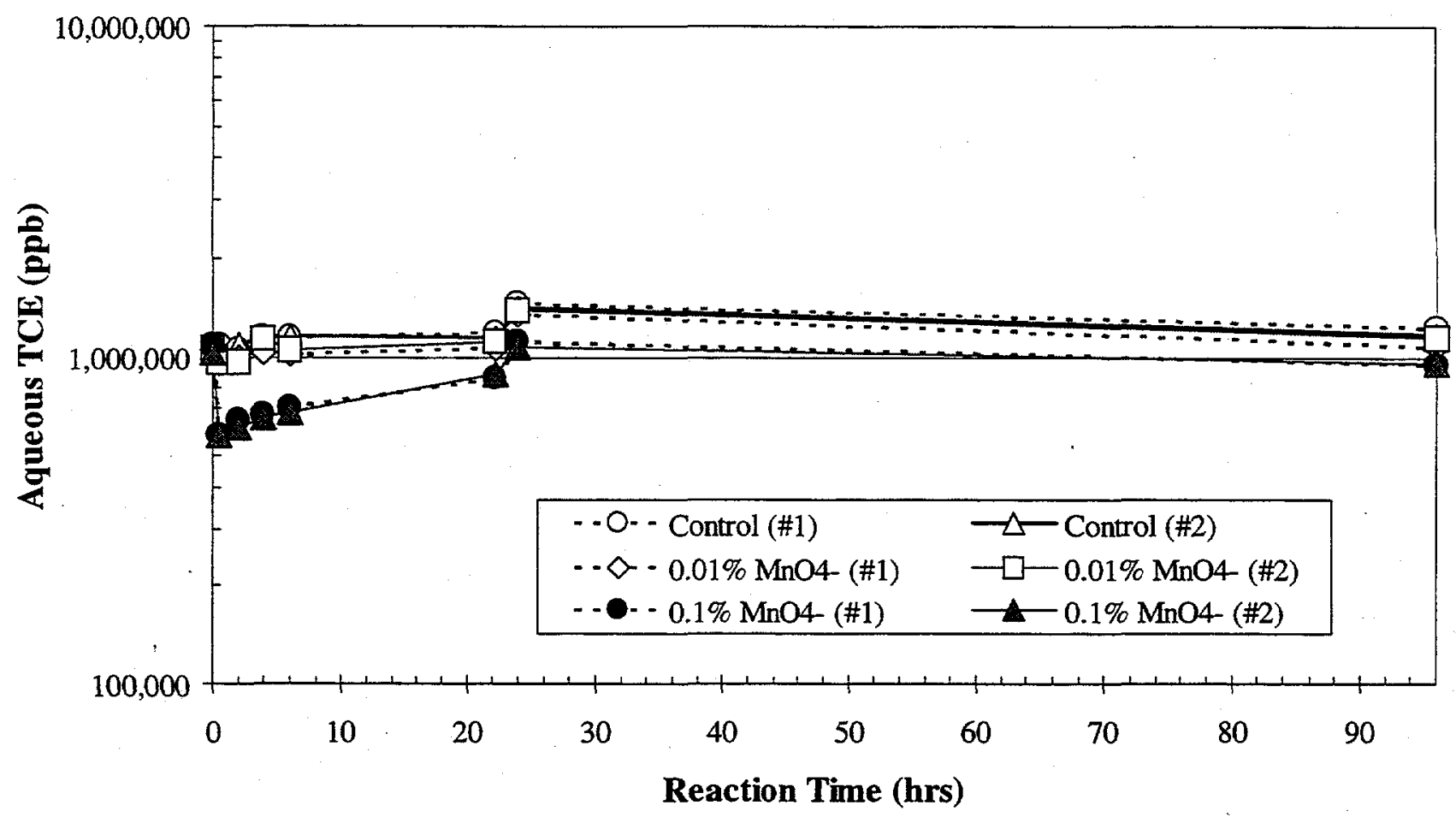

Figure 89. TCE vs. Time, TSF-05 GW, (ORNL Exp. 4b-R7, Initial TCE=DNAPL, Conducted at $12^{\circ} \mathrm{C}$ )

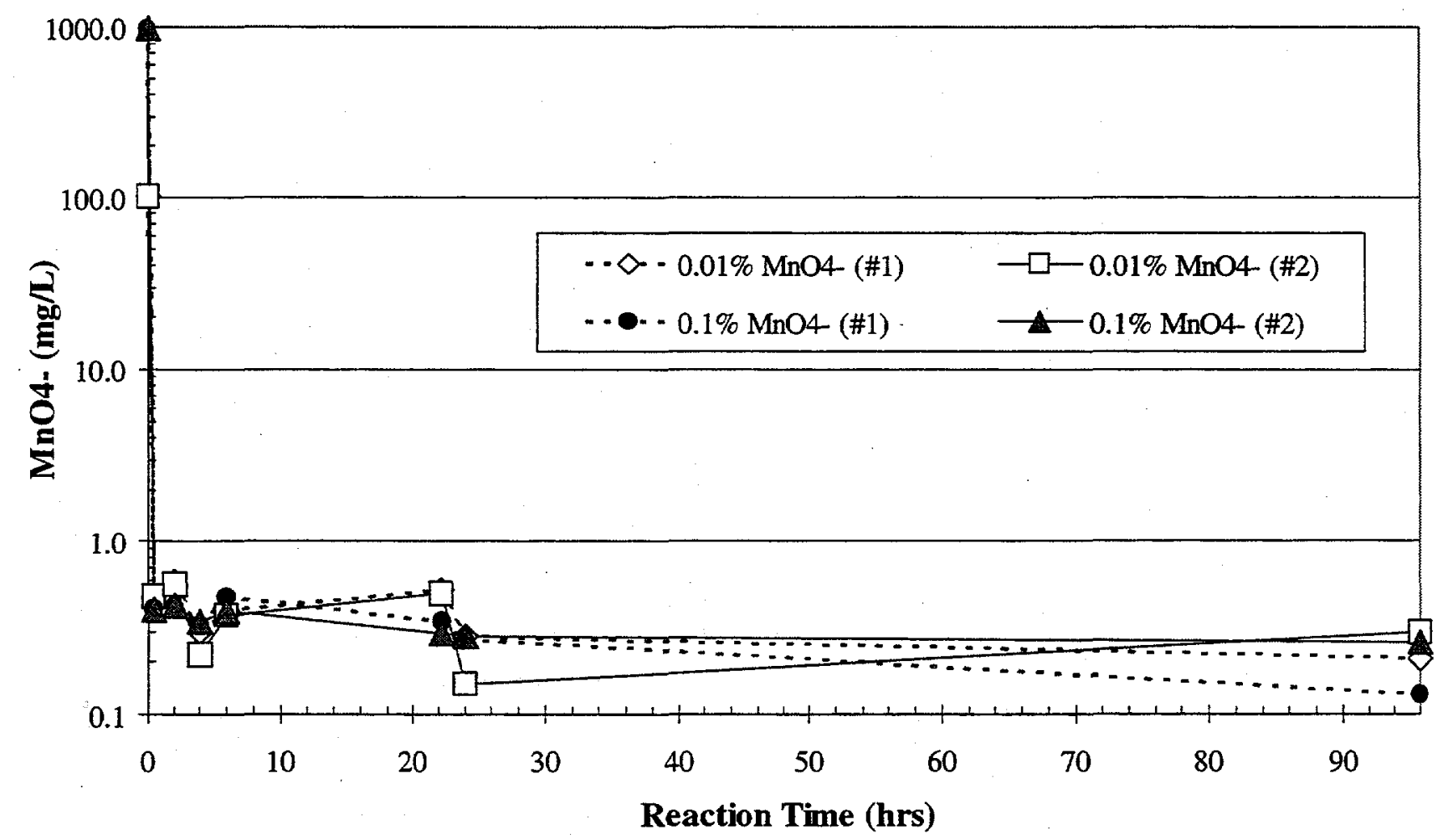

Figure 90. $\mathrm{MnO}_{4}{ }^{-}$vs. Time, TSF-05 GW, (ORNL Exp. 4b-R7, Initial TCE= DNAPL, Conducted at $12^{\circ} \mathrm{C}$ ) 


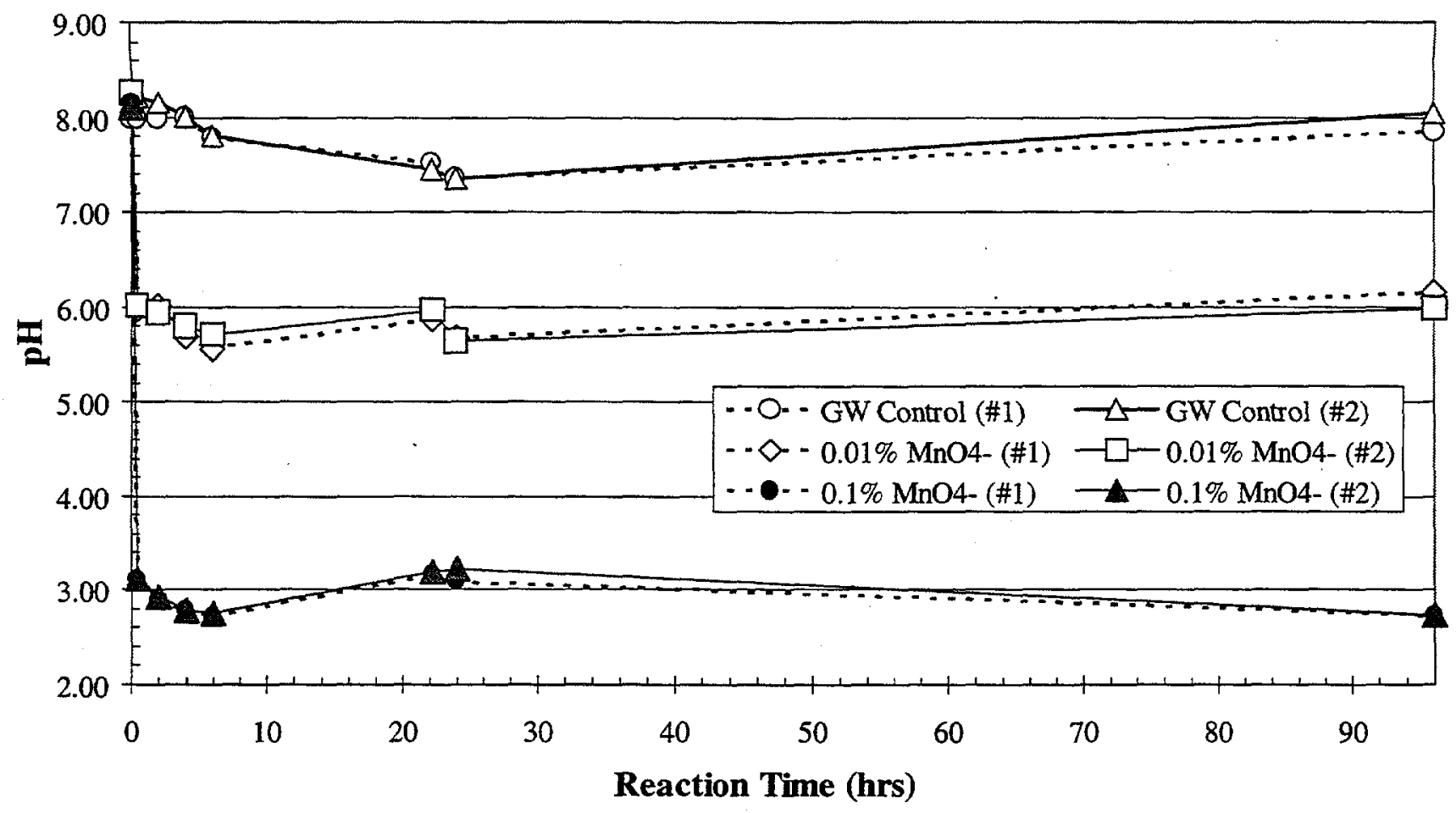

Figure 91. pH vs. Time, TSF-05 GW, (ORNL Exp. 4b-R7, Initial TCE= DNAPL, Conducted at $\left.12^{\circ} \mathrm{C}\right)$ 
Table 51. TCE Mass Balance for ORNL Exp. 4b-R7 (TSF-05 GW). ${ }^{\text {a. }}$

\begin{tabular}{|l|c|l|l|l|l|l|l|}
\hline Test Condition & $\begin{array}{l}\text { Total } \\
\text { Initial } \\
\text { Mass } \\
(\mathrm{mg})\end{array}$ & $\begin{array}{l}\text { Initial } \\
\text { Aqueous } \\
\text { Mass } \\
(\mathrm{mg})\end{array}$ & $\begin{array}{l}\text { Mass } \\
\text { Sorbed on } \\
\text { Orbo Tubes } \\
(\mathrm{mg})\end{array}$ & $\begin{array}{l}\text { Mass } \\
\text { Remaining in } \\
\text { Reactor (mg) } \\
\text { (Aqueous) }\end{array}$ & $\begin{array}{l}\text { lum. } \\
\text { Mass } \\
\text { Removed } \\
\text { in Aliquots } \\
(\mathrm{mg})\end{array}$ & $\begin{array}{l}\text { TCE } \\
\text { Oxidized }\end{array}$ & $\begin{array}{l}\text { Total Mass } \\
\text { Recovered } \\
(\mathrm{mg})\end{array}$ \\
\hline Control (\#1) & 798 & 433 & 0.59 & 366 & 119 & NA & 485 \\
& & & $0 \%$ & $46 \%$ & $15 \%$ & NA & $61 \%$ \\
\hline Control (\#2) & 815 & 434 & 0.22 & 349 & 115 & NA & 465 \\
& & & $0 \%$ & $43 \%$ & $14 \%$ & NA & $57 \%$ \\
\hline $0.01 \%(\# 1)$ & 807 & 418 & 0.25 & 333 & 95 & 35 & 462 \\
& & & $0 \%$ & $41 \%$ & $12 \%$ & $4 \%$ & $57 \%$ \\
\hline $0.01 \%(\# 2)$ & 795 & 426 & 2.89 & 357 & 99 & 46 & 505 \\
& & & $0 \%$ & $45 \%$ & $12 \%$ & $6 \%$ & $64 \%$ \\
\hline $0.1 \%(\# 1)$ & 806 & 435 & 2.12 & 302 & 73 & 206 & 582 \\
& & & $0 \%$ & $37 \%$ & $9 \%$ & $26 \%$ & $72 \%$ \\
\hline $0.1 \%(\# 2)$ & 808 & 410 & 4.44 & 305 & 73 & 180 & 563 \\
& & & $1 \%$ & $38 \%$ & $9 \%$ & $22 \%$ & $70 \%$ \\
\hline
\end{tabular}

a. Total Initial is assumed to be the actual DNAPL TCE mass added to each reactor.

Final Remaining TCE only represents the final TCE in the aqueous phase.

TCE oxidized only includes mass associated with the difference in the aqueous TCE concentrations between $0-0.5 \mathrm{hrs}$.

Total Recovered values do not include remaining non-aqueous phase TCE

Table 52. $\mathrm{MnO}_{4}{ }^{-}$Consumption Data for ORNL Exp. 4b-R7 (TSF-05 GW).

\begin{tabular}{|l|c|l|l|l|}
\hline Test Condition & $\begin{array}{l}\text { Initial } \\
\text { Oxidant } \\
\left(\mathrm{mg} \mathrm{MnO}_{4}\right)\end{array}$ & $\begin{array}{l}\text { Initial } \\
\text { Loading } \\
\left(\mathrm{mg} \mathrm{MnO}_{4} / \mathrm{g}\right)\end{array}$ & $\begin{array}{l}\text { Cum. } \\
\text { Consumed } \\
\left(\mathrm{mg} \mathrm{MnO}_{4}^{-}\right)\end{array}$ & $\begin{array}{l}\text { Cum. } \\
\text { Consumed } \\
\left(\mathrm{mg} \mathrm{MnO}_{4} / \mathrm{g}\right)\end{array}$ \\
\hline $0.01 \%(\# 1)$ & 39.6 & 0.10 & 39.5 & 0.10 \\
\hline $0.01 \%(\# 2)$ & 39.6 & 0.10 & 39.5 & 0.10 \\
\hline $0.1 \%(\# 1)$ & 396.0 & 0.99 & 395.9 & 0.99 \\
\hline $0.1 \%(\# 2)$ & 396.0 & 0.99 & 395.9 & 0.99 \\
\hline
\end{tabular}

a. Consumption is computed after $96 \mathrm{hr}$ reaction time. 
ORNL Exp. 4b-R8

(TSF-05 GW, No Sludge, DNAPL TCE, 0 Other, $1 \%$ and $3 \% \mathrm{MnO}_{4}{ }^{-}$)

This experiment investigated the oxidation of TSF-05 GW spiked at DNAPL TCE Levels; i.e., the groundwater was spiked at $\approx 2 \times 10^{6} \mu \mathrm{g} / \mathrm{L}$ TCE so that a saturated aqueous solution was created.

The TCE, $\mathrm{MnO}_{4}{ }^{-}$and $\mathrm{pH}$ values with time are presented in Figures 92,93 , and 94 , respectively. Tables 53 and 54 provide additional TCE mass balance and oxidant consumption information. The (\#1) and (\#2) notations included in both the figure legends and the first column of these tables refer to the duplicate reactors evaluated for that test condition. Note that some of the columns in the mass balance table were computed differently than the method described at the beginning of Section 2.4.3. The deviations to this computational approach are clearly defined in the upcoming discussion of this experiment.

As presented in the testplan, a single TCE spiking solution could not be made and then subsequently distributed among the test reactors for the DNAPL experiments. Instead, a known mass (gravimetric determination) of pure TCE was added directly to each reactor and allowed to equilibrate at $12^{\circ} \mathrm{C}$. Since the initial target TCE concentration $\left(2 \times 10^{6} \mu \mathrm{g} / \mathrm{L}\right)$ was $\approx$ twice the aqueous solubility of TCE, a non-aqueous TCE phase (i.e., DNAPL) was expected to exist within each reactor. At the $\mathrm{T}=0$ time period, the aqueous TCE concentrations were indeed indicative of TCE saturation (average $=1,031,000 \mu \mathrm{g} / \mathrm{L}, \sigma=40,600 \mu \mathrm{g} / \mathrm{L}$ ). Due to the spiking approach used, the reactors could potentially have very different initial TCE masses. There was no means of obtaining the total TCE mass in each reactor following equilibration (i.e., at the $T=0$ hrs sampling period). Thus, the gravimetric spiking data was used to compute the total initial TCE mass present in each reactor with the gross assumption that no TCE was volatilized during equilibration (Table 53, Column 2).

A reaction period of $96 \mathrm{hrs}$ was evaluated for this experiment rather than the $24 \mathrm{hr}$ period called for in the testplan procedure.

To accurately compute the TCE recoveries for the control and treatment reactors, each reactor should have been extracted at the end of the reaction period. The step was unfortunately not included in the testplan procedure developed for this particular experiment, and the "Final Remaining" column in Table 53 only represents the TCE mass present in the aqueous phase at $\mathrm{T}=96 \mathrm{hrs}$. As a result, total TCE recoveries for the reactors also do not account for any nonaqueous phase TCE that may be present. (Note that the step to extract each reactor following treatment was properly incorporated into the test procedure prepared for the two DNAPL experiments involving the TSF-05 GW and sludge that are to be discussed later.)

Although total TCE recoveries were not determined for the reactors, TCE oxidation is quite evident in Figure 92. Here, the overall reductions in TCE concentrations for the treatment reactors are significant and by far exceed the reductions observed for the control reactors. The oxidation reactions occurring were robust. Laboratory observations indicated significant pressure build up and release at the $0.5 \mathrm{hr}$ aliquot sampling time for the $3 \%$ reactors. As noted in Figure 92 , the first $1 \% \mathrm{MnO}_{4}^{-}$reactor was cracked and replaced after $\mathrm{t}=4 \mathrm{hrs}$. The contents of 
the cracked reactor were transferred into an intact reactor. Some TCE may have volatilized during this transfer, but oxidation was likely still the primary removal mechanism since the oxidant consumption values presented in Table 54 are the same for both of the $1 \% \mathrm{MnO}_{4}{ }^{-}$ reactors. Given the fact that residual oxidant was present and TCE was not detected in the $96 \mathrm{hr}$ aqueous aliquots, complete oxidation of both the aqueous and non-aqueous TCE phase is suspected. The TCE oxidized masses presented in Table 53, Column 7 represent the maximum TCE that could have been oxidized within a given reactor. The values were calculated by subtracting the TCE mass present in the desorption tubes and sample aliquots from the total initial TCE.

Furthermore, the oxidation for both oxidant loadings appears to be a 2-step process, where the bulk of the TCE is oxidized rapidly, followed by a slower oxidation step. Due to the presence of the non-aqueous phase in these reactors, oxidation rate constants cannot be accurately computed. The mechanism controlling the oxidation of the DNAPL is not well understood. It is not known how or when the non-aqueous phase TCE is being oxidized (e.g., is it solubilized first?). If it is assumed that all TCE is oxidized by $\mathrm{T}=0.5 \mathrm{hrs}$, a maximum oxidation rate of $1,620 \mathrm{mg} \mathrm{TCE} / \mathrm{hr}$ would be obtained for both the $1 \%$ and $3 \% \mathrm{MnO}_{4}{ }^{-}$reactors in this experiment.

As evidenced in Figure 93 and in Table 54, residual oxidant was still present in all the treatment reactors after the $96 \mathrm{hr}$ reaction time. In fact, only $35 \%$ and $14 \%$ of the initial oxidant mass was consumed in the $1 \%$ and $3 \%$ reactors, respectively. Nearly all of this consumption occurred within the first $0.5 \mathrm{hrs}$.

Trends in $\mathrm{pH}$ values for these reactors as similar to those observed in Experiments $4 \mathrm{~b}-\mathrm{R} 2$ and $4 \mathrm{~b}$ R4 (Figures 68 and 74) in which all experimental variables except for the initial TCE concentration were the same. The magnitude of the $\mathrm{pH}$ decrease, however, is greatest for this DNAPL experiment ( $>6.3 \mathrm{pH}$ units). Thus, the degree of $\mathrm{pH}$ change again appears to be dependent upon the initial TCE concentration present.

In TSF-05 GW experiments not involving a non-aqueous phase, the $1 \%$ and $3 \% \mathrm{MnO}_{4}{ }^{-}$reactors typically resulted in net $\mathrm{pH}$ decreases smaller is magnitude than those observed for the $0.01 \%$ and $0.1 \% \mathrm{MnO}_{4}{ }^{-}$reactors. This was attributed to the greater ionic strength of the more concentrated oxidant solution. This trend was not observed for the DNAPL experiments, for the $\mathrm{pH}$ decreases observed in this experiment were greater than those observed in Experiment 4b-R7. For the high TCE concentrations evaluated in this experiment, the release of $\mathrm{H}^{+}$ions during TCE oxidation likely had a greater effect on the system $\mathrm{pH}$ than did the ionic strength of the oxidant solution. 


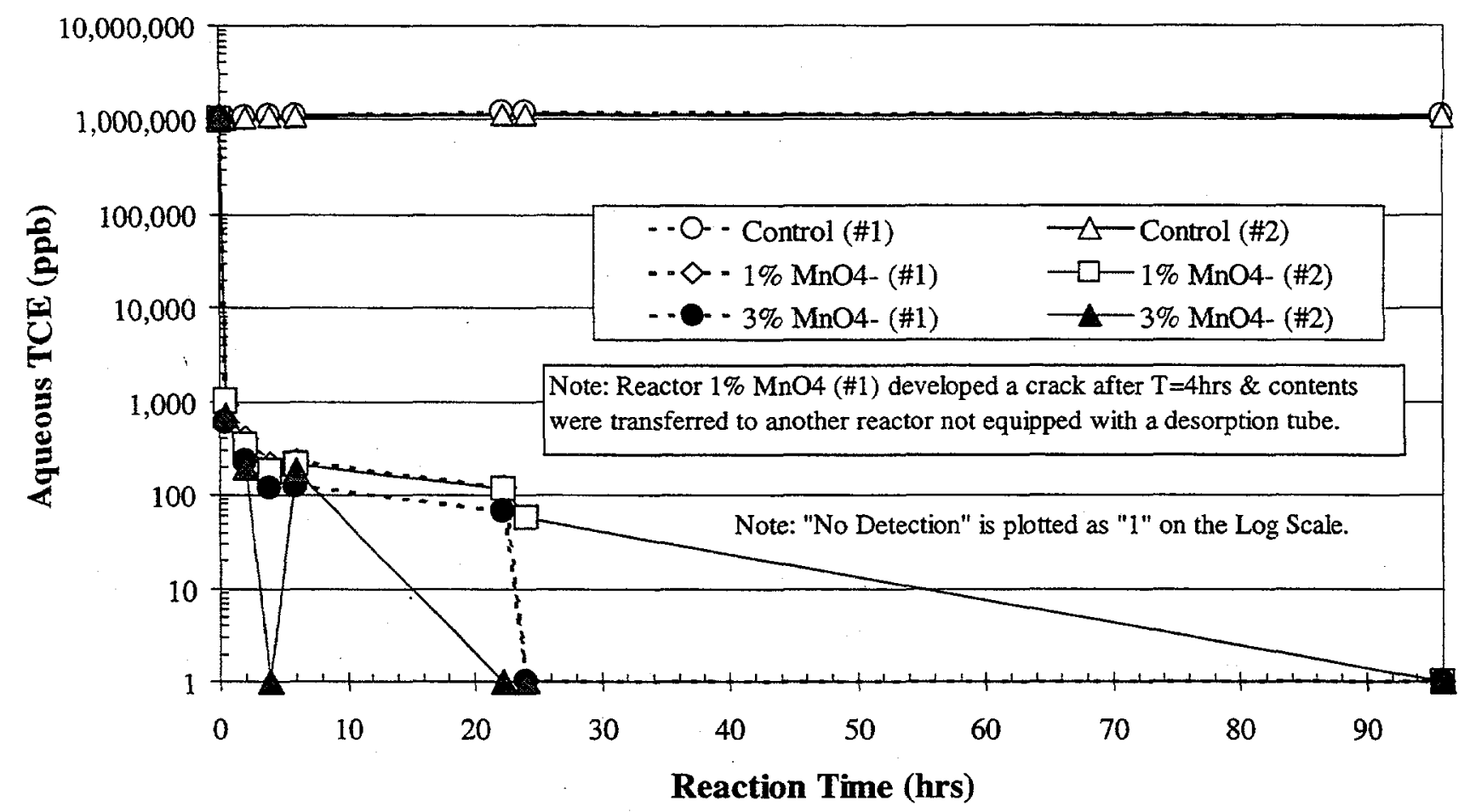

Figure 92. TCE vs. Time, TSF-05 GW, (ORNL Exp. 4b-R8, Initial TCE= DNAPL, Conducted at $12^{\circ} \mathrm{C}$ )

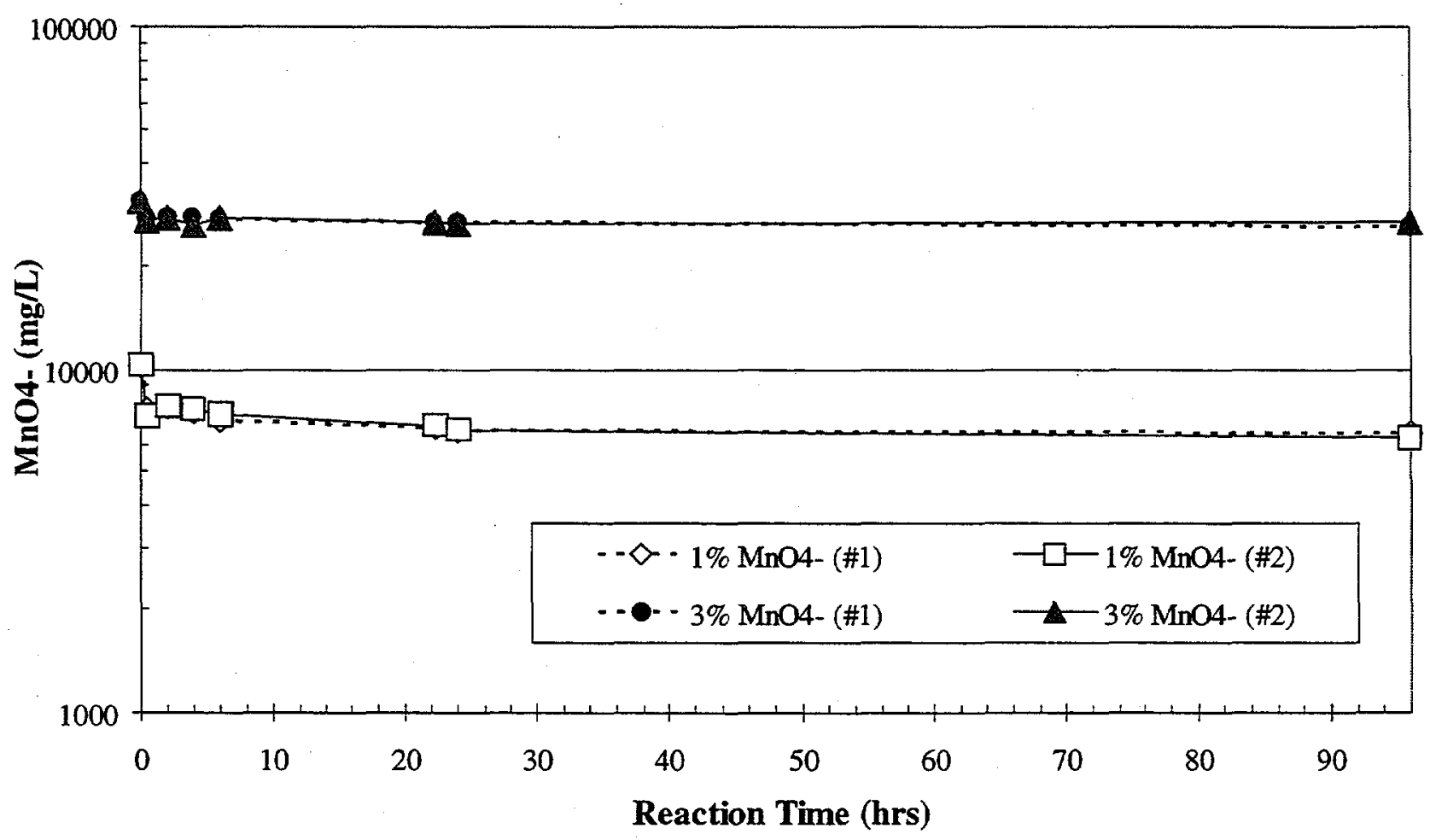

Figure 93. $\mathrm{MnO}_{4}{ }^{-}$vs. Time, TSF-05 GW, (ORNL Exp. 4b-R8, Initial TCE= DNAPL, Conducted at $12^{\circ} \mathrm{C}$ ) 


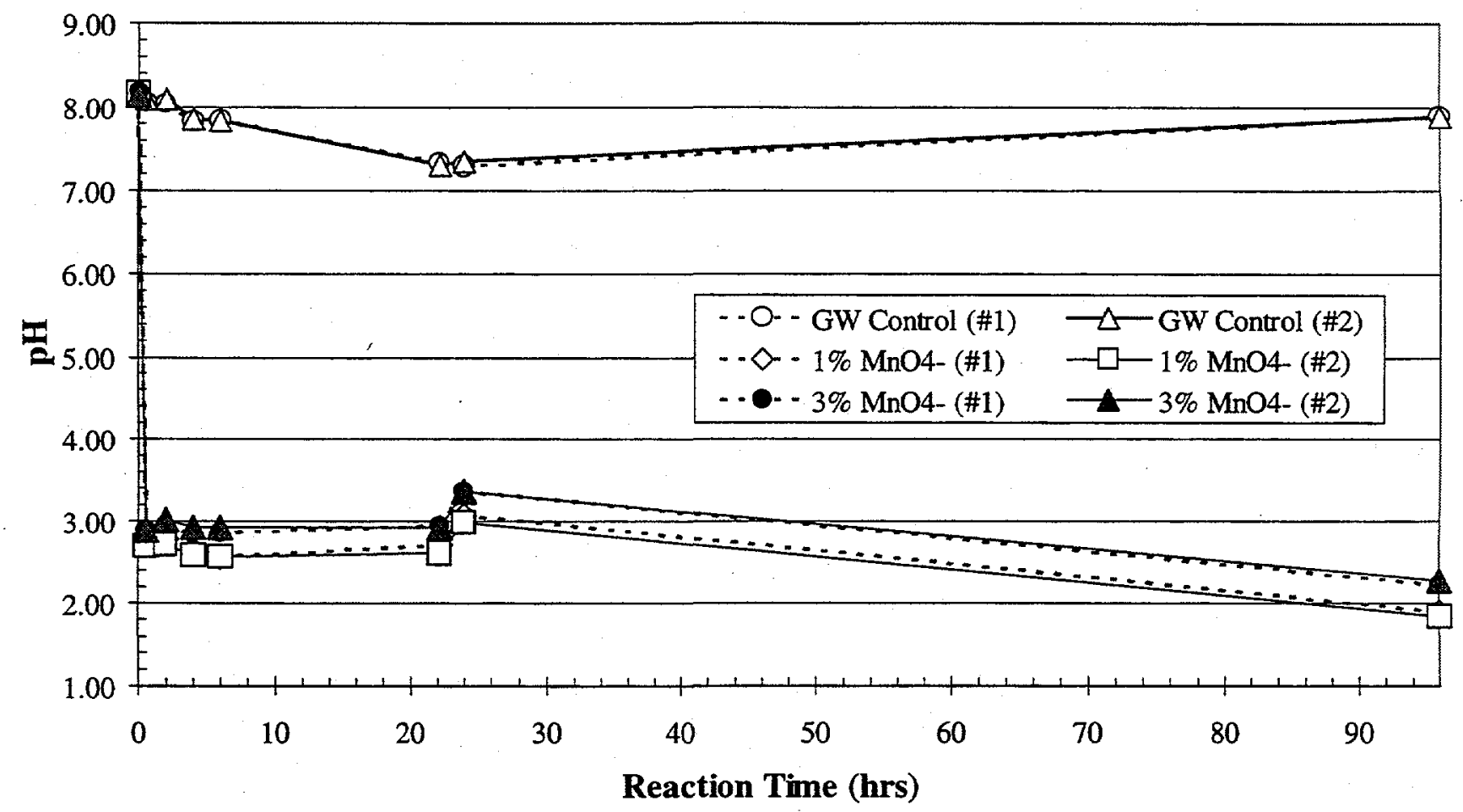

Figure 94. pH vs. Time, TSF-05 GW, (ORNL Exp. 4b-R8, Initial TCE= DNAPL, Conducted at $12^{\circ} \mathrm{C}$ ) 
Table 53. TCE Mass Balance for ORNL Exp. 4b-R8 (TSF-05 GW) ${ }^{\text {a. }}$

\begin{tabular}{|c|c|c|c|c|c|c|c|}
\hline Test Condition & \begin{tabular}{|l|} 
Total \\
Initial \\
Mass \\
(mg)
\end{tabular} & \begin{tabular}{|l|} 
Initial \\
Aqueous \\
Mass \\
(mg)
\end{tabular} & $\begin{array}{l}\text { Mass } \\
\text { Sorbed on } \\
\text { Orbo Tubes } \\
(\mathrm{mg})\end{array}$ & \begin{tabular}{|l|} 
Mass \\
Remaining in \\
Reactor (mg) \\
(Aqueous)
\end{tabular} & \begin{tabular}{|l|} 
Cum. \\
Mass \\
Removed \\
in Aliquots \\
(mg) \\
\end{tabular} & $\begin{array}{l}\text { Max.TCE } \\
\text { Oxidized }^{\dagger}\end{array}$ & $\begin{array}{l}\text { Total Mass } \\
\text { Recovered } \\
(\mathrm{mg})\end{array}$ \\
\hline Control (\#1) & 812 & 396 & & $\begin{array}{l}32 \\
40\end{array}$ & $\begin{array}{l}109 \\
13 \%\end{array}$ & $\begin{array}{l}\text { NA } \\
\text { NA }\end{array}$ & $\begin{array}{l}436 \\
54 \%\end{array}$ \\
\hline Control (\#2) & 806 & 417 & $\begin{array}{c}0.142 \\
0 \%\end{array}$ & & & $\begin{array}{l}\mathrm{NA} \\
\mathrm{NA}\end{array}$ & $\begin{array}{l}440 \\
55 \%\end{array}$ \\
\hline $1 \%(\# 1)$ & 810 & 404 & $\begin{array}{c}0.000 \\
0 \%\end{array}$ & $\begin{array}{c}0 \\
0 \%\end{array}$ & $\begin{array}{l}10 \\
1 \%\end{array}$ & $\begin{array}{l}799^{\dagger} \\
99 \%\end{array}$ & $\begin{array}{l}\text { Not compured } \\
\text { Not computed }\end{array}$ \\
\hline $1 \%(\# 2)$ & 817 & 411 & $\begin{array}{c}0.032 \\
0 \%\end{array}$ & $\begin{array}{c}0 \\
0 \%\end{array}$ & $\begin{array}{l}10 \\
1 \%\end{array}$ & $\begin{array}{l}807^{\dagger} \\
99 \%\end{array}$ & $\begin{array}{l}\text { Not computed } \\
\text { Not computed }\end{array}$ \\
\hline $3 \%(\# 1)$ & 806 & 404 & $\begin{array}{c}0.013 \\
0 \%\end{array}$ & $\begin{array}{c}0 \\
0 \%\end{array}$ & $\begin{array}{l}10 \\
1 \%\end{array}$ & $\begin{array}{l}796^{\dagger} \\
99 \%\end{array}$ & $\begin{array}{l}\text { Not computed } \\
\text { Not computed }\end{array}$ \\
\hline & 809 & 442 & $\begin{array}{c}0.033 \\
0 \% \\
\end{array}$ & $\begin{array}{c}0 \\
0 \%\end{array}$ & $\begin{array}{l}11 \\
1 \% \\
\end{array}$ & $\begin{array}{l}798^{\dagger} \\
99 \% \\
\end{array}$ & $\begin{array}{l}\text { Not computed } \\
\text { Not compured }\end{array}$ \\
\hline
\end{tabular}

a. Total Initial is assumed to be the actual DNAPL TCE mass added to each reactor.

Final Remaining TCE only represents the final TCE in the aqueous phase.

$\dagger$ Max. TCE Oxidized= Total Initial-Orbo Tube-Cum. Aliquot.

Table 54. $\mathrm{MnO}_{4}{ }^{-}$Consumption Data for ORNL Exp. 4b-R8 (TSF-05 GW).

\begin{tabular}{|c|l|l|l|l|}
\hline Test Condition & $\begin{array}{l}\text { Initial } \\
\text { Oxidant } \\
\left(\mathrm{mg} \mathrm{MnO}_{4}^{-}\right)\end{array}$ & $\begin{array}{l}\text { Initial } \\
\text { Loading }^{\prime} \\
\left(\mathrm{mg} \mathrm{MnO}_{4} / \mathrm{g}\right)\end{array}$ & $\begin{array}{l}\text { Cum. } \\
\text { Consumed } \\
\left(\mathrm{mg} \mathrm{MnO}_{4}^{-}\right)\end{array}$ & $\begin{array}{l}\text { Cum. } \\
\text { Consumed } \\
\left(\mathrm{mg} \mathrm{MnO}_{4} / \mathrm{g}\right)\end{array}$ \\
\hline $1 \%(\# 1)$ & 4017 & 10.3 & 1421 & 3.6 \\
\hline $1 \%(\# 2)$ & 4017 & 10.3 & 1421 & 3.6 \\
\hline $3 \%(\# 1)$ & 12051 & 30.9 & 1649 & 4.2 \\
\hline $3 \%(\# 2)$ & 12051 & 30.9 & 1680 & 4.3 \\
\hline
\end{tabular}

a. Consumption is computed after $96 \mathrm{hr}$ reaction time. 
Summary - VOC Oxidation Rate Measurements, Hot Spot Groundwater

This set of experiments measured the rate of TCE oxidation in groundwater from the hot spot. The concentrations of TCE used in these experiments are higher than those used in the 'dissolved plume' experiments, reflecting the higher in situ TCE concentrations in the hot spot. The $\mathrm{MnO}_{4}{ }^{-}$ concentrations used were also higher in the 'hot spot' experiments due to the greater oxidant demand of hot spot media and the potentially higher oxidant concentrations needed to achieve rapid and complete oxidation of the higher TCE concentrations.

- Permanganate concentrations ranged from $0.01 \%$ (100 $\mathrm{mg} / \mathrm{L})$ to $3 \%(30 \mathrm{~g} / \mathrm{L})$, which is close to the solubility limit for potassium permanganate at groundwater temperature. TCE concentrations ranged from approximately $10,000 \mu \mathrm{g} / \mathrm{L}$ to approximately $1,000,000 \mu \mathrm{g} / \mathrm{L}$; TCE was present as a non-aqueous phase liquid at the highest concentrations. The nominal TCE and oxidant concentrations and the associated experiment identification number are tabulated below in Table 55 .

Table 55. Experimental Identification for Hot Spot Groundwater Experiments.

\begin{tabular}{|c|c|c|c|c|}
\hline \multirow{2}{*}{$\begin{array}{c}\text { Nominal } \\
\mathrm{MnO}_{4}^{-} \\
\text {Concentration }\end{array}$} & \multicolumn{4}{|c|}{ Nominal TCE Concentration } \\
\hline & $\begin{array}{l}10,000 \\
(\mu \mathrm{g} / \mathrm{L})\end{array}$ & $\begin{array}{c}100,000^{\dagger} \\
(\mu \mathrm{g} / \mathrm{L})\end{array}$ & $\begin{array}{c}100,000 \\
(\mu \mathrm{g} / \mathrm{L})\end{array}$ & $\begin{array}{c}1,000,000 \\
(\mu \mathrm{g} / \mathrm{L})\end{array}$ \\
\hline $0.01 \%$ & $4 \mathrm{bR} 1$ & $4 \mathrm{bR} 5$ & $4 \mathrm{bR} 3$ & $4 \mathrm{bR} 7$ \\
\hline $0.1 \%$ & $4 \mathrm{bR} 1$ & $4 \mathrm{bR} 5$ & $4 \mathrm{bR} 3$ & $4 \mathrm{bR} 7$ \\
\hline $1 \%$ & $4 \mathrm{bR} 2$ & 4bR6 & $4 \mathrm{bR} 4$ & $4 \mathrm{bR} 8$ \\
\hline $3 \%$ & $4 \mathrm{bR} 2$ & $4 \mathrm{bR} 6$ & $4 \mathrm{bR} 4$ & $4 \mathrm{bR} 8$ \\
\hline
\end{tabular}

With DCE isomers as co-contaminants

- Most experiments were performed with TCE as the only VOC, but a few included DCE isomers as well to evaluate the effect of co-contaminants on the rate of TCE oxidation.

- Similar to the observations from the dissolved plume media experiments, concentrations of TCE and DCE isomers remained constant in reactors without permanganate, and generally declined rapidly to less than MDLs if a sufficient mass of permanganate was present. This again demonstrates that oxidation of TCE and DCE isomers by $\mathrm{MnO}_{4}{ }^{-}$is the predominant mechanism whereby these VOCs were destroyed.

- Cases in which TCE concentrations did not decline to less than MDLs can be attributed to insufficient $\mathrm{MnO}_{4}{ }^{-}$to oxidize the mass of TCE present; to the presence TCE as a nonaqueous phase liquid in the reactor; and to analytical problems caused by contamination of the hexane used for extracting samples prior to analysis. Even in reactors in which there was insufficient $\mathrm{MnO}_{4}{ }^{-}$for all of the TCE to be oxidized, oxidation was rapid until the $\mathrm{MnO}$ was depleted.

- In several cases, insufficient $\mathrm{MnO}_{4}{ }^{-}$was added and TCE concentrations remained high. Initial and final $\mathrm{MnO}_{4}{ }^{-}$concentrations for this experimental series is presented in Tables 56 and 57 , respectively. 
Table 56. Initial $\mathrm{MnO}_{4}{ }^{-}$Concentrations for the Hot Spot Groundwater Experiments. ${ }^{\text {a. }}$

\begin{tabular}{|c|c|c|c|c|}
\hline \multirow{2}{*}{$\begin{array}{c}\text { Nominal } \\
\mathrm{MnO}_{4}^{-} \\
\text {Concentration }\end{array}$} & \multicolumn{4}{|c|}{ Nominal TCE Concentration } \\
\hline & $\begin{array}{l}10,000 \\
(\mu \mathrm{g} / \mathrm{L})\end{array}$ & $\begin{array}{c}100,000^{\dagger} \\
(\mu \mathrm{g} / \mathrm{L})\end{array}$ & $\begin{array}{c}100,000 \\
(\mu \mathrm{g} / \mathrm{L})\end{array}$ & $\begin{array}{c}1,000,000 \\
(\mu \mathrm{g} / \mathrm{L})\end{array}$ \\
\hline $0.01 \%$ & 102 & 99 & 101 & 101 \\
\hline $0.1 \%$ & 1008 & 956 & 989 & 990 \\
\hline $1 \%$ & 10,120 & 10,380 & 10,200 & 10,300 \\
\hline $3 \%$ & 30,475 & 31,900 & 30,900 & 30,900 \\
\hline 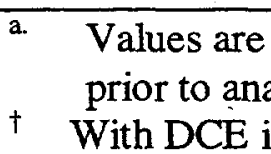 & as co- & tors (mg & All sam & $\operatorname{red}(0.45$ \\
\hline
\end{tabular}

Table 57. Final $\mathrm{MnO}_{4}{ }^{-}$Concentrations for the Hot Spot Groundwater Experiments. ${ }^{\text {a. }}$

\begin{tabular}{|c|c|c|c|c|}
\hline $\begin{array}{c}\text { Nominal } \\
\begin{array}{c}\mathrm{MnO}_{4}^{-} \\
\text {Concentration }\end{array}\end{array}$ & $\begin{array}{c}10,000 \\
(\mu \mathrm{g} / \mathrm{L})\end{array}$ & $\begin{array}{c}\text { Nominal TCE Concentration } \\
(\mu \mathrm{g} / \mathrm{L})\end{array}$ & $\begin{array}{c}100,000 \\
(\mu \mathrm{g} / \mathrm{L})\end{array}$ & $\begin{array}{c}1,000,000 \\
(\mu \mathrm{g} / \mathrm{L})\end{array}$ \\
\hline $0.01 \%$ & 27 & 38 & $1.1 \mathrm{U}$ & $0.3 \mathrm{U}$ \\
\hline $0.1 \%$ & 419 & 861 & 804 & $0.2 \mathrm{U}$ \\
\hline $1 \%$ & 10,070 & 10,105 & 10,145 & 6,420 \\
\hline $3 \%$ & 27,650 & 24,580 & 30,160 & 26,400 \\
\hline
\end{tabular}

a. Values are the average of 2 test reactors $\left(\mathrm{mg} / \mathrm{L} \mathrm{MnO}_{4}{ }^{-}\right)$. All samples filtered $(0.45 \mu \mathrm{m})$ prior to analysis.

$\doteqdot$ With DCE isomers as co-contaminants

A value followed by " $U$ " represents cases where the measured concentration is less than the MDL.

- The initial concentration of TCE varied between different experiments that were intended to have the same initial concentration. In most cases, the actual initial concentrations were close to the intended concentrations. However, in the experiments with DCE isomers as cocontaminants, the initial TCE concentrations (Table 58) were only $11-41$ percent of the intended concentration. 
Table 58. Initial Aqueous TCE Concentrations for the Hot Spot Groundwater Experiments. ${ }^{\text {a. }}$

\begin{tabular}{|c|c|c|c|c|}
\hline $\begin{array}{c}\text { Nominal } \\
\mathrm{MnO}_{4}^{-} \\
\text {Concentration }\end{array}$ & $\begin{array}{c}10,000 \\
(\mu \mathrm{g} / \mathrm{L})\end{array}$ & $\begin{array}{c}100,000^{\dagger} \\
(\mu \mathrm{g} / \mathrm{L})\end{array}$ & $\begin{array}{c}100,000 \\
(\mu \mathrm{g} / \mathrm{L})\end{array}$ & $\begin{array}{c}1,000,000^{\dagger \dagger} \\
(\mu \mathrm{g} / \mathrm{L})\end{array}$ \\
\hline $0.01 \%$ & 14,525 & 21,680 & 106,540 & $1,054,500$ \\
\hline $0.1 \%$ & 13,775 & 30,500 & 100,810 & $1,056,500$ \\
\hline $1 \%$ & 10,590 & 14,020 & 109,395 & $1,017,500$ \\
\hline $3 \%$ & 9,990 & 36,300 & 104,970 & $1,057,600$ \\
\hline
\end{tabular}

a. Values are the average of 2 test reactors $(\mu \mathrm{g} / \mathrm{L} \mathrm{TCE})$.

$\doteqdot$ With DCE isomers as co-contaminants

i† Estimated Concentration

TCE oxidation generally proceeded rapidly. In many cases, oxidation was essentially complete when the first or second sample was collected, and thus there is insufficient data resolution to determine reaction rate parameter values, such as first order rate constants. In this case, a zero order reaction rate was estimated by assuming that the TCE concentration declined to zero when the first or second sample was collected. If there were two or more values greater than the MDL, a first order rate constant was determined. The final TCE concentrations are tabulated in Table 59 , and the percentage of the initial mass of TCE oxidized and removed by sampling is shown in Table 60 .

Table 59. Final Aqueous TCE Concentrations for the Hot Spot Groundwater Experiments. ${ }^{\text {a. }}$

\begin{tabular}{|c|c|c|c|c|}
\hline \multirow{2}{*}{$\begin{array}{c}\text { Nominal } \\
\mathrm{MnO}_{4}^{-} \\
\text {Concentration }\end{array}$} & $\begin{array}{c}10,000 \\
(\mu \mathrm{g} / \mathrm{L})\end{array}$ & $\begin{array}{c}100,000^{\dagger} \\
(\mu \mathrm{g} / \mathrm{L})\end{array}$ & $\begin{array}{c}100,000 \\
(\mu \mathrm{g} / \mathrm{L})\end{array}$ & $\begin{array}{c}1,000,000 \\
(\mu \mathrm{g} / \mathrm{L})\end{array}$ \\
\hline $0.01 \%$ & 277 & 165,25 & 37,440 & $952,400^{\dagger \dagger}$ \\
\hline $0.1 \%$ & 204 & $3 \mathrm{U}$ & $\mathrm{ND}$ & $573,820^{\dagger \dagger}$ \\
\hline $1 \%$ & $\mathrm{ND}$ & $2 \mathrm{U}, 11 \mathrm{U}$ & $\mathrm{ND}$ & $\mathrm{ND}$ \\
\hline $3 \%$ & $\mathrm{ND}$ & $1 \mathrm{U}$ & $\mathrm{ND}$ & $\mathrm{ND}$ \\
\hline
\end{tabular}

2. Values are the average of 2 test reactors ( $\mu \mathrm{g} / \mathrm{L}$ TCE).

$\mathrm{ND}=$ Not Detected.

A value followed by "U" represents cases where the measured concentration is less than the MDL.

$\dagger$ With DCE isomers as co-contaminants

it Final Value at $T=0.5 \mathrm{hrs}$ rather than $\mathrm{T}=24 \mathrm{hrs}$. 
Table 60. Percentage of Initial TCE Mass Oxidized and Removed via Sampling. ${ }^{\text {a. }}$

\begin{tabular}{|c|c|c|c|c|}
\hline \multirow{2}{*}{$\begin{array}{c}\text { Nominal } \\
\mathrm{MnO}_{4}^{-} \\
\text {Concentration }\end{array}$} & \multicolumn{4}{|c|}{ Nominal TCE Concentration } \\
\hline & $\begin{array}{l}10,000 \\
(\mu \mathrm{g} / \mathrm{L})\end{array}$ & $\begin{array}{c}100,000^{\dagger} \\
(\mu \mathrm{g} / \mathrm{L})\end{array}$ & $\begin{array}{c}100,000 \\
(\mu \mathrm{g} / \mathrm{L})\end{array}$ & $\begin{array}{c}1,000,000 \\
(\mu \mathrm{g} / \mathrm{L})\end{array}$ \\
\hline $0.01 \%$ & 98 & 100 & 77 & $17^{\dagger \dagger}$ \\
\hline $0.1 \%$ & 101 & 102 & 102 & $33^{\text {t† }}$ \\
\hline $1 \%$ & 100 & 100 & 100 & 100 \\
\hline $3 \%$ & 100 & 100 & 100 & 100 \\
\hline
\end{tabular}

a. Values are the average of 2 test reactors (wt\%).

$\dagger$ With DCE isomers as co-contaminants

ti Final Value at $\mathrm{T}=0.5 \mathrm{hrs}$ rather than $\mathrm{T}=24 \mathrm{hrs}$.

Observed zero order reaction rates for TCE destruction are presented below in Table 61 on the basis of mass of TCE per unit time per reactor and in Table 62 on the basis of mass of TCE per unit time per liter. Trends in the $\mathrm{pH}$ values of the test reactors are presented in Table 63. Finally, the entire series of hot spot groundwater experiments (Tables 55 through 63) are summarized in Table 64.

Table 61. Observed Minimum Zero Order TCE Destruction Rates - Per Reactor Basis, Hot Spot Groundwater. ${ }^{\text {a. }}$

\begin{tabular}{|c|c|c|c|c|}
\hline $\begin{array}{c}\text { Nominal } \\
\begin{array}{c}\mathrm{MnO}_{4}^{-} \\
\text {Concentration }\end{array}\end{array}$ & $\begin{array}{c}10,000 \\
(\mu \mathrm{g} / \mathrm{L})\end{array}$ & $\begin{array}{c}100,000^{\dagger} \\
(\mu \mathrm{g} / \mathrm{L})\end{array}$ & $\begin{array}{c}100,000 \\
(\mu \mathrm{g} / \mathrm{L})\end{array}$ & $\begin{array}{c}1,000,000 \\
(\mu \mathrm{g} / \mathrm{L})\end{array}$ \\
\hline $0.01 \%$ & $0.5^{1}$ & $5.0^{1}$ & $7.3^{2}$ & $80^{2}$ \\
\hline $0.1 \%$ & $13.8^{1}$ & 7.7 & 82 & $386^{2}$ \\
\hline $1 \%$ & 2.7 & 6.9 & 88 & 1,628 \\
\hline $3 \%$ & 10.0 & 17.4 & 84 & 1,616 \\
\hline
\end{tabular}

a. Values are the average of 2 test reactors (mg TCE/hr per reactor). Computed by dividing the Average Initial TCE Mass present in each reactor by the earliest aliquot sampling time at which TCE was not detected. Each reactor contained nominally $400 \mathrm{~mL}$. See Appendix C for actual GW masses in each reactor.

$\dagger$ With DCE isomers as co-contaminants

1 Possibly affected by contamination of hexane used for extracting samples.

$2 \mathrm{MnO}_{4}^{-}$depleted before TCE oxidized. Rate Estimated from period while $\mathrm{MnO}_{4}^{-}$was present. 
Table 62. Observed Minimum Zero Order TCE Destruction Rates -Per Unit Volume Basis, Hot Spot Groundwater. ${ }^{\text {a. }}$

\begin{tabular}{|c|c|c|c|c|}
\hline $\begin{array}{c}\text { Nominal } \\
\mathrm{MnO}_{4}^{-} \\
\text {Concentration }\end{array}$ & $\begin{array}{c}10,000 \\
(\mu \mathrm{g} / \mathrm{L})\end{array}$ & $\begin{array}{c}100,000^{\dagger \dagger} \\
(\mu \mathrm{g} / \mathrm{L})\end{array}$ & $\begin{array}{c}100,000 \\
(\mu \mathrm{g} / \mathrm{L})\end{array}$ & $\begin{array}{c}1,000,000 \\
(\mu \mathrm{g} / \mathrm{L})\end{array}$ \\
\hline $0.01 \%$ & $1^{1}$ & $10^{1, \dagger}$ & $18^{2}$ & $200^{2}$ \\
\hline $0.1 \%$ & $27^{1}$ & 15 & 200 & $940^{2}$ \\
\hline $1 \%$ & 5 & 14 & 220 & 4,100 \\
\hline $3 \%$ & 20 & 36 & 210 & 4,040 \\
\hline
\end{tabular}

a. Values are the average of 2 test reactors (mg TCE/L/hour). Values were computed by dividing the Average Initial TCE Mass present in each reactor by both (1) the earliest aliquot sampling time (hrs) at which TCE was not detected and (2) the average initial liquid volume in the reactor ( $\mathrm{GW}$ and $\mathrm{MnO}_{4}{ }^{-}$stock solution, when applicable).

$\dagger$ A corresponding first order rate constant is included in Table 64 for this test case.

ti With DCE isomers as co-contaminants

1 Possibly affected by contamination of hexane used for extracting samples.

$2 \mathrm{MnO}_{4}{ }^{-}$depleted before TCE oxidized. Rate Estimated from period while $\mathrm{MnO}_{4}{ }^{-}$was present.

Table 63. Observed pH Trends in the Hot Spot Groundwater Experiments. ${ }^{\text {a. }}$

\begin{tabular}{|c|c|c|c|c|}
\hline $\begin{array}{c}\text { Nominal } \\
\mathrm{MnO}_{4}^{-} \\
\text {Concentration }\end{array}$ & $\begin{array}{c}10,000 \\
(\mu \mathrm{g} / \mathrm{L})\end{array}$ & $\begin{array}{c}100,000^{\dagger} \\
(\mu \mathrm{g} / \mathrm{L})\end{array}$ & $\begin{array}{c}100,000 \\
(\mu \mathrm{g} / \mathrm{L})\end{array}$ & $\begin{array}{c}1,000,000 \\
(\mu \mathrm{g} / \mathrm{L})\end{array}$ \\
\hline $0.01 \%$ & -0.8 & -1.0 & -1.5 & -2.1 \\
\hline $0.1 \%$ & -0.9 & -0.3 & -1.8 & -5.4 \\
\hline $1 \%$ & -0.1 & -1.2 & -1.6 & -6.3 \\
\hline $3 \%$ & +0.4 & -1.0 & -1.0 & -6.3 \\
\hline
\end{tabular}

$\mathrm{pH}$ Trends are the average of 2 test reactors 
Table 64. Summary of the Hot Spot Groundwater Oxidation Rate Experiments.

\begin{tabular}{|c|c|c|c|c|c|c|}
\hline \begin{tabular}{l|} 
ORNL \\
Exp. \\
No.
\end{tabular} & $\begin{array}{l}\text { Nominal } \\
\text { Initial } \\
\text { TCE } \\
(\mu \mathrm{g} / \mathrm{L})\end{array}$ & $\begin{array}{l}\text { Avg. } \\
\text { Initial } \\
\text { TCE } \\
\text { Mass } \\
\text { (mg) }\end{array}$ & $\begin{array}{l}\text { TCE Oxidation } \\
\text { Observed Rates } \\
\text { (mg TCE/hr·Reactor } \\
\text { Contents) }\end{array}$ & $\begin{array}{l}\text { Initial } \\
\mathrm{MnO}_{4}^{-} \\
(\mathrm{wt} \%)\end{array}$ & 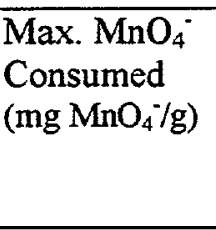 & pH Trends \\
\hline \multirow[t]{2}{*}{ 4b-R1 } & \multirow[t]{2}{*}{10,000} & 7.4 & $\begin{array}{l}\text { Complete }^{\mathrm{l}}(\approx 15 \mathrm{hrs}) \\
\text { Obs. Rate } \geq 0.5\end{array}$ & $0.01 \%$ & 0.08 & $\begin{array}{l}>0.8 \text { Net } \\
\text { Decrease }\end{array}$ \\
\hline & & 6.9 & $\begin{array}{l}\text { Complete }^{1}(\approx 0.5 \mathrm{hrs}) \\
\text { Obs. Rate } \geq 13.8\end{array}$ & $0.1 \%$ & 0.6 & $\begin{array}{l}>0.9 \text { Net } \\
\text { Decrease }\end{array}$ \\
\hline \multirow[t]{2}{*}{ 4b-R2 } & \multirow[t]{2}{*}{10,000} & 5.3 & $\begin{array}{l}\text { Complete }(<2 \mathrm{hrs}) \\
\text { Obs. Rate } \geq 2.65\end{array}$ & $1 \%$ & 0.6 & $\begin{array}{l}<0.1 \text { Net } \\
\text { Decrease }\end{array}$ \\
\hline & & 5.0 & $\begin{array}{l}\text { Complete }(<0.5 \mathrm{hrs}) \\
\text { Obs. Rate } \geq 10.0\end{array}$ & $3 \%$ & 3.5 & $\begin{array}{l}\approx 0.4 \mathrm{Net} \\
\text { Increase }\end{array}$ \\
\hline \multirow[t]{2}{*}{ 4b-R3 } & \multirow[t]{2}{*}{100,000} & 43 & $\begin{array}{l}\text { Incomplete } \\
(68 \% \text { oxidized })^{4} \\
\text { Obs. } \text { Rate } \geq 7.25\end{array}$ & $0.01 \%$ & 0.1 & $\begin{array}{l}>1.5 \mathrm{Net} \\
\text { Decrease }\end{array}$ \\
\hline & & 41 & $\begin{array}{l}\text { Complete }(<0.5 \text { hrs }) \\
\text { Obs. Rate } \geq 82\end{array}$ & $0.1 \%$ & 0.2 & $\begin{array}{l}>1.8 \text { Net } \\
\text { Decrease }\end{array}$ \\
\hline \multirow[t]{2}{*}{ 4b-R4 } & \multirow[t]{2}{*}{100,000} & 44 & $\begin{array}{l}\text { Complete }(0.5 \text { hrs }) \\
\text { Obs. Rate } \geq 88\end{array}$ & $1 \%$ & 0.2 & $\begin{array}{l}>1.6 \mathrm{Net} \\
\text { Decrease }\end{array}$ \\
\hline & & 42 & $\begin{array}{l}\text { Complete (0.5 hrs) } \\
\text { Obs. Rate } \geq 84\end{array}$ & $3 \%$ & 0.4 & $\begin{array}{l}>1.0 \text { Net } \\
\text { Decrease }\end{array}$ \\
\hline \multirow[t]{2}{*}{ 4b-R5 } & \multirow{2}{*}{$\begin{array}{l}100,000 \\
\& \text { Other } \\
\text { VOCs }\end{array}$} & 10.8 & $\begin{array}{l}\text { Complete }^{1}(\approx 5 \mathrm{hrs}) \\
\text { Avg } k=1.66 \mathrm{hr}^{-1}\end{array}$ & $0.01 \%$ & 0.06 & $\begin{array}{l}>1.0 \text { Net } \\
\text { Decrease }\end{array}$ \\
\hline & & 15.4 & $\begin{array}{c}\text { Complete }<2 \text { hrs) } \\
\text { Obs. Rate } \geq 7.7 \\
\end{array}$ & $0.1 \%$ & 0.12 & $\begin{array}{l}>1.3 \mathrm{Net} \\
\text { Decrease }\end{array}$ \\
\hline \multirow[t]{2}{*}{ 4b-R6 } & \multirow[t]{2}{*}{$\begin{array}{l}100,000 \\
\& \text { Other } \\
\text { VOCs }\end{array}$} & 6.9 & $\begin{array}{c}\text { Complete }(<1 \text { hr }) 1 \\
\text { Obs. Rate } \geq 6.9 \\
\end{array}$ & $1 \%$ & 0.4 & $\begin{array}{l}>1.2 \mathrm{Net} \\
\text { Decrease }\end{array}$ \\
\hline & & 17.4 & $\begin{array}{l}\text { Complete }(<\mathbf{~ h r}) \mathbf{1} \\
\text { Obs. Rate } \geq 17.4\end{array}$ & $3 \%$ & 7.9 & $\begin{array}{l}>1.0 \mathrm{Net} \\
\text { Decrease }\end{array}$ \\
\hline \multirow[t]{2}{*}{ 4b-R7 } & \multirow[t]{2}{*}{ DNAPL $^{3}$} & 800 & $\begin{array}{l}\text { Incomplete } \\
(\approx 5 \% \text { Oxidized })^{4} \\
\text { Obs. Rate } \geq 80^{5}\end{array}$ & $0.01 \%$ & 0.1 & $\begin{array}{l}>2.1 \text { Net } \\
\text { Decrease }\end{array}$ \\
\hline & & 807 & $\begin{array}{l}\text { Incomplete } \\
(\approx 24 \% \text { Oxidized })^{4} \\
\text { Obs. Rate } \geq 386^{5}\end{array}$ & $0.1 \%$ & 1.0 & $\begin{array}{l}>5.4 \mathrm{Net} \\
\text { Decrease }\end{array}$ \\
\hline \multirow[t]{2}{*}{$4 b-R 8$} & \multirow[t]{2}{*}{ DNAPL $^{3}$} & 814 & $\begin{array}{c}\text { Complete (0.5 hrs)1 } \\
\text { Obs. Rate } \geq 1628 \\
\end{array}$ & $1 \%$ & 3.6 & $\begin{array}{l}>6.3 \mathrm{Net} \\
\text { Decrease }\end{array}$ \\
\hline & & 808 & $\begin{array}{l}\text { Complete }(0.5 \mathrm{hrs})^{1} \\
\text { Obs. Rate } \geq 1616\end{array}$ & $3 \%$ & 4.3 & $\begin{array}{l}>6.3 \text { Net } \\
\text { Decrease }\end{array}$ \\
\hline
\end{tabular}

For footnotes, see next page. 
$\dagger$ Observed Oxidation Rate $=$ (Total Initial mg TCE)/(X hrs-Reactor Contents); Where $X$ represents the earliest sampling time at which TCE was not detected in the aqueous aliquot. Where available, the predicted first order reaction rate constant, $k$, is presented.

"Reactor Contents" are nominally $400 \mathrm{~mL}$ TCE-spiked GW. See Appendix C for actual GW mass in each reactor.

${ }^{1}$ It is assumed that the reactions were essentially completed at this time point, even though a low residual TCE concentration was present. The reported values are estimates.

${ }^{2}$ Co-contaminants also present at approximately $10,000 \mathrm{ppb}$ each.

3 "DNAPL" equates to an aqueous concentration of $2 \times 10^{6} \mu \mathrm{g} / \mathrm{L}$ TCE.

${ }^{4}$ Oxidant depleted before all TCE could be oxidized.

${ }^{5}$ A conservative value which does take account for any non-aqueous TCE which was oxidized.

- There is a general trend of increasing TCE oxidation rate with increasing $\mathrm{MnO}_{4}{ }^{-}$ concentration and a general trend of increasing TCE oxidation rate with increasing TCE concentration, as observed in the dissolved plume media experiments. The observed zero order rates ranged from $>0.5 \mathrm{mg} / \mathrm{hr}$ to $>1600 \mathrm{mg} / \mathrm{hr}$ on per reactor basis, and from $>1$ $\mathrm{mg} / \mathrm{L} / \mathrm{hr}$ to $>4000 \mathrm{mg} / \mathrm{L} / \mathrm{hr}$ on a unit volume basis.

- DCE isomers were rapidly oxidized by $\mathrm{MnO}_{4}^{-}$, but rates were not determined.

- Evaluation of the effect of co-contaminants on the rate of TCE oxidation is confounded by inconsistent TCE concentrations between oxidation rate measurements with and without cocontaminants present. Co-contaminants are an additional sink for $\mathrm{MnO}_{4}^{-}$, and therefore $\mathrm{MnO}_{4}{ }^{-}$concentrations would be lower if co-contaminants were present than if they were not. The data show that the TCE oxidation rate increases with $\mathrm{MnO}_{4}{ }^{-}$loading, and thus it is likely that the presence of co-contaminants does slow the rate of TCE oxidation. In these experiments, TCE was rapidly oxidized with co-contaminants present, but the degree that the presence of co-contaminants affects the rate of TCE oxidation cannot be determined from this data set.

- In general, if sufficient $\mathrm{MnO}_{4}{ }^{-}$was present, TCE concentrations rapidly declined to approximately the MDL.

- Production of $\mathrm{H}^{+}$during oxidation of TCE causes the $\mathrm{pH}$ to decline. However, $\mathrm{pH}$ increased by 0.4 units in one experiment; this observation is problematic. In other experiments, the $\mathrm{pH}$ decline is generally greater with larger initial concentrations of TCE, presumably due to a greater mass of oxidant consumed and $\mathrm{H}^{+}$produced as more TCE is available to reduce $\mathrm{MnO}_{4}{ }^{-}$. In the absence of a TCE non-aqueous phase, the $\mathrm{pH}$ shifts were on the order of 0.1 $2 \mathrm{pH}$ units. With a non-aqueous phase present, much larger $\mathrm{pH}$ shifts occurred $(2-6 \mathrm{pH}$ units). Trends as a function of $\mathrm{MnO}_{4}{ }^{-}$concentration are less distinct, except where a nonaqueous phase was present. Note that there was not a solid phase present to buffer the $\mathrm{pH}$ change; $\mathrm{pH}$ changes might be smaller if buffered by a solid phase. 


\subsubsection{Oxidation Rate of Organic Contaminants in Hot Spot Sludge}

Six (6) separate oxidation rate experiments were performed for the hot spot sludge (TSF-05 Sludge). Each experiment is discussed below and identified by the ORNL Experiment IDs presented earlier in Table 7. In general, plots of "TCE vs. Time", " $\mathrm{MnO}_{4}$ " vs. Time", and "pH vs. Time" are presented for each experiment. For all plots of TCE vs. Reaction time: any values resulting from analyses in which the sample extract concentration was out of the GC calibration range are clearly labeled. Note that some experiments were continued after $24 \mathrm{hrs}$. Such a modification is clearly noted in the experimental discussions.

In addition to the plots, summary tables for the TCE and $\mathrm{MnO}_{4}{ }^{-}$data are also presented for each experiment. Several parameters are included in the TCE mass balance tables (e.g., Table 65). The approach and/or calculations made to obtain each of the values presented in the mass balance tables are presented below. (Descriptions of the $\mathrm{MnO}_{4}{ }^{-}$consumption tables are presented at the beginning of Section 2.4.2.)

- Column 1, "Test Conditions" refers the experimental condition. In this column "Control" refers to reactors containing only TSF-05 GW and no oxidant. The (\#1) and (\#2) notations included in parentheses refer to the duplicate reactors evaluated. The number followed by the percentage sign is the nominal initial $\mathrm{MnO}_{4}{ }^{-}$concentration added to the treatment reactors.

- Column 2, "Total Initial Mass" refers to the TCE mass added to each reactor. For the GW control reactors, this value is determined by the following equation: (Aqueous TCE Conc. at $\mathrm{T}=0$ ) $\times$ (GW Volume in the Control Reactor) Note: $\mathrm{T}=0$ sampling occurred after overnight equilibration and immediately before oxidant addition to the treatment reactors. For reactors containing both TSF-05 GW and Sludge, the initial total TCE mass is computed by the following equation: (Average Aqueous TCE Conc. at $T=0$ of the $2 \mathrm{GW}$ Controls) $\mathrm{x}$ (GW volume in the Slurry Reactor). It is computed in this way in the event that some TCE is sorbed to the TSF-05 sludge at $\mathrm{T}=0$.

- Column3, "Initial Aqueous Mass" For all cases (with exception of DNAPL case), this value is computed by multiplying the Aqueous TCE Conc. at $\mathrm{T}=0$ for a given reactor by the volume of GW added to that reactor. Note: The aqueous concentration at $T=0$ for each reactor is used here rather than the concentration of the spiked GW before it is distributed to the individual reactors and equilibrated. (This approach effectively "removes" or accounts for the any TCE lost during equilibration from the mass balance calculations performed for the actual oxidation reactions.) For the treatment reactors containing both $\mathrm{GW}$ and sludge, another value is also presented in Columns 2 and 3 of the mass balance tables. This "\% Sorbed" value represents the fraction of TCE at T=0 partitioned to the sludge. It is computed for each GW/sludge slurry via the following equation:

\%Sorbed=100 x [1-(Initial Aqueous Mass/Total Initial Mass)] or $100 \times$ [1-(Col. 3/Col. 2)]

- Column 4, "Mass Sorbed on Orbo Tubes" represents the summed TCE mass found on each charcoal bed of the reactor's desorption tube at the end of the reaction period. The TCE mass 
was obtained by extraction of charcoal beds with hexane. If TCE is detected on the desorption tubes, it is realized that the value obtained represents a minimum that was volatilized since the entire reactor headspace volume would not pass through the desorption tube. The values in parentheses for this column represent the percentage of the Total Initial Mass (Column 1 of the Table) found within the Orbo Tube.

- Column 5, "Mass Remaining in Reactor" represents the TCE mass still present in each reactor following the reaction period. For the control reactors, this value was computed by the following equation: (Aqueous TCE concentration at $\mathrm{T}=24 \mathrm{hrs}$ ) $\mathrm{x}$ (Init. GW volume Cum. Vol. of Aliquot Samples). For treatment reactors containing a slurry of GW and sludge, the remaining TCE mass in the reactor was obtained by extracting the entire contents remaining in the reactor after $T=24 \mathrm{hrs}$ with hexane $(\approx 1: 1 \mathrm{v} / \mathrm{v}$ extraction). For both cases, the values in parentheses for this column represent the percentage of the Total Initial Mass (column 1 of the Table) still present in the reactor.

- Column 6, "Cum. Mass Removed in Aliquots" represents the mass of TCE removed from the reactor as a result of the aliquot sampling. In all cases, this column is computed by summing the masses of TCE that were found in each aliquot interval for a given reactor, i.e., $\Sigma$ (Aqueous TCE Conc. $x$ Aliquot Volume). The values in parentheses for this column represent the percentage of the Total Initial Mass (Column 1 of the Table) removed from the reactor (and thereby not subjected to oxidation) during the course of the experiment.

- Column 7, "Cum. Aqueous Mass Oxidized" represents the TCE mass initially in the aqueous phase that was considered to have been oxidized during the reaction period. The oxidized TCE masses presented in this column were computed by summing the change in aqueous TCE mass obtained for each sampling period, i.e., $\Sigma$ I(Aq. TCE Conc. $\mathrm{T}=\mathrm{x}-\mathrm{Aq}$. TCE Conc. $\mathrm{T}=\mathrm{x}+1) \times \mathrm{GW}$ Vol. $\mathrm{T}=\mathrm{x}$ ]. Thus, this approach corrects for TCE removed via previous aliquot samplings. Again, the values in parentheses for this column represent the percentage of the Total Initial Mass (Column 1 of the Table) believed to have been oxidized. It is important to note that this component of the mass balance does not take into account any TCE initially sorbed to the sludge, i.e., TCE that desorbed and was oxidized would not be included in this column. Hence, this column represents the minimum mass oxidized.

- Column 8, "Total Mass Recovered" is the sum of the TCE masses found in four (4) different "compartments" at the end of the reaction period, i.e., Col. $4+\mathrm{Col} .5+\mathrm{Col} .6+\mathrm{Col}$. 7. The values in parentheses for this column represent the percentage of the Total Initial Mass (Column 1 of the Table) that was accounted for during the course of the experiment.

Also note that variation in the initial TSF-05 GW and sludge chemistry, e.g. pH values, is expected since each hot spot media experiment was conducted using a different batch of hot spot material. (The various containers of TAN site materials received from INEEL were not combined/mixed prior to experimentation).

NOTE: A different mass balance approach was required for the experiments involving DNAPL phase TCE. Deviations and/or variations of the above approach are presented in the individual results and discussion sections for those experiments. 
ORNL Exp. 4b-R11

(TSF-05, Sludge, 10,000 TCE, 0 Other, $0.01 \%$ and $0.1 \% \mathrm{MnO}_{4}{ }^{-}$)

(Replaced Exp. 4b-R9)

This experiment investigated the oxidation of TSF-05 GW and sludge spiked at $10,000 \mu \mathrm{g} / \mathrm{L}$ TCE. The TCE, $\mathrm{MnO}_{4}{ }^{-}$and $\mathrm{pH}$ values with time are presented in Figures 95, 96, and 97 , respectively. Tables 65 and 66 provide additional TCE mass balance and oxidant consumption information. The (\#1) and (\#2) notations included in both the figure legends and the first column of these tables refer to the duplicate reactors evaluated for that test condition.

No deviations were made to the testplan during the conduct of this experiment.

After equilibration, the average initial aqueous TCE concentration of the spike solution (TSF-05 $\mathrm{GW})$ was $42,756 \mu \mathrm{g} / \mathrm{L}(\sigma=721 \mu \mathrm{g} / \mathrm{L})$. After transfer to the test reactors and equilibration with the TSF-05 sludge, the aqueous TCE concentrations in the slurries were lower than those observed in the groundwater controls. In fact, the sludge adsorbed an average of $56 \%$ of the total initial TCE added to each treatment reactor. Final TCE recovery values of $100 \%$ and $110 \%$ were obtained for the first and second control reactors, respectively. The first groundwater control yielded initial and final TCE concentrations of $30,900 \mu \mathrm{g} / \mathrm{L}$ and $32,000 \mu \mathrm{g} / \mathrm{L}$, respectively. Similarly, the initial aqueous TCE concentration for the second control reactor was $30,078 \mu \mathrm{g} / \mathrm{L}$, and the final concentration was $33,544 \mu \mathrm{g} / \mathrm{L}$. The larger final TCE values are likely not a result of a sample holding time effect since there is no observed trend between TCE conc. and sample collection time. Instead, the higher recovery of the second control appears to result from sample to sample variability (See data in Appendix C).

From Figure 95, the aqueous TCE concentrations of the treatment reactors are quickly reduced as oxidation occurs. In Figure $96, \mathrm{MnO}_{4}{ }^{-}$is quickly consumed. The $\mathrm{MnO}_{4}{ }^{-}$variability between 0 and $6 \mathrm{hrs}$ is small when compared to the initial $\mathrm{MnO}_{4}{ }^{-}$concentrations that existed for each reactor (note use of log scale). When Figures 95 and 96 are examined in concert, the observed rise in aqueous coincides with the time the oxidant is depleted. This increase in aqueous TCE may be due to (1) the release of TCE from the organic sludge that was initially oxidized and/or (2) the transfer of sludge bound TCE into the aqueous phase in order to establish equilibrium conditions within each test reactor.

TCE was still present in the reactors following the reaction period. The TCE mass extracted from the final reactors are presented in Table 65. Likewise, a small amount of TCE was found on the first charcoal bed of each desorption tube, indicating that some TCE was lost to volatilization. (Although small, the amount of TCE on the charcoal beds of the $0.1 \% \mathrm{MnO}_{4}^{-}$ reactors was approximately three times that found on the control and $0.01 \% \mathrm{MnO}_{4}{ }^{-}$reactors.) Since oxidant consumption occurred within the first $0.5 \mathrm{hrs}$ of reaction, it is plausible to assume that TCE oxidization only occurred during the same time interval. Therefore, the mass of TCE oxidized in Table 65, Column 7 includes only the TCE associated with the difference in aqueous TCE concentrations between $0-0.5$ hrs. Basing the oxidized TCE mass on this experimentally determined difference yields oxidation percentages of $10-12 \%$ for the $0.01 \% \mathrm{MnO}_{4}^{-}$reactors and 20-35\% for the $0.1 \% \mathrm{MnO}_{4}{ }^{-}$reactors. The computed total TCE recoveries presented in 44 , certainly do not equate to $100 \%$. As discussed in previous sections, some of the unrecovered 
TCE may have escaped from the reactors since the desorption tubes were not configured to capture $100 \%$ of the vapor phase when the port was in the open position (See Section 2.2.1). It is also possible that complete extraction of the remaining GW \& sludge slurry did not occur (Exp. $2 \mathrm{~b}-3$ in Section 2.2.2). However, the preliminary data presented in Figure 9 indicated that at least $90 \%$ of the starting TCE mass can be extracted from the TSF- 05 slurry within $2 \mathrm{hrs:}$

As discussed in the experiments for the dissolved plume media, the TCE oxidation component of the mass balance does not take into account any TCE initially bound to solid phase. If the highly organic sludge was being oxidized, it would seem plausible that TCE originally sorbed onto the sludge could have been partitioned into the aqueous phase and subsequently oxidized. Furthermore, it is possible, particularly for the $0.1 \% \mathrm{MnO}_{4}{ }^{-}$reactors, that the chosen aliquot sampling times did not temporally capture the exact point in time that oxidant depletion occurred. At the point of oxidant depletion, the reactors would have reached their lowest initial aqueous TCE concentration before the subsequent rise in aqueous TCE concentrations due to TCE DNAPL dissolution. (In the earlier experiments with TSF-05 GW, complete oxidation of all initial TCE often occurred prior to $\mathrm{T}=0.5 \mathrm{hrs}$.) Thus, the low total TCE recoveries reported in Table 65 may actually be due to the inability to quantify additional TCE oxidation that was occurring. The computation of reaction rates was not attempted for this experiment since the use of $0.01 \%$ and $0.1 \% \mathrm{MnO}_{4}{ }^{-}$loadings do not adequately satisfy the oxidant demand of the TCE contaminated sludge.

As mentioned above oxidant depletion occurred rapidly for both the $0.01 \%$ and $0.1 \% \mathrm{MnO}_{4}{ }^{-}$ reactors. It should be noted that in Figure 96 all of the measured $\mathrm{MnO}_{4}{ }^{-}$concentrations after the $\mathrm{T}=0 \mathrm{hrs}$ are below that of the lowest $\mathrm{MnO}_{4}{ }^{-}$calibration standard $(5 \mathrm{mg} / \mathrm{L})$. Thus, any $\mathrm{MnO}_{4}{ }^{-}$ trends presented in Figure 96 are of little significance.

From Figure 97, there is a marked difference in the initial $\mathrm{pH}$ of the reactors due to the presence of the sludge itself. In fact, the initial $\mathrm{pH}$ value of the treatment reactors (before oxidant addition) was approximately $1 \mathrm{pH}$ unit less than that of the GW controls. (Slurries of the dissolved plume media had $\mathrm{pH}$ values similar to that of TSF-05 $\mathrm{GW}$ ) The overall $\mathrm{pH}$ values of the test reactors increased slightly after the oxidant mass was depleted. Since the presence of the sludge resulted in initial $\mathrm{pH}$ decreases, the observed $\mathrm{pH}$ increases may have been caused by the oxidation of the organic sludge itself. 


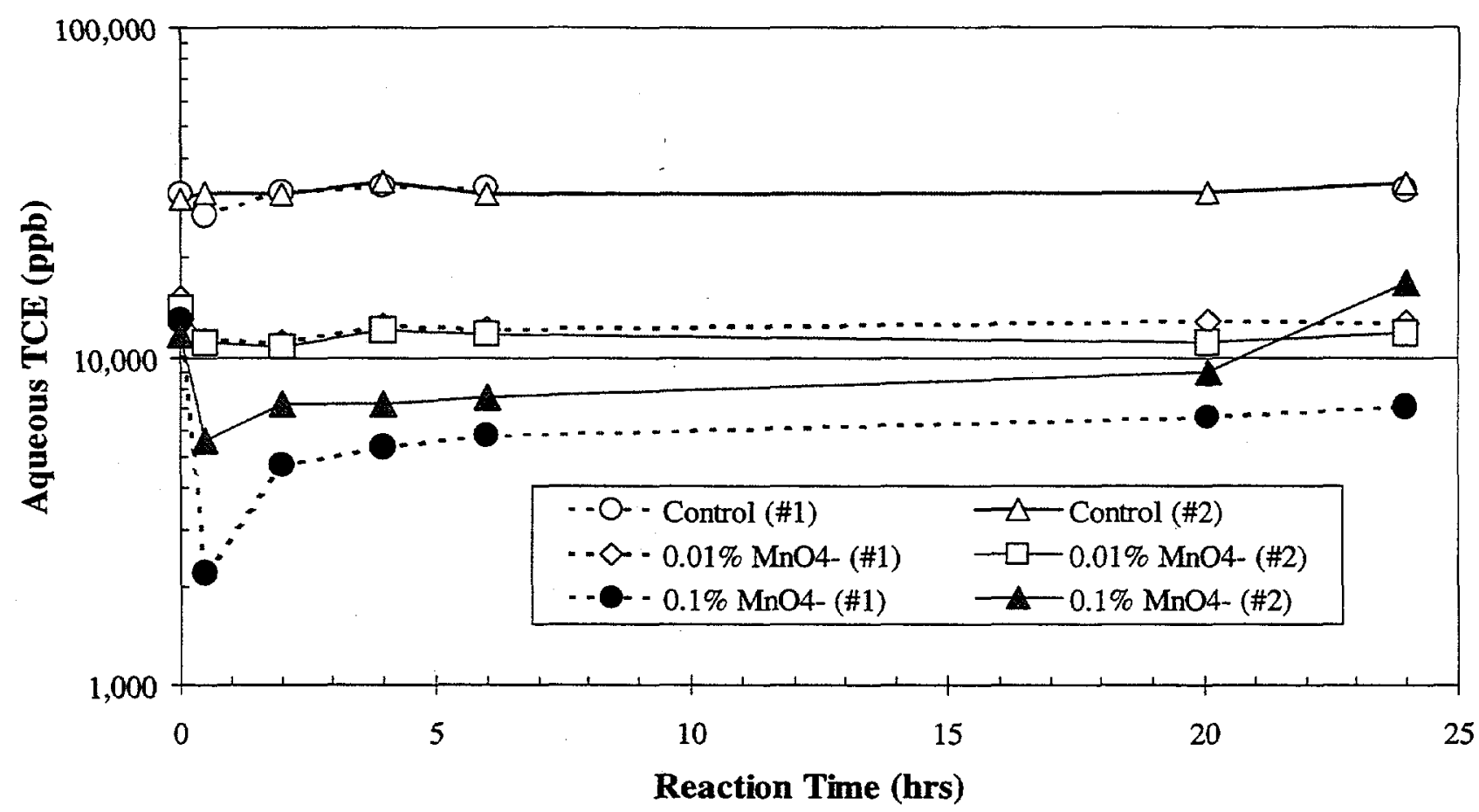

Figure 95. TCE vs. Time, TSF-05 GW\& Sludge, (ORNL Exp. 4b-R11, Initial TCE=10,000 $\mu \mathrm{g} / \mathrm{L}$, Conducted at $12^{\circ} \mathrm{C}, 4: 1 \mathrm{~L} / \mathrm{S}$ Ratio)

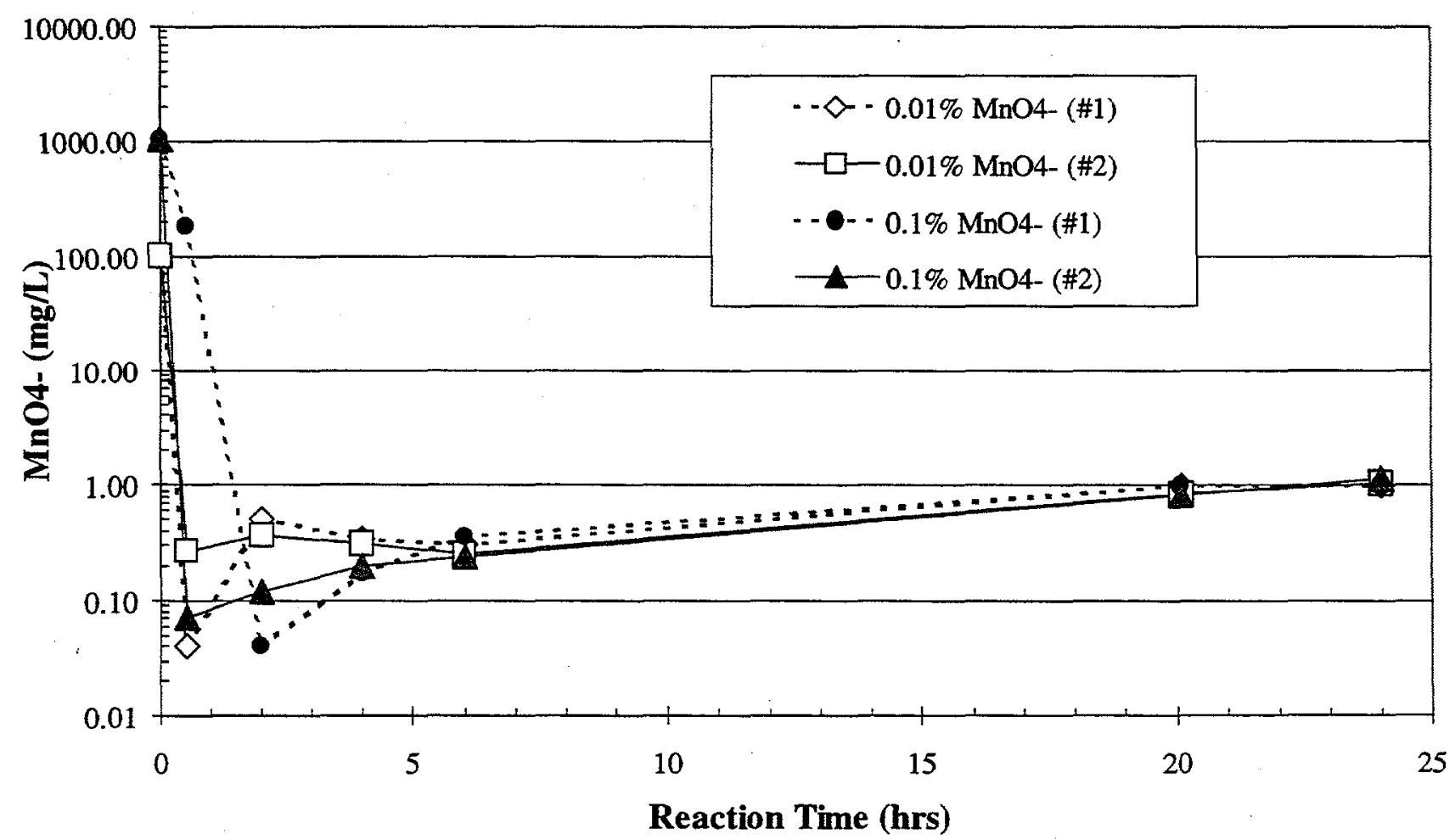

Figure 96. $\mathrm{MnO}_{4}{ }^{-}$vs. Time, TSF-05 GW \& Sludge, (ORNL Exp. 4b-R11, Initial TCE=10,000 $\mu \mathrm{g} / \mathrm{L}$, Conducted at $12^{\circ} \mathrm{C}, 4: 1 \mathrm{~L} / \mathrm{S}$ Ratio) 


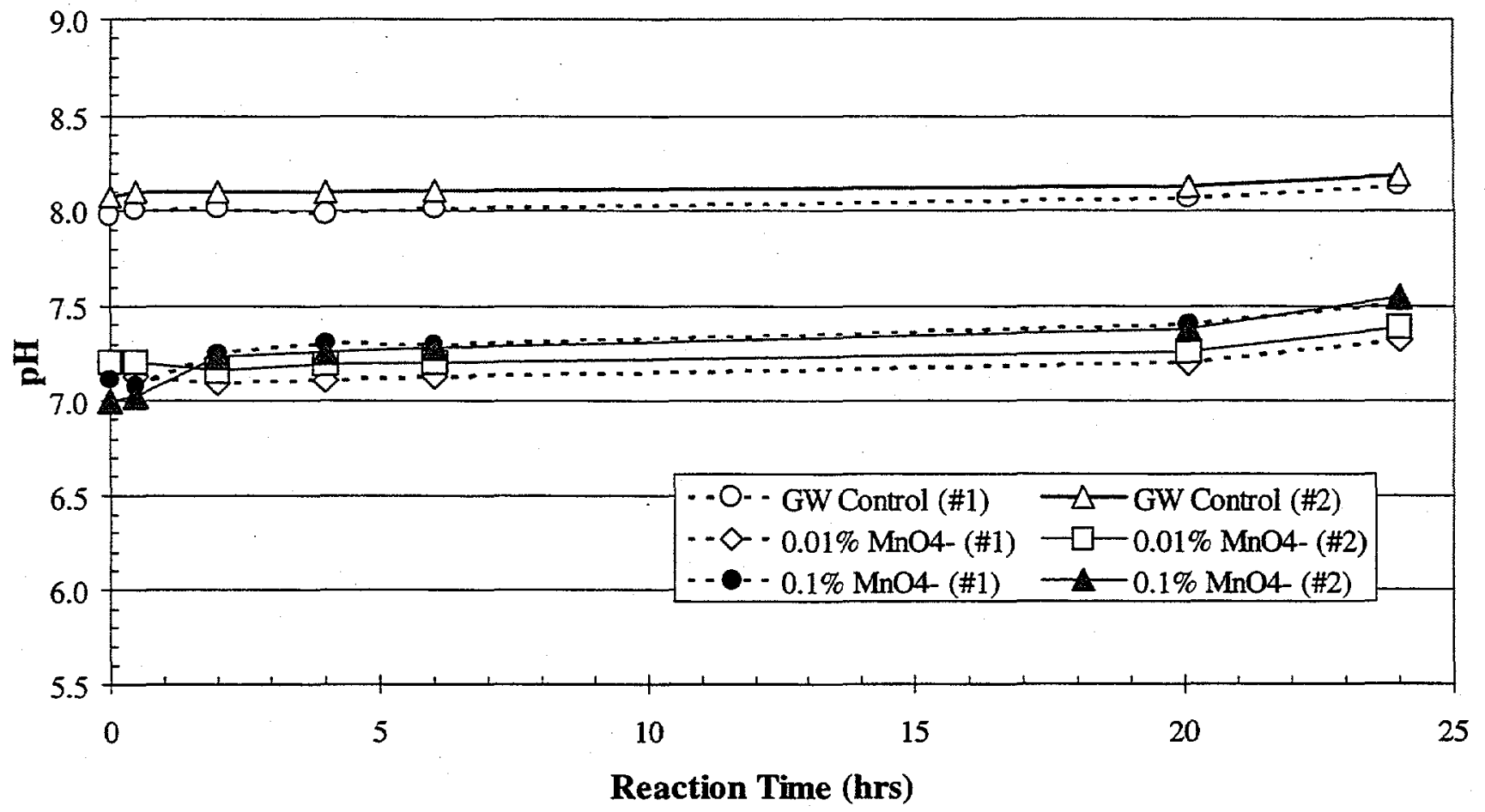

Figure 97. pH vs. Time, TSF-05 GW \& Sludge, (ORNL Exp. 4b-R11, Initial TCE $=10,000$ $\mu \mathrm{g} / \mathrm{L}$, Conducted at $12^{\circ} \mathrm{C}, 4: 1 \mathrm{~L} / \mathrm{S}$ Ratio) 
Table 65. TCE Mass Balance for ORNL Exp. 4b-R11 (TSF-05 GW \& Sludge). ${ }^{\text {. }}$

\begin{tabular}{|c|c|c|c|c|c|c|c|}
\hline Test Condition & \begin{tabular}{|l} 
Total \\
Initial \\
Mass \\
(mg)
\end{tabular} & \begin{tabular}{|l} 
Initial \\
Aqueous \\
Mass \\
(mg)
\end{tabular} & $\begin{array}{l}\text { Mass } \\
\text { Sorbed on } \\
\text { Orbo Tubes } \\
\text { (mg) }\end{array}$ & $\begin{array}{l}\text { Mass } \\
\text { Remaining in } \\
\text { Reactor (mg) }\end{array}$ & \begin{tabular}{|l|} 
Cum. \\
Mass \\
Removed \\
in Aliquots \\
(mg) \\
\end{tabular} & $\begin{array}{l}\text { TCE } \\
\text { Oxidized }\end{array}$ & $\begin{array}{l}\text { Total Mass } \\
\text { Recovered } \\
\text { (mg) }\end{array}$ \\
\hline \multirow{2}{*}{ Control (\#1) } & 11.1 & 11.1 & 0.00 & 8.6 & 2.5 & NA & 11.1 \\
\hline & & & $0 \%$ & $78 \%$ & $22 \%$ & NA & $100 \%$ \\
\hline \multirow{2}{*}{ Control (\#2) } & 10.9 & 10.9 & 0.00 & 9.5 & 2.5 & NA & 12.0 \\
\hline & & & $0 \%$ & $87 \%$ & $23 \%$ & NA & $110 \%$ \\
\hline \multirow{2}{*}{$0.01 \%(\# 1)$} & 11.6 & 5.7 & \multirow{2}{*}{$\begin{array}{c}0.00 \\
0 \%\end{array}$} & \multirow{2}{*}{$\begin{array}{c}8.6 \\
75 \%\end{array}$} & \multirow{2}{*}{$\begin{array}{l}1.0 \\
9 \%\end{array}$} & \multirow{2}{*}{$\begin{array}{c}1.4 \\
12 \%\end{array}$} & \multirow{2}{*}{$\begin{array}{l}11.1 \\
96 \%\end{array}$} \\
\hline & \%osorbed: & $50 \%$ & & & & & \\
\hline \multirow{2}{*}{$0.01 \%(\# 2)$} & 11.62 & 5.38 & \multirow{2}{*}{$\begin{array}{l}0.00 \\
0 \%\end{array}$} & \multirow{2}{*}{$\begin{array}{r}7.2 \\
62 \% \\
\end{array}$} & \multirow{2}{*}{$\begin{array}{l}0.9 \\
8 \%\end{array}$} & \multirow{2}{*}{$\begin{array}{c}1.1 \\
10 \%\end{array}$} & \multirow{2}{*}{$\begin{array}{c}9.3 \\
80 \%\end{array}$} \\
\hline & \%Sorbed: & $54 \%$ & & & & & \\
\hline \multirow{2}{*}{$0.1 \%(\# 1)$} & 11.46 & 4.84 & \multirow{2}{*}{$\begin{array}{c}0.00 \\
0 \%\end{array}$} & \multirow{2}{*}{$\begin{array}{c}4.3 \\
38 \%\end{array}$} & \multirow{2}{*}{$\begin{array}{l}0.5 \\
4 \% \\
\end{array}$} & \multirow{2}{*}{$\begin{array}{c}4.0 \\
35 \%\end{array}$} & \multirow{2}{*}{$\begin{array}{c}8.8 \\
77 \%\end{array}$} \\
\hline & \%oSorbed: & $58 \%$ & & & & & \\
\hline \multirow{2}{*}{$0.1 \%(\# 2)$} & 11.13 & 4.28 & \multirow{2}{*}{$\begin{array}{c}0.00 \\
0 \%\end{array}$} & \multirow{2}{*}{$\begin{array}{c}5.4 \\
48 \%\end{array}$} & \multirow{2}{*}{$\begin{array}{l}0.7 \\
7 \%\end{array}$} & \multirow{2}{*}{$\begin{array}{c}2.2 \\
20 \%\end{array}$} & \multirow{2}{*}{$\begin{array}{c}8.4 \\
75 \% \\
\end{array}$} \\
\hline & \%Sorbed: & $61 \%$ & & & & & \\
\hline
\end{tabular}

a. Total Initial for slurries computed using the average initial aqueous TCE concentration of the GW control samples (Avg $=30,491 \mu \mathrm{g} / \mathrm{L}, \sigma=584 \mu \mathrm{g} / \mathrm{L}$ ). For $\mathrm{GW}$ controls, Total Initial =Initial Aqueous.

TCE Oxidized only includes mass associated with the difference in the aqueous TCE concentrations between $0-0.5$ hrs.

Table 66. $\mathrm{MnO}_{4}{ }^{-}$Consumption Data for ORNL Exp. 4b-R11 (TSF-05 GW \& Sludge).

\begin{tabular}{|l|l|l|l|l|}
\hline Test Condition & $\begin{array}{l}\text { Initial } \\
\text { Oxidant } \\
\left(\mathrm{mg} \mathrm{MnO}_{4}^{-}\right)\end{array}$ & $\begin{array}{l}\text { Initial } \\
\text { Loading } \\
\left(\mathrm{mg} \mathrm{MnO}_{4}^{-} / \mathrm{g}\right)\end{array}$ & $\begin{array}{l}\text { Cum. } \\
\text { Consumed } \\
\left(\mathrm{mg} \mathrm{MnO}_{4}^{-}\right)\end{array}$ & $\begin{array}{l}\text { Cum. } \\
\text { Consumed } \\
\left(\mathrm{mg} \mathrm{MnO}_{4}^{-} / \mathrm{g}\right)\end{array}$ \\
\hline $0.01 \%(\# 1)$ & 38.0 & 0.08 & 37.64 & 0.08 \\
\hline $0.01 \%(\# 2)$ & 38.2 & 0.08 & 37.81 & 0.08 \\
\hline $0.1 \%(\# 1)$ & 386.8 & 0.82 & 386.40 & 0.82 \\
\hline $0.1 \%(\# 2)$ & 376.8 & 0.83 & 376.34 & 0.83 \\
\hline
\end{tabular}

a. Consumption is computed after $24 \mathrm{hr}$ reaction time. 
ORNL Exp. 4b-R15

(TSF-05, Sludge, 10,000 TCE, 0 Other, $1 \%$ and $3 \% \mathrm{MnO}_{4}{ }^{-}$)

(Repeat of Exp. 4b-R10)

This experiment investigated the oxidation of TSF- $05 \mathrm{GW}$ and sludge spiked at $10,000 \mu \mathrm{g} / \mathrm{L}$ TCE. The TCE, $\mathrm{MnO}_{4}{ }^{-}$and $\mathrm{pH}$ values with time are presented in Figures 98, 99, and 100, respectively. Tables 67 and 68 provide additional TCE mass balance and oxidant consumption information. The (\#1) and (\#2) notations included in both the figure legends and the first column of these tables refer to the duplicate reactors evaluated for that test condition.

This experiment was primarily conducted according the testplan. However, a crack was observed in the second $1 \% \mathrm{MnO}_{4}{ }^{-}$reactor immediately following the overnight equilibrium and before collection of the $\mathrm{T}=0$ aliquots. The contents of this reactor were quickly transferred to a spare reactor flask but a spare stopcock adapter (Figure 3) was not available. Instead, a solid glass stopper was used, and its removal was required each time an aliquot sample was collected. Therefore, losses of TCE due to volatilization may have been greater for this reactor than for the other reactors.

After equilibration, the average initial aqueous TCE concentration of the spike solution prepared (TSF-05 GW) was $9,180 \mu \mathrm{g} / \mathrm{L}(\sigma=93 \mu \mathrm{g} / \mathrm{L})$. After transfer to the test reactors and equilibration with the TSF-05 sludge, the aqueous TCE concentrations in the slurries were lower than those observed in the groundwater controls. In fact, the sludge adsorbed an average of $45 \%$ of the total initial TCE added to each reactor. Final TCE recovery values of $93 \%$ and $94 \%$ were obtained for the first and second control reactors, respectively. Closer examination of the aqueous TCE values obtained with time for the control samples suggest that the $<100 \%$ recovery is likely a result of volatilization. In fact, the control reactors were the only reactors in this experiment that had any detectable amount of TCE present on their charcoal desorption tube beds.

From Figure 98, the aqueous TCE concentrations of the treatment reactors are quickly reduced as oxidation occurs. A low residual TCE concentration is present in the first $1 \% \mathrm{MnO}_{4}{ }^{-}$reactor throughout the remainder of the reaction period. This residual is likely not associated with any solvent contamination problems during analysis since TCE was not detected in other samples collected and analyzed at the same time. The corresponding oxidant consumption curve for this reactor (Figure 99 ) indicates that $\approx 100 \mathrm{mg} / \mathrm{L} \mathrm{MnO}_{4}{ }^{-}$residual also exists. Thus, it is unknown why both TCE and $\mathrm{MnO}_{4}{ }^{-}$co-existed in this reactor. While there is no evidence to the effect, the residual oxidant concentration may not have been great enough to drive the oxidation reaction to completion. Examination of the mass balance components for this reactor (Table 67) revealed that at least $58 \%$ of the initial TCE was oxidized and that $32 \%$ (0.92 mg TCE) of the initial TCE mass was still present in the reactor after $24 \mathrm{hrs}$. Of this remaining TCE mass, a maximum of $0.002 \mathrm{mg}$ was associated with the $\approx 300 \mathrm{~mL}$ of TSF-05 GW present following the last aliquot sampling. Hence, essentially all of remaining TCE was associated with the sludge. Since $41 \%$ of the initial TCE was originally adsorbed by the sludge and $32 \%$ remains, the fate of the "missing" 9\% is unknown. It may have been (1) oxidized, (2) volatilized, or (3) present in the sludge but not measured due to the hexane extraction efficiency being $<100 \%$. The volatilization option is supported by the comparable total recoveries obtained for the control reactors. 
It appears from figure 89 , that complete oxidation also occurred for the second $1 \% \mathrm{MnO}_{4}{ }^{-}$ reactor. Recall, however, that this reactor developed a crack during contaminant equilibration. While the TCE mass actually present in the reactor at $\mathrm{T}=0$ was likely oxidized, a good mass balance cannot be made for this reactor since the initial total TCE in the reactor is unknown. Very little TCE was present in the final extraction of the reactor.

The experimental data collected suggest that complete oxidation did occur for the $3 \% \mathrm{MnO}_{4}{ }^{-}$ reactors. TCE was not detected in the aqueous aliquot samples after $0.5 \mathrm{hrs}$, and little, if any, TCE was present in the extraction of the remaining slurry. TCE was not detected on these sample extracts which were diluted 20 fold. Thus, the $0.04 \mathrm{mg}$ TCE value presented in Table 67 is an assumed maximum (Assumed Conc. $=$ Min. Detection Limit X 20). As discussed previously, the TCE oxidation component of the mass balance does not take into account any TCE initially bound to the sludge. Since TCE was not detected in the final extraction of these test reactors and a large $\mathrm{MnO}_{4}{ }^{-}$residual existed, it is suspected that the unaccounted for TCE was likely oxidized. Thus, the low total TCE recoveries reported in Table 67 for the $3 \% \mathrm{MnO}_{4}{ }^{-}$ reactors may actually be due to the inability to quantify the additional TCE oxidation that was occurring. Although enough data points are not available to compute a reaction rate constant, an observed oxidation rate of approximately $5.8 \mathrm{mg} / \mathrm{hr}$ was computed for both the $1 \%$ the $3 \%$ $\mathrm{MnO}_{4}{ }^{-}$reactors.

During this experiment, greater than $90 \%$ of the oxidant mass in the $1 \% \mathrm{MnO}_{4}{ }^{-}$reactors was consumed. Consumption of $\mathrm{MnO}_{4}{ }^{-}$throughout the reaction period was also observed. Since there was little TCE oxidation beyond $\mathrm{T}=3 \mathrm{hrs}$, it is suspected that the TSF-05 sludge was the source of the continued oxidant demand. Approximately $50 \%$ of the initial $\mathrm{MnO}_{4}{ }^{-}$added to the $3 \% \mathrm{MnO}_{4}^{-}$reactors was consumed during this experiment.

As observed in the other sludge experiments, there is a marked difference in the initial $\mathrm{pH}$ of the treatment reactors due to the presence of the sludge itself. Following an initial drop associated with the oxidation reaction, the $\mathrm{pH}$ values eventually increased by approximately 0.7 and $0.1 \mathrm{pH}$ units for the $1 \%$ and $3 \% \mathrm{MnO}_{4}{ }^{-}$reactors, respectively. Other experiments involving the $1 \%$ and $3 \% \mathrm{MnO}_{4}{ }^{-}$loadings have also resulted in similar net increases in overall system $\mathrm{pH}$, which is likely due to destruction of the organic sludge and /or the increased ionic strength imparted by the residual oxidant solution. 


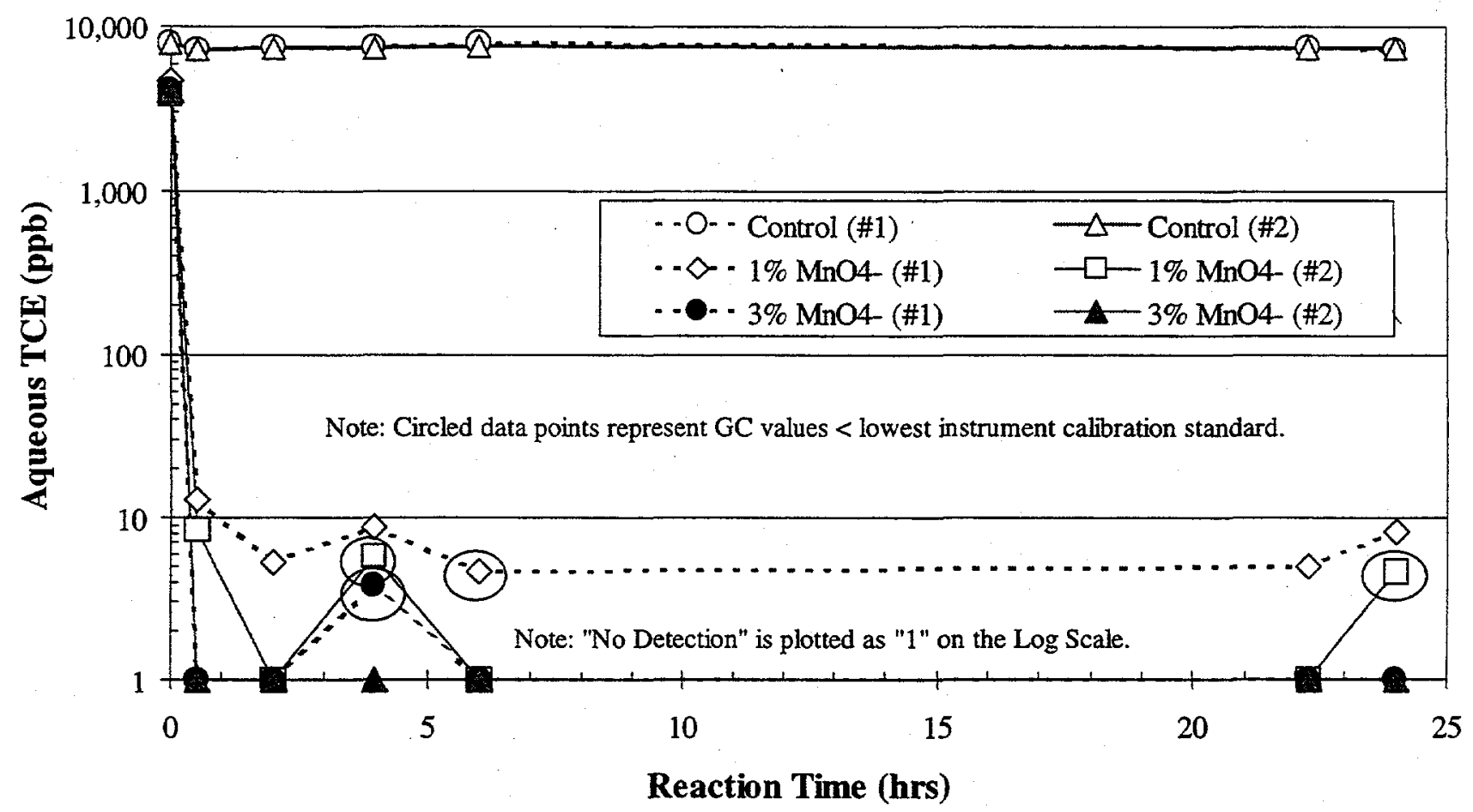

Figure 98. TCE vs. Time, TSF-05 GW \& Sludge, (ORNL Exp. 4b-R15, Initial TCE=10,000 $\mu \mathrm{g} / \mathrm{L}$, Conducted at $12^{\circ} \mathrm{C}, 4: 1 \mathrm{~L} / \mathrm{S}$ Ratio)

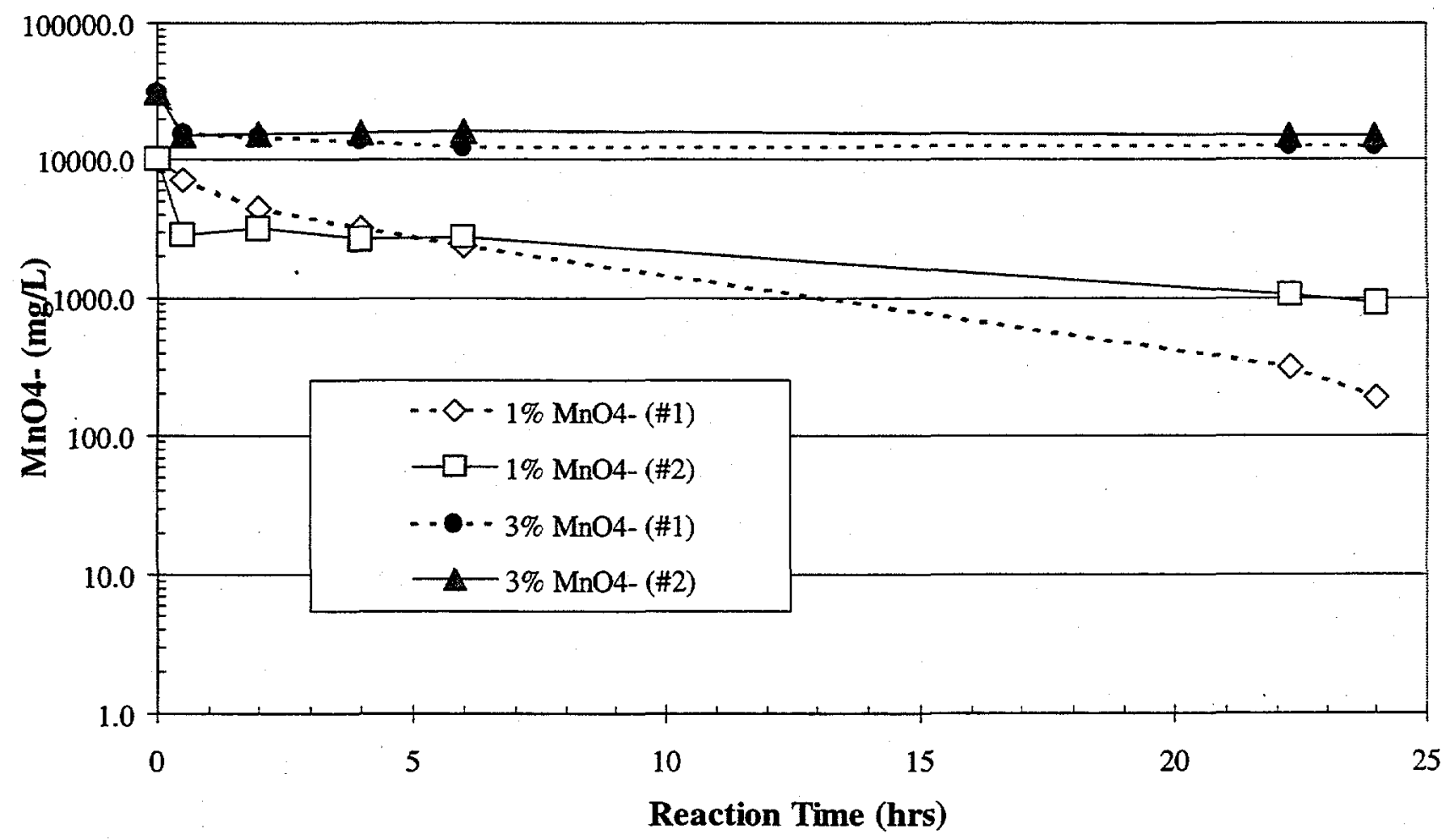

Figure 99. $\mathrm{MnO}_{4}{ }^{-}$vs. Time, TSF-05 GW \& Sludge, (ORNL Exp. 4b-R15, Initial TCE=10,000 $\mu \mathrm{g} / \mathrm{L}$, Conducted at $12^{\circ} \mathrm{C}, 4: 1 \mathrm{~L} / \mathrm{S}$ Ratio) 


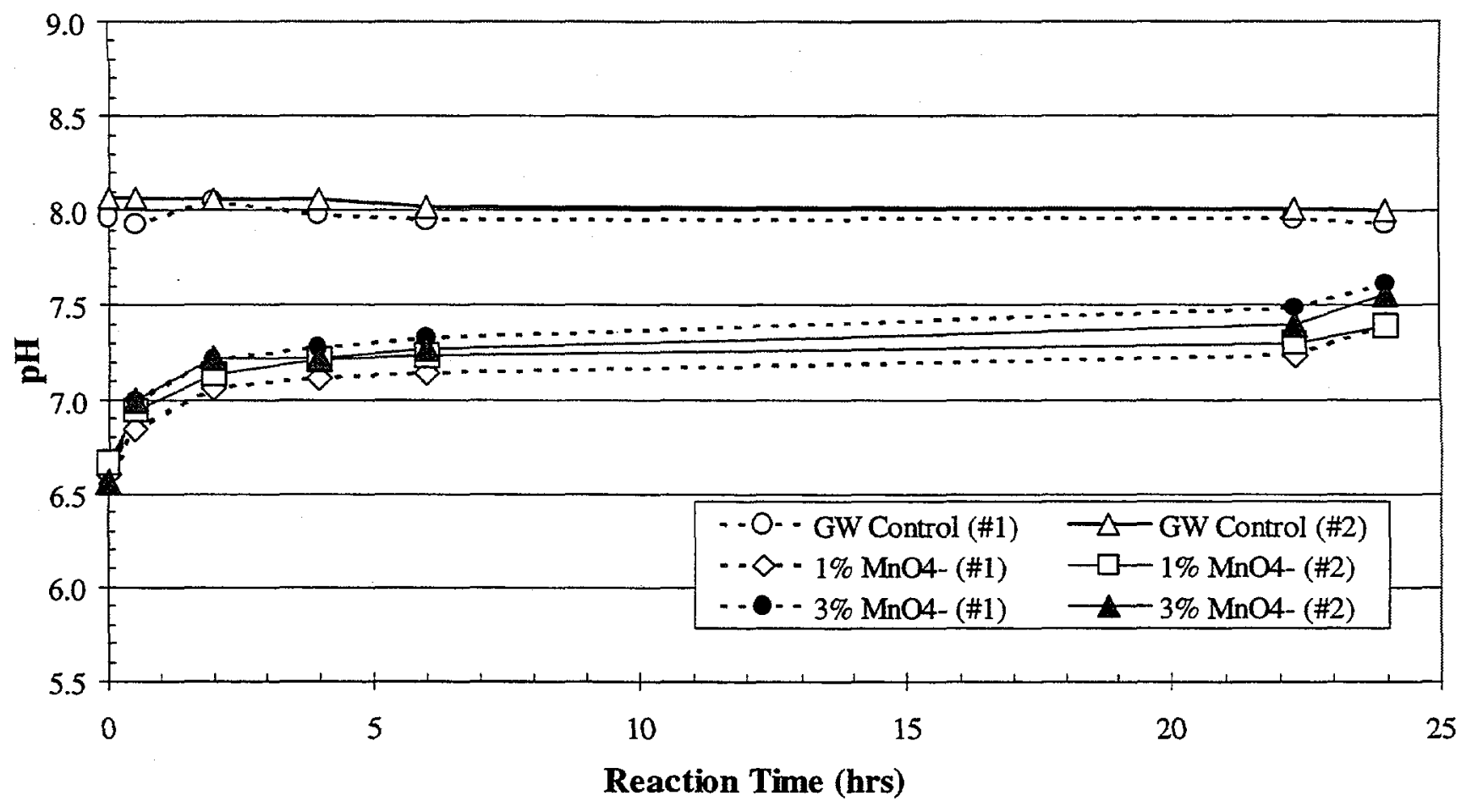

Figure 100. pH vs. Time, TSF-05 GW \& Sludge, (ORNL Exp. 4b-R15, Initial TCE $=10,000$ $\mu \mathrm{g} / \mathrm{L}$, Conducted at $12^{\circ} \mathrm{C}, 4: 1 \mathrm{~L} / \mathrm{S}$ Ratio) 
Table 67. TCE Mass Balance for ORNL Exp. 4b-R15 (TSF-05 GW \& Sludge). ${ }^{2}$

\begin{tabular}{|c|c|c|c|c|c|c|c|}
\hline Test Condition & $\begin{array}{l}\text { Total } \\
\text { Initial } \\
\text { Mass } \\
(\mathrm{mg})^{\text {a. }}\end{array}$ & \begin{tabular}{|l} 
Initial \\
Aqueous \\
Mass \\
(mg)
\end{tabular} & $\begin{array}{l}\text { Mass } \\
\text { Sorbed on } \\
\text { Orbo Tubes } \\
\text { (mg) }\end{array}$ & $\begin{array}{l}\text { Mass } \\
\text { Remaining in } \\
\text { Reactor (mg) }\end{array}$ & $\begin{array}{l}\text { Cum. } \\
\text { Mass } \\
\text { Removed } \\
\text { in Aliquots } \\
\text { (mg) } \\
\end{array}$ & $\begin{array}{l}\text { Cum. } \\
\text { Aqueous } \\
\text { Mass } \\
\text { Oxidized } \\
\text { (mg) }\end{array}$ & $\begin{array}{l}\text { Total Mass } \\
\text { Recovered } \\
\text { (mg) }\end{array}$ \\
\hline \multirow{2}{*}{ Control (\#1) } & 2.9 & 2.9 & 0.000 & 2.0 & 0.7 & NA & 2.7 \\
\hline & & & $0 \%$ & $69 \%$ & $24 \%$ & NA & $93 \%$ \\
\hline \multirow[t]{2}{*}{ Control (\#2) } & 2.8 & 2.8 & 0.000 & 2.1 & 0.6 & NA & 2.6 \\
\hline & & & $0 \%$ & $73 \%$ & $21 \%$ & NA & $94 \%$ \\
\hline \multirow{2}{*}{$1 \%(\# 1)$} & 2.9 & 1.7 & \multirow{2}{*}{$\begin{array}{c}0.000 \\
0 \% \\
\end{array}$} & \multirow{2}{*}{$\begin{array}{l}0.92 \\
32 \% \\
\end{array}$} & \multirow{2}{*}{$\begin{array}{l}0.05 \\
2 \% \\
\end{array}$} & \multirow{2}{*}{$\begin{array}{r}1.7 \\
58 \% \\
\end{array}$} & \multirow{2}{*}{$\begin{array}{r}2.6 \\
91 \% \\
\end{array}$} \\
\hline & \%Sorbed: & $41 \%$ & & & & & \\
\hline \multirow{2}{*}{$1 \%(\# 2)$} & $2.9^{\dagger}$ & 1.4 & \multirow{2}{*}{$\begin{array}{l}\text { No Sample } \\
\text { No Sample }\end{array}$} & \multirow{2}{*}{$\begin{array}{l}0.16 \\
6 \%^{\dagger} \\
\end{array}$} & \multirow{2}{*}{$\begin{array}{l}0.04 \\
1 \%{ }^{\dagger} \\
\end{array}$} & \multirow{2}{*}{$\begin{array}{c}1.4 \\
48 \%^{\dagger} \\
\end{array}$} & \multirow{2}{*}{$\begin{array}{c}1.6 \\
55 \%^{\dagger} \\
\end{array}$} \\
\hline & \%Sorbed: & $51 \%^{\dagger}$ & & & & & \\
\hline \multirow{2}{*}{$3 \%(\# 1)$} & 2.9 & 1.5 & \multirow{2}{*}{$\begin{array}{c}0.000 \\
0 \% \\
\end{array}$} & \multirow{2}{*}{$\begin{array}{l}0.04 \\
1 \% \\
\end{array}$} & \multirow{2}{*}{$\begin{array}{c}0.04 \\
1 \% \\
\end{array}$} & \multirow{2}{*}{$\begin{array}{r}1.5 \\
51 \% \\
\end{array}$} & \multirow{2}{*}{$\begin{array}{r}1.5 \\
54 \% \\
\end{array}$} \\
\hline & \%Sorbed: & $48 \%$ & & & & & \\
\hline \multirow{2}{*}{$3 \%(\# 2)$} & 2.9 & 1.5 & \multirow{2}{*}{$\begin{array}{c}0.000 \\
0 \%\end{array}$} & \multirow{2}{*}{$\begin{array}{c}0.04 \\
1 \%\end{array}$} & \multirow{2}{*}{$\begin{array}{c}0.04 \\
1 \%\end{array}$} & \multirow{2}{*}{$\begin{array}{c}1.5 \\
51 \%\end{array}$} & \multirow{2}{*}{$\begin{array}{c}1.6 \\
54 \%\end{array}$} \\
\hline & \%Sorbed: & $47 \%$ & & & & & \\
\hline
\end{tabular}

a. Total Initial for slurries computed using the average initial aqueous TCE concentration of the GW control samples (Avg=7,841 $\mu \mathrm{g} / \mathrm{L}, \sigma=66 \mu \mathrm{g} / \mathrm{L})$. For $\mathrm{GW}$ controls, Total Initial =Initial Aqueous.

$\doteqdot$ There is uncertainty in the Initial Total value due to a leak in this reactor prior to $\mathrm{T}=0 \mathrm{hrs}$.

Table 68. $\mathrm{MnO}_{4}{ }^{-}$Consumption Data for ORNL Exp. 4b-R15 (TSF-05 GW \& Sludge).

\begin{tabular}{|c|c|c|l|l|}
\hline Test Condition & $\begin{array}{l}\text { Initial } \\
\text { Oxidant } \\
\left(\mathrm{mg} \mathrm{MnO}_{4}{ }^{-}\right)\end{array}$ & $\begin{array}{l}\text { Initial } \\
\text { Loading } \\
\left(\mathrm{mg} \mathrm{MnO}_{4}^{-} / \mathrm{g}\right)\end{array}$ & $\begin{array}{l}\text { Cum. } \\
\text { Consumed } \\
\left.\left(\mathrm{mg} \mathrm{MnO}_{4}\right)^{-}\right)\end{array}$ & $\begin{array}{l}\text { Cum. } \\
\text { Consumed } \\
\left(\mathrm{mg} \mathrm{MnO}_{4} / \mathrm{g}\right)\end{array}$ \\
\hline $1 \%(\# 1)$ & 3683 & 8.1 & 3614 & 8.0 \\
\hline $1 \%(\# 2)$ & 3630 & 8.1 & 3301 & 7.4 \\
\hline $3 \%(\# 1)$ & 11026 & 24.6 & 6574 & 14.7 \\
\hline $3 \%(\# 2)$ & 11147 & 24.7 & 5761 & 12.7 \\
\hline
\end{tabular}

a. Consumption is computed after $24 \mathrm{hr}$ reaction time. 
ORNL Exp. 4b-R16

(TSF-05, Sludge, 100,000 TCE, 0 Other, $0.01 \%$ and $0.1 \% \mathrm{MnO}_{4}{ }^{-}$)

(Repeat of $4 b-R 11$ )

This experiment investigated the oxidation of TSF-05 GW and sludge spiked at $100,000 \mu \mathrm{g} / \mathrm{L}$ TCE. The TCE, $\mathrm{MnO}_{4}{ }^{-}$and $\mathrm{pH}$ values with time are presented in Figures 101, 102, and 103, respectively. Tables 69 and 70 provide additional TCE mass balance and oxidant consumption information. The (\#1) and (\#2) notations included in both the figure legends and the first column of these tables refer to the duplicate reactors evaluated for that test condition.

This experiment was conducted in accordance to the appropriate testplan procedure.

After equilibration, the average initial aqueous TCE concentration of the spike solution (TSF-05 $\mathrm{GW})$ was $90,483 \mu \mathrm{g} / \mathrm{L}(\sigma=2,123 \mu \mathrm{g} / \mathrm{L})$. After transfer to the test reactors and equilibration with the TSF-05 sludge, the aqueous TCE concentrations in the slurries were lower than those observed in the groundwater controls. In fact, the sludge adsorbed an average of $34 \%$ of the total initial TCE added to each reactor. Final TCE recovery values of only $80 \%$ and $83 \%$ were obtained for the first and second control reactors, respectively. Closer examination of the aqueous TCE values revealed that most of this TCE loss was experienced between the $\mathrm{T}=0 \mathrm{hrs}$ and $\mathrm{T}=0.5 \mathrm{hrs}$ sampling periods. Detectable amounts of TCE were present on the first charcoal bed extracts for both control samples.

All of the experimental results lead to the conclusion that little of the initial TCE mass was oxidized during the experiment. This was not unexpected due to the (1) high TCE spike levels (2) the presence of the highly organic sludge and (3) the use of the lower $0.01 \%$ and $01 \% \mathrm{MnO}_{4}{ }^{-}$ loadings. Table 69 and Figure 101 do indicate that the higher initial oxidant loadings resulted in the greatest amount of TCE oxidation (16\% max). It should also be noted that the apparent decrease in TCE for the second $0.01 \% \mathrm{MnO}_{4}{ }^{-}$reactor is likely because the TCE concentration determined for the hexane extract exceeded that of the maximum calibration standard (Figure 101).

As observed in Exp. 4b-R11, aqueous TCE concentrations appeared to gradually increase following $\mathrm{MnO}_{4}{ }^{-}$depletion, suggesting that TCE might have been released into the aqueous phase as a result of sludge oxidation. Total TCE recoveries for the treatment reactors (88\%97\%) are much higher than those obtained for the GW control reactors (see Table 69). TCE was present on most of the desorption tubes used for the treatment reactors. The largest percentage of the initial TCE mass recovered was found in the slurry that remained following completion of the test. To determine how much of the remaining TCE was partitioned to the sludge, the TCE mass expected to be associated with the aqueous portion of the slurry was computed using the concentration of the final aliquot sample. For the $0.01 \%$ and $0.1 \% \mathrm{MnO}_{4}{ }^{-}$reactors, an average of $32 \%$ and $37 \%$ of the remaining TCE was present on the solid phase. These values are comparable to the initial sorption values reported in Table 69.

The computation of reaction rates was not attempted for this experiment since the use of $0.01 \%$ and $0.1 \% \mathrm{MnO}_{4}{ }^{*}$ loadings do not adequately satisfy the oxidant demand of the TCE contaminated sludge. 
As mentioned above, oxidant depletion occurred rapidly for both the $0.01 \%$ and $0.1 \% \mathrm{MnO}_{4}{ }^{\circ}$ reactors. It should be noted that in Figure 102 all of the measured $\mathrm{MnO}_{4}{ }^{-}$concentrations after the $\mathrm{T}=0 \mathrm{hrs}$ are below that of the lowest $\mathrm{MnO}_{4}{ }^{-}$calibration standard $(5 \mathrm{mg} / \mathrm{L})$. Thus, any $\mathrm{MnO}_{4}{ }^{-}$ trends presented in Figure 102 are of little significance.

From Figure 103, there is again a marked difference in the initial $\mathrm{pH}$ of the reactors due to the presence of the sludge itself. As observed in other hot spot sludge experiments, the overall $\mathrm{pH}$ values of the treatment reactors increases of less than 0.2 and $0.4 \mathrm{pH}$ units for the $0.01 \%$ and $0.1 \% \mathrm{MnO}_{4}{ }^{-}$reactors, respectively. 


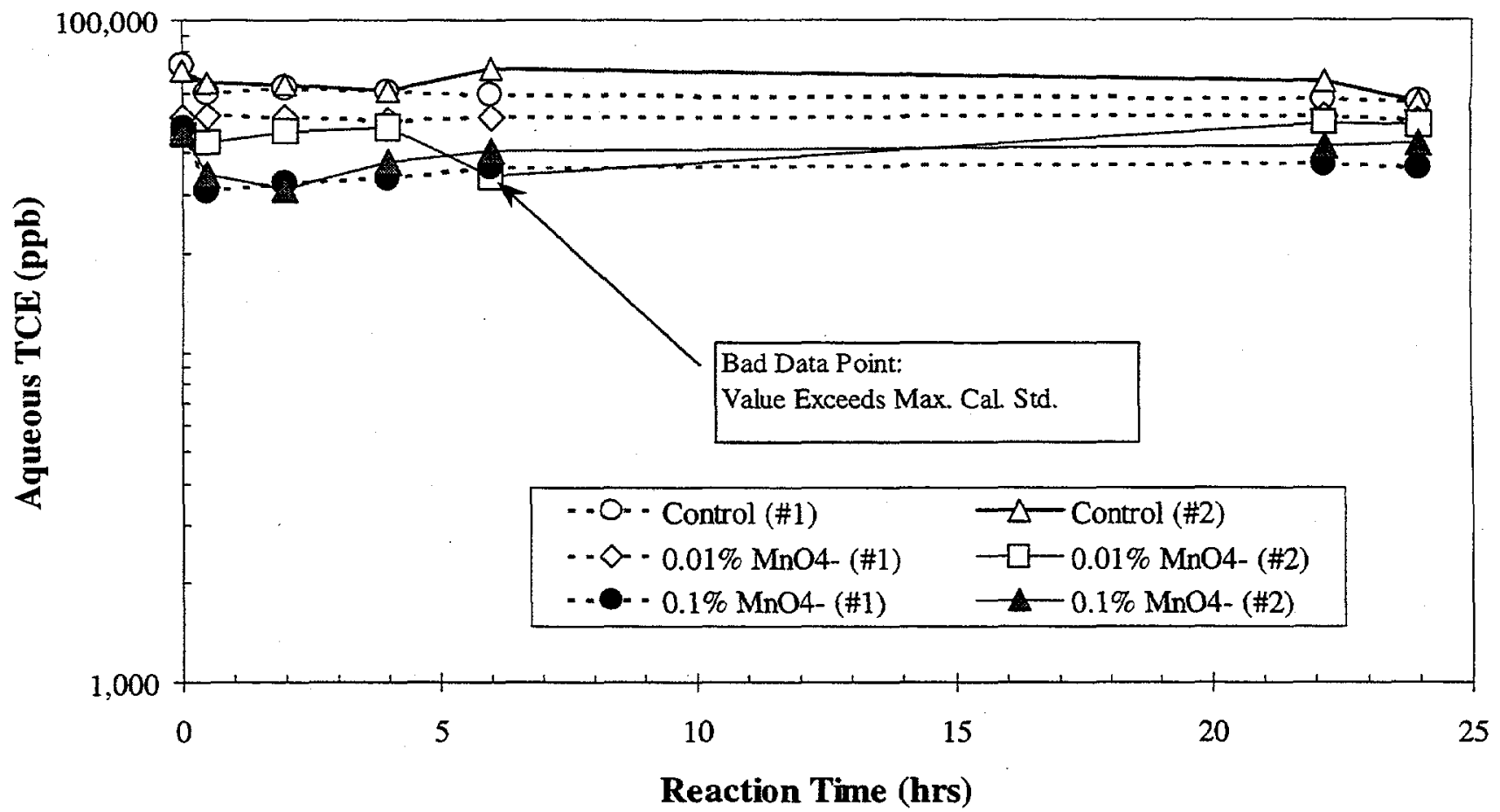

Figure 101. TCE vs. Time, TSF-05 GW \& Sludge, (ORNL Exp. 4b-R16, Initial TCE=100,000 $\mu \mathrm{g} / \mathrm{L}$, Conducted at $12^{\circ} \mathrm{C}, 4: 1 \mathrm{~L} / \mathrm{S}$ Ratio)

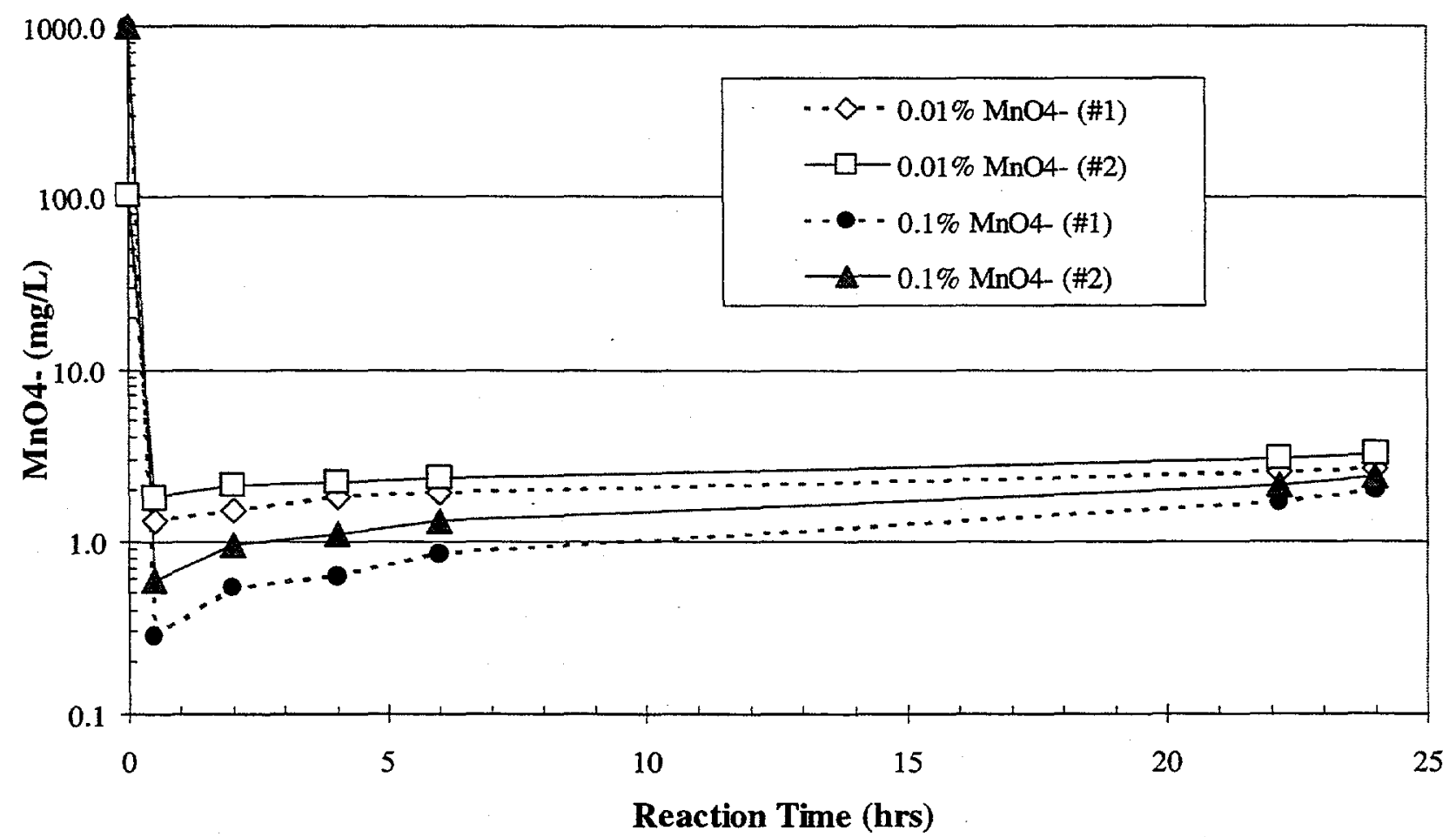

Figure 102. $\mathrm{MnO}_{4}{ }^{-}$vs. Time, TSF-05 GW \& Sludge, (ORNL Exp. 4b-R16, Initial TCE $=100,000$ $\mu \mathrm{g} / \mathrm{L}$, Conducted at $12^{\circ} \mathrm{C}, 4: 1 \mathrm{~L} / \mathrm{S}$ Ratio) 


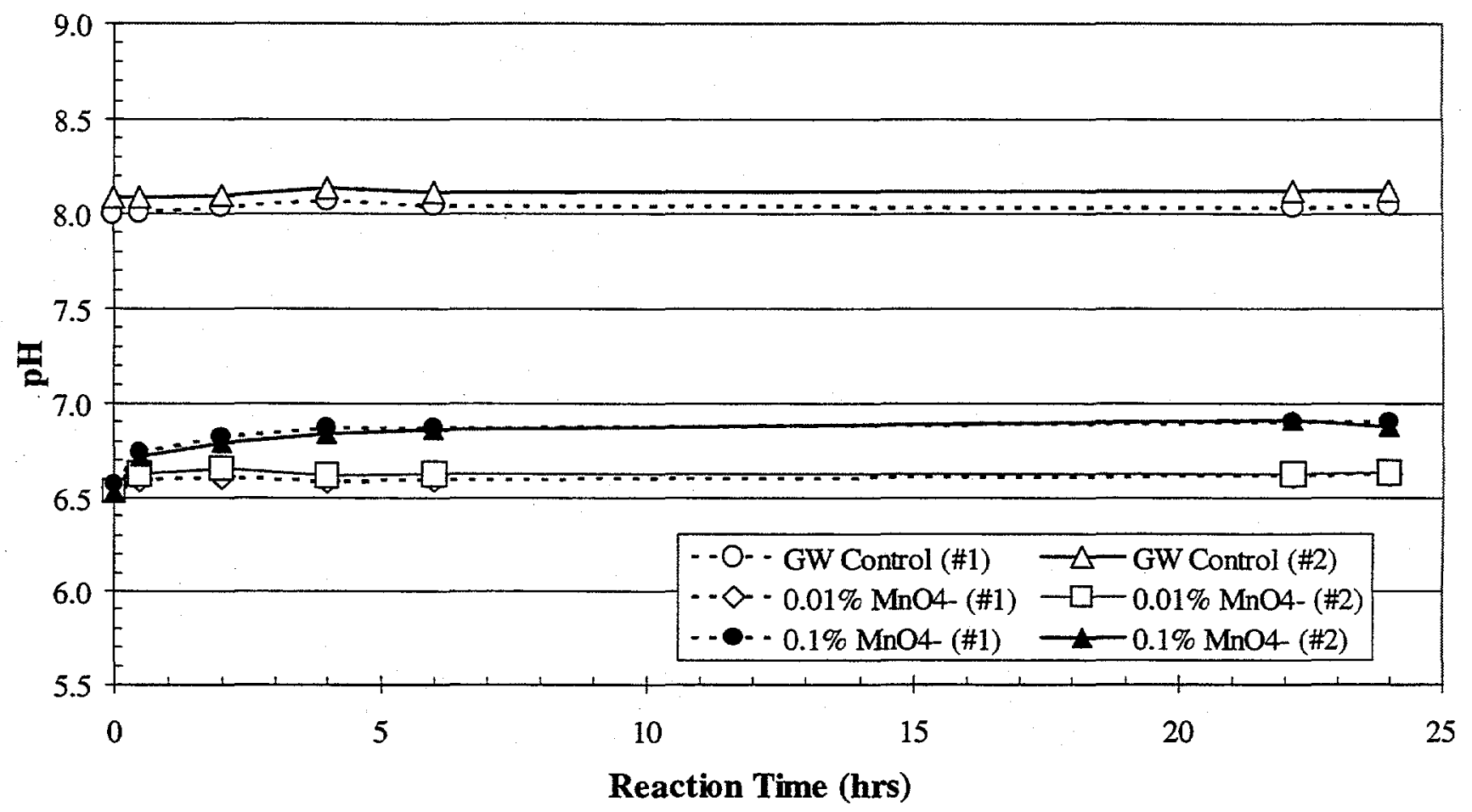

Figure 103. pH vs. Time, TSF-05 GW \& Sludge, (ORNL Exp. 4b-R16, Initial TCE $=100,000$ $\mu \mathrm{g} / \mathrm{L}$, Conducted at $12^{\circ} \mathrm{C}, 4: 1 \mathrm{~L} / \mathrm{S}$ Ratio) 
Table 69. TCE Mass Balance for ORNL Exp. 4b-R16 (TSF-05 GW \& Sludge).

\begin{tabular}{|c|c|c|c|c|c|c|c|}
\hline Test Condition & $\begin{array}{l}\text { Total } \\
\text { Initial } \\
\text { Mass } \\
(\mathrm{mg})^{\mathrm{a}}\end{array}$ & $\begin{array}{l}\text { Initial } \\
\text { Aqueous } \\
\text { Mass } \\
\text { (mg) }\end{array}$ & \begin{tabular}{|l|} 
Mass \\
Sorbed on \\
Orbo Tubes \\
(mg)
\end{tabular} & $\begin{array}{l}\text { Mass } \\
\text { Remaining in } \\
\text { Reactor (mg) }\end{array}$ & \begin{tabular}{|l|} 
Cum. \\
Mass \\
Removed \\
in Aliquots \\
(mg) \\
\end{tabular} & $\begin{array}{l}\text { Cum. } \\
\text { Aqueous } \\
\text { Mass } \\
\text { Oxidized } \\
\text { (mg) }\end{array}$ & $\begin{array}{l}\text { Total Mass } \\
\text { Recovered } \\
\text { (mg) }\end{array}$ \\
\hline \multirow{2}{*}{ Control (\#1) } & \multirow[t]{2}{*}{26.5} & \multirow[t]{2}{*}{26.5} & 0.001 & 15.6 & 5.6 & $\mathrm{NA}$ & 21.2 \\
\hline & & & $0 \%$ & $59 \%$ & $21 \%$ & NA & $80 \%$ \\
\hline \multirow{2}{*}{ Control (\#2) } & \multirow[t]{2}{*}{25.4} & \multirow[t]{2}{*}{25.4} & 0.001 & 16.0 & 5.2 & $\mathrm{NA}$ & 21.2 \\
\hline & & & $0 \%$ & $63 \%$ & $20 \%$ & $\mathrm{NA}$ & $83 \%$ \\
\hline \multirow{2}{*}{$0.01 \%(\# 1)$} & 26.1 & 18.7 & \multirow{2}{*}{$\begin{array}{c}0.000 \\
0 \% \\
\end{array}$} & \multirow{2}{*}{$\begin{array}{c}20.88 \\
80 \% \\
\end{array}$} & \multirow{2}{*}{$\begin{array}{l}4.07 \\
16 \% \\
\end{array}$} & \multirow{2}{*}{$\begin{array}{l}0.5 \\
2 \% \\
\end{array}$} & \multirow{2}{*}{$\begin{array}{l}25.4 \\
97 \% \\
\end{array}$} \\
\hline & \%Sorbed: & $28 \%$ & & & & & \\
\hline \multirow{2}{*}{$0.01 \%(\# 2)$} & 26.2 & 16.6 & \multirow{2}{*}{$\begin{array}{c}0.001 \\
0 \%\end{array}$} & \multirow{2}{*}{$\begin{array}{c}20.28 \\
78 \%\end{array}$} & \multirow{2}{*}{$\begin{array}{l}3.62 \\
14 \% \\
\end{array}$} & \multirow{2}{*}{$\begin{array}{l}-1.0 \\
-4 \% \\
\end{array}$} & \multirow{2}{*}{$\begin{array}{l}22.9 \\
88 \% \\
\end{array}$} \\
\hline & \%Sorbed: & $37 \%$ & & & & & \\
\hline \multirow{2}{*}{$0.1 \%(\# 1)$} & 26.2 & 17.2 & \multirow{2}{*}{$\begin{array}{c}0.004 \\
0 \%\end{array}$} & \multirow{2}{*}{$\begin{array}{c}17.08 \\
65 \%\end{array}$} & \multirow{2}{*}{$\begin{array}{l}2.89 \\
11 \% \\
\end{array}$} & \multirow{2}{*}{$\begin{array}{c}4.1 \\
16 \% \\
\end{array}$} & \multirow{2}{*}{$\begin{array}{l}24.1 \\
92 \% \\
\end{array}$} \\
\hline & \%Sorbed: & $34 \%$ & & & & & \\
\hline \multirow{2}{*}{$0.1 \%(\# 2)$} & 25.7 & 16.7 & \multirow{2}{*}{$\begin{array}{c}0.002 \\
0 \%\end{array}$} & \multirow{2}{*}{$\begin{array}{c}19.34 \\
75 \%\end{array}$} & \multirow{2}{*}{$\begin{array}{l}3.16 \\
12 \%\end{array}$} & \multirow{2}{*}{$\begin{array}{l}1.6 \\
6 \% \\
\end{array}$} & \multirow{2}{*}{$\begin{array}{l}24.1 \\
94 \% \\
\end{array}$} \\
\hline & \%Sorbed: & $35 \%$ & & & & & \\
\hline
\end{tabular}

a. Total Initial for slurries computed using the average initial aqueous TCE concentration of the GW control samples (Avg $=71,490 \mu \mathrm{g} / \mathrm{L}, \sigma=1.805 \mu \mathrm{g} / \mathrm{L}$ ). For $\mathrm{GW}$ controls, Total Initial $=$ Initial Aqueous.

Table 70. $\mathrm{MnO}_{4}{ }^{-}$Consumption Data for ORNL Exp. 4b-R16 (TSF-05 GW \% Sludge).

\begin{tabular}{|c|c|c|c|c|}
\hline Test Condition & $\begin{array}{l}\text { Initial } \\
\text { Oxidant } \\
\left.\left(\mathrm{mg} \mathrm{MnO}_{4}\right)^{-}\right) \\
\end{array}$ & \begin{tabular}{|l|} 
Initial \\
Loading \\
$\left(\mathrm{mg} \mathrm{MnO}_{4}^{-} / \mathrm{g}\right)$ \\
\end{tabular} & $\begin{array}{l}\text { Cum. } \\
\text { Consumed } \\
\left.\text { (mg } \mathrm{MnO}_{4}^{-}\right) \\
\end{array}$ & \begin{tabular}{|l|} 
Cum. \\
Consumed \\
$\left(\mathrm{mg} \mathrm{MnO}_{4} / \mathrm{g}\right)$ \\
\end{tabular} \\
\hline $0.01 \%(\# 1)$ & 36.2 & 0.08 & 35.3 & 0.08 \\
\hline $0.01 \%(\# 2)$ & 36.3 & 0.08 & 35.1 & 0.08 \\
\hline $0.1 \%(\# 1)$ & 363.1 & 0.80 & 362.4 & 0.79 \\
\hline $0.1 \%(\# 2)$ & 357.1 & 0.80 & 356.3 & 0.79 \\
\hline
\end{tabular}

\footnotetext{
a. Consumption is computed after $24 \mathrm{hr}$ reaction time.
} 
ORNL Exp. 4b-R12

(TSF-05, Sludge, 100,000 TCE, 0 Other, $1 \%$ and $3 \% \mathrm{MnO}_{4}{ }^{-}$)

This experiment investigated the oxidation of TSF-05 GW and sludge spiked at $100,000 \mu \mathrm{g} / \mathrm{L}$ TCE. The TCE, $\mathrm{MnO}_{4}{ }^{-}$and $\mathrm{pH}$ values with time are presented in Figures 104, 105, and 106, respectively. Tables 71 and 72 provide additional TCE mass balance and oxidant consumption information. The (\#1) and (\#2) notations included in both the figure legends and the first column of these tables refer to the duplicate reactors evaluated for that test condition.

Significant deviations from the procedure were not noted for this experiment.

After equilibration, the average initial aqueous TCE concentration of the spike solution prepared (TSF-05 GW) was $100,290 \mu \mathrm{g} / \mathrm{L}(\sigma=1,422 \mu \mathrm{g} / \mathrm{L})$. After transfer to the test reactors and equilibration with the TSF-05 sludge, the aqueous TCE concentrations in the slurries were lower than those observed in the groundwater controls. In fact, the sludge adsorbed an average of $35 \%$ of the total initial TCE added to each reactor. Despite the presence of TCE on the desorption tubes, final TCE recovery values of $103 \%$ and $97 \%$ were obtained for the first and second control reactors, respectively. Closer examination of the aqueous TCE values for the first control indicate that that final aqueous TCE concentration is slightly greater than what was obtained at the $\mathrm{T}=0 \mathrm{hrs}$. Both samples were analyzed on the same day, and the variation may have been a result of the sample holding times for these samples. At any rate, the control reactors indicate that the experiment was conducted under well-controlled conditions.

From Figure 104, the control reactors exhibited steady TCE values, and the aqueous TCE concentrations of the treatment reactors were quickly reduced several orders of magnitude as oxidation occurred. Some problems were experienced in analyzing the aliquots collected between $\mathrm{T}=6 \mathrm{hrs}$ and $\mathrm{T}=24 \mathrm{hrs}$. A TCE residual definitely existed, but it could not be properly quantified. The samples in questions were over diluted on the first round of analysis, resulting in $\mathrm{GC}$ values less than that of the lowest calibration standard ( $5 \mu \mathrm{g} / \mathrm{L} \mathrm{TCE}$ ). When the samples were prepared with a smaller dilution factor $(\approx 24-30 \mathrm{hrs}$ after the initial analysis) TCE was no longer detected in the samples.

A small amount of TCE was also present in the final extractions of the slurry reactors. There is a strong possibility that all of these residual TCE values are the result of a solvent contamination problem. TCE was not detected in the GC hexane blanks, however, the actual test samples were collected and prepped (extracted with hexane) at RMAL, and the GC hexane blank used in the analytical sequence originated within ESD. Based upon observations made from other experiments already conducted, it seems improbable that a residual TCE concentration would exist in the presence of a large $\mathrm{MnO}_{4}{ }^{-}$residual (3\% $\mathrm{MnO}_{4}{ }^{-}$reactors in Figure 105).

To be conservative in the computation of the oxidized TCE component of the mass balance (Table 71, Column 7), it was assumed that the residual TCE values observed were real. Since excellent mass balances were obtained for the control reactors, the amount of TCE oxidized was computed as follows: Mass TCE oxidized= (Total Initial- Orbo Tube -Final Remaining- Cum. Aliquot). Based on this conservative approach, TCE oxidation values of $98 \%$ were obtained for all four of the treatment reactors. 
Since the TCE concentrations for the aliquots are likely a result of solvent contamination, reaction rate constants were not computed. Instead, it was assumed that oxidant essentially occurs in the first $0.5 \mathrm{hrs}$, and observed oxidation rates of $59.6 \mathrm{mg} \mathrm{TCE} / \mathrm{hr}$ was computed for both the $1 \%$ and $3 \% \mathrm{MnO}_{4}{ }^{-}$reactors.

After the initial oxidant demand, the mass of $\mathrm{MnO}_{4}{ }^{-}$present in the $1 \%$ reactors gradually decreased during the reaction period. It is assumed that the continued decrease in oxidant was a result of continued oxidation and breakdown of the TSF-05 sludge. Laboratory comments indicate a "yellowing" of the aqueous samples and hexane extracts after a $24 \mathrm{hr}$ period of contact/agitation. Final $\mathrm{MnO}_{4}{ }^{-}$consumption was $94 \%$ and $100 \%$ of the initial $\mathrm{MnO}_{4}{ }^{-}$mass added to the first and second $1 \% \mathrm{MnO}_{4}{ }^{-}$reactors. Note that the apparent large discrepancy between the $\mathrm{MnO}_{4}{ }^{-}$data for the $1 \%$ reactor at $24 \mathrm{hrs}$ (see Figure 105 ) is accentuated by the use of a semi-log plot. Approximately $60 \%$ of the initial oxidant mass was consumed within the $3 \%$ reactors.

For these higher $1 \%$ and $3 \% \mathrm{MnO}_{4}{ }^{-}$loadings, the overall $\mathrm{pH}$ (Figure 106) eventually increased following an initial drop associated with the oxidation reaction. These net increases were less than 0.8 and $1.1 \mathrm{pH}$ units for the $1 \%$ and $3 \% \mathrm{MnO}_{4}{ }^{-}$reactors, respectively. Other experiments involving the $1 \%$ and $3 \%$ loadings for the hot spot sludge have also resulted in similar trend in overall increase in system $\mathrm{pH}$. 


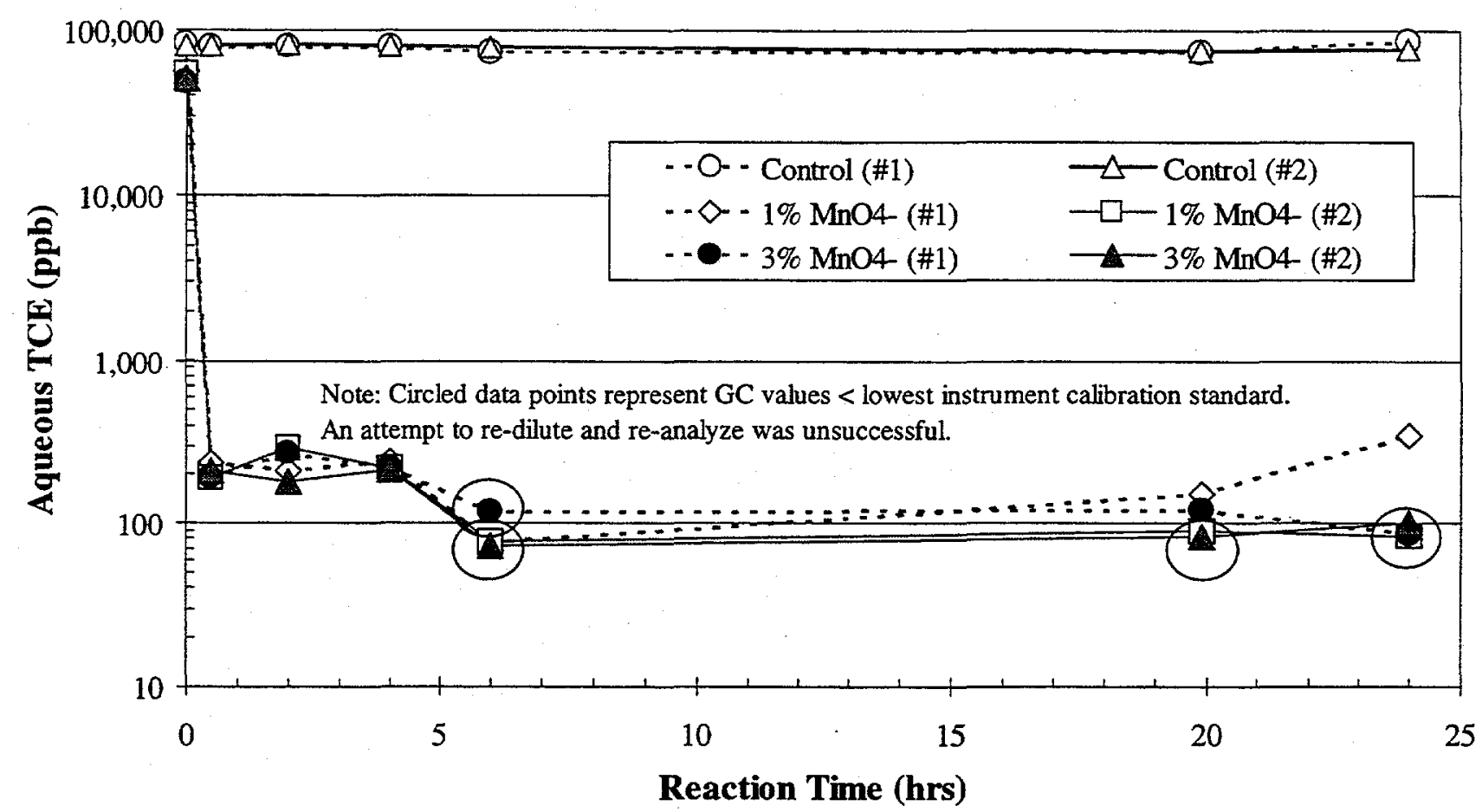

Figure 104. TCE vs. Time, TSF-05 GW \& Sludge, (ORNL Exp. 4b-R12, Initial TCE=100,000 $\mu \mathrm{g} / \mathrm{L}$, Conducted at $12^{\circ} \mathrm{C}, 4: 1 \mathrm{~L} / \mathrm{S}$ Ratio)

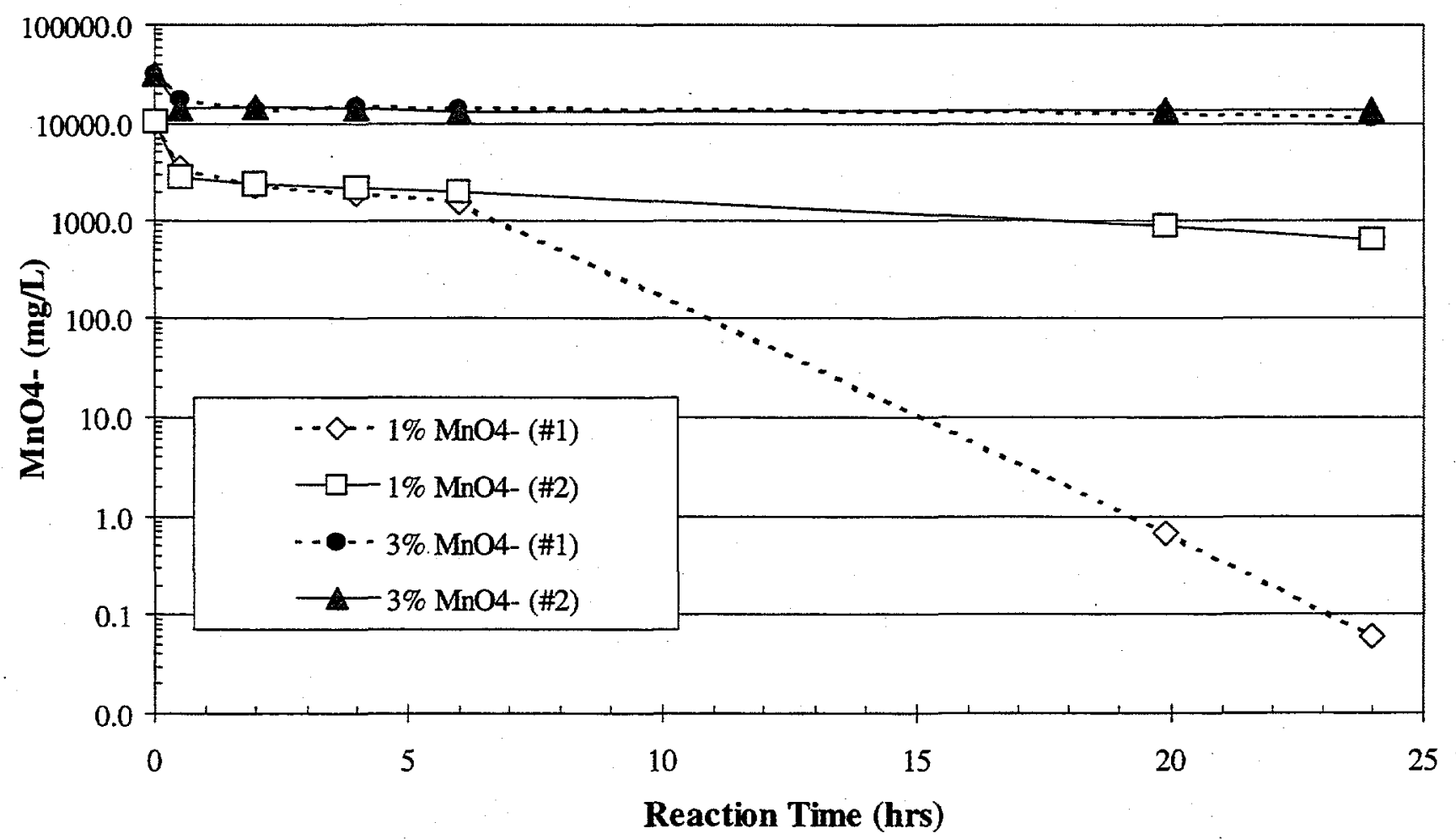

Figure 105. $\mathrm{MnO}_{4}{ }^{-}$vs. Time, TSF-05 GW \& Sludge, (ORNL Exp. 4b-R12, Initial TCE=100,000 $\mu \mathrm{g} / \mathrm{L}$; Conducted at $12^{\circ} \mathrm{C}, 4: 1 \mathrm{~L} / \mathrm{S}$ Ratio) 


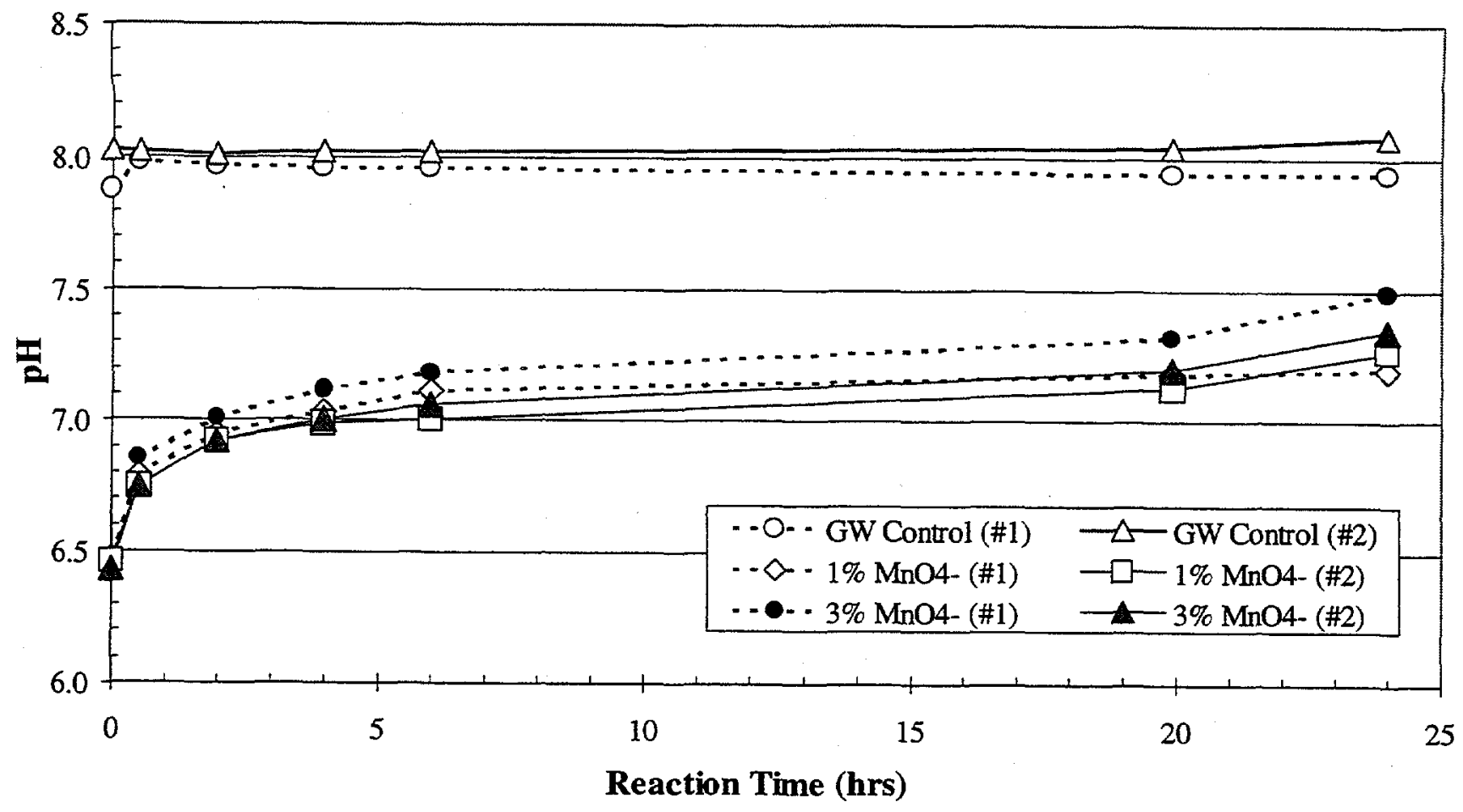

Figure 106. pH vs. Time, TSF-05 GW \& Sludge, (ORNL Exp. 4b-R12, Initial TCE $=100,000$ $\mu \mathrm{g} / \mathrm{L}$, Conducted at $12^{\circ} \mathrm{C}, 4: 1 \mathrm{~L} / \mathrm{S}$ Ratio) 
Table 71. TCE Mass Balance for ORNL Exp. 4b-R12 (TSF-05 GW \& Sludge). ${ }^{\text {a }}$

\begin{tabular}{|c|c|c|c|c|c|c|c|}
\hline Test Condition & \begin{tabular}{|l|} 
Total \\
Initial \\
Mass \\
(mg)
\end{tabular} & $\begin{array}{l}\text { Initial } \\
\text { Aqueous } \\
\text { Mass } \\
\text { (mg) }\end{array}$ & \begin{tabular}{|l|} 
Mass \\
Sorbed on \\
Orbo Tubes \\
(mg)
\end{tabular} & \begin{tabular}{|l|} 
Mass \\
Remaining in \\
Reactor (mg)
\end{tabular} & \begin{tabular}{|l|} 
Cum. \\
Mass \\
Removed \\
in Aliquots \\
(mg) \\
\end{tabular} & \begin{tabular}{|l} 
TCE \\
Oxidized
\end{tabular} & $\begin{array}{l}\text { Total Mass } \\
\text { Recovered } \\
\text { (mg) }\end{array}$ \\
\hline \multirow{2}{*}{ Control (\#1) } & 29.3 & 29.3 & 0.002 & 22 & 7.2 & NA & 30.1 \\
\hline & & & $0 \%$ & $78 \%$ & $24 \%$ & NA & $103 \%$ \\
\hline \multirow{2}{*}{ Control (\#2) } & 28.7 & 28.7 & 0.001 & 21.4 & 6.3 & $\mathrm{NA}$ & 27.8 \\
\hline & & & $0 \%$ & $75 \%$ & $22 \%$ & $\mathrm{NA}$ & $97 \%$ \\
\hline \multirow{2}{*}{$1 \%(\# 1)$} & 29.6 & 20.3 & 0.000 & 0.15 & 0.57 & 28.9 & Not Computed \\
\hline & \%Sorbed: & $31 \%$ & $0 \%$ & $1 \%$ & $2 \%$ & $98 \%$ & Not Computed \\
\hline \multirow{2}{*}{$1 \%(\# 2)$} & 29.9 & 20.2 & 0.000 & 0.09 & 0.56 & 29.2 & Not Conputed \\
\hline & \%Sorbed: & $32 \%$ & $0 \%$ & $0 \%$ & $2 \%$ & $98 \%$ & Not Computed \\
\hline \multirow{2}{*}{ 3\% (\#1) } & 29.7 & 17.7 & 0.000 & 0.06 & 0.49 & 29.2 & Not Computed \\
\hline & \%Sorbed: & $41 \%$ & $0 \%$ & $0 \%$ & $2 \%$ & $98 \%$ & Not Conputed \\
\hline \multirow{2}{*}{$3 \%(\# 2)$} & 30.0 & 19.1 & 0.000 & 0.06 & 0.52 & 29.4 & Not Computed \\
\hline & \%Sorbed: & $36 \%$ & $0 \%$ & $0 \%$ & $2 \%$ & $98 \%$ & Not Compute- \\
\hline
\end{tabular}

a. Total Initial for slurries computed using the average initial aqueous TCE concentration of the GW control samples (Avg= 80,565 $\mu \mathrm{g} / \mathrm{L}, \sigma=1,330 \mu \mathrm{g} / \mathrm{L}$ ). For $\mathrm{GW}$ controls, Total Initial =Initial Aqueous.

TCE oxidized $=$ Total Initial- Orbo Tube - Final Remaining- Cum. Aliquot.

Table 72. $\mathrm{MnO}_{4}{ }^{-}$Consumption Data for ORNL Exp. 4b-R12 (TSF-05 GW \& Sludge).

\begin{tabular}{|c|c|l|l|l|}
\hline Test Condition & $\begin{array}{l}\text { Initial } \\
\text { Oxidant } \\
\left(\mathrm{mg} \mathrm{MnO}_{4}\right)\end{array}$ & $\begin{array}{l}\text { Initial } \\
\mathrm{Loading}^{\prime} \\
\left(\mathrm{mg} \mathrm{MnO}_{4} / \mathrm{g}\right)\end{array}$ & $\begin{array}{l}\text { Cum. } \\
\text { Consumed } \\
\left.\left(\mathrm{mg} \mathrm{MnO}_{4}\right)^{-}\right)\end{array}$ & $\begin{array}{l}\text { Cum. } \\
\text { Consumed } \\
\left(\mathrm{mg} \mathrm{MnO}_{4} / \mathrm{g}\right)\end{array}$ \\
\hline $1 \%(\# 1)$ & 3660 & 8.1 & 3660 & 8.1 \\
\hline $1 \%(\# 2)$ & 3691 & 8.1 & 3461 & 7.6 \\
\hline $3 \%(\# 1)$ & 11124 & 24.7 & 7021 & 15.6 \\
\hline $3 \%(\# 2)$ & 11200 & 24.7 & 6351 & 14.0 \\
\hline
\end{tabular}

a. Consumption is computed after $24 \mathrm{hr}$ reaction time. 
ORNL Exp. 4b-R13

(TSF-05, Sludge, DNAPL TCE, 0 Other, $0.01 \%$ and $0.1 \% \mathrm{MnO}_{4}{ }^{-}$)

This experiment investigated the oxidation of TSF-05 GW and sludge spiked at DNAPL TCE levels; i.e., the groundwater was spiked at $\approx 2 \times 10^{6} \mu \mathrm{g} / \mathrm{L} \mathrm{TCE}$ so that a saturated aqueous solution was created.

The TCE, $\mathrm{MnO}_{4}{ }^{-}$and $\mathrm{pH}$ values with time are presented in Figures 107, 108, and 109, respectively. Tables 73 and 74 provide additional TCE mass balance and oxidant consumption information. The (\#1) and (\#2) notations included in both the figure legends and the first column of these tables refer to the duplicate reactors evaluated for that test condition. Note that some of the columns in the mass balance table were computed differently than the method described at the beginning of Section 2.4.4. The deviations to this computational approach are clearly defined in the upcoming discussion of this experiment.

As presented in the testplan, a single TCE spiking solution could not be made and then subsequently distributed among the test reactors for the DNAPL experiments. Instead, a known mass (gravimetric determination) of pure TCE was added directly to each reactor and allowed to equilibrate at $12^{\circ} \mathrm{C}$ with the TSF-05 sludge. Since the initial target TCE concentration $\left(2 \times 10^{6}\right.$ $\mu \mathrm{g} / \mathrm{L}$ ) was $\approx$ twice the aqueous solubility of TCE, a non-aqueous TCE phase (i.e., DNAPL) was expected to exist within each reactor.

The experiment was conducted according to the testplan procedure, with the exception that the reaction period was extended from $24 \mathrm{hrs}$ to $120 \mathrm{hrs}$.

At the $\mathrm{T}=0$ time period, the aqueous $\mathrm{TCE}$ concentrations within the six reactors were indeed indicative of TCE saturation. The TSF-05 GW controls exhibited an average initial aqueous TCE concentration of $1,312,000 \mu \mathrm{g} / \mathrm{L}(\sigma=32,060 \mu \mathrm{g} / \mathrm{L})$. The four treatment reactors containing the TSF-05 sludge slurries experienced TCE concentrations on the order of $665,000 \mu \mathrm{g} / \mathrm{L}(\sigma=$ $61,400 \mu \mathrm{g} / \mathrm{L}$ ) after the overnight equilibration period. Due to the spiking approach used, the reactors could potentially have very different total initial TCE masses. There was no means of obtaining the total initial TCE mass in each reactor following equilibration (i.e., at the $\mathrm{T}=0 \mathrm{hrs}$ sampling period). Thus, the gravimetric spiking data was used to compute the total initial TCE mass present in each reactor with the gross assumption that no TCE was volatilized during equilibration (Table 73, Column 2).

Using this approach, the data suggests that approximately $36 \%$ of the TCE initially present in the GW controls existed as DNAPL. Similarly, 65-70\% of the initial TCE within the treatment reactors would have either been adsorbed to the sludge and/or present in the reactors as DNAPL.

Little variation in the aqueous concentration of the GW control reactors was observed during the experiment. In fact, the average aqueous TCE concentration for all of the control reactor aliquots during the $120 \mathrm{hr}$ reaction time was $1,250,000 \mu \mathrm{g} / \mathrm{L}(\sigma=57,200 \mu \mathrm{g} / \mathrm{L})$. This was expected since the presence of a DNAPL phase in the reactors enables continuous TCE saturation of the aqueous phase. Thus, TCE losses from the control reactors could not be obtained via simple evaluation of the aqueous TCE concentrations with time. To accurately 
compute the TCE recoveries for the control reactors, each was extracted at the end of the reaction period with a known volume of hexane $(1: 1 \mathrm{v} / \mathrm{v}$ extraction). Adding the TCE quantities of each mass balance component listed in Table 73 yielded total TCE recoveries of $74 \%$ and $76 \%$ for the first and second TSF- $05 \mathrm{GW}$ control reactors. It is expected that the majority of this $25 \%$ loss occurred during the overnight equilibration period when the reactors were sealed with the glass stoppers. (Recall that all recoveries for this DNAPL experiment are based on the initial TCE mass added to each reactor before equilibration and rather than a value obtained after equilibration; i.e., the $\mathrm{T}=0 \mathrm{hrs}$ sampling point) This estimated $25 \%$ loss during equilibration is comparable to that observed during equilibration of all the experiments performed during this treatability study.

Apparent TCE oxidation during at least the early portion of the reaction period is observed in Figure 107. As evidenced in Figure 108 and in Table 74, complete consumption of $\mathrm{MnO}_{4}{ }^{-}$ occurred within the first $0.5 \mathrm{hrs}$. It is interesting to note that aqueous TCE in the treatment reactors was initially less than aqueous saturation due to the large sorption capacity of highly organic TSF-05 sludge. However, there was a gradual increase in aqueous TCE for the treatment reactors to aqueous saturation levels following the rapid oxidation reaction that occurred. This increase is attributed to (1) pure phase TCE (not sorbed to the sludge) remaining in the reactors being solubilized and/or (2) the dissolution of TCE originally sorbed onto the sludge once the sludge as a result of the sludge itself being oxidized.

Since all oxidant was consumed quickly, the TCE oxidized mass presented in Table 73 , Column 7 for each reactor represents the change in TCE mass associated with the difference in aqueous TCE concentration between $0-0.5 \mathrm{hrs}$. Using this approach, essentially no TCE is removed from the $0.01 \% \mathrm{MnO}_{4}{ }^{-}$reactors, and approximately $50-100 \mathrm{mg}$ of TCE were oxidized from the $0.1 \%$ $\mathrm{MnO}_{4}{ }^{-}$reactors. In contrast, averages of $40 \mathrm{mg}$ TCE and $193 \mathrm{mg}$ TCE were oxidized from the $0.01 \%$ and $0.1 \% \mathrm{MnO}_{4}{ }^{-}$reactors of Exp. $4 \mathrm{~b}-\mathrm{R} 7$, where TSF-05 GW was evaluated in the absence of TSF-05 sludge. Via comparison of these two experiments, the reduced TCE oxidation values may be a direct result of competition by the TSF- 05 sludge for the available oxidant.

Since oxidation depletion likely occurred before the $0.5 \mathrm{hr}$ sampling point, the true aqueous TCE mass oxidized cannot be determined. (At the point of oxidant depletion, the reactors would have reached their lowest initial aqueous TCE concentration before the subsequent rise in aqueous TCE concentrations due to TCE DNAPL dissolution.) Thus, the low values obtained for the total aqueous TCE mass oxidized (Table 73, Column 7) may be due to the inability to quantify all of the TCE oxidation that was occurring.

The computation of reaction rates was not attempted for this experiment since the use of $0.01 \%$ and $0.1 \% \mathrm{MnO}_{4}{ }^{-}$loadings do not adequately satisfy the oxidant demand of the TCE contaminated sludge.

Finally, the total TCE recoveries determined for the treatment reactors were in the range of 75\%$80 \%$ and were very comparable to that obtained by the GW control reactors. Again, it is assumed that the majority of this unaccounted for TCE $(\approx 25 \%)$ was lost during contaminant equilibration and cannot be explicitly determined or verified with the approach used to spike these reactors. 
As mentioned above, the $\mathrm{MnO}_{4}{ }^{-}$was quickly consumed in all treatment reactors within $0.5 \mathrm{hrs}$. The apparent rise in $\mathrm{MnO}_{4}{ }^{-}$concentrations at the $120 \mathrm{hr}$ sampling period is likely caused by the breakdown of the sludge after such a long agitation period. As observed in other TSF-05 sludge experiments, the aqueous samples and hexane extracts collected after more than $6 \mathrm{hrs}$ were yellow in color. This "yellowing" likely biased the colorimetric $\mathrm{MnO}_{4}{ }^{-}$analyses.

Figure 109 indicates some initial $\mathrm{pH}$ reductions as the oxidation of the sludge and/or TCE occurs. However, following oxidant depletion, the $\mathrm{pH}$ values of the treatment reactors begin to increase. Net $\mathrm{pH}$ increases of approximately 0.5 and $1.2 \mathrm{pH}$ units were observed for the $0.01 \%$ and $0.1 \% \mathrm{MnO}_{4}{ }^{-}$reactors, respectively. Higher $\mathrm{pH}$ 's for $0.1 \% \mathrm{MnO}_{4}{ }^{-}$reactors is likely due to the fact that more of the sludge was oxidized in these reactors. Because less sludge is present after oxidation, the contribution of the $\mathrm{GW}$ in the $\mathrm{pH}$ of the slurry may now be more significant. 


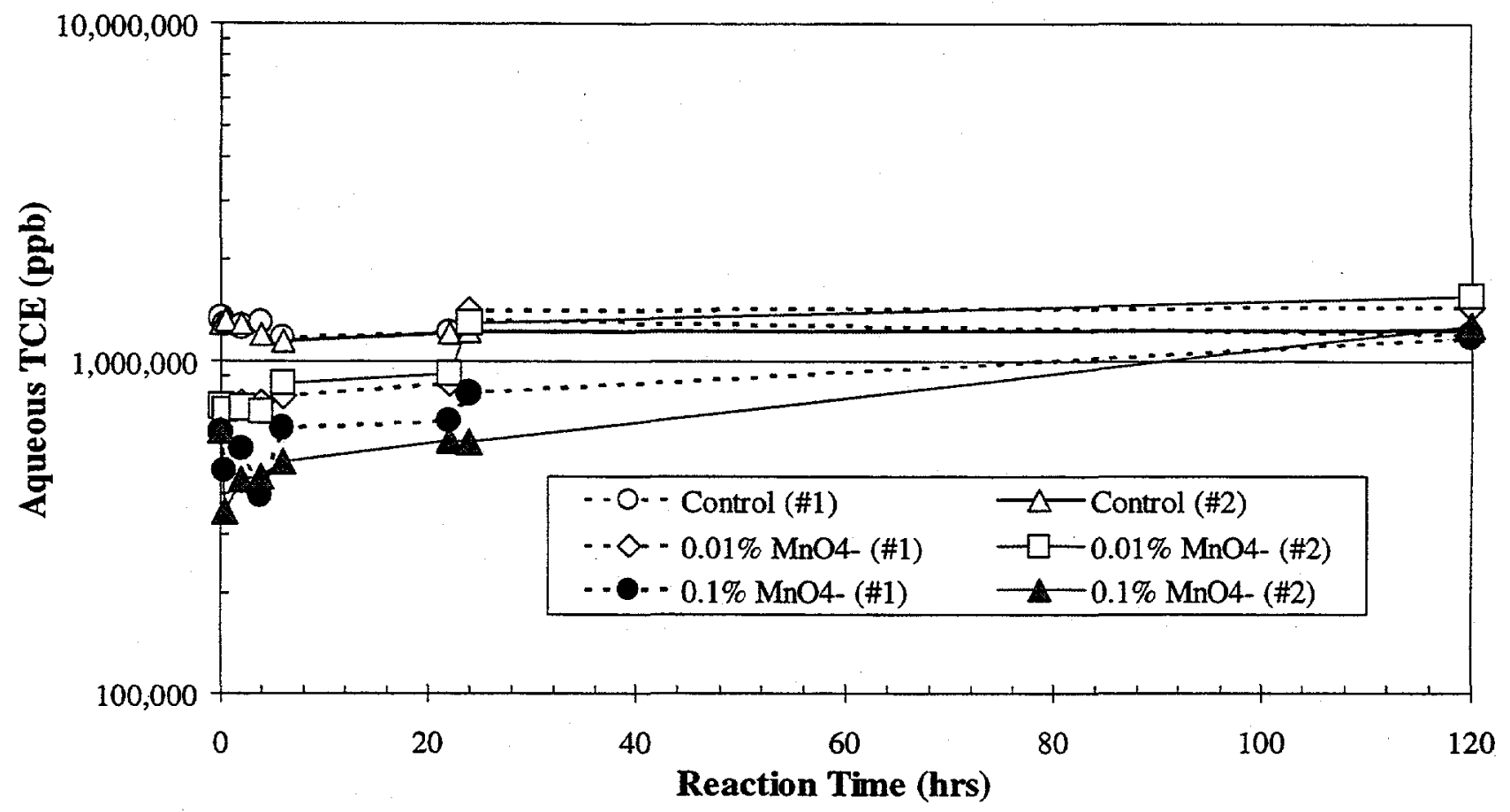

Figure 107. TCE vs. Time, TSF-05 GW \& Sludge, (ORNL Exp. 4b-R13, Initial TCE= DNAPL, Conducted at $12^{\circ} \mathrm{C}, 4: 1 \mathrm{~L} / \mathrm{S}$ Ratio)

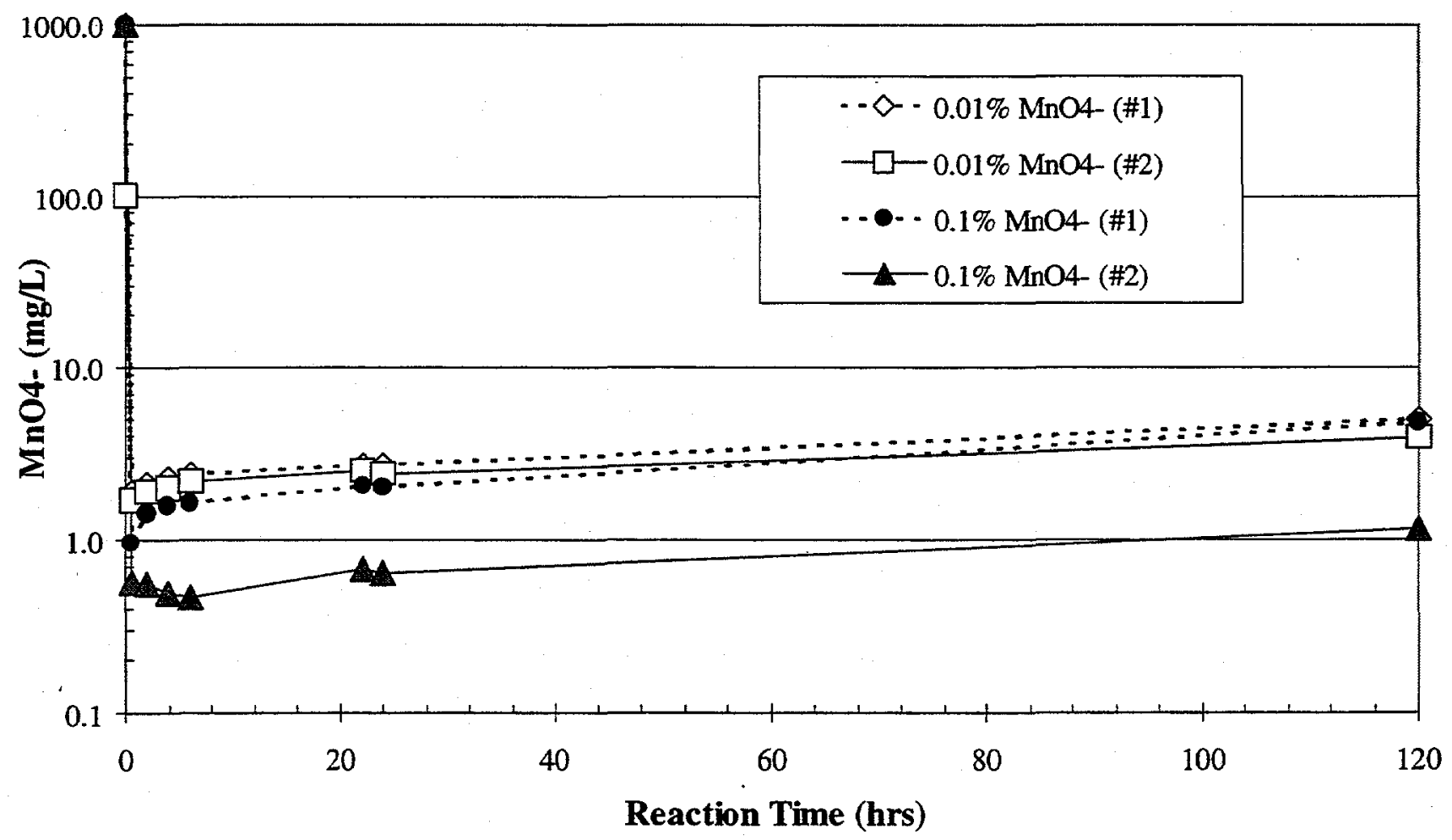

Figure 108. $\mathrm{MnO}_{4}{ }^{-}$vs. Time, TSF-05 GW \& Sludge, (ORNL Exp. 4b-R13, Initial TCE= DNAPL, Conducted at $12^{\circ} \mathrm{C}, 4: 1 \mathrm{~L} / \mathrm{S}$ Ratio) 


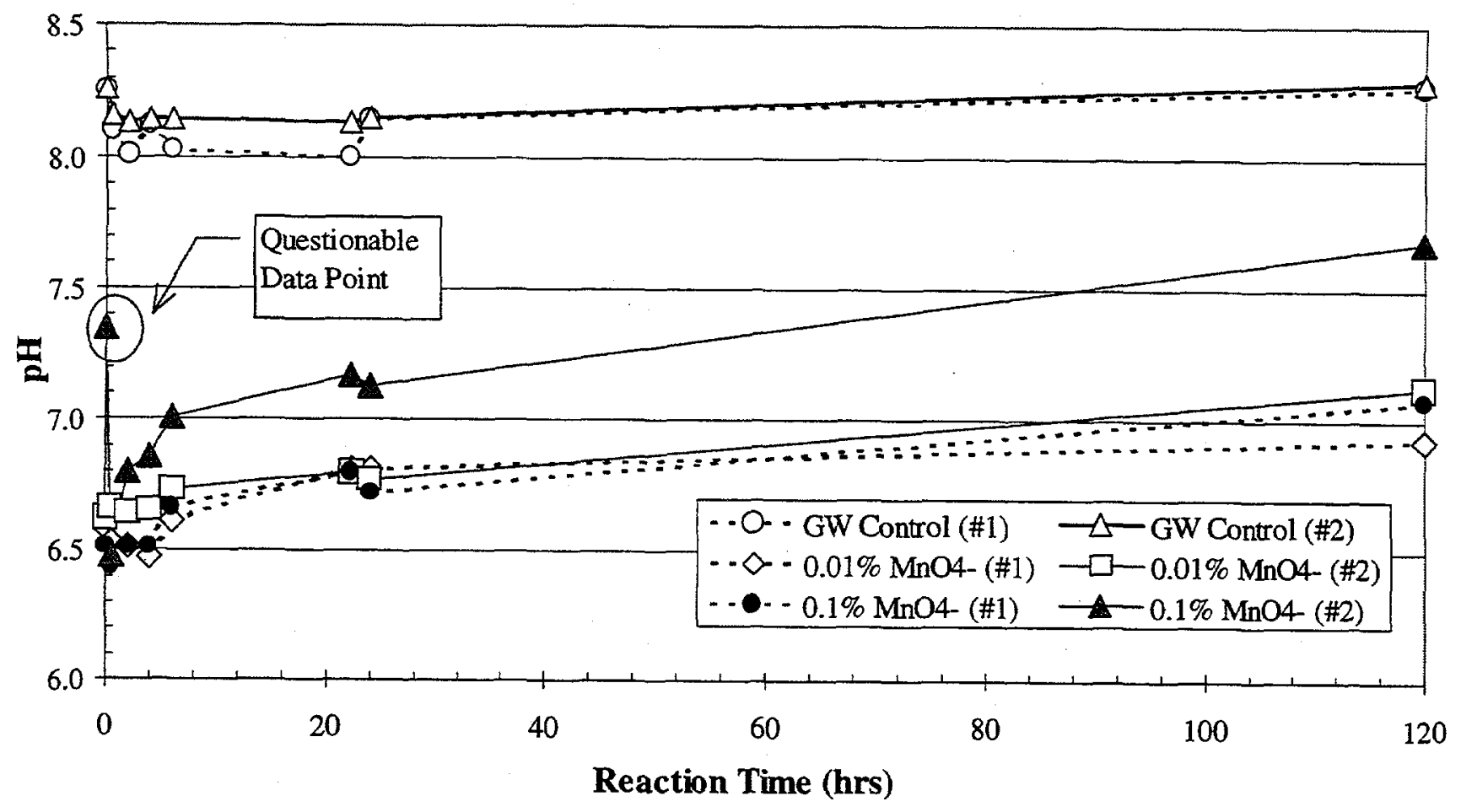

Figure 109. pH vs. Time, TSF-05 GW \& Sludge, (ORNL Exp. 4b-R13, Initial TCE= DNAPL, Conducted at $12^{\circ} \mathrm{C}, 4: 1 \mathrm{~L} / \mathrm{S}$ Ratio) 
Table 73. TCE Mass Balance for ORNL Exp. 4b-R13 (TSF-05 GW \& Sludge). ${ }^{a}$

\begin{tabular}{|c|c|c|c|c|c|c|c|}
\hline Test Condition & \begin{tabular}{|l|} 
Total \\
Initial \\
Mass \\
(mg)
\end{tabular} & $\begin{array}{l}\text { Initial } \\
\text { Aqueous } \\
\text { Mass } \\
\text { (mg) }\end{array}$ & \begin{tabular}{|l|} 
Mass \\
Sorbed on \\
Orbo Tubes \\
(mg)
\end{tabular} & \begin{tabular}{|l|} 
Mass \\
Remaining in \\
Reactor (mg)
\end{tabular} & \begin{tabular}{|l|} 
Cum. \\
Mass \\
Removed \\
in Aliquots \\
(mg) \\
\end{tabular} & $\begin{array}{l}\text { TCE } \\
\text { Oxidized }\end{array}$ & $\begin{array}{l}\text { Total Mass } \\
\text { Recovered } \\
\text { (mg) }\end{array}$ \\
\hline \multirow{2}{*}{ Control (\#1) } & 751 & 480 & 2.20 & 425 & 127 & $\mathrm{NA}$ & 555 \\
\hline & & & $0 \%$ & $57 \%$ & $17 \%$ & NA & $74 \%$ \\
\hline \multirow{2}{*}{ Control (\#2) } & 727 & 467 & 0.43 & 424 & 124 & NA & 549 \\
\hline & & & $0 \%$ & $58 \%$ & $17 \%$ & NA & $76 \%$ \\
\hline \multirow{2}{*}{$0.01 \%(\# 1)$} & 736 & 256 & 0.42 & 475 & 81 & -2 & 556 \\
\hline & \%Non-Aq: & $65 \%$ & $0 \%$ & $65 \%$ & $11 \%$ & $0 \%$ & $75 \%$ \\
\hline \multirow{2}{*}{$0.01 \%(\# 2)$} & 721 & 266 & 0.48 & 485 & 82 & 8 & 576 \\
\hline & \%Non-Aq: & $63 \%$ & $0 \%$ & $67 \%$ & $11 \%$ & $1 \%$ & $80 \%$ \\
\hline \multirow{2}{*}{$0.1 \%(\# 1)$} & 728 & 225 & 0.74 & 438 & 59 & 55 & 553 \\
\hline & \%Non-Aq: & $69 \%$ & $0 \%$ & $60 \%$ & $8 \%$ & $8 \%$ & $76 \%$ \\
\hline \multirow[t]{2}{*}{$0.1 \%(\# 2)$} & 725 & 221 & 0.04 & 408 & 53 & 95 & 556 \\
\hline & | $\%$ Non-Aq: & $70 \%$ & $0 \%$ & $56 \%$ & $7 \%$ & $13 \%$ & $77 \%$ \\
\hline
\end{tabular}

a. Total Initial is assumed to be the actual DNAPL TCE mass added to each reactor. TCE oxidized only includes mass associated with the difference in the aqueous TCE concentrations between 0-0.5 hrs (Does not take non-aqueous phase TCE into account)

Table 74. $\mathrm{MnO}_{4}{ }^{-}$Consumption Data for ORNL Exp. 4b-R13 (TSF-05 GW \& Sludge).

\begin{tabular}{|l|l|l|l|l|}
\hline Test Condition & $\begin{array}{l}\text { Initial } \\
\text { Oxidant } \\
\left.\left(\mathrm{mg} \mathrm{MnO}_{4}\right)^{-}\right)\end{array}$ & $\begin{array}{l}\text { Initial } \\
\begin{array}{l}\text { Loading } \\
\left(\mathrm{mg} \mathrm{MnO}_{4}^{-} / \mathrm{g}\right)\end{array}\end{array}$ & $\begin{array}{l}\text { Cum. } \\
\text { Consumed } \\
\left.\left(\mathrm{mg} \mathrm{MnO}_{4}\right)^{-}\right)\end{array}$ & $\begin{array}{l}\text { Cum. } \\
\text { Consumed } \\
\left(\mathrm{mg} \mathrm{MnO}_{4} / \mathrm{g}\right)\end{array}$ \\
\hline $0.01 \%(\# 1)$ & 36.6 & 0.08 & 35.6 & 0.08 \\
\hline $0.01 \%(\# 2)$ & 36.1 & 0.08 & 35.2 & 0.08 \\
\hline $0.1 \%(\# 1)$ & 366.5 & 0.80 & 365.8 & 0.80 \\
\hline $0.1 \%(\# 2)$ & 358.6 & 0.80 & 358.3 & 0.80 \\
\hline
\end{tabular}

a. Consumption is computed after a $120 \mathrm{hr}$ reaction time. 
ORNL Exp. 4b-R14

(TSF-05, Sludge, DNAPL TCE, 0 Other, $1 \%$ and $3 \% \mathrm{MnO}_{4}{ }^{-}$)

This experiment investigated the oxidation of TSF-05 GW and sludge spiked at DNAPL TCE levels; i.e., the groundwater was spiked at $\approx 2 \times 10^{6} \mu \mathrm{g} / \mathrm{L}$ TCE so that a saturated aqueous solution was created.

The TCE, $\mathrm{MnO}_{4}{ }^{-}$and $\mathrm{pH}$ values with time are presented in Figures 110, 111, and 112, respectively. Tables 75 and 76 provide additional TCE mass balance and oxidant consumption information. The (\#1) and (\#2) notations included in both the figure legends and the first column of these tables refer to the duplicate reactors evaluated for that test condition. Note that some of the columns in the mass balance table were computed differently than the method described at the beginning of Section 2.4.4. The deviations to this computational approach are clearly defined in the upcoming discussion of this experiment.

As presented in the testplan, a single TCE spiking solution could not be made and then subsequently distributed among the test reactors for the DNAPL experiments. Instead, a known mass (gravimetric determination) of pure TCE was added directly to each reactor and allowed to equilibrate at $12^{\circ} \mathrm{C}$ with the TSF-05 sludge. Since the initial target TCE concentration $\left(2 \times 10^{6}\right.$ $\mu \mathrm{g} / \mathrm{L}$ ) was $\approx$ twice the aqueous solubility of TCE, a non-aqueous TCE phase (i.e., DNAPL) was expected to exist within each reactor.

The experiment was conducted according to the testplan procedure, with the exception that the reaction period was extended from $24 \mathrm{hrs}$ to $120 \mathrm{hrs}$.

At the $\mathrm{T}=0$ time period, the aqueous $\mathrm{TCE}$ concentrations within the six reactors were indeed indicative of TCE saturation. The TSF-05 GW controls exhibited an average initial aqueous TCE concentration of $1,274,000 \mu \mathrm{g} / \mathrm{L}(\sigma=45,060 \mu \mathrm{g} / \mathrm{L})$. The four treatment reactors containing the TSF-05 sludge slurries experienced TCE concentrations on the order of $757,000 \mu \mathrm{g} / \mathrm{L}(\sigma=$ $24,430 \mu \mathrm{g} / \mathrm{L}$ ) after the overnight equilibration period. Due to the spiking approach used, the reactors could potentially have very different initial TCE masses. There was no means of obtaining the total TCE mass in each reactor following equilibration (i.e., at the $\mathrm{T}=0 \mathrm{hrs}$ sampling period). Thus, the gravimetric spiking data was used to compute the total initial TCE mass present in each reactor with the gross assumption that no TCE was volatilized during equilibration (Table 75, Column 2).

Using this approach, the data suggests that approximately $40 \%$ of the TCE initially present in the GW controls existed as DNAPL. Similarly, $\approx 62 \%$ of the initial TCE. within the treatment reactors would have either been adsorbed to the sludge and/or present in the reactors as DNAPL.

Little variation in the aqueous concentration of the GW control reactors was observed during the experiment. In fact, the average aqueous TCE concentration for all of the control reactor aliquots during the $120 \mathrm{hr}$ reaction time was $1,252,000 \mu \mathrm{g} / \mathrm{L}(\sigma=57,280 \mu \mathrm{g} / \mathrm{L})$. This was expected since the presence of a DNAPL phase in the reactors enables continuous TCE saturation of the aqueous phase. Thus, TCE losses from the control reactors could not be obtained via simple evaluation of the aqueous TCE concentrations with time. To accurately 
compute the TCE recoveries for the control reactors, each was extracted at the end of the reaction period with a known volume of hexane (1:1 v/v extraction). Adding the TCE quantities of each mass balance component listed in Table 75 yielded total TCE recoveries of $79 \%$ and $72 \%$ for the first and second TSF-05 GW control reactors. It is expected that the majority of this 20-25\% loss occurred during the overnight equilibration period when the reactors were sealed with the glass stoppers. (Recall that all recoveries for this DNAPL experiment are based on the initial TCE mass added to each reactor before equilibration and rather than a value obtained after equilibration; i.e., the $\mathrm{T}=0 \mathrm{hrs}$ sampling point) This estimated $25 \%$ loss during equilibration is comparable to that observed during equilibration of all the experiments performed during this treatability study.

Reductions in aqueous TCE concentrations were observed for all treatment reactors. The aqueous TCE concentration data was more variable for the $1 \% \mathrm{MnO}_{4}{ }^{-}$reactors. Complete oxidation was not observed for the $1 \% \mathrm{MnO}_{4}$ reactors. (TCE was observed in both the aqueous aliquot at $\mathrm{T}=120 \mathrm{hrs}$ and in the final reactor extractions.) However, there was a gradual increase in aqueous TCE for the $1 \% \mathrm{MnO}_{4}{ }^{-}$treatment reactors which ultimately approached aqueous saturation levels following the rapid oxidation reaction that occurred. This increase is attributed to (1) pure phase TCE (not sorbed to the sludge) remaining in the reactors being solubilized and/or (2) the dissolution of TCE originally sorbed onto the sludge once the sludge itself is oxidized. The computation of a reaction rate was not attempted for the $1 \% \mathrm{MnO}_{4}{ }^{-}$reactors since this loading does not adequately satisfy the oxidant demand of the TCE contaminated sludge.

Due to the fluctuations observed in the $1 \% \mathrm{MnO}_{4}{ }^{-}$aqueous TCE concentrations, the "oxidized" component of the TCE mass balance in Table 75, Column 7 was computed differently in this experiment. This value represents the maximum observed aqueous TCE mass oxidized during the course of aliquot sampling. Using this approach, an average of $265 \mathrm{mg}$ of TCE is oxidized $36 \%$ ) from the aqueous phase from the $1 \% \mathrm{MnO}_{4}{ }^{-}$reactors. These values are similar to the initial mass predicted to be in the aqueous phase at $\mathrm{T}=0$ (Table 75 , Column 3 ). It is expected that oxidation of some TCE originally present as non-aqueous phase TCE also occurred for the $1 \%$ reactors. (Unlike treatment reactors in Exp. 4b-R13, the final aqueous concentrations at $\mathrm{T}=120$ hrs for the $1 \% \mathrm{MnO}_{4}{ }^{-}$reactors were less than the aqueous TCE saturation value of $\approx 1,100,000$ $\mu \mathrm{g} / \mathrm{L}$.) Unfortunately, better estimates of the amount of non-aqueous phase TCE that was oxidized in the $1 \% \mathrm{MnO}_{4}{ }^{-}$reactors cannot be obtained since it is unknown how much of the initial total TCE was loss to volatilization during equilibration (20-25\% for the GW control reactors).

Complete TCE is indicated for the $3 \% \mathrm{MnO}_{4}{ }^{-}$reactors, in which no detectable TCE was observed in the post-treatment extractions of these reactors. For the $3 \%$ reactors, an average of $270 \mathrm{mg}$ of TCE is oxidized from the aqueous phase (Table 75, Column 7). These values are similar to the initial mass predicted to be in the aqueous phase at $\mathrm{T}=0$ (Table 75, Column 3 ). Of course, this value does not take into account the non-aqueous TCE mass that was oxidized.

It is plausible to assume that complete TCE oxidation of the total initial TCE mass for the 3\% $\mathrm{MnO}_{4}{ }^{-}$reactors occurred within $2 \mathrm{hrs}$. (The $2 \mathrm{hrs}$ estimate was determined by extrapolating the initially rapid portion of the curves in Figure 110 to a concentration of $1 \mu \mathrm{g} / \mathrm{L} \mathrm{TCE}$.) Hence, an observed zero order oxidation rate of approximately $730 \mathrm{mg} \mathrm{TCE} / \mathrm{hr}$ is obtained for the $3 \%$ 
$\mathrm{MnO}_{4}$ reactors. The actual rate may be less since some $(\approx 20-25 \%)$ of the initial TCE mass (Table 75, Column 2) added to the reactors was likely volatilized during the equilibration step. Although the TCE sample data from $\mathrm{T}=0.5$ through $\mathrm{T}=24 \mathrm{hrs}$ are questionable due to samples dilution problems, a first order reaction rate constant of $\mathrm{k}=4.1 \mathrm{hr}^{-1}$ was computed for the second $3 \% \mathrm{MnO}_{4}{ }^{-}$reactor and is presented in Figure 113.

The TCE observations correspond well with the $\mathrm{MnO}_{4}{ }^{-}$data. As evidenced in Figure 111 and in Table 76, complete consumption of $\mathrm{MnO}_{4}{ }^{-}$occurred within the first 6-10 hrs for the $1 \% \mathrm{MnO}_{4}{ }^{-}$ reactors, and a residual oxidant was still present in the $3 \% \mathrm{MnO}_{4}{ }^{-}$reactors at $\mathrm{T}=120 \mathrm{hrs}$. For the two $3 \% \mathrm{MnO}_{4}{ }^{-}$reactors, an average oxidant consumption value of $64 \%$ was observed (see Table 76). The apparent rise in $\mathrm{MnO}_{4}{ }^{-}$concentrations at the $120 \mathrm{hr}$ sampling period is likely caused by the breakdown of the sludge after such a long agitation period. As observed in other TSF-05 sludge experiments, the aqueous samples and hexane extracts collected after more than $6 \mathrm{hrs}$ were yellow in color. This "yellowing" likely biased the colorimetric $\mathrm{MnO}_{4}{ }^{-}$analyses.

Figure 112, indicates initial $\mathrm{pH}$ reductions on the order of $1 \mathrm{pH}$ unit or less as oxidation of the sludge and/or TCE occurs. The $\mathrm{pH}$ values of the treatment reactors begin to increase after the initial reaction. In fact, net $\mathrm{pH}$ increases of less than $0.5 \mathrm{pH}$ units were observed for both the $1 \%$ and 3\% reactors. It is interesting that these net increases are smaller in magnitude than those observed in the DNAPL sludge experiment evaluating 0.01\% and $0.1 \% \mathrm{MnO}_{4}{ }^{-}$(Exp. 4b-R13). The difference is likely because significantly more TCE was oxidized in this experiment, thereby producing more $\mathrm{H}^{+}$as a reaction product. Thus, the net $\mathrm{pH}$ increases expected (and observed in Exp. 4b-R13) due to oxidation of the sludge were offset by the destruction of TCE. 


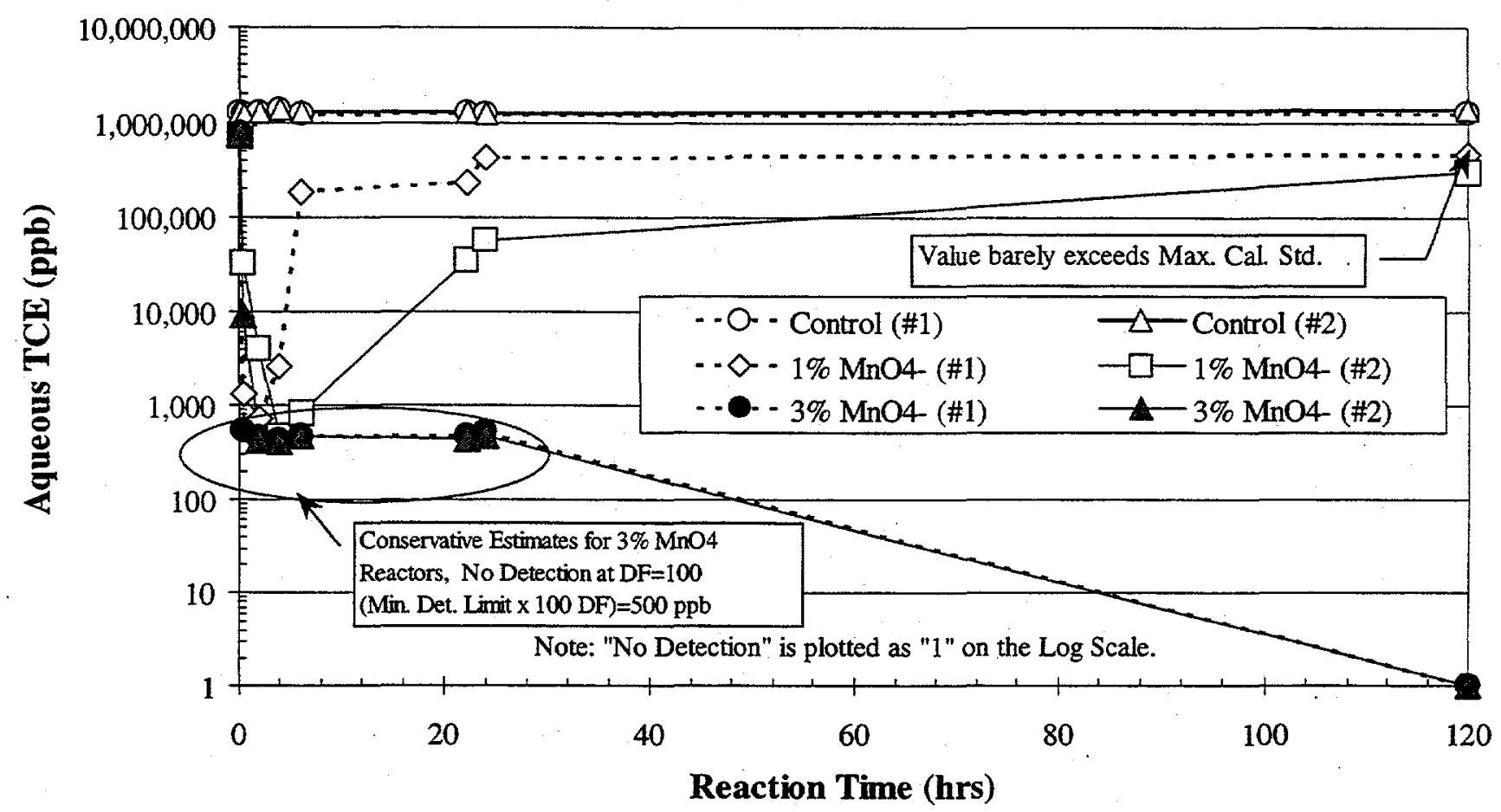

Figure 110. TCE vs. Time, TSF-05 GW \& Sludge, (ORNL Exp. 4b-R14, Initial TCE= DNAPL, Conducted at $12^{\circ} \mathrm{C}, 4: 1 \mathrm{~L} / \mathrm{S}$ Ratio)

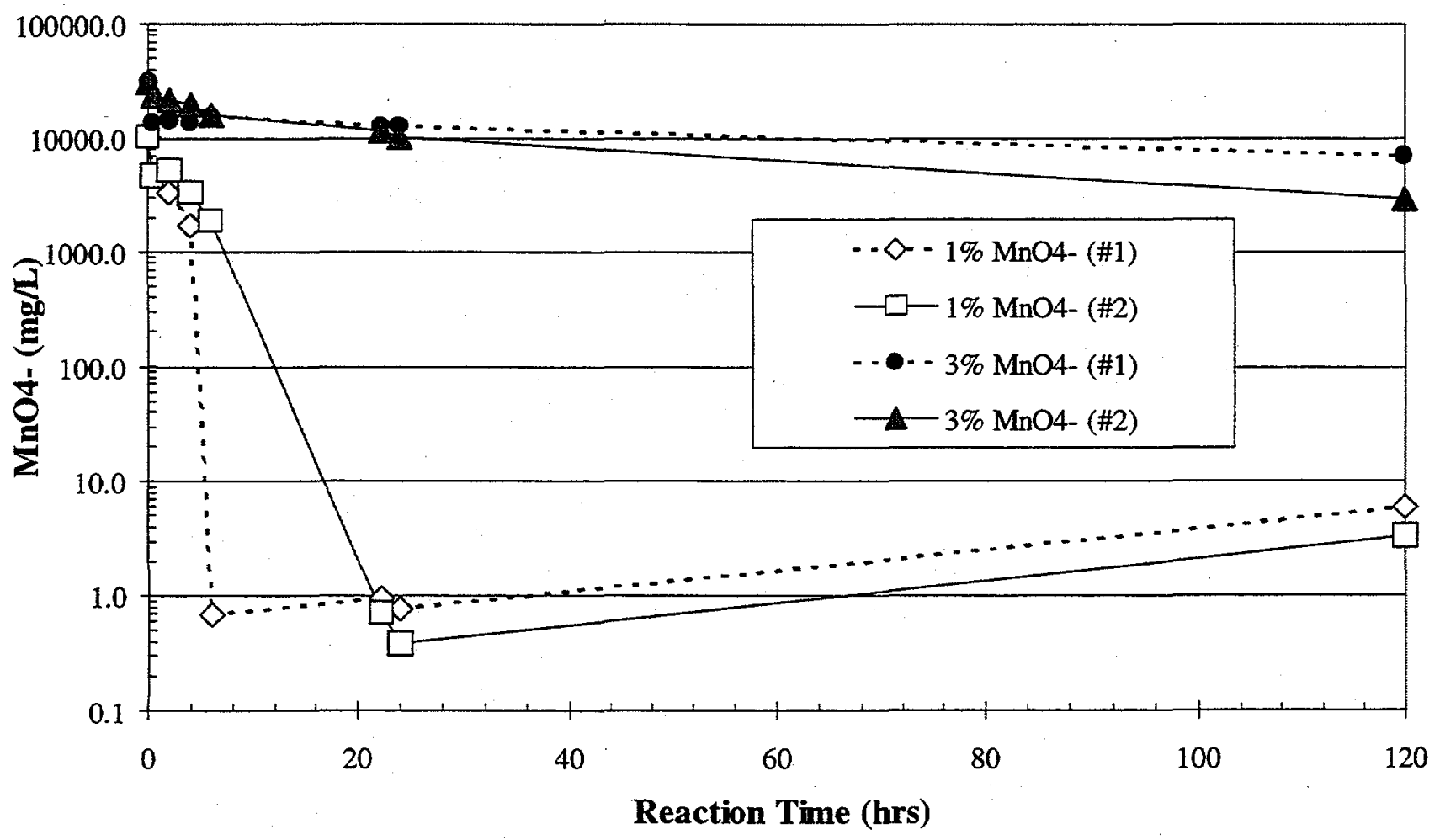

Figure 111. $\mathrm{MnO}_{4}{ }^{-}$vs. Time, TSF-05 GW \& Sludge, (ORNL Exp. 4b-R14, Initial TCE= DNAPL, Conducted at $12^{\circ} \mathrm{C}, 4: 1 \mathrm{~L} / \mathrm{S}$ Ratio) 


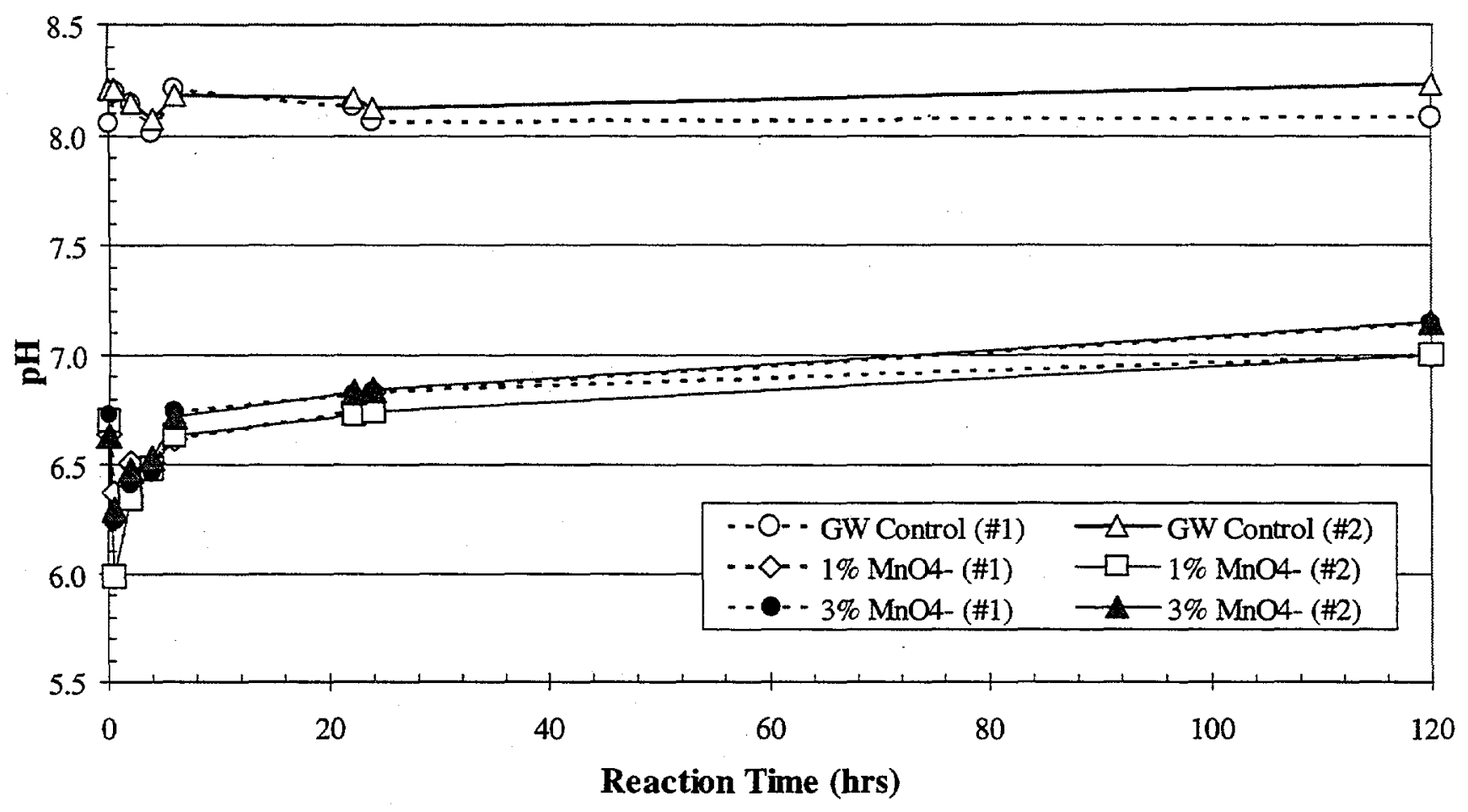

Figure 112. pH vs. Time, TSF-05 GW \& Sludge, (ORNL Exp. 4b-R14, Initial TCE= DNAPL, Conducted at $12^{\circ} \mathrm{C}, 4: 1 \mathrm{~L} / \mathrm{S}$ Ratio)

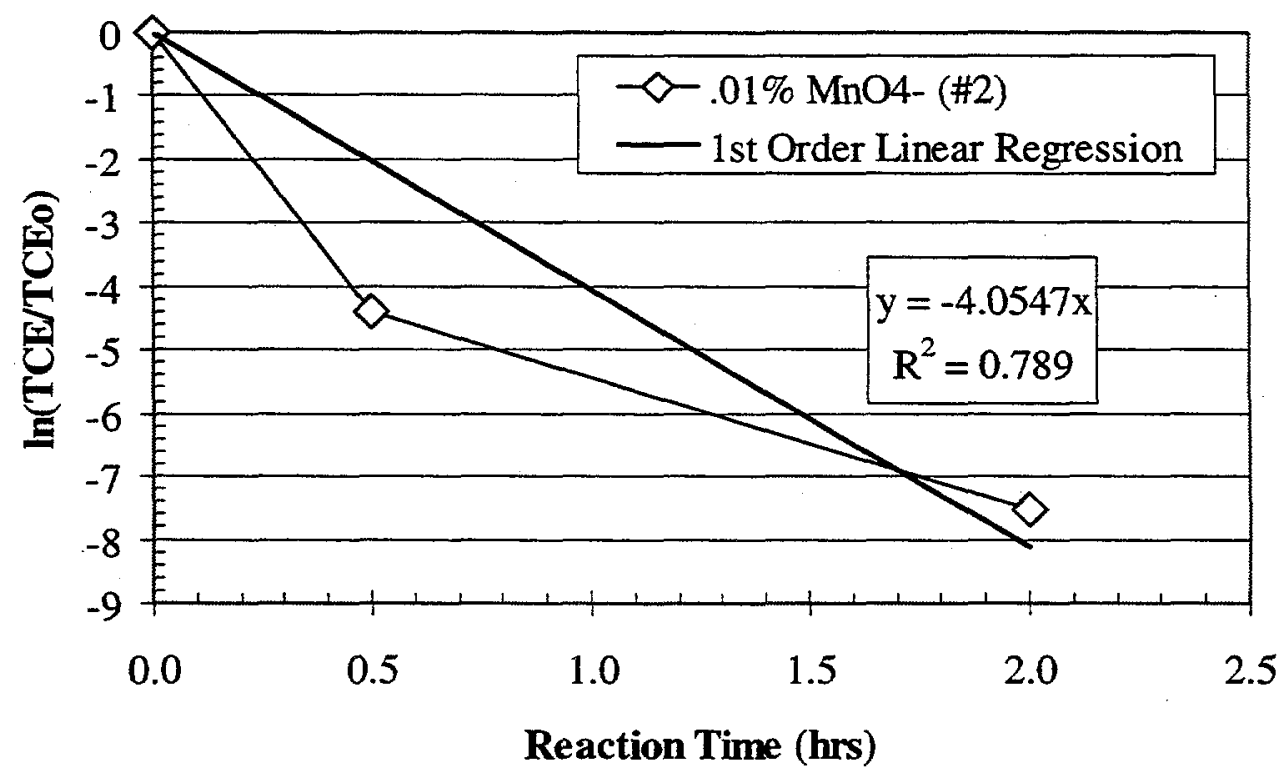

Figure 113. First Order TCE Oxidation Rate Constant for the $3 \% \mathrm{MnO}_{4}{ }^{-}$(\#2) Reactor, TSF-05 GW \& Sludge, (ORNL Exp. 4b-R14, Initial TCE= DNAPL, Conducted at $12^{\circ} \mathrm{C}, 4: 1$ L/S Ratio) 
Table 75. TCE Mass Balance for ORNL Exp. 4b-R14 (TSF-05 GW \& Sludge). ${ }^{\text {a. }}$

\begin{tabular}{|c|c|c|c|c|c|c|c|}
\hline Test Condition & $\begin{array}{l}\text { Total } \\
\text { Initial } \\
\text { Mass } \\
\text { (mg) }\end{array}$ & \begin{tabular}{|l} 
Initial \\
Aqueous \\
Mass \\
(mg)
\end{tabular} & \begin{tabular}{|l|} 
Mass \\
Sorbed on \\
Orbo Tubes \\
(mg)
\end{tabular} & $\begin{array}{l}\text { Mass } \\
\text { Remaining in } \\
\text { Reactor (mg) }\end{array}$ & \begin{tabular}{|l|} 
Cum. \\
Mass \\
Removed \\
in Aliquots \\
(mg)
\end{tabular} & $\begin{array}{l}\text { MAX. } \\
\text { Cum Aq. } \\
\text { Oxidized }\end{array}$ & $\begin{array}{l}\text { Total Mass } \\
\text { Recovered } \\
\text { (mg) }\end{array}$ \\
\hline \multirow{2}{*}{ Control (\#1) } & \multirow[t]{2}{*}{734} & \multirow[t]{2}{*}{447} & 1.19 & 458 & 123 & $\mathrm{NA}$ & 581 \\
\hline & & & $0 \%$ & $62 \%$ & $17 \%$ & NA & $79 \%$ \\
\hline \multirow[t]{2}{*}{ Control (\#2) } & \multirow[t]{2}{*}{791} & \multirow[t]{2}{*}{470} & 0.16 & 437 & 129 & NA & 566 \\
\hline & & & $0 \%$ & $55 \%$ & $16 \%$ & NA & $72 \%$ \\
\hline \multirow{2}{*}{$1 \%(\# 1)$} & 736 & 286 & \multirow{2}{*}{$\begin{array}{c}0.72 \\
0 \%\end{array}$} & \multirow{2}{*}{$\begin{array}{l}152 \\
21 \%\end{array}$} & \multirow{2}{*}{$\begin{array}{l}23 \\
3 \%\end{array}$} & \multirow{2}{*}{$\begin{array}{l}278 \\
38 \%\end{array}$} & \multirow{2}{*}{$\begin{array}{l}453^{\dagger} \\
62 \%^{\dagger}\end{array}$} \\
\hline & \%Non-Aq: & $61 \%$ & & & & & \\
\hline \multirow{2}{*}{$1 \%(\# 2)$} & 718 & 269 & \multirow{2}{*}{$\begin{array}{c}0.01 \\
0 \%\end{array}$} & \multirow{2}{*}{$\begin{array}{l}104 \\
15 \% \\
\end{array}$} & \multirow{2}{*}{$\begin{array}{l}12 \\
2 \% \\
\end{array}$} & \multirow{2}{*}{$\begin{array}{l}251 \\
35 \%\end{array}$} & \multirow{2}{*}{$\begin{array}{c}367^{\dagger} \\
51 \%^{\dagger}\end{array}$} \\
\hline & \%Non-Aq: & $62 \%$ & & & & & \\
\hline \multirow{2}{*}{$3 \%(\# 1)$} & 720 & 271 & \multirow{2}{*}{$\begin{array}{c}0.18 \\
0 \%\end{array}$} & \multirow{2}{*}{$\begin{array}{c}0 \\
0 \%\end{array}$} & \multirow{2}{*}{$\begin{array}{c}7 \\
1 \% \\
\end{array}$} & \multirow{2}{*}{$\begin{array}{r}264 \\
37 \% \\
\end{array}$} & \multirow{2}{*}{$\begin{array}{c}271^{\dagger} \\
38 \%^{\dagger}\end{array}$} \\
\hline & \%Non-Aq: & $62 \%$ & & & & & \\
\hline \multirow{2}{*}{$3 \%(\# 2)$} & 734 & 279 & \multirow{2}{*}{$\begin{array}{c}0.10 \\
0 \%\end{array}$} & \multirow{2}{*}{$\begin{array}{c}0 \\
0 \%\end{array}$} & \multirow{2}{*}{$\begin{array}{c}8 \\
1 \%\end{array}$} & \multirow{2}{*}{$\begin{array}{l}268 \\
37 \%\end{array}$} & \multirow{2}{*}{$\begin{array}{c}276^{\dagger} \\
38 \%^{\dagger}\end{array}$} \\
\hline & \%Non-Aq: & $62 \%$ & & & & & \\
\hline
\end{tabular}

a. Total Initial is assumed to be the actual DNAPL TCE mass added to each reactor.

TCE oxidized is the maximum observed aqueous TCE mass oxidized during the course of aliquot sampling (Does not account for oxidation of TCE in non-aqueous phase)

$\dagger$ The un-recovered TCE is that which was oxidized from the non-aqueous phase and/or volatilized during equilibration.

Table 76. $\mathrm{MnO}_{4}{ }^{-}$Consumption Data for ORNL Exp. 4b-R14 (TSF-05 GW \& Sludge).

\begin{tabular}{|c|c|c|c|c|}
\hline Test Condition & $\begin{array}{l}\text { Initial } \\
\text { Oxidant } \\
\left.\left(\mathrm{mg} \mathrm{MnO}_{4}\right)^{-}\right)\end{array}$ & $\begin{array}{l}\text { Initial } \\
\text { Loading } \\
\left(\mathrm{mg} \mathrm{MnO}_{4}^{-} / \mathrm{g}\right) \\
\end{array}$ & $\begin{array}{l}\text { Cum. } \\
\text { Consumed } \\
\left(\mathrm{mg} \mathrm{MnO}{ }_{4}^{-}\right)\end{array}$ & $\begin{array}{l}\text { Cum. } \\
\text { Consumed } \\
\left(\mathrm{mg} \mathrm{MnO}_{4} / \mathrm{g}\right) \\
\end{array}$ \\
\hline $1 \%(\# 1)$ & 3610 & 8.1 & 3610 & 8.1 \\
\hline $1 \%(\# 2)$ & 3649 & 8.1 & 3649 & 8.1 \\
\hline $3 \%(\# 1)$ & 11028 & 24.6 & 6588 & 14.7 \\
\hline $3 \%(\# 2)$ & 10998 & 24.6 & 7353 & 16.5 \\
\hline
\end{tabular}

a. Consumption is computed after a $120 \mathrm{hr}$ reaction time. 
Summary - VOC Oxidation Rate Measurements, Hot Spot Sludge

Organic sludge from TSF-05 was included in reaction vessels in this suite of experiments. Thus, this set of experiments measured the rate of TCE oxidation in the presence of both groundwater and organic sludge from the hot spot. The experiments were designed to evaluate the effect of the presence of sludge on TCE oxidation and the effect of oxidation on organic sludge. Nominal TCE and permanganate concentrations were the same as those used in the Hot Spot Groundwater' series of experiments. The nominal TCE and permanganate concentrations and the associated experiment identification number are below in Table 77.

Table 77. Experimental Identification for Hot Spot Sludge Experiments.

\begin{tabular}{|c|c|c|c|}
\hline \multirow{2}{*}{$\begin{array}{c}\text { Nominal } \\
\mathrm{MnO}_{4}^{-} \\
\text {Concentration }\end{array}$} & \multicolumn{3}{|c|}{ Nominal TCE Concentration } \\
\hline & $\begin{array}{l}10,000 \\
(\mu \mathrm{g} / \mathrm{L})\end{array}$ & $\begin{array}{c}100,000 \\
(\mu \mathrm{g} / \mathrm{L})\end{array}$ & $\begin{array}{c}1,000,000 \\
(\mu g / L)\end{array}$ \\
\hline $0.01 \%$ & $4 \mathrm{bR} 11$ & $4 \mathrm{bR} 16$ & $4 \mathrm{bR} 13$ \\
\hline $0.1 \%$ & $4 \mathrm{bR} 11$ & $4 \mathrm{bR} 16$ & 4bR13 \\
\hline $1 \%$ & 4bR15 & 4bR12 & 4bR14 \\
\hline $3 \%$ & $4 \mathrm{bR} 15$ & $4 \mathrm{bR} 12$ & $4 \mathrm{bR} 14$ \\
\hline
\end{tabular}

- TCE concentrations in 'control' reactors, which did not contain permanganate, remained constant, while concentrations declined in reactors that contained permanganate. This demonstrates that oxidation is the major removal mechanism in these experiments.

The results of these experiments fall into two general categories, depending on whether the mass of permanganate was sufficient or insufficient to oxidize the mass of TCE present. Nominal permanganate concentrations ranged from $0.01 \%(100 \mathrm{mg} / \mathrm{L})$ to $3 \%(30 \mathrm{~g} / \mathrm{L})$. The average initial permanganate concentration for each experiment is tabulated below (Table 78). 
Table 78. Initial $\mathrm{MnO}_{4}{ }^{-}$Concentrations for the Hot Spot Sludge Experiments. ${ }^{\text {a. }}$

\begin{tabular}{|c|c|c|c|}
\hline \multirow{2}{*}{$\begin{array}{c}\text { Nominal } \\
\mathrm{MnO}_{4}^{-} \\
\text {Concentration }\end{array}$} & $\begin{array}{c}\mid 3 \\
10,000 \\
(\mu \mathrm{g} / \mathrm{L})\end{array}$ & $\begin{array}{c}100,000 \\
(\mu \mathrm{g} / \mathrm{L})\end{array}$ & $\begin{array}{c}1,000,000 \\
(\mu \mathrm{g} / \mathrm{L})\end{array}$ \\
\hline $0.01 \%$ & 103 & 102 & 102 \\
\hline $0.1 \%$ & 1,032 & 995 & 999 \\
\hline $1 \%$ & 10,220 & 10,225 & 10,225 \\
\hline $3 \%$ & 30,970 & 30,965 & 30,980 \\
\hline
\end{tabular}

a. Values are the average of 2 test reactors $\left(\mathrm{mg} / \mathrm{L} \mathrm{MnO}_{4}{ }^{-}\right)$. All samples filtered $(0.45 \mu \mathrm{m})$ before analysis.

The permanganate concentrations at the end of each experiment are presented below in Table 79 . All experiments were performed in duplicate, and replicate reactors generally exhibited similar behavior. In contrast, the reactors for experiment $4 \mathrm{bR} 12$ had very different final permanganate concentrations; both values are tabulated. There was excess permanganate (i.e. sufficient permanganate to react with all of the oxidizable material) only for initial concentrations of $1 \%$ and $3 \%$. This is attributed to complete consumption of oxidant by reaction with organic sludge and TCE in the cases with lower initial permanganate concentrations. The $\approx 4-5 \mathrm{mg} / \mathrm{L}$ residual $\mathrm{MnO}_{4}{ }^{-}$concentrations presented in Table 79 for the nominal $1,000,000 \mu \mathrm{g} / \mathrm{L}$ TCE case, it likely due to interferences during the colorimetric $\mathrm{MnO}_{4}{ }^{-}$analyses. As noted earlier, these experiments were conducted using a $120 \mathrm{hr}$ reaction time, and yellowing of the slurry was observed during the course of the reaction.

Table 79. Final $\mathrm{MnO}_{4}{ }^{-}$Concentrations for the Hot Spot Sludge Experiments. ${ }^{\text {a. }}$

\begin{tabular}{|c|c|c|c|}
\hline \multirow{2}{*}{$\begin{array}{c}\text { Nominal } \\
\mathrm{MnO}_{4}^{-} \\
\text {Concentration }\end{array}$} & \multicolumn{3}{|c|}{ Nominal TCE Concentration } \\
\hline & $\begin{array}{l}10,000 \\
(\mu \mathrm{g} / \mathrm{L})\end{array}$ & $\begin{array}{c}100,000 \\
(\mu \mathrm{g} / \mathrm{L})\end{array}$ & $\begin{array}{c}1,000,000 \\
(\mu \mathrm{g} / \mathrm{L})\end{array}$ \\
\hline $0.01 \%$ & 1 & 3 & $4^{2}$ \\
\hline $0.1 \%$ & 1 & 2 & $5^{2}$ \\
\hline $1 \%$ & $190 / 930^{1}$ & $0.1 / 636^{1}$ & $5^{2}$ \\
\hline $3 \%$ & 13,740 & 12,410 & $7,000 / 2,950^{1}$ \\
\hline
\end{tabular}

a. Values are the average of 2 test reactors $\left(\mathrm{mg} / \mathrm{L} \mathrm{MnO}_{4}{ }^{-}\right)$. All samples filtered $(0.45 \mu \mathrm{m})$ before analysis.

1 Values for replicates that exhibited substantially different behavior.

2 Value likely resulted from yellow of slurry due to sludge breakdown with $120 \mathrm{hr}$ reaction period. 
Initial TCE concentrations ranged from $10,000 \mu \mathrm{g} / \mathrm{L}$ to $1,000,000 \mu \mathrm{g} / \mathrm{L}$. TCE was present as a non-aqueous phase at the highest concentration. The actual (as opposed to nominal) concentrations initially present are presented below in Table 80. TCE concentrations in experiment $4 \mathrm{bR} 11$ were substantially higher than the target concentrations, but other concentrations were fairly close to the intended concentrations. These values are the initial concentrations in the 'groundwater control' reactors. Although a similar mass of TCE was present in reactors that contained organic sludge, sorption of TCE by sludge (on the order of $50 \%$ ) would cause the aqueous concentrations to be less than those in the aqueous controls.

Table 80. Initial Aqueous TCE Concentrations for the Hot Spot Sludge Experiments. ${ }^{\text {a. }}$

\begin{tabular}{|c|c|c|c|}
\hline $\begin{array}{c}\text { Nominal } \\
\mathrm{MnO}_{4}^{-} \\
\text {Concentration }\end{array}$ & \multicolumn{3}{|c|}{ Nominal TCE Concentration } \\
\cline { 2 - 4 } & $\begin{array}{c}10,000 \\
(\mu \mathrm{g} / \mathrm{L})\end{array}$ & $\begin{array}{c}100,000 \\
(\mu \mathrm{g} / \mathrm{L})\end{array}$ & $\begin{array}{c}1,000,000 \\
(\mu \mathrm{g} / \mathrm{L})\end{array}$ \\
\hline $0.01 \%$ & 30,500 & 71,500 & $1,311,950$ \\
\hline $0.1 \%$ & 30,500 & 71,500 & $1,311,950$ \\
\hline $1 \%$ & 7,840 & 80,560 & $1,273,650$ \\
\hline $3 \%$ & 7,840 & 80,560 & $1,273,650$ \\
\hline
\end{tabular}

2. Values are the average of the 2 "Groundwater Control" reactors ( $\mu \mathrm{g} / \mathrm{L}$ TCE) used in each experiment.

The aqueous TCE concentrations at the end of the reaction period are presented below in Table 81. (Note that direct comparison with Table 80 is not appropriate in all cases since the values presented here are from reactors containing a slurry of sludge and groundwater) Two types of behavior were observed: either TCE concentrations declined orders of magnitude from the initial concentration, or they declined only slightly. If there was sufficient permanganate present for there to be a permanganate residual at the end of the experiment, than TCE concentrations declined to low concentrations $(\approx 100 \mu \mathrm{g} / \mathrm{L}$ or less). If permanganate was exhausted before the end of the experiment, then TCE concentrations remained high. 
Table 81. Final Aqueous TCE Concentrations for the Hot Spot Sludge Experiments. ${ }^{\text {a. }}$

\begin{tabular}{|c|c|c|c|}
\hline \multirow{2}{*}{$\begin{array}{c}\text { Nominal } \\
\mathrm{MnO}_{4}^{-} \\
\text {Concentration }\end{array}$} & \multicolumn{3}{|c|}{ Nominal TCE Concentration } \\
\cline { 2 - 4 } & $\begin{array}{c}10,000 \\
(\mu \mathrm{g} / \mathrm{L})\end{array}$ & $\begin{array}{c}100,000 \\
(\mu \mathrm{g} / \mathrm{L})\end{array}$ & $\begin{array}{c}1,000,000 \\
(\mu \mathrm{g} / \mathrm{L})\end{array}$ \\
\hline $0.01 \%$ & 12,300 & 49,125 & $1,502,350$ \\
\hline $0.1 \%$ & 11,930 & 39,360 & $1,220,900$ \\
\hline $1 \%$ & $6^{2}$ & $83 / 350^{1,2}$ & $380,850^{3}$ \\
\hline $3 \%$ & $\mathrm{ND}$ & $95^{2}$ & $\mathrm{ND}$ \\
\hline
\end{tabular}

a. Values are the average of 2 test reactors ( $\mu \mathrm{g} / \mathrm{L}$ TCE).

1 Values for replicates that exhibited substantially different behavior.

2 One replicate value $<\mathrm{MDL}$.

3 One replicate exceeded instrument calibration.

The percentage of TCE initially present that was oxidized in each experiment is presented below in Table 82 . The cases in which $~ 100 \%$ of the TCE was oxidized correspond with the cases in which there was a permanganate residual at the end of the experiment.

Table 82. Percentage of TCE Oxidized for the Hot Spot Sludge Experiments. ${ }^{\text {a. }}$

\begin{tabular}{|c|c|c|c|}
\hline \multirow{2}{*}{$\begin{array}{c}\text { Nominal } \\
\mathrm{MnO}_{4}^{-} \\
\text {Concentration }\end{array}$} & \multicolumn{3}{|c|}{ Nominal TCE Concentration } \\
\cline { 2 - 4 } & $\begin{array}{c}10,000 \\
(\mu \mathrm{g} / \mathrm{L})\end{array}$ & $\begin{array}{c}100,000 \\
(\mu \mathrm{g} / \mathrm{L})\end{array}$ & $\begin{array}{c}1,000,000 \\
(\mu \mathrm{g} / \mathrm{L})\end{array}$ \\
\hline $0.01 \%$ & 11 & $2^{1}$ & 1 \\
\hline $0.1 \%$ & 28 & $16^{1}$ & 10 \\
\hline $1 \%$ & $58^{1}$ & 100 & 36 \\
\hline $3 \%$ & 100 & 100 & 100 \\
\hline
\end{tabular}

a. Values are the average of 2 test reactors (wt\%).

1 Value from only a single reactor.

Zero order TCE oxidation rates were estimated for the cases in which there was a permanganate residual. The estimated rates are presented in Table 83 and 84 on a 'per reactor' basis and on a 'unit volume' basis, respectively. Although the data set is limited, the TCE oxidation rate increases with initial TCE concentration. A trend as a function of initial permanganate concentration cannot be determined from this data set, although experiments described previously indicate that the TCE oxidation rate is proportional to the permanganate concentration. 
Table 83. Observed Minimum Zero Order TCE Destruction Rates - Per Reactor Basis, Hot Spot Sludge. ${ }^{\text {a. }}$

\begin{tabular}{|c|c|c|c|}
\hline \multirow{2}{*}{$\begin{array}{c}\text { Nominal } \\
\mathrm{MnO}_{4}^{-}\end{array}$} & \multicolumn{3}{|c|}{ Nominal TCE Concentration } \\
\cline { 2 - 4 } Concentration & $\begin{array}{c}10,000 \\
(\mu \mathrm{g} / \mathrm{L})\end{array}$ & $\begin{array}{c}100,000 \\
(\mu \mathrm{g} / \mathrm{L})\end{array}$ & $\begin{array}{c}1,000,000 \\
(\mu \mathrm{g} / \mathrm{L})\end{array}$ \\
\hline $0.01 \%$ & $\mathrm{NC}^{\dagger}$ & $\mathrm{NC}^{\dagger}$ & $\mathrm{NC}^{\dagger}$ \\
\hline $0.1 \%$ & $\mathrm{NC}^{\dagger}$ & $\mathrm{NC}^{\dagger}$ & $\mathrm{NC}^{\dagger}$ \\
\hline $1 \%$ & 5.8 & 59.6 & $\mathrm{NC}^{\dagger}$ \\
\hline $3 \%$ & 5.8 & 59.6 & 730 \\
\hline
\end{tabular}

a. Values are the average of 2 test reactors (mg TCE/hr per reactor). Computed by dividing the Average Initial TCE Mass present in each reactor by the earliest aliquot sampling time at which TCE was not detected. Each reactor contained nominally $400 \mathrm{~mL}$. See Appendix C for actual $\mathrm{GW}$ masses in each reactor.

$\doteqdot$ Value not calculated, oxidant was depleted rapidly before all TCE was oxidized.

Table 84. Observed Minimum Zero Order TCE Destruction Rates - Per Unit Volume Basis, Hot Spot Sludge. ${ }^{\text {a. }}$

\begin{tabular}{|c|c|c|c|}
\hline \multirow{2}{*}{$\begin{array}{c}\text { Nominal } \\
\begin{array}{c}\mathrm{MnO}_{4}^{-} \\
\text {Concentration }\end{array}\end{array}$} & \begin{tabular}{c}
$\mid 3$ \\
$(\mu, 000$ \\
\cline { 2 - 4 }
\end{tabular} & $\begin{array}{c}100,000 \\
(\mu \mathrm{g} / \mathrm{L})\end{array}$ & $\begin{array}{c}1,000,000 \\
(\mu \mathrm{g} / \mathrm{L})\end{array}$ \\
\hline $0.01 \%$ & $\mathrm{NC}^{\dagger \dagger}$ & $\mathrm{NC}^{\dagger \dagger}$ & $\mathrm{NC}^{\dagger \dagger}$ \\
\hline $0.1 \%$ & $\mathrm{NC}^{\dagger \dagger}$ & $\mathrm{NC}^{\dagger \dagger}$ & $\mathrm{NC}^{\dagger \dagger}$ \\
\hline $1 \%$ & 16 & 162 & $\mathrm{NC}^{\dagger \dagger}$ \\
\hline $3 \%$ & 16 & 162 & $2000^{\dagger}$ \\
\hline
\end{tabular}

a. Values are the average of 2 test reactors (mg TCE/L/hour). Values were computed by dividing the Average Initial TCE Mass present in each reactor by both (1) the earliest aliquot sampling time (hrs) at which TCE was not detected and (2) the average initial liquid volume in the reactor ( $\mathrm{GW}$ and $\mathrm{MnO}_{4}{ }^{-}$stock solution, when applicable).

$\dagger$ A corresponding first order rate constant is included in Table 86 for this test case.

i† Value not calculated, oxidant was depleted rapidly before all TCE was oxidized.

- The results of this experiment differ from those of the parallel experiment with groundwater from the same source but no sludge (Section 2.4.3). In the 'sludge' experiments, there were fewer cases in which there was a permanganate residual than in the 'groundwater' experiments. This can be attributed to consumption of oxidant by reaction with the organic sludge. Oxidation of sludge would cause lower permanganate concentrations. Previous experiments indicate that the TCE oxidation rate is proportional to the permanganate concentration, and hence lower permanganate concentrations in the 'sludge' experiments would be expected to cause lower TCE oxidation rates. TCE oxidation rates in the 'sludge' experiments were less than the TCE oxidation rates in the corresponding 'groundwater' experiments. This indicates that the presence of organic sludge would have two effects on 
TCE oxidation: (1) Sludge will exert an additional oxidant demand, which may exhaust the supply of oxidant before all of the TCE has been oxidized. (2) Oxidation of sludge will lower permanganate concentrations and thus lead to slower TCE oxidation rates. However, it should be noted that the rate of TCE oxidation is very rapid, even in the presence of organic sludge.

Trends in $\mathrm{pH}$ are presented in Table 85 below. $\mathrm{pH}$ values increased by approximately $0.1-1 \mathrm{pH}$ units. This behavior is in marked contrast to that observed in the 'groundwater' experiments, in which $\mathrm{pH}$ decreased, and the changes were much larger. The smaller $\mathrm{pH}$ changes observed in the 'sludge' experiments are attributed to the buffering capacity of the organic sludge. The reason for the difference in the sign of the $\mathrm{pH}$ change between the 'sludge' and 'groundwater' experiments is unknown. However, the effect may be associated with oxidation of the organic sludge since the initial pHs of the slurry reactors (containing TSF-05 GW and sludge) were significantly lower than the pHs of control reactors containing only TSF-05 GW.

- Changes in $\mathrm{pH}$ were so small that $\mathrm{pH}$ would not useful for monitoring the progress of ISCO at the field scale

Table 85. Observed pH Trends in the Hot Spot Groundwater Experiments. ${ }^{a}$

\begin{tabular}{|c|c|c|c|}
\hline $\begin{array}{c}\text { Nominal } \\
\mathrm{MnO}_{4}^{-} \\
\text {Concentration }\end{array}$ & $\begin{array}{c}10,000 \\
(\mu \mathrm{g} / \mathrm{L})\end{array}$ & $\begin{array}{c}100,000 \\
(\mu \mathrm{g} / \mathrm{L})\end{array}$ & $\begin{array}{c}1,000,000 \\
(\mu \mathrm{g} / \mathrm{L})\end{array}$ \\
\hline $0.01 \%$ & +0.2 & +0.2 & +0.5 \\
\hline $0.1 \%$ & +0.6 & +0.4 & +1.2 \\
\hline $1 \%$ & +0.7 & +0.8 & +0.5 \\
\hline $3 \%$ & +0.1 & +1.1 & +0.5 \\
\hline
\end{tabular}

A summary of the TSF-05 Slurry experiments (GW and sludge) is presented in Table 86 . This table in essence is a summary of the preceding Tables 77 through 85 .

It was determined that available oxidant was depleted when it was attempted to use an initial loading of $0.01 \% \mathrm{MnO}_{4}{ }^{-}$to treat any TCE contaminated sludge (regardless of TCE spike level). Similarly, complete treatment of TSF- $05 \mathrm{GW}$ and sludge spiked with $\approx 2 \times 10^{6} \mu \mathrm{g} / \mathrm{L}$ (DNAPL) could only be achieved using an oxidant loading of $3 \% \mathrm{MnO}_{4}^{-}$.

For the $3 \% \mathrm{MnO}_{4}{ }^{-}$cases, in which $\mathrm{MnO}_{4}{ }^{-}$was in excess, it is interesting to note from Table 86 that the amount of oxidant consumed does not increase significantly although the initial TCE masses are orders of magnitude different. In fact, $56 \%, 60 \%$, and $64 \%$ of the initial oxidant mass added was consumed in experiments having initial nominal TCE concentrations of $10,000 \mu \mathrm{g} / \mathrm{L}$; $100,000 \mu \mathrm{g} / \mathrm{L}$; and $2 \times 106 \mu \mathrm{g} / \mathrm{L}$ (DNAPL), respectively.

As observed for the TSF- $05 \mathrm{GW}$, the higher the oxidant loading, the higher the oxidant consumption ( $\mathrm{mg} \mathrm{MnO}_{4}{ }^{-1} \mathrm{~g}$ media) for oxidizing the same mass of TCE. It is not known precisely what causes this phenomenon. However, from a cost effectiveness standpoint, this 
result points to the need to closely tailor the oxidant loading to the field observed VOC contamination levels.

Table 86. Summary of the Hot Spot Sludge Oxidation Rate Experiments.

\begin{tabular}{|c|c|c|c|c|c|c|}
\hline $\begin{array}{l}\text { ORNL } \\
\text { Exp. } \\
\text { No. }\end{array}$ & $\begin{array}{l}\text { Nominal } \\
\text { Initial } \\
\text { TCE } \\
(\mu g / L)\end{array}$ & $\begin{array}{l}\text { Avg. } \\
\text { Initial } \\
\text { TCE } \\
\text { Mass } \\
\text { (mg) }\end{array}$ & $\begin{array}{l}\text { TCE Oxidation } \\
\text { Observed Rates } \\
\text { (mg TCE/hr.Reactor } \\
\text { Contents) }\end{array}$ & $\begin{array}{l}\text { Initial } \\
\mathrm{MnO}_{4}^{-} \\
(\mathrm{wt} \%)\end{array}$ & $\begin{array}{l}\mathrm{Max} . \mathrm{MnO}_{4}^{-} \\
\text {Consumed } \\
\left(\mathrm{mg} \mathrm{MnO}_{4}^{-} / \mathrm{g}\right)\end{array}$ & pH Trends \\
\hline \multirow[t]{2}{*}{$4 b-R 11$} & \multirow[t]{2}{*}{10,000} & 11.6 & $\begin{array}{l}\text { Incomplete } \\
(\text { Min } 12 \% \text { oxidized })^{1}\end{array}$ & $0.01 \%$ & 0.08 & $\begin{array}{l}<0.2 \mathrm{Net} \\
\text { Increase }\end{array}$ \\
\hline & & 11.3 & $\begin{array}{l}\text { Incomplete } \\
(\text { Min } 38 \% \text { oxidized })^{1}\end{array}$ & $0.1 \%$ & 0.8 & $\begin{array}{l}<0.6 \mathrm{Net} \\
\text { Increase }\end{array}$ \\
\hline \multirow[t]{2}{*}{$4 b-R 15$} & \multirow[t]{2}{*}{10,000} & 2.9 & $\begin{array}{l}\text { Residual Present } \\
\text { (Min 58\% oxidized) } \\
\text { Obs. Rate: } 5.8^{2}\end{array}$ & $1 \%$ & 7.7 & $\begin{array}{l}<0.7 \mathrm{Net} \\
\text { Increase }\end{array}$ \\
\hline & & 2.9 & $\begin{array}{l}\text { Complete }(<0.5 \mathrm{hrs}) \\
\text { Obs. Rate } \geq 5.8\end{array}$ & $3 \%$ & 13.7 & $\begin{array}{l}<1.0 \mathrm{Net} \\
\text { Increase }\end{array}$ \\
\hline \multirow[t]{2}{*}{$4 b-R 16$} & \multirow[t]{2}{*}{100,000} & 26.2 & $\begin{array}{l}\text { Incomplete } \\
(\approx 2 \% \text { oxidized })^{1}\end{array}$ & $0.01 \%$ & 0.08 & $\begin{array}{l}<0.2 \mathrm{Net} \\
\text { Increase }\end{array}$ \\
\hline & & 26.4 & $\begin{array}{l}\text { Incomplete } \\
(\approx 16 \% \text { oxidized })^{1}\end{array}$ & $0.1 \%$ & 0.8 & $\begin{array}{l}<0.4 \mathrm{Net} \\
\text { Increase }\end{array}$ \\
\hline \multirow[t]{2}{*}{ 4b-R12 } & \multirow[t]{2}{*}{100,000} & 29.8 & $\begin{array}{l}\text { Complete }(<0.5 \mathrm{hrs}) \\
\text { Obs.Rate } \geq 59.6\end{array}$ & $1 \%$ & 8.1 & $\begin{array}{l}<0.8 \mathrm{Net} \\
\text { Increase }\end{array}$ \\
\hline & & 29.8 & $\begin{array}{l}\text { Complete }(<0.5 \mathrm{hrs}) \\
\text { Obs.Rate } \geq 59.6\end{array}$ & $3 \%$ & 15.6 & $\begin{array}{l}<1.1 \text { Net } \\
\text { Increase }\end{array}$ \\
\hline \multirow[t]{2}{*}{$4 \mathrm{~b}-\mathrm{R} 13$} & \multirow[t]{2}{*}{$\mathrm{DNAPL}^{3}$} & 729 & $\begin{array}{l}\text { Incomplete (Min } 1 \% \\
\text { oxidized) }\end{array}$ & $0.01 \%$ & 0.08 & $\begin{array}{l}\approx 0.5 \mathrm{Net} \\
\text { Increase }\end{array}$ \\
\hline & & 727 & $\begin{array}{l}\text { Incomplete ( Min } 10 \% \\
\text { oxidized) }\end{array}$ & $0.1 \%$ & 0.8 & $\begin{array}{l}\approx 1.2 \mathrm{Net} \\
\text { Increase }\end{array}$ \\
\hline \multirow[t]{2}{*}{$4 \mathrm{~b}-\mathrm{R} 14$} & \multirow[t]{2}{*}{$\mathrm{DNAPL}^{3}$} & 727 & $\begin{array}{l}\text { Incomplete (Min } 36 \% \\
\text { oxidized) }\end{array}$ & $1 \%$ & 8.1 & $\begin{array}{l}<0.5 \mathrm{Net} \\
\text { Increase }\end{array}$ \\
\hline & & 727 & $\begin{array}{l}\text { Complete }(<2 \mathrm{hrs}) \\
k=4.1 \mathrm{hr}^{-1} \\
\text { Obs. Rate } \approx 730\end{array}$ & $3 \%$ & 16.5 & $\begin{array}{l}<0.5 \mathrm{Net} \\
\text { Increase }\end{array}$ \\
\hline
\end{tabular}

$\dagger$ Observed Oxidation Rate= (Total Initial mg TCE)/(X hrs.Reactor Contents); Where X represents the earliest sampling time at which TCE was not detected in the aqueous aliquot. Where available, the predicted first order reaction rate constant, $k$, is presented.

"Reáctor Contents" are nominally $400 \mathrm{~mL}$ TCE-spiked GW and $100 \mathrm{~g}$ TSF-05 Sludge. See Appendix C for actual masses added to each reactor.

1 Oxidant depleted before all TCE could be oxidized.

2 It is assumed that the reactions were essentially completed at this time point, even though a low residual TCE concentration was present. The reported values are estimates.

3 "DNAPL" equates to an aqueous concentration of $2 \times 10^{6} \mu \mathrm{g} / \mathrm{L} \mathrm{TCE}$.

4 A conservative value which does take into account for any non-aqueous TCE which was oxidized. 


\subsubsection{TSF-05 Sludge Baseline Characteristics and Effect of Oxidation}

Various baseline measurements were performed on the TSF-05 sludge prior to the start of the consumption and oxidation experiments. These measurements consisted of bulk density, percent moisture, radiochemical analysis (gross alpha, gross beta, and gamma scan), and total carbon content (see Appendix B). Carbon content was measured on portions of the TSF-05 sludge prior to the oxidant demand and oxidation rate studies and after reaction to determine sludge oxidation trends for each experiment.

The bulk density measurement was used to calculate the total weight of sludge received for sample tracking purposes. The percent moisture was used to convert the raw (as received) sample carbon results to a dry weight basis so that the values could be compared to the dried sample carbon measurements. This was done to ascertain if any loss of sample carbon occurred during the drying process. The radiochemical measurements were conducted to confirm INEEL isotopic data and to establish the radioactive hazards associated with the sludge. Total carbon measurements were performed (1) to establish a baseline carbon value, (2) to determine posttreatment carbon values in the sludge following the oxidant demand and oxidation rate studies, and (3) to determine the effect (if any) that the presence of varying concentrations of TCE would have on the oxidation of the sludge. The average baseline carbon value obtained on the dried sample portions prior to the oxidation studies was compared with the post-treatment values to determine oxidation trends for each experiment. It should be noted that the TSF-05 sludge samples were highly heterogeneous containing such material as fine silt particles, small rocks, thin "shale-like" chips, and other debris that was not specifically identified. Overall, the sludges had a dark reddish brown color, and all containers had a liquid phase, making up half of the sample's weight, separated from the solid material. The sludge samples were homogenized as much as possible by hand stirring prior to subsampling for the baseline characterization work and for the project experiments. However, the sludges could never be described as completely homogeneous. This fact affects the precision of the baseline measurements. Thus, these values should not be interpreted as absolute. The post reaction carbon analyses were less affected by sample non-homogeneity because the sludge would breakdown into a more homogeneous slurry after undergoing $24 \mathrm{hrs}$ or more of shaking during the reaction studies. The color of the sludge slurry remained a dark reddish brown.

\subsubsection{Baseline Characterization}

\section{Bulk Density and Percent Moisture}

The bulk density was determined on two 5 gram portions of the raw sludge which were randomly sampled from the one liter containers after hand stirring to homogenize. A Grabner Instruments MiniDens analyzer was used for the measurements. The MiniDens analyzer measures sample density by first obtaining a weight for the sample aliquot using a microbalance. Once the weight is obtained, the instrument then seals the sample in an air-tight chamber, filled only with air and the sludge sample, for volume determination. The volume determination is accomplished by using a piston to increase the pressure in the sealed chamber in $2 \mathrm{KPa}$ increments. The amount of movement required for the piston to obtain a $2 \mathrm{KPa}$ pressure change is directly proportional to the volume of the sample. Once the weight and the volume is known, the instrument's software computes and reports a density value. 
The percent moisture determination, defined as $\left[M_{\text {water }} /\left(M_{\text {water }}+M_{\text {solids }}\right)\right]$ x 100, was performed using a 250 gram sample portion which was randomly sampled from a one liter container after hand stirring to homogenize. The sample portion was weighed then dried in an oven $\left(105^{\circ} \mathrm{C}\right)$, cooled in a desiccator, and weighed again. This process was repeated until a stable dry weight was achieved. The density and the percent moisture results are summarized in Table 87.

Table 87. Baseline TSF-05 Sludge Density and Percent Moisture.

\begin{tabular}{|c|c|c|}
\hline Sample & Moisture (wt\%) & $\begin{array}{l}\text { Wet } \\
\text { Bulk density }(\mathrm{g} / \mathrm{mL})\end{array}$ \\
\hline 1 & 58.4 & 1.878 \\
\hline 2 & NA & 1.855 \\
\hline Average: & 58.4 & 1.867 \\
\hline
\end{tabular}

\section{Radiochemical Measurements}

After similar subsampling, radiochemical measurements were also performed. The aliquot was acid digested using the protocol set forth in SW846 method 3051 then analyzed for gross alpha, gross beta, and gamm using the procedures listed in Table 88. The results, which are corrected back to the original wet weight of the sludge, are reported as Bq/g and are presented in Table 89. The RMAL's radiochemical analytical results have good agreement with those values supplied by INEEL's radiochemical laboratory (Rowley, 1997).

Table 88. Radiochemical Methods used for TSF-05 Sludge Determinations.

\begin{tabular}{|l|l|}
\hline Method & Analysis \\
\hline $\begin{array}{l}\text { Gross Alpha and Gross Beta Radioactivity in } \\
\text { Drinking Water (CASD-AM-EPA-900.0) }\end{array}$ & $\begin{array}{l}\text { Gross alpha and beta radioactivity sample } \\
\text { preparation }\end{array}$ \\
\hline $\begin{array}{l}\text { Gamma-emitting Radionuclides in Drinking } \\
\text { Water (CASD-AM-EPA-901.1) }\end{array}$ & $\begin{array}{l}\text { Gamma emitting radionuclides sample } \\
\text { preparation }\end{array}$ \\
\hline $\begin{array}{l}\text { Operation of Packard MO 2500TR Liquid } \\
\text { Scintillation Counter } \\
\text { (CASD-AM-RML-RA12) }\end{array}$ & $\begin{array}{l}\text { 1. Total activity by liquid scintillation } \\
\text { 2. Sum of alpha- and beta-emitting } \\
\text { radionuclides analysis }\end{array}$ \\
\hline $\begin{array}{l}\text { Operation and Calibration of the Tennelec } \\
\text { LB4000 (CASD-AM-RML-RA02) }\end{array}$ & Gross alpha and gross beta analysis \\
\hline $\begin{array}{l}\text { Operation and Calibration of the Canberra, } \\
\text { Nuclear Data Genie - ESP Data Acquisition } \\
\text { and Processing (CASD-AM-RML-RA04) }\end{array}$ & $\begin{array}{l}\text { Alpha and gamma spectroscopy data } \\
\text { acquisition and processing system }\end{array}$ \\
\hline
\end{tabular}


Table 89. Baseline TSF-05 Sludge Radiochemical Analytical Results.

\begin{tabular}{|c|c|}
\hline Analysis & Results $(\mathrm{Bq} / \mathrm{g})$ \\
\hline Gross Beta & 4400 \\
\hline Gross Alpha & 3.3 \\
\hline Cs-137 & 460 \\
\hline Co-60 & 100 \\
\hline
\end{tabular}

Throughout the project the hexane extractions performed for TCE analyses on the sludge/groundwater slurries were monitored for total activity at random intervals prior to transfer to ESD. No activity was detected in any of these extractions.

\section{Total Carbon Data}

For the carbon determinations, a Shimadzu TOC 5000 carbon analyzer interfaced with a solid sample module (SSM 5000) was used. The analyses were performed following the guidance set forth in EPA's SW846 method 9060 and the manufacturer's operation instructions provided with the instrument.

Initial carbon baseline results were obtained prior to the start of the project experiments involving the TSF-05 sludge. Carbon content was measured in both raw (as received) and dried portions of the sludge. The baseline values obtained are presented in Table 90.

Table 90. Baseline Total Carbon Values for Raw and Dried TSF-05 Sludges.

\begin{tabular}{|c|c|c|}
\hline Sample & \multicolumn{2}{|c|}{ Total Carbon (\%) } \\
\hline Pre-treatment: & None (as received) & Dried at $105^{\circ} \mathrm{C}$ \\
\hline 1 & 2.7 & 9.2 \\
\hline 2 & 3.1 & 8.1 \\
\hline Average: & 2.9 & 8.6 \\
\hline
\end{tabular}

The raw sample result corrected for moisture is $6.9 \%$ total carbon. The average, measured dried sample result was $8.6 \%$. The calculated dry value is $20 \%$ lower than the measured value with a relative percent difference of $22 \%$. Given the highly heterogeneous matrix of the sludge samples these deviations are considered acceptable. Any loss of carbon as a result of drying the sludge is assumed to be within this percent error. Therefore, it was also assumed that the post reaction sludges could be dried to remove the hexane extraction medium without significant loss of sludge carbon. 


\subsubsection{Effect of Oxidation}

As discussed above, a baseline total carbon value of $8.6 \%$ was used to determine (1) how much carbon was oxidized in the sludge following the oxidant demand and oxidation rate studies and (2) the effect that the presence of varying concentrations of TCE would have on the oxidation of the sludge.

At the completion of the oxidant demand (Task 3b) and the degradation rate (Task 4b) experiments, portions of all sludges were dried at a temperature of $105^{\circ} \mathrm{C}$ to a constant weight to remove water and hexane (Task $4 \mathrm{~b}$ only) from the samples. Total carbon analyses were then performed on each sample. The oxidant demand (Task $3 \mathrm{~b}$ ) results are presented in Table 91 , and the oxidation rate studies (Task $4 \mathrm{~b}$ ) are presented in Table 92. The total carbon values presented in these tables for the \#1 and \#2 treatment reactors represent the values obtained for each duplicate sample for a given test condition.

Table 91. Post Oxidant Demand Results (Task 3b), TSF-05 Sludge Total Carbon.

\begin{tabular}{|c|c|c|c|c|}
\hline \multirow{2}{*}{$\begin{array}{c}\text { ORNL Exp. } \\
\text { No. }\end{array}$} & $\begin{array}{c}\text { Oxidant } \\
\text { Loading }\end{array}$ & $\begin{array}{c}\text { Treatment } \\
\text { Reactor \#1 }\end{array}$ & $\begin{array}{c}\text { Treatment } \\
\text { Reactor \#2 }\end{array}$ & $\begin{array}{c}\text { Average } \\
\text { Value }\end{array}$ \\
\hline 3b-R1 & $0.01 \% \mathrm{MnO}_{4}^{-}$ & 4.9 & 3.8 & 4.4 \\
\hline $3 b-\mathrm{R} 2$ & $0.1 \% \mathrm{MnO}_{4}^{-}$ & 3.0 & 2.4 & 2.7 \\
\hline $3 \mathrm{~b}-\mathrm{R} 3$ & $1 \% \mathrm{MnO}_{4}^{-}$ & 1.8 & 2.3 & 2.1 \\
\hline $3 \mathrm{~b}-\mathrm{R} 4$ & $3 \% \mathrm{MnO}_{4}^{-}$ & 1.4 & 1.5 & 1.5 \\
\hline
\end{tabular}


Table 92. Post-Treatment Degradation Rate Results (Task 4b) TSF-05 Sludge Total Carbon.

\begin{tabular}{|c|c|c|c|c|c|}
\hline \multirow{2}{*}{$\begin{array}{l}\text { Nominal } \\
\text { Aq. TCE } \\
(\mu \mathrm{g} / \mathrm{L})\end{array}$} & \multirow{2}{*}{$\begin{array}{c}\text { ORNL Exp. } \\
\text { No. }\end{array}$} & \multirow{2}{*}{$\begin{array}{l}\text { Oxidant } \\
\text { Loading }\end{array}$} & \multicolumn{3}{|c|}{ Total Carbon (\%) } \\
\hline & & & $\begin{array}{l}\text { Treatment } \\
\text { Reactor \#1 }\end{array}$ & $\begin{array}{l}\text { Treatment } \\
\text { Reactor \#2 }\end{array}$ & $\begin{array}{c}\text { Average } \\
\text { Value }\end{array}$ \\
\hline \multirow{2}{*}{40,000} & \multirow{2}{*}{$4 b-R 11$} & $0.01 \% \mathrm{MnO}_{4}^{-}$ & 7.1 & 6.1 & 6.6 \\
\hline & & $0.1 \% \mathrm{MnO}_{4}^{-}$ & 5.5 & 5.4 & 5.5 \\
\hline \multirow{2}{*}{10,000} & \multirow{2}{*}{$4 b-R 15$} & $1 \% \mathrm{MnO}_{4}^{-}$ & 2.7 & 2.1 & 2.4 \\
\hline & & $3 \% \mathrm{MnO}_{4}^{-}$ & 1.4 & 1.9 & 1.7 \\
\hline \multirow{4}{*}{100,000} & \multirow{2}{*}{ 4b-R12 } & $0.01 \% \mathrm{MnO}_{4}^{-}$ & 4.4 & 6.7 & 5.6 \\
\hline & & $0.1 \% \mathrm{MnO}_{4}^{-}$ & 4.8 & 5.9 & 5.4 \\
\hline & \multirow{2}{*}{$4 b-R 16$} & $1 \% \mathrm{MnO}_{4}^{-}$ & 1.7 & 3.0 & 2.4 \\
\hline & & $3 \% \mathrm{MnO}_{4}^{-}$ & 2.6 & 2.6 & 2.6 \\
\hline \multirow{4}{*}{ DNAPL } & \multirow{2}{*}{$4 b-R 13$} & $0.01 \% \mathrm{MnO}_{4}^{-}$ & 2.0 & 3.8 & 2.9 \\
\hline & & $0.1 \% \mathrm{MnO}_{4}^{-}$ & 3.5 & 2.5 & 3.0 \\
\hline & \multirow{2}{*}{ 4b-R14 } & $1 \% \mathrm{MnO}_{4}^{-}$ & $5.5^{\dagger}$ & 2.5 & $2.5^{\dagger \dagger}$ \\
\hline & & $3 \% \mathrm{MnO}_{4}^{-}$ & 2.4 & 3.4 & 2.9 \\
\hline
\end{tabular}

\footnotetext{
Outlier (biased high)

if Did not average/use the outlier value.
}

The average post-treatment total carbon values from the oxidant demand data in Table 91 was plotted in Figure 114 verses the initial oxidant loading. The data suggests a logarithmic decrease of the TSF-05 sludges; total carbon content with increasing permanganate concentration during the twenty-four hour reaction period. The trendline is a best fit only and does not exactly describe the data trend. Figure 115 depicts another view of the same carbon data. Here, the total carbon oxidized (calculated by subtracting the baseline value of $8.6 \%$ from the averaged measured post reaction values) is plotted versus initial oxidant loading. Here, the plot illustrates a logarithmic increase (essentially a mirror image of Figure 114) of the carbon oxidized with increasing permanganate concentration. As in Figure 114, a trendline is fitted to the data with its equation displayed. 


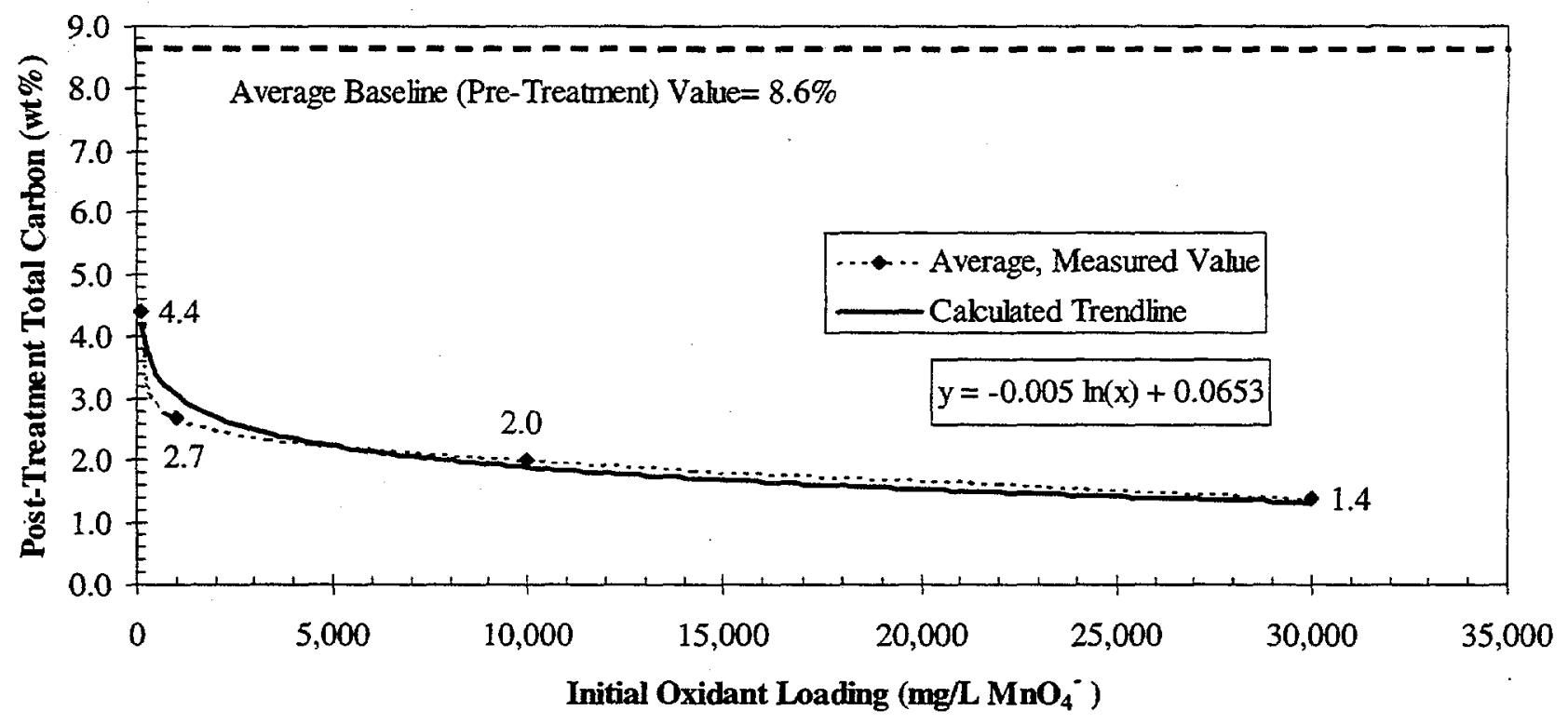

Figure 114. Post-Treatment \%Carbon Value vs. Oxidant Loading for the Task $3 \mathrm{~b}$, Oxidant Demand Experiments. (TSF-05 Sludge, $0 \mu \mathrm{g} / \mathrm{L}$ TCE, $4: 1 \mathrm{~L} / \mathrm{S}$ Ratio, $12^{\circ} \mathrm{C}$ ).

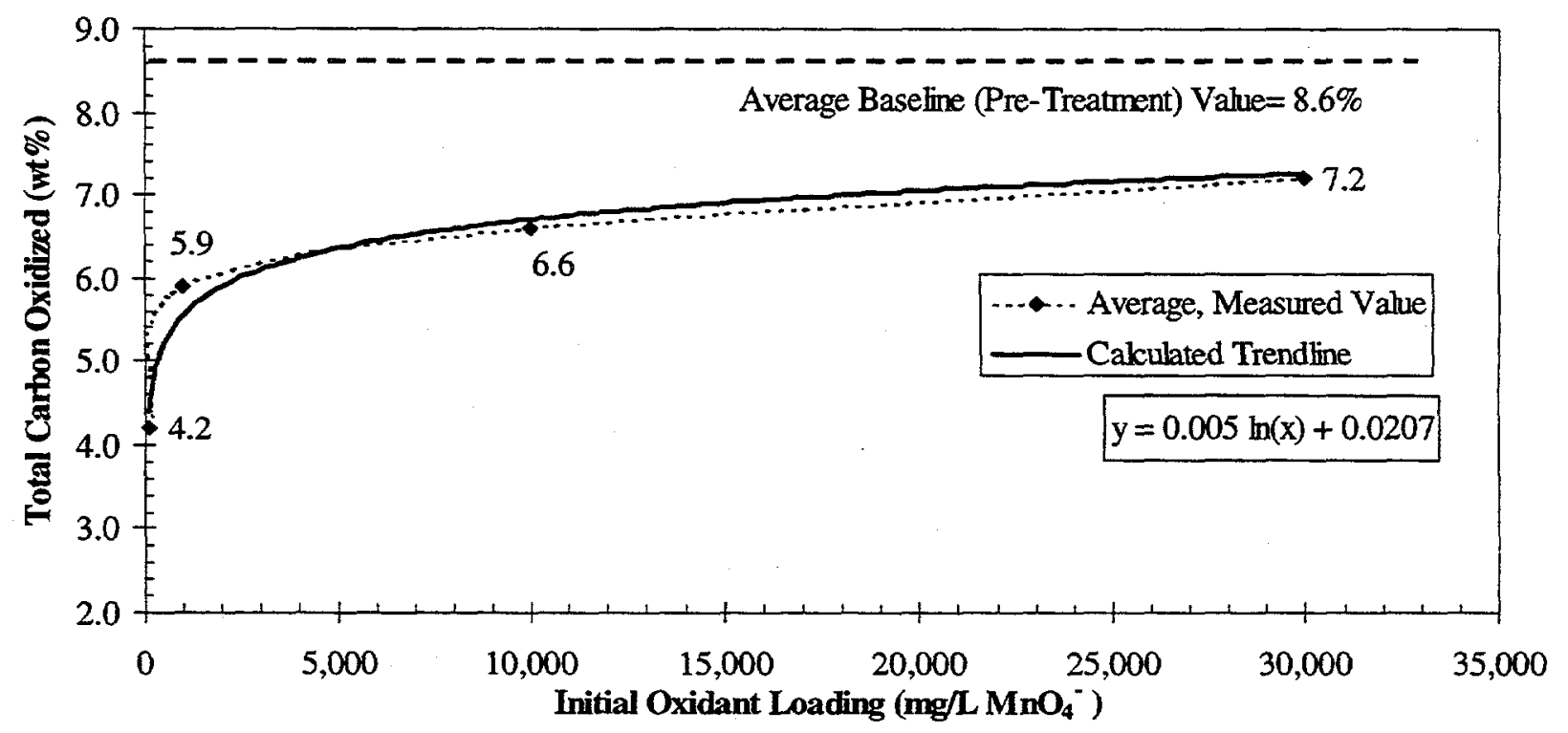

Figure 115. Post-Treatment \%Carbon Oxidized vs. Oxidant Loading for the Task 3b, Oxidant Demand Experiments. (TSF-05 Sludge, $0 \mu \mathrm{g} / \mathrm{L}$ TCE, 4:1 L/S Ratio, $12^{\circ} \mathrm{C}$ ). 
The average post-treatment total carbon values for the oxidation rate studies in Table 92 are plotted in Figure 116 versus the initial TCE spike concentration. The same data is also presented in Figure 117 but expressed as the percent of initial sludge total carbon that was oxidized. The carbon measurement obtained for the first $1 \% \mathrm{MnO}_{4}{ }^{-}$reactor in experiment $4 \mathrm{~b}-\mathrm{R} 14$, (TCE present as DNAPL) is believed to be biased high when compared to the other carbon values measured in the DNAPL experiments. Instead of averaging the two $1 \% \mathrm{MnO}_{4}{ }^{-}$samples, the second $\mathrm{MnO}_{4}{ }^{-}$sample from experiment $4 \mathrm{~b}-\mathrm{R} 14$ was used. The bar graphs in Figures 116 and 117 are grouped according to TCE concentrations to illustrate the effect that varying concentrations of TCE have on the oxidation of the carbon in the TSF-05 sludge. The first group of data $(0 \mu \mathrm{g} / \mathrm{L} \mathrm{TCE})$ is from the oxidant demand study (Table 91$)$.

Several conclusions can be drawn from the oxidation rate carbon data. First, when TCE is present, there is generally a decrease in the amount of carbon oxidized in the sludge. (This trend is most obvious for the initial oxidant loadings of $0.01 \%$ and $0.1 \% \mathrm{MnO}_{4}{ }^{\circ}$ ). It is believed that the permanganate is preferentially oxidizing the TCE in solution over the sludge carbon before it is completely consumed (i.e., there is competition for the oxidant). Although some carbon is oxidized when the sludge is spiked with TCE, the amount oxidized is less than what was observed when no TCE was present (oxidant demand studies).

For all TCE concentrations observed, the amount of carbon oxidized with the $1 \%$ and $3 \%$ permanganate solutions appears to be fairly similar, suggesting that sludge oxidation is less dependent on initial TCE concentration at higher oxidant loadings. With the $1 \%$ and $3 \% \mathrm{MnO}_{4}$ loadings, there is sufficient oxidant available to destroy the TCE as well as the sludge carbon to approximately the same levels as were observed when no TCE was present.

Finally, when the TCE is present as DNAPL the post reaction sludge carbon concentrations are essentially equivalent regardless of the initial oxidant loading. This last conclusion is more difficult to explain. The data indicates that approximately $3 \%$ of the carbon remains in the sludges after the reaction period regardless of the initial permanganate concentrations (Note: All studies using TCE present as DNAPL had reaction periods of 120 hours verses 24 hours). After $24 \mathrm{hrs}$, only the $3 \%$ permanganate reaction flasks had any measurable permanganate still present (approx. $1.1 \%$ ). After 120 hours, this permanganate concentration was approximately $0.5 \%$. Regardless, all sludges were oxidized to the same carbon levels. A possible explanation may be that, at higher concentrations, the TCE is enhancing, or possibly adding to, the oxidation reaction between the TSF-05 sludge and the permanganate. For the DNAPL case, conditions may be present that are preventing the oxidation reaction from achieving a final carbon level significantly less than $3 \%$ (as observed in the oxidant demand study). For example, the TCE mass present may be competing for available oxidant and/or reaction products formed via TCE oxidation may have altered the degradation kinetics within the reactors. Without a detailed look at the oxidation/reductions (redox) reactions occurring among the sludge, TCE, and $\mathrm{MnO}_{4}{ }^{-}$a completely satisfactory explanation cannot be given for these observations. 


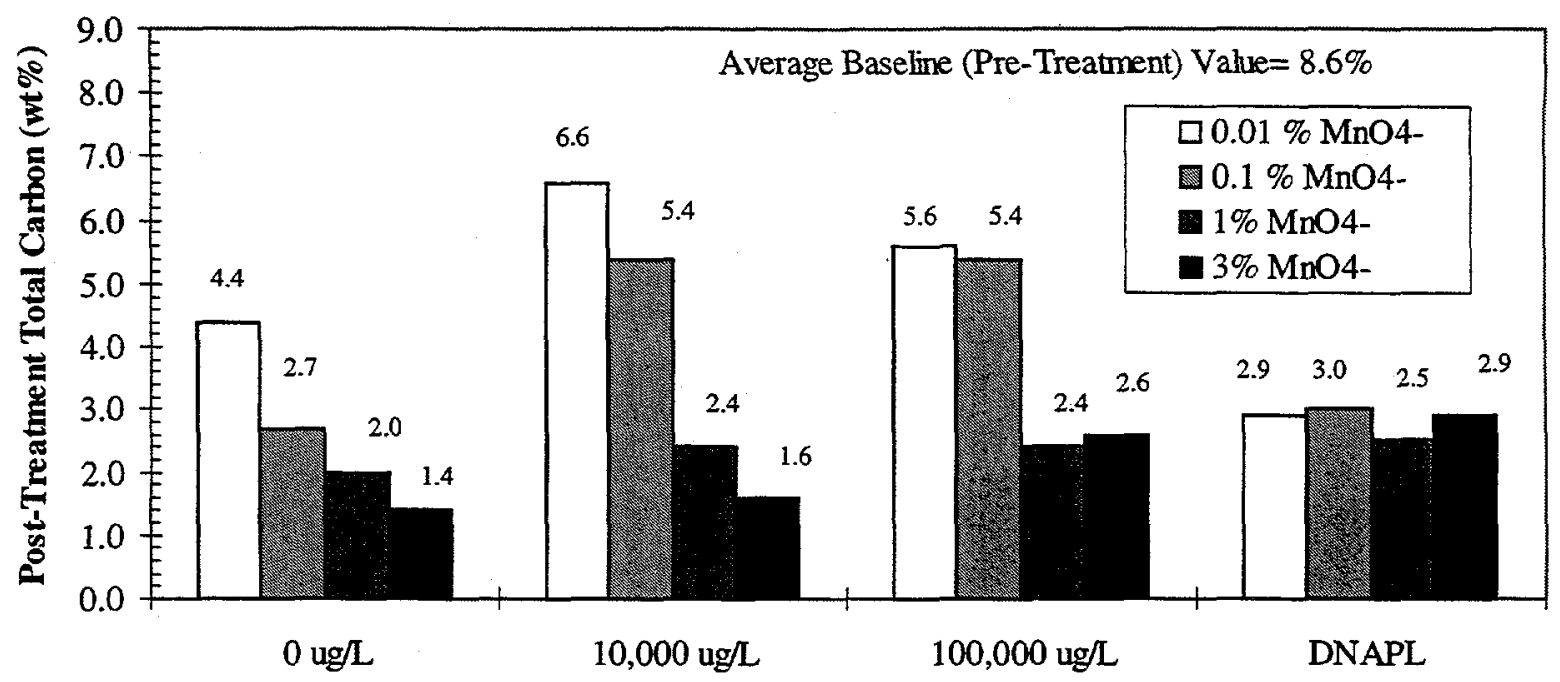

Initial TCE Spike Concentration

Figure 116. Post-Treatment Carbon Values vs TCE Spike Concentration for the Task 4b, TCE Degradation Experiments. (TSF-05 Sludge, 4:1 L/S Ratio, $12^{\circ} \mathrm{C}$ ).

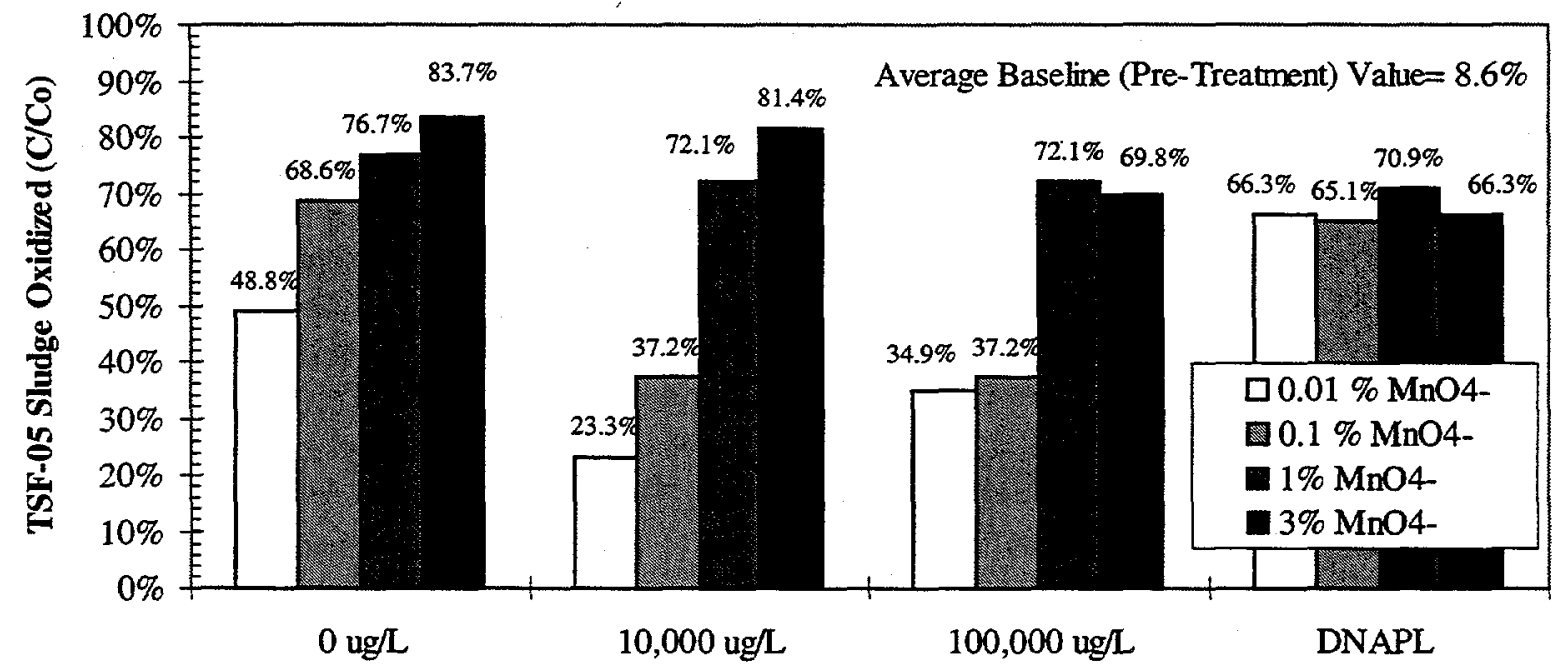

Initial TCE Spike Concentration

Figure 117. Percent of Initial Sludge Carbon Oxidized vs TCE Spike Concentration for the Task 4b, TCE Degradation Experiments. (TSF-05 Sludge, 4:1 L/S Ratio, $12^{\circ} \mathrm{C}$ ). 


\subsubsection{Matrix Spike Experiments}

Following completion of Tasks $2-4$, INEEL requested that a matrix spike experiment be performed for each TAN Site media (dissolve plume and hot spot media) being evaluated at ORNL. The results of these additional experiments are presented below.

ORNL Exp. 2b-1b, Matrix Spike Experiment for the Dissolved Plume Media (TAN-40 GW, Basalt, Sediment, TCE $=275 \mu \mathrm{g} / \mathrm{L}, 0 \% \mathrm{MnO}_{4}{ }^{-}$)

The matrix spike experiment involving the dissolved plume media was conducted without incident. (The detailed procedure used is included in Appendix B, page 16). Unfortunately, problems arose during GC analysis. The matrix spike TCE samples were analyzed using the GC that had been used for nearly all of the Task 4 work (with the exception of the co-contaminants experiments). This instrument had performed remarkably well throughout the entire project, requiring only two (2) calibrations between January and August 1998. This matrix spike experiment, however, was conducted several weeks after the completion of the task 4 work. All QA blanks, calibration checks, and test sample results contained numerous unidentified peaks, likely from capillary column and/or detector "bleeding". TCE could not be adequately resolved from the other eluting compounds. It is believed that the more than 2,000 hexane extracts that had been analyzed during the preceding months contaminated the detector, which had not been periodically baked out during the course of the project. The detrimental consequence of this activity did not surface until after the instrument had been placed in stand-by mode after completion of the Task 4 work. As a result, the ECD was removed from the instrument and returned to the manufacturing for refurbishing. The detector has just recently been returned, but it has not yet been re-installed.

With the current project funding, the experiment will not be re-performed. However, it is believed that the hexane extraction technique used for this project produced reliable results, particularly for the dissolved plume media. TCE recoveries from the control reactors (in Task 2 and Task 4 ) were high and little TCE sorption $(<8 \%)$ by the basalt or sediment was observed during the project. (TCE sorption by the hot spot sludge was on the order of 50\%.) 
ORNL Exp. 2b-3b, Matrix Spike Experiment for the Hot Spot Media (TSF-05 Sludge and GW, TCE $=1,000 \mu \mathrm{g} / \mathrm{L}, 0 \% \mathrm{MnO}_{4}{ }^{-}$)

Nearly identical to the Task 4 TCE spiking procedure, samples for this matrix spike experiment (TSF-05 slurries and TSF-05 groundwater only) were spiked with 1,000 $\mu \mathrm{g} / \mathrm{L}$ TCE at a 4:1 L/S ratio and equilibrated overnight at $12^{\circ} \mathrm{C}$. The main difference between the two experimental setups was the use of $40 \mathrm{~mL}$ VOA vials here instead of the $500 \mathrm{~mL}$ reactors used in Task 4 . (The detailed procedure used is included in Appendix B, page 21). As in Task 4, these samples were then extracted with hexane at a $1: 1 \mathrm{v} / \mathrm{v}$ ratio for various time periods. The hexane aliquots hexane were then analyzed (1) to determine the extent of recovery and (2) to determine if the amount recovered is significantly affected by the extraction time. Since the results of experiment $2 \mathrm{~b}-3$ (Section 2.2.2) suggested that some TCE may still be bound to the sludge after $24 \mathrm{hrs}$, a 48 hr extraction period was also evaluated in this experiment. Since sample holding time effect had been observed in a few of the Task 4 experiments, samples collected between $\mathrm{T}=0$ and $24 \mathrm{hrs}$ were analyzed immediately after the $\mathrm{T}=24 \mathrm{hr}$ samples were collected. Due to the instrument problem discussed above in the dissolved plume media experiment, these samples were analyzed using the GC that had been used for the co-contaminants experiments. The MDL for this instrument calibration was $10 \mu \mathrm{g} / \mathrm{L}$ rather than $5 \mu \mathrm{g} / \mathrm{L} \mathrm{TCE}$.

One of the three vials containing TSF-05 sludge and groundwater was broken soon after TCE equilibration has been initiated. Thus, only the results of 2 slurries samples and 1 groundwater only sample are presented here. Gravimetric analyses indicated that $>98 w t \%$ of the contents from each of the $40 \mathrm{~mL}$ VOA vials was successfully transferred into each reactor of hexane. The TCE concentrations measured for each hexane aliquot are presented in Figure 118. Note that many of the TCE values presented in Figure118 just barely exceeded that of the largest calibration standard $(1,169 \mu \mathrm{g} / \mathrm{L})$. As was observed in the first hexane extraction time experiment (Exp. 2b-3), hexane rapidly extracts TCE from both the sludge and groundwater samples. The measured TCE concentrations for the groundwater only sample are lower than those of the slurries because a larger volume of groundwater was present in that vial (i.e., lower initial aqueous concentration).

From Figure 118, it also appears that the amount of TCE being extracted is increasing with time for each sample. However, the concentrations presented in Figure 118 only represent the concentrations of TCE in the $1 \mathrm{~mL}$ hexane aliquot and does not take into account any TCE that was removed from the extracting slurry by previous aliquot sampling event(s). Thus, the same TCE sample data is expressed in \% TCE mass recovered in Figures 119, 120, and 121 for the first, second, and third test reactors, respectively. The percentage of the TCE removed from each reactor via previous aliquot samplings is also presented in Figures 119-121. Upon adding the sample TCE recovery and the aliquot recoveries in these figures, one can observe that there is little variation in the total TCE recovery (sum of the two fractions) with extraction time. This result further substantiates the use of a $24 \mathrm{hr}$ hexane extraction time for the hot spot media.

Because of the spiking technique employed (use of a saturated TCE solution), the initial amount of TCE present in each reactor was not directly measured. However, each reactor should have initially contained $\approx 44 \mu \mathrm{g}$ TCE at the start of equilibration, if one assumes that the saturated TCE solution used to spike the test reactors was $1,100 \mathrm{mg} / \mathrm{L}$. It is realized that a matrix spike 
experiment will yield results that are more definitive if the initial spiking concentration is known. Measurement of the saturated TCE solution concentration was an oversight. This is likely why the total TCE recoveries presented in Figures 119-121 are all greater than 100\%.(Average 106\%, $\sigma=1.4 \%$ ). However, it is believed that all of the initial TCE has been extracted from both the slurry and groundwater only matrices. In addition, the total TCE masses represented by Figures 119-121 do not vary by more than $2.2 \mu \mathrm{g}$ TCE for any sample matrix or extraction time examined. Hence, the use of hexane to extract TCE from the TAN site matrices is believed to be valid. (Additional information and calculations are presented in Appendix $\mathbf{C}$ for this experiment.)

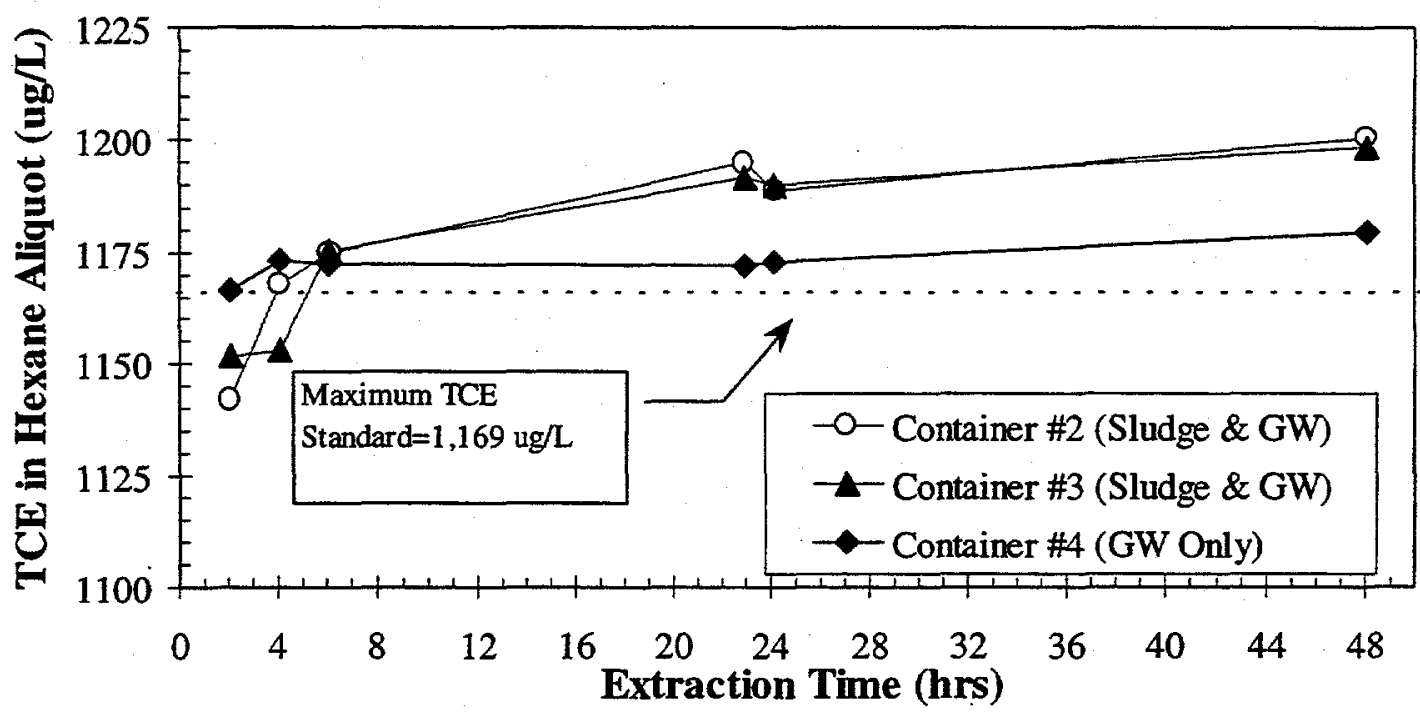

Figure 118. Hexane Aliquot TCE vs. Extraction Time, TSF-05 Sludge \& Groundwater, (ORNL Exp. $2 \mathrm{~b}-3 \mathrm{~b}$, Initial TCE $=1,000 \mu \mathrm{g} / \mathrm{L}$, Conducted at $12^{\circ} \mathrm{C}, 4: 1 \mathrm{~L} / \mathrm{S}$ Ratio where applicable, $0 \% \mathrm{MnO}_{4}^{-}$) 


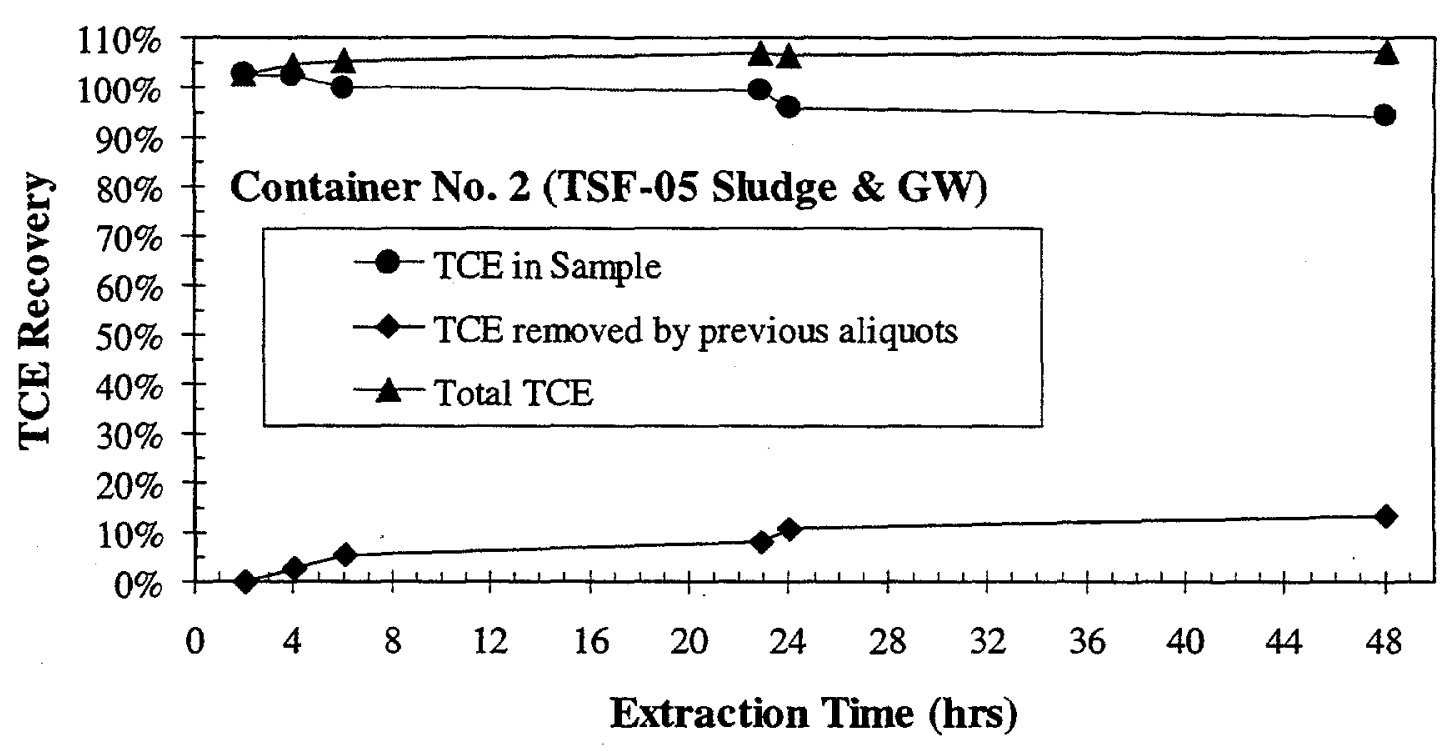

Figure 119. , TCE Recovery vs. Hexane Extraction Time, TSF-05 Sludge \& Groundwater (\#1), (ORNL Exp. 2b-3b, Initial TCE $=1,000 \mu \mathrm{g} / \mathrm{L}$, Conducted at $12^{\circ} \mathrm{C}, 4: 1 \mathrm{~L} / \mathrm{S}$ Ratio, $0 \%$ $\mathrm{MnO}_{4}^{-}$)

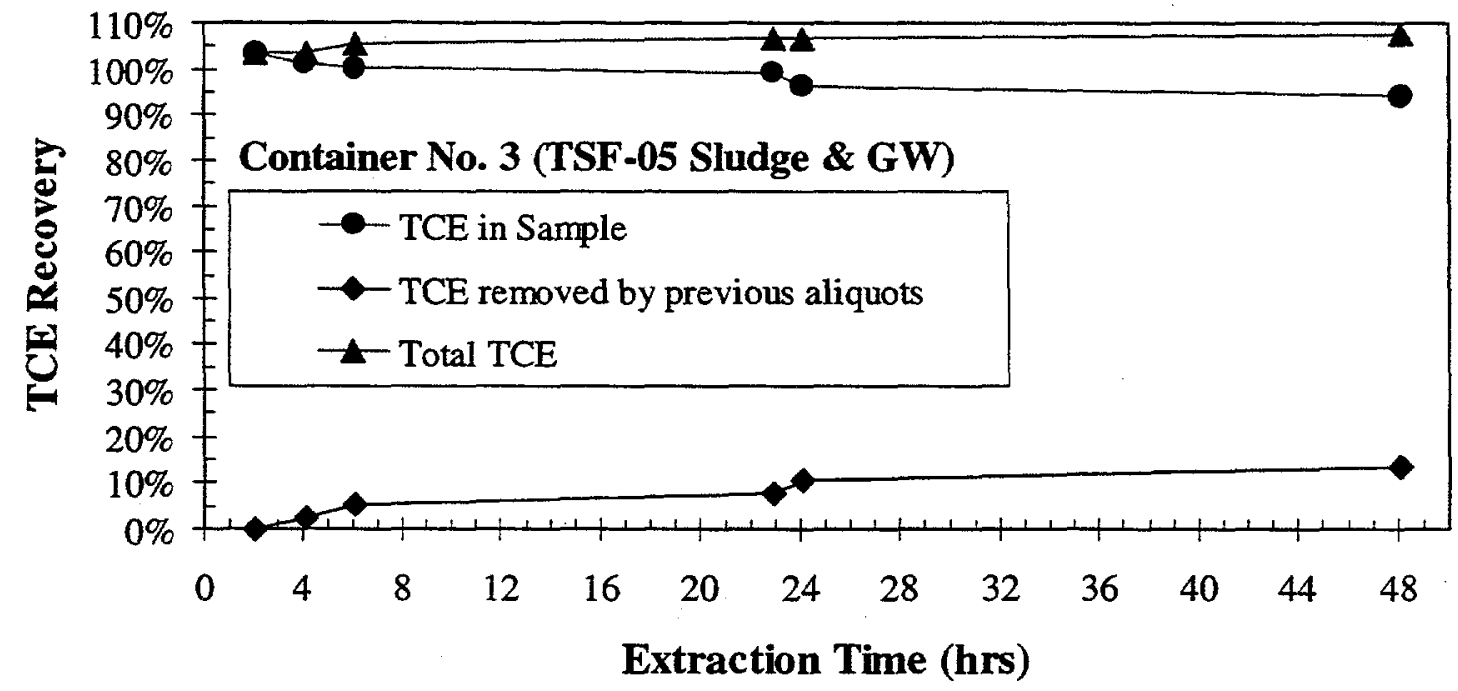

Figure 120. TCE Recovery vs. Hexane Extraction Time, TSF-05 Sludge \& Groundwater (\#2), (ORNL Exp. 2b-3b, Initial TCE $=1,000 \mu \mathrm{g} / \mathrm{L}$, Conducted at $12^{\circ} \mathrm{C}, 4: 1 \mathrm{~L} / \mathrm{S}$ Ratio, $0 \%$ $\mathrm{MnO}_{4}{ }^{-}$) 


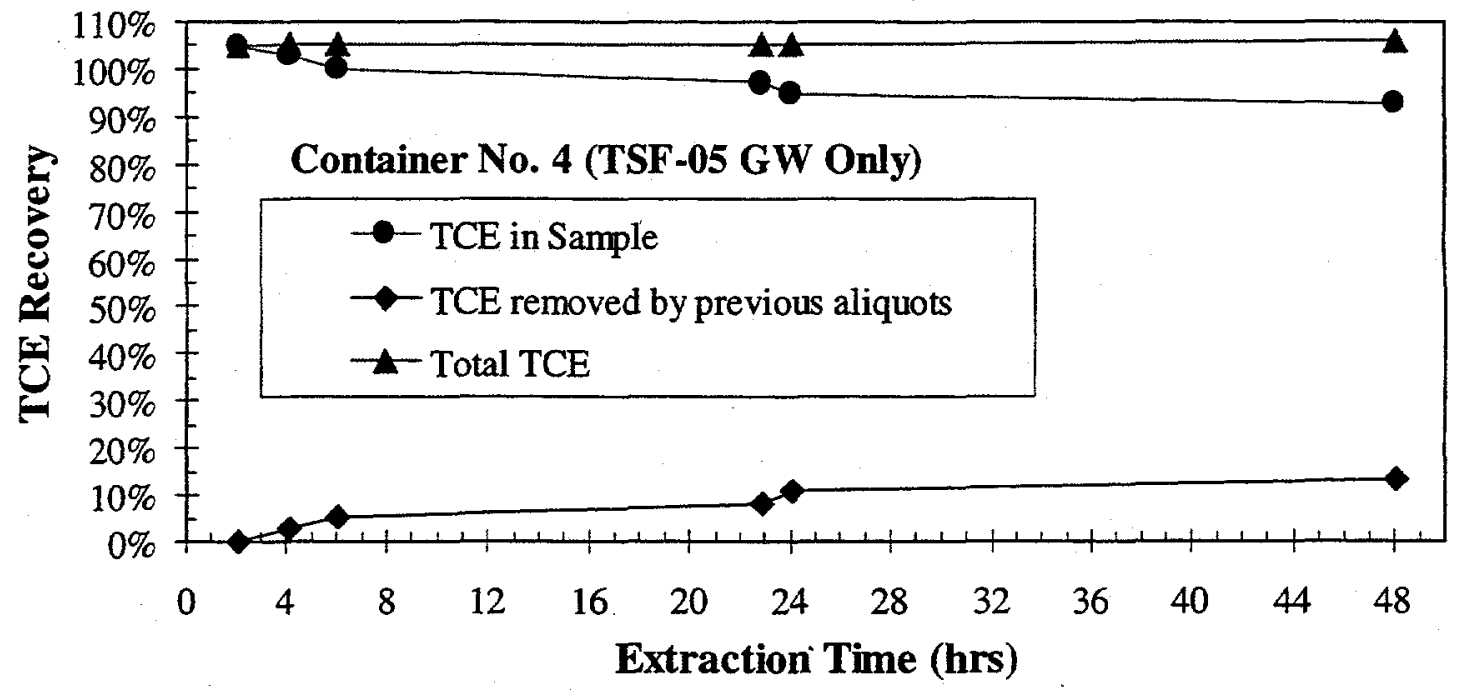

Figure 121. TCE Recovery vs. Hexane Extraction Time, TSF-05 Groundwater Only, (ORNL Exp. $2 \mathrm{~b}-3 \mathrm{~b}$, Initial TCE $=1 ; 000 \mu \mathrm{g} / \mathrm{L}$, Conducted at $12^{\circ} \mathrm{C}, 4: 1 \mathrm{~L} / \mathrm{S}$ Ratio, $0 \% \mathrm{MnO}_{4}{ }^{-}$) 


\subsubsection{TASK 5. WASTE DISPOSAL}

All VOC-spiked TAN Site media used in this project have been declared as solid level waste and RCRA hazardous waste. The material is currently being handled and will ultimately be treated and/or stored according to both RCRA regulations and ORNL guidelines. Per the SOW, all unused TAN media is currently being prepared for shipment back to INEEL as the original generator of the RCRA material used in this US EPA treatability study. 


\section{CONCLUSIONS AND RECOMMENDATIONS}

In general, the oxidant demand of the geologic media (groundwater, basalt, and fracture-fill material) was low, while the oxidant demand of organic sludge from TSF- 05 was very high. The rate of TCE oxidation was rapid, and when sufficient permanganate was available for oxidation to proceed to completion, TCE concentrations declined to less than the MDL. Permanganate oxidation was effective for destroying (1) TCE in the dissolved phase, (2) TCE initially present as a non-aqueous phase, (3) DCE isomers, and (4) organic sludge.

These observations indicate that ISCO is well suited for remediating both dissolved phase contamination and secondary sources of contamination in the hot spot, if oxidant can be delivered to the in situ contaminants.

A field evaluation at the hot spot should be performed to evaluate the performance of ISCO under field conditions.

Conclusions and recommendations are presented below for each task. Additional details are available for each task in Section 2.0

\subsection{TASK 1 - PREPARATION OF PROJECT PLANNING DOCUMENTS}

Conclusions:

All project planning documents needed to execute this study were obtained.

Recommendations: None.

\subsection{TASK 2 - PRELIMINARY LABORATORY STUDIES}

\subsubsection{Reactor Development}

Conclusion:

- A reactor suitable for executing this study was developed. In general, it performed well.

Recommendation:

- Procedures should be modified to allow quantification of the mass of individual VOCs in the headspace in order to determine better mass balance estimates. 


\subsubsection{Hexane Extraction Time}

\section{Conclusions:}

- The 2-hour extraction time was adequate for groundwater, crushed basalt, sediment, and sludge.

- A 2-hour extraction time was assumed to be adequate for extraction of VOCs from aggregate basalt, but this assumption has not been rigorously evaluated.

Recommendation:

- The adequacy of the hexane extraction time for aggregate basalt should be further evaluated before performing additional laboratory studies of ISCO using these materials.

\subsubsection{Determination of Equilibration Time for Aggregate Basalt with TCE}

Conclusion:

- This activity was attempted twice without success. These equilibration experiments are conducted for time periods on the order of days to weeks. Due to the delays that would have been encountered in beginning the Task 3 and Task 4 experiments, a third attempt at this task was not performed. Instead, an overnight equilibration period was selected for the aggregate basalt medium in the Task 4 experiments.

Recommendation:

- The adequacy of the overnight equilibration period should be further evaluated before performing additional laboratory studies of ISCO using this material. This will require the preparation of new test methods and equipment to better minimize TCE losses.

\subsection{TASK 3 - MEASUREMENT OF OXIDANT DEMAND OF TAN SUBSURFACE MATERIALS}

\subsubsection{Laboratory Controls and QA}

Conclusion:

- Due to the low oxidant demand observed for most of the TAN site media, the spectrophotometric method used for $\mathrm{MnO}_{4}{ }^{-}$analyses was not capable of quantifying the very small changes in $\mathrm{MnO}_{4}{ }^{-}$concentrations that appeared to be occurring for groundwater and the dissolved plume media. However, it was determined prior to the start of the ORNL studies that the use of the spectrophotometric technique would be suitable for the level of QA desired for this parameter.

\section{Recommendation:}

- If extremely precise determinations of small $\mathrm{MnO}_{4}{ }^{-}$concentration changes are needed in the future, a more time-consuming standard titration method should be considered for the $\mathrm{MnO}_{4}{ }^{-}$ analyses. 


\subsubsection{Oxidant Demand in Dissolved Plume Media}

Conclusions:

- The oxidant demand of groundwater, aggregate basalt, crushed basalt, and sediment were all low, approximately 0.01 to $0.2 \mathrm{mg} \mathrm{MnO}_{4}^{-} / \mathrm{g}$ medium. These values are less than the value determined in a preliminary study conducted elsewhere, on the order of $1 \mathrm{mg} \mathrm{MnO}_{4}^{-} / \mathrm{g}$ basalt.

- Fracture fill material, i.e. sediment, had the highest oxidant demand of the geologic materials examined.

Recommendation:

- Field scale measurement of oxidant demand in the dissolved plume is not needed.

\subsubsection{Oxidant Demand in Hot Spot Media}

\section{Conclusions:}

- The oxidant demand of groundwater from TSF-05 is small and comparable to the demand measured on groundwater from the dissolved plume (TAN-40).

- The oxidant demand of organic sludge from TSF-05 is approximately three orders of magnitude greater than the oxidant demand of basalt and sediment, on the order of $70 \mathrm{mg}$ $\mathrm{MnO}_{4}{ }^{-} / \mathrm{g}$ sludge. This sludge has the highest oxidant demand of any material examined in this study.

- Consumption of oxidant by reactions with sludge would be a substantial sink of oxidant in a field scale application of ISCO.

- Oxidation by $\mathrm{MnO}_{4}{ }^{-}$is an effective means of destroying organic sludge.

Recommendation:

- Evaluation of ISCO via a field test at the hot spot is warranted. 


\subsection{TASK 4 - MEASUREMENT OF OXIDATION RATES OF TAN SUBSURFACE MATERIALS}

\subsubsection{Laboratory Controls and QA}

Conclusions:

- Over 2,200 samples were uniquely labeled, tracked, and analyzed for VOCs via gas chromatography. Proper instrument performance was validated via calibration checks for over $95 \%$ of the samples analyzed. In addition, there is no information available to suggest that the instrument(s) was not performing properly for the remaining $5 \%$ of the samples.

- Analyses of duplicate aliquots for 160 test samples resulted in an average percent difference of $3 \%$ between duplicates.

- TCE was found in the sample blanks from some of the TCE degradation experiments. Such occurrences are clearly noted in the experimental discussions. Contamination of these blanks, however, did not severely affect the results/interpretation of the experiments. The amount of TCE found is such blanks (typically $<10 \mu \mathrm{g} / \mathrm{L}$ TCE) was several orders of magnitude less than the amount of TCE that was oxidized by $\mathrm{MnO}_{4}{ }^{-}$.

Recommendation:

- Given the large number of samples managed and analyzed in this study, the level of QA/QC imposed upon these VOC analyses should be considered acceptable for evaluating the results of this ISCO treatability study. If a higher level of QA is needed in future ISCO studies, enough funds should be allocated to have the VOC analyses subcontracted out to a certified analytical laboratory.

\subsubsection{Oxidation Rate of Organic Contaminants in Dissolved Plume Media}

Conclusions:

- TCE was readily oxidized at the $\mathrm{MnO}_{4}{ }^{-}$concentrations used, $0.01 \%$ and $0.1 \%(100 \mathrm{mg} / \mathrm{L}$ and $1 \mathrm{~g} / \mathrm{L}$ ).

- TCE oxidation was so fast that the data resolution was generally not sufficient to determine reliable reaction rate parameter values because TCE concentrations generally declined to < MDL concentrations before the first or second samples were collected. The lower bound of the zero order reaction rates was estimated by assuming that the TCE concentration reached zero when the first or second sample, as appropriate, was collected.

- The estimated zero order reaction rates increased with both initial $\mathrm{MnO}_{4}{ }^{-}$and TCE concentrations, and ranged from 0.1 to $4 \mathrm{mg} \mathrm{TCE} / \mathrm{L}$ /hour.

- Sufficient data were available in a few cases to determine first order reaction rate constants. These range from $1.64 \mathrm{hr}^{-1}$ to $4.28 \mathrm{hr}^{-1}$ (average $=22.2 \mathrm{hr}^{-1}, \sigma=1 \mathrm{hr}^{-1}$ ). All of the first order reaction rate constants correspond to experiments involving $0.01 \% \mathrm{MnO}_{4}{ }^{-}$. There appears to be no trend with initial TCE concentration for these rate constants. Reaction rates were too rapid for the $0.1 \% \mathrm{MnO}_{4}{ }^{-}$case to allow for their computation. 
- There were no differences in reaction rate that could be attributed to different media (groundwater only, crushed basalt, aggregate basalt, and sediment).

- Changes in $\mathrm{pH}$ are too small to be of practical use for monitoring the progress of a field application of ISCO.

Recommendation:

- Oxidation of TCE by $\mathrm{MnO}_{4}{ }_{4}^{-}$is sufficiently rapid that field scale evaluation of ISCO is warranted.

\subsubsection{Oxidation Rate of Organic Contaminants in Hot Spot Media}

\subsubsection{Hot Spot Groundwater}

Conclusions:

- Higher concentrations of both $\mathrm{MnO}_{4}{ }^{-}$and TCE were used in this set of experiments than in the 'dissolved plume' experiments. Initial $\mathrm{MnO}_{4}{ }^{-}$concentrations ranged from $0.01 \%$ to $3 \%$ $(100 \mathrm{mg} / \mathrm{L}$ to $30 \mathrm{~g} / \mathrm{L})$. Initial TCE concentrations ranged from 10,000 to $1,000,000 \mu \mathrm{g} / \mathrm{L}$ (10 to $1,000 \mathrm{mg} / \mathrm{L}$ ). TCE was present as a non-aqueous phase liquid at the highest concentration.

- These experiments suggest that approximately $50 \%$ of the initial aqueous TCE added to the test reactors is immediately sorbed to the sludge during the equilibration period.

- In some cases; the mass of $\mathrm{MnO}_{4}{ }^{-}$was insufficient to oxidize all of the TCE present, and TCE concentrations remained high.

- If the concentration of $\mathrm{MnO}_{4}{ }^{-}$was sufficient, TCE was rapidly oxidized to less than MDLs.

- TCE oxidation was so fast that the data resolution is generally not sufficient to determine reliable reaction rate parameter values because TCE concentrations generally declined to < MDL concentrations before the first or second samples were collected. The lower bound of the zero order reaction rates was estimated by assuming that the TCE concentration reached zero when the first or second sample, as appropriate, was collected.

- The zero order reaction rate estimates increased with both initial $\mathrm{MnO}_{4}{ }^{-}$and TCE concentrations, and ranged from 1 to $4,100 \mathrm{mg}$ TCE /L/hour. The rates observed in this set of experiments are faster than those observed in the 'dissolved plume' experiments largely because of the higher TCE concentrations used in the 'hot spot' experiments

- Sufficient data were available in only one case to determine first order reaction rate constant. ( $1.7 \mathrm{hr}^{-1}$ for the $0.01 \% \mathrm{MnO}_{4}{ }^{-}$reactors in Exp. 4b-R5) Again, the overall faster degradation rates observed for this series of experiments were likely influenced by the higher TCE concentrations in these 'hot spot' experiments.

- Permanganate rapidly oxidized TCE that was initially present as a non-aqueous phase liquid.

- Changes in pH were very large compared to the changes observed in the 'dissolved plume' experiments. The magnitude of the $\mathrm{pH}$ changes increased with both initial $\mathrm{MnO}_{4}{ }^{-}$and TCE concentrations. However, the reaction vessels used in these experiments did not contain a solid phase, which could buffer $\mathrm{pH}$ changes. Therefore, it cannot be concluded that $\mathrm{pH}$ changes of this magnitude would be observed in a field application of ISCO. 


\section{Recommendation:}

- Oxidation of high concentrations of TCE, including TCE initially present as a non-aqueous phase, is sufficiently rapid that field evaluation of ISCO in the hot spot is warranted.

\subsubsection{Hot Spot Sludge}

Conclusions:

- The concentrations of $\mathrm{MnO}_{4}{ }^{-}$and TCE used in this set of experiments was the same as that used in the 'hot spot - groundwater' experiments.

- In some cases, the mass of $\mathrm{MnO}_{4}{ }^{-}$was insufficient to oxidize all of the TCE present, and TCE concentrations remained high.

- TCE was rapidly oxidized to less than MDLs if the concentration of $\mathrm{MnO}_{4}{ }^{-}$was sufficient.

- TCE oxidation was so fast that the data resolution is generally not sufficient to determine reliable reaction rate parameter values because TCE concentrations generally declined to $<$ MDL concentrations before the first or second samples were collected. The lower bound of the zero order reaction rates was estimated by assuming that the TCE concentration reached zero when the first or second sample, as appropriate, was collected.

- The zero order reaction rate estimates increased with both initial $\mathrm{MnO}_{4}{ }^{-}$and TCE concentrations, and ranged from 16 to $2,000 \mathrm{mg}$ TCE $/ \mathrm{L} /$ hour. The rates observed in this set of experiments are faster than those observed in the 'dissolved plume' experiments largely because of the higher TCE concentrations used in the 'hot spot' experiments, but lower than those observed in the 'hot spot - groundwater' experiments because of reduced $\mathrm{MnO}_{4}{ }^{-}$ concentrations resulting from sludge oxidation.

- Sufficient data were available in most cases to determine first order reaction rate constants due to (1) very rapid TCE degradation or (2) insufficient initial oxidant loading. However, the case in which the TCE-spiked (DNAPL) sludge was treated with $3 \% \mathrm{MnO}_{4}^{-}$, a first order reaction rate constant of $4 \mathrm{hr}^{-1}$ was computed.

- Permanganate rapidly oxidized TCE that was initially present as a non-aqueous phase liquid.

- Consumption of $\mathrm{MnO}_{4}{ }^{-}$during oxidation of sludge reduced oxidant concentrations and slowed the rate of TCE oxidation compared to the rates observed at similar concentrations in the 'hot spot - groundwater' experiment. However, even the slower rates observed in these experiments are extremely rapid relative to the time scale needed for field application of ISCO.

- In some cases, oxidation of sludge consumed the available $\mathrm{MnO}_{4}{ }^{-}$before all of the TCE was oxidized, while at similar concentrations without sludge present TCE was oxidized to $\angle \mathrm{MDL}$ concentrations. This illustrates that the oxidant demand of sludge must be satisfied in order to achieve complete oxidation of TCE.

- Baseline characterization work on the TSF-05 revealed an initial dried total carbon value of $\approx$ 8.6\%. After oxidation by $\mathrm{MnO}_{4}{ }^{-}$in the Task 4 experiments, post-treatment carbon values ranged between $1.6 \%$ and $6.6 \%$. The degree to which the sludge is oxidized during ISCO appears to be dependent on both the initial TCE and initial oxidant loading. 
- $\quad$ pH changes were much smaller than those observed in the 'hot spot - groundwater' experiments, presumably due to buffering of $\mathrm{pH}$ by organic sludge. The $\mathrm{pH}$ changes are so small that $\mathrm{pH}$ would not be suitable for monitoring the progress of a field application of ISCO.

Recommendations

- The rate of TCE and sludge oxidation are fast enough, and the TCE concentrations that remain after oxidation are low enough, that further field scale evaluation of ISCO at the hot spot is warranted.

\subsection{TASK 5 - WASTE DISPOSAL}

- This task is currently being conducted. ORNL personnel will ensure that all treatment residuals are properly stored and/or disposed of. Unused TAN material currently present at ORNL will be returned. INEEL officials will handle its ultimate disposition. 



\section{REFERENCES}

Ball, William. 1991. "Long-Term Sorption of Halogenated Organic Chemicals by Aquifer Material: 1. Equilibrium," Environmental Science and Technology, 25(7):1223-1249.

Istok, J. D. 1998. Unpublished Data, Measurement of Oxidant Demand of Surficial Samples from Hell's Half Acre, Idaho. Oregon State University, Corvallis, Oregon.

Pavlostathis, S.G., and K. Jaglal. 1991. "Desorptive Behavior of Trichloroethylene in Contaminated Soil," Environmental Science and Technology, 25(2):274-279.

Rowley, Debbie. 1997. "Shipment of Sludge and Groundwater Samples from TAN RCS-3397," INEEL Interdepartmental Memo to Bob Starr, October 27, 1997.

US EPA (U.S. Environmental Protection Agency). 1997. Test Methods for Evaluating Solid Waste, Physical/Chemical Methods (SW-846). CD-ROM, Version 2.0. (3rd Edition with Final Updates I, II, IIA, IIB, and III). National Technical Information Service, Springfield, Virginia.

Verschueren, K. 1983. Handbook of Environmental Data on Organic Chemicals, $2^{\text {nd }}$ edition. Van Nostrand Reinhold Co., New York. 
Appendix A-Scope of Work 



\section{Scope of Work for \\ Laboratory Evaluation of In Situ Chemical Oxidation \\ as a Technology for Groundwater Restoration \\ at the INEEL TAN Site}

December 10, 1997

$\begin{array}{ll}\text { Subcontractor: } & \text { Oak Ridge National Laboratory } \\ \text { Environmental Sciences Division } \\ \text { P.O. Box 2008 } \\ \text { Oak Ridge, TN 37831-6036 }\end{array}$

Technical Contact: Dr. Olivia R. West

(423) 576-0505 voice

(423) 576-8543 Fax

\section{Background}

The use of in situ chemical oxidation (ISCO) as a technology for remediating the secondary source of groundwater contamination at the INEEL near injection well TSF-05 is being evaluated. Oxidant demand and reaction rates will be measured in laboratory studies, which will be followed by field evaluations if the results from the laboratory investigation are promising.

Laboratory studies will be performed by researchers at the Oak Ridge National Laboratory, Environmental Sciences Division. The ORNL research team has been performing laboratory and field investigations on ISCO for subsurface remediation for approximately four years, and has the laboratory facilities and experience needed to perform the required experiments.

\section{Assumptions}

The following assumptions were made to prepare this scope of work.

1. Organic sludge from TSF- 05 contains radionuclides at sufficiently high activities that experiments in which organic sludge is used must be conducted in the Radioactive Materials Analytical Laboratory at ORNL, but cannot be conducted in the Environmental Sciences Division laboratories.

2. Groundwater, basalt, and sediment from fractures in basalt do not contain radionuclides at activities that would preclude their use in experiments conducted in the Environmental Sciences Division laboratories.

3. Groundwater, basalt, and sediment will be delivered to ORNL by January 6, 1998 . 
4. Organic sludge from TSF-05 does not contain PCBs at concentrations greater than 50 ppm, and therefore is not regulated by the Toxic Substances Control Act.

5. Organic sludge will be delivered to ORNL by January 26,1998 .

6. Temperature control equipment will be delivered by a vendor to ORNL by January 30 , 1998.

If information generated during this investigation invalidates the assumptions made to prepare this Scope of Work, then ORNL should notify the INEEL Technical Point of Contact, Dr. Robert Starr, and request any changes in scope, schedule, and budget required because the actual conditions differ from the assumed conditions.

\section{Scope of Work}

The majority of the work to be performed by the subcontractor is described in Draft In Situ Chemical Oxidation Implementation Plan Test Area North Final Groundwater Remediation Operable Unit 1-07B, INEEL/EXT/97-01111, Revision 0, which will be referred to as the 'Implementation Plan'. Chapter 2 Laboratory Studies has been substantially revised in accordance with agency review comments. References to Chapter 2 of the Implementation Plan are intended to refer to the revised Chapter 2 that is presented in Appendix A of this Scope of Work.

\section{Task 1 Prepare Project Planning Documents}

Project planning documents include:

- A Laboratory Test Plan that describes the technical aspects of the research, including quality assurance, in greater detail than presented in the Draft Implementation Plan;

- Environmental, safety, and health (ES\&H) planning documentation;

- RCRA treatability study notification;

- Any other documentation required for conducting laboratory studies at ORNL.

\section{Task 1a Prepare Laboratory Test Plan}

Prepare a Laboratory Test Plan that describes the laboratory experiments in detail, and refers to or includes quality assurance procedures. The activities to be addressed are described in Tasks 2 through 4 of this scope of work. Submit a draft to INEEL for review and a final version that has been modified in response to INEEL review comments. 


\section{Task $1 b$ Prepare Other Planning Documents and Obtain Permits}

Prepare the ES\&H documentation required by ORNL. Submit RCRA treatability study notification. Prepare any other planning documents required by ORNL.

The ES\&H documentation will be prepared under the assumption that the material to be shipped from INEEL will be below TSCA action limits of $50 \mathrm{ppm}$. PCB analyses of the material will be conducted PRIOR to shipment to ORNL. If the material is found to have PCB concentrations near or greater than $50 \mathrm{ppm}$, the material will not be shipped to ORNL until additional arrangements and changes in both ESH\&Q documentation and work scope are made.

\section{Task 2 Preliminary Laboratory Studies}

Preliminary studies are needed to refine laboratory procedures that will be used to measure oxidation demand (Task 3) and oxidation rates (Task 4).

\section{Task $2 a$ Reactor Development}

Purchase and test reaction vessels that will be used for the oxidant consumption and oxidation rate studies.

\section{Task $2 b$ Determine Time Required for Hexane Extraction of TCE from Aqueous Samples, Organic Sludge, Sediment, and Basalt}

Samples for analysis of organic analytes (TCE, DCE, etc.) are prepared by extracting organic solutes from solution into an organic solvent, hexane, and then determining the concentration of the solutes in hexane. The transfer of organic solutes into hexane is not instantaneous, particularly if the organic solute is associated with solid phase material such as basalt or organic sludge. The goal of this task is to determine the length of time necessary for the transfer of organic solutes from aqueous samples, sludge, sediment, and both crushed and aggregate basalt into hexane.

Perform a study to determine the length of time required for hexane extraction to transfer essentially all of the mass of TCE from either aqueous samples, organic sludge, sediment, or basalt into the organic (i.e. hexane) phase. Select extraction times to be used in subsequent experiments.

Submit a prelíminary report that presents the principal results of this task, followed by more detailed information in the final report. The analytical and final reporting procedures shall comply with sections 2.4 and 9.1 of the Draft Implementation Plan. 


\section{Task 2c Determine Time Required to Equilibrate Basalt Aggregate with TCE Solutions}

Basalt aggregate, i.e. $1 / 2$ to 1 inch diameter pieces of vesicular basalt, will be used in the laboratory experiments described in the Implementation Plan. One step in the experiments is to equilibrate TCE concentrations in matrix pore water of the basalt pieces with TCE concentrations in the surrounding water. The length of time needed for this equilibration process to occur is unknown. The goal of this task is to determine the length of time required for equilibrium to be reached between TCE in the matrix pore water and the surrounding solution.

Perform a study to determine the relationship between equilibration time, i.e. the length of time that aggregate is immersed in a TCE solution, and the mass of TCE that can be extracted per unit mass of aggregate basalt.

Submit a preliminary report that presents the principal results of this task, followed by more detailed information in the final report. The analytical and final reporting procedures shall comply with sections 2.4 and 9.1 of the Draft Implementation Plan.

\section{Task 3 Measure Oxidant Demand of TAN Subsurface Materials}

The oxidant demand exerted by materials present in the subsurface at TAN will influence the mass and concentration of oxidant that must be injected during field evaluations and full scale implementation of ISCO.

\section{Task $3 a$ Measure the Oxidant Demand of Reactive Zone Media}

Measure the oxidant demand of groundwater from TAN-29, crushed and aggregate basalt, and sediment (fracture fill material). Use the approach described in Section 2.2 of the Implementation Plan, and the experimental treatments described in Table 2-3.

Submit a preliminary report that presents the principal results of this task, followed by more detailed information in the final report. The analytical and final reporting procedures shall comply with sections 2.4 and 9.1 of the Draft Implementation Plan.

\section{Task $3 b$ Measure the Oxidant Demand of Hot Spot Media}

Measure the oxidant demand of groundwater and organic sludge from TSF-05. Use the approach described in Section 2.2 of the Implementation Plan, and the experimental treatments described in Table 2-4.

Submit a preliminary report that presents the principal results of this task, followed by more detailed information in the final report. The analytical and final reporting procedures shall comply with Sections 2.4 and 9.1 of the Draft Implementation Plan. 


\section{Task 4 Measure Oxidation Rates}

Oxidation rates as a function of oxidant and contaminant concentration must be determined in order to evaluate the feasibility of ISCO and to design field evaluations and full scale implementations of ISCO.

\section{Task 4a Measure the Oxidation Rate of Organic Contaminants in Reactive Zone Media}

Measure the rate of TCE oxidation in groundwater from TAN-29, crushed and aggregate basalt, and sediment (fracture fill material). Use the approach described in Section 2.2 of the Implementation Plan, and the experimental treatments described in Table 2-5.

Submit a preliminary report that presents the principal results of this task, followed by more detailed information in the final report. The analytical and final reporting procedures shall comply with sections 2.4 and 9.1 of the Draft Implementation Plan.

\section{Task $4 b$ Measure the Oxidation Rate of Organic Contaminants in Hot Spot Media}

Measure the rate of TCE oxidation in groundwater and organic sludge from TSF-05. Use the approach described in Section 2.2 of the Implementation Plan, and the experimental treatments described in Tables 2-6 and 2-7.

Submit a preliminary report that presents the principal results of this task, followed by more detailed information in the final report. The analytical and final reporting procedures shall comply with sections 2.4 and 9.1 of the Draft Implementation Plan.

\section{Task 5 Waste Disposal}

The laboratory residuals generated in this investigation must be disposed in accordance with applicable regulations. Dispose of wastes and unaltered samples according to the procedures described in Section 7.3 of the Implementation Plan. All laboratory residuals generated in this study will be disposed by ORNL, with the following exceptions:

1. Unused, unaltered samples may be returned to INEEL for disposal;

2. If sludge from TSF-05 is determined to be regulated under the Toxic Substances Control Act, then samples and apparatus that contacted the sludge shall be returned to INEEL for disposal. Lab residuals that did not contact sludge will be disposed by ORNL.

\section{Task 6 Progress Reports}

Submit monthly reports that summarize the budget status and technical progress during the last month and for the project to date. An example of a monthly report is attached. 


\section{Task 7 Final Report}

Submit a final report as described in Section 9.1 of the Implementation Plan, and data packages.

\section{Task 8 Present Results of the Laboratory Study}

Present the results of the laboratory study in a one-day meeting to be held in either Idaho Falls, Idaho, Boise, Idaho, or Seattle, Washington. The location and date will be determined approximately one month in advance of the meeting. 


\section{Schedule and Deliverables}

Table A1. Schedule and deliverables

\begin{tabular}{|c|c|c|}
\hline \multirow{3}{*}{ 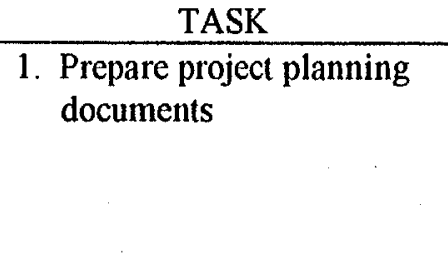 } & DELIVERABLE & SUBMITTAL DATE \\
\hline & $\begin{array}{c}\text { la Laboratory Test Plan - draft for review } \\
\text { - final version }\end{array}$ & $\begin{array}{l}\text { December } 19,1997 \\
\text { January } 7,1998\end{array}$ \\
\hline & $\begin{array}{l}\text { lb Letter confirming that all permits, permissions, and documents } \\
\text { needed to perform Tasks } 2-5 \text { are in place. }\end{array}$ & December 23, 1997 \\
\hline $\begin{array}{l}\text { 2. Refine laboratory } \\
\text { procedures }\end{array}$ & 2a-c Preliminary report & January 30, 1998 \\
\hline \multirow[t]{2}{*}{ 3. Measure oxidant demands } & 3a Preliminary report. & February 23, 1998 \\
\hline & 3b Preliminary report & March 20, 1998 \\
\hline \multirow[t]{2}{*}{ 4. Measure oxidation rates } & 4a Preliminary report & April 14, 1998 \\
\hline & 4b Preliminary report & May 29, 1998 \\
\hline 5. Waste disposal & $\begin{array}{l}\text { Letter confirming that all laboratory residuals and unaltered } \\
\text { samples have been disposed in compliance with applicable } \\
\text { regulations }\end{array}$ & June 19,1998 \\
\hline 6. Progress Reports & Monthly reports of costs and technical progress. & $\begin{array}{l}\text { Ten days after the end of each } \\
\text { accounting month }\end{array}$ \\
\hline 7. Final Report & Final report & June 12,1998 \\
\hline 8 Present Results & Presentation of results. & To be determined. \\
\hline
\end{tabular}




\section{Sample Monthly Report}

Month

\section{Budget}

Labor Hours

Labor Cost

Non-Labor Cost

Total Monthly Cost

Cumulative Project Cost

Total Budget

Technical Progress

Technical Problems and Proposed Resolutions 


\section{A2. LABORATORY STUDIES \\ Excerpted from Draft In Situ Chemical Oxidation Implementation Plan Test Area North Final Groundwater Remediation Operable Unit 1-07B, INEEL/EXT-97-01111, Rev 1.}

This section describes laboratory studies that will be used to evaluate the feasibility of implementing ISCO to remove TCE contamination from the TAN site, and to provide data that will be used to design field evaluations, including both short term single well tests and longer term, larger scale evaluations in a reactive zone and at the hot spot. Lab studies will focus on quantifying oxidant consumption by groundwater, basalt, sludge, and sediment that fills basalt fractures, as well as reaction kinetics between potassium permanganate and TCE. Bench-scale experiments using materials taken from the TAN site will be conducted to establish the effectiveness of ISCO for removing TCE from the hot spot and the reactive zone. Furthermore, the optimum range of oxidant loadings for the hot spot and reactive zone will be determined based on TCE degradation kinetics and the amount of oxidant consumed by the natural (basalt and sediment) and anthropogenic (organic sludge) materials underlying the TAN site.

The effect of chemical oxidation on the migration of radionuclides and metals will not be investigated in the laboratory, but instead will be assessed via a transport modeling study.

\section{A2.1 Objectives and Data Gaps}

Results of laboratory studies will be used to evaluate the feasibility of ISCO for aquifer remediation, and for designing field evaluations of ISCO. The major questions addressed by laboratory studies are:

1. What are suitable concentrations of oxidant for use in single well tests, a field evaluation at the hot spot, and full scale implementation at the hot spot?

2. How much oxidant will be needed for single well tests, field evaluations, and full scale implementation at the hot spot?

Suitable concentrations can be determined based on the organic contaminant destruction rate as a function of oxidant concentration and on the amount of oxidant consumed by other reactions. The amount of oxidant needed can be determined from measurements of oxidant demand by materials present in the subsurface at TAN.

The objectives of this task are:

1. To determine potassium permanganate consumption rate and amount as a function of medium type (groundwater, basalt, sediment, sludge), potassium permanganate loading, and initial TCE concentration; and,

2. To determine the destruction rate and extent of TCE oxidation as a function of medium type, potassium permanganate loading, and initial contaminant concentration (including the presence of a non-aqueous phase).

The objectives, data gaps, and test methods developed through agency consensus are summarized in Table A2.1. 
Table A2.1. Laboratory reaction studies objectives.

\begin{tabular}{|c|c|c|}
\hline Objective & Data Gap & Test Method \\
\hline \multirow[t]{3}{*}{$\begin{array}{l}\text { Determine the effectiveness of } \\
\text { chemical oxidation for } \\
\text { destroying TCE in TAN } \\
\text { media under ideal conditions }\end{array}$} & $\begin{array}{l}\text { Oxidant demand of TAN } \\
\text { groundwater, basalt, sludge, } \\
\text { and sediment that fills } \\
\text { fractures }\end{array}$ & Lab batch experiments \\
\hline & $\begin{array}{l}\text { TCE destruction rate and } \\
\text { extent, and formation of } \\
\text { chlorinated daughter products } \\
\text { as a function of oxidant } \\
\text { concentration and } \\
\text { contaminant concentration }\end{array}$ & Lab batch experiments \\
\hline & $\begin{array}{l}\text { Rate of DNAPL depletion by } \\
\text { chemical oxidation }\end{array}$ & Lab batch experiments \\
\hline
\end{tabular}

\section{A2.2 Experimental Approach}

Bench-scale batch reaction experiments will be conducted wherein residual TCE and $\mathrm{MnO}_{4}{ }^{-}$is measured in mixtures of TAN groundwater and solid material spiked with TCE and subsequently treated with potassium permanganate. Groundwater for the experiments will be taken from TAN-29 (representative of the reactive zone) and TSF-05 (representative of the hot spot). Organic sludge will be collected from TSF-05. Basalt will be collected from TAN-37 core, and sediment will be collected from fractures in TAN-48 core or archived core.

Experimental variables to be considered in the batch experiments include the following:

- Solid Medium - Within the hot spot, a majority of the TCE is believed to be associated with the organic sludge. Degradation of aqueous TCE in the presence of basalt and sediment present as fracture-fill material is relevant for both the hot spot and reactive zones.

- Basalt Form - Comparison of TCE degradation kinetics between systems with crushed and aggregate basalt may indicate diffusion-limitations that will impact the effectiveness of ISCO for removing TCE from the fractured basalt.

- Liquid-to-Solid Ratio - TCE degradation and potassium permanganate consumption will be measured in systems with groundwater alone (from the reactive zone and hot spot) and groundwater + solid at a 4:1 mass ratio.

- TCE Concentration - TCE concentrations range from low levels (1 ppm) representative of contamination in the reactive zone to DNAPL levels that are potentially present in the hot spot.

- Organic Co-Contaminants - Other chlorinated alkenes (cis-1,2-dichloroethene (DCE), trans-1,2-DCE, and vinyl chloride (VC)) will be included in a subset of the reaction experiments; these compounds have been detected at elevated levels within the TAN site.

- Potassium Permanganate Concentration - Previous studies have indicated that TCE degradation kinetics increase with permanganate concentration. A wide range of potassium permanganate concentrations will be evaluated, with lower and higher oxidant concentrations anticipated for the reactive zone and hot spot respectively.

- Temperature - Oxidant consumption and oxidation rate will be measured at 12 Celsius. 
Table A2.2 summarizes the conditions/levels to be tested for each experimental variable while Tables A2.3 to A2.7 contain specific combinations of experimental conditions to be investigated in this laboratory study. The following general procedure will be followed for the reaction experiments:

1. Measured amounts of matrix material (groundwater + air-dried sludge, basalt, or sediment) are placed into multiple reaction vessels. Glass flasks or beakers will be used as reaction vessels for the oxidant consumption studies (Tables A2.3 and A2.4). Reaction vessels for the TCE degradation studies (Tables 2-5 through 2-7) will consist either of stainless steel zeroheadspace extractors (ZHE's) or glass vessels equipped with Tedlar bags to capture generated gases (e.g., $\mathrm{CO}_{2}$ ). In the oxidant demand studies (Tables A2.3 and A2.4) and the degradation studies (Tables A2.5 to A2.7) each experimental condition will be conducted in duplicate (i.e., two different reactor setups). In addition, duplicate control reactors will also be prepared for the degradation experiments in Tables A2.5 to A2.7. These control reactors will be spiked with TCE (and other co-contaminants when applicable) and aliquots will be collected at time zero and periodically thereafter to quantify changes in concentration due to processes other than oxidation. The actual number of control samples needed will be controlled by the approach in which the test series are conducted. For example, one set of control reactors could serve as the control for two experimental test conditions if the reactors had the same test medium and initial target TCE concentration. Residual volatile contaminants in the groundwater and solid materials will be removed by purging with $\mathrm{N}_{2}$ and air-drying, respectively, before being placed into the reaction vessels. This will enable experiments to be conducted on materials with consistent and controlled initial levels of TCE contamination.

2. For the TCE degradation experiments, pre-determined amounts of TCE (either as a methanolic stock solution or as a pure-phase) will be added to the reaction vessels. After spiking, all the reaction vessels will be sealed and allowed to equilibrate for at least 24 hours (equilibration times will be longer for the tests on aggregate basalt). A preliminary study will be conducted to determine the necessary equilibration time. During equilibration, the reaction vessels will be gently agitated. Immediately prior to potassium permanganate additions (Step 3), duplicate reaction vessels will be sacrificially analyzed to obtain the initial TCE concentration (or mass).

1. Predetermined amounts of solid industrial-grade potassium permanganate will be added to the reaction vessels (except for a few which will serve as controls). Reaction vessels will be shaken immediately after potassium permanganate additions to ensure rapid dissolution of the crystalline oxidant. The reaction vessels will be gently agitated until extraction.

2. At predetermined reaction time intervals, liquid aliquots from the duplicate control and duplicate potassium permanganate-treated reaction vessels will be withdrawn for analysis. TCE will be measured through hexane extraction of the aliquot and analysis of the extract on a gas chromatograph (GC) equipped with an electron capture detector (ECD). The gas chromatograph/electron capture detector $(\mathrm{GC} / \mathrm{ECD})$ will also be calibrated for less chlorinated alkenes. Analysis of vinyl chloride may require a different analytical technique, as described in Section A2.4.2. Vinyl chloride concentrations will be measured in experimental treatments in which vinyl chloride is added as a co-contaminant, but will be measured in other experimental treatments only if it can be analyzed using the GC/ECD technique. For the experiments conducted in glass vessels equipped with Tedlar bags, TCE will also be measured in the gas collected by the Tedlar bag. Residual $\mathrm{MnO}_{4}^{-}$will be 
quantified using a spectrophotometric technique. $\mathrm{pH}$ will also be measured in the aqueous aliquots.

3. After aliquot sampling for the final predetermined reaction time interval, the entire contents of the reaction vessels will be extracted with hexane. The extracts will then be analyzed for TCE and potential oxidation by-products on the GC/ECD. The total organic carbon content of organic sludge will be measured. Mn speciation in the treated media at the final reaction interval will also be attempted.

4. The total organic carbon content of organic sludge will be determined once before the oxidant demand and oxidation rate studies, and will be measured again at the end of the experiments described in Tables A2.4 and A2.7. 
Table A2.2. Experimental variables in reaction studies.

\begin{tabular}{|c|c|c|}
\hline Parameter & Number of Values & Values \\
\hline \multirow[t]{3}{*}{ Media } & \multirow[t]{3}{*}{3} & $\begin{array}{l}\text { Groundwater from TAN-29+ Basalt from TAN-37 } \\
\text { (representing the reactive zone) }\end{array}$ \\
\hline & & $\begin{array}{l}\text { Groundwater from TAN- } 29+\text { sediment from fractures } \\
\text { (representing the reactive zone) }\end{array}$ \\
\hline & & $\begin{array}{l}\text { Groundwater from TSF- } 05 \text { + organic sludge from TSF- } 05 \\
\text { (representing the hot spot) }\end{array}$ \\
\hline $\begin{array}{l}\text { Liquid (groundwater) to } \\
\text { solid (basalt, sludge, or } \\
\text { sediment) ratios }\end{array}$ & 2 & $\begin{array}{l}\text { 1:0 (groundwater alone) } \\
4: 1 \text { (groundwater : basalt, sludge, or fracture fill material) }\end{array}$ \\
\hline Basalt form & 2 & $\begin{array}{l}\text { Crushed }(<3 \mathrm{~mm}) \\
\text { Aggregate }(1.3 \text { to } 2.5 \mathrm{~cm})\end{array}$ \\
\hline $\begin{array}{l}\text { TCE concentrations } \\
\text { (in the aqueous phase) }\end{array}$ & 5 & $\begin{array}{l}0 \mathrm{mg} / \mathrm{L}^{\mathrm{a}} \\
1 \mathrm{mg} / \mathrm{L} \\
10 \mathrm{mg} / \mathrm{L} \\
100 \mathrm{mg} / \mathrm{L} \\
\text { DNAPL }\end{array}$ \\
\hline $\begin{array}{l}\text { Organic co-contaminants } \\
\text { (cis-1,2-dichloroethylene, } \\
\text { trans-1,2-dichloroethylene, } \\
\text { and vinyl chloride) }\end{array}$ & 2 & $\begin{array}{l}0 \mathrm{mg} / \mathrm{L} \\
10 \mathrm{mg} / \mathrm{L}\end{array}$ \\
\hline $\begin{array}{l}\text { Potassium permanganate } \\
\text { concentrations }\end{array}$ & 4 & $\begin{array}{l}0.01 \% \\
0.1 \% \\
1.0 \% \\
3.0 \%\end{array}$ \\
\hline Temperature & 1 & $12 \mathrm{C}$ \\
\hline a. This will provide matrix oxida & sumption. & 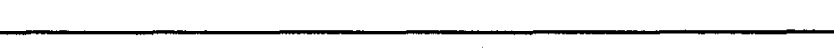 \\
\hline
\end{tabular}

Table A2.3. Oxidant consumption by reactive zone media.

\begin{tabular}{|c|c|c|c|c|c|}
\hline Media & $\begin{array}{l}\text { Basalt } \\
\text { Form }\end{array}$ & $\begin{array}{l}\text { Liquid : } \\
\text { Solid Ratio }\end{array}$ & $\begin{array}{c}\text { Initial TCE } \\
\text { Concentration } \\
(\mathrm{mg} / \mathrm{L})\end{array}$ & $\begin{array}{c}\text { Initial Organic } \\
\text { Co-Contaminant } \\
\text { Concentration } \\
(\mathrm{mg} / \mathrm{L})\end{array}$ & $\begin{array}{c}\text { Initial } \\
\text { Potassium } \\
\text { Permanganate } \\
\text { Concentration } \\
(\%)\end{array}$ \\
\hline Groundwater & NA & $\mathrm{NA}$ & 0 & 0 & 0.01 \\
\hline Groundwater/basalt & Crushed & $4: 1$ & 0 & 0 & 0.01 \\
\hline Groundwater/basalt & Aggregate & $4: 1$ & 0 & 0 & 0.01 \\
\hline Groundwater/sediment & NA & $4: 1$ & 0 & 0 & 0.01 \\
\hline Groundwater & $\mathrm{NA}$ & NA & 0 & 0 & 0.10 \\
\hline Groundwater/basalt & Crushed & $4: 1$ & 0 & 0 & 0.10 \\
\hline Groundwater/basalt & Aggregate & $4: 1$ & 0 & 0 & 0.10 \\
\hline Groundwater/sediment & $\mathrm{NA}$ & $4: 1$ & 0 & 0 & 0.10 \\
\hline Groundwater & NA & $\mathrm{NA}$ & 0 & 0 & 1.00 \\
\hline Groundwater/ basalt & Crushed & $4: 1$ & 0 . & 0 & 1.00 \\
\hline Groundwater/ basalt & Aggregate & $4: 1$ & 0 & 0 & 1.00 \\
\hline Groundwater/sediment & $\mathrm{NA}$ & $4: 1$ & 0 & 0 & 1.00 \\
\hline
\end{tabular}


Table A2.4. Oxidant consumption by hot spot media.

\begin{tabular}{lccccc}
\hline & & & Initial Organic & Initial Potassium \\
\multicolumn{1}{c}{ Media } & Basalt & Liquid : Solid & $\begin{array}{c}\text { Initial TCE } \\
\text { Concentration } \\
\text { Ratio }\end{array}$ & $\begin{array}{c}\text { Co-Contaminant } \\
\text { Concentration } \\
(\mathbf{m g} / \mathrm{L})\end{array}$ & $\begin{array}{c}\text { Permanganate } \\
\text { Concentration } \\
(\%)\end{array}$ \\
Groundwater & NA & NA & 0 & 0 & 0.01 \\
Groundwater/sludge & NA & $4: 1$ & 0 & 0 & 0.01 \\
Groundwater & NA & NA & 0 & 0 & 0.10 \\
Groundwater/sludge & NA & $4: 1$ & 0 & 0 & 0.10 \\
Groundwater & NA & NA & 0 & 0 & 1.00 \\
Groundwater/sludge & NA & $4: 1$ & 0 & 0 & 1.00 \\
Groundwater & NA & NA & 0 & 0 & 3.00 \\
Groundwater/sludge & NA & $4: 1$ & 0 & 0 & 3.00 \\
\hline
\end{tabular}

Table A2.5. TCE degradation rate in reactive zone groundwater and basalt

\begin{tabular}{|c|c|c|c|c|c|}
\hline Media & $\begin{array}{l}\text { Basalt } \\
\text { Form }\end{array}$ & $\begin{array}{c}\text { Liquid : Solid } \\
\text { Ratio }\end{array}$ & $\begin{array}{c}\text { Initial TCE } \\
\text { Concentration } \\
(\mathrm{mg} / \mathrm{L})\end{array}$ & $\begin{array}{c}\text { Initial Organic } \\
\text { Co-Contaminant } \\
\text { Concentration } \\
(\mathrm{mg} / \mathrm{L})\end{array}$ & $\begin{array}{c}\text { Initial Potassium } \\
\text { Permanganate } \\
\text { Concentration } \\
(\%)\end{array}$ \\
\hline Groundwater & NA & NA & 0.1 & 0 & 0.01 \\
\hline Groundwater & NA & NA & 0.1 & 0 & 0.10 \\
\hline Groundwater & $\mathrm{NA}$ & NA & 1 & 0 & 0.01 \\
\hline Groundwater & NA & NA & 1 & 0 & 0.10 \\
\hline Groundwater/basalt & Crushed & $4: 1$ & 0.1 & 0 & 0.01 \\
\hline Groundwater/basait & Crushed & $4: 1$ & 0.1 & 0 & 0.10 \\
\hline Groundwater/ basalt & Aggregate & $4: 1$ & 0.1 & 0 & 0.01 \\
\hline Groundwater/basalt & Aggregate & $4: 1$ & 0.1 & 0 & 0.10 \\
\hline Groundwater/basalt & Crushed & $4: 1$ & 1 & 0 & 0.01 \\
\hline Groundwater/basalt & Crushed & $4: 1$ & 1 & 0 & 0.10 \\
\hline Groundwater/basalt & Aggregate & $4: 1$ & 1 & 0 & 0.01 \\
\hline Groundwater/basalt & Aggregate & $4: 1$ & 1 & 0 & 0.10 \\
\hline Groundwater/sediment & NA & $4: 1$ & 0.1 & 0 & 0.01 \\
\hline Groundwater/sediment & NA & $4: 1$ & 0.1 & 0 & 0.10 \\
\hline Groundwater/sediment & $\mathrm{NA}$ & $4: 1$ & 1.0 & 0 & 0.01 \\
\hline Groundwater/sediment & NA & $4: 1$ & 1.0 & 0 & 0.10 \\
\hline
\end{tabular}


Table A2.6. TCE degradation rate in hot spot groundwater.

\begin{tabular}{|c|c|c|c|c|c|}
\hline Media & $\begin{array}{c}\text { Basalt } \\
\text { Form }\end{array}$ & $\begin{array}{c}\text { Liquid:Solid } \\
\text { Ratio }\end{array}$ & $\begin{array}{c}\text { Initial TCE } \\
\text { Concentration } \\
(\mathrm{mg} / \mathrm{L})\end{array}$ & $\begin{array}{c}\text { Initial Organic } \\
\text { Co-Contaminant } \\
\text { Concentration } \\
(\mathrm{mg} / \mathrm{L})\end{array}$ & $\begin{array}{c}\text { Initial Potassium } \\
\text { Permanganate } \\
\text { Concentration } \\
(\%)\end{array}$ \\
\hline Groundwater & NA & NA & 10 & 0 & 0.01 \\
\hline Groundwater & $\mathrm{NA}$ & NA & 10 & 0 & 0.10 \\
\hline Groundwater & $\mathrm{NA}$ & NA & 10 & 0 & 1.00 \\
\hline Groundwater & $\mathrm{NA}$ & NA & 10 & 0 & 3.00 \\
\hline Groundwater & NA & NA & 100 & 0 & 0.01 \\
\hline Groundwater & NA & NA & 100 & 0 & 0.10 \\
\hline Groundwater & $\mathrm{NA}$ & $\mathrm{NA}$ & 100 & 0 & 1.00 \\
\hline Groundwater & NA & NA & 100 & 0 & 3.00 \\
\hline Groundwater & NA & NA & 100 & 10 & 0.01 \\
\hline Groundwater & NA & NA & 100 & 10 & 0.10 \\
\hline Groundwater & NA & NA & 100 & 10 & 1.00 \\
\hline Groundwater & NA & $\mathrm{NA}$ & 100 & 10 & 3.00 \\
\hline Groundwater & $\mathrm{NA}$ & NA & $2,000 *$ & 0 & 0.01 \\
\hline Groundwater & NA & NA & $2,000^{*}$ & 0 & 0.10 \\
\hline Groundwater & NA & NA & $2,000 *$ & 0 & 1.00 \\
\hline Groundwater & NA & NA & $2,000^{*}$ & 0 & 3.00 \\
\hline
\end{tabular}

Table A2.7. TCE degradation rate in hot spot groundwater and sludge.

\begin{tabular}{cccccc}
\hline \multicolumn{1}{c}{ Media } & Basalt & Liquid : Solid & $\begin{array}{c}\text { Initial TCE } \\
\text { Concentration } \\
(\mathrm{mg} / \mathrm{L})\end{array}$ & $\begin{array}{c}\text { Initial Organic } \\
\text { Co-Contaminant } \\
\text { Concentration } \\
(\mathrm{mg} / \mathrm{L})\end{array}$ & $\begin{array}{c}\text { Initial Potassium } \\
\text { Permanganate } \\
\text { Concentration } \\
\text { (\%) }\end{array}$ \\
Groundwater/sludge & NA & $4: 1$ & 0 & 0 & 0 \\
Groundwater/sludge & NA & $4: 1$ & 10 & 0 & 0.01 \\
Groundwater/sludge & NA & $4: 1$ & 10 & 0 & 0.10 \\
Groundwater/sludge & NA & $4: 1$ & 10 & 0 & 1.00 \\
Groundwater/sludge & NA & $4: 1$ & 10 & 0 & 3.00 \\
Groundwater/sludge & NA & $4: 1$ & 100 & 0 & 0.01 \\
Groundwater/sludge & NA & $4: 1$ & 100 & 0 & 0.10 \\
Groundwater/sludge & NA & $4: 1$ & 100 & 0 & 1.00 \\
Groundwater/sludge & NA & $4: 1$ & 100 & 0 & 3.00 \\
Groundwater/sludge & NA & $4: 1$ & $2,000^{*}$ & 0 & 0.01 \\
Groundwater/sludge & NA & $4: 1$ & $2,000^{*}$ & 0 & 0.10 \\
Groundwater/sludge & NA & $4: 1$ & $2,000^{*}$ & 0 & 1.00 \\
Groundwater/sludge & NA & $4: 1$ & $2,000^{*}$ & 0 & 3.00 \\
$*$ Indicates that TCE is present as a DNAPL. & & & \\
\hline
\end{tabular}


Sacrificial sampling (i.e., extraction of reaction vessel contents) at reaction intervals will be conducted for one test series on TAN sludge (Table A2.7). The TCE level and potassium permanganate loading for this test series will be determined from results of the TCE degradation experiments where aliquot sampling was used.

The experimental procedures and conditions described above may be modified during the course of the laboratory study. Possible changes include the following:

- Modification of procedures to satisfy laboratory ES\&H requirements. An ES\&H evaluation of the planned laboratory experiments will be conducted before any work is initiated.

- Deletion of experiments from the test matrix deemed unnecessary based on completed tests. For example, $0.01 \%$ permanganate experiments will not be included in the TCE degradation and contaminant immobilization tests on TAN sludge if the sludge consumes significant amounts of potassium permanganate.

- Revision of reaction times to better capture temporal trends in TCE based on observations in completed experiments.

\section{A2.3 Data Analysis and Interpretation}

The first and second test series (Table A2.3 and A2.4) will provide oxidant consumption by TAN basalt, sediment from fractures, and organic sludge. The tests will be the first indicators of whether ISCO is feasible at the TAN reactive zone and hot spot. Excessive oxidant consumption will result in large amounts of oxidant required for the full-scale process. If this were the case, ISCO may be cost-prohibitive. Results of the oxidant consumption measurements series will serve as a basis for deciding whether to continue the laboratory studies and ISCO field evaluations at the hot spot or reactive zone. Oxidant consumption may be high for the organic sludge; it is not expected to be significant for the fractured basalt or sediment.

The reaction test matrix (Table A2.5 to A2.7) has been designed to provide TCE degradation rate as a function of potassium permanganate loading for each matrix type (groundwater from the hot spot with and without organic sludge, groundwater from the reactive zone with and without basalt). The relationship between degradation rate and potassium permanganate concentration will be used to select optimum potassium permanganate loading for each matrix.

Significant differences between TCE degradation trends in the crushed and aggregate basalt (Tables A2.3 and A2.5) will indicate diffusion limitation effects of TCE chemical oxidation in TAN basalt. The results of these experiments combined with results of the modeling described in Section A3.2 will determine whether matrix diffusion can impact the effectiveness of ISCO for remediating the hot spot and reactive zone at TAN.

\section{A2.4 Analytical Methods and Quality Assurance}

\section{A2.4.1 Summary of Analytical Data from Laboratory Studies}

The laboratory treatability studies described in the previous subsections will provide quantitative information regarding the technical feasibility and environmental impact of performing ISCO at the TAN site. This quantitative information can be categorized into the following groups of parameters:

- Parameter Group I - Consumption rate and extent of potassium permanganate by the contaminated matrix as a function of oxidant concentration and matrix type (Tables 
A2.3 - A2.4). These will be used to assess the practicality of ISCO at the TAN site, as well as to determine optimum oxidant loadings.

- Parameter Group 2 - Degradation rate and extent of chlorinated organics by potassium permanganate as a function of initial organic contaminant level, oxidant concentration, and matrix type (Tables A2.5 - A2.7). These will be used to assess the effectiveness of ISCO for reducing organic contamination at the TAN site.

The following chemical measurements will be conducted to generate the parameter groups given above:

1. $\mathrm{MnO}_{4}^{-}$in an aqueous matrix

2. Chlorinated organics in aqueous and solid matrices

Other physical and chemical measurements will be made during the laboratory experiments (e.g., $\mathrm{pH}$, total organic content); however, use of these other parameters in any decision making process related to the evaluation of ISCO for the TAN site is not anticipated. This subsection focuses on the primary analyses mentioned above and associated quality assurance/quality control requirements deemed appropriate for the use of the analytical data.

Formal data packages will only be provided for the chlorinated organics analyses. The components of the data packages are also described in the following subsections. The data will be reported in sample data groups for the organic analyses. This will simplify preparation of the data packages without sacrificing the quality of information provided.

\section{A2.4.2 Permanganate Analysis of Aqueous Samples}

A2.4.2.1 Method Description. $\mathrm{MnO}_{4}{ }^{-}$concentrations in aqueous samples will be quantified using a spectrophotometric technique developed by researchers at ORNL who have been conducting $\mathrm{R} \& \mathrm{D}$ work related to chemical oxidation by potassium permanganate. Five $\mathrm{MnO}_{4}{ }^{-}$ standard solutions will prepared in distilled water (concentration ranging from 5 to $50 \mathrm{ppm}$ ) using reagent grade potassium permanganate, and their respective absorbances will be measured at a wavelength of $525 \mathrm{~nm}$ using a Hach 2000 spectrophotometer. A calibration curve is then prepared from the absorbance vs standard concentration data. The $\mathrm{MnO}_{4}^{-}$concentration of an aqueous sample will be quantified by measuring its absorbance at $525 \mathrm{~nm}$, and calculating the corresponding concentration from the previously generated five-point calibration curve. Samples with concentrations greater than the calibrated range will be diluted to bring the concentration within the calibration range. Samples will be filtered with a $0.45 \mu \mathrm{m}$ membrane prior to analysis via spectrophotometry to remove particulate matter that could interfere with the analysis.

This spectrophotometric method is substantially less time consuming than a more standard titration method for measuring $\mathrm{MnO}_{4}^{-}$. The quality of the data generated by the spectrophotometric method is deemed suitable for its use in defining optimum oxidant loadings for ISCO implementations at the TAN site.

A2.4.2.2 Quality Assurance/Quality Control. Calibration will be verified on each analysis day by analyzing check standard solutions (10 and $50 \mathrm{ppm}$ ) prepared on the same day using distilled water and reagent-grade potassium permanganate. If the absorbance varies by $15 \%$ from the predicted absorbance based on the calibration curve, than a new calibration curve will be constructed.

A2.4.2.3 Data Package Components. A formal data package is deemed unnecessary for these analyses since the $\mathrm{MnO}_{4}^{-}$measurements will only be used for establishing oxidant loadings. 


\section{A2.4.3 Analysis of Aqueous and Solid Samples for TCE and DCE}

A2.4.3.1 Method Description. Target chlorinated organic contaminants (TCE, cis- and trans-1,2DCE) in aqueous and solid samples from the ISCO reaction rate studies will be measured through hexane extraction followed by gas chromatographic analysis of the hexane extracts. Chlorinated organics in the hexane extract will be quantified using an HP5890 II GC/ECD and HP ChemStation Software. Wherever possible, procedural and quality control guidelines from SW846/Method 8000A (Gas Chromatography) will be followed to ensure the quality of the GC analyses of the hexane extracts. Previous experience at ORNL has demonstrated that TCE concentrations in aqueous and solid matrices as low as $10 \mathrm{ppb}$ can be reliably measured with this method.

Aqueous Extraction - Five $\mathrm{mL}$ aliquots of liquid from the reaction study vessels will be placed in 5-mL of hexane and shaken on a reciprocal shaker for at least 30 minutes prior to analysis. Aqueous samples from the reactive experiments must be extracted with hexane immediately in order to quench any oxidative reactions.

Solids Extraction - After pouring out any excess fluid from the reaction vessel, $100 \mathrm{~mL}$ of hexane will be added to the reaction vessel to extract residual chlorinated organics from the solid $(\sim 100 \mathrm{~g})$. The reaction vessel with the hexane and solid matrix will be shaken for at least 30 minutes prior to analysis.

\section{Analysis of Hexane Extract}

Calibration: The procedure for external calibration found in Section 7.4.2 of SW846/Method $8000 \mathrm{~A}$ will be followed. Calibration standards in hexane will be prepared from certified calibration methanolic solutions and will include the following levels: $10,50,100,500,1000$ $\mathrm{ppb}$. One $\mathrm{mL}$ aliquots of these standards will be injected into the GC/ECD using an autosampler; area count vs standard concentration data will be used to construct calibration curves. The working calibration curve will be verified through the injection of a QC check standard ( $100 \mathrm{ppb})$ at least once every analysis day. If the response for any analyte varies from the predicted response by more than $\pm 15 \%$, a new calibration curve will be prepared.

Retention Time Windows: These will be established following Section 7.5 in SW846/Method 8000A.

GC Analysis: One $\mu \mathrm{L}$ aliquots of the extracts will be injected directly into the GC/ECD using an auto sampler. If the response for any of the target analytes exceeds the response for the $1000 \mathrm{ppb}$ standard, the hexane extract is diluted and reanalyzed.

\section{A2.4.3.2 Quality Control Quality Assurance.}

Calibration Checks - A QC check sample (100 ppb) will be analyzed on each analysis day. If the response for any of the target analytes varies from the predicted response by more than $15 \%$, a new calibration curve will be prepared before any more samples are analyzed.

Method Blanks - A blank hexane sample will be analyzed between every 10 samples.

Precision and Accuracy - The precision and accuracy of the hexane extract analysis will be established by four replicate analysis of a QC check standard prepared independently from the calibration standards. The recovery (in ppb) and standard deviation (in ppb) of the recovery for each target chlorinated organic will be tabulated and included in the QC data for the organics analyses. This precision/accuracy check will be done once before initiating the laboratory studies.

Duplicate aliquots will be collected, extracted, and analyzed for at least every tenth test sample.

Matrix Interference - Matrix spike and matrix spike duplicate analyses will not be conducted because the water and solid materials will be artificially spiked with the target VOCs. Thus, 
extraction efficiency will be measured by comparing the analysis of the control samples (no treatment) with the theoretical spiking levels.

Calculations -Equation 3 calculates the concentration of target organic contaminants in the aqueous and solid samples.

$\mathrm{C}_{\text {sample }}=\mathrm{C}_{\text {extract }} \times \mathrm{V}_{\text {extract }} / \mathrm{M}_{\text {sample }}$

where

$$
\begin{aligned}
& \mathrm{C}_{\text {sample }}=\text { the concentrations in the sample } \\
& \mathrm{C}_{\text {extract }}=\text { the concentrations in the hexane extracts } \\
& \mathrm{V}_{\text {extract }}=\text { the volume of hexane used to extract the sample } \\
& \mathrm{M}_{\text {sample }}=\text { the mass of sample extracted. }
\end{aligned}
$$

A2.4.3.3 Data Package Components. An organics data package will be prepared based on requirements for a Tier 2 sample data package outlined in Part II of the "Statement of work for organics analyses performed for the Idaho National Engineering Laboratory Sample Management Office" INEL-95/006 ER-SOW-169. Some components deemed inapplicable for this laboratory treatability study have been eliminated.

The data package will include the following:

1. Narrative:
a. Laboratory name
b. Table of samples including sample number (assigned by ORNL), date prepared/collected, date analyzed, calibration curve used (identified by date), and description of when/where samples were collected

c. Summary of QC and analytical problems.

2. Chain of Custody forms:

a. Chain of custody forms will only be used for treatability study materials (groundwater, sludge and basalt) that will be sent by INEEL to ORNL. These will be included in the data package. Chain of custody forms are unnecessary for the samples that will be generated during the laboratory experiments.

3. GC QC Data:
a. Method Blank Summary (Form IV VOA)
b. QC check sample summary (Form XI VOA including only target organics).

4. GC Sample Data:

a. Target analyte results (Form I VOA including only target organics).

5. Standards Data:

Initial (FORM VI including only target organics) and continuing calibration (FORM VII including only target organics).

\section{A2.4.4 Analysis of Aqueous and Solid Samples for Vinyl Chloride}

\section{A2.4.4.1 Method Description}

It is suspected that the analysis of vinyl chloride will require a different analytical approach. In gas chromatography analysis, the elution of vinyl chloride is often masked by the presence of the extraction solvent (i.e., hexane). In order to effectively quantify vinyl chloride, purge and trap analysis is preferred over solvent extraction. Upon purging, the aqueous samples will be will be quantified using an HP5890 II GC/FID and HP ChemStation Software. Wherever possible, procedural and quality control guidelines from SW846/Method 8000A (Gas Chromatography) will be followed to ensure the quality of the GC 
analyses of the hexane extracts. Previous experience at ORNL has demonstrated that vinyl chloride in aqueous systems as low as $10 \mathrm{ppb}$ can be reliably measured with this method. Analysis of vinyl chloride will only be performed on the test series defined in Table A2.6 where co-contaminants are added to the test reactors. For the vinyl chloride analysis, a separate $5 \mathrm{~mL}$ aliquot will have to be collected (in addition to the $5 \mathrm{~mL}$ extract for hexane extraction) for the purge and trap analysis. It may not possible to determine the remaining mass of vinyl chloride in the test reactors following sampling of the last time interval. Calibration and Retention Time Windows, etc. will be conducted similar to the approach outlined in 2.4.3.

\section{A2.4.4.2 Quality ControlQuality Assurance}

Calibration checks, method blanks, precision and accuracy, matrix interference, and calculations will be conducted and reported in a fashion similar to that described in Section A2.4.3.2

\section{A2.4.4.3 Data Package Components}

The vinyl chloride data package will be generated following the format discussed in 2.4.3.3 for the TCE and DCE analyses.

\section{A2.4.5 Analysis of Aqueous Samples for $\mathrm{pH}$}

\section{A2.4.5.1 Method Description}

$\mathrm{pH}$ analyses will be conducted on aqueous aliquots collected from the test reactors. The analyses will be conducted using conventional $\mathrm{pH}$ meter/electrode procedures. Previous experience at ORNL does not indicate that matrix interferences are created by the presence of $\mathrm{KMnO}_{4}$ in the test samples

\section{A2.4.5.2 Quality Assurance/Quality Control}

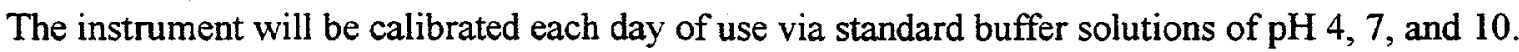
A calibration check will also be conducted following the final $\mathrm{pH}$ sample to be analyzed at the end of each day. Values obtained for the samples will be corrected via linear interpolation if a significant drift occurred in the calibration check.

\section{A2.4.5.3 Data Package Components}

a. As discussed in 2.4.1, $\mathrm{pH}$ measurements will most likely not be used in any decision making process regarding ISCO implementation. Hence, a formal data package is deemed unnecessary for $\mathrm{pH}$ analyses.

\section{A2.5 INEEL Activities to Support Off-Site Laboratory Studies}

\section{A2.5.1 General}

Laboratory studies will be performed in laboratories at the Oak Ridge National Laboratory (ORNL). INEEL will perform a variety of activities such as the following to support the laboratory studies:

- Audit by the INEEL Sample Management Office of ORNL laboratories confirm that the experimental results are technically sound

- $\quad$ Audit by the INEEL Environmental Affairs Department of ORNL laboratories to confirm that the permits and procedures needed to comply with environmental regulations are in place 
- Collection, packaging, and shipping of samples of groundwater, sludge, sediment, and basalt to ORNL

- Disposal of the excess, unaltered samples

- Disposal of lab residuals that contacted organic sludge from TSF-05 if the sludge is found to contain greater than $50 \mathrm{ppm}$ PCB.

Laboratory audits and waste disposal are described in Section 7. Sample collection and shipment are described in Section A2.5.2 through A2.5.6.

\section{A2.5.2 Collection of Groundwater Samples}

Groundwater will be collected from TSF-05 and TAN 29 to support the laboratory studies described in Sections A2.1 and A2.2. There will be $80 \mathrm{~L}$ (21 gal) of water collected from TSF-05 and $30 \mathrm{~L}(8 \mathrm{gal})$ collected from TAN-29.

Groundwater will be collected following procedures described in Environmental Restoration SOP-11.8, Groundwater Sampling, April 1994. Sampling equipment will be decontaminated between wells following procedures described in Environmental Restoration SOP-11.5, Field Decontamination of Sampling Equipment, July 1994. The exceptions to SOP-11.5 are that either deionized water or a detergent solution will be used instead of isopropanol as the decontaminating solution, and that decontamination will be performed by wiping equipment with a terry cloth towel soaked in the decontaminating solution instead of spraying the equipment with the decontaminating solution.

\section{A2.5.3 Sampling and Analysis Plan Tables for Groundwater and Sludge}

The sampling and analysis plan (SAP) for collecting groundwater and sludge samples is included in a document action request (DAR) for the Surge and Stress Plan Test Area North Groundwater Remediation Operable Unit 1-07B (Tomlinson et al. 1996).

\section{A2.5.4 Collection of Sludge Samples}

Sludge samples will be collected from TSF-05 to support the laboratory studies described in Sections A2.1 and A2.2. There will be $20 \mathrm{~L}$ (5 gal) of sludge collected.

Sludge samples will be collected in accordance with procedures described in TSF-05 Sludge Sampling Procedure, September 3, 1997.

\section{A2.5.5 Collection of Basalt Samples}

Two samples of basalt will be collected to support the lab studies described in Sections A2.1 and A2.2. Both samples will be collected by subsampling core from TAN-37, which will then be processed to generate two grain-size ranges. The core was surveyed for radiological contamination as it was collected, and was found to be free of radiological contamination above background levels.

Core from TAN 37 is presently stored at the temporary accumulation area (TAA) at the TAN Groundwater Treatment Facility (GWTF).

The procedure for subsampling the core and sizing the material is described below.

1. Collect samples from the interflow zones between depths of 61 and $122 \mathrm{~m}$ (200 and $400 \mathrm{ft}$ ) below ground surface. Collect material from the uppermost interflow first, and then from successively deeper interflow zones until sufficient material has been 
collected. Collect samples from the vesicular portions of flows, but not from the massive flow interiors.

2. Air dry the samples.

3. Two grain-size fractions are required for laboratory studies: (1) a coarse fraction with pieces falling between $1.8-$ to $2.5-\mathrm{cm}(1 / 2-$ to $1-$ in.), and (2) a fine fraction with pieces smaller than $0.3-\mathrm{cm}(1 / 8$-in.) in diameter.

a. Generate the coarse fraction by manually selecting pieces in this size range and larger than this size range. Using the hammer and chisel and rock crusher in custody of the Subsurface Science Program and located in building TAN607 , reduce the size of larger pieces. Sieve the crushed rock using $2.5-\mathrm{cm}(1-$ in.) and 1.8-cm (1/2-in.) sieve. Keep the fraction that passes the 2.5-cm (1in.) sieve but is retained on the $1.8-\mathrm{cm}(1 / 2-\mathrm{in}$.) sieve. There are $5 \mathrm{~kg}(11 \mathrm{lb})$ of this size fraction required.

Contact Rick Colwell at 526-0097 to coordinate use of the rock crusher. Remove the rock crusher from the glove bag prior to use.

b. Generate the fine fraction by using the rock crusher to reduce the size of larger pieces of basalt until they are in the desired size range. Sieve the crushed rock using a $0.4-\mathrm{cm}$ (1/8-in.) sieve and a pan. Keep the fraction that passes through the $0.4-\mathrm{cm}(1 / 8-i n$.$) sieve. There are 7.5 \mathrm{~kg}(16.5 \mathrm{lb})$ of this size fraction required.

4. Store processed basalt samples in two liter wide mouth plastic bottles, such as Fisher Scientific Catalog number 11-815-11A or similar. Samples can be stored at room temperature.

5. After collection of the samples, they will be assayed for radiological contamination and shipped to the ORNL laboratory.

Basalt that is crushed but does not fall into the required size fractions will be disposed in the existing OU 1-07B drill cutting waste streams.

Equipment used for preparing the basalt samples will be decontaminated by wiping it with terry cloth towels soaked in a detergent solution and then with a terry cloth towel soaked in deionized water. The used towels will be disposed in the Waste Stream 1935.

A job safety analysis will be prepared prior to commencing this activity.

\section{A2.5.6 Collection of Sediment from Fractures in Basalt}

Sediment will be collected from fractures in basalt core samples from TAN. Sediment will be collected from core from TAN-48 below the PQ interbed. If more sediment than can be collected from this core is needed, then additional sediment will be collected from archived core samples.

Approximately $2 \mathrm{~kg}$ of sediment will be placed into a $2 \mathrm{~L}$ plastic bottle for storage and shipment. 


\section{A2.5.7 Sample Storage and Shipment}

Groundwater and sludge samples will be stored at $4^{\circ} \mathrm{C}$ between collection and shipment.

Groundwater and sludge samples will be shipped in insulated containers with reusable cold packs.

Basalt and sediment samples will be stored at room temperature between processing and shipment, and will be shipped at room temperature.

Groundwater, basalt, and sediment samples will be shipped to:

Dr. Olivia West

Oak Ridge National Laboratory

Building 1505, Room 224

Bethel Valley Road

Oak Ridge, TN 37831

(423) 576-0505

Sludge samples will be shipped to:

Joe Giaquinto

Oak Ridge National Laboratory

Bethel Valley Road

Building 2026

Oak Ridge, TN 37831

(423)574-4887 
Appendix B- Test Procedures 



\title{
Appendix B \\ Laboratory Test Plan for the \\ Laboratory Evaluation of In Situ Chemical Oxidation as a Technology for Groundwater Restoration at the INEEL TAN Site.
}

\author{
$S$ R. Cline \\ J. M. Giaquinto \\ M K. McCracken \\ D. L. Denton \\ Oak Ridge National Laboratory, Oak Ridge, TN
}

Prepared: September 1998

Revision 2

Prepared by Oak Ridge National Laboratory

Oak Ridge, TN 37831

Managed by:

LOCKHEED MARTIN ENERGY RESEARCH CORPORATION

for the

U.S. DEPARTMENT OF ENERGY

under contract DE-AC05-84OR21400 


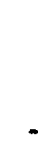

- 


\section{Table of Contents}

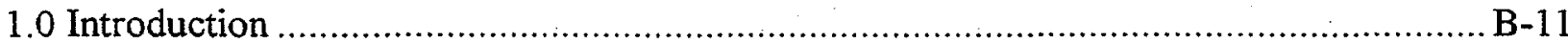

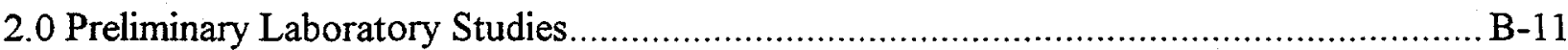

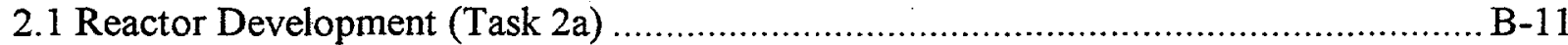

Experiment 2a-1. Evaluation of the rubber septum to reduce TCE losses. ................. B-12

Experiment 2a-2. Eval. of the fitting to minimize \& quantify TCE losses ................... B-13

Experiment 2a-3-A. Overall performance of the test reactor..................................... B-14

Experiment 2a-3-B. Overall performance of the test reactor ................................... B-16

2.2 Determine Time Required for Hexane Extraction of TCE from Media (Task 2b)......... B-17

Experiment 2b-1. Hexane Extraction Test for the Reactive Zone Media .................... B-18

Experiment 2b-1b Matrix Spike Study (September 1998) ......................................... B-19

Experiment 2b-2. Hexane Extraction Test for Aggregate Basalt............................. B-20

Experiment 2b-3. Hexane Extraction Test for the Hot Spot Media .......................... B-22

Experiment 2b-4. (Exp 2b-3b) Matrix Spike Experiment (September 1998) ……...... B-25

2.3 Determine Time Required to Equilibrate Basalt Aggregate with TCE (Task 2c) .......... B-26

Background and Experimental Approach ............................................................ B-26

Experiment 2c-1. Sorption Kinetics Test for Crushed and Aggregate Basalt.............. B-26

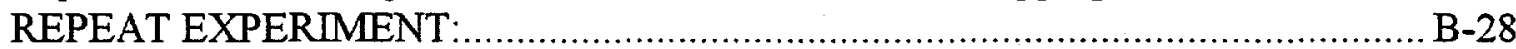

Experiment 2c-1B. Sorption Kinetics Test for Crushed and Aggregate Basalt. .......... B-28

3.0 Measure Oxidant Demand of TAN Subsurface Materials .............................................. B-30

3.1 Measure the Oxidant Demand of Reactive Zone Media (Task 3a) ............................ B-30

Gen. Procedure for Task 3a Exps.- Oxidant Demand of Reactive Zone Media ............ B-30

3.2 Measure the Oxidant Demand of Hot Spot Media (Task 3b) ................................... B-31

Gen. Procedure for Task 3b Exps- Oxidant Demand of Hot Spot Zone Media …….... B-31

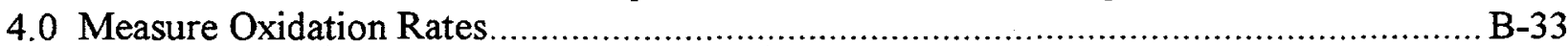

4.1 Measure the Oxidation Rate of Organics in Reactive Zone Media (Task 4a) .............. B-33

Gen. Procedure for Task 4a Experiments ............................................................. B-33

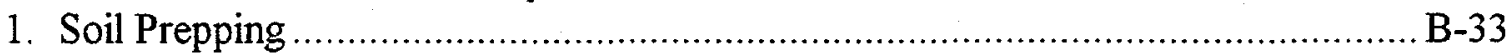

2. TCE Stock Solution Preparation .................................................................. B-34

3. TCE Spike Solution Preparation, PART 1.................................................... B-34

4. TCE Spike Solution Preparation, PART II ………........................................... B-34

5. Obtain Tare Weights of Reactors …................................................................. B-34

6. Fill with Solid Phase Media ............................................................................. B

7. Collection of Initial Spike Solution Samples ...................................................... B-34

8. Distribution of Spike Solution to Reactors .................................................... B-35

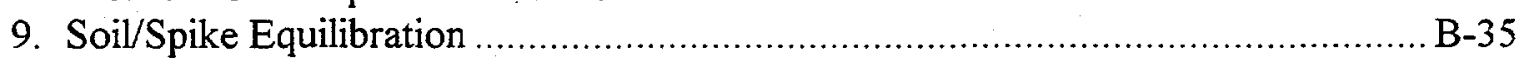

10. Preparation of Stock $\mathrm{MnO}_{4}^{-}$Solution (4 wt\%) …............................................35

11. Prepare Reactor Closure/Carbon Tube .........................................................35

12. Collection of Pre-Reaction Sample from Each Reactor ...................................... B-35

13. Preparation of Pre Reaction TCE Sample ..........................................................35

14. Measurement of Pre Reaction $\mathrm{pH}$ Value.......................................................... B-35

15. Addition of Stock MnO4- Solution into Reactors............................................. B-36

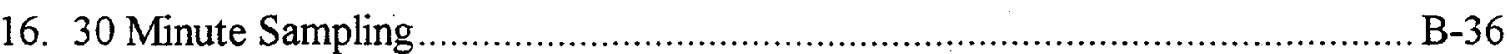

17. Preparation of 30 Minute TCE Sample ......................................................

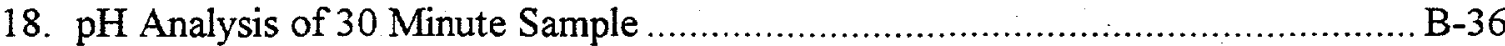


19. $\mathrm{MnO}_{4}{ }^{-}$Analysis of the 30 Minute Sample ....................................................... B-36

20. Collection and Analysis of Additional Aliquot Samples..................................... B-36

21. Extraction of Residual TCE in Reactor ........................................................ B

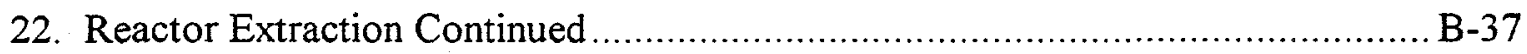

23. Extraction of Charcoal Desorption Tubes .................................................... B-37

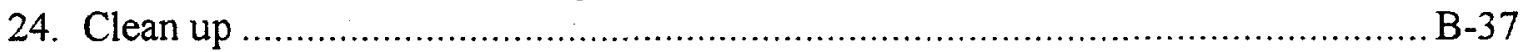

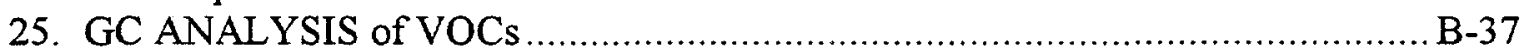

4.2 Measure the Oxidation Rate of Organic Contaminants in Hot Spot Media (Task 4b)... B-38 General Procedure for Task 4b Experiments .......................................................... B-38

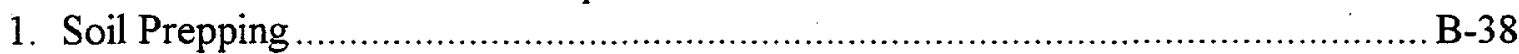

2. TCE Stock Solution Preparation................................................................... B-38

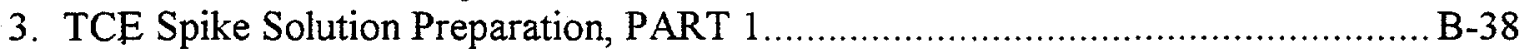

4. TCE Spike Solution Preparation, PART II ................................................... B-39

5. Obtain Tare Weights of Reactors ......................................................................

6. Collection of Initial Spike Solution Samples .................................................... B-39

7. Distribution of Spike Solution to Reactors ..................................................... B-39

8. Keep Cool until Experiment is initiated. ........................................................ B-39

9. $>2,000 \mathrm{mg} / \mathrm{L}$ Spiking: Obtain Tare Weights of Reactors ...................................... B-39

10. $>2,000 \mathrm{mg} / \mathrm{L}$ Spiking: Reactor Filling .......................................................... B-40

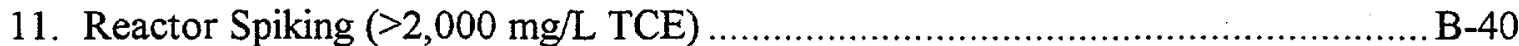

12. Spike Solution Equilibration $(>2,000 \mathrm{mg} / \mathrm{L}$ Spike Condition) …...................... B-40

13. For Loadings of 01 and $0.1 \mathrm{wt} \% \mathrm{MnO}_{4}{ }^{-}$in Table 2-6 ONLY .............................

14. Prepare Reactor Closure/Carbon Tube ………........................................

15. Collection of Pre-Reaction Sample from Each Reactor ................................... B-40

16. Preparation of Pre Reaction TCE Sample ................................................ B-40

17. Measurement of Pre Reaction pH Value............................................................

18. For Loadings of 01 and $0.1 \mathrm{wt} \% \mathrm{MnO}_{4}{ }^{-}$in Table 2-6 ONLY............................ B-41

19. For the Oxidant Loadings of 1 and $3 \mathrm{wt} \% \mathrm{MnO}_{4}{ }^{-}$in Table 2-6 ONLY ................... B-41

20. For the Oxidant Loadings of 1 and $3 \mathrm{wt}^{\%} \mathrm{MnO}_{4}{ }^{-}$in Table 2-6 ONLY .................... B-41

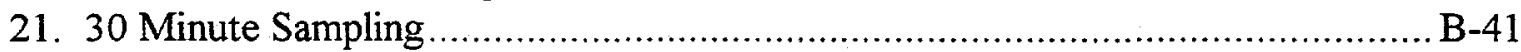

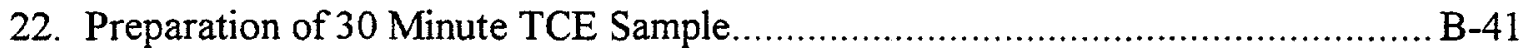

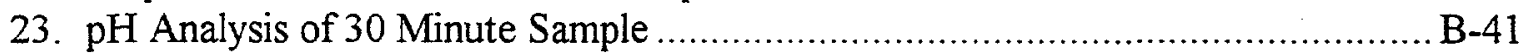

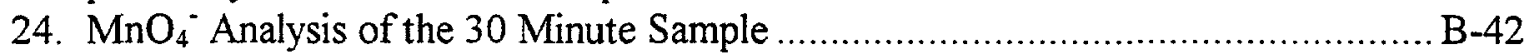

25. Collection and Analysis of Additional Aliquot Samples..................................... B-42

26. Extraction of Charcoal Desorption Tubes...................................................... B-42

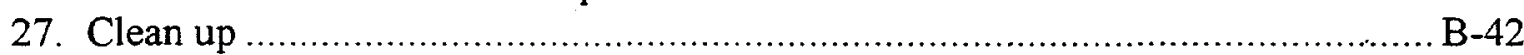

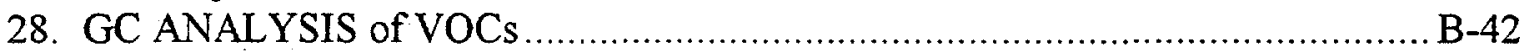

General Procedure for Task 4b Experiments …………......................................... B-43

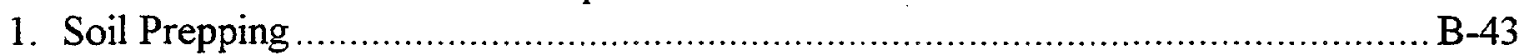

2. TCE Stock Solution Preparation................................................................... B-43

3. TCE Spike Solution Preparation, PART 1 ……........................................ B-44

4. TCE Spike Solution Preparation, PART II ....................................................

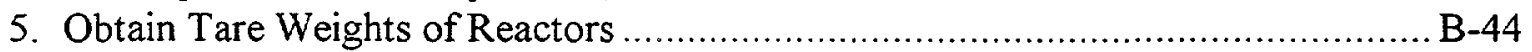

6. Fill with Solid Phase Media .................................................................................

7. Collection of Initial Spike Solution Samples...................................................... B-44 
8. Distribution of Spike Solution to Reactors .................................................... B-44

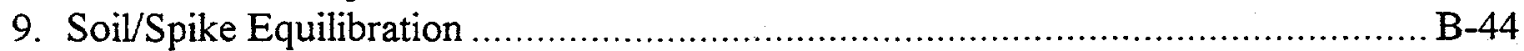

10. $>2,000 \mathrm{mg} / \mathrm{L}$ Spiking: Obtain Tare Weights of Reactors.................................... B-45

11. Sludge Addition $(>2,000 \mathrm{mg} / \mathrm{L}$ Spiking Condition)....................................... B-45

12. $>2,000 \mathrm{mg} / \mathrm{L}$ Spiking: Reactor Filling..........................................................

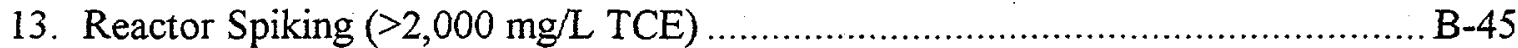

14. Spike Solution Equilibration $(>2,000 \mathrm{mg} / \mathrm{L}$ Spike Condition) …...................... B-45

15. For the Oxidant Loadings of 01 and $0.1 \mathrm{wt} \% \mathrm{MnO}_{4}{ }_{4}$ in Table 2-7 ONLY ........... B-45

16. Prepare Reactor Closure/Carbon Tubes....................................................... B-45

17. Collection of Pre-Reaction Sample from Each Reactor ....................................... B-45

18. Preparation of Pre Reaction TCE Sample...................................................... B-46

19. Measurement of Pre Reaction $\mathrm{pH}$ Value........................................................ B-46

20. For the Oxidant Loadings of 01 and $0.1 \mathrm{wt} \% \mathrm{MnO}_{4}{ }^{-}$in Table 2-7 ONLY ............ B-46

21. For the Oxidant Loadings of 1 and $3 \mathrm{wt} \% \mathrm{MnO}_{4}{ }^{-}$in Table 2-7 ONLY ................... B-46

22. For the Oxidant Loadings of 1 and $3 \mathrm{wt} \% \mathrm{MnO}_{4}{ }^{-}$in Table 2-7 ONLY .................. B-46

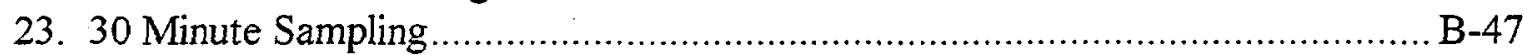

24. Preparation of 30 Minute TCE Sample........................................................ B-47

25. $\mathrm{pH}$ Analysis of 30 Minute Sample ………....................................................

26. $\mathrm{MnO}_{4}{ }^{-}$Analysis of the 30 Minute Sample ....................................................... B-47

27. Collection and Analysis of Additional Aliquot Samples..................................... B-47

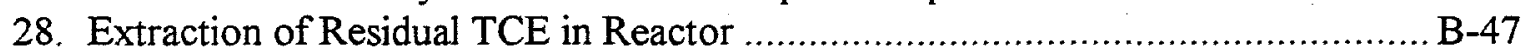

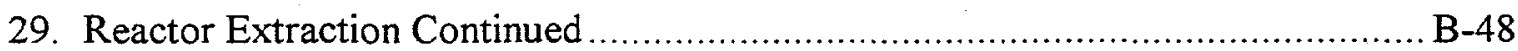

30. Extraction of Charcoal Desorption Tubes.................................................... B-48

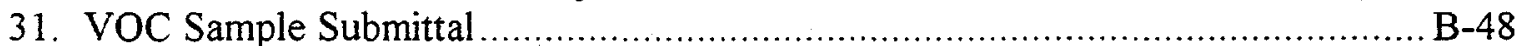

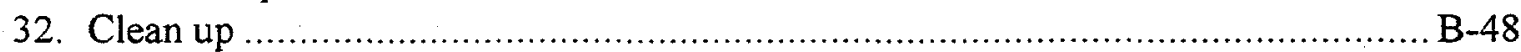

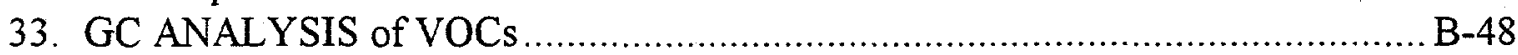

34. Post Treatment TSF-05 Sludge TOC Analysis.................................................. B-49

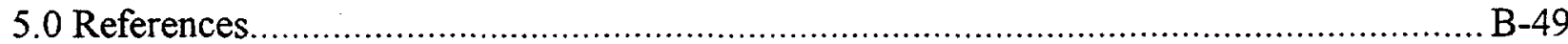


CASD

ECD

ESD

FID

GC

INEEL

$\mathrm{KMnO}_{4}$

L/S

ORNL

QAVQC

RMAL

SOW

TAN

TCE

TOC

$\mathrm{VC}$

VOA

cis-1,2 DCE

trans-1,2 DCE

ZHE

\section{Acronyms}

Chemical and Analytical Sciences Division

Electron capture detector

Environmental Sciences Division

Flame ionization detector

Gas Chromatography

Idaho National Environmental Engineering Laboratory

Potassium permanganate

Liquid/Soil

Oak Ridge National Laboratory

Quality Assurance and Quality Control

Radioactive Material Analytical Laboratory

Statement of Work

Test Area North

Trichloroethylene

Total Organic Carbon

Vinyl chloride

Volatile Organic Analysis

cis-1,2 dichloroethylene

trans-1,2 dichloroethylene

Zero headspace extraction vessel 


\section{Laboratory Test Plan \\ Laboratory Evaluation of In Situ Chemical Oxidation as a Technology for Groundwater Restoration at the INEEL TAN Site}

\section{B1. Introduction}

This laboratory test plan, completed to fulfill the requirements of SOW Task 1a, describes, in detail, the laboratory experiments to be performed during SOW Tasks 2-4. The discussion of these tasks also includes information about the quality assurance and control (QA/QC) elements that will be used during performance of the treatability study. The experiments described in this test plan serve as the current approach expected to be conducted; however, the materials and/or methodology may be modified if actual conditions in the laboratory warrant. Any modifications will be clearly noted and documented.

\section{B2 Preliminary Laboratory Studies}

These studies will be conducted to assess whether the equipment and/or approach planned for the experiments in Tasks 3 and 4 is appropriate. In particular, Task 2 studies include: (a) development and assessment of a reaction vessel (reactor) to be used in the Task 4 experiments, (b) determination of the optimum hexane extraction time for each media being evaluated in Task 4 , and (c) the optimal equilibration time to use for TCE spiking of the aggregate basalt for Task 4 .

\section{B2.1 Reactor Development (Task 2a)}

The reaction studies with TCE and $\mathrm{KMnO}_{4}$ (Task 4) will be performed under controlled conditions. VOC losses from the reaction vessels due to volatilization mechanisms need to be minimized and quantified. Zero headspace extraction vessels (ZHEs) often used by ORNL researchers cannot be used due to their small sample capacity $(130 \mathrm{~mL})$. Thus, alternative reactors will be needed. Upon acquisition of new reactor vessels, this laboratory task will evaluate the performance of these vessels. In particular, the amount of TCE expected to be lost from the reactors will be quantified via a mass balance approach. The Task 4 reaction studies will be conducted using approximately $500 \mathrm{~mL}$ of INEEL TAN groundwater or a $500 \mathrm{~mL}$ slurry $(4: 1$ $\mathrm{L} / \mathrm{S}$ weight ratio) of TAN groundwater and solid phase media at a temperature of $12^{\circ} \mathrm{C}$. This evaluation task, however, will be conducted using distilled water at room temperature spiked with TCE.

Currently, a glass reaction kettle will be evaluated. This reactor has a total gross volume near 500 $\mathrm{mL}$, and consists of a glass reactor body and adapter top. A Teflon ${ }^{\mathrm{TM}}$ sleeve will be used as a seal to maintain liquid and gas-tight conditions. This port will be used for sampling, introducing $\mathrm{KMnO}_{4}$, etc.

Due to the high organic content of the TAN site media, particularly the TSF-05 sludge, the reactor(s) may pressurize while the oxidation reaction(s) occurs. To reduce the health and safety risk, the reactors may need to be vented. For this situation, the bottom opening of a sampling port adapter will be covered with a thin LDPE film such as Parafilm $\mathrm{M}^{\mathrm{TM}}$ or aluminum foil to serve as a "pressure relief valve," with the assumption that the pressure buildup to rupture this thin film is much less than that required to force the ground glass adapter from the top of the reactor. Any emissions escaping through this film via either rupture or natural diffusion will be passed through 
a desorption tube for quantification prior to its release to the atmosphere. (The quantity of TCE that may diffuse across this thin film under non-pressurized conditions is expected to be minimal but will be evaluated). Such desorption tubes contain two (2) successive activated charcoal filter beds and are typically used in industrial hygiene air sampling devices. Any TCE that is volatilized from the reactor should be retained via adsorption onto the charcoal media and can later be extracted with hexane for quantification. The overall performance of this reactor configuration will be evaluated to complete this task.

Experiment 2a-1. Evaluation of the rubber septum to reduce TCE losses.

(To be conducted at ORNL/ESD)

The reactor sampling port may be fitted with a thick rubber septum for the purpose of sample collection via a wide bore needle. Thus, this experiment will assess how well the fitting between the septum and the ground glass port opening minimizes TCE losses. The effect of performing repeated aliquot sampling through the septum will also be evaluated.

A $250 \mathrm{~mL}$ flask or equivalent having only a single $24 / 40$ std taper opening will be used. This experiment will be conducted at room temperature.

1. A $100 \mathrm{mg} / \mathrm{L}$ aqueous TCE solution $(\approx 650 \mathrm{~mL})$ will be prepared and allowed to equilibrate for at least 30 minutes. The solution will be prepared in a Tedlar Bag using DI water and pure TCE. Measure the mass of the spiking syringe when filled and then after spiking to record the total TCE mass added to the reactor (a QC check on the initial TCE analysis). Information regarding the preparation of the spiking solution will be recorded in the laboratory research notebook.

2. Dispense the solution into 2 tared test containers, re-weigh and record the mass of TCE spike solution added to each. Duplicate $0.5 \mathrm{~mL}$ samples of the spike solution will be collected immediately before the septa is added to the test containers in order to determine the initial TCE concentration.

3. The aliquot samples will be added to pre-weighed vials holding a known volume of hexane. Each sample container will be weighed again after sample addition to determine the actual weight of sample added. (A calibration check of the gravimetric scale will be performed each day of use.) All such extracts will be placed on a horizontal shaker for 30 minutes. Store the extracts at $4^{\circ} \mathrm{C}$ until G.C. analysis.

4. Record the time that these duplicate samples are collected and the septum is placed onto each container. (Complete zero headspace conditions cannot be achieved here since excess water cannot be expelled from the containers as the septa are applied.)

5. After 2 hours, collect duplicate aqueous samples from one of the containers by puncturing the septum with the sampling syringe (wide bore needle desired since later experiments will be soil/sludge slurries). The septum will have to be punctured by a second needle in order to pull the samples into the syringe body. Do nothing to the other test container.

6. Extract and dilute the samples as needed (described above). 
7. Repeat this sampling technique at least 5 more times over a period of 24 hours for the $1^{\text {st }}$ test container.

8. Collect duplicate aqueous samples from the second test container after 24 hours. (This will be the first time that the septum of the $2^{\text {nd }}$ test container is punctured.)

9. Analyze the extracts via GC/ECD for TCE quantification. G.C. analyses will be conducted closely following EPA Method 8000B, ensuring that a daily calibration check, blanks, etc. are also analyzed on each analysis day. Formal data packages, as outlined in Section 2.4.3.3 of the Chapter 2 Implementation Plan will not be prepared for this experiment.

10. Prepare a TCE mass balance to determine total mass of TCE not accounted for in either the remaining spike solution in the vial or in the sample aliquots for each test container. Also place any waste materials generated from the experiment in the appropriate satellite accumulation area.

\section{Experiment 2a-2. Evaluation of the pressure relief fitting to minimize and quantify TCE losses} (To be conducted at ORNL/ESD)

A shakedown experiment already conducted has shown that a thin layer of Parafilm-M material (wax based) is easily ruptured when placed on an otherwise sealed container in less time than is required to remove a rubber septum when a constant volume and rate of air is added to the container. However, a high degree of TCE diffusion is suspected through this type of material. A similar test was performed using aluminum foil as the thin film covering the bottom of the adapter. While desirable in the fact that TCE diffusion is likely minimal, the aluminum foil possessed a great deal of tensile strength in this configuration and could not be easily ruptured by pressurization of an erlenmeyer flask with air. For the purpose of this experiment four (4) different conditions will be evaluated: (a) no thin film, (b) Parafilm M, (c) aluminum foil punctured with a single pinhole (to reduce tensile strength), and (d) DuraSeal ${ }^{\mathrm{TM}}$, a solvent resistant LDPE film. Erlenmeyer flasks $(125 \mathrm{~mL}$ ) or equivalent containers having a $24 / 40$ std. taper opening will be used in this experiment. There will not be an attempt to pressurize these containers. The "no thin film" set-up will represent the ruptured film case. This experiment will be conducted at room temperature.

1. Prepare the 24/40 std. Taper adapters as described above (a-d), securing the edges of each thin film by addition of a Teflon sleeve onto the ground glass fitting.

2. Assemble the ORBO-32 Tubes. Two ORBO- 32 tubes will be used in series for each container in the event that the TCE adsorption capacity of the first tube is exceeded. Using Pliers, break the ends of two ORBO tubes. Smooth the broken ends with a file and connect them in series using tygon tubing. Orient them such that the " $\mathrm{A}$ " charcoal bed of each tube is first in line.

[" $\mathrm{A}$ " is the larger of the two (100 mg charcoal), "B" contains $50 \mathrm{mg}$ charcoal.]

NOTE: STORE THE OPENED ORBO TUBES OUTSIDE OF THE LABORATORY FUME HOODS. THE HOODS LIKELY HAVE THE GREATEST POTENTIAL FOR "CONTAMINATING" THE TUBES WITH TCE AND OTHER VOCS. 
3. A $100 \mathrm{mg} / \mathrm{L}$ aqueous TCE solution $(\approx 1200 \mathrm{~mL})$ will be prepared in a Tedlar bag and allowed to equilibrate overnight prior to being distributed into each container. (Preparing only one spiking solution, allows for each test set-up to have the same initial conditions). Measure the mass of the spiking syringe when filled and then after spiking to record the total TCE mass added to the reactor (a QC check on the initial TCE analysis). Information regarding the preparation of the spiking solution will be recorded in the laboratory research notebook.

4. Fill each test container and collect duplicate $0.5 \mathrm{~mL}$ samples of the spike solution immediately before the containers are sealed in order to determine the initial TCE concentration in each.

5. The duplicate aliquot samples will be added to pre-weighed vials holding a known volume of hexane. Each sample container will be weighed again after sample addition to determine the actual weight of sample added. (A calibration check of the gravimetric scale will be performed each day of use.) All such extracts will be placed on a horizontal shaker for 30 minutes. Store the extracts at $4^{\circ} \mathrm{C}$ until G.C. analysis.

6. Record the time at which each sample is collected and the container is closed.

7. After 4 hours, remove the adapter from each container and collect an aqueous sample $(0.5$ $\mathrm{mL}$ ) Extract and dilute the samples as needed for G.C. analysis for eventual analysis of the remaining TCE concentration in the solution. Store the extracts at $4^{\circ} \mathrm{C}$ until G.C. analysis.

8. For each container, separate the contents of each charcoal bed into separate vials pre-weighed with a known volume of hexane then reweigh the vials to determine the mass of charcoal present.

9. Extract these samples for 30 minutes and dilute as needed for G.C. analysis as done for the aqueous aliquots.

10. Analyze the extracts via GC/ECD for TCE quantification. G.C. analyses will be conducted closely following EPA Method $8000 \mathrm{~B}$, ensuring that a daily calibration check, blanks, etc. are also analyzed on each analysis day. Formal data packages, as outlined in Section 2.4.3.3 of the Chapter 2 Implementation Plan will not be prepared for this experiment.

11. Prepare a TCE mass balance on each container to determine which thin film configuration best minimized the mass of TCE that escaped from the reaction chamber. Also place any waste materials generated from the experiment in the appropriate satellite accumulation area.

Experiment 2a-3-A. Overall performance of the test reactor

(To be conducted at ORNL/ESD)

In this experiment a complete reactor will be set up using the most optimal component(s) from the previous Task $2 \mathrm{a}$ experiments described above. To be consistent, a $100 \mathrm{mg} / \mathrm{L}$ TCE spike solution will be used here as well; however, this experiment will be conducted at approximately $12-15^{\circ} \mathrm{C}$. 
1. Set up a reactor, ensuring that a Teflon sleeve is fitted onto the glass adapter to be used. The top of the adapter will be sealed (Teflon stopper) during spiking and equilibration to minimize the mass of TCE lost.

2. Fill the reactor with distilled water, minimizing the headspace volume inside of the reactor. A record of the DI water volume added will be maintained.

3. Spike the reactor with TCE, Desired Concentration: $100 \mathrm{mg} / \mathrm{L}$

Add a mass of pure phase TCE (density of $1.456 \mathrm{~g} / \mathrm{mL}$ ) to the liquid volume inside of the reactor that will yield a TCE solution of $100 \mathrm{mg} / \mathrm{L}$. Measure the mass of the spiking syringe when filled and then after spiking to record the total TCE mass added to the reactor (a QC check on the initial TCE analysis). Information regarding the preparation of the spiking solution will be recorded in the laboratory research notebook.

4. Replace the removed stopper back onto the adapter and allow the solution to equilibrate at least overnight in an incubator maintained at $12-15^{\circ} \mathrm{C}$. (Record the equilibration period and temperature).

5. During the equilibration period, prepare an ORBO-32 assembly in the standard taper adapter and cover the bottom end of the adapter with the selected thin film [parafilm]. STORE UN-SEALED ORBO TUBES OUTSIDE OF THE LABORATORY FUME HOODS. THE HOODS LIKELY HAVE THE GREATEST POTENTIAL FOR "CONTAMINATING" THE TUBES WITH TCE AND OTHER VOCS.

6. After equilibration, collect duplicate $(\approx 0.5 \mathrm{~mL})$ aqueous samples from the reactor (from the glass adapter that is sealed with a stopper) The aliquot samples will be added to pre-weighed sample containers holding a known volume of hexane $(\approx 5 \mathrm{~mL})$. Each sample container will be weighed again after sample addition to determine the actual weight of sample added. (A calibration check of the gravimetric scale will be performed each day of use.) All such extracts will be placed on a horizontal shaker for 30 minutes. Store the extracts at $4^{\circ} \mathrm{C}$ until G.C. analysis.

7. Replace the adapter sealed with the stopper with one fitted with the charcoal desorption tube assembly from Step 5. Record the time the samples in the step above are collected and the desorption tube is added as Start Time $=0$.

8. Collect at the following time intervals in the same manner as performed in step 6: $30 \mathrm{~min}, 60$ $\mathrm{min}, 2 \mathrm{hrs}, 4 \mathrm{hrs}, 24 \mathrm{hrs}$ (duplicate), $30 \mathrm{hrs}, 48 \mathrm{hrs}$. The exact time at which each aliquot is collected will be recorded.

9. Breakdown the reactor after the last sample is collected. The charcoal desorption tube will then be removed from the reactor. Each charcoal bed contained in the tube will be placed into a pre-filled and pre-weighed vial containing a known volume of hexane $(\approx 5 \mathrm{~mL})$. These extracts will be processed and analyzed in the same manner as the aqueous aliquots. 
NOTE: The contents of such a test reactor will be extracted at the end of the experiments in Task 4 but is not necessary here since a solid phase is not present.

10. Analyze the sample and charcoal extracts via GC/ECD for TCE. G.C. analyses will be conducted closely following EPA Method $8000 \mathrm{~B}$, ensuring that a daily calibration check, blanks, etc. are also analyzed on each analysis day. Formal data packages, as outlined in Section 2.4.3.3 of the Chapter 2 Implementation Plan will not be prepared for this experiment.

11. Perform a mass balance for the reactor, taking sample aliquot volumes, initial concentrations, etc. into account to determine the overall reactor performance in maintaining gas-tight conditions. Also place any waste materials generated from the experiment in the appropriate satellite accumulation area.

\section{Experiment 2a-3-B. Overall performance of the test reactor}

(To be conducted at ORNL/ESD)

In this experiment a complete reactor will be set up using the most optimal component(s) from the previous Task 2a experiments. A 100 ppb TCE spike solution will be used here as well; however, this experiment will be conducted at approximately $12-15^{\circ} \mathrm{C}$.

1. Set up a $500 \mathrm{~mL}$ Flask (29/42 S.T.), ensuring that a Teflon sleeve is fitted onto a Standard Taper Stopper. (Will used during spiking and equilibration to minimize the mass of TCE lost)

2. Fill the reactor with 500 mLled water. A record of the DI water volume added will be maintained.

3. Spike the reactor with TCE, Desired Concentration: $100 \mathrm{ppb}$ Add approximately 50 microliters of SATURATED TCE solution to the flask. Information regarding the preparation of the spiking solution will be recorded in the laboratory research notebook.

4. Replace the stopper back and allow the solution to equilibrate at least overnight in an incubator maintained at $12-15^{\circ} \mathrm{C}$. (Record the equilibration period and temperature).

5. During the equilibration period, prepare an ORBO-32 assembly and connect it to the stopcock adapter.

STORE UN-SEALED ORBO TUBES OUTSIDE OF THE LABORATORY FUME HOODS. THE HOODS LIKELY HAVE THE GREATEST POTENTIAL FOR "CONTAMINATING" THE TUBES WITH TCE AND OTHER VOCS.

6. After equilibration, replace the stopper with the stopcock assembly.

7. Collect duplicate $(\approx 5 \mathrm{~mL})$ aqueous samples from the reactor by opening the stopcock and inserting the long sampling needle. (collect one using a glass syringe and one using $a$ plastic disposable syringe) The aliquot samples will be added to pre-weighed sample containers holding a known volume of hexane $(\approx 5 \mathrm{~mL})$. Each sample container will be 
weighed again after sample addition to determine the actual weight of sample added. (A calibration check of the gravimetric scale will be performed each day of use.) All such extracts will be placed on a horizontal shaker for 2 hours. Store the extracts at $4^{\circ} \mathrm{C}$ until G.C. analysis.

8. Record the time the last sample in the step above is collected and record as Time $=0$.

9. Collect at the following time intervals in the same manner as performed in step 7: 1 hour, 2 hrs, $4 \mathrm{hrs}, 18$ hours, and $24 \mathrm{hrs}$ (in duplicate-collect one using a glass syringe and one using a plastic disposable syringe). The exact time at which each aliquot is collected will be recorded.

10. Breakdown the reactor after the last sample is collected. The charcoal desorption tube will then be removed from the reactor. Each charcoal bed contained in the tube will be placed into a pre-filled and pre-weighed vial containing a known volume of hexane $(\approx 5 \mathrm{~mL})$. These extracts will be processed and analyzed in the same manner as the aqueous aliquots.

11. Analyze the sample and charcoal extracts via GC/ECD for TCE. G.C. analyses will be conducted closely following EPA Method $8000 \mathrm{~B}$, ensuring that a daily calibration check, blanks, etc. are also analyzed on each analysis day. Formal data packages, as outlined in Section 2.4.3.3 of the Chapter 2 Implementation Plan will not be prepared for this experiment.

12. Perform a mass balance for the reactor, taking sample aliquot volumes, initial concentrations, etc. into account to determine the overall reactor performance in maintaining gas-tight conditions. Also place any waste materials generated from the experiment in the appropriate satellite accumulation area.

\section{B2.2 Determine Time Required for Hexane Extraction of TCE from Organic Sludge, Sediment, and Basalt (Task 2b)}

A 30 minute extraction time period was used for the Task 2a Reactor Development experiments involving only aqueous TCE solutions; however, this task will help determine what the most effective extraction period is for each medium being evaluated: groundwater or groundwater with crushed basalt, aggregate basalt (following experiment 2c-1), sludge, or sediment at a 4:1 Liquid/Solid ratio. (Note that the hexane extraction period for aggregate basalt cannot be evaluated until after Task 2c, "TCE equilibration with aggregate basalt" is completed.) In this batch experiment, several aliquot samples will be taken with time as a TCE spiked mixture is being extracted with hexane. Samples will be taken of both the solvent and aqueous phases. The aqueous phase will be further evaluated by determining the fraction of TCE present in both the liquid and solid phases at each time interval. All media to be used in this experiment will be ovendried, and the groundwater will be sparged to remove any initial TCE in order to conduct this test under controlled laboratory conditions. Each media type will be evaluated in duplicate. For these experiments, only a single initial TCE concentration will evaluated: $1 \mathrm{mg} / \mathrm{L}$ TCE for the reactive zone media and $100 \mathrm{mg} / \mathrm{L}$ TCE for the hot spot media. The contaminant equilibration period will be conducted at $12-15^{\circ} \mathrm{C}$; however, the hexane extraction portion of the experiment will be conducted at room temperature. 
Experiment 2b-1. Hexane Extraction Test for the Reactive Zone Media

(To be conducted at ORNL/ESD)

1. Prepare a STOCK (Saturated) TCE solution $(2000 \mathrm{mg} / \mathrm{L}$ ) by adding $100 \mu \mathrm{L}$ of Pure TCE into a $12 \mathrm{~mL}$ VOA vial filled to volume with DI Water and allow to equilibrate overnight at room temperature. (Use of a STOCK solution rather than pure phase TCE to prepare the spiking solution affords better accuracy in obtaining the target concentration.)

2. Obtain the tare weight of the container to be used to prepare the spike solution (Tedlar bag, flask, or equivalent). Fill with approximately $300 \mathrm{~mL}$ of groundwater from TAN-40 previously sparged of any residual TCE or other VOCs that may have been present. (Properly indicate usage of this media in the treatability study tracking logbook.). By gravimetric methods, determine the amount of groundwater added to the container, and then place in an environmental chamber at $12-15^{\circ} \mathrm{C}$ overnight. (A calibration check of the gravimetric scale will be performed each day of use.)

3. After temperature equilibration of the groundwater, remove the container from the incubator and add the appropriate quantity of the Saturated STOCK TCE solution to produce a TCE spike concentration of $1.0 \mathrm{mg} / \mathrm{L}$. (Reactive zone media will only be spiked at 0.1 and $1 \mathrm{mg} / \mathrm{L} \mathrm{TCE}$ during the Task 4 degradation studies.) This solution can be mixed and equilibrated within a few minutes.

4. After mixing, obtain duplicate aqueous samples $(\approx 5 \mathrm{~mL})$ of the spike solution to obtain the initial TCE concentration of the spiked groundwater. The duplicate aliquot samples will be added to pre-weighed sample containers holding a known volume of hexane $(\approx 5 \mathrm{~mL})$. Each sample container will be weighed again after sample addition to determine the actual weight of sample added. These extracts will be placed on a horizontal shaker for 30 minutes. Store the extracts at $4^{\circ} \mathrm{C}$ until G.C. analysis.

5. Obtain the tare weight of six (6) $40 \mathrm{~mL}$ VOA vials. Add approximately $10 \mathrm{~g}$ of crushed (< $1 / 8$ " size fraction) basalt to two of these vials, and approximately $10 \mathrm{~g}$ of sediment to two more of the vials. These materials should be previously dried to remove any residual TCE that might have been present. Re-weigh the vials to determine the exact masses added. (Properly indicate usage of this media in the treatability study tracking logbook.)

6. Completely fill the remaining volume of all of the $40 \mathrm{~mL}$ vials with the spiked groundwater, and reweigh each vial to determine the total volume of spike solution added. Record the time each vial is filled and capped. Place the vials on an orbital shaker maintained at $12-15^{\circ} \mathrm{C}$ and allow the spike solution and media (if applicable) to equilibrate overnight.

7. Obtain a tare weight on six empty containers to be used for the hexane extractions ( $125 \mathrm{~mL}$ VOA bottles with Teflon lined caps). Add $40 \mathrm{~mL}$ of hexane to each of these and reweigh.

8. Remove the $40 \mathrm{~mL}$ vials from the shaker/incubator. Pour the entire contents of each $40 \mathrm{~mL}$ vial into a separate $125 \mathrm{~mL}$ extraction bottle. Reweigh each extraction bottle and record the time as "extraction time $=0$ ". (The amount of TCE that may have been lost during contaminant 
equilibration will not be directly determined, but would be expected to be approximately the same for each $40 \mathrm{~mL}$ vial.)

9. Place each extraction jar on a horizontal reciprocating shaker at room temperature. Collect a $1 \mathrm{~mL}$ aliquot of the hexane layer from each extraction bottle at the following approximate time periods: 5 minutes, 30 minutes, 2 hours, and 24 hrs. Place these samples directly into a GC Vial ( $2 \mathrm{~mL}$ ). (Calibrate the pipette used to collect the aliquot) Record the time the sample was collected. Store at $4^{\circ} \mathrm{C}$ until analyzed (no dilution will be necessary).

10. Also collect (using a disposable syringe with a luer-lok tip) a $6 \mathrm{~mL}$ aliquot of the aqueous layer from the extraction bottle at the same time periods used in Step 9: 5 minutes, 30 minutes, 1 hour, 3 hours, and 24 hrs. Dispense $1 / 2$ of the aliquot $(\approx 3 \mathrm{~mL})$ directly into $12 \mathrm{~mL}$ VOA vial that is pre-weighed and pre-filled with hexane $(\approx 3 \mathrm{~mL})$. Using a $0.45 \mu \mathrm{m}$ syringe filter, filter the remaining aliquot volume in the syringe $(\approx 3 \mathrm{~mL})$ into another $12 \mathrm{~mL}$ VOA vial that is preweighed and pre-filled with hexane $(\approx 3 \mathrm{~mL})$.

11. Re-weigh each of these $12 \mathrm{~mL}$ VOA vials in the above step to determine the total sample volume added to each. Place these samples on a reciprocating shaker for at least 30 minutes. Store these extractions at $4^{\circ} \mathrm{C}$ if not analyzed immediately.

12. Analyze via GC/ECD for TCE, diluting if necessary. G.C. analyses will be conducted closely following EPA Method $8000 \mathrm{~B}$, ensuring that a daily calibration check, blanks, etc. are also analyzed on each analysis day. Formal data packages, as outlined in Section 2.4.3.3 of the Chapter 2 Implementation Plan will not be prepared for this experiment.

13. Using the analytical results (TCE in the hexane phase, aqueous phase, and solid phases), select the extraction time period that is most effective and efficient for each media type evaluated. Also place any waste materials generated from the experiment in the appropriate satellite accumulation area.

\section{Experiment 2b-1b Matrix Spike Study (September 1998)}

(To be Conducted by ESD)

Make sure all scales and pipettes used are properly calibrated.

All TAN material is to be sparged or dried prior to use in the experiment.

Obtain Tare Weights of twelve (12) $40 \mathrm{~mL}$ VOA Vials

Fill Vials $1 \& 2$ almost to volume with DI Water

Fill Vials $3 \& 4$ almost to volume with TAN-40 GW

Fill Vials $5 \& 6$ almost to volume with TSF-05 GW

Fill Vials $7 \& 8$ with $10 \mathrm{~g}$ Aggregate Basalt

Fill Vials $9 \& 10$ with $10 \mathrm{~g}$ Crushed Basalt

Fill Vials $11 \& 12$ with $10 \mathrm{~g}$ Sediment ( $2^{\text {nd }}$ shipment) 
Re-weigh Vials 7-12.

Now add DI water to vials $7-12$, almost filling to volume.

Using a SATURATED TCE solution, add $10 \mathrm{uL}(.01 \mathrm{~mL})$ into each vial and quickly fill to volume using DI water, cap.

THIS IS THE PIPETTE THAT REALLY NEEDS CALIBRATED PRIOR!!!!

NOTE: DO THE ABOVE STEP ONE AT A TIME!!-Record time of spiking

Re-weigh all vials to obtain final masses of material added.

Allow the vials to equilibrate at $12 \mathrm{C}$ overnight.

\section{NEXT MORNING:}

Obtain tare weights of twelve $125 \mathrm{~mL}$ jars (provided)

Add approx $40 \mathrm{~mL}$ of hexane to each jar

Reweigh to obtain the amount of hexane added

Remove the $12-40 \mathrm{~mL}$ vials from the incubator.

Transfer contents of each $40 \mathrm{~mL}$ vial into each $125 \mathrm{~mL}$ jar- Record Time

Re-weigh both the jar and the "emptied" VOA vial.

Extract the jars on a shaker for 2 hrs and then collect a $1 \mathrm{~mL}$ sample from each for GC analysis (no dilutions will be needed)

Run Samples on GC, lab 211 method: ineelecd.mth

\section{Experiment 2b-2. Hexane Extraction Test for Aggregate Basalt.}

(To be conducted at ORNL/ESD)

NOTE: This experiment cannot be completed until Exp. 2c-1, Aggregate Basalt Equilibration is completed.

1. Sparge any residual TCE or other VOCs from the TAN-40 groundwater to be used. Also oven-dry the TAN-37 aggregate basalt sample to be used. (Properly indicate usage of this media in the treatability study tracking logbook.)

2. Prepare a STOCK (Saturated) TCE solution ( $2000 \mathrm{mg} / \mathrm{L}$ ) by adding $100 \mu \mathrm{L}$ of Pure TCE into a $12 \mathrm{~mL}$ VOA vial filled to volume with DI Water and allow to equilibrate overnight at room temperature. (Use of a STOCK solution rather than pure phase TCE to prepare the spiking solution affords better accuracy in obtaining the target concentration.)

3. Obtain the tare weight of the container to be used to prepare the spike solution (Tedlar bag, flask, or equivalent). Fill with approximately $200 \mathrm{~mL}$ of groundwater from TAN-40 previously sparged of any residual TCE or other VOCs that may have been present. By gravimetric methods, determine the amount of groundwater added to the container, and then place in an 
environmental chamber at $12-15^{\circ} \mathrm{C}$ overnight. (A calibration check of the gravimetric scale will be performed each day of use.)

4. After temperature equilibration of the groundwater, remove the container from the incubator and add the appropriate quantity of the Saturated STOCK TCE solution to produce a TCE spike concentration of $1.0 \mathrm{mg} / \mathrm{L}$. (SHOULD BE APPROX. $0.2 \mathrm{~mL}$ for $200 \mathrm{~mL}$ of $\mathrm{gw}$ ) Record the actual weight used. (Reactive zone media will only be spiked at 0.1 and $1 \mathrm{mg} / \mathrm{L}$ TCE during the Task 4 degradation studies.) This solution can be mixed and equilibrated within a few minutes.

5. After mixing, obtain duplicate aqueous samples $(\approx 5 \mathrm{~mL})$ of the spike solution to obtain the initial TCE concentration of the spiked groundwater. The duplicate aliquot samples will be added to pre-weighed sample containers holding a known volume of hexane $(\approx 5 \mathrm{~mL})$. Each sample container will be weighed again after sample addition to determine the actual weight of sample added. These extracts will be placed on a horizontal shaker for $2 \mathrm{hrs}$. Store the extracts at $4^{\circ} \mathrm{C}$ until G.C. analysis.

6. Obtain the tare weight of four (4) $40 \mathrm{~mL}$ VOA vials. Add approximately $10 \mathrm{~g}$ of aggregate basalt to two of these vials. Re-weigh these vials to determine the exact masses added.

7. Completely fill the remaining volume of all of the $40 \mathrm{~mL}$ vials with the spiked groundwater, and reweigh each vial to determine the total volume of spike solution added. Record the time each vial is filled and capped. Place the vials on an orbital shaker maintained at $12-15^{\circ} \mathrm{C}$ and allow the spike solution and media (if applicable) to equilibrate for the length of time determined in Exp. 2c-1.

8. Obtain a tare weight on four empty containers to be used for the hexane extractions ( $125 \mathrm{~mL}$ VOA bottles with Teflon lined caps). Add $40 \mathrm{~mL}$ of hexane to each of these and reweigh.

9. Remove the $40 \mathrm{~mL}$ vials from the shaker/incubator. Pour the entire contents of each $40 \mathrm{~mL}$ vial into a separate $125 \mathrm{~mL}$ extraction bottle. Reweigh each extraction bottle to obtain the mass of material actually transferred and record the time as "extraction time=0". (The amount of TCE that may have been lost during contaminant equilibration will not be directly determined, but would be expected to be approximately the same for each $40 \mathrm{~mL}$ vial.)

10. Place each extraction jar on a horizontal reciprocating shaker at room temperature. Collect a $1 \mathrm{~mL}$ aliquot of the hexane layer from each extraction bottle at the following approximate time periods: 2 hours, 4 hours, 6 hrs, and 24 hrs. Place these samples directly into a $2 \mathrm{~mL} \mathrm{GC} \mathrm{Vial.}$ Record the time the sample was collected. Store at $4^{\circ} \mathrm{C}$ until analyzed (no dilution will be necessary).

11. Also collect (using a disposable syringe with a luer-lok tip) a $6 \mathrm{~mL}$ aliquot of the aqueous layer from the extraction bottle at the same time periods used in Step 10: 2 hours, 4 hours, 6 hrs, and 24 hrs. Dispense $1 / 2$ of the aliquot $(\approx 3 \mathrm{~mL})$ directly into $12 \mathrm{~mL}$ VOA vial that is pre-weighed and pre-filled with hexane $(\approx 3 \mathrm{~mL})$. Using a $0.45 \mu \mathrm{m}$ syringe filter, filter the remaining aliquot 
volume in the syringe $(\approx 3 \mathrm{~mL})$ into another $12 \mathrm{~mL}$ VOA vial that is pre-weighed and pre-filled with hexane $(\approx 3 \mathrm{~mL})$.

12. Re-weigh each of these $12 \mathrm{~mL}$ VOA vials in the above step to determine the total sample volume added to each. Place these samples on a reciprocating shaker for at least 30 minutes. Store these extractions at $4^{\circ} \mathrm{C}$ if not analyzed immediately. No dilutions should be necessary.

13. Analyze via GC/ECD for TCE, diluting if necessary. G.C. analyses will be conducted closely following EPA Method $8000 \mathrm{~B}$, ensuring that a daily calibration check, blanks, etc. are also analyzed on each analysis day. Formal data packages, as outlined in Section 2.4.3.3 of the Chapter 2 Implementation Plan will not be prepared for this experiment.

14. Using the analytical results (TCE in the hexane phase, aqueous phase, and solid phases), select the extraction time period that is most effective and efficient for each media type evaluated. Also place any waste materials generated from the experiment in the appropriate satellite accumulation area.

\section{Experiment 2b-3. Hexane Extraction Test for the Hot Spot Media}

(To be conducted at RMAL)

In conjunction with the hexane extraction time studies, a baseline characterization of the hot spot media will be performed. This characterization will involve a total organic carbon analysis, a gross alpha and beta determination, and finally a gamma scan of the material.

The total organic carbon analysis will be performed on the TSF-05 sludge (wet and dry) following the guidance in SW846 method 9060 and the manufacturer's operating instructions provided with the instrument. Since a dried aliquot of the sludge will be used in the tests, moisture content of the sludge will also be obtained.

The radiochemical analysis will be performed on an acid digested portion of the dried sludge. The digestion will be performed following CASD-AM-SW846-3051 Microwave Assisted Acid Digestion of Sediments, Sludges, and Oils. The digestates will then be analyzed for gross alpha and beta and a gamma scan will be performed using the appropriate procedures in Table B2.1. 
Table B2.1. Analytical Methods for Hot Spot Media Sludges

\begin{tabular}{|l|l|}
\hline \multicolumn{1}{|c|}{ Methods } & \multicolumn{1}{c|}{ Analysis } \\
\hline $\begin{array}{l}\text { Gross Alpha and Gross Beta Radioactivity in } \\
\text { Drinking Water (CASD-AM-EPA-900.0) }\end{array}$ & $\begin{array}{l}\text { Gross alpha and beta radioactivity sample } \\
\text { preparation }\end{array}$ \\
\hline $\begin{array}{l}\text { Gamma-emitting Radionuclides in Drinking } \\
\text { Water (CASD-AM-EPA-901.1) }\end{array}$ & $\begin{array}{l}\text { Gamma emitting radionuclides sample } \\
\text { preparation }\end{array}$ \\
\hline $\begin{array}{l}\text { Operation of Packard MO 2500TR Liquid } \\
\text { Scintillation Counter } \\
\text { (CASD-AM-RML-RA12) }\end{array}$ & $\begin{array}{l}\text { 1. Total activity by liquid scintillation } \\
\text { 2. Sum of alpha- and beta-emitting } \\
\text { radionuclides analysis }\end{array}$ \\
\hline $\begin{array}{l}\text { Operation and Calibration of the Tennelec } \\
\text { LB4000 (CASD-AM-RML-RA02) }\end{array}$ & Gross alpha and gross beta analysis \\
\hline $\begin{array}{l}\text { Operation and Calibration of the Canberra, } \\
\text { Nuclear Data Genie - ESP Data Acquisition } \\
\text { and Processing (CASD-AM-RML-RA04) }\end{array}$ & $\begin{array}{l}\text { Alpha and gamma spectroscopy data } \\
\text { acquisition and processing system }\end{array}$ \\
\hline
\end{tabular}

The hexane extraction time experiment will be performed according to the following steps:

1. Sparge any residual TCE or other VOCs from the TSF-05 groundwater to be used. Also ovendry the sludge sample to be used. (Properly indicate usage of this media in the treatability study tracking logbook.)

2. Prepare approximately $200 \mathrm{~mL}$ of TCE spiking solution in a Tedlar ${ }^{\top M}$ bag, which allows for effective mixing under zero headspace conditions. Record the tare weight of the Tedlar bag. Fill the bag using groundwater from TSF-05. By gravimetric methods, determine the amount of groundwater actually added to the Tedlar bag. Next, add the appropriate quantity of pure phase TCE to produce a TCE spike concentration of $100 \mathrm{mg} / \mathrm{L}$. SHOULD BE APPROXIMATELY 14 $\mu L$ NOTE: $T C E \mathrm{spg}=1.456 \mathrm{mg} / \mathrm{uL}$ Please record the actual mass added by determining the weight of the spiking syringe when it is "full" and after the TCE has been delivered. (The hot spot media will actually be evaluated using initial concentrations of 10,100 , and $>1,000 \mathrm{mg} / \mathrm{L}$ TCE in the Task 4 degradation studies.) This solution will be equilibrated overnight in an incubator or refrigeration unit at $12-15^{\circ} \mathrm{C}$.

3. After equilibration, obtain duplicate aqueous samples $(\approx 5 \mathrm{~mL})$ from the Tedlar bag to obtain the initial TCE concentration of the spiked groundwater. The duplicate aliquot samples will be added to pre-weighed $12 \mathrm{~mL}$ VOA vials holding a known volume of hexane $(\approx 5 \mathrm{~mL})$. Each sample container will be weighed again after sample addition to determine the actual weight of sample added. (A calibration check of the gravimetric scale will be performed each day of use.) These extracts will be placed on a horizontal shaker for 2 hours. Store the extracts at $4^{\circ} \mathrm{C}$ until G.C. analysis.

4. Obtain the tare weight of four (4) $40 \mathrm{~mL}$ VOA vials. Add approximately $10 \mathrm{~g}$ of TSF-05 sludge to two of these vials, (This material should be previously dried to remove any residual 
TCE or moisture that might have been present.) Re-weigh these two vials to determine the exact masses added.

5. Completely fill the remaining volume of all four of the $40 \mathrm{~mL}$ vials with the spiked groundwater from the Tedlar bag. Record the time each vial is filled and capped. Reweigh each vial to determine the total volume of spike solution added. Place the vials on an orbital shaker maintained at $12-15^{\circ} \mathrm{C}$ and allow the spike solution and sludge (if applicable) to equilibrate overnight.

6. Obtain a tare weight on four extraction bottles to be used for the hexane extractions ( $125 \mathrm{~mL}$ VOA bottles with Teflon lined caps). Add approximately $40 \mathrm{~mL}$ of hexane to each of these and reweigh to determine the actual hexane volume added (specific gravity $=0.66$ ).

7. Remove the $40 \mathrm{~mL}$ vials from the shaker/incubator. Pour the entire contents of each $40 \mathrm{~mL}$ vial into a separate $125 \mathrm{~mL}$ extraction bottle. Reweigh each $125 \mathrm{~mL}$ extraction bottle to obtain the actual quantity transferred and record the time as "extraction time=0". (Any TCE that may have been lost during contaminant equilibration will not be directly determined, but would be expected to be approximately the same for each $40 \mathrm{~mL}$ vial.)

8. Place each extraction jar on a horizontal reciprocating shaker at room temperature. Collect a $0.1 \mathrm{~mL}(100 \mu \mathrm{L})$ aliquot of the hexane layer from each extraction bottle at the following approximate time periods: 30 minutes, 2 hours, 4 hours, and $24 \mathrm{hrs}$. Place these samples into 12 $\mathrm{mL}$ VOA vials already tared and containing a known volume of hexane $(\approx 10 \mathrm{~mL})$. Record the time each sample is collected. Store at $4^{\circ} \mathrm{C}$ until analyzed.

9. Collect (using a disposable syringe with a luer-lok tip) a $6 \mathrm{~mL}$ aliquot of the aqueous layer from each extraction bottle at roughly the same time periods used in Step 8: 30 minutes, 2 hours, 4 hours, and 24 hrs. Dispense $1 / 2$ of the aliquot $(\approx 3 \mathrm{~mL})$ directly into a $12 \mathrm{~mL}$ VOA vial that is pre-weighed and pre-filled with hexane $(\approx 3 \mathrm{~mL})$. Add a $0.45 \mu \mathrm{m}$ syringe filter onto the disposable syringe, filter the remaining aliquot volume $(\approx 3 \mathrm{~mL})$ into another $12 \mathrm{~mL}$ VOA vial that is preweighed and pre-filled with hexane $(\approx 3 \mathrm{~mL})$.

10. Re-weigh each of these $12 \mathrm{~mL}$ VOA vials in the above step to determine the total sample volume added to each. Place these samples on a reciprocating shaker for at least 30 minutes. Store these extractions at $4^{\circ} \mathrm{C}$ if not analyzed immediately. Dilutions will have to be performed before being submitted to ESD. For the hexane layer, no additional dilution should be expected, simply transfer $1 \mathrm{~mL}$ of the sample into a $2 \mathrm{~mL} \mathrm{G}$.C. vial. The dilutions for the aqueous samples are not as predictable. Please provide a sample not diluted (ie, the top layer of hexane in the vials from step 9). If required, a sample with a DF of $11 .(0.1 \mathrm{~mL}$ of the hexane layer into $1 \mathrm{~mL}$ of clean hexane in a $2 \mathrm{~mL} \mathrm{G.G.} \mathrm{Vial} \mathrm{may} \mathrm{be} \mathrm{needed.)}$

11. NOTE: This step to be conducted at ESD. Analyze via GC/ECD for TCE. G.C. analyses will be conducted closely following EPA Method $8000 \mathrm{~B}$, ensuring that a daily calibration check, blanks, etc. are also analyzed on each analysis day. Formal data packages, as outlined in Section 2.4.3.3 of the Chapter 2 Implementation Plan will not be prepared for this experiment. Using the 
analytical results, select the extraction time period that is most effective and efficient for each media type evaluated.

12. Place any waste materials generated from the experiment in the appropriate satellite accumulation area.

Experiment 2b-4. (Exp 2b-3b) Matrix Spike Experiment (September 1998)

(To be conducted at RMAL)

1. Sparge any residual TCE or other VOCs from the TSF-05 groundwater to be used. Also ovendry the sludge sample to be used. (Properly indicate usage of this media in the treatability study tracking logbook.)

2. Obtain the tare weight of four (4) $40 \mathrm{~mL}$ VOA vials.

3. Add approximately $10 \mathrm{~g}$ of TSF- 05 sludge to THREE of these vials.

4. Re-weigh these THREE vials to determine the exact masses added.

5. Fill each of the 4 VOA vials (ALMOST TO VOLUME) with TSF-05 groundwater

6. Add $0.04 \mathrm{~mL}$ of a SATURATED TCE solution to each vial. Quickly fill the remaining volume with DI water of gw (whichever is easiest) and cap. Record the time each vial is filled.

THIS TCE VOLUME NEEDS TO BE VERY ACCURATE. MAKE SURE PIPETTE IS CALIBRATED.

7. Reweigh each vial to determine the total quantities of material added. Place the vials on an orbital shaker maintained at $12-15^{\circ} \mathrm{C}$ and allow to equilibrate overnight.

NEXT DAY:

8. Obtain tare weight on four extraction bottles to be used for the hexane extractions ( $125 \mathrm{~mL}$ VOA bottles with Teflon lined caps). Add approximately $40 \mathrm{~mL}$ of hexane to each of these and reweigh to determine the actual hexane volume added.

9. Remove the $40 \mathrm{~mL}$ vials from the shaker/incubator. Pour the entire contents of each $40 \mathrm{~mL}$ vial into a separate $125 \mathrm{~mL}$ extraction bottle. Reweigh each $125 \mathrm{~mL}$ extraction bottle to obtain the actual quantity transferred and record the time as "extraction time $=0$ ". Also re-weigh the "empty" VOA vials to determine mass that was NOT transferred.

10. Place each extraction jar on a horizontal reciprocating shaker at room temperature. Collect a $1 \mathrm{~mL}$ aliquot of the hexane layer from each extraction bottle at the following approximate time periods: 2 hours, 4 hours, $6 \mathrm{hrs}, 20 \mathrm{hrs}, 24 \mathrm{hrs}$, and $\approx 48 \mathrm{hrs}$. PLACE DIRECTLY INTO GC VIALS FOR ESD ANALYSIS-NO dilutions should be needed. 


\section{B2.3 Determine Time Required to Equilibrate Basalt Aggregate with TCE (Task 2c)}

\section{Background and Experimental Approach}

Aggregate basalt (1/4" -1 " size fraction) will also be investigated as a reactive zone medium from the TAN site. The needed length of time to spike or contaminant the aggregate basalt is currently unknown. The ultimate goal of this task is to determine the time required for the TCE concentration of the basalt's pore water to be in equilibrium with the TCE concentration in the bulk solution (TAN Site groundwater) via a sorption kinetics experiment.. The equilibration experiment will be conducted with an initial TCE concentration of $1 \mathrm{mg} / \mathrm{L}$ and at $12-15^{\circ} \mathrm{C}$. A study by Pavlostathis and Jaglal (1991) involving TCE sorption onto a silty sand indicated quasiequilibrium within a period of three (3) days. However, other studies with PCE and course grain bulk material show equilibration to be on the order of 20 days, whereas equilibration using pulverized material was approximately 1 day (Ball, 1991). Thus, a couple of the batch sorption test samples will be examined after a long time period (i.e., 14 days) to determine if such is the case of aggregate basalt.

Experimental controls (groundwater with no solid phase) will also be carried through the experiment to help account for losses via volatilization, biodegradation, or sorption of TCE onto the test equipment, etc. There will be no attempt to assess other factors commonly evaluated during laboratory sorption kinetics work such as ionic strength, $\mathrm{pH}$, etc.

The preferred hexane extraction time (Exp. 2b-2) for the aggregate basalt will also be evaluated once the desired equilibration time is determined. As in Section 2.2, the hexane extraction will be performed at room temperature.

\section{Experiment 2c-1. Sorption Kinetics Test for Crushed and Aggregate Basalt.} (To be conducted at ORNL/ESD)

1. All soil and groundwater to be used in these experiments (TAN-40 groundwater, TAN-37 crushed and aggregate basalt) will be prepped by sparging and/or drying to remove any residual TCE present on the media. (Properly indicate usage of this media in the treatability study tracking logbook.) Doing so will allow this experiment to be conducted with consistent and controlled initial TCE concentrations via contaminant spiking.

2. Prepare a STOCK (Saturated) TCE solution $(2000 \mathrm{mg} / \mathrm{L}$ ) by adding $100 \mu \mathrm{L}$ of Pure TCE into a $12 \mathrm{~mL}$ VOA vial filled to volume with DI Water and allow to equilibrate overnight at room temperature. (Use of a STOCK solution rather than pure phase TCE to prepare the spiking solution affords better accuracy in obtaining the target concentration.)

3. Sparge approximately $3100 \mathrm{~mL}$ of groundwater from TAN-40 of any residual TCE or other VOCs that may have been present and then place the groundwater into an incubator at $12-15^{\circ} \mathrm{C}$. After temperature equilibration of the groundwater (likely overnight), remove the container from the incubator. 
4. Obtain the tare weight of the container to be used to prepare the spike solution (Tedlar bag). Fill with the Tedlar bag with the chilled TAN-40 GW. By gravimetric methods, determine the amount of groundwater added to the container. (A calibration check of the gravimetric scale will be performed each day of use.) All information regarding the preparation of the spiking solution will be recorded in the laboratory research notebook.

5. Add the appropriate quantity of the Saturated STOCK TCE solution into the Tedlar bag to produce a TCE spike concentration of $1.0 \mathrm{mg} / \mathrm{L}$. SHOULD BE APPROXIMATELY 3 ML Record volume and/or weight added. (Reactive zone media will only be spiked at 0.1 and $1 \mathrm{mg} / \mathrm{L}$ TCE during the Task 4 degradation studies.) This solution can be mixed and equilibrated within a few minutes.

6. After mixing, obtain duplicate aqueous samples $(\approx 5 \mathrm{~mL})$ of the spike solution to obtain the initial TCE concentration of the spiked groundwater. The duplicate aliquot samples will be added to pre-weighed sample containers holding a known volume of hexane $(\approx 5 \mathrm{~mL})$. Each sample container will be weighed again after sample addition to determine the actual weight of sample added. These extracts will be placed on a horizontal shaker for 2 hours. Store the extracts at $4^{\circ} \mathrm{C}$ until G.C. analysis.

7. Obtain the tare weights of seventy two (72) $40 \mathrm{~mL}$ VOA vials. Add approximately $10 \mathrm{~g}$ of aggregate basalt to 24 of the vials and $10 \mathrm{~g}$ of the crushed basalt to another 24 of the these vials. Gravimetrically determine the actual amount of solid media added.

8. Dispense the spiked groundwater from the Tedlar bag into each of the 72 VOA vials that have been prepared, filling them completely with no headspace and cap them. Record the time that each vial is filled as " $\mathrm{T}=0$ " for that vial.

9. Re-weigh each vial after it is completely filled to determine the actual weight of spiked groundwater added to it. Place the vials back into the environmental chamber at $12-15^{\circ} \mathrm{C}$ Slowly agitate the vials during this step.

The remaining steps will be performed at the time intervals of approximately $2 \mathrm{~h}$, $4 h, 6 h, 18 h, 24 h, 4 d, 5 d, 6 d, 7 d, 12 d, 14 d$, and $21 d$. The latter times may be changed depending upon results of the samples obtained for the earlier time periods.

10. Remove six (6) $40 \mathrm{~mL}$ vials from the incubator (two with groundwater only, two with crushed basalt, and two containing aggregate basalt.) Collect an aqueous sample $(\approx 5 \mathrm{~mL})$ from each vial using a disposable syringe with luer lok needle. Record the time the sample is collected.

11. Filter $(0.45 \mu \mathrm{m}$ membrane) and dispense the sample into to a pre-weighed vial holding a known volume of hexane $(\approx 5 \mathrm{~mL})$. This sample vial will be weighed again after sample addition to determine the actual weight of sample added. A new syringe and filter will be used for each 
sample. All such extracts will be placed on a horizontal shaker for 2 hours. Store the extracts at $4^{\circ} \mathrm{C}$ until G.C. analysis.

12. Randomly collect and process (steps 10 and 11) a duplicate VOC sample from one of the six VOA vials during every other sampling period.

13. FOR THE LAST SAMPLING PERIOD STUDIED ONLY: Extract he remaining contents of each vial with hexane. (The mass of any remaining TCE on the solid phase can be determined with this extraction when a mass balance is performed using data from the aqueous aliquot sample) To accomplish this, transfer the remaining sample in the six $40 \mathrm{~mL}$ VOA vials (including basalt material) into a $125 \mathrm{~mL}$ extraction jar that has been pre-weighed and holding a known volume of hexane $(\approx 35 \mathrm{~mL})$. The extraction jar will be weighed again after sample addition to determine the actual mass of sample (solid + Liquid) added.

14. FOR THE LAST SAMPLING PERIOD STUDIED ONLY: The extracts in the above step will be placed on a horizontal or reciprocating shaker for 2 hours. A $1 \mathrm{~mL}$ aliquot of the hexane phase will be placed into a $2 \mathrm{~mL} \mathrm{G.C}$. vial and stored at $4^{\circ} \mathrm{C}$ until analysis.

GC ANALYSIS of VOCs

All VOC analyses for this experiment will be conducted using a G.C./ECD detector. The instrument will calibrated for TCE using a 5 point calibration curve with standard concentrations ranging from $10-1000 \mu \mathrm{g} / \mathrm{L}(\mathrm{ppb})$

The VOC analyses of the hexane extracts will closely follow EPA Method 8000B. Significant deviations from this method will be clearly documented.

\section{REPEAT EXPERIMENT:}

\section{Experiment 2c-1B. Sorption Kinetics Test for Crushed and Aggregate Basalt.} (To be conducted at ORNL/ESD)

1. All soil and groundwater to be used in these experiments (TAN-40 groundwater, TAN-37 crushed and aggregate basalt) will be prepped by sparging and/or drying to remove any residual TCE present on the media. (Properly indicate usage of this media in the treatability study tracking logbook.) Doing so will allow this experiment to be conducted with consistent and controlled initial TCE concentrations via contaminant spiking.

2. Prepare a STOCK (Saturated) TCE solution $(2000 \mathrm{mg} / \mathrm{L}$ ) by adding $100 \mu \mathrm{L}$ of Pure TCE into a $12 \mathrm{~mL}$ VOA vial filled to volume with DI Water and allow to equilibrate overnight at room temperature. (Use of a STOCK solution rather than pure phase TCE to prepare the spiking solution affords better accuracy in obtaining the target concentration.)

3. Sparge approximately $1600 \mathrm{~mL}$ of groundwater from TAN-40 of any residual TCE or other VOCs that may have been present. 
4. Obtain the tare weight of the container to be used to prepare the spike solution (Tedlar bag). Fill with the Tedlar bag with the sparged TAN- $40 \mathrm{GW}$. By gravimetric methods, determine the amount of groundwater added to the container. (A calibration check of the gravimetric scale will be performed each day of use.) All information regarding the preparation of the spiking solution will be recorded in the laboratory research notebook.

5. (TUESDAY AFTERNOON) Add the appropriate quantity of the Saturated STOCK TCE solution into the Tedlar bag to produce a TCE spike concentration of $1.0 \mathrm{mg} / \mathrm{L}$. SHOULD BE APPROXIMATELY 1.6 ML Record volume and/or weight added. (Reactive zone media will only be spiked at 0.1 and $1 \mathrm{mg} / \mathrm{L}$ TCE during the Task 4 degradation studies.) This solution can be mixed and equilibrated at least overnite at $12^{\circ} \mathrm{C}$ in the incubator.

6. After mixing, obtain duplicate aqueous samples using a glass syringe with a valve stopcock and luer needle $(5 \mathrm{~mL})$ of the spike solution to obtain the initial TCE concentration of the spiked groundwater. Weigh the syringe when filled and then again after the sample is dispensed to the P\&T. The duplicate aliquot samples will be analyzed immediately using the Lab 211 P\&T (30 minutes each).

7. Obtain the tare weights of thirty six (36) $40 \mathrm{~mL}$ VOA vials. Add approximately $10 \mathrm{~g}$ of aggregate basalt to 12 of the vials and $10 \mathrm{~g}$ of the crushed basalt to another 12 of these vials. Gravimetrically determine the actual amount of solid media added.

8. Dispense the spiked groundwater from the Tedlar bag into each of the 36 VOA vials that have been prepared, filling them completely with no headspace and cap them. Record the time that each vial is filled as " $\mathrm{T}=0$ " for that vial.

9. Re-weigh each vial after it is completely filled to determine the actual weight of spiked groundwater added to it. Place the vials back into the environmental chamber at $12^{\circ} \mathrm{C}$ Agitate the vials during this step (200 rpm or greater)

\section{The remaining steps will be performed at the time intervals of approximately 4 hrs, 24h, 2d, 5d, 7d, and TBD. The latter times may be changed depending upon results of the samples obtained for the earlier time periods.}

10. Remove six (6) $40 \mathrm{~mL}$ vials from the incubator (two with groundwater only, two with crushed basalt, and two containing aggregate basalt.) Collect an aqueous sample $(\approx 5 \mathrm{~mL})$ [allow the crushed basalt to settle a little before sampling) from each vial using a glass with valve stopcock and luer needle.

11. Weigh the full syringe and Record the time the sample is collected. Reweigh the syringe after the sample is dispensed into the P\&T.

12. Randomly collect and process (steps 10 and 11) a duplicate VOC sample from one of the six VOA vials during each sampling period. 
13. FOR THE LAST SAMPLING PERIOD STUDIED ONLY: Extract the remaining contents of each vial with hexane. (The mass of any remaining TCE on the solid phase can be determined with this extraction when a mass balance is performed using data from the aqueous aliquot sample) To accomplish this, transfer the remaining sample in the six $40 \mathrm{~mL}$ VOA vials (including basalt material) into a $125 \mathrm{~mL}$ extraction jar that has been pre-weighed and holding a known volume of hexane $(\approx 35 \mathrm{~mL})$. The extraction jar will be weighed again after sample addition to determine the actual mass of sample (solid + Liquid) added.

14. FOR THE LAST SAMPLING PERIOD STUDIED ONLY: The extracts in the above step will be placed on a horizontal or reciprocating shaker for 2 hours. A $1 \mathrm{~mL}$ aliquot of the hexane phase will be placed into a $2 \mathrm{~mL} \mathrm{G.C}$. vial and stored at $4^{\circ} \mathrm{C}$ until analysis.

\section{B3 Measure Oxidant Demand of TAN Subsurface Materials}

The oxidant demand experiments planned for Task 3 of the project will assess, for selected oxidant loadings, the effect of the TAN site media (soil and groundwater) upon the amount of oxidant remaining or available for TCE degradation. All Task 3 experiments will be conducted in duplicate at $12^{\circ} \mathrm{C}$ using non-contaminated media; hence, there are no contaminant equilibration or TCE analysis steps in the following Task 3 experiments.

\section{B3.1 Measure the Oxidant Demand of Reactive Zone Media (Task 3a)}

\section{General Procedure for Task 3 a Experiments - Oxidant Demand of Reactive Zone Media} (To be conducted at ORNL/ESD)

1. All soil and groundwater to be used in these experiments (TAN-40 groundwater, TAN-37 crushed and aggregate basalt, and sediment) will be prepped by sparging and/or drying to remove any residual TCE present on the media. Doing so will allow this experiment to be conducted with a consistent and controlled initial TCE concentration $(\approx 0 \mathrm{mg} / \mathrm{L})$. Properly indicate usage of this media in the treatability study tracking logbook.

2. Follow Table 2-3 in Chapter 2 of the Implementation Plan to obtain which test conditions to evaluate (soil type, oxidant concentration, etc.) The use of glass, wide-mouth erlenmeyer flasks, beakers, or equivalent will be used. It is currently planned to run four (4) test conditions from Table 2-3 each time this procedure is used. Thus, 8 reactors will be used during each run of this procedure.

3. Obtain the tare weight of each reactor. Add approximately $100 \mathrm{~g}$ of solid media to the reactors in Table 2-3 that require it $\mathrm{Re}$-weigh the reactors to determine the actual mass added. To each reactor, add $400 \mathrm{~mL}$ of TAN-40). Re-weigh each reactor to determine the actual weight of solution added. (A calibration check of the gravimetric scale will be performed each day of use.)

4. Place the reactors in the incubator at $12^{\circ} \mathrm{C}$ and allow to equilibrate to that temperature. Slowly agitate the reactors during this step. 
5. Once temperature equilibrium is reached, remove the reactors from the incubator and collect a $5 \mathrm{~mL}$ aliquot (using a disposable syringe) of the water and/or slurry from each for $\mathrm{pH}$ analysis.

6. The $\mathrm{pH}$ analyses will be conducted using conventional $\mathrm{pH}$ meters/electrodes, calibrated each day of use via a minimum of two standard buffer solutions $(4,7$, and 10$)$. Values obtained for each sample will be recorded. A calibration check will also be conducted following the last sample to be measured each day. Values obtained for the samples will be corrected if a significant drift (i.e., > 15\%) occurred.

7. Add the appropriate mass of crystalline $\mathrm{KMnO}_{4}$ (Carus ${ }^{\mathrm{TM}}$ Free Flowing Technical Grade) into each reactor according to which test condition in Table 2-3 is being evaluated. The exact mass of $\mathrm{KMnO}_{4}$ added to each reactor will be determined gravimetrically and recorded. The time that $\mathrm{KMnO}_{4}$ is added to each individual reactor shall also be recorded (reaction start time).

8. Place each reactor back into the $12^{\circ} \mathrm{C}$ incubator as the oxidant consumption reaction proceeds. For each reactor, remove the reactor from the incubator at approximately 5-10 minutes from the reaction start time, and collect a 5-10 mL aliquot (using a disposable plastic syringe with a Luer Tip). Record the time the sample was collected and replace the reactor back into the incubator.

9. Add a $0.45 \mu \mathrm{m}$ syringe filter onto the end of the syringe and filter approximately $1-2 \mathrm{~mL}$ into a beaker. Remove the syringe filter and dispense the remaining (unfiltered) portion of the sample into another beaker for $\mathrm{pH}$ analysis. Measure and record the $\mathrm{pH}$ of each sample as done in Step 6.

10. Perform a $\mathrm{MnO}_{4}{ }^{-}$analysis on the filtered sample from the previous step. (The sample is filtered to remove particulate matter that could interfere with the analysis.) The filtered sample will likely have to be diluted with DI water so that its spectrophotometric absorbance (at $\lambda=525$ $\mathrm{nm}$ ) is less than that of the highest standard to be prepared ( $50 \mathrm{mg} / \mathrm{L} \mathrm{MnO4-).} \mathrm{Check} \mathrm{standards}$ (10 and $50 \mathrm{mg} / \mathrm{L} \mathrm{MnO4-)}$ will be prepared with reagent grade $\mathrm{KMnO}_{4}$ and measured each analysis day. A new 5 point calibration curve will be prepared if the absorbance of these check standards differs from the expected value by $>15 \%$.

11. Collect and analyze aliquots from each reactor for $\mathrm{pH}$ and $\mathrm{KMnO}_{4}$ (Steps 8-10) at the following ADDITIONAL time periods: $1 \mathrm{hr}, 2 \mathrm{hrs}, 4 \mathrm{hrs}, 18 \mathrm{hrs}$, and $24 \mathrm{hrs}$.

12. Interpret results and clean up the reactors for re-use in the next run of the experiment. Also place any waste materials generated from the experiment in the appropriate satellite accumulation area.

\subsection{Measure the Oxidant Demand of Hot Spot Media (Task 3b)}

General Procedure for Task 3b Experiments - Oxidant Demand of Hot Spot Zone Media (To be conducted at RMAL)

1. All soil and groundwater to be used in these experiments (TSF-05 groundwater, TSF-05 sludge) will be prepped by sparging and/or drying to remove any residual TCE present on the 
media. Doing so will allow this experiment to be conducted with a consistent and controlled initial TCE concentration $(\approx 0 \mathrm{mg} / \mathrm{L})$. Properly indicate usage of this media in the treatability study tracking logbook.

2. Follow Table 2-4 in Chapter 2 of the Implementation Plan to obtain which test conditions to evaluate (soil type, oxidant concentration, etc.) The use of glass, wide-mouth erlenmeyer flasks or equivalent will be used. It is currently planned to run two (2) test conditions from Table 2-4 each time this procedure is used. Thus, 4 reactors will be used during each run of this procedure.

3. Obtain the tare weight of each reactor. Add approximately $100 \mathrm{~g}$ of solid media to the reactors in Table 2-4 that require it Re-weigh the reactors to determine the actual mass added. To each reactor, add $400 \mathrm{~mL}$ of TSF-05 groundwater. Re-weigh each reactor to determine the actual weight of solution added. (A calibration check of the gravimetric scale will be performed each day of use.)

4. Place the reactors in the incubator at $12^{\circ} \mathrm{C}$ and allow to equilibrate to that temperature. Slowly agitate the reactors during this step.

5. Once temperature equilibrium is reached, remove the reactors from the incubator and collect a $5 \mathrm{~mL}$ aliquot (using a disposable plastic syringe) of the water and/or slurry from each for $\mathrm{pH}$ analysis.

6. The $\mathrm{pH}$ analyses will be conducted using conventional $\mathrm{pH}$ meters/electrodes, calibrated each day of use via standard buffer solutions of $\mathrm{pH} 7$, and 10 . Values obtained for each sample will be recorded. A calibration check will also be conducted following the last sample to be measured each day. Values obtained for the samples will be corrected if a significant drift (i.e., > 15\%) occurred.

7. Add the appropriate mass of crystalline $\mathrm{KMnO}_{4}$ (Carus ${ }^{\mathrm{TM}}$ Free Flowing Technical Grade) into each reactor according to which test condition in Table 2-4 is being evaluated. The exact mass of $\mathrm{KMnO}_{4}$ added to each reactor will be determined gravimetrically and recorded. The time that $\mathrm{KMnO}_{4}$ is added to each individual reactor shall also be recorded (reaction start time).

8. Place each reactor back into the $12^{\circ} \mathrm{C}$ incubator as the oxidant consumption reaction proceeds. For each reactor, remove the reactor from the incubator at approximately 5-10 minutes from the reaction start time, and collect a 5-10 $\mathrm{mL}$ aliquot (using a disposable plastic syringe with a Luer Tip). Record the time the sample was collected and replace the reactor back into the incubator.

9. Add a $0.45 \mu \mathrm{m}$ syringe filter onto the end of the syringe and filter approximately $1-2 \mathrm{~mL}$ into a beaker. Remove the syringe filter and dispense the remaining (unfiltered) portion of the sample into another beaker for $\mathrm{pH}$ analysis. Measure and record the $\mathrm{pH}$ of the sample as done in Step 6 .

10. Perform a $\mathrm{MnO}_{4}^{-}$analysis on the filtered sample from the previous step. (The sample is filtered to remove particulate matter that could interfere with the analysis.) The filtered sample will likely have to be diluted with DI water so that its spectrophotometric absorbance (at $\lambda=525$ 
$\mathrm{nm}$ ) is less than that of the highest standard to be prepared (50 $\mathrm{mg} / \mathrm{L} \mathrm{MnO4-)}$. Check standards (10 and $50 \mathrm{mg} / \mathrm{L} \mathrm{MnO} 4-$ ) will be prepared with reagent grade $\mathrm{KMnO}_{4}$ and measured each analysis day. A new 5 point calibration curve will be prepared if the absorbance of these check standards differs from the expected value by $>15 \%$.

11. Collect and analyze aliquots from each reactor for $\mathrm{pH}$ and $\mathrm{KMnO}_{4}$ (Steps 8-10) at the following ADDITIONAL time periods: 30 minutes, 1 hour, $2 \mathrm{hrs}, 4 \mathrm{hrs}$, and $24 \mathrm{hrs}$.

12. Upon completion of the test period, the post-treatment sludges will be analyzed for total organic carbon content following the guidance in SW846 method 9060 and the manufacturer's operating instructions provided with the instrument. The carbon results will be corrected back to the original dried starting weight of the sludge used in the test.

13. Interpret the results and clean up the reactors for re-use in the next run of the experiment. Also place any waste materials generated from the experiment in the appropriate satellite accumulation area.

\section{B4 Measure Oxidation Rates}

The TCE degradation experiments will be conducted in Task 4 to determine the oxidation rate of TCE as a function of oxidant concentration and initial contaminant concentrations. All Task 4 experiments will be conducted in duplicate. The procedures presented below will be used to guide the experiments presented in Tables 2-5 through 2-7 in the Implementation Plan. Both the contaminant equilibration and oxidant reaction phases of these experiments will be conducted at $12^{\circ} \mathrm{C}$.

\section{B4.1 Measure the Oxidation Rate of Organic Contaminants in Reactive Zone Media (Task 4a)}

General Procedure for Task 4a Experiments - Measure the oxidation rate of organic contaminants in the Reactive Zone Media

(To be conducted at ORNL/ESD)

NOTE: This experiment will be used to conduct the various test conditions presented in Table 25 in Chapter 2 of the Implementation Plan. Control samples will be prepared and sampled throughout the reaction period to quantify changes in concentration due to mechanisms other than oxidation. In addition to the duplicate control samples, it is currently planned to run two (2) test conditions (in duplicate) from Table 2-5 each time this procedure is used. Thus, 6 reactors will be used during each run of this procedure, and this procedure will be conducted 8 times. The controls and the treatment reactors will all contain the same media type and initial contaminant concentrations (i.e., all conditions will be the same for each run of this procedure with the exception of the $\mathrm{MnO} 4-$ concentration used).

1. Soil Prepping

All soil and groundwater to be used in these experiments (TAN-40 groundwater, TAN-37 crushed and aggregate basalt, and sediment) will be prepped by sparging and/or drying to remove any residual TCE present on the media. Doing so will allow this experiment to be 
conducted with consistent and controlled initial TCE concentrations via contaminant spiking. (Properly indicate usage of this media in the treatability study tracking logbook.) TAN-40 GW will also be temperature equilibrated to $12^{\circ} \mathrm{C}$ in this experiment.

2. TCE Stock Solution Preparation

Prepare a STOCK (Saturated) TCE solution $(\approx 1100 \mathrm{mg} / \mathrm{L})$ by adding greater than $100 \mu \mathrm{L}$ of Pure TCE into a $12 \mathrm{~mL}$ VOA vial filled to volume with DI Water and keep refrigerated. (Use of a STOCK solution rather than pure phase TCE to prepare the spiking solution affords better accuracy in obtaining the target concentration.) This can easily be stored and used again in subsequent experiments.

\section{TCE Spike Solution Preparation, PART 1}

Obtain the tare weight of the container to be used to prepare the spike solution (Tedlar bag, flask, or equivalent). Fill with approximately $3100 \mathrm{~mL}$ of $12^{\circ} \mathrm{C} \mathrm{TAN}-40$ groundwater. By gravimetric methods, determine the amount of groundwater added to the container. (A calibration check of the gravimetric scale will be performed each day of use.)

4. TCE Spike Solution Preparation, PART II

Add the appropriate quantity of the Saturated STOCK TCE solution to produce a TCE spike solution with the concentration prescribed in Table 2-5 for the particular test series being ran. The reactive zone media will only be spiked at 0.1 and $1 \mathrm{mg} / \mathrm{L} \mathrm{TCE}$ during this experiment, thus the volume of saturated STOCK TCE needed should be on the order of $0.3 \mathrm{~mL}$ and $3.0 \mathrm{~mL}$, respectively. This solution can be mixed and equilibrated within a few minutes. All Information regarding the preparation of the spiking solution will be recorded in the laboratory research notebook. Place the spike solution in the incubator overnight at $12 \mathrm{C}$ for temperature equilibration.

\section{Obtain Tare Weights of Reactors}

Prepare the test reactors to be used. (The gas-tight reaction vessels acquired and tested in Task $2 \mathrm{a}$ will be used as the reactors in this experiment.) Obtain the tare weight of each, including the weight of a ground glass standard taper stopper fitted with a Teflon sleeve.

\section{Fill with Solid Phase Media}

Add approximately 100-110 g of the solid phase material desired for this particular test series (See Table 2-5 in the Implementation Plan). Re-weigh each reactor to determine the actual amount of solid media added (when applicable).

\section{Collection of Initial Spike Solution Samples}

Remove the spike solution from the incubator, and obtain duplicate aqueous samples $(\approx 5 \mathrm{~mL})$ of the spike solution to obtain the initial TCE concentration of the spiked groundwater. Record the time the sample is collected. The duplicate aliquot samples will be added to pre-weighed sample containers holding a known volume of hexane $(\approx 5 \mathrm{~mL})$. Each sample container will be weighed again after sample addition to determine the actual weight of sample added. These extracts will be placed on a horizontal shaker for 2 hours. Store the extracts at $4^{\circ} \mathrm{C}$ until G.C. analysis. 
8. Distribution of Spike Solution to Reactors

Quickly dispense the spike solution into each of the reactors to be used. Add $\approx 500 \mathrm{~mL}$ to each reactor. Immediately replace the ground glass stopper and re-weigh each to determine the actual weight of spiked groundwater.

9. Soil/Spike Equilibration

Place the reactors in the incubator at $12^{\circ} \mathrm{C}$ and allow the spike solution to equilibrate for 24 hours. (For aggregate basalt, equilibrate for the length of time determined in Exp. 2c-1., unless shorter than 24 hours) Agitate the reactors at $\approx 200 \mathrm{rpm}$ during this step.

10. Preparation of Stock $\mathrm{MnO}_{4}^{-}$Solution (4 wt\%) Add $2.66 \mathrm{~g}$ of crystalline $\mathrm{KMnO} 4$ (Carus ${ }^{\mathrm{TM}}$ Free Flowing Technical Grade) into a $50 \mathrm{~mL}$ Flask and fill to volume with DI water, and allow to mix for at least 2 hours.

11. Prepare Reactor Closure/Carbon Tube

During equilibration period, prepare the standard taper adapters/stopcock valve. (Only one ORBO tube will be used for each reactor.) The vertical sampling port will be fitted with a small septum) STORE UN-SEALED ORBO TUBES OUTSIDE OF THE LABORATORY FUME HOODS. THE HOODS LIKELY HAVE THE GREATEST POTENTIAL FOR "CONTAMINATING" THE TUBES WITH TCE AND OTHER VOCS.

\section{Collection of Pre-Reaction Sample from Each Reactor}

After equilibration, collect $\mathrm{a} \approx 10 \mathrm{~mL}$ aqueous sample using a long need and disposable syringe from each of the reactors and quickly reseal. Record the time the sample is collected and note whether solids were present in the aqueous sample (particularly the groundwater/sediment reactors). If significant solids are present, a portion of this aliquot volume may be used for a total solids analysis.

\section{Preparation of Pre Reaction TCE Sample}

Dispense (unfiltered) $\approx 3 \mathrm{~mL}$ of this aliquot sample into to a pre-weighed vial holding a known volume of hexane $(\approx 3 \mathrm{~mL})$. This sample vial will be weighed again after sample addition to determine the actual weight of sample added. All such extracts will be placed on a horizontal shaker for 2 hours. Store the extracts at $4^{\circ} \mathrm{C}$ until G.C. analysis. Record the time this sample is taken.

\section{Measurement of Pre Reaction $\mathrm{pH}$ Value}

Tare a small beaker for $\mathrm{pH}$ analysis. Add a 0.45 micron filter to the sample syringe and dispense (filtered) the remaining portion of the sample in the syringe $(\approx 7 \mathrm{~mL})$ into the tared beaker. Reweigh the beaker to determine the volume of the sample (assuming that the solids fraction is negligible). The $\mathrm{pH}$ analyses will be conducted using conventional $\mathrm{pH}$ meters/electrodes, calibrated each day of use via a minimum of two standard buffer solutions. Values obtained for each sample will be recorded. A calibration check will also be conducted following the last sample to be measured each day. Values obtained for the samples will be corrected if a significant drift (i.e., $>15 \%$ ) occurred. 
15. Addition of Stock MnO4- Solution into Reactors

Quickly remove the ground glass stopper and add the needed volume of stock $\mathrm{KMnO}_{4}$ to obtain the $\mathrm{MnO}_{4}{ }^{-}$concentrations in Table $2-5$ (approximately $1.25 \mathrm{~mL}$ and $12.5 \mathrm{~mL}$ for the 0.01 and $.01 \% \mathrm{MnO}_{4}{ }^{\circ}$ concentrations respectively). Replace the glass ground stoppers with the adapters fitted with the stopcock and charcoal desorption tubes and quickly hand shake each reactor to ensure rapid dissolution of the oxidant. (No oxidant will be added to the control reactors). The time that the stock $\mathrm{KMnO}_{4}$ is added to each individual reactor shall also be recorded (reaction start time). Place each reactor back into the $12^{\circ} \mathrm{C}$ incubator.

16. 30 Minute Sampling

At approximately 30 minutes from the reaction start time, remove the reactors from the incubator and collect a $10 \mathrm{~mL}$ aliquot (using a long needle and syringe with a Luer Tip). Record the time the sample is collected. Replace the reactor(s) back into the incubator.

17. Preparation of 30 Minute TCE Sample

Dispense (unfiltered) $\approx 3 \mathrm{~mL}$ of the collected aliquot into a pre-weighed vial holding a known volume of hexane $(\approx 3 \mathrm{~mL})$. This sample vial will be weighed again after sample addition to determine the actual weight of sample added. All such extracts will be placed on a horizontal shaker for 2 hours. Store the extracts at $4^{\circ} \mathrm{C}$ until G.C. analysis.

18. $\mathrm{pH}$ Analysis of 30 Minute Sample

Tare a small beaker. Add a $0.45 \mu \mathrm{m}$ syringe filter unto the end of the syringe and dispense (filtered) the remaining portion of the sample in the syringe $(\approx 7 \mathrm{~mL})$ into a tared beaker for $\mathrm{pH}$

analysis. Reweigh the beaker to determine the volume of the sample (assuming that the solids fraction is negligible). Measure and record the $\mathrm{pH}$ of the sample as done in Step 13

19. $\mathrm{MnO}_{4}^{-}$Analysis of the 30 Minute Sample

Use a portion of the filtered $\mathrm{pH}$ sample to perform a $\mathrm{MnO}_{4}{ }^{-}$analysis. The sample may have to be diluted (likely DF3 and DF30 for the .01 and 0.1\% MnO4- loadings, respectively) so that its spectrophotometric absorbance (at $\lambda=525 \mathrm{~nm}$ ) is less than that of the highest standard to be prepared ( $50 \mathrm{mg} / \mathrm{L}$ MnO4-). Check standards ( 10 and $50 \mathrm{mg} / \mathrm{L} \mathrm{MnO4-)}$ will be prepared with reagent grade $\mathrm{KMnO}_{4}$ and measured each analysis day. A new 5 point calibration curve will be prepared if the absorbance of these check standards differs from the expected value by $>15 \%$.

20. Collection and Analysis of Additional Aliquot Samples

Collect and analyze aliquots from each reactor for TCE, $\mathrm{pH}$, and $\mathrm{KMnO}_{4}$ (Steps 16-19) at the following ADDITIONAL time periods: $2 \mathrm{hrs}, 4 \mathrm{hrs}, 6 \mathrm{hrs}, 20 \mathrm{hrs}$, and $24 \mathrm{hrs}$.

IMPORTANT-For each reactor collect and extract a duplicate sample (Steps 16-19) from one of the 6 time intervals being evaluated.

21. Extraction of Residual TCE in Reactor

The entire contents of each reactor will be extracted with hexane. First, obtain a tare weight on six (6) empty containers to be used for the hexane extraction (1 liter VOA bottles). Measure out $400 \mathrm{~mL}$ of hexane into two (2) $200 \mathrm{~mL}$ volumetric flasks. Add $200 \mathrm{~mL}$ of the hexane directly into the $1 \mathrm{~L}$ extraction bottle. Quickly pour the contents of each test reactor into a separate extraction bottle. Use the remaining $200 \mathrm{~mL}$ flask of hexane to rinse any residual slurry from the test reactor into the extraction bottle. Weigh and record the mass of the filled extraction bottle to 
determine the mass of the slurry and hexane added (taking into account the fact that hexane has a specific gravity of 0.66 ).

(The mass of any remaining TCE on the solid phase can be determined with this extraction when a mass balance is performed using data from the aqueous aliquot sampling that was conducted throughout the test.)

22. Reactor Extraction Continued

Place each extraction bottle on a horizontal reciprocating shaker for a minimum of 2 hours (May be longer for aggregate basalt samples, depending upon the results of Exp. 2b-2.) then collect duplicate $1 \mathrm{~mL}$ hexane aliquots from each extraction bottle and place into $2 \mathrm{~mL} \mathrm{G.C}$. vials (dilution is not expected to be necessary).

23. Extraction of Charcoal Desorption Tubes

Remove the charcoal desorption tube(s) from each reactor. Each charcoal bed contained in the tube(s) will be placed into pre-filled and pre-weighed vials containing a known volume of hexane $(\approx 5 \mathrm{~mL})$. These extracts will be processed and analyzed in the same manner as the aqueous aliquots for TCE.

24. Clean up

Clean up the reactors for re-use in the next run of the experiment. Also place any waste materials generated from the experiment in the appropriate satellite accumulation area.

\section{GC ANALYSIS of VOCs}

All VOC analyses for this experiment will be conducted using a G.C./ECD detector. The instrument will calibrated for TCE using a 5 point calibration curve with standard concentrations ranging from $5-1000 \mu \mathrm{g} / \mathrm{L}(\mathrm{ppb})$

The VOC analyses of the hexane extracts will closely follow EPA Method 8000B. Significant deviations from this method will be clearly documented.

Formal data packages will be prepared for the analyses performed for all Task 3 and 4 samples will be prepared as discussed in Sections 2.4.3 and 2.4.4 in Chapter 2 of the Implementation Plan. The major QA/QC items pertaining to the VOC analyses include:

Calibration standards will be prepared from a certified, custom VOC mix stock solution containing each analyte of interest. The lot number of this custom mix will be included on each initial calibration data form.

The working calibration curve will be verified through injection of a QC check standard (100 $\mu \mathrm{g} / \mathrm{L}$ ) at least once each analysis day. If the response for any analyte varies from the predicted response by more than $\pm 15 \%$, a new calibration curve will be prepared.

A blank hexane sample will be analyzed between every 10 test samples.

A sample will be diluted and reanalyzed if its GC peak area response is greater than that of the highest calibration standard being used that analysis day. 


\section{B4.2 Measure the Oxidation Rate of Organic Contaminants in Hot Spot Media (Task 4b)}

General Procedure for Task $4 \mathrm{~b}$ Experiments - Measure the oxidation rate of organic contaminants in the hot spot groundwater

(To be conducted by both ORNL/ESD and RMAL)

NOTE: This experiment will be used to conduct the various test conditions presented in Table 26 in Chapter 2 of the Implementation Plan.

Control samples (no $\mathrm{KMnO}_{4}$ ) will be prepared and sampled throughout the reaction period to quantify changes in concentration due to mechanisms other than oxidation. In addition to the duplicate control samples, it is currently planned to run two (2) test conditions (in duplicate) from Table 2-6 each time this procedure is used. Thus, 6 reactors will be used during each run of this procedure, and this procedure will be conducted a total of 8 times ( 4 times at each facility). The controls and the treatment reactors will all contain the same initial contaminant concentrations (i.e., all conditions will be the same for each run of this procedure with the exception of the $\mathrm{KMnO}_{4}$ concentration used).

Note: The 2,000 $\mathrm{mg} / \mathrm{L}$ TCE spike solution in Table 2-6 experiments cannot be prepared in the same manner as the spike solution for the 10 and $100 \mathrm{mg} / \mathrm{L}$ spike levels. Both spiking methods are included in this procedure.

1. Soil Prepping

All groundwater to be used in these experiments (TSF-05 groundwater) will be prepped by sparging to remove any residual TCE present on the media. Doing so will allow this experiment to be conducted with consistent and controlled initial TCE concentrations via contaminant spiking. (Properly indicate usage of this media in the treatability study tracking logbook.)

For the 10 and $100 \mathrm{mg} / \mathrm{L}$ Spike concentrations ONLY. --Proceed to step 9 if spiking at DNAPL levels $(2,000 \mathrm{mg} / \mathrm{L}$ TCE) in Table 2-6

2. TCE Stock Solution Preparation

Prepare a STOCK (Saturated) TCE solution $(\approx 1100 \mathrm{mg} / \mathrm{L})$. (Use of a STOCK solution rather than pure phase TCE to prepare the spiking solution affords better accuracy in obtaining the target concentration.) This can easily be stored and used again in subsequent experiments

For 10 ppm TCE spiking (Runs $1 \& 2$ ): Add $>0.1 \mathrm{~mL}$ of Pure TCE into $65-70 \mathrm{~mL}$ of TSF-05 groundwater and keep refrigerated.

For $100 \mathrm{ppm}$ TCE spiking (Runs 5\&6): Add $>0.6 \mathrm{~mL}$ of Pure TCE into $625 \mathrm{~mL}$ of TSF=05 GW $\&$ keep refrigerated.

3. TCE Spike Solution Preparation, PART 1

Obtain the tare weight of the container to be used to prepare the spike solution (Tedlar bag, flask, or equivalent). Fill with unspiked $12^{\circ} \mathrm{C}$ TSF-05 groundwater $(\approx 3070 \mathrm{~mL}$ or $\approx 2800 \mathrm{~mL}$ for the 10 and $100 \mathrm{mg} / \mathrm{L}$ spike condition, respectively). By gravimetric methods, determine the 
amount of unspiked groundwater added to the container. (A calibration check of the gravimetric scale will be performed each day of use.)

\section{TCE Spike Solution Preparation, PART II}

Add the appropriate quantity of the Saturated STOCK TCE solution to produce a TCE spike solution with the concentration prescribed in Table 2-6 for the particular test series being ran. The hot spot groundwater will only be spiked at 10 and $100 \mathrm{mg} / \mathrm{L} \mathrm{TCE}$ via this method, thus the volume of saturated STOCK TCE needed should be on the order of $30 \mathrm{~mL}$ and $300 \mathrm{~mL}$, respectively. Please record the volume of STOCK TCE added (NOTE: will also added any contaminants required during this step.) Place the spike solution in the incubator overnight at $12 \mathrm{C}$ for temperature equilibration. Ensure that all Information regarding the preparation of the spiking solution will be recorded in the laboratory research notebook.

5. Obtain Tare Weights of Reactors

Prepare the test reactors to be used. (The gas-tight reaction vessels acquired and tested in Task $2 \mathrm{a}$ will be used as the reactors in this experiment.) Obtain the tare weight of each, including the weight of a ground glass standard taper stopper fitted with a Teflon sleeve.

\section{Collection of Initial Spike Solution Samples}

Remove the spike solution from the incubator, and obtain duplicate aqueous samples $(\approx 5 \mathrm{~mL})$ of the spike solution to obtain the initial TCE concentration of the spiked groundwater. Record the time the sample is collected. The duplicate aliquot samples will be added to pre-weighed sample containers holding a known volume of hexane $(\approx 5 \mathrm{~mL})$. Each sample container will be weighed again after sample addition to determine the actual weight of sample added. These extracts will be placed on a horizontal shaker for 2 hours. Store the extracts at $4^{\circ} \mathrm{C}$ until G.C. analysis.

7. Distribution of Spike Solution to Reactors

Quickly dispense the spike solution into each of the reactors to be used. Add $\approx \mathbf{5 0 0} \mathbf{~ m L}$ to each reactor. Immediately replace the ground glass stopper and re-weigh each to determine the actual weight of spiked groundwater added.

8. Keep Cool until Experiment is initiated:

Place the reactors in the incubator at $12^{\circ} \mathrm{C}$ until the experiment is initiated. Agitate the reactors at $\approx 200$ rpm during this step.

\section{For the DNAPL Spiking Level (2,000 mg/L TCE) in Table 2-6 ONLY --Proceed to Step 13 if spiking at 10 or $100 \mathrm{mg} / \mathrm{L}$}

9. $>2,000 \mathrm{mg} / \mathrm{L}$ Spiking: Obtain Tare Weights of Reactors

Prepare the test reactors to be used. (The gas-tight reaction vessels acquired and tested in Task $2 \mathrm{a}$ will be used as the reactors in this experiment.) Obtain the tare weight of each, including the weight of a ground glass standard taper stopper fitted with a Teflon sleeve. 
10. $>2,000 \mathrm{mg} / \mathrm{L}$ Spiking: Reactor Filling

Dispense $\approx \mathbf{5 0 0} \mathbf{~ m L}$ un-spiked TSF-05 groundwater into each of the reactors to be used.

Immediately replace the ground glass stopper/sleeve and re-weigh each to determine the actual weight of groundwater added.

11. Reactor Spiking ( $>2,000 \mathrm{mg} / \mathrm{L}$ TCE)

To each of the six reactors, add enough pure phase TCE to achieve a TCE concentration of 2,000 $\mathrm{mg} / \mathrm{L}$ (should be around $700 \mu \mathrm{L}$ pure TCE for $500 \mathrm{~mL}$ of groundwater). Measure the mass of the spiking syringe when filled and then after spiking to determine the actual contaminant mass added (a QC check on the initial TCE analysis). Information regarding the preparation of each spiking solution will be recorded in the laboratory research notebook.

12. Spike Solution Equilibration ( $>2,000 \mathrm{mg} / \mathrm{L}$ Spike Condition)

Place the reactors into the incubator at $200 \mathrm{rpm}$ or greater and allow the spike solutions to equilibrate at $12^{\circ} \mathrm{C}$ (likely overnight)

13. For Loadings of .01 and $0.1 \mathrm{wt}^{\mathrm{O}} \mathrm{MnO}_{4}{ }^{-}$in Table 2-6 ONLY. Preparation of Stock $\mathrm{MnO}_{4}^{-}$Solution (4 wt\%)

Add $2.66 \mathrm{~g}$ of crystalline $\mathrm{KMnO} 4$ (Carus ${ }^{\mathrm{TM}}$ Free Flowing Technical Grade) into a $50 \mathrm{~mL}$ Flask and fill to volume with DI water, and allow to mix for at least 2 hours.

\section{Prepare Reactor Closure/Carbon Tube}

During equilibration period, prepare the standard taper adapters/stopcock valve. (One Orbo tubes will be used.) The vertical sampling port will be fitted with a small septum) STORE UNSEALED ORBO TUBES OUTSIDE OF THE LABORATORY FUME HOODS. THE HOODS LIKELY HAVE THE GREATEST POTENTIAL FOR “CONTAMINATING” THE TUBES WITH TCE AND OTHER VOCS.

\section{Collection of Pre-Reaction Sample from Each Reactor}

After equilibration, collect $\mathrm{a} \approx 10 \mathrm{~mL}$ aqueous sample using a long need and disposable syringe from each of the reactors and quickly reseal. Record the time the sample is collected and note whether solids were present in the aqueous sample. If significant solids are present, a portion of this aliquot volume may be used for a total solids analysis.

16. Preparation of Pre Reaction TCE Sample

Dispense (unfiltered) $\approx 3 \mathrm{~mL}$ of this aliquot sample into to a pre-weighed vial holding a known volume of hexane $(\approx 3 \mathrm{~mL})$. This sample vial will be weighed again after sample addition to determine the actual weight of sample added. All such extracts will be placed on a horizontal shaker for 2 hours. Store the extracts at $4^{\circ} \mathrm{C}$ until G.C. analysis. Record the time this sample is taken.

17. Measurement of Pre Reaction $\mathrm{pH}$ Value

Tare a small beaker for $\mathrm{pH}$ analysis. Add a 0.45 micron filter to the sample syringe and dispense (filtered) the remaining portion of the sample in the syringe $(\approx 7 \mathrm{~mL})$ into the tared beaker.

Reweigh the beaker to determine the volume of the sample (assuming that the solids fraction is negligible). The $\mathrm{pH}$ analyses will be conducted using conventional $\mathrm{pH}$ meters/electrodes, calibrated each day of use via a minimum of two standard buffer solutions. Values obtained for 
each sample will be recorded. A calibration check will also be conducted following the last sample to be measured each day. Values obtained for the samples will be corrected if a significant drift (i.e., $>15 \%$ ) occurred.

\section{For Loadings of .01 and 0.1 wt \% $\mathrm{MnO}_{4}{ }^{-}$in Table 2-6 ONLY.}

Addition of Stock MnO4- Solution into Reactors

Quickly remove the ground glass stopper and add the needed volume of stock $\mathrm{KMnO}_{4}$ to obtain the $\mathrm{MnO}_{4}{ }^{-}$concentrations in Table 2-6 (approximately $1.25 \mathrm{~mL}$ and $12.5 \mathrm{~mL}$ for the 0.01 and $.01 \% \mathrm{MnO}_{4}{ }^{-}$concentrations respectively). Replace the glass ground stoppers with the adapters fitted with the stopcock and charcoal desorption tubes and quickly hand shake each reactor to ensure rapid dissolution of the oxidant. (No oxidant will be added to the control reactors). The time that the stock $\mathrm{KMnO}_{4}$ is added to each individual reactor shall also be recorded (reaction start time). Place each reactor back into the $12^{\circ} \mathrm{C}$ incubator and $200 \mathrm{rpm}$ or greater.

\section{For the Oxidant Loadings of 1 and 3wt \% $\mathrm{MnO}_{4}{ }^{-}$in Table 2-6 ONLY}

Addition of Crystalline KMnO4 to Reactors, Part I

Pre-weigh out (into disposable tare boats) the needed quantities of crystalline $\mathrm{KMnO}_{4}\left(\mathrm{Carus}^{\mathrm{TM}}\right.$

Free Flowing Technical Grade) that is needed for each reactor according to which test condition in Table 2-6 is being evaluated. For the 1 and $3 \mathrm{wt} \% \mathrm{MnO}_{4}{ }^{-}$loadings, $\approx 6.6 \mathrm{~g}$ and $\approx 20 \mathrm{~g}$ of $\mathrm{KMnO} 4$ will be needed for each reactor, respectively. Record the actual mass of $\mathrm{KMnO}_{4}$ weighed out for each reactor.

\section{For the Oxidant Loadings of 1 and $3 w t \% \mathrm{MnO}_{4}{ }^{-}$in Table 2-6 ONLY}

Addition of Crystalline $\mathrm{KMnO} 4$ to Reactors, Part II

Quickly remove the ground glass stopper and add these pre-weighed quantities of $\mathrm{KMnO}_{4}$ into the applicable reactors. Replace the glass ground stoppers with the adapters fitted with the charcoal desorption tube assemblies and quickly hand shake each reactor to ensure rapid

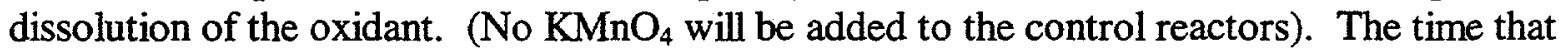
$\mathrm{KMnO}_{4}$ is added to each individual reactor shall also be recorded (reaction start time). Place each reactor back into the $12^{\circ} \mathrm{C}$ incubator and at $200 \mathrm{rpm}$ of greater.

\section{30 Minute Sampling}

At approximately 30 minutes from the reaction start time, remove the reactors from the incubator and collect a $10 \mathrm{~mL}$ aliquot (using a long needle and syringe with a Luer Tip). Record the time the sample is collected. Replace the reactor(s) back into the incubator.

\section{Preparation of 30 Minute TCE Sample}

Dispense (unfiltered) $\approx 3 \mathrm{~mL}$ of the collected aliquot into a pre-weighed vial holding a known volume of hexane $(\approx 3 \mathrm{~mL})$. This sample vial will be weighed again after sample addition to determine the actual weight of sample added. All such extracts will be placed on a horizontal shaker for 2 hours. Store the extracts at $4^{\circ} \mathrm{C}$ until G.C. analysis.

23. $\mathrm{pH}$ Analysis of 30 Minute Sample

Tare a small beaker. Add a $0.45 \mu \mathrm{m}$ syringe filter unto the end of the syringe and dispense (filtered) the remaining portion of the sample in the syringe $(\approx 7 \mathrm{~mL})$ into a tared beaker for $\mathrm{pH}$ 
analysis. Reweigh the beaker to determine the volume of the sample (assuming that the solids fraction is negligible). Measure and record the $\mathrm{pH}$ of the sample as done in Step **

24. $\mathrm{MnO}_{4}^{-}$Analysis of the 30 Minute Sample

Use a portion of the filtered $\mathrm{pH}$ sample to perform a $\mathrm{MnO}_{4}{ }^{-}$analysis. The sample may have to be diluted so that its spectrophotometric absorbance (at $\lambda=525 \mathrm{~nm}$ ) is less than that of the highest standard to be prepared ( $50 \mathrm{mg} / \mathrm{L} \mathrm{MnO4-).} \mathrm{Check} \mathrm{standards} \mathrm{(10} \mathrm{and} 50 \mathrm{mg} / \mathrm{L} \mathrm{MnO4-)}$ will be prepared with reagent grade $\mathrm{KMnO}_{4}$ and measured each analysis day. A new 5 point calibration curve will be prepared if the absorbance of these check standards differs from the expected value by $>15 \%$.

25. Collection and Analysis of Additional Aliquot Samples

Collect and analyze aliquots from each reactor for TCE, $\mathrm{pH}$, and $\mathrm{KMnO}_{4}$ (Steps 21-24) at the following ADDITIONAL time periods: $2 \mathrm{hrs}, 4 \mathrm{hrs}, 6 \mathrm{hrs}, 20 \mathrm{hrs}$, and $24 \mathrm{hrs}$.

IMPORTANT-For each reactor collect and extract a duplicate sample (Steps 21-24) from one of the 6 time intervals being evaluated.

26. Extraction of Charcoal Desorption Tubes

After the final aliquot samples are collected, remove the charcoal desorption tube(s) from each reactor. Each charcoal bed contained in the tube(s) will be placed into pre-filled and pre-weighed vials containing a known volume of hexane $(\approx 5 \mathrm{~mL})$. These extracts will be processed and analyzed in the same manner as the aqueous aliquots for TCE.

27. Clean up

Clean up the reactors for re-use in the next run of the experiment. Also place any waste materials generated from the experiment in the appropriate satellite accumulation area.

\section{GC ANALYSIS of VOCs}

All VOC analyses for this experiment will be conducted using a G.C./ECD detector. The instrument will calibrated for TCE (and also for cis-1,2 DCE, trans-1,2 DCE, and vinyl chloride for the co-contaminants experiment), using a 5 point calibration curve with standard concentrations ranging from $5-1000 \mu \mathrm{g} / \mathrm{L}(\mathrm{ppb})$

The VOC analyses of the hexane extracts will closely follow EPA Method 8000B. Significant deviations from this method will be clearly documented.

Formal data packages will be prepared for the analyses performed for all Task 3 and 4 samples will be prepared as discussed in Sections 2.4.3 and 2.4.4 in Chapter 2 of the Implementation Plan. The major QA/QC items pertaining to the VOC analyses include:

Calibration standards will be prepared from a certified, custom VOC mix stock solution containing each analyte of interest. The lot number of this custom mix will be included on each initial calibration data form.

The working calibration curve will be verified through injection of a QC check standard (100 $\mu \mathrm{g} / \mathrm{L})$ at least once each analysis day. If the response for any analyte varies from the predicted response by more than $\pm 15 \%$, a new calibration curve will be prepared. 
A blank hexane sample will be analyzed between every 10 test samples.

A sample will be diluted and reanalyzed if its GC peak area response is greater than that of the highest calibration standard being used that analysis day.

General Procedure for Task 4b Experiments - Measure the oxidation rate of organic contaminants in the hot spot groundwater and sludge

(To be conducted at RMAL)

IMPORTANT: Per the SOW, page 2-11, one of the duplicates for a single test condition listed in Table 2-7 of the plan will be sacrificially extracted with hexane at reaction intervasl. Selection of the test series for this task to be performed will be determined at a later date.

NOTE: This experiment will be used to conduct the various test conditions presented in Table 27 in Chapter 2 of the Implementation Plan. Control samples will be prepared and sampled throughout the reaction time interval to quantify changes in concentration due to processes other than oxidation. In addition to the duplicate control samples, it is currently planned to run two (2) test conditions (in duplicate) from Table 2-7 each time this procedure is used. Thus, 6 reactors will be used during each run of this procedure, and this procedure will be conducted 6-7 times, depending upon how/when the "blank" test series (NO TCE) is performed. The controls and the treatment reactors will all contain the same media type and initial contaminant concentrations (i.e., all conditions will be the same for each run of this procedure with the exception of the $\mathrm{KMnO}_{4}$ concentration used.

Note: The 2,000 $\mathrm{mg} / \mathrm{L}$ TCE spike solution in Table 2-7 experiments cannot be prepared in the same manner as the spike solution for the 10 and $100 \mathrm{mg} / \mathrm{L}$ spike levels. Both spiking methods are included in this procedure.

\section{Soil Prepping}

All groundwater and media to be used in these experiments (TSF-05 groundwater and sludge) will be prepped by sparging to remove any residual TCE present on the media. Doing so will allow this experiment to be conducted with consistent and controlled initial TCE concentrations via contaminant spiking. (Properly indicate usage of this media in the treatability study tracking logbook.)

For the 10 and $100 \mathrm{mg} / \mathrm{L}$ Spike concentrations ONLY. --Proceed to step 10 if spiking at DNAPL levels $(2,000 \mathrm{mg} / \mathrm{L}$ TCE) in Table 2-7.

2. TCE Stock Solution Preparation

Prepare a STOCK (Saturated) TCE solution $(\approx 1100 \mathrm{mg} / \mathrm{L}$ ) by adding greater than $0.5 \mathrm{~mL}$ of Pure TCE into a $500 \mathrm{~mL}$ flask filled to volume with TSF-05 groundwater and keep refrigerated. 
(Use of a STOCK solution rather than pure phase TCE to prepare the spiking solution affords better accuracy in obtaining the target concentration.) This can easily be stored and used again in subsequent experiments.

\section{TCE Spike Solution Preparation, PART 1}

Obtain the tare weight of the container to be used to prepare the spike solution (Tedlar bag, flask, or equivalent). Fill with unspiked $12^{\circ} \mathrm{C}$ TSF-05 groundwater $(\approx 3070 \mathrm{~mL}$ or $\approx 2800 \mathrm{~mL}$ for the 10 and $100 \mathrm{mg} / \mathrm{L}$ spike condition, respectively). By gravimetric methods, determine the amount of unspiked groundwater added to the container. (A calibration check of the gravimetric scale will be performed each day of use.)

\section{TCE Spike Solution Preparation, PART II}

Add the appropriate quantity of the Saturated STOCK TCE solution to produce a TCE spike solution with the concentration prescribed in Table 2-7 for the particular test series being ran. The hot spot groundwater will only be spiked at 10 and $100 \mathrm{mg} / \mathrm{L}$ TCE via this method, thus the volume of saturated STOCK TCE needed should be on the order of $30 \mathrm{~mL}$ and $300 \mathrm{~mL}$, respectively. Please record the volume of STOCK TCE added (NOTE: will also added any contaminants required during this step.) Place the spike solution in the incubator overnight at $12 \mathrm{C}$ for temperature equilibration. Ensure that all Information regarding the preparation of the spiking solution will be recorded in the laboratory research notebook.

\section{Obtain Tare Weights of Reactors}

Prepare the test reactors to be used. (The gas-tight reaction vessels acquired and tested in Task $2 \mathrm{a}$ will be used as the reactors in this experiment.) Obtain the tare weight of each, including the weight of a ground glass standard taper stopper fitted with a Teflon sleeve.

6. Fill with Solid Phase Media

Add approximately $100-110 \mathrm{~g}$ of the TSF-05 sludge desired for this particular test series (See Table 2-7 in the Implementation Plan). Re-weigh each reactor to determine the actual amount added (when applicable).

\section{Collection of Initial Spike Solution Samples}

Remove the spike solution from the incubator, and obtain duplicate aqueous samples $(\approx 5 \mathrm{~mL})$ of the spike solution to obtain the initial TCE concentration of the spiked groundwater. Record the time the sample is collected. The duplicate aliquot samples will be added to pre-weighed sample containers holding a known volume of hexane $(\approx 5 \mathrm{~mL})$. Each sample container will be weighed again after sample addition to determine the actual weight of sample added. These extracts will be placed on a horizontal shaker for 2 hours. Store the extracts at $4^{\circ} \mathrm{C}$ until G.C. analysis.

\section{Distribution of Spike Solution to Reactors}

Quickly dispense the spike solution into each of the reactors to be used. Add $\approx 500 \mathrm{~mL}$ to each reactor. Immediately replace the ground glass stopper and re-weigh each to determine the actual weight of spiked groundwater added.

\section{Soil/Spike Equilibration}

Place the reactors in the incubator at $12^{\circ} \mathrm{C}$ and allow the spike solution to equilibrate for 24 hours with the sludge. Agitate the reactors at $\approx 200 \mathrm{rpm}$ during this step. 
For the DNAPL Spiking Level (2,000 $\mathrm{mg} / \mathrm{L}$ TCE) in Table 2-7 ONLY --Proceed to Step 15 if the samples were spiked at 10 or $100 \mathrm{mg} / \mathrm{L}$

10. $>2,000 \mathrm{mg} / \mathrm{L}$ Spiking: Obtain Tare Weights of Reactors

Prepare the test reactors to be used. (The gas-tight reaction vessels acquired and tested in Task 2a will be used as the reactors in this experiment.) Obtain the tare weight of each, including the weight of a ground glass standard taper stopper fitted with a Teflon sleeve.

11. Sludge Addition ( $>2,000 \mathrm{mg} / \mathrm{L}$ Spiking Condition)

Add approximately 100-110 g of the TSF-05 sludge to each reactor. Re-weigh each reactor (with stopper/sleeve) to determine the actual amount of sludge added

12. $>2,000 \mathrm{mg} / \mathrm{L}$ Spiking: Reactor Filling

Dispense $\approx 500 \mathrm{~mL}$ un-spiked TSF-05 groundwater into each of the reactors to be used.

Immediately replace the ground glass stopper/sleeve and re-weigh each to determine the actual weight of groundwater added.

\section{Reactor Spiking $(>2,000 \mathrm{mg} / \mathrm{L}$ TCE)}

To each of the six reactors, add enough pure phase TCE to achieve a TCE concentration of 2,000 $\mathrm{mg} / \mathrm{L}$ (should be around $700 \mu \mathrm{L}$ pure TCE for $500 \mathrm{~mL}$ of groundwater). Measure the mass of the spiking syringe when filled and then after spiking to determine the actual contaminant mass added (a QC check on the initial TCE analysis). Information regarding the preparation of each spiking solution will be recorded in the laboratory research notebook.

14. Spike Solution Equilibration ( $>2,000 \mathrm{mg} / \mathrm{L}$ Spike Condition)

Place the reactors into the incubator at $200 \mathrm{rpm}$ or greater and allow the spike solutions to equilibrate at $12^{\circ} \mathrm{C}$ (likely overnight).

\section{For the Oxidant Loadings of .01 and $0.1 \mathrm{wt} \% \mathrm{MnO}_{4}^{-}$in Table 2-7 ONLY}

Preparation of Stock $\mathrm{MnO}_{4}^{-}$Solution (4 wt\%)

Add $2.66 \mathrm{~g}$ of crystalline $\mathrm{KMnO} 4$ (Carus ${ }^{\mathrm{TM}}$ Free Flowing Technical Grade) into a $\mathbf{5 0}$ mL Flask and fill to volume with DI water, and allow to mix for at least 2 hours.

16. Prepare Reactor Closure/Carbon Tubes

During equilibration period, prepare the standard taper adapters/stopcock valve. (One Orbo tubes will be used for each reactor). The vertical sampling port will be fitted with a small septum. STORE UN-SEALED ORBO TUBES OUTSIDE OF THE LABORATORY FUME HOODS. THE HOODS LIKELY HAVE THE GREATEST POTENTIAL FOR "CONTAMINATING" THE TUBES WITH TCE AND OTHER VOCS.

17. Collection of Pre-Reaction Sample from Each Reactor

After equilibration, collect $a \approx 10 \mathrm{~mL}$ aqueous sample using a long need and disposable syringe from each of the reactors and quickly reseal. Record the time the sample is collected and note whether solids were present in the aqueous sample. If significant solids are present, a portion of this aliquot volume may be used for a total solids analysis. 


\section{Preparation of Pre Reaction TCE Sample}

Dispense (unfiltered) $\approx 3 \mathrm{~mL}$ of this aliquot sample into to a pre-weighed vial holding a known volume of hexane $(\approx 3 \mathrm{~mL})$. This sample vial will be weighed again after sample addition to determine the actual weight of sample added. All such extracts will be placed on a horizontal shaker for 2 hours. Store the extracts at $4^{\circ} \mathrm{C}$ until G.C. analysis. Record the time this sample is taken. (These samples will require Beta/Gamma Screenings before submittal to ESD.)

\section{Measurement of Pre Reaction $\mathrm{pH}$ Value}

Tare a small beaker for $\mathrm{pH}$ analysis. Add a 0.45 micron fiter to the sample syringe and dispense (filtered) the remaining portion of the sample in the syringe $(\approx 7 \mathrm{~mL})$ into the tared beaker. Reweigh the beaker to determine the volume of the sample (assuming that the solids fraction is negligible). The $\mathrm{pH}$ analyses will be conducted using conventional $\mathrm{pH}$ meters/electrodes, calibrated each day of use via a minimum of two standard buffer solutions. Values obtained for each sample will be recorded. A calibration check will also be conducted following the last sample to be measured each day. Values obtained for the samples will be corrected if a significant drift (i.e., $>15 \%$ ) occurred.

\section{For the Oxidant Loadings of .01 and $0.1 \mathrm{wt} \% \mathrm{MnO}_{4}{ }^{-}$in Table 2-7 ONLY} Addition of Stock MnO4- Solution into Reactors

Quickly remove the ground glass stopper and add the needed volume of stock $\mathrm{KMnO}_{4}$ to obtain the $\mathrm{MnO}_{4}{ }^{-}$concentrations in Table 2-7 (approximately $1.25 \mathrm{~mL}$ and $12.5 \mathrm{~mL}$ for the 0.01 and $.01 \% \mathrm{MnO}_{4}{ }^{-}$concentrations respectively). Replace the glass ground stoppers with the adapters fitted with the stopcock and charcoal desorption tubes and quickly hand shake each reactor to ensure rapid dissolution of the oxidant. (No oxidant will be added to the control reactors). The time that the stock $\mathrm{KMnO}_{4}$ is added to each individual reactor shall also be recorded (reaction start time). Place each reactor back into the $12^{\circ} \mathrm{C}$ incubator and $200 \mathrm{rpm}$ or greater.

\section{For the Oxidant Loadings of 1 and $3 \mathrm{wt} \% \mathrm{MnO}_{4}{ }^{-}$in Table 2-7 ONLY} Addition of Crystalline $\mathrm{KMnO} 4$ to Reactors, Part I

Pre-weigh out (into disposable tare boats) the needed quantities of crystalline $\mathrm{KMnO}_{4}\left(\mathrm{Carus}^{\mathrm{TM}}\right.$

Free Flowing Technical Grade) that is needed for each reactor according to which test condition in Table $2-6$ is being evaluated. For the 1 and 3 wt\% $\mathrm{MnO}_{4}{ }^{-}$loadings, $\approx 6.6 \mathrm{~g}$ and $\approx 20 \mathrm{~g}$ of $\mathrm{KMnO}_{4}$ will be needed for each reactor, respectively. Record the actual mass of $\mathrm{KMnO}_{4}$ weighed out for each reactor.

\section{For the Oxidant Loadings of 1 and $3 \mathrm{wt} \% \mathrm{MnO}_{4}{ }^{-}$in Table 2-7 ONLY} Addition of Crystalline $\mathrm{KMnO}_{4}$ to Reactors, Part II

Quickly remove the ground glass stopper and add these pre-weighed quantities of $\mathrm{KMnO}_{4}$ into the applicable reactors. Replace the glass ground stoppers with the adapters fitted with the charcoal desorption tube assemblies and quickly hand shake each reactor to ensure rapid dissolution of the oxidant. ( $\mathrm{No} \mathrm{KMnO}_{4}$ will be added to the control reactors). The time that $\mathrm{KMnO}_{4}$ is added to each individual reactor shall also be recorded (reaction start time). Place each reactor back into the $12^{\circ} \mathrm{C}$ incubator and at $200 \mathrm{rpm}$ of greater. 
23. 30 Minute Sampling

At approximately 30 minutes from the reaction start time, remove the reactors from the incubator and collect a $10 \mathrm{~mL}$ aliquot (using a long needle and syringe with a Luer Tip). Record the time the sample is collected. Replace the reactor(s) back into the incubator.

24. Preparation of 30 Minute TCE Sample

Dispense (unfiltered) $\approx 3 \mathrm{~mL}$ of the collected aliquot into a pre-weighed vial holding a known volume of hexane $(\approx 3 \mathrm{~mL})$. This sample vial will be weighed again after sample addition to determine the actual weight of sample added. All such extracts will be placed on a horizontal shaker for 2 hours. Store the extracts at $4^{\circ} \mathrm{C}$ until G.C. analysis. (These samples will require Beta/Gamma Screenings before submittal to ESD.)

25. $\mathrm{pH}$ Analysis of 30 Minute Sample

Tare a small beaker. Add a $0.45 \mu \mathrm{m}$ syringe filter unto the end of the syringe and dispense (filtered) the remaining portion of the sample in the syringe $(\approx 7 \mathrm{~mL})$ into a tared beaker for $\mathrm{pH}$ analysis. Reweigh the beaker to determine the volume of the sample (assuming that the solids fraction is negligible). Measure and record the $\mathrm{pH}$ of the sample as done in Step **

26. $\mathrm{MnO}_{4}^{-}$Analysis of the 30 Minute Sample

Use a portion of the filtered $\mathrm{pH}$ sample to perform a $\mathrm{MnO}_{4}{ }^{-}$analysis. The sample may have to be diluted so that its spectrophotometric absorbance (at $\lambda=525 \mathrm{~nm}$ ) is less than that of the highest standard to be prepared ( $50 \mathrm{mg} / \mathrm{L} \mathrm{MnO4-).} \mathrm{Check} \mathrm{standards} \mathrm{(10} \mathrm{and} 50 \mathrm{mg} / \mathrm{L} \mathrm{MnO4-)}$ will be prepared with reagent grade $\mathrm{KMnO}_{4}$ and measured each analysis day. A new 5 point calibration curve will be prepared if the absorbance of these check standards differs from the expected value by $>15 \%$.

27. Collection and Analysis of Additional Aliquot Samples

Collect and analyze aliquots from each reactor for TCE, $\mathrm{pH}$, and $\mathrm{KMnO}_{4}$ (Steps 23-26) at the following ADDITIONAL time periods: $2 \mathrm{hrs}, 4 \mathrm{hrs}, 6 \mathrm{hrs}, 20 \mathrm{hrs}$, and $24 \mathrm{hrs}$.

IMPORTANT_For each reactor collect and extract a duplicate sample (Steps 23-26) from one of the 6 time intervals being evaluated.

\section{Extraction of Residual TCE in Reactor}

The entire contents of each reactor will be extracted with hexane. First, obtain a tare weight on six (6) empty containers to be used for the hexane extraction ( 1 liter VOA bottles). Measure out $400 \mathrm{~mL}$ of hexane into two (2) $200 \mathrm{~mL}$ volumetric flasks. Add $200 \mathrm{~mL}$ of the hexane directly into the $1 \mathrm{~L}$ extraction bottle. Quickly pour the contents of each test reactor into a separate extraction bottle. Use the remaining $200 \mathrm{~mL}$ flask of hexane to rinse any residual slurry from the test reactor into the extraction bottle. Weigh and record the mass of the filled extraction bottle to determine the mass of the slurry and hexane added (taking into account the fact that hexane has a specific gravity of 0.66 ).

(The mass of any remaining TCE on the solid phase can be determined with this extraction when a mass balance is performed using data from the aqueous aliquot sampling that was conducted throughout the test.) 
29. Reactor Extraction Continued

Place each extraction bottle on a horizontal reciprocating shaker for a minimum of 2 hours then collect duplicate hexane aliquots from each extraction bottle for G.C. analysis (dilutions may be necessary).

30. Extraction of Charcoal Desorption Tubes

After the final aliquot samples are collected, remove the charcoal desorption tube(s) from each reactor. Each charcoal bed contained in the tube(s) will be placed into pre-filled and pre-weighed vials containing a known volume of hexane $(\approx 5 \mathrm{~mL})$. These extracts will be processed and analyzed in the same manner as the aqueous aliquots for TCE.

31. VOC Sample Submittal

Submit $1 \mathrm{~mL}$ aliquots of the hexane extracts collected during the experiment to ESD personnel (diluted to $<1000 \mathrm{ppb}$, if necessary). These aliquots will be surveyed by health physics before release to ESD.

\section{Clean up}

Clean up the reactors for re-use in the next run of the experiment. Also place any waste materials generated from the experiment in the appropriate satellite accumulation area.

33. GC ANALYSIS of VOCs

All VOC analyses for this experiment will be conducted using a G.C./ECD detector. The instrument will calibrated for TCE, using a 5 point calibration curve with standard concentrations ranging from $5-1000 \mu \mathrm{g} / \mathrm{L}(\mathrm{ppb})$

The VOC analyses of the hexane extracts will closely follow EPA Method 8000B. Significant deviations from this method will be clearly documented.

Formal data packages will be prepared for the analyses performed for all Task 3 and 4 samples will be prepared as discussed in Sections 2.4.3 and 2.4.4 in Chapter 2 of the Implementation Plan. The major QA/QC items pertaining to the VOC analyses include:

Calibration standards will be prepared from a certified, custom VOC mix stock solution containing each analyte of interest. The lot number of this custom mix will be included on each initial calibration data form.

The working calibration curve will be verified through injection of a QC check standard (100 $\mu \mathrm{g} / \mathrm{L})$ at least once each analysis day. If the response for any analyte varies from the predicted response by more than $\pm 15 \%$, a new calibration curve will be prepared.

A blank hexane sample will be analyzed between every 10 test samples.

A sample will be diluted and reanalyzed if its GC peak area response is greater than that of the highest calibration standard being used that analysis day. 
34. Post Treatment TSF-05 Sludge TOC Analysis

Upon completion of the test period, the post-treatment sludges will be analyzed for total organic carbon content following the guidance in SW846 method 9060 and the manufacturer's operating instructions provided with the instrument. The carbon results will be corrected back to the original dried starting weight of the sludge used in the test.

\section{B5. References}

Ball, William. 1991. "Long-Term Sorption of Halogenated Organic Chemicals by Auquifer material: 1. Equilibrium," Environmental Science and Technology 25(7):1223-1249.

Pavlostathis, S. G., and K. Jaglal. 1991. "Desorptive Behavior of Trichloroethylene in Contaminated Soil," Environmental Science and Technology 25(2):274-279. 


\section{INTERNAL DISTRIBUTION}

1. S. R. Cline, 1505, MS-6035

2. D. L. Denton, 2026, MS-6043

3. J. M. Giaquinto, 2026, MS-6043

4. M. K. McCracken, 1504, MS-6351

5. R. L. Siegrist, 1505, MS-6036

6. O. R. West, 1505, MS-6036

7. Central Research Library

8-10. ESD Library

11. Laboratory Records, ORNL-RC

\section{EXTERNAL DISTRIBUTION}

12. E. G. Cumesty, Assistant Manager for Laboratories and Site Manager, Department of Energy, Oak Ridge National Site Office, P. O. Box 2008, Oak Ridge, TN 37831-6269.

13. J. Elwood, Director, Environmental Sciences Division, ER-74, Department of Energy, 19901 Germantown Road, Germantown, MD 20874

14. J.P. Giesy, Michigan State University, College of Natural Science, Department of Zoology, 203 Natural Science Building, East Lansing, MI 48824-1115

15-16. Office of Scientific and Technical Information, P.O. Box 62, Oak Ridge, TN 37831

17. L. Robinson, Director, Environmental Sciences Institute, Florida A\&M University Science Research Facility, 1520 S. Bronough Street, Tallahassee, FL 32307

18-30. Bob Starr, LMITCO, TSB-1-K1-3953, 2525 North Fremont Avenue, Idaho Falls, ID 83415-3953 